
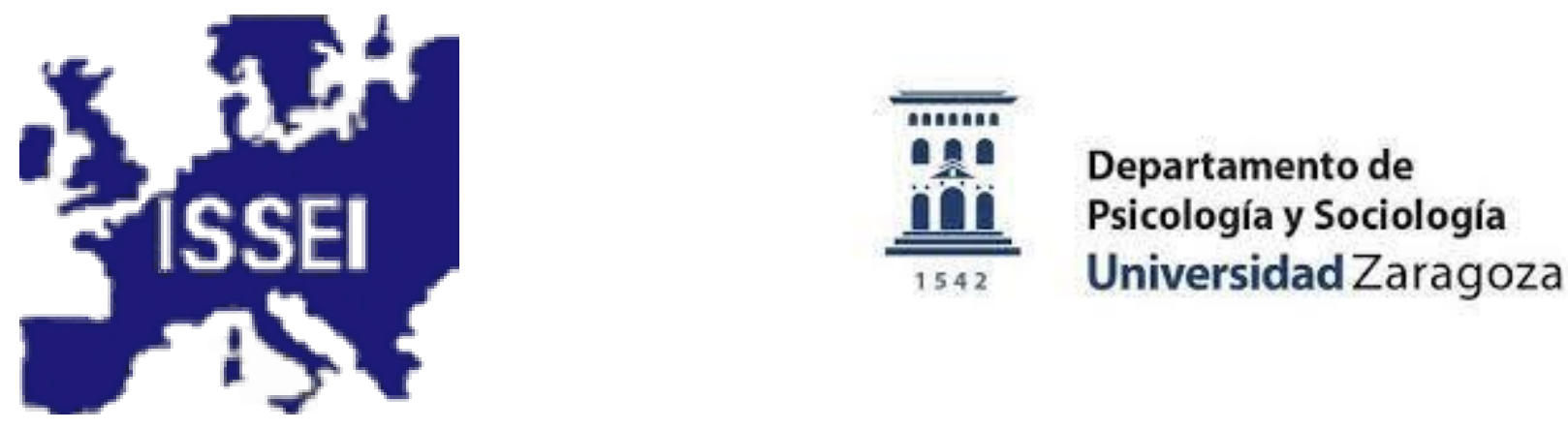

\title{
Aftershocks: Globalism and the Future of Democracy
}

ISSEI - XVI International Conference

The University of Zaragoza, Spain

July 2-5, 2019 
Aftershocks: Globalism and the Future of Democracy

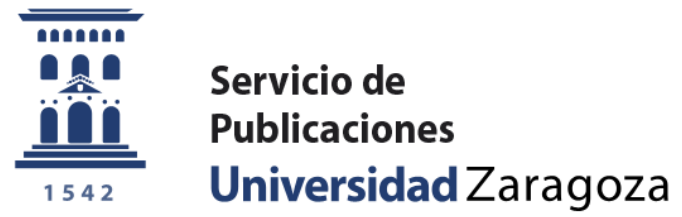

Date published: March 2021

Iván López (ed.)

ISBN 978-84-18321-12-2 


\section{CONFERENCE CO-CHAIRS}

Dr. Edna Rosenthal, ISSEI/The European Legacy

Professor Jose Angel Bergua

Department of Psychology and Sociology,

University of Zaragoza

Professor Ivan López

Department of Psychology and Sociology,

University of Zaragoza

\section{SPONSOR}

Aragonese Association of Sociology

http://www.aragonsociologia.org/ 


\section{ISSEI EXECUTIVE COMMITTEE}

Edna Rosenthal, editor, The European Legacy, Israel

Neri Sévenier, academic programme coordinator, Israel

Wayne Cristaudo, editor, The European Legacy,

Charles DarwinUniversity, Australia

Gesine Palmer, Independent Scholar, Germany

Marianna Papastephanou, advisory editor, University of Cyprus

Ruvik Rosenthal, The Open University, Israel

Heinz-Uwe Haus, University of Denver, USA

Richard Weiner, Rhode Island College, USA

José Ángel Bergua, University of Zaragoza, Spain

Iván López, University of Zaragoza, Spain

\section{ZARAGOZA UNIVERSITY ORGANIZING COMMITTEE}

José Ángel Bergua

Iván López

Elena Oliete-Aldea

$\mathrm{M}^{\mathrm{a}}$ José González Ordovás

Marisa Feijó

Cecilia Serrano

Tatiana Iñiguez-Berrozpe

Francesco Marcaletti

Juan David Gómez Quintero

Jesús Carreras

Pablo Gómez Muñoz

Noelia Marqués Cobeta

Andrés Bartolomé

Silvia Murillo

Marta Pérez

Suleydi Mora Barragán

Nataly Pasachova Sanchez 


\section{Table of Contents}

Editor's Note

Iván López

Welcoming Address

Edna Rosenthal

Opening Speech

Transnational History, Transnational Space, Transnational Law

Professor Richard R. Weiner.

Workshop 1:

Approaches to God

Chair: Stanley Tweyman

Hume's Dialogues Concerning Natural Religion and the Six Moments of

Scepticism

Philip MacEwen

Descartes' Failure in the Third Meditation to Prove that God Created

Descartes

Stanley Tweyman

Workshop 2:

Democracies with a Human Face: Writers, Moviemakers, and Migration

Chair: Hans J. Rindisbacher

Integration, Assimilation, Marginalization, and Expulsion

Vesna Kondrič Horvat

Changing Her Tune: Antihumanism in Monika Maron's Munin oder Chaos im Kopf

Eva B. Revesz. 66

Robert Menasse's Die Hauptstadt: How Europe Dis/Connects in Brussels

Hans J. Rindisbacher.

Novels Assessing Global Mobility Through the Lens and Legacy of the GDR

Friederike von Schwerin-High.

Workshop 3:

Democracies, Demagogues, and Despots: Pre-Globlized Precursors and A New "Age of Tyrannies"?

Chair: Victor Castellani

Over-organization, Multilayered Conflict, and the Risk of a New Era of Tyrannies

Cristiana Senigaglia 
Appraising the Oldest 'Era of Tyrannies' (Toward a Tyrannology?)

Victor Castellani.

Who's Afraid of Globalization?

Erik M. Vogt....

Workshop 4:

Film, Culture and the Struggle for Democratic Governance

Chairs: Juan Tarancón and Elena Oliete-Aldea.

The Globalism of Contemporary Jacobean Films: The Case of Emilio

Estévez's The Way

Carmen Induráin

Workshop 5:

From Polis to Nation to Global Community and Back Again

Chair: Ann Ward

Nationalism and Globalism: A Canadian Perspective

Leah Bradshaw.

Nietzsche Against the Sovereign Individual in the Second Essay of the

Genealogy

Matthew Dinan.

Neither Patriot Nor Saint: The Theological Implications of Twain's Defense of Nationalism in Personal Recollections of Joan of Arc

Bernard J. Dobski 168

Judith Hermann's Nichts als Gespenster: Globality, Ambient Romance and Identity Tourism

Steven Joyce..... 178

Joyful Contests: Nietzsche and the Politics of Friendship

Paul Kirkland

Global Enframing, Authentic History, Dasein: Thoughts on the "Preview" of Heidegger's Beiträge zur Philosophie (Contributions to Philosophy) José Daniel Parra

To "Persuade Without Convincing": Rousseau as the Legislator of Nature

Emma Planinc

A Few, But Really Determined Women and Men Can Make a Difference Even Today: Lessons from Fiume after the Summer of 1919

Haimo Schulz Meinen.

Rootedness and National Identity in the 21st Century

Luma Simms

The Bayeux Tapestry: Nationalism before Nations and Globes

Marlene K. Sokolon 239 
"Forced to be free": Nationalism and the Hijab Controversy in France

Glocalism and Democracy in James Tully's Critique of Cosmopolitanism and Imperialism

Lee Ward 260

Workshop 6

Historical Memory in a Global World

Chair: Boris Gubman

Arthur Danto on Historical Narrative: Between Past and Present

Carina Anufrieva....

New Horizons of History and Historical Memory Relations in the Age of

Globalization

Gubman Boris.

Representations of the Chuvash People's National Narrative

Erbina Nikitina and Gennadiy Trifonov

Dominick LaCapra: Trauma and the Politics of Memory

Vera Potamskaya.

Workshop 7

Language and Nationality: Between Globalization and Localization; and Journalism, the Media and the Viability of Democracies

Chair: Ruvik Rosenthal

The Struggle for Spanish Identity in the Press Coverage of the Third Reich, 1930-1936

Kenneth Alarcón Negy

The "Non-Ideaist" View of Humanity in J.G. Hamann, J.G. Herder, and

Eugen Rosenstock-Huessy

Wayne Cristaudo

The Spread of Chinese Films in Italy

Beibei Guan

The Bible and the Zionist Lexicon

Ruvik Rosenthal

Workshop 8:

Nationalisms and Democracies: Theory, History, Literature, Culture

Chair: Mark Gelber.

Workshop 9:

Necessity vs. Progress: The 'Use Value' of Ancient Greek Drama

Chair: Heinz-Uwe Haus

Prometheus: The Power of Fire

Claudine Elnécavé 
Brecht's "Use Value" and Aristotle's "Artistic Proofs"

Heinz-Uwe Haus.

Workshop 10:

Philosophies and Pedagogies of Inclusion and Exclusion

Chairs: Marianna Papastephanou and Torill Strand.

Affected But Not Heard: Democratic Iterations and the Restricted Language of Human Rights

Inga Bostad.

A Janus-Faced Democracy: On the Autoimmune Condition in the Body of Politics

Mark Debono

Identity versus Alterity and Inclusion versus Exclusion: Unavoidable

Dipoles?

Kalli Drousioti

Who can teach what none have learned?" Pedagogies of Inclusion and

Exclusion in Thomas Hobbes' Behemoth

Giorgos Kataliakos

The Inclusive Qualities of the Homeric Concept of Daimôn beyond the Dipole of the One and the Many

Eleni Katsiai, Marianna Papastephanou, and Mary Koutselini-Ioannides . 421

Inclusion, Self-Exclusion, and Public Debates on Teachers and Education

Marianna Papastephanou.

Rosi Braidotti on the Exclusion of the Female Subject

Christos Pavlides

Marginality and the Insignificance of Choice

Daniele Santoro

"We are striking because we have done our homework": Two Perspectives on Contemporary Youths' Emerging Ethical-Political Awareness

Torill Strand

Workshop 11:

Social Work in Uncertain Times

Chairs: Cecilia Serrano Martínez and Domingo Carbonero

Challenges in the Context of Uncertainty: Implications for Diversity

Management in Spain

Cecilia Serrano-Martínez and Domingo Carbonero Muñoz

Workshop 12:

Some Considerations Concerning a New Ethics of Warning

Chair: Gesine Palmer

From Warning to Stigma: The Danger of Purity in Today's Europe

Frank Hahn 488 
Structural Violence in Society: An Anchor Point for Anti-democratic Movements

Reinhard Hildebrandt

The Franco-German Relations: A Shining Example of International

Understanding or a Myth?

Simone Lück-Hildebrandt.

Some Considerations Concerning a New Ethics of Warning

Gesine Palmer

Workshop 13:

Subjectivism and Globalism: The Metaphysical Self in the Post-Truth Era between Now and Tomorrow

Chair: Theodor Damian

Relativism: The Erosion of Objectivity. The Truth is in the "Eye" of the

Beholder

Theodor Damian

Against Immorality

Michael Manfé

La identidad nacional rumana en la poesía de Mihai Eminescu

Anca Sîrghie

Goalball y perspectivismo: una aproximación multinaturalista al deporte inclusivo

Carlos García Grados.

Workshop 14:

The Post-Secular Condition: Democracy and the Return of Religion

Chairs: Rita Šerpytytė and Tomas Sodeika

Post-Secular and Post-Democratic India: A Study of the Digital Dissolution of the State

Rianka Roy

The Birth of Post-secularity from the Spirit of Religious Unmusicality

Tomas Sodeika

The Rehabilitation of Myth, Post-Ontology, and Rhetoric

Lina Vidauskytè .

Homage to Professor Ezra Talmor, Founder of ISSEI

Edna Rosenthal 


\section{Editor's Note}

\section{Iván López}

University of Zaragoza

This digital publication consists of a selection of 56 papers presented at the $16^{\text {th }}$ International Conference of the International Society for the Study of European Ideas (ISSEI), held at the University of Zaragoza, 2-5 July 2019, the general theme of which was 'Aftershocks: Globalism and the Future of Democracy'. Sponsored by The Aragonese Association of Sociology, the conference was well-attended - 170 participants from 28 countries met to discuss a wide variety of topics in 29 workshops. The feedback we received from participants confirmed that they had greatly enjoyed the venue of the conference, that they appreciated the warm welcome they had received and the congenial social atmosphere and opportunity to attend workshops on subjects that were not only in their own field of expertise.

No one, of course, could have predicted that our world - our work and life as individuals, as communities and as nations - would change so suddenly and radically eighteen months after the conference, with the rapid and devastating spread of the Convid-19 pandemic. The current deepening global crisis along with the challenge of climate change and growing international tensions are a stark reminder of how vulnerable our societies, our civilization, and our species are.

The shocks and aftershocks of these crises are felt today in every corner of the world and in every aspect of our global and local economies, and most obviously in the sociopolitical arena. As several of the conference workshops on the multiple crises Europe and the world face today - from the migrant crisis to the rise of populism and deepening inequality between rich and poor - showed - and as the Covid-19 pandemic has so cruelly brought home to us - we simply 
cannot take the achievements of human civilization for granted and must find ways to meet the fundamental social and political needs of human beings not only in our own neighborhoods, cities and countries, but ultimately in the world as a whole: their living conditions, livelihoods, social services, education and healthcare, human rights and political representation.

Several of the workshops, as I mentioned, directly addressed these issues and emphasized the need for building social resilience based on tolerance, solidarity and equity. This too is why, as academics, we should continue to initiate and engage in collective reflection and debate on how to foster and strengthen human communities and human solidarity.

Finally, I want to thank the participants and workshop chairs for their contribution to the success of the conference. It was a pleasure for me to work with the university organizing team and with ISSEI's team in bringing this about, and I am particularly proud that my university and the city of Zaragoza hosted this conference. 


\section{Welcoming Address}

\section{Edna Rosenthal}

\section{The European Legacy / ISSEI}

On behalf of the editors of The European Legacy and ISSEI's organizing team, and members at large, I want express our gratitude to the University of Zaragoza for hosting our $16^{\text {th }}$ conference.

We thank Mr. Jose Azcòn, Mayor of Zaragoza, for honouring us with his presence; Professor Gerardo Sanz Saiz, Vice-Rector of Academic Policy;

Professor Santos Orejudo Hernández, Director of the Department of Psychology and Sociology; Professor Julio Latorre Peña, Dean of the Faculty of Education; Professor Javier López Sánchez, Dean of the Faculty of Law; and Professor Ruth Vallejo Da Costa, Dean of the Faculty of Social Science and Work for their support of the conference, and all those who have generously given of their time, hard work, and good advice in bringing this event to fruition. Our special thanks go to our co-chairs, Professor José Ángel Bergua and Professor Ivan Lopez for their faith in our joint endeavor and for overseeing the complex administrative work. We wish to express our special thanks to their dedicated 10-strong organizing team without whose dedication, stamina, and efficiency this four-day gathering would not have been possible.

I want, finally, to thank Richard Weiner, Wayne Cristaudo, Ruvik Rosenthal, Heinz-Uwe Haus, Gesine Palmer, board members Ann Ward and Marianna Papastephanou, and Neri Sevenier, for their invaluable support, encouragement, and hard work at all stages of organizing this conference, from start to finish.

We are very fortunate to be gathered here in this remarkably beautiful, historic town and its ancient university - the full credit for 
which goes to Richard Weiner, who first suggested the University of Zaragoza and introduced us to his colleague here Professor Ivan Lopez. This venue offers an ideal setting and ambience for indulging our academic freedom, as well as our inborn curiosity in meeting and talking with colleagues whose histories and memories may be very different from our own. If, as a recent Guardian editorial put it, "humans need the humanities," I wish to add that because thinking and writing are solitary tasks, what researchers and writers like us need are gatherings of this sort - where we can share, test, refresh, refine and fructify our ideas, theories, interpretations, projects, and even intellectual dreams.

For those who wonder what ISSEI stands for, allow me to read Professor David Lovell's, my former co-editor's, succinct description: "ISSEI was always more an ideal, than an organization with newsletters, organizing committees, and annual fees. It is an ideal of cooperative inquiry into the ideas of Europe, the idea of Europe itself, and... the influences of Europe on the rest of the world."

ISSEI, in other words, is a voluntary association of those who are interested in attending our conferences and contributing to our journal.

Over the next four days we are all ISSEI members...

A few words on the Conference theme:

Although conceived three years ago, our theme has not lost an iota of relevance: quite the opposite: for everything - from the state of the world, probably the state of our own countries, and no less the state of universities everywhere and our particular faculties and departments - seems to have become even more complicated and intertangled since 2016. It would not be an exaggeration to say that even for academics the world today may seem incomprehensible, and therefore all the 
more dangerous. For when we feel unable to make sense of the world we are at our most vulnerable: our sense of being - our identity - is shaken. Yet, as experience teaches us, this sense of crisis is also a call to stop and look around, to rethink, retry, and finally find the courage to act. When bewildered, we are desperate for new ideas, new ways of looking at things. In my often unmethodical habit of reading I recently came across a sentence that encapsulated this sense of bewilderment: it read: "Identities our forged through crisis." 1 I seized on this sentence perhaps because of that powerful verb "to forge," that is, to make or mold something by heating or hammering it, often by 'concentrated effort'. Of course, I reminded myself, identities are not static or unalterable, but responsive, dynamic, adaptable, throughout life. I took the sentence to mean that a crisis 'forges' or beats an identity into shape by demanding self-reflection, by demanding an answer, by being a call to action.

This sentence soon merged with another from some other text I came across, which spelled all this out: "People don't have simple identities any more, they aren't just a member of their own nation. They have a complex identity" (Charles Taylor). ${ }^{2}$

The combination of the two sentences gave me a momentary sense of a new understanding, though I doubt that human identity - that anything human, for that matter, is or was, or ever will be, 'simple'. True, we all have complex identities - in which family and nation, city and region, profession, religion, politics, culture, gender, collective memories and other factors - play a part. And from all of these each of us 'beats into shape' their own individual complex identity. Speaking for myself, for example, I would say that formally I am NOT a European; but professionally and by choice - I AM, in some sense of the word - a European. And this fruitful ambiguity -as insider and outsider at one and the same time - underlies my belief that Europe, 
particularly the European Union - with all its shortcomings, which theorists are so quick to call out and politicians so quick to weaponise - is still a source of hope for the rest of the world.

Why so?

Because Europe is a place where people take for granted what has been won by centuries-old struggles: here human rights are not systemically abused; speech is free, movement is free, differences are accepted; here religious tolerance, peace, and social justice are not empty words. Here cooperation, conflict resolution, compromise and dialogue are guiding principles of diplomacy. While cynics and pessimists will reject this as utopian thinking, I see Europe as a source of hope for the rest of the world also because it is in the making, or should I say, the re-making of itself - which guarantees the preservation of its layered histories and traditions, so visibly embodied here in the city of Zaragoza - Greek, Roman, JudeoChristian, and Muslim - its many languages, its many cultures, its many ethnicities and complex identities... but above all, I wish to stress, its political legacy: the unending battle for democracy.

To conclude: the crises implied by the word 'aftershocks' in our conference theme, and the repercussions and impacts of Globalism on democracies, on Europe, and the rest of the world - force us to seek precedents of sorts in history so as to understand our current reality and to fortify our hopes for the future, by which I mean, the future of democracy. For me, one such precedent is the message delivered by British historian Thomas Macaulay in his speech in the House of Commons in 1831 on extending the vote to a new segment of the population. He said: "Reform, that you may preserve." Which freely adapted is: Reform, Europe, that you may preserve." But which can also be read with a slightly different stress as a direct address to all Europeans: Reform Europe, that you may preserve. 


\section{I welcome you all - hosts, chairs, participants, guests - and wish us a wonderful conference with its 29 workshops and 170 participants! Thank you the University of Zaragoza! Thank you Zaragoza!}

\section{Notes}

1Yuval Noah Harari, “We Need a Post-liberal Order Now,” The Economist, September 26, 2018.

"In the 21 st century we face global problems that even large nations cannot solve by themselves, hence it makes sense to switch at least some of our loyalties to a global identity."

"Yet that is not our inescapable destiny. We can still push forward with a truly global agenda, going beyond mere trade agreements, and stressing the loyalty all humans should owe to our species and our planet. Identities are forged through crisis. Humankind now faces the triple crisis of nuclear war, climate change and technological disruption. Unless humans realise their common predicament and make common cause, they are unlikely to survive this crisis."

"Contrary to common wisdom, there is nothing natural about nationalism. It is not rooted in human biology or psychology."

"I can be loyal at one and the same time to several identities - to my family, my village, my profession, my country, and also to my planet and the whole human species."

2 Charles Taylor, "Federations and Nations: Living Among Others," in Richard Kearney, States of Mind: Dialogues with Contemporary Thinkers on the European Mind (Manchester: Mancherster University Press, 1995), 23. 


\section{Opening Speech}

\section{Transnational History, Transnational Space, Transnational Law Professor Richard R. Weiner}

Department of Political Science, Rhode Island College, Providence, RI, USA

In the 1990s academic marketplace, transnational history emerged in the wake of the sprouting of international history, global history, and postcolonial history as historical subject fields. Christopher Bayly's TheBirth of the Modern World, 1780-1914 (2004) was a landmark in its emergence as an academic subject stressing connectedness in history, as a narrative of accelerating cross-border métissage, intercontextuality, and polycontextuality. As another historian of this school Sven Beckert reminds us, transnational history is more than an academic brand: it is a fundamentally different analytical space as well as a social movement in itself.

Transnational history gives us a sense of movement, flows, circulation, and intercultural interpretation, and an insight into the whole range of networked institutional connexions and contested history. Bayly's transnational history recognizes how the most ideological, social, cultural, economic and political movements have operated across politically bounded territory. These are now flows and movements within the interconnectedness of plural material and virtual worlds. The flows are not organized around a center.

Transnational history is neither the history of national selfdetermination that was the internationalism at "the Wilsonian moment," nor schematic universal history in the sense of some master teleological narrative. Indeed, transnational history denaturalizes the nation. Beyond the methodological nationalism of international relations and international law, jurists like Max Gutzwiller (1931) and 
Philip C. Jessup (1956) forged the concept of the "transnational" as not just the lex mercatoria but as a space of respective self-regulatory frameworks transcending national frontiers. The historian Ferdnand Braudel - in the spirit of Montesquieu - put into practice the same conceptual perspective in his chronicling the Mediterranean.

Thus transnational denotes both movement and flows provided by heterogeneous forces, and a sense of cooperative coordination, mutual trust and reciprocity in building institutionalized webs of governance. This is not a practice of nation-state projects, nor is it the interrelationships of nation-states. Rather, it refers predominantly to non-statist enterprises and associations operating across the borders once associated with nation-states and empire (reminiscent of practices in The Hanseatic League of the fourteenth century). Beyond movements, the transnational involves efforts to minimize collisions between associational interests by setting up protocols and standards. Nowadays, the transnational often tends to point beyond the value chains and supply chains of markets and the protection of private property relationships, as well as beyondresurgent deterritorialized banking's mobile digitized capital being able to move rapidly and easily. Transnational attributes permeate environmental protection issues such as global warming, climate change, carbon pollution emissions, and global water policies. Further, we note here: professional rules; "best practices;" threshold indicators; sensor verifiers; technical standards; operability standards; inter-operability protocols; performance criteria; and the constituting of human rights protections. We can also note institutionalized forms that mirror the global awareness of the negative externalities of markets and the limits to and vulnerabilities of the earth's sustainability. For examples, we may note: forestry stewardship councils; maritime stewardship councils dealing with fisheries; negotiated-network 
connected contracts among franchised commerce and e-businesses; transnational advocacy networks (TANs); and multi-scalar interregional and inter-urban constellations like the Network for Regional Governments for Sustainable Development (nrg4SD).

The transnational amounts to a steady decrease in the relevance of center/periphery functional differentiation. It is not oriented toward imposed hierarchy or central coordination. Instead, it is marked by a combining of the distributed capacities of the parts to build emergent properties of the whole. The transnational is a movement toward greater cognitive complexity marked by heterarchy, hybridity, and polycontextural logic.

The transnational relates to a growing functionally differentiated complexity of re-scaled cognitive spaces oriented toward a purpose of stabilizing social-economic dynamics. It thusrelates to mediating some sense of normative stabilization among a pluralism of contextual logics manifest as practices; as well as to mediatingsome sense of cognitive stabilization of legal pluralisms. This involves multilayered, polycentric self-regulating spaces outside formal nation-state government and vertical arborescent prescriptive standard-setting. This conceptually illuminates the complexity at, between, above, below, and alongside spaces or scales.

The transnational denotes space rather than place. Transnational space is the discretionary space of enterprises and associations acting across nation-state and associational borders. Territory/place does not disappear; rather, it becomes embedded in broader and more fluid constellations - as in a plasma of flow and movement powered by heterogeneous forces. Connections are important, not just some particular territory. Digital media can be a transnational space that sacrifices geography and racial backgrounds by bringing people together around shared interests rather than where they live. 
The transnational denotes spacefor thestandard-setting and rulemaking protocolisms involved in complexly functionally differentiated communications and social learning processes. These serve as guidelines for iterative negotiations to enable coordination and regulation. It deals with colliding systemic and subsystemic logics, aggregating and regulating them within an organization of recursive feedback relations.

Transnational law is what Max Weber referred to as "soft law" and "associational governance" created by non-statist enterprises rather than by the nation-state. Thus, protocolism denotes an ensemble of expectations, responsibilities and institutions of conflict regulation. The attendant norms imbuing transnational law revolve around and are determined by relational contracts and voluntary compliance that generate obligatory reciprocities within sustainability limits that we need toacknowledge.These are referred to as self-enforcing reciprocity norms (SERN).

All of these attributes enable us to comprehend connected histories within an emerging polycentric globalization. This iswhat Helmut Willke referred to in Smart Governance as concatenation, as in the mathematical theory of "string concatenation": the interlinking together of contexts that are systemic or subsystemic operational logics in interwoven meshwork or interlinked "chains." This linking develops in operations that are causally and interdependently interconnected. The word "concatenation" derivesfrom catena, which means "chain." Dense systemic and subsystemic institutional links/chains of a complex transnational world society emerge and tend toward a purpose of mutual stabilization.

Relentless functional differentiation intensifies and accelerates societal complexity of self-regulatory operative subsystems in cyberspace, where such complexity is subjected to new and 
unprecedented stress of intertwined autonomous systems and their operative logics.

Transnational space is a discretionary mutually referential space tending towards what is commensurate with complexity, and not necessarily tending toward convergence. It is a topography for webs of practices and meaning of what are often overlapping or complementary regulatory regimes; and of what are seemingly incommensurable complex colliding discourses and operational logics. On the one hand, such webs establish ordinates to facilitate cooperative capacity-building and coordination of multiple spatial operational logics and stabilization dynamics. On another, they respond to volatility, asymmetries, externalities, and looming crises. Such transnational space is configurative - enacted as ordinates (i.e., guidelines) - within metaphoric loops and loops within loops.

Transnational space reveals emergent trajectories of a global socioeconomic system, but not as a fully established system, given continued territorial hedges. This is nota world social system per se, but, as Willke notes, global webs of governance constituted in adecentered lateral world system crisscrossing and interconnecting transnational space. These include the subsystems in nation-states such as finance, science, health, environmental policy, higher education, sports. The world is lateral as Jeremy Rifkin puns in the

\section{Third Industrial Revolution.}

Each of these subsystems is pressured laterally to extend into a complementary world systemic trajectory by intensified and accelerated functional differentiation. They are pressured to fulfill the purposes and tasks of its operational logic within nation-state territorial boundaries. Each is propelled outward into the cyberspace and its complexity: manifested in telecommunications, transaction networks, and globally operating media. Each subsystem, in meshing 
into networks beyond its territorial boundaries, extends and mergesinto intertwined concatenated transnational space. And in so doing, each projects its needs, wants and claims with an appreciation for interest articulation, interest aggregation, and feedback dynamics. Concretely and substantively, the interaction between the subsystems and the lateral world system trajectories is observed and measured in impacts of deforestation, global warming, and pandemics.

Beyond a functional differentiation of role expectations, there also develops what Cornelius Castoriadis (1975) tagged as "the imaginary institution of society." Transnational space reveals institutionalizing trajectories of normative commitments, each as an unfolding normative order with its own entelechies. Socioeconomic systems move from pluralism to complexity. Here social-economic rights of organized capitalism are increasingly superseded by what Danilo Zolo designated in Democracy and Complexity as "rights of complexity." These are rights to preserve practices necessary for socioeconomic systems to sustain pattern maintenance, whether these practices are ethnic, linguistic, community or neighborhood based, craftsman or expert based. At their core, these are membership competences and responsibilities necessary for both functional and - what we refer to as reflexive - interdependence.

Transnational space of negotiated rule-making amounts to a space for interfaces of functioning and coding among cross-cutting institutional forms. These are interfaces for mutually referring relations among fragmented webs of governance regimes. Such ordered rule in transnational space can be understood in terms of its normative turn and its cognitive turn. First, there is understanding of an emergent normative foundation to transnational ordering (rather than a reversion to project nation-state ordering of a now superseded organized state capitalism). We may again recall and follow 
Montesquieu's method of defining the principequality of a regime's sustaining normative ordering in The Spirit of the Laws: the respective circumscribing principes of comparative regimes are virtue, honor, or fear. Montesquieu reminds us how we can crack the decentered network codes that define normative coherence in an ensemble of value priorities underlying institutionalizing practices. In the case of the transnational, we can characterize the principe of an emergent reconfigured and historically path-dependent ensemble of institutionalizing network practices in a word: reflexivity.

Reflexivity/reflexive capacity-building denote the recognition of recurrent mutual relations among multiple autonomous subsystem codings. The codes are procedural discourses framing our communicative interactions. The normative turn here circumscribes, infers, and induces. But in a reflexive sense it induces complementarity, not convergence. Reflexivity is necessitated by the challenges of complexity. Specifically, these are the overlapping webs of governance, and the trajectories of lateral world systems, intercontextuality and polycontextuality that characterize the normative ordering that defines and circumscribes.

Reflexivity means that society - here a world society - is understood only in our mutual recognition of the blind-spots that comes from seeing the world from the operant logic of our own lateral world system. It signifies how such particularistic needs are to be overcome, so that we recognize the external effects of our operant subsystem, and the need to get beyond the disposition to see the emergent world system in terms of a unified non-contextualized homogeneity. We are sensitized to the complexity we engage, leaving us open to continuous recursive social learning, leaving us open to new possibilities for "best practices," for new benchmarking possibilities. Institutions allow for a 
reflexive adaptation of rules and procedures on the circumscribed cognitive level.

Thus reflexive network governance denotes designed coordinating of interconnected and intertwined regulatory frameworks. It connects heterarchy with the need for coordinating the resolution of the colliding autonomous subsystemic regime operant logics. Through transnational law, such governance takes resolution of conflict of laws beyond nation-state federal boundaries. It responds to socio-ecological vulnerability, and encourages recursive social learning through mutual monitoring with a purpose of establishing sustainable development.

Transnational law is triggered by the mutual referents that rein in the processes of functional differentiation without recourse to steering from a single center of control causing de-differentiation. It functions in terms of practices of procedural rationality with which we: (1) establish the mutual trust necessary for interaction; (2) mutually monitor so that the protocols of trust are carried out; and (3) often regulate and reconcile conflicts of subsystemic procedural rationalities. It procedurally assures the reproduction of complementary practices, and operates in the realm of contingency and material practice. It operates typically in the register of rulecompliance rather than evaluations of the rules themselves. And it does so with the purpose of responding to a need for institutional complementarity and coupling - weaving together fragmented protocolisms rather than resorting to command-sanction-control regulation.

Transnational law does so on a cognitive level as an institutional facticity of standards and protocolisms we develop, rather than in being understood in an exterior sense of circumscribing values: that is, of an external underlying normative order. By institutional facticity, 
following the jurisprudence of Neil MacCormick, we denote a legitimated fact having phenomenological meaning, rather than a brute physical or instrumental fact; and we resist a theory of gapless normativism, as in Hans Kelsen's foundationalist Grundnorm. Institutional facticity for MacCormick emphasizes the nature of our participation in protocols of obligation and responsibility. As such, normativity itself is not to be understood as a secondary derivative feature but as grounded in our own practical reasoning in developing procedures. These procedures of practical rationality sustain mutual trust and reconcile collisions and conflicts of laws. Institutional facticity on the cognitive and phenomenological level serves as the ontological foundation to the normative, and not vice versa. Accordingly, this is an ontological foundation to hermeneutical internal relations of justification, themselves expressed in discourse theoretical terms rather than in causal terms of effect.

Transnational law can be understood in terms of institutionalizing practices:

- voluntary benchmarking;

- protocols of fair trade and fair labor practice;

- threshold sensors and threshold triggering sanctions;

- triggered rolling rule updating;

- performance audits;

- sustainability impact assessment audits;

- engaging in feedback reflection to set goals for the improvement or modification of standards and protocols.

To conclude, transnational law is the vital infrastructure of a global social-economic system, providing a core institutional framework for the continuing creation and distribution of norms in discretionary 
transnational space. My argument is framed dialectically: the institutionalist/ institutionalizing perspective needs to be better aligned with the systems perspective. My purpose, in the spirit of Montesquieu, is to decode implicit normative claims in institutionalizing practices. Specifically: (1) to frame the institutionally guaranteeing of the intercontextuality and open-ness of each operant sphere in the trajectory of lateral world systems; and (2) to rationally reconstruct practices in terms of the internal relations justifying a realm of legitimations, in a manner characterized by Frank Michelman as an "internal rules antipositivism."

$* * *$

Prepared in the summer before the Covid-19 pandemic shocked the modern faith that humankind can reshape the natural world as it pleases, this essay retains relevancy and timeliness. It frames the multiple contexts that must be considered, besides the disruption of and resiliency of supply-side chains and demand-side expectations. Besides and beyond, there is our capacity of interconnectedness beyond nation-state boundaries for relating to one another, and sharing in reflexive monitoring and regulating of risks and shocks. The risks and shocks relate specifically to biosecurity, ecological destruction, intergenerational inequity, as well as labor market precarities. While there is little consensus on basic values in dealing with the pandemic or the future, and while nation-states increasingly insulate all forms of movements, flows will continue. And both transnational space and transnational law will persist. 


\section{$\underline{\text { Acknowledgment }}$}

My choice of subject was inspired by the revived appreciation of Montesquieu's concept of principe as developed by Charles S. Maier at the Minda de Gunzburg Center for European Studies at Harvard University since the publication of his book Once Within Borders: Territories of Power, Wealth and Belonging since 1500 (2016). This spur to ruminating has reinforced three decades of my own great regard for the writings of Günther Teubner of the Goethe Universität, Frankfurt a.M., as well as my correspondence this past decade with Peter Feindt, now at the Humboldt Universität in Berlin.

\section{Works Cited}

Bayly, Christopher.TheBirth of the Modern World, 1780-1914: Global Connections and Comparisons.Oxford: Blackwell, 2004.

Bayly, Christopher, Sven Beckert, et al. "AHR Conversation: On Transnational History." American Historical Review 11, no. 5 (2006): 1441-64.

Beckert, Sven. Empire of Cotton: A Global History. New York: Knopf, 2014.

Beckert, Sven, and Dominic Sachsenmaier, eds. Global History, Globally: Research and Practice Around the World. London: Bloomsbury Academic, 2018.

Castoriadis, Cornelius. The Imaginary Institution of Society. Translated by Kathleen Blarney. Cambridge: Polity, 1987. Originally published as L'institution imaginaire de la Société. Paris: Seuil, 1975.

Feindt, Peter, and Sabine Wieland. "Reflexive Governance: Exploring the Concept and Assessing its Critical Potential for Sustainable Development." Journal of Environmental Policy and Planning 20, no. 6 (2018): 661-74.

Habermas, Jürgen. Between Facts and Norms: Contribution to a Discourse Theory of Law and Democracy. Translated by W. Rehg. Cambridge, MA: MIT Press, 1996.

Kjaer, Poul. Constitutionalism in the Global Realm: A Sociological Approach. New York: Routledge, 2014.

Lofdahl, Corey. Environmental Impacts of Globalization and Trade: A Systems Study. Cambridge, MA: MIT Press, 2002.

MacCormick, Neil. The Institutions of Law: An Essay in Legal Theory. Oxford: Oxford University Press, 2007.

MacCormick, Neil. Practical Reason in Law and Morality. Oxford: Oxford University Press, 2011.

Michelman, Frank. "Political Truth and the Rule of Law." Tel Aviv University Studies in Law 8 (1988): 281-91.

Rifkin, Jeremy. The Third Industrial Revolution: How Lateral Power is Transforming Energy, the Economy and the World. New York: Palgrave Macmillan, 2011.

Sassen, Saskia. Territory and Territoriality in the Global Economy."International Sociology 15, no. 2 (2000): 373-93. 
Teubner, Günther. Constitutional Fragments: Societal Constitutionalism and Globalization. Translated by G. Norbury. Oxford: Oxford University Press, 2012.

Teubner, Günther. De Collisione Discursuum: Communicative Rationalities in Law, Morality and Politics." Cardozo Law Review 17, no. 4 (1996): 901-18.

Teubner, Günther. "Transnational Economic Constitutionalism in the Varieties of Capitalism." Italian Law Journal 1, no. 2 (2015): 219-48.

Willke, Helmut. Smart Governance: Governing the Global Knowledge Society. Frankfurt: Campus Verlag, 2007.

Zolo, Danilo. Democracy and Complexity: A Realistic Approach. University Park, PA: Penn State University Press, 1992. 
Workshop 1:

Approaches to God

Chair: Stanley Tweyman 


\section{Hume's Dialogues Concerning Natural Religion and the Six Moments}

of Scepticism

Philip MacEwen

Departments of Philosophy and Humanities, York University, Toronto, Canada

Students of the Enlightenment are divided on whether it was a radical or religious period. One of the most important Enlightenment publications on religion is Hume's Dialogues Concerning Natural Religion (1779). I argue that it is dominantly radical and recessively religious. This feature can perhaps be best understood in terms of six moments of scepticism, generated from Hume's treatment of scepticism in An Enquiry concerning Human Understanding (1748), which provide the context of my discussion.

\section{a. Hume on Scepticism}

In An Enquiry concerning Human Understanding (hereafter E), Section 12, "Of the Academical or Sceptical Philosophy,"1 Hume identifies four types of scepticism, two of which are antecedent to, and two consequent upon, all study and philosophy. The first type of antecedent skepticism

... recommends an universal doubt, not only of our former opinions and principles, but also of our very faculties, of whose veracity, say they [i.e., "Descartes and others" who endorse it] we must assure ourselves, by a chain of reasoning, deduced from some original principle... ${ }^{2}$ 
Hume's response to this type of scepticism is brief. First, there is no such original principle, and second, even if there were, we could not advance beyond it except by using the very faculties which it places in doubt. $^{3}$

The second type of scepticism is "more moderate" than the first, and is “... a necessary preparative to the study of philosophy by weaning our minds from all those prejudices, which we may have imbibed from education and rash opinion." "Since Hume calls the second type of scepticism "more moderate" than the first, we might call the first "excessive" scepticism. Given that both types of scepticism are antecedent to study and philosophy, we shall call them "antecedent excessive" and "antecedent moderate" scepticism respectively.

The third and fourth types of scepticism are consequent upon all study and philosophy or, more precisely, once positions and arguments have been presented:

\begin{abstract}
There is another species of scepticism, consequent to science and enquiry, when men are supposed to have discovered, either the absolute fallaciousness of their mental faculties, or their unfitness to reach any fixed determination in all those curious subjects of speculation, about which they are commonly employed. ${ }^{5}$
\end{abstract}

We can discern two types of consequent scepticism here: excessive and moderate. The first discovers "the absolute fallaciousness of [the] mental faculties [of those concerned]" with respect to the positions and arguments presented and the second "the unfitness [of their mental faculties] to reach any fixed determination in all those curious speculations, about which they are commonly employed.” Accordingly, 
the third and fourth types of scepticism might be called "consequent excessive" and "consequent moderate" scepticism respectively.

Since Hume denies any role in thought for antecedent excessive scepticism, there can be no conflict between it and antecedent moderate scepticism. However, there can be, and frequently is, a conflict between consequent excessive and consequent moderate scepticism. Hume sometimes refers to consequent excessive scepticism as "Pyrrhonism" or "Pyrrhonian doubt" and those who employ it as "Pyrrhonians,"6 and to consequent moderate scepticism as "academical." The conflict between the two is that the former is an antidote to dogmatism which, in turn, “... see[s] objects only on one side, and ha[s] no idea of any counterposing argument." 8 The role of consequent excessive scepticism, or Pyrrhonism, is to neutralize dogmatism by showing "the absolute fallaciousness of [its votaries'] mental faculties." However, Pyrrhonian arguments typically overshoot their mark, because they do not distinguish between what is acceptable or unacceptable in the tenets of dogmatists, thereby generating "undistinguished doubts" which need to be corrected by "common sense and reflection." The role of consequent moderate scepticism is to correct these doubts, by neutralizing the tenets of dogmatists and reaching conclusions which are consistent with common sense and reflection, conclusions with which erstwhile dogmatists, given the kind of belief that may be involved in their tenets, i.e., natural belief, will themselves agree.

Accordingly, a polemic between Hume's sceptic and dogmatist should consist of the following moments: (1) the sceptic endorses antecedent moderate scepticism regarding the subject at hand; (2) the dogmatist responds by propounding a dogmatic position on the subject at hand which, (3) the sceptic neutralizes with consequent excessive, or Pyrrhonian, sceptical arguments; (4) the dogmatist is thereby 
dispossessed of dogmatism regarding the subject at hand, but (5) the sceptic has to go back and, by common sense and reflection, correct the undistinguished doubts that have been raised by the sceptic's Pyrrhonian critique of the dogmatist's position, which ultimately results in (6) the sceptic and the erstwhile dogmatist finding themselves in agreement on the subject at hand.

\section{b. Philo's Scepticism and Cleanthes' Argument from Design}

My discussion will focus on moments (1)-(3) (Parts 2, and 4-8), which confirm the dominantly radical nature of $\mathrm{D}$, and (4)-(6) (Part 12,) which confirm the recessively religious nature of $\mathrm{D}$.

(1) Philo's first observations in Part 2 counsel the interlocutors to adopt antecedent moderate scepticism with respect to natural religion:

Our ideas reach no farther than our experience: We have no experience of divine attributes and operations: I need not conclude my syllogism; You can draw the inference yourself... [J]ust reasoning and sound piety here concur ... [and] establish the adorably mysterious and incomprehensible nature of the Supreme Being. ${ }^{10}$

Cleanthes responds by propounding his dogmatical argument from design. This argument is dogmatical because it does precisely what Philo's antecedent moderate scepticism counsels against, i.e., reasoning about things of which we have no ideas because they go beyond our experience.

(2) Cleanthes' argument consists of two arguments which can be mapped as one argument as follows: Premise 1 Human artifacts have attributes A (means to ends relations) and B (coherence of parts); 
Premise 2 The world/universe has A and B; Premise 3 In addition, human artifacts have attribute $\mathrm{C}$ (mind or intelligence as their cause of design); Conclusion/Premise 4 Therefore the world/universe also has C; Premise 5 Human artifacts have C; Premise 6 The world/universe has $\mathrm{C}$; Premise $7 \mathrm{In}$ addition, human artifacts have attribute D (an external cause of design); Conclusion Therefore, the world/universe also has D. ${ }^{11}$

Once Demea expresses his horror that Cleanthes' argument is not a priori, ${ }^{12}$ Philo begins his extended consequent extreme, or Pyrrhonian, sceptical critique of it. This is the third moment of the (1)-(6) pattern outlined above. It occupies most of the remainder of Part 2, the entire second half of Part 4, with the exception of one response from Cleanthes, and all of Parts 5-8 with intermittent responses from Cleanthes and, occasionally, Demea.

(3) The main criticisms Philo makes of Cleanthes' argument from design, using consequent excessive, or Pyrrhonian scepticism, are the following: the argument (a) involves an infinite regress, ${ }^{13}$ (b) is susceptible of reduction to absurdity, ${ }^{14}$ and (c) uses "...data which are equally supportive (and therefore not supportive at all) of an openended list of alternative hypotheses to a Designer of the world who is intelligent and external (Parts 6-8). ${ }^{15}$ The cumulative effect of these three criticisms is that Cleanthes' argument is no more or less plausible than any of the alternative hypotheses, in which case there is no reason to prefer it over them. Based on Parts 2 and 4-8, then, D is a radical document, because it places belief about natural religion, or what we can know about the nature of God based on a study of the natural world, outside the realm of reasonable discourse. 


\section{c. Philo, Cleanthes, and "True Religion"}

(4) Cleanthes is dispossessed of dogmatism regarding natural religion, not by an overt confession on his part, but by a dramatic shift in the relationship between him and Philo. At the beginning of Part 12, the dialogue between Cleanthes and Philo transitions from a polemic on the benevolence and power of the Deity (Parts 10 and 11) to a personal, even confessional, reconsideration of natural religion. ${ }^{16}$

Of Cleanthes, we can rightfully say that his changed attitude confirms that he has been dispossessed of his dogmatism on the subject of natural religion. No dogmatist would ever respond to a sceptical opponent in such a manner, particularly immediately after suffering a humiliating defeat by Philo. Of Philo, we can see that the process of correcting by common sense and reflection the undistinguished doubts of his consequent excessive, or Pyrrhonian, critique of Cleanthes' argument from design has begun in earnest. Indeed, Philo will use this process to articulate his own religious commitment, i.e., natural belief in true religion, something he could not do, both epistemologically and dialogically, before he had brought Cleanthes to the point where he had abandoned his religious dogmatism regarding natural religion.

What are Philo's undistinguished doubts about Cleanthes' argument from design, and how does he correct them by common sense and reflection?

(5) Philo's confession at the beginning of Part 12 corrects Philo's undistinguished doubts by common sense through aligning itself with the common sense view that the world exhibits design as seen "...in the inexplicable contrivance and artifice of nature." Even "the most careless, the most stupid thinker" and those "hardened in absurd 
systems," are unable "at all times to reject it" (the common sense belief that the world exhibits design). ${ }^{17}$

Not only does common sense hold that the world exhibits design, but, also, that it was designed by an intelligent Designer:

That the works of nature bear a great analogy to the productions of art is evident; and according to all the rules of good reasoning, we ought to infer... that their causes have a proportional analogy... Here then the existence of a DEITY is plainly ascertained by reason... ${ }^{18}$

Philo corrects his undistinguished doubts about Cleanthes' argument from design by reflection via his consequent moderate sceptical observations regarding "verbal disputes." Verbal disputes are "...controversies concerning the degrees of quality or circumstance." 19 Unlike disputes about quantity and number, that are "susceptible of exact mensuration...,"20 verbal disputes “...can never, by any precautions or any definitions, ...reach a reasonable certainty or precision." 21

One of the main verbal disputes is about theism. The theist believes that there is a great, even immeasurable, difference between the divine and the human mind. "The atheist," says Philo, “...who, I assert is only nominally so, and can never possibly be in earnest," 22 believes that the world exhibits design and that it has an original principle of order. Furthermore, the atheist believes that the original principle of order in the world bears "some remote inconceivable analogy" 23 to the other operations of nature, including the human mind and thought. "Where then," cries Philo to the theist and the professed atheist, "is the subject of your dispute?"24 
In his conclusion to the argument from design in Part 2, Cleanthes said that "...the Author of Nature is somewhat similar to the mind of man; though possessed of much larger faculties, proportioned to the grandeur of the work, which he has executed." 25 The words "somewhat similar to" and "much larger faculties" show, in Philo's terminology, that Cleanthes argument is a "dispute of words." It is on a par with questions about the greatness of Hannibal, the degree of beauty of Cleopatra, and the epithet of praise to which Livy or Thucydides is entitled. Philo is able to correct his undistinguished doubts about Cleanthes' argument from design by reflection because he now realizes that, the virtues of his friend's argument notwithstanding, it is ultimately a verbal dispute which can never be definitely resolved. Because of the common sense nature of the beliefs concerned, Philo always held them - indeed, he could not help but hold them, though he was never able to express his belief until he had dispossessed Cleanthes of his dogmatism, using consequent excessive, or Pyrrhonian, scepticism to critique the argument from design. Epistemologically and dialogically, it is not until Part 12, as we can now see, that Philo is able to do this.

(6) The last moment of the (1)-(6) pattern occurs when the sceptic and the erstwhile dogmatist find themselves in substantial agreement on the subject at hand. Given what has already been said, we can establish where Philo and Cleanthes concur vis-à-vis natural religion. Their point of contact on what both parties call "true religion" 26 and what Philo calls "the philosophical and rational kind [of religion]" 27 is in contrast to what Cleanthes calls "false religion"28 and "[r]eligion, however corrupted"29 and Philo variously refers to as "vulgar superstition/s,"30 "popular religion/s,"31 "religion as it has commonly been found in the world," 32 and "superstition or enthusiasm." 33 Cleanthes holds that "Religion, however corrupted, is still better than 
no religion at all" 34 because it is a "security to morals" through its doctrine of a future state. ${ }^{35}$ Philo, on the other hand, counters that religion thus construed does the contrary. ${ }^{36}$

Cleanthes and Philo never reach agreement on "false religion," the former contending that it is better than no religion at all, given its salutary effects on individual and social morality thanks to the doctrine of a future state, while the latter maintains that it has an adverse effect on morality, both personal and social, often resulting in "Factions, civil wars, persecutions, subversions of government, oppression, [and] slavery." 37

D concludes with an extended soliloquy by Philo on the virtue of true religion. As the final speech, it may fairly be said to capture the confirmed view of the speakers:

If the whole of natural theology...resolves itself into one simple...proposition, that the causes of order in the universe probably bear some remote analogy to human intelligence: ...what can the most inquisitive, contemplative, and religious man do more than... believe, that the arguments, on which it is established, exceed the objections...? ${ }^{38}$

Philo has already given a heartfelt expression of his natural belief in natural religion. "These, Cleanthes are my unfeigned sentiments on this subject [natural religion]; and these sentiments, you know, I have ever cherished and maintained." 39 It is because of his natural belief in natural religion that Philo has the intellectual response to natural religion he does. Since Cleanthes never speaks again after his conversation with Philo on false religion has concluded, ${ }^{40}$ he does not get a chance to give his intellectual response to natural religion. 
However, if what I have said above is true, there is no need for him to do so. Because the belief that the world exhibits design and is the product of an intelligent Designer is a natural belief, then Cleanthes must have it too! Neither he, nor Philo, nor anyone else reaches it by reasoning and argument, much less via the argument from design. Cleanthes and Philo find themselves in agreement, because they hold the same natural belief. Compared with this, their disagreements about false religion and the argument from design pale into insignificance. The fact that moment (6) happens so late, and is prefaced by Philo's extended critique of the argument from design using consequent excessive, or Pyrrhonian, scepticism (Parts 2 and 48 ), means that religion is recessive in $\mathrm{D}$, both in terms of its place and its role. Nevertheless, this should not obscure the startling truth that the ultimate verdict on religion in $\mathrm{D}$ is affirmative, not negative.

\section{Notes}

\footnotetext{
${ }^{1}$ David Hume, An Enquiry concerning Human Understanding (hereafter E) (1748), in Enquiries concerning Human Understanding and concerning the Principles of Morals, ed. L.A. Selby-Bigge, 3rd ed. revised by P.H. Nidditch (Oxford: Clarendon Press, 1975).

2 Ibid., 149-50.

${ }^{3}$ Ibid., 150.

${ }^{4}$ Ibid.

${ }^{5}$ Ibid. In Hume's Dialogues Concerning Natural Religion (hereafter D), Philo gives three examples of "all those curious subjects of speculation, about which they [the mental faculties of human beings] are commonly employed," and describes the nature of this speculation. "Men may argue to eternity, whether Hannibal be great, or a very great, or a superlatively great man, what degree of beauty Cleopatra possessed, what epithet of praise Livy or Thucydides is entitled to, without bringing the controversy to any determination... Because the degrees of these qualities are not, like quantity or number, susceptible to any exact mensuration, which may be the standard in the controversy. That the dispute concerning theism is of this nature, and consequently is merely verbal, or perhaps, if possible, still more incurably ambiguous, will appear upon the slightest enquiry." David Hume, Dialogues Concerning Natural
} Religion, ed. Stanley Tweyman (Ann Arbour: Caravan Books, 2000), 175. All references to D are from this edition.). 
${ }^{6} \mathrm{E}, 158 ; 160-62$.

${ }^{7}$ Ibid., 161.

${ }^{8}$ Ibid.

${ }^{9}$ Ibid.

${ }^{10} \mathrm{D}, 108$.

${ }^{11}$ I am indebted to Stanley Tweyman for this map of Cleanthes' argument from design (see Tweyman's Introduction in his edition of D, 1-94, 5. The only change I have made is to map the two arguments as one argument.

12 "What! No demonstrations of the being of a God? No abstract arguments! No proofs a priori! Are these, which have hitherto been so much insisted on by philosophers, all fallacy, all sophism?" (D, 109).

${ }^{13} \mathrm{D}$, Part $4,125$.

${ }^{14}$ D, Part 5, 129-31.

${ }^{15}$ Stanley Tweyman, Scepticism and Belief in Hume's 'Dialogues Concerning Natural Religion' (Dordrecht: Martinus Nijhoff Publishers, 1986), 122. Philo's list of alternative hypotheses to a Designer of the world who is intelligent and external to it is presented in D, Parts 6-8, 133-43.

${ }^{16} \mathrm{D}, 172-73$.

${ }^{17} \mathrm{D}, 172$.

${ }^{18} \mathrm{D}, 174-75$.

${ }^{19} \mathrm{D}, 175$.

${ }^{20}$ Ibid.

${ }^{21}$ Ibid.

${ }^{22} \mathrm{D}, 176$. We shall see in a moment why Philo's atheist can never possibly be in earnest.

${ }^{23}$ Ibid.

${ }^{24}$ Ibid.

${ }^{25} \mathrm{D}, 109$.

${ }^{26} \mathrm{D}, 177$ and 182 (Cleanthes); 181 (Philo).

${ }^{27} \mathrm{D}, 178$.

${ }^{28} \mathrm{D}, 182$.

${ }^{29} \mathrm{D}, 177$.

${ }^{30} \mathrm{D}, 177 ; 180$.

${ }^{31} \mathrm{D}, 180-81$.

${ }^{32} \mathrm{D}, 181$.

${ }^{33}$ Ibid.

${ }^{34} \mathrm{D}, 177$.

${ }^{35}$ Ibid.

${ }^{36} \mathrm{D}, 177$.

${ }^{37}$ Ibid. 
${ }^{38} \mathrm{D}, 184-85$.

${ }^{39} \mathrm{D}, 177$.

${ }^{40}$ The conversation on false religion occupies about half of Part 12, beginning with the first paragraph on page 177 and concluding at the end of the second paragraph on page 184 . 


\section{Descartes' Failure in the Third Meditation to Prove that God Created}

\section{Descartes $^{1}$}

Stanley Tweyman

Departments of Philosophy and Humanities, York University, Toronto, Canada

In the third meditation, Descartes moves beyond the knowledge of his existence, when he attempts to establish the existence of a veracious God as his creator. He informs us that, although no deception is possible in regard to the clear and distinct apprehension of his existence, he is concerned about other clear and distinct ideas, particularly those in mathematics. Clear and distinct conceptions in mathematics are as psychologically irresistible as is the connection between thought and existence; only in the former, however, is he concerned that a deceiving deity may have so constituted his mind that he is deceived in regard to all mathematical calculations and theorems. Accordingly, Descartes sets for himself the task of determining whether he was created by God, and if he finds that this is the case, he must also inquire whether God may be a deceiver: he maintains that, without a knowledge of these two truths, he can never be certain of anything, other than his own existence.

I have two concerns regarding Descartes' procedure in the third meditation.

(1) Descartes introduces the hypothesis of a deceiving deity as a means of questioning the truth of mathematics, and yet, the 'proofs' regarding God's existence in the third meditation involve a number of calculations centering on objective and formal reality. He argues that ideas, when regarded as representations of things, differ in terms of the amount of objective reality they contain: ideas representing 
substances contain more objective reality than ideas of modes, and the idea through which we apprehend God has more objective reality than those through which finite substances are represented. Granting that "there must at least be as much reality in the efficient and total cause as in its effect" (M. 63), and that "in order that an idea should contain some one certain objective reality rather than another, it must without doubt derive it from some cause in which there is at least as much formal reality as this idea contains of objective reality" (M. 64), he goes on to prove that only God could have given him the idea of God, and subsequently, in the second 'proof', that only God could have created the idea of God, and Descartes, who possesses the idea of God. Now, for the point I am going to make, it is not necessary to enter into a detailed analysis of Descartes' arguments for God's existence in the third meditation. ${ }^{2}$ Rather, what I now propose to examine is the acceptability of the calculus which the argument evidently requires the calculus involved in deciding what can, and cannot, be posited as a possible cause of an idea with a certain objective reality. To decide this question, I want to turn to Descartes' doubts in the first meditation regarding mathematics. One of the reasons given for doubting mathematics is the possibility that God might have endowed him with such a nature that he may be deceived, even where matters appear to him most manifest. In the first meditation, the examples he uses are adding two and three and counting the sides of a square, or judging "of things yet simpler, if anything simpler can be imagined" (M. 48). In other words, he worries that he is (or may be) erring in cases where simple calculations are made, and he claims that only by proving the existence of a veracious God who created him can such concerns can be removed. Now, the task of deciding what can be regarded as the cause of the objective reality of a certain idea involves a number of calculations, namely, the precise amount of objective reality an idea 
possesses, the precise amount of formal (or eminent) reality causal candidates possess, and a comparison involving the amounts of reality possessed by each. Such calculations appear to be on a par with, if not more difficult than, counting the sides of a square or adding three and two, and consequently, Descartes should have rejected such a procedure as an acceptable approach to a knowledge of God's existence. In short, the 'proofs' of God's existence utilize a procedure which has, in fact, been rejected by Descartes, in that it is subject to hyperbolic doubt.

(2) In The Preface to the Principles of Philosophy, Descartes informs us that his Meditations contains his metaphysics, which is concerned with the first principles of human knowledge, "amongst which is the explanation of the principal attributes of God" (HRI, 211). First principles are self-evident, and are accepted as true, once they are grasped by the mind. In the Replies to the Second Set of Objections, Descartes contrasts the method used in geometry (he calls it 'synthesis'), with the method he uses in his Meditations, when he is attempting to uncover the first principles of human knowledge (he refers to this method as 'analysis'). He informs us that synthesis demonstrates its conclusions, employs definitions, postulates, axioms, theorems, and problems, "so that if one of the conclusions that follow is denied, it may at once be shown to be contained in what has gone before." He claims not to have used this method in his Meditations "because it does not show the way in which the matter taught was discovered." Analysis, on the other hand, the method in his Meditations "shows the true way by which a thing was methodically discovered and derived... so that, if the reader cares to follow it and give sufficient attention to everything, he understands the matter no less perfectly and makes it as much his own as if he had discovered it" (M.101-102). Analysis is employed to assist with focusing our 
attention on the appropriate ideas which constitute a metaphysical first principle, and assists in intuiting the self-evidence of this first principle.

The cumulative effect of these two concerns is to convince me that Descartes considers knowledge of God in the third meditation to be a metaphysical first principle, and that, therefore, God must be known through intuition. Descartes' intuitive treatment of God as a first principle appears in the last three paragraphs in the third mediation, in which he speaks of the idea of God as "innate in me, just as the idea of myself is innate in me," and that God has placed this idea within him "to be like the mark of the workman imprinted on his work; and it is likewise not essential that the mark shall be something different from the work itself" (M. 71). In the Reply to Objections $V$, Descartes attempts to clarify the latter, by explaining that his idea of God stands to the idea he has of himself as the technique of a painting stands to the painting of which it is the technique.

When you ask whence I get my proof that the idea of God is, as it were, the mark of the workman imprinted on his work, and what is the mode in which it is impressed and what is the form of that mark, it is very much as if I, coming across a picture which showed a technique that pointed to Apelles alone as the painter, were to say that the inimitable technique was, so to speak, a mark impressed by Apelles on all his pictures in order to distinguish them from others, but you replied with the questions: "what is the form of that mark?" and what is its mode of impression?" Such an inquiry would seem to merit laughter rather that any reply" (HR11, 221).

When Descartes discovers the necessary connection between thought and existence in the second meditation, he finds that he can trust this connection, because in this case, both thought and existence are selfreferential, that is, it is his thought and his existence to which he is 
attending, and not a copy or representation of his thought and his existence. Therefore, there is no concern here as to whether what he is thinking corresponds to what he is thinking about. Now, in telling us that the idea of God is contained in the idea he has of himself, and that this idea is like the mark of the workman imprinted on his work, Descartes is, once again, attempting to avoid the problem of correspondence. That is, if all that he finds in the idea of the self is self-evident, and if he finds that the idea of God is contained in the idea of the self in a non-copy manner, as the technique of a painting is found in the painting, then Descartes would have us believe that he must accept that he was created by God. I will now attempt to show that he is not convincing here.

An illustration (adapted from Descartes) will be helpful. An art forger masters the technique employed by Apelles, and produces a counterfeit painting that deceives the art world. The fact that the technique of the artist is in the painting and not simply represented in the painting does not prevent the forgery from occurring. In short, self-reference in the painting does not guarantee truth about the artist, or the technique used to produce the painting. Now, Descartes discovers what he regards as God's mark imprinted on the idea he has of himself. Why should he trust what he finds? It cannot be because he has 'proved' that the objective reality of the idea of God could only have come from God (who possesses formally what the idea of God possesses objectively), given his doubts about mathematical calculations. Descartes tells us that the idea of God is like the mark of the workman imprinted on his work; hence, the idea of God for Descartes is supposedly self-referential, as the technique of a painting is self-referential. That is, the technique of the painting is in the painting, and the idea of God is in Descartes, qua thinking thing. Regarding his treatment of the existence of the self in the second 
meditation, we have seen that, because it is his thought and his existence which he intuits, he concludes that whatever further he intuits as necessarily connected with the idea he has of himself as a thinking thing is necessarily true, as well. It is in this spirit in the second meditation that Descartes concludes that, insofar as he is a thinking thing, he is "a thing which doubts, understands, affirms, denies, will, refuses, which also imagines and feels" (M. 54). In the third meditation, he holds that he has, once again, added to his knowledge of himself, once he discovers the idea of God in the idea he has of himself.

The difficulty with this defense of the idea of God and its accompanying awareness of God as Descartes' creator is that Descartes cannot establish that the idea of the self which he has, and its accompanying awareness of the idea of God was not given to him by the evil genius, or a deceiving deity. Regardless of the origin of the idea he possesses of himself - a veracious God, a deceiving deity, or the evil genius - Descartes still has the problem, which he cannot solve within his philosophical framework, of establishing that he was created by God, and not by the evil genius, or a deceiving deity. The proofs of God's existence are themselves based on calculations and, therefore, are dubitable in the way that mathematics is regarded as dubitable in the first meditation; hence, they cannot be of assistance here. And, the fact that Descartes finds the idea of God in the same idea through which he knows himself helps him not at all: he still must prove that the idea of the self and the idea of God were created by a non-deceiving God, and this he cannot do in a manner which carries with it indubitability and truth. It may be the case that the self which Descartes intuits in the second meditation, which has within it an idea of God as Descartes' creator, was given to him by the 
evil genius, or a deceiving deity, and Descartes has no means of ruling this out.

If Descartes was created by the evil genius or a deceiving deity, he can still accept that he exists as a thinking thing. Deception is not possible here, because his awareness of his existence as a thinking thing with its attendant modes of thought is not a copy of anything. In short, the knowledge he intuits of himself in the second meditation is free from all doubt and uncertainty, no matter who, or what, created him.

But when Descartes proceeds in the third meditation with his inquiry into the existence and nature of God, he cannot establish claims about God with indubitability and certainty. It is true that the nonreferential character of the idea he has of himself is sufficient to convince him that he is a thinking thing (res cogitans). It is also true that he finds within the intuition of himself, the idea of God as his creator (as the technique of a painting is in the painting), and this persuades Descartes that he was created by God. However, whereas the idea of the self involves no reference beyond Descartes, and hence is self-referential and indubitable, the idea of God purports to provide knowledge of God, who Descartes holds is his creator. Notice that in the passage which I have already quoted from the Fifth Set of Objections, Descartes speaks of "coming across a picture which showed a technique that pointed to Apelles alone as the painter..." (HR 11, 221, my italics). The technique discovered in the painting points to the artist (Apelles), whose technique is already known by us. The success of this process requires that one already knows the essentials of Apelles' technique in producing a painting; otherwise, the forgery would be taken to be an authentic work of art. Now, to deem Descartes' approach acceptable, prior to giving his attention to the idea of God which he finds in himself, he would already have to know God's technique when God creates anything, including Descartes. But, 
Descartes claims to learn God's technique in creating him from the idea of God which he intuits in the idea he has of himself as a thinking thing. The Apelles illustration works, because we have prior knowledge of the technique employed by Apelles, so that the technique found in the painting can be compared to the technique we know is Apelles' technique. But since Descartes does not have prior knowledge of God's technique in creating Descartes, or for that matter in creating anything at all, Descartes cannot hold that it is indubitable that the idea of God was given to him by God. The idea that he has of God could have been given to him by the evil genius, or a deceiving deity. Descartes has no way of ruling out these alternatives, as the source of his creation. Accordingly, he also cannot accept as reliable the repugnancy he intuits between the idea of a supremely perfect being and deception. A deceiving genius might have so constituted him that he cannot but think that God is the cause of his existence and that the cause of his existence cannot be a deceiver. The self's existence is indubitable and true (for the reasons discussed earlier), but claims to know the cause of the self and its non-deceiving nature through the idea of God can be subjected to doubt. Further, since Descartes' demonstration in the fourth meditation of the truth of the principle concerning clarity and distinctness depends upon a knowledge of God as his creator and as not being a deceiver, it follows, from the considerations put forth above, that he has also been unsuccessful in establishing the truth of this principle.

I will conclude my paper by inquiring into the relation in the third meditation between Descartes' two 'proofs' for the existence of God and his intuitive knowledge of God as his creator. The first 'proof', even if accepted, only establishes that God is the cause of his idea of God. The second 'proof' is intended to establish that God is the cause of Descartes' idea of God and the cause of Descartes who possesses the 


\section{idea of God. Since this knowledge is a Cartesian first principle, Descartes insists that the only means of knowing this connection is through intuition, and not through argumentation.}

\section{Notes}

\footnotetext{
${ }^{1}$ All references to Descartes' Meditations on First Philosophy are taken from the In Focus edition, edited and with a critical introduction by Stanley Tweyman (London: Routledge), 1993; hereafter cited as M. followed by the page number. All references to Descartes' other writings are taken from the Haldane and Ross two-volume edition The Philosophical Works of Descartes (Cambridge: Cambridge University Press, 1970), and hereafter cited as HR followed by the volume and page number.

${ }^{2}$ Nevertheless, if we do inquire into the principles which the argument employs, we can find them to be unacceptable in terms of the rigor demanded by Cartesian doubt. For example, the principle 'that there must be at least as much reality in the efficient and total cause as in the effect' is accepted within the proof without any concern for the fact that it relies on a mathematical conception as to how things come to be, and yet the reliability of mathematics is one of the matters to be settled by the proof of God's existence. The distinction between formal and objective reality is also central to the proof, and it too falls short of the indubitability which is regarded by Descartes as essential to acceptability. The distinction between formal and objective reality requires that we have an understanding of how effects are brought about, even before we are acquainted with any actual case of a causal relation, and that some causal knowledge can be obtained a priori. This position is, to say the least, highly doubtful.
} 
Workshop 2:

Democracies with a Human Face: Writers, Moviemakers, and Migration

Chair: Hans J. Rindisbacher 


\section{Integration, Assimilation, Marginalization, and Expulsion}

Vesna Kondrič Horvat

Department of German, Unversity Maribor, Slovenia

\section{Introduction}

In a time of globalization and in the midst of current antiglobalization sentiments across the world, it is important to examine the different ways in which writers address these challenges. For authors with personal experiences with integration, assimilation, marginalization and expulsion, these subjects are omnipresent. The works of Erica Pedretti, Lojze Kovačič, Vladimir Vertlib, Franco Supino, and Melinda Nadj Abonji thematize precisely these issues.

Erica Pedretti (b. 1930) is a Sudeten German who had to leave her homeland of Czechoslovakia in 1945 at the age of 15. In her short book, fremd genug [Strange enough, 2010], she describes her experiences of never showing resentment and of trying to understand them in the context of the political situation. She recalls returning to Czechoslovakia as soon as she was allowed, first in 1976 and then again in 1990. Lojze Kovačič (1928-2004) was a Slovenian writer born in Switzerland to a Slovenian father and a German mother. His novel, Basel (1986), deals with his expulsion from Switzerland at the age of ten because his father had previously refused Swiss citizenship. Vladimir Vertlib (b. 1966) is a Russian Jew whose parents fled the Soviet Union in 1971 when he was just five years old. In search of a better life, his family moved back and forth between Europe, Israel, and the USA, but due to anti-immigrant resentments became deeply disillusioned no matter where they lived. Vertlib talks about his various cultural encounters in his novel $Z$ wischenstationen [Layovers, 1999]. Franco Supino (b. 1965), the son of Italian immigrants in Switzerland, reacts in his book, Solothurn liegt am Meer [Solothurn 
Lies at the Seaside, 2009] to the sentence "Go back if you don't like it here!"1, which was said to him when he complained about Switzerland, the country where he was born. Where should he go back to, he wonders. Finally, there is Melinda Nadj Abonji, whose family belonged to the Hungarian minority in former Yugoslavia. At the age of five, she left for Switzerland with her younger sister, joining her parents who had previously moved there. In her 2010 novel, Tauben fliegen auf [Fly Away, Pigeon, English translation by Tess Lewis, 2015], she deals with this part of her family history and the hatred they experienced because they were foreigners and had to work much harder than the Swiss, while at the same time still not being fully accepted.

Each of these writers has a very sharp eye for the plurality not only of historical worlds, but also of these issues in the world today. Each demonstrates the important role that cultural history plays in framing a literary work; each shows that our cultures are not separate but are interrelated. Though these eloquent artists have a strong desire for aesthetic expression, they never forget that aesthetic expression contributes to both social and historical interweaving. Each explores explosive social questions based on their own experiences, ultimately leading to the disruption of their own worldview. The reader follows each author's painful attempts to seek understanding through writing.

\section{Erica Pedretti - "Why are you still here?"}

Expulsion, escape and migration are constant motifs in the writings of Erica Pedretti. In December 1945, 15-year-old Erica, along with her two younger sisters, brother and cousin, were put into a Red Cross train and transported to St. Margrethen on the Swiss border, along

with "Auslandschweizer" (Swiss expatriates) and concentration camp 
survivors, coming from Warsaw, Auschwitz, Prague, and Munich. The children were joined by their parents soon after, but then the family had to leave the country because they only had temporary permission to stay. ${ }^{2}$ In 1950 , they moved to the USA, where Erica stayed for two years working as a silversmith until her former classmate, painter, and writer, Gian Pedretti, went over to bring her back to Switzerland; they married and have remained there ever since.

Erica Pedretti began to write because, in her own words, she could not talk about her experiences with anybody in her new homeland. In her first book, Harmloses bitte [Harmless, Please, 1970], we can sense her hesitation and uneasiness not only at speaking but also writing about certain incidents. These hesitations are marked by the omission of words, leaving only white spaces, or a sudden jump from one line to the middle of the next, which the reader does not expect. What is special about her writing: despite her early life in Czechoslovakia where she experienced war and was expelled in 1945 because she was a Sudeten German, her 1995 novel, Engste Heimat [Closest Homeland, speaks strongly against hatred and is without resentment. While writing about and fictionalizing her experiences ever since her first book, Harmloses bitte, she only speaks openly and autobiographically in her 2010 book, fremd genug, which was published on her $80^{\text {th }}$ birthday. This work is a summary of everything we know from her previous publications. Nobody ever asked her whether she wanted to leave her homeland for Switzerland in 1945, or whether she would have liked to stay. Her parents had joined her in Switzerland at a later date, but then were summoned every three months and questioned by Swiss authorities with the repeated: "Why are you still here?" And she experienced the same questions and harassment from her teenage peers: "if on some occasions I forgot about my being a stranger and behaved badly like every other fifteen- 
or sixteen-year old: What are you doing here? Go back where you came from! I would, in spite of everything, have loved to go back but could not" (fremd genug, 40). When she was ultimately allowed to return to her homeland in 1976, after 30 years, nine months and eight days, it was not a pleasant experience. We learn in Engste Heimat that her father hated the Czechs and therefore she could only learn Czech secretly with her friend. Her father would have been hurt if he had known that she had returned to her old homeland. She, on the contrary, had been yearning to go back all those years. "Hate" 3 is the title of a chapter in Engste Heimat, in which the narrator is searching for the paintings of her uncle, the primary goal for returning, but the museum director, a former janitor, had burnt all the paintings as they had meant nothing to him. During her visit she senses a lot of hatred everywhere. But how could that be in her beloved homeland. Yet even Marx and Kafka were controversial. The character Anna ponders: “'Karl Marx could not exist in the ČSSR' [...]: 'In this Marxist country Marx, as a German would be expelled, as a civil man he would be reduced to silence and as a Jew he would be despised, monitored three times as much."'4

\section{Lojze Kovačič - Writing in a New, Slovenian Language}

Another author who had to deal with expulsion at an even earlier age, but in the opposite direction, is Slovenian writer Lojze Kovačič (19282004). He was born to a German mother and a Slovenian father in Switzerland. When he was ten, in 1938, his family was expelled from Switzerland. He started writing in 1944 at the age of 16 when his father died. From this point on, he continually wrote novels, short stories, radio plays, essays, journals and children's books in his new Slovenian language, which is remarkable, because until age ten he had spoken only German. His writing can be read as autobiographical. 
When he published his novel, Deček in smrt [A Boy and Death], in 1968, he was proclaimed the "Slovenian Proust" and a candidate for the Nobel Prize. All of his works have a fragmented structure, including Otroške stvari [Childhood Things, 2004] - his last book before his death on May 1, 2004.

Some pertinent background information: his father had left Slovenia at that time part of Austria-Hungary - for Germany to become a tailor. There he met his future wife, the daughter of a German tailor. They had two daughters and a son, named Alois (Lojze, 1928) after the father, though everyone called him "Bubi" [Boy]. The parents lived in various places: Saarlouis, Vienna, Brussels, Strasbourg and in the Swiss canton Ticino. In 1912, they settled in Basel, where Kovačič's father was a respected tailor and furrier and his mother handled the business. In his novel, Basel, ${ }^{5}$ Kovačič speaks very positively of the city, which he calls "Babylonien," as there one could meet people of different nationalities and hear French, German, and English. He liked life in Basel, even though after his fifth birthday he had to spend almost two years in hospitals and spas because he had contracted pneumonia - the reason he started school one year later than other children his age; because of this he was always mocked as a "stranger."

In 1938 the impoverished family was expelled from Switzerland, since his father once a wealthy man, had rejected an offer of Swiss citizenship for patriotic reasons, exclaiming: "Ich bin und bleibe Slowener!"6 His mother wanted to return to Germany, but his father insisted on Slovenia. Kovačič wrote often about his traumatic experience as a young writer who loved Basel and who later in life still considered childhood to be the defining period in his life. He was able to return to his beloved city only in 1974 and even then was afraid of being denied entry because of his family's earlier expulsion. 
Kovačič remembers the year 1938 well. The family came to live with their relatives in a small village near the city of Novo mesto but the families did not get along with one another. The relatives considered them strangers and even worse, they viewed them as Germans, whereas in Switzerland they were labeled Serbs, following the assassination in Sarajevo in 1914. In Otroške stvari Kovačič recalls the sentence: "Mit den serbischen Mördern raus aus der Schweiz!"7 His mother felt like a stranger in the village, and the family moved to Ljubljana in 1939. Due to financial problems and the constant moving from place to place, life was not good there either and it was detrimental that the family spoke German. When his father died in 1944, Lojze became responsible for the family. Following the Second World War, his mother, his sister, and his niece were expelled from Yugoslavia and were sent to a camp for displaced persons in Austria, ${ }^{8}$ whereas he was allowed to stay in Ljubljana. For a long time, he did not know where they were. He was considered a "suspicious person" by the authorities and was constantly harassed. Upon completion of his military service he became homeless, living on Ljubljana's streets and parks, and with friends. He married in 1951 and had two sons. For almost 30 years he worked in the Center for Youth Culture as a mentor and was very successful with his puppet-theatre group. But he is mostly known for his literary works and as an unbending critic of his time.

Kovačič complained that he did not drink the Slovenian language with his mother's milk. When he came to Slovenia as a ten-year-old boy he didn't speak Slovenian and was silent most of the time. He continued to use the word "Vati" (daddy in German) even in his Slovenian texts. When they arrived in the village Cegelnica, he heard his father speak Slovenian and was impressed at how smoothly he spoke. He compares his father's speaking of Slovenian to the eating of hot potatoes. Even 
as he learned the language he continued to dream and think in German and then translated everything into Slovenian. Indeed, his Slovenian texts often contain German and Swiss expressions. ${ }^{9}$ But he learned Slovenian quickly because his mother urged him to, so that they would get along better with his uncles: "Du mußt Slowenisch lernen, daß wir uns mit den Stritzen [uncles] besser verstehen." 10 In Deček in smrt, he writes about his father's death. He integrated some earlier texts, and this remained his way of writing throughout his career: repeated integration of previous texts and situations into the new text, often as a fragmented montage. In this way he can be compared to Erica Pedretti. Since 1965, Kovačič' works have been translated into Serbian, French, Hungarian, German, Spanish, Czech and Dutch, but the international breakthrough came only after his death with the translation of his three-volume book, Prišleki [The Newcomers], into Spanish (2007), German (2008-11), Dutch (20102013), French (2011), Croatian (2017), and English (Book 1, 2016).

\section{Vladimir Vertlib - Fighting against Prejudice}

Vladimir Vertlib is yet another author whose novels closely parallel his biography and migration experiences. He was born in 1966 in Leningrad into a Russian-Jewish family. When he was five his family fled Russia. From 1971 to 1981 their pursuit of a better life took them to various countries, such as Israel, Italy, Holland, and America, but they finally settled in Austria. There Vladimir studied and has lived there since 1981. He writes in German and was therefore awarded the "Adalbert von Chamisso Preis" - a prize given to an author whose mother tongue is not German. ${ }^{11}$

From the outset, the major theme of his writing was exile. In his first novel, Abschiebung [Expulsion, 1995], he writes about how it feels to 
be a foreigner and searching for his own identity. In the novel, a young boy narrates the story of a Russian migrants' family that travels from Russia to Israel, Austria, the Netherlands, Italy, Germany, and ultimately, full of optimism, to the United States. But America does not welcome them either. As the novel opens, the family is waiting to leave this dream-like country from which they have just been expelled. The boy recounts their entire story since their departure from Russia up through to their arrival in America. He describes their daily life, the school, and his mother's search for work. Though she was a chemist in Russia, she is now content simply to have a job as a cleaning woman so that she can support the family. The father, who had studied journalism and literature in Russia, has no chance of finding work. Especially traumatic is the depiction of the family's experiences in the days leading up to their expulsion. The narrative style is varied, with the inclusion of intermittent excerpts from the narrator's journal through which we are offered insights into his hopes, fears, and disappointments, along with further depictions of humiliation and insults. Through the journal we also see his futile attempts to comprehend the world in which he lives. Particularly poignant are the depictions of the humiliation that he experiences in the American school.

Zwischenstationen recounts the family's search for paradise in European cities like Leningrad, Vienna, Amsterdam, Rome, and in Israel and Boston, as well as their experiences in various embassies, airports, police stations, schools, offices, and so forth. We also learn that the father had originally left Russia because of growing antisemitism there but found that in those places where he wished to remain, he was not welcome, and where he was welcome, he did not wish to stay. The father figure portrays crucial experiences common to many migrants. He is persistent and fights for a better tomorrow yet 
is unable to take care of family finances. He is like a mythical figure, a Don Quixote, who, in his struggle against merciless reality, is both a hero and a buffoon. This places the entire burden on the mother. Although she has a doctorate in mathematics and physics she does not mind working as a cleaning woman. She makes it possible for the man to follow his dreams even though he claims he does everything only because of his son. However, the son is caught up in a vicious cycle; whenever he makes new friends, the father decides it is time for them to leave. As soon as he acquires some of the language and starts liking the new country, they are expelled, leaving him continuously disappointed and confused. His only true and lasting companions become his books. With these "friends" he survives puberty. In the end, the son becomes the one to disappoint the parents because he chooses to live in the province-Salzburg-instead of remaining in Vienna as was his parents' wish.

\section{Franco Supino - "Go back if you don't like it here!"}

The younger generation of authors in Switzerland focuses on the private rather than the public. The remaining two authors whose lives and works I wish to address represent migrants and migration, much like Erica Pedretti; but they are much younger and write about their family stories. We must understand these family stories as representing emerging phenomena within a multicultural Europe at the particular point in time when they happen. The stories shed light on the fact that transculturality remains one of the opportunities-yet also a potential danger-in modern-day Europe.

Transculturality is important in forming one's identity, not only for people who live within two cultures, but in the culture of modern society as a whole. Wolfgang Welsch, who introduced the term 
transculturality in the 1990s, states, "Work on one's identity is becoming more and more work on the integration of components of differing cultural origin. And only the ability to cross over transculturally will guarantee us identity and competence in the long run." 12

Franco Supino addresses these competences in his literary works. He was born in Switzerland to Italian parents and was raised bilingual in the Swiss city of Solothurn, where he still lives. He returned to Solothurn after studying German and Romance languages in Zurich and Florence. In all of his works he speaks about "the Clash of Cultures" - about Italian migrants in Switzerland and about the "secondos" - second generation Italian immigrants in Switzerland. This position makes him receptive to different cultures. He tries to show that thinking in the categories of "own" and "foreign" does not help, and in one of his books he writes, "the world won't get better if you try to concentrate on weaknesses."13 One can find great enrichmentin the nexus of different cultures. He deals with these issues in his collection of essays, entitled, Solothurn liegt am Meer. Here he reacts to the sentence, "Go back if you don't like it here!" referring to his own experience when he complained about Switzerland, the country in which he was born. Yet, where should he go back to, he wonders.

In his first novel, Musica Leggera [1995], Supino depicts a love story in which cultural differences play an important role. The Italian character Maria falls in love with a Swiss man but in the end chooses an Italian, as was her parents' wish. The narrator feels betrayed, since he always wanted "secondos" to integrate into Swiss society, even against their parents' wishes. Initially, the parents of "secondos" came to Switzerland to make money with the goal of returning to Italy. But as the second novel, Die Schöne der Welt oder Der Weg zurück [The 
Beauty of the World or The Way Back, 1997], elucidates, after living in Switzerland for 15 years, a return to the parents' homeland can have a negative impact on the children. The protagonists of the novel are two boys. One of them succeeds in persuading his parents to remain in Switzerland. He studies law and becomes successful. The other son, also born and raised in Switzerland, is dragged "back" to Italy but is unable to adapt to the culture and becomes completely disoriented. The reason he fails is because he feels like a total stranger in Italy.

Musica Leggera was Supino's first example of writing about children of immigrants, the so called "secondos," who on the one hand want to please their parents but on the other have grown up in a world completely different to theirs and wish to be free to live in their own space. Supino's character Maria, his schoolmate, symbolizes the failure of the "secondos" to convince their parents that they belong and wish to live in both cultures, both of which they love and respect. The narrator in particular - who goes to the same school as Maria and her Swiss friend Marcus - desires this dual life for himself. He wants to please his very traditional parents, yet at the same time help them see that their notion of a cultural either/or is merely a construct, and that the connection of Swiss and Italian cultures actually creates a new dimension. He shows how important it is to get involved in the other culture rather than to exclude it, although one should anticipate potential conflicts and look for ways to resolve them. For these reasons, Maria's marriage to an Italian appears to him as a betrayal. She avoids potential parental conflicts and goes to Italy instead. His parents thus praise Maria as a dutiful daughter, while at the same time consider him a loser. 


\section{Melinda Nadj Abonji - The Homo Balcanicus}

In her autobiographical novel, Tauben fliegen auf, Melinda Nadj Abonji writes about a family from the Hungarian minority in former Yugoslavia. The parents moved to Switzerland, worked as dry cleaners, and were eventually able to buy and run their own restaurant. At first the daughters remained behind in the Vojvodina region of former Yugoslavia with the grandmother but then joined the parents at a later stage. The family integrated easily into Swiss life, yet were constantly reminded that they did not belong, especially by immigrants who had arrived there long before them but had chosen to ignore their own immigrant status and did not want to be reminded of it. Abonji offers a sad and vulgar example of their bullying and intimidation in a scene in which feces are smeared on the bathroom walls of the family restaurant. Nonetheless, these same immigrants continue to patronize the restaurant, all the while complaining about the newer arrivals. Ildiko, the narrator, has studied history and knows just as much about Switzerland as the Swiss "Herr Pfister" who also complains about them, but then realizes that this is not appropriate and backs down: "With you it is different. You are already naturalized and you know the customs and conventions of our country. But the ones who have been coming since the 1990s, this is raw material ... you know the homo balcanicus hasn't gone through enlightenment yet."14

We see the second-generation trauma in this novel as well. Even though the two girls are only three and five when they follow their parents to Switzerland, they cannot forget their former homeland and feel extremely happy when visiting their grandmother in the Vojvodina. As they grow, Ildiko and Nomi continue to be pulled in two directions. The girls dream of their grandmother (mamika), drink a traditional Yugoslav beverage called Traubisoda, and fondly recollect 
a marriage ceremony they remember from a recent visit when a variety of traditional dishes were served, including pigeon-soup: “... Traubisoda! This is the name of a magic drink in our homeland, ... we love Traubi so much that we consider taking some bottles home, to Switzerland, to show our friends that in our homeland there is something that tastes really good."15

\section{Conclusion}

Authors who had to leave their homeland deal with this experience in sensitive ways. They depict a viewpoint that can be labeled transcultural. This means that in light of the multiple cultures they not only describe but in which they also live, their observations become sharper, the individual differences and the pluralism of the cultures are expressed more clearly and in each text we find their selfreflection with regard to "the other."

All works discussed here have an autobiographical background, though their stories are fictionalized. Unlike in autobiographies, the emphasis is not placed on the emotional coping with one's own life crises; rather, the emphasis lies with the literary form and with creating a distance through literary mechanisms. It is a conscious stylization of one's own life.

\section{Notes}

\footnotetext{
${ }^{1}$ Franco Supino, Solthurn liegt am Meer (Olten: Knapp, 2009).

2 “...eine Aufenthaltsbewilligung zwecks Weitereise," Erica Pedretti, fremd genug (Frankfurt/Main: Suhrkamp, 2015), 39. All quotes, except from Wolfgang Welsch's work, are originally in German; translations are my own.

${ }^{3}$ Erica Pedretti, Engste Heimat (Frankfurt/Main: Suhrkamp, 1995), 62.

${ }^{4}$ Ibid, 136.

${ }^{5}$ Lojze Kovačič, Basel (Ljubljana: Beletrina, 2011).
} 
${ }^{6}$ German in the Slovenian original, Otroške stvari [Childhood Things], (Ljubljana: Beletrina, 2003). "I am and I will remain a Slovenian!"

${ }^{7}$ German in the Slovenian original, Otroške stvari. "You Serbian murderers get out of Switzerland!"

${ }^{8}$ Described in Prišleki [The Newcomers, a trilogy, 1983-1985], (Ljubljana: Beletrina, 2007).

9 E.g.: "gasa" for "street": in Slovenian this would be "uličica" or "steza."

${ }^{10}$ German in the Slovenian original, Zrele reči [Mature Things] (Ljubljana: Beletrina, 2009). "You have to learn Slovenian so that we get along with our uncles."

${ }^{11}$ The Robert Bosch Stiftung awarded the Adalbert von Chamisso Preis from 1985-2017.

12 Wolfgang Welsch, "Transculturality: The Puzzling Form of Culture Today," in Featherstone and Lash, eds., Spaces of Culture: City - Nation - World (London: Thousand Oaks/New Delhi, 1999), 194-213, 199.

${ }^{13}$ Franco Supino, Die Schöne der Welt oder Der Weg zurück (Zürich/Frauenfeld, 1997).

${ }^{14}$ Melinda Nadj Abonji, Tauben fliegen auf (Salzburg: Jung und Jung, 2010), 108.

${ }^{15}$ Ibid, 15. 


\section{Changing Her Tune: Antihumanism in Monika Maron's Munin oder}

Chaos im Kopf

Eva B. Revesz

Department of Modern Languages, Denison University, Granville, Ohio, USA

The fame and positive reputation of former GDR author Monika Maron has rested in large part on her extremely critical literary portraits of the former East German state. Even after the fall of the Berlin wall, her work continued to focus on exposing the abuses of this authoritarian communist regime, such as in her 1992 novel Stille Zeile Sechs (Silent Close No.6), for which she was awarded Germany's prestigious Kleist Prize. The novel is a scathing portrayal of a former GDR high party official from the perspective of a female journalist who has been commissioned to transcribe his memoirs. Critique of the East German system also characterizes a number of her other wellreceived works, from her 1981 debut novel Flugasche (Flight of Ashes) to Pawels Briefe (Pawel's Letters, 2002). Maron herself had grown up in the GDR in a privileged position as the stepdaughter of a high GDR party official until she was able to leave the country for the FRG in 1988. Flugasche, banned at the time in the GDR and only published in West Germany, is a semi-autobiographical account of the censorship and repressive methods a newspaper reporter faces when she attempts to expose the harmful environmental pollution of the brown coal industry in the GDR. Her later novel Pawels Briefe also has a strong autobiographical component, chronicling the persecution her Jewish grandfather and his family endured during the Hitler regime, a regime she repeatedly compares to the GDR. Her 2013 penultimate novel Zwischenspiel (Interlude) continues to thematize the human rights abuses of the former East German state. No question that 
Maron has thus gained the reputation of an author promoting a liberal, humanist agenda.

Her characteristically bleak and pessimistic portrayal of the political and social order also distinguishes her latest novel, Munin oder Chaos im Kopf, ${ }^{1}$ published in 2018. Yet in this novel, Maron's focus has switched from her discontent with an authoritarian regime to its opposite: the current liberal democracy of the FRG is now her target, specifically what she sees as a culture of "political correctness" that is bound to spell Germany's downfall. The novel's main plotline revolves around a frustrated wannabe opera singer who "terrorizes" a peaceful Berlin neighborhood by belting out off-key opera arias from her balcony at all hours of the day. The protagonist Mina Wolf, a freelance journalist commissioned to write an article on the Thirty Years' War, finds the noise pollution so unbearable that she turns to writing at night, when the crazy balcony singer is asleep, while she herself sleeps during the day. The deranged woman disturbs the peace to the point that nearly the entire neighborhood bands together against her. Yet the more liberal inhabitants of the neighborhood come to her defense. They assert that forcefully removing her from her living quarters and having her placed into a mental institution would be a violation of her human rights. They thereby align themselves with her government-appointed social worker in recognizing her protected disability status. The situation escalates into a police intervention in which the deranged woman attacks the police officers with a knife, only to fall down the stairs, accidentally plunging the knife into her own heart. Maron's point seems obvious: had she been placed into a mental institution where she belonged, she would still be alive. Indeed, her suicide can be read as symbolic of Germany's own impending self-imposed ruin due to the liberalism of its government policies. The confrontation with the mentally disabled balcony singer 
thus serves as an allegory for the country's debilitating culture of "political correctness."

Maron herself speaks about what she sees as the "collective suicide" into which Germany is headed in an article written for the Frankfurter Allgemeine Zeitung, entitled "Merkel's Mindless Politics are Strengthening the Right." 2 Maron takes issue especially with Merkel's "open border" refugee policy, which is also one of the main targets in her novel Munin with its explicit doomsday prophecy of an imminent war in Germany caused by the influx of North African and Muslim refugees and the possibility "that African tribal and religious wars could move into Germany."3 Here as elsewhere, the first-person narrator expresses her fear of an Islamic takeover in Germany. Especially problematic is the legitimacy Maron gives this fear with repeated reference to newspaper articles that her protagonist reads, the most dubious of which is an article that makes an entirely erroneous assertion, alleging the number of asylum seekers who have been deported back into their home countries to be exceedingly small thanks to leftist protests on behalf of the imperiled deportees: "I had just read in the newspaper that morning that of the millions of young men whom one had allowed into the country, 18 of them, under massive left-wing protests, were deported back to their home countries, 18 out of a million." 4 For her Frankfurter Rundschau review of the novel, Cornelia Geißler did a fact check. She reports that in 2016 alone, the German government deported 25, 375 people. ${ }^{5}$ By using fictitious newspaper reporting to support her erroneous statistics, Maron's novel transgresses into irresponsible fearmongering.

Another aspect of the current climate of "political correctness" with which Maron takes issue in her novel is what she sees as the folly of the LGBT movement. And once again, Maron is guilty of extreme 
exaggeration when at one point her narrator agrees with the ridiculous claim made by a frustrated school teacher "that there are supposedly 60 genders now ... way more than simply hetero and homo."6 The first-person narrator repeatedly refers to this as "Genderscheiße," the gender "shit" that has also led to "the nonsense of gender specific language adulteration." who has been celebrated as a committed feminist, this too appears like a complete ideological turnaround.

Maron admits as much in an article she wrote for the Neue Zürcher Zeitung in June of 2017, titled "I Haven't Been on the Left for a Long

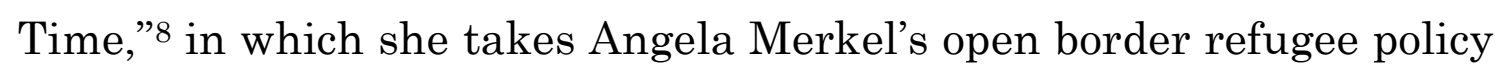
to task. She has also taken issue with Merkel's plaidoyer for gender equality in the online monthly journal Cicero, wondering in the title "Is Parity Achieved when Women Chop Wood and Men Knit?"9 Maron's question is a direct response to Merkel's proclamation in an interview with Die Zeit that we as a society must work together to ensure that, in Merkel's words, "we will one day arrive at a true parity of the sexes. Parity in all areas seems to me simply logical."10 Maron's myopic claim about the silliness of women chopping wood and of men knitting reduces Merkel's insistence that Germany has still not achieved gender equality to a problematic biological essentialism. This essentialism is taken to an absurd level with Maron's follow-up allegation: "Should one do research on an external uterus so that men can also finally bear children and become mother-fathers, which would doubly boost parity; just nursing would still remain a problem."11 Maron's outright rejection and ridicule of Merkel's position demonstrates how conservative, if not to say reactionary, her approach to gender has become. It is this kind of biological essentialism that Maron raises to what one could term a higher-order metaphysical level in Munin. At the heart of the novel is, I claim, a 
decidedly anti-humanist stance that promotes a questionable social Darwinism.

The novel's focus on the nonhuman is signaled already in the title. The eponymous character Munin is none other than a crow that the protagonist Mina Wolf lures into her Berlin apartment with food and names after one of the two crows that proverbially sat on the Norse god Odin's shoulder. ${ }^{12}$ Before long, Mina steps into an intense metaphysical dialogue with her crow about "God and the world,"13 as the familiar German saying has it. This fairytale element serves as more than simply a literary device to represent the "chaos" both in Mina Wolf's own head and in the world around her. It is also an attempt to place humans and animals - what animal rights activists have come to refer to as "nonhuman animals" - on the same plane. Indeed, to deny humans a more rational human nature, distinguished from "nonhuman animals" is precisely the final message of the novel. Mina Wolf makes the pronouncement on the penultimate page that humanity - and with it any belief in a higher God - have become defunct since we have decoded the genome and now know "that mice and men genetically overlap to 99\%." ${ }^{14}$ The crow Munin declares herself, "ich bin Gott" (116), with which she espouses a pantheism that places all living beings on an equal moral or perhaps more accurately, amoral footing. ${ }^{15}$

Munin repeatedly voices her critique of what she sees as the misplaced rationalism of a human moral code, holding up base animalistic instincts as a much more sensible alternative. Chiding human beings especially for their inability to learn from their mistakes, Munin claims that Germany has gone much too far in atoning for the crimes committed against "the weak and the insane" 16 under Hitler's euthanasia program. Here the anti-humanist bent of 
the narrative becomes explicit, which is clearly why these words are placed into the mouth of a non-human creature:

And you did precisely that later, having annihilated the weak and the insane, simply killing lovable, stupid people. And if you hadn't also murdered six million Jews and had lost the war on top of it, the rest of the world would probably never have noticed. Lots of people thought that way back then. But you were shocked at your own misdeeds and have sworn lifelong atonement. Since then you throw yourself protectively over everything that you consider weak and helpless. You save children that are born half-dead, who then need to be feed and diapered their entire lives, without ever being able to utter a word of thanks with their spastic lips; you no longer allow the terminally ill to die, but rather let them rot away for years in their beds. That's what you have learned from your moral turpitude. ${ }^{17}$

Munin claims that following the horrific human rights abuses committed during the Holocaust, the pendulum for what counts as morally responsible behavior has swung much too far in the other direction. Morally responsible behavior has as a result been perverted into its precise opposite: humankinds' morality has become a type of new immorality. ${ }^{18}$

One might even be inclined to agree with this assessment, provocative and extreme as it may be. Yet as is so often the case in this exaggerated and fearmongering text, when Mina asks her loquacious crow where all of this will lead, Munin has an alarming forecast. Humankind will be "enslaved," she argues, by their growing elderly and infirm populations. It will thus only be a matter of time before humans revolt and turn against the old. Claiming that "there is no cruelty to which you are not capable," Munin predicts a type of "elder" Holocaust: 
Do you think that your few descendants will want to sacrifice their lives in order to diaper, wash, and feed a growing mass of helpless old people? That they won't ask themselves why they don't have the right to a life outside of this deadly tomb? One of these days they will give a hoot about the holiness of human life because they will want to have their own lives. In their rage and despair over their enslavement, they will get rid of their old people, they'll kill them or simply let them die. That's what will happen, Munin said, jumping on the table in my direction until she was right in front of me, looking me directly in the eyes. We have been watching you for hundreds of thousands of years. There is no cruelty to which you are not capable. ${ }^{19}$

When Mina then asks Munin what would be the right thing for humans to do, Munin answers with the following questionable words of wisdom: "Let die, what cannot live. That's at least how we do it.' 'You are animals.' 'So are you."'20 This forced equivalence between humans and animals espouses a type of biological continuism that flies in the face of Enlightenment values centered on a human moral code that is clearly distinguishable from the amorality of animals. ${ }^{21} \mathrm{At}$ its core, Munin oder Chaos im Kopf may be read as promoting a type of Nietzschean "transvaluation of values" as put forth in his Geneology of Morals, in which human rights exist for the weak to constrain the strong.

In short, what are we to make of a novel in which a bird is portrayed as superior to humans? Munin is certainly correct in her assessment that humans are incapable of peace, and that waging war appears as a part of humankind's genetic makeup. Yet this pessimistic, 
misanthropic novel fails to convince due to its blatant exaggerations and gross overstatements on a number of counts. The unlikelihood that German society is currently threatened by an imminent religious war waged by émigré Islamic terrorists is about as certain as the prediction that it will wage war against its elderly population. It is also safe to say that Germany is not on the brink of a "collective suicide," as Maron's novel implies. ${ }^{22}$ Her scathing critique of the current climate of "political correctness" in Germany reveals more about Maron's questionable ideological turnabout than it does about the country's current state of affairs.

\section{Notes}

\footnotetext{
${ }^{1}$ This novel has not yet appeared in English translation, and all translations are my own. Literally, the title translates to Munin or Chaos in the Head, though a more idiomatic translation might be Munin or my Chaotic Mind. It is however significant that the German does not simply refer to chaos in "the head" presumably in the protagonist Mina Wolf's own mind - but to the chaos in the contemporary world in general.

2 “Merkels kopflose Politik macht die Rechten stark,” FAZ, 14 January 2016.

3 “[...] dass afrikanische Stammes- und Religionskriege in Deutschland einziehen könnten” (11).

4 "Ich hatte am Morgen gerade in der Zeitung gelesen, dass man unter massiven Protest der linken Bewegung achtzehn von den Millionen jungen Männern, die man zuvor ins Land gelassen hatte, nun wieder in ihre Heimat befördert hatte, achtzehn von einer Million” (209).

5 "2016 wurden laut Auskunft der Bundesregierung 25,375 Menschen aus Deutschland abgeschoben.." Frankfurter Rundschau, 13 July 2018.

6 “[...] es plötzlich sechzig Geschlechter geben soll [...] eben viel mehr als hetero und homo” (74).

7 “der Unsinn genderspezifischer Sprachverhunzung” (75).

8 “Links bin ich schon lange nicht mehr.” Neue Zürcher Zeitung, 30 June 2017.

9 “Ist Parität erreicht, wenn Frauen Holz hacken und Männer stricken?” Cicero Online: Magazin für politische Kultur, 26 January 2019.

10 “[...] dass wir eines Tages wirklich zu einer Parität der Geschlechter finden. Parität in allen Bereichen erscheint mir einfach logisch." "Parität erscheint mir logisch," Zeit Online, 23 January 2019.

11 “Wird am externen Uterus geforscht, damit Männer endlich gebären können und Mutterväter werden, womit sogar die Steigerung der Parität erreicht wird, beides in einem, nur das Stillen wäre noch ein Problem." Cicero Online, 26 January 2019.
} 
${ }^{12}$ Maron's fascination with crows is evidenced in a short text published in 2016, Krähengekrächz (Crowscreeching) in which she indicates that her text was conceived as a preliminary study for her next novel. What fascinates Maron about crows in not just their proven intelligence but also the long legendary and literary tradition this bird has enjoyed. Indeed, a clever feature of Munin oder Chaos im Kopf is the protagonist's repeated reference to this text in order to support her various claims about crows. While one might take issue with this self-referentiality here - using a book Maron herself authored in order to substantiate her claims - it does give the novel an interesting narrative metalevel.

13 "Gott und die Welt" (162).

14 “[...] dass sogar die Maus und der Mensch zu neunundneunzig Prozent genetisch übereinstimmen” (221).

${ }^{15}$ Although Mina cannot determine the gender of her crow, she designates it as female mainly because "die Krähe" is a feminine noun in German. She also decides on the female gender because the name Munin has the feminine ending "in." However, this stands in a skewed relationship to her critique, if not to say ridicule, of the feminine suffix “in” in an effort to arrive at gender equality. See Cornelia Geißler's commentary in her review of the novel, "Monika Maron: Das In und andere Ärgernisse."

16 "Schwache und Verrückte" (111).

17 “Und das [...] habt ihr ja später auch gemacht, das Schwache und Verrückte ausgemerzt, liebe, blöde Menschen einfach umgebracht. Und hättet ihr nicht auch noch sechs Millionen Juden ermordet und außerdem den Krieg verloren, wäre es der restlichen Welt vielleicht gar nicht aufgefallen. Damals dachten viele so. Aber ihr wart erschrocken über eure Missetaten und habt euch lebenslange Sühne geschworen. Seitdem werft ihr euch schützend über alles, was ihr für schwach und hilflos haltet. Ihr rettet halbtotgeborene Kinder, die dann ein Leben lang gefüttert und gewindelt werden müssen, ohne je ein Wort des Dankes über ihre spastischen Lippen bringen zu können, ihr lasst Todgeweihte nicht mehr sterben, sondern lieber jahrelang faulend in den Betten siechen. Das habt ihr aus euren Schandtaten gelernt" (111).

${ }^{18}$ It should be noted that Munin's claim is problematic on a number of levels. For one, to judge a person's right to life by his or her ability to verbally express thanks clearly misunderstands the nature of physical disability. Furthermore, the description of how terminally ill patients are artificially kept alive to "rot in their beds" is also clearly overstated as Germany has had laws allowing for assisted suicide since 2015, and passive euthanasia (rejecting life support) for even longer.

19 “Glaubst du, dass eure wenigen Nachkommen ihr Leben dem Windeln, Waschen und Füttern einer Jahr für Jahr anschwellenden Masse hilfloser Greise opfern wollen? Dass sie sich nicht fragen, warum sie kein Recht auf ein Leben außerhalb dieser Sterbegruften haben? Eines Tages werden sie pfeifen auf die Heiligkeit des Menschenlebens, weil sie ihr eigenes Leben haben wollen. In ihrer Wut und Verzweiflung über ihr versklavtes Dasein werden sie sich der Alten entledigen, sie werden sie umbringen oder einfach sterben lassen. Das wir passieren, sagte Munin, hüpfte auf dem Tisch in meine Richtung, bis sie dicht vor mir saß, sah mich gerade in die Augen: Wir haben euch seit Hunderttausend Jahren zugesehen. Es gibt keine Grausamkeit, zu der ihr nicht fähig wärt” (113).

20 “Sterben lassen, was nicht leben kann. So jedenfalls machen wir es. 
Ihr seid Tiere.

Ihr auch" (114)

${ }^{21}$ This was also the well-known journalist Thea Dorn's critique of the novel in the popular German talkshow, Das literarische Quartett. https://www.youtube.com/ watch?v=lngnd7BXTRM. Paraphrasing Munin's contention about humans that "ihr würdet weniger Unheil anrichten, wenn ihr erkennen würdet, dass ihr Tiere seid" and referring to the novel's concluding point that humans and mice are genetically nearly identical, Dorn offers the following insightful critique of the novel: "Was, um Himmelswillen, fangen wir mit dieser Erkenntnis an? Wenn wir angesichts der gesellschaftlichen Bedrohung unseren Glauben an Aufklärung, an Menschenrechte, an Individualismus hochhalten wollen, was fangen wir mit einer solchen biologistischen Erkenntnis an?" Dorn was the only one of the four panelists to critique the novel. Following its generally positive reception in the German press, the other three journalists showered the novel with praise, especially for Maron's ability to craft a complex narrative and for the simple elegance of her style.

${ }^{22}$ Maron is by no means alone with such a negative prognosis. Especially the SPD senior politician and former Berlin Senator of Finance Thilo Sarrazin has contributed significantly to giving an authoritative voice to the notion that Islam constitutes a threat to German society. In the wake of his 2010 bestseller, Deutschland schafft sich ab (Germany abolishes itself) and even more so following his most recent book, Feindliche Übernahme: Wie der Islam den Fortschritt behindert und die Gesellschaft bedroht (Hostile Takeover: How Islam Impedes Progress and Threatens Society) published in 2018, such an anti-Islamic stance is becoming progressively mainstream. And very much like Maron with her leftist origins, Sarrazin too has "switched sides," so to speak. As a result, the SPD launched three attempts to have him officially removed from the party. After two unsuccessful lawsuits against him, the third legal proceeding was finally successful in July of 2019 and Sarrazin was officially barred from the SPD. 


\section{Robert Menasse's Die Hauptstadt: How Europe Dis/Connects in}

\section{Brussels}

Hans J. Rindisbacher

Department of German and Russian, Pomona College, Claremont, CA, USA

"Die Krone der Schöpfung, das Schwein, der Mensch."

-Gottfried Benn ${ }^{1}$

Robert Menasse's most recent book, Die Hauptstadt (The Capital), was published in 2017 and awarded the German Book Prize that year. ${ }^{2}$ It was well received and solidified his status as an engaged European. Andreas Isenschmid in Die Zeit calls it "the first EU-novel, an entertaining farce on the Brussels scene" 3 ; Paul Jandl, under the heading "Europe isn't lost yet," wonders whether the novel is a "tragedy or a comedy" and notes that Menasse "is looking for strong symbols for the EU in his big novel." 4 The German book review site Perlentaucher lists further positive reactions, such as Carsten Otte's, who seems to have been "swept off his feet by Robert Menasse's EU novel"5; and by Tobias Lehmkuhl who "appreciates the Viennese author ... as a person deeply knowledgeable about the structures of the EU."' Even the New York Times weighed in under the heading "Brussels, E.U. Capital, Gets a Novel, Both Tart and Empathic." Thus, the Deutscher Buchpreis award only provided an official seal of approval.The eulogy notes that Menasse "shows poignantly" how "the human/e [das Humane] is always worth striving for but never fully a given"; and "he skillfully digs into the deep structure of the world we call our own," revealing that "the economy alone will not be able to assure a peaceful future." 8 
With this positive reception of the book, what does the production side look like? How is the complexity of the European Union convincingly captured in a 450-page narrative? How is "Brussels," the EU, a political bureaucracy, turned into a literary protagonist? These questions serve as my departure point for this article, but Harald Jähner of the Frankfurter Rundschau already gave this some thought. $\mathrm{He}$ is glad that finally someone discovered "the great untouched novelistic potential" that Brussels offers, the EU capital and "place of lonely souls," where "ten thousand people are not at home" but live in service for their home countries. ${ }^{9}$ I am taking a narratological, structural approach: how does Menasse go about representing "Brussels" - not as a city, like Döblin's Berlin in Berlin Alexanderplatz or John Dos Passos's New York in Manhattan Transfer - but as the political power center of Europe? What is at the heart of Europe? And what makes this heart beat? How does he depict an organism that is characterized more by its reputed non-transparency than its universally agreed-upon contours? What does Menasse select and represent in order to depict the many bureaucratic entities, their human occupants, loyalties, interests, powerplays and their complex interconnections as they interact in Brussels? As it turns out: through a relatively small set of people and their human, all-too-human, pursuits and concerns as individuals, meshed with the possibilities and limits of their specific EU or Brussels institutions. These characters' work finds its realization or annihilation usually at the hard edges of national interests. All this is geographically precisely located in the city of Brussels, with far wider perspectives integrated in biographical backstories and characters' travels integrated into the narrative. And there is a pig which has, as we will see, a dark atavistic cousin in Jean-Baptiste Del Amo's 2016 novel Tierreich (Règne Animal). ${ }^{10}$ 
In his other writings on Europe, notably in the political essay, Der europäische Landbote, Menasse lays out the unifying idea at the origin of the EU. It is the overcoming of nationalism in Europe and the development of joint political structures. "The nations, according to the idea of the founding fathers of the European peace project, would have to be tied together institutionally and economically and brought into mutual dependence in such a way that the pursuit of individual interests would be possible only in joint action."11 Already when writing the Landbote, Menasse reveals, was he toying with the idea of an EU novel. The Landbote thus serves as historical background, political theory, and call to action; Die Haupstadt would become the literary, fictional depiction of the institutions that the European idea had brought forth and use their workings for its plot. The Landbote is political theory and pamphlet, Die Haupstadt is literary practice. The political task of merging individual, national interests into an indissoluble whole appears as the real-world analog to the narrative challenge of weaving diverse strands of personal stories, institutional processes, and political discourse into a coherent and pleasing fiction.

Menasse realized that in order to turn the EU into an imagined and emotionally invested figure for readers he would have to take the fiction beyond the set of historical ideas and ideals as which it appears in the essay. He decided to set the plot in Brussels and choose as his main characters precisely those much maligned "officials in their castle" who are widely considered to be the "arch evil" of the European Union. ${ }^{12}$ Pondering further the conversion of political, institutional and historical reality into literature, Menasse wondered whether EU officials, for whom the special term "Eurocrats" had been created and not as a compliment - would have enough of a face as literary characters. Could they be typecast? What do their everyday lives look 
like? And how do they make their decisions? Not only was he unsure about his characters, he also had to find specific protagonists and a plot. But first of all, he had to find out whether Brussels, "the engine room that generated our reality was suitable for a novel and whether the people working there could serve as 'figures'. [He] therefore flew to Brussels, rented an apartment, and tried ... to get to know as many Eurocrats as possible." 13 Because, as he argued, "if it's still possible to write a realist novel ..., then ... I would have to go to the place where this reality is being created...."14 Menasse ended up living in Brussels for four years.

Given the narrative complexities of the book, commentators and reviewers have inevitably felt the need to provide summaries to accompany their comments. Here are three illustrative examples that show both different emphases and commonalities. The first is from the website of the German Book Prize:

The official Fenia Xenopoulou is tasked with polishing the image of the European Commission. She delegates this task to her consultant, Martin Susman. His idea awakens a ghost from history and creates anxiety in the EU institutions. Police inspector Brunfaut has to abandon a murder case due to political considerations. Alois Erhart, an economics professor emeritus, is to speak about the future of Europe before a think tank in words that could be his last. And what does Brussels do? It is searching for a name, a name for a pig that is galloping through city streets. ${ }^{15}$ 
Annette König from Swiss Radio writes this:

Die Haupstadt is about a pig. And then also about seven people whose paths cross in Brussels. David de Vriend, over 80, is an Auschwitz survivor. Alois Erhart, an economist emeritus works in a think tank on the future of Europe. Kai-Uwe Frigge, EU official and director of the DG [directorate general] for trade is a cool type, that's why his girlfriend calls him 'Fridge'. She is Greek, her name is Fenia Xenopoulou, and she directs 'Noah's Ark,' the department of culture in Brussels. She plans to polish the image of the EU Commission by means of a Jubilee event. Martin Susman is her 'gango' who is supposed to do the heavy lifting. He is depressed and guzzles Belgian beer. Another good drinker: Police inspector Brunfaut; he is hunting the murderer Ryszard Oswiecki. And there is a dirty pink domestic pig that runs through Brussels's streets. ${ }^{16}$

The third is from the German Wikipedia site for the novel, which the site labels "a satire":

The story puts officials of the Culture department in the center that is asked to polish the image of the EU Commission on the occasion of its birthday. This is supposed to happen by means of a 'Big Jubilee Project' event with concentration camp survivors in Auschwitz. Besides the EU officials, the focus is on a retired Jewish teacher and Auschwitz survivor in an old-folks home, an Austrian pork breeder who represents the agriculture and meat lobbies, a Belgian criminal investigator who is trying to solve a murder, and a hired killer from Poland. The life stories of the 
protagonists lead into six EU countries. A returning motif that also opens the book, is a pig, running around in the middle of Brussels.With this metaphor Menasse attempts to link everyone, 'from the lucky-charm piglet to the filthy swine'. ${ }^{17}$

It is noteworthy how these (and other) summaries of the novel quickly agree on a half dozen key characters, among them always the pig. They confirm that the essential task any novelist faces when converting complex reality into plausible fiction has been successfully met, the need for representative selection and efficient combination. I will address Menasse's authorial tools for this conversion broadly before focusing on the pig as a striking Dingsymbol, a leitmotif, far beyond the novel. These tools include the establishment of plot and characters; descriptions, situations, settings, and places; and creating atmosphere and mood.

Menasse succeeds in mapping plot and character requirements closely onto each other. That reviewers generally concur acknowledges his ability to personalize and humanize a giant bureaucracy. The conversion of political processes and power structures into human interactions is a major achievement that individualizes, localizes, biographizes, historicizes and thus truly represents the diversity of the European Union. Menasse's characters run important plot lines and have been made carriers of the action. They also allow the author to interlink larger issues, such as the history, economy, and cultures of the places they come from, with national identities, their own identities, self-expression, and job functions in their work; we recognize these characters simultaneously as administrators within the institutions of the EU and as representatives of their countries. Additionally, they all are migrants of sorts and inhabitants of the city of Brussels; they are people going about life in the round. 
In a novel as multiperspectival as Die Haupstadt, description must be more than background; it needs to be made narratively functional and carry aspects of plot and focalization to a significant degree. Clifford Geertz's concept of thick description helps elucidate Menasse's writing in this regard.A detailed observational approach to both settings and human behaviors, thick description is deepening, but also specifying and directing attention, and can thus serve as a corrective, even a challenge to preconceived, stereotypical claims. Menasse, who moved to Brussels in 2010 in order to observe both "natives" and "immigrants," the ever-changing personnel of the EU offices, uses thick description as a structural dimension of his writing, not unlike an anthropologist. Concrete names of restaurants and institutions, streets, squares, metro stations, etc. provide both orientation and information.

However, there is a key difference between the anthropologist and the literary author: the former has to reduce the impact of the observer's role on subjects as much as possible - or at least account for interpolations and claims he or she makes. The author of fiction, by contrast, is to a significant extent the very creator of the world described. Thick description, certainly of action, here drifts easily into the realm of plot but also carries the author's voice in "narrating Brussels," "narrating the EU" besides simply describing it.

Beyond plot, characters, and description, authors have at their disposal yet another set of tools to direct readers' attention. It is the establishment of atmosphere and mood through a narrator's voice. It modulates tone (sincerity, reliability, irony), structures motifs or leitmotifs (the pig), metaphors, symbols, images - in sum, it steers the whole literary discursive and rhetorical machinery. For one, there is language itself: Menasse uses several languages and makes the Flemish-French linguistic contrast in Brussels narratively functional; 
there is the distribution of themes and their (re)appearance and gathering into motifs; there are paradigmatic and syntagmatic links, representing institutional structures and narratives that link plot elements throughout the text. There are analogy and parallels, (literary) allusions, intertextuality, and pastiche. Prominent in Die Haupstadt is Robert Musil's novel, Der Mann ohne Eigenschaften that serves as a veritable parallel action for Menasse's plot. And not last, the novel's narrative voice, filtered through the main characters, serves to express the author's (political) views quite transparently.

There is one more connective device that has been overlooked so far in the critical writing about Die Haupstadt; this is the epigrams that appear at the beginning of each chapter. They provide a kind of metathroughline with an additional layer of references beyond the plot in more suggestive and complex ways than simply summarizing it and for this very reason are eminently interpretable. They challenge readers historically and conceptually, asking them for intellectual input, teasing out positionalities on matters at hand, calling out temperamental inclinations and political and philosophical positions. A mixture of Menasse's own coinages and quotes from others, they invite reflection and expand readers' perspective on the novel's settings, plot, and characters.

However tempting it is to pursue these epigraphs as the highest ideational connective tissue of the novel, I want to conclude this essay on a more down-to-earth element, directly tied into the plot, that nevertheless also opens up a broad view on human behavior and the human mind, throwing both into question. This element is the pig that all critics include when enumerating the novel's main characters.

"There's a pig on the loose," is the novel's opening sentence, and the pig appears in at least twenty passages, some of them extensive (a page or more). The animal is shown in many of the domains it has 
carved into the world of humans over the roughly eight millenia of human-porcine cohabitation. In the EU bureaucracy itself the pig is considered a "Querschnittmaterie" (129); it is intersectional, interdepartmental, an administrative object for numerous offices, depending on whether it is alive, in the form of meat, leather, an object of trade or a veterinary, sanitary, or genetic concern. It appears out of the blue on the opening day of the novel, beyond the reach of the $\mathrm{EU}$ or the Brussels police. It runs through the city from the first page of the prologue to the last of the epilogue, linking all the main characters by its random gallop. It appears and disappears unpredictably as the novel progresses and the media try to stay on its trail. Both learned and silly news features appear and newspapers and electronic media attempt to cash in on the popular appeal of the pig - or perhaps pigs? - among their readers and consumers. There is something anarchic to how quickly the pig turns into a media icon, triggering both discourse and discord. In the end it rises to a religious provocation when a website asks readers to name it and "Mohamed" climbs to the top of the list of suggestions with viral speed. Deployed by Menasse as the concrete object of several plot lines, notably around Alois Susman, the Austrian president of the EPP, the European Pork Producers - an acronym hilariously identical to the European People's Party in the EU - the pig is also meant to carry the broad array of symbolic meanings that language carries around it (in German, for one, running the gamut from the abusive appellation Schweinehund to the happy emblem of a Glücksschweinchen). But the rosy, at times almost ethereal, pig that eventually dissipates into cyberspace has a much darker backstory that the author largely, although not toally eschews.

That story, as if to complement Menasse's novel, is told by Del Amo in Tierreich. It is also a European, but a specifically French, narrative 
(whereas Menasse's novel overall, nationally speaking, leans more Austrian). Del Amo's is the account of a peasant family in Gascogny over four generations, desperately poor and benighted when the story opens in 1898, less poor but if anything more desperate, brutalized, and dehumanized, in the 1980's. By that time their small farm has developed into an industrial hog-breeding plant that leaves unclear who damages whom more: the humans the pigs or the pigs the humans. It is a world, bleak and ominous to the core, literally drowning in stench and pig manure, about the darkest sides of progress, the soul-crushing deformative forces of both poverty and social isolation, but above all of industrial animal husbandry. Relentlessly physical, harshly, ghastly sensory, unenlightened and unenlightenable, the book's material world is characterized through most revolting impressions from the chemical senses and the sense of touch, enveloping the reader in nightmares of contact, contagion, and disgust. At the end, both the world of humans and that of the pigs are on the point of implosion, the humans through cancer, alcoholism, sociopathy, and mental illness, the pigs through disease and degeneration.

Henri, the domineering pater familias in the latter part of the novel, ravaged by cancer, is obsessed with their giant boar, la Bête, a 470kilogram ur-beast of an animal that has been accidentally set free by one of his sons and is now roaming the countryside, occasionally seen or at least rumored to have been seen - the dark, ferocious forebear of Menasse's rosy EU pig, a force of animality in history, that Henri hunts like Ahab the Whale. Del Amo writes about the pig as an elemental force, an economic power, and ultimately a symbolic standin for humans themselves in all their contradictions.

The two pigs on the loose and the worlds they inhabit in these novels could not be more different. Menasse's civilized Brussels contains the 
near-immaterial administrative pig of the EU, rootless and ungrounded among the people, the citizens, the nations of the European Union, a specter more than a chunk of meat and as such somehow representative of the EU itself, the distanced, aloof cadre of bureaucrats as its detractors claim that is nevertheless able to reach out and affect people's lives across the continent. It is this perception of the EU that Menasse counters, both in the fiction of the novel and in the politics of Der Landbote. And while a more solid anchoring of EU ideas across its peoples might be desirable, he would certainly not want to exchange EU-Europe for Del Amo's deeply grounded French countryside. Del Amo's pig, a product of determined breeding, lacks any civilizational dimension. It is the epitomy of stubborn localness, a veritable seeding machine of toxic maleness. ${ }^{18}$ As the farm goes down in infection and disease and its owners in cancer, alcoholism, and madness, the epilogue of the book is told from the boar's perspective, now feral, rediscovering an outside of the barn, the pen, the animalindustrial complex. The last image is of the boar, who at that point has behind him a long time of recovery from a life imprisoned by humans, in his new hideout, "his keen eye penetrating the night."19 Del Amo's book is more narrowly focused as an indictment of industrial livestock breeding (with its own globalized logic) and makes its point specifically, materially, and physically. Menasse's is less visceral, more intellectual, although it cannot be overlooked that in the family history of Alois and Martin Susman, whose father expanded their Austrian hog farm into an industrial pork-breeding business, the darker side of the swine is present, too: he gets killed, "screaming like a pig" as he is "pulled into the machine," the industrial feed mixer. ${ }^{20}$

The two novels thus complement each other. Menasse's is the world of administrative-technical feasibility in need of some more solid local 
grounding; Del Amo's is that grounding, brutal and material. Menasse's pig is only a mild reminder of the animal's disruptive potential - so fully visible in Del Amo's account. The two pigs juxtaposed, then, stand symbolically for crude local materiality and transnational bureaucratic enlightenment. Both show the moral ambiguity of their respective systems, Del Amo physically, Menasse in terms of the logic of bureaucratic rationality that nevertheless often only succeeds in displacing, repressing but also conjuring up the darker forces. While he succeeds in humanizing the administrative apparatus itself, fleshing it out, as it were, through a rich series of portraits of the people in it, behind his rosy pig still lurks Del Amo's boar, symbol of the nether regions of human interaction with both other humans and animals.

\section{Notes}

\footnotetext{
${ }^{1}$ Gottfried Benn, Gesammelte Werke I, Gedichte (Wiesbaden: Limes, 1960), 12. "The crown of creation, swine, man."

${ }^{2}$ Robert Menasse, Die Hauptstadt (Berlin: Suhrkamp, 2017). The American translation appeared as The Capital (New York: Liveright, 2019). Quotes are from the German edition. All translations are my own.

${ }^{3}$ Die Zeit, 6 September 2017, https://www.zeit.de/2017/37/robert-menasse-die-hauptstadt-roman.

${ }^{4}$ Neue Zürcher Zeitung, 8 September 2019, https://www.perlentaucher.de/buch/robert-menasse/diehauptstadt.html.

${ }^{5}$ Die Tageszeitung, 16 September 2017, https://www.perlentaucher.de/buch/robert-menasse/diehauptstadt.html.

${ }^{6}$ Süddeutsche Zeitung, 9 September 2017, https://www.perlentaucher.de/buch/robert-menasse/diehauptstadt.html.

${ }^{7}$ Steven Erlanger, New York Times, 14 Januarty 2018, https://www.nytimes.com/2018/01/14/books/new-novel-about-european-union.html. The review is based on the German edition. The American hardcopy edition features the outline of a pig prominently in the cover, positioned on top of the Brussels Atomium sculpture.

${ }^{8}$ German Book Prize, https://www.deutscher-buchpreis.de/archiv/autor/91-menasse/.

${ }^{9}$ Frankfurter Rundschau, 13 September 2017, https://www.fr.de/kultur/literatur/diese-gluecklichelangeweile-friedens-11029464.html.
} 
${ }^{10}$ Jean-Baptiste Del Amo, Tierreich, trans. from the French by Karin Uttendörfer (Berlin: Matthes and Seitz, 2019). French original, Règne Animal (Paris: Gallimard, 2016), references are to the German edition.

${ }^{11}$ Robert Menasse, Der Europäische Landbote, Die Wut der Bürger und der Friede Europas oder Warum die geschenkte Demokratie einer erkämpften weichen muss (Vienna: Paul Zsolnay, 2012), 8-9.

${ }^{12}$ Menasse, Landbote, 17.

${ }^{13}$ Menasse, Landbote, 18.

${ }^{14}$ Menasse, Landbote, 17

${ }^{15}$ Deutscher Buchpreis, https://www.deutscher-buchpreis.de/archiv/autor/91-menasse/.

${ }^{16}$ SRF (Swiss Radio and Television), https://www.srf.ch/radio-srf-1/die-buchkoenig-bloggt/diebuchkoenig-bloggt-der-neue-roman-die-hauptstadt-von-robert-menasse-ist-saugut.

${ }^{17}$ Wikipedia, Robert Menasse, Romane, https://de.wikipedia.org/ wiki/Robert_Menasse\#Romane.

${ }^{18}$ Tierreich, 274.

${ }^{19}$ Tierreich, 435.

${ }^{20}$ Die Hauptstadt, 68. 


\section{Novels Assessing Global Mobility Through the Lens and Legacy of the GDR}

Friederike von Schwerin-High

Department of German and Russian, Pomona College, Claremont, CA, USA

"The fact that after 1990 borders were transcended which were considered indissoluble before 1990 accounts for the new quality of the discourses about the past."

"The GDR and the Wende are supposed to be a closed chapter in history. However, pairing East German themes with wider, societal ones forces this chapter open, and the reader must participate in the negotiation with the past... in contemporary literature. ${ }^{\prime 2}$

\section{Introduction}

In historiography, the social sciences and cultural studies, the global turn designates a move toward considerations of the embeddedness of the objects we study within highly interactive large-scale systems. ${ }^{3}$ These systems range from the local to the regional, national, transnational, and planetary. Additionally, the global turn endeavors to characterize historical situations as circumstances that were always already part of a highly interdependent world order. My essay analyzes memories of the isolationist German Democratic Republic, a country that existed between 1948 and 1989, within a contemporary discourse of ever-increasing geographic mobility. Recent imaginative literature offers striking confluences between feelings of confinement, immobility, and stagnation experienced during the GDR and a new ontology shaped by a relentless schema of globalization. Three 
representative German novels published within the last fifteen years, Katharina Hacker's The Have-Nots (2006), Eugen Ruge's In Times of FadingLight (2011) and Jenny Erpenbeck's Go, Went, Gone (2015) showcase precisely these stark contrasts between the GDR and the global scale. ${ }^{4}$

Noting that borders began to mean relatively little after the fall of Communism and the defeat of the Soviet Empire, Peter Lecouras has argued that American identity, through its multi-national corporations, bent the very idea of associating country with space or even time. Until, that is, History returned with a vengeance on September 11, 2001.5 About that singular event of Nine-Eleven, Jean Baudrillard has remarked: "There is, indeed, a fundamental antagonism here, but one which points past the specter of America and the specter of Islam, to triumphant globalization battling against itself."6 Similarly, prominent British Labor Party member Jonathan Powell observed: "The destruction of the twin towers graphically illustrated the dark side of globalization." " $\mathrm{He}$ cites the internet, open borders, and hi-tech airplanes as the tools of modern global society that had been used to attack the west at home. The intervening years of wars, uprisings, international crises, and installments of authoritarian regimes have brought to the fore a new face of globalization. In the words of German Finance Minister Wolfgang Schaeuble, "[t]he influx of hundreds of thousands of refugees into Europe is part of the reality of globalization. In a way, with the refugee crisis we are now experiencing in Germany and in Europe a meeting with the realities of globalization." 


\section{The Have-Nots}

In 2006, the German Book Prize, awarded by the Publishers \& Booksellers Association and then only in the second year of its existence, went to Katharina Hacker for her novel The Have-Nots. The novel focuses on Isabelle and Jakob, a young upwardly mobile couple who move from Berlin to London. A number of readers felt that this book merely catered to contemporary preoccupations and preconceptions, touching as it did on such marketable tropes as NineEleven, the war in Iraq, the pervasive land ownership disputes in the newly unified Germany and on metropolitan, global hubs recognizable to English-speaking consumers of literature. Others, by contrast, praised the novel's psychological breadth, timeliness, intelligence, and critical stance. ${ }^{9}$ Christian Sieg argues that this novel belongs to the genre of "migrant literature," a category he expands to include all stories that foreground migratory realities, regardless of an author's actual migratory status. ${ }^{10}$ Sieg's reading attends to the, at times phantasmagoric, deterritorialization that pervades this novel and contemporary culture in general and which he, borrowing from Robert Robertson and Anthony Giddens, calls glocal.

From Nine-Eleven accrues a distinctly personal meaning to Isabelle and Jakob; having just chanced upon Isabelle again in Berlin after an entire decade of being unable to forget her, Jakob cuts his quick visit in New York short. He moves his business meeting, scheduled for September 11, to September 9. Meanwhile, Robert, a colleague and friend, also on a New York business trip, who has been offered the firm's coveted London job, dies on September 11. This vacates the position in London for Jakob, a lawyer specializing in the restitution of Berlin and Brandenburg family realty to British clients of German- 
Jewish descent. Like the other protagonists discussed below, Jakob had initially felt like an immigrant in the new, unified Germany:

On the day after the Wall came down [Jakob] went to a travel agent's first thing in the morning, waited for the owner to arrive and bought two tickets to Berlin ... Later Jakob's curiosity waned; ... . [and he] felt as if the ground were being cut from under his feet: his country, the Federal Republic, was disappearing, so that he was emigrating willy-nilly, without moving from the spot...But then the unification treaty and the law to settle disputes over the ownership of property did become a long-time preoccupation. ${ }^{11}$

While the GDR existed, it was nearly impossible for former owners to obtain legal redress against the misappropriation of their possessions that had occurred prior to 1945 . One consequence of the fall of the Wall was that as the restitution of houses and businesses seized by the Communists from 1949 onwards grew in number, compensation actions for loss and damage caused by the Nazi regime were also launched. ${ }^{12} J a k o b$ has come to see "German unification as an opportunity, even at this late date, to apply the rule of law to some tiny fraction of the old injustice." ${ }^{13}$ All the same, he eventually concludes that, "[r]estitution was a farce, since it was ultimately not about places, but about lost years of life and memory."14

The two financially well-established newlyweds Jakob and Isabelle are, both in their own way, 'space professionals'; Isabelle works as a graphic designer and delivers her work - drawings of street scenes and artistic illustrations of venues and businesses - remotely to the Berlin office in which she is a partner and which relocates during her sojourn in London. Increasingly, Isabelle's and Jakob's life unfolds within a disconcerting global landscape. Everything seems both close and far away; it is not a matter of reversal of proximity and distance, 
but rather a deconstruction of such an opposition in all things. This gives rise to a net cast too wide and to feelings of unbelonging and rootlessness. ${ }^{15}$

\section{In Times of Fading Light}

In the late 1990s prominent journalist and cultural critic Daniela Dahn observed that the long-awaited Fall of the Wall novel had not yet been written. ${ }^{16}$ In 2009 Uwe Tellkamp's book The Tower was celebrated as such a novel, drawing comparisons to Thomas Mann's Buddenbrooks. ${ }^{17}$ The Tower is deliberately limited to a certain period of time in the GDR era, the 1980s. By contrast, Eugen Ruge's In Times of Fading Light, which was also praised as the new Buddenbrooks, ${ }^{18}$ is not confined to a time period during the GDR, but jumps back and forth between various points in GDR history and the year 2001. Award-winning book reviewer Dieter Wunderlich noted that the chapters starting in 2001 diminish the novel's effectiveness. ${ }^{19}$ Seen through the lens of a globalized world, however, the chapters taking place after the turn of the millennium are essential for the novel's design and its protagonist Alexander, the novel's cancer-stricken central perceiver and the archivist and memory inheritor of the once Communist family.

Born in mid-1950s East Germany, Alexander used to imagine Mexico as an unattainable and, from his vantage point, forevermore unreachable country. Like a museum, this country of longing was kept in the conservatory room of his grandmother in her house in the East Berlin suburb. The room seemed enchanted, containing all those Jorge Negrete records, stuffed iguanas, Aztec-inspired cufflinks, and other near-magical items that the grandson was allowed to visit as a child. Now, in 2001, the GDR, Alexander's former reality, has long since 
become a museum. Conversely, Mexico, once preserved in the conservatory of the grandmother, has stepped out of its museum existence. When Alexander finally visits Mexico in 2001, it hardly corresponds to the picture he had fashioned out of the memories of his Communist grandparents exiled there during World War II. He meets many international world travelers in Mexico City. Among them are Kati and Nadja, two young Swiss women whose wisdom and worldliness astonish Alexander:

They are still under thirty. They wear flip-flops. And they are in the middle of a trip around the world. It turns out that they have already spent two months in Africa, going on to Brazil, Argentina, Tierra del Fuego, Chile, Peru, Ecuador and somewhere else as well. Now they are here for a week, in Mexico City, or DF, as they knowledgeably call it, they have taken a language course somewhere along the way. . . once they are through with Mexico, they are going to fly to Sydney to honor the southeast - or was it the northwest - of Australia with their presence, as they jokingly put it, touring in a van, then on to New Zealand to meet the Kiwis, and finally to Bangkok, from where - if they don't take a side trip to the Mekong Delta, as recommended by their Backpacker's Guide, they will return to Europe...Amazing how easily all this passed their lips, how naturally and effortlessly they reconciled it, how airy and weightless this new world religion of theirs was, like a watercolor hastily dashed off, thinks Alexander . . . 20

Alexander, the former citizen of the GDR, prepares to revise his worldview in light of this global, evidently boundless scale. The circle of past memory closes in on itself in the Mexican port city of Puerto Angel for Alexander. Here, at the former place of residence of his exiled grandparents, Alexander begins to read his father's memoirs. 
Furthermore, he ritually rereads the 12 September 2001 issue of an unspecified Mexican daily newspaper about the collapsing World Trade Center every day, which improves his Spanish, but does not make the strange world events any clearer. ${ }^{21}$ Curiously, Alexander also experiences a developing friendship with a handful of West Germans and Austrians who have been living fulltime or part-time in Mexico since the 1970s and whom he now gets to know, as if making up for lost time. Twelve years after the fall of the wall and while marveling at the "airy and weightless...new world religion" of global mobility, Alexander nevertheless still sees powerful colorings and reminiscences of the GDR everywhere, both at home and abroad.

\section{Go, Went, Gone}

Whereas East Germans once dreamed of the freedom of travel, and even had a word for it, 'Reisefreiheit', in March of 2016, holders of a German passport were allowed to visit more countries visa-free than any other passport holders on earth. Persons in possession of a German passport could enter 177 countries easily. At the other end of the spectrum were holders of an Afghan passport: they were able to enter only 25 countries without a visa. ${ }^{22}$ Set in 2014, Jenny Erpenbeck's Berlin novel Go, Went, Gone centers around Raschid and his friends, a group of young asylum seekers from Nigeria, Niger, Ghana and Burkina Faso. Richard, a recently retired professor of classical philology starts to befriend and interview the young men. He witnesses their forced and frequent relocations within Berlin as they navigate an exhaustingly complex web of rules and regulations prescribed by the EU, the German government, and the Berlin Senate.

Feeling fundamentally like a foreigner in unified Germany, Richard identifies with the refugees' state of disorientation as they face 
possible deportation. Like Alexander, Richard lives in an unspecified East Berlin suburb and has a view of the world animated by the ways of life and vantage points of the old GDR. Gradually, Richard comes to learn that his hometown Berlin is not entirely constituted and consumed by its own history. Instead, a phenomenological space opens up in which new experiences occur. When Richard first looks at Oranienplatz Square with the international refugees' protest camp, his mind only produces a narration of absences:

In any case, no one is sitting here for recreation anymore.... Sitting on a park bench has ceased to be a matter of course because of the refugees camping on the lawns behind the benches. Berliners, who knew since Lenné's days how to behave in this park, sitting on a bench, no longer know: no old woman feeds the sparrows, no mother gently rocks the stroller back and forth, no student reads, no three Drinkers hold their morning meeting here, no official eats his lunch, no lovers hold hands. . .23

As Richard meets the refugees from Oranienplatz in person, his mind's narrative changes from the "no" pattern to a "not only but also" thinking. Richard's realizations are brought to light through what we may term a transcultural or affiliating memory. ${ }^{24}$

The professor emeritus, who is hearing so many things for the first time that it's as if he's become a child again, now suddenly understands that Oranienplatz is not only the square designed in the 19th century by the famous landscape architect Lenné, not only the square where an elderly woman daily walks her dog, or a girl on a park bench kissed her boyfriend for the first time. For a boy who has grown up among the nomads, Oranienplatz, where he made his home for a year and a half, is one station on a long journey, a temporary place leading to the 
next temporary place. When they tore down the shacks, purely a political issue for Berlin's interior minister - this boy was thinking of his life in the desert. ${ }^{25}$

Richard's altered thoughts yield a protocol from an altered Germany that is broadened by the gaze of traumatized young refugees who have created new realities for themselves and others. Even so, during every one of his visits Richard observes the asylum-seekers feeling more at home in their wireless networks, a system of numbers and passwords extending across the continents, than in the country in which they await an uncertain future:

What belongs to them is invisible and made of air.... In his contacts [Karon] has Italian, Finnish, French, and Belgian telephone numbers - of African friends who, like him, are drifting through Europe: friends who also come from Ghana originally, or who worked in Libya on the same construction site, or were with him on the same boat for the crossing, friends he met in Lampedusa, in the camp, in some train station or Caritas housing. All of them friends who, because they have no work, also have no apartment and no address, who aren't registered anywhere... ${ }^{26}$

\section{Conclusion}

This essay has focused on text passages that stage aspects of globalization and raise complicated questions about living in a global society that is at once more closely connected and more ephemeral. Several book reviews highlight the globally oriented, universalizable content of these three works of fiction. Concerning Hacker's The HaveNots, Verena Auffermann writes that, "our vague present got a tough portrait here that illuminates its contours." Similarly, Stefana Sabin 
assesses Erpenbeck's text as a realistic novel, "because it establishes a literary reality that reflects global reality," and Sophia Ebert reads Ruge's novel as a work of fiction that "resonates with world history." 27 What I have argued here is that each of these frequently discussed novels employs a double perspective as the protagonists send their gaze from memories of the formerly divided Germany via reunified Germany across the increasingly globalizing earth inhabited by mixed nationals, world travelers, and refugees. Such juxtapositions of divided Germany and the globalized world lend themselves to the following conclusions:

1. The fall of the Wall is shown as coinciding with the beginnings of worldwide technology networking.

2. Memories of a place of enforced spatial limitation put the phenomenology of global planetary connectivity into high relief.

3. The singular event represented by the Fall of the Wall confronts other fundamental paradigm shifts, in the case of The HaveNots and In Times of Fading Light Nine-Eleven and in the case of Go, Went, Gone the current refugee situation.

As a genre, the novel continues to be well-suited for the depiction of a contest of memories. Contemporary novels provide access to complex, nuanced and sometimes contradictory interior views of characters thrust into both a sharply globalized and a strikingly localized world, a world in which some live with the privilege and others with the curse of constantly moving about.

\section{Notes}

\footnotetext{
${ }^{1}$ Anette Horn and Peter Horn, Die doppelte Vergangenheit der Gegenwart: Der deutsche Roman seit 2000 (Oberhausen: Athena, 2014), 17.

${ }^{2}$ Derek Schaefer, “The past does not end here: Memory and 'Collective Enunciation' in Antje Rávic Strubel's Sturz der Tage in die Nacht (2011)," German Quarterly 91:2 (2018): 186-201, 194.
} 
${ }^{3}$ Eve Darian-Smith and Philip C. McCarty, The Global Turn: Theories, Research Designs, and Methods for Global Studies (Oakland: University of California Press, 2017). Richard J. Evans, The Third Reich in History and Memory (Oxford: Oxford University Press, 2015), vi-viii.

${ }^{4}$ Katharina Hacker, Die Habenichtse (Frankfurt: Suhrkamp, 2006); Katharina Hacker, The Have-Nots, translated by Helen Atkins (Europa, 2008). Eugen Ruge, In Zeiten des abnehmenden Lichts: Roman einer Familie (Hamburg: Rowohlt, 2011); Eugen Ruge, In Times of Fading Light: The Story of a Family, trans. Anthea Bell (Minneapolis: Graywolf Press, 2013). Jenny Erpenbeck, Gehen, Ging, Gegangen (München: Knaus, 2015); Jenny Erpenbeck, Go, Went, Gone, trans. Susan Bernofsky (New York: New Directions, 2017).

${ }^{5}$ Peter Lecouras, “9/11, Critical Theory, and Globalization,” Interdisciplinary Literary Studies, 12:1 (Fall 2010), 78-90.

${ }^{6}$ Jean Baudrillard, The Spirit of Terrorism, trans. Chris Turner (London and New York: Verso, 2013) 11.

${ }^{7}$ Jonathan Powell, “Opinion: What impact did 9/11 have on the world?” The Guardian, 5 Sep. 2011, Web.

8 "Refugee crisis shows reality of globalization, says Germany's Schaeuble," Reuters World News, 8 Oct. 2015, Web.

${ }^{9}$ Helga Druxes, "The Indictment of Neoliberalism and Communism in the Novels of Katharina Hacker, Nikola Richter, Judith Schalansky, and Julia Schoch,” German Women's Writing in the Twenty-First Century, edited by Hester Baer and Alexandra Merley Hill (Suffolk: Boydell and Brewer, 2015), 154174.

${ }^{10}$ Christian Sieg, "Deterritorialisierte Räume. Katharina Hackers Die Habenichtse und Terézia Moras Alle Tage im Spiegel des Globalisierungsdiskurses," Weimarer Beiträge: Zeitschrift für

Literaturwissenschaft, Ästhetik und Kulturwissenschaften 57:1 (2011): 36-56.

${ }^{11}$ Hacker, The Have-Nots, 23-24.

${ }^{12}$ Evans, History and Memory, 436-437; See also Hans Pötter, "Rückgabe feststellbarer Vermögensgegenstände an jüdische Berechtigte. ..," Zeitschrift für offene Vermögensfragen (1995): 415.

${ }^{13}$ Hacker, The Have-Nots, 206.

${ }^{14}$ Ibid., 211.

${ }^{15}$ Ibid., 251. For displacement as a destabilizing universal social and aesthetic condition in The Have-

Nots, see Sieg, "Deterritorialisierte"; and Katharina Gerstenberger, "Fictionalizations: Holocaust Memory and the Generational Construct in the Works of Contemporary Women Writers," in: Generational Shifts in Contemporary German Culture, edited by Laurel Cohen-Pfister and Susanne Vees-Gulani (Suffolk: Boydell and Brewer, 2010), 95-114, 106-107.

${ }^{16}$ Daniela Dahn, "Die ostdeutschen Schriftsteller nach der Vereinigung. Veränderte Schreibbedingungen, Erwartungen, Themen," in Schreiben im heutigen Deutschland, ed. Ursula E. Beitter (New York, Washington, Baltimore: Peter Lang, 1997). 
${ }^{17}$ Uwe Tellkamp, Der Turm: Geschichte aus einem versunkenen Land (Frankfurt am Main: Suhrkamp, 2008). For the Buddenbrooks comparison, see Helmut Böttinger, "Weißer Hirsch, Schwarzer Schimmel," Die Zeit, 12 Sep. 2011: 2, Web.

${ }^{18}$ Armgard Seegers "Die Buddenbrooks des Ostens: Porträt einer Familie," Hamburger Abendblatt, 17 Sep. 2011, Web.

${ }^{19}$ Dieter Wunderlich, "Eugen Ruge: In Zeiten des abnehmenden Lichts,” 2012, Web.

${ }^{20}$ Ruge, Fading Light, 166; 171.

${ }^{21}$ Ibid., 295.

${ }^{22}$ Maria Menzel, "Deutsche genießen weltweit größte Reisefreiheit," Die Welt, 7 March 2016, Web.

${ }^{23}$ Erpenbeck, Gehen, ging, gegangen, 46, my translation.

${ }^{24}$ See, for instance, Brangwen Stone, "Trauma, Postmemory, and Empathy: The Migrant Crisis and the German Past in Jenny Erpenbeck’s Gehen, Ging, Gegangen," Humanities 6:4 (2017): 1-12.

${ }^{25}$ Erpenbeck, Gehen, ging, gegangen, 70, my translation.

${ }^{26}$ Ibid., 221.

${ }^{27}$ Verena Auffermann, "Schlimme brave Welt," Die Zeit, 6 Mar. 2006, Web. Sophia Ebert, "Der Unbarmherzige," KulturSpiegel, Oct. 2011, Web. Stefana Sabin, [Review of Gehen, ging, gegangen], NZZ am Sonntag, 30 Aug. 2015, Print. My translations. 
Workshop 3:

Democracies, Demagogues, and Despots: Pre-Globlized

Precursors and A New "Age of Tyrannies"?

Chair: Victor Castellani 
Over-organization, Multilayered Conflict, and the Risk of a New Era of Tyrannies

Cristiana Senigaglia

University of Passau, Germany; and University of Trieste, Italy

\section{The Genesis of Élie Halévy's Theory}

In considering theories about totalitarian states and systems, Élie Halévy's The Era of Tyrannies, published in the late 1930s, plays a paramount role. Indeed, the author cannot only be evaluated as a forerunner of the later analyses of totalitarianism by Raymond Aron, ${ }^{1}$ on whom he exerted a profound influence despite significant differences, or of Hannah Arendt; ${ }^{2}$ but he has also to be appreciated for his astonishing farsightedness and intuition. In fact, already at the outbreak of the First World War, Halévy was deeply concerned because he was aware that the reasons for the conflict were deeprooted and hardly solvable, predicting that "we have before us ten or fifteen, or thirty years of war," 3 in which the warfare "will be suspended by false peace, precarious peace, and truces." ${ }^{4}$ Although Halévy was not a pacifist, since he judged that wars are sometimes unavoidable, ${ }^{5}$ he also reflected on the consequences of armed conflict on political democratic life because wars impose a centralization of economy and organization that leads to a concentration of power and a diminution of individual freedom. ${ }^{6}$ His concerns were to be repeatedly confirmed after the war, with the advent of Stalinism in Russia and the rise to power of Mussolini in Italy and Hitler in Germany, and additionally with the realization that authoritarian tendencies were intensifying in several other European countries. ${ }^{7}$ Although Halévy distinguished between communism and fascism, he was primarily interested in the sociological traits that define tyrannies and oppose 
them to parliamentary democracies. ${ }^{8}$ However, he rarely used the word "totalitarian." He prefered instead to refer to "tyranny," which he described as a "bad" form of government exerted through personal power over the state. In fact, the word "totalitarian" had not yet entered the vocabulary of the time. Moreover, this word "tyranny" presented theoretical advantages, as it was more comprehensive, less pretentious, and yet desirably judgmental. In other words, it could also be applied to "bad" authoritarian tendencies and situations without requiring the extreme consequences of totalitarianism.

\section{Halévy's Connections between Theory, History, and Life}

In his diagnosis of the postwar epoch as an age of tyrannies, it is possible to find anew the theoretical issues, the historical studies, and the personal experiences that shaped Élie Halévy's life (1870-1937). Son of the successful playwright Ludovic Halévy, who was the librettist of Bizet's opera Carmen, Élie had attended the École Normale Supérieure in Paris and proved to be an eclectic intellectual. Indeed, he combined philosophical studies, bound up with his cofoundation of the journal Revue de Métaphysique et de Morale and of the French Society of Philosophy, with his activity as lecturer at the École des Sciences Politiques. He undertook thorough analyses that concentrated on English history of the $19^{\text {th }}$ century as well as of the history and theory of European socialism. ${ }^{9}$ This interlacing intellectual activity contributed to his privileging the role of theoretical forces in historical processes and their influence on political agency. On the other hand, it induced him to root ideas and theories in their historical context and to be sensitive to distinct cultural backgrounds and historical developments. Nevertheless, this did not prevent Halévy from ascertaining some general tendencies over the course of the $19^{\text {th }}$ century in which he saw a substantial 
dialectic between a power-freeing élan that strengthened freedom of individuals on the one hand, and opposite trends toward centralization and organization on the other. Such a dialectic permeated the life of the modern state, torn between the progressive reinforcement of rights and political entitlements of citizens, despite social and economic differences, and the increase of bureaucratic organization and centralization of power in order to meet ever more demanding responsibilities of state-level management. ${ }^{10}$

Among the historical factors favoring the centralization of power and diminution of freedom, Halévy counted warfare in particular as representing for him the circumstance most demanding of organization and of the concentration of power that progressively eroded democracy. ${ }^{11}$ With increasing distress Halévy followed the policies of several states that plunged them progressively into irreconcilable conflicts before the First World War and thereafter. Furthermore, he drew upon his personal experience as a hospital nurse during the war, his participation in debates with other outstanding intellectuals, and his scientific and historical analyses. These led him to closely connect the mechanisms created by war with the enhancement of tyrannical modes in the exertion of power. ${ }^{12}$

\section{“The Era of Tyrannies"}

The Era of Tyrannies was originally a collection of Halévy's texts published in 1938, a year after he died. Its title derives from that of a conference held in 1936 some months before his unexpected death. It refers to the contemporary period, perceived as an era in which democracies were successively replaced by authoritarian and antidemocratic regimes or threatened with this fate. In this context, "tyranny" for Halévy had to be understood as distinct from 
"dictatorship."13 While dictatorship is temporary and depicts an exceptional condition of exerted power that ends upon the reaffirmation of a democratic political system, tyranny is a stable condition that indicates an authoritarian monopoly of power accompanied by an autocratic leadership, which can be traced back to historical models in ancient Greece. Thus, tyranny assumes the character of an enduring political system with its own distinctive nature and typical features, whose common traits in Halévy's opinion transcend ideological differences. An era of tyrannies therefore entails a historical time in which a systematic disempowerment of parliamentary democracies is effected in favor of a self-centered leadership concentrated on a single person and including a cult of personality. The leader assumes a position above the law and state institutions, which on their part are eroded, eliminated, or rendered impotent. ${ }^{14}$

Tyrannies are nourished by a previous state of war, whose aftermath often provokes revolutions because warfare has established a legitimacy of violence. In general, Halévy identifies the following factors present in a war that prepare the conditions favorable to tyranny:

(1) mass arming of people in consequence of which many persons become familiar with weapons and accustomed to resort to them in order to solve major problems;

(2) centralization of organization, required by the necessity of controlling life among the civilian population in order to support the troops at the front and to regulate the sustenance of all;

(3) nationalization of the economy, imposed by the necessity of adapting production to the needs of the military, which means 
supporting heavy armaments industry as well as providing rations and gear for the troops;

(4) a state of siege, favoring security, but also aiming at the avoidance of forms of protest that could endanger the internal order and 'morale';

(5) limitation of the freedom of thought, since priority of national security becomes more urgent until it prompts control over public debates and expression of opinions, and finally over the press.

\section{The Typical Features of Tyranny}

Proceeding from a conception of war that facilitates the concentration of power and progressively reduces the enjoyment of freedom among the citizens, Halévy explains the increasing prevalence of tyrannies or at least of authoritarian regimes with non-democratic traits and illiberal tendencies. In his view, some typical features characterize tyrannies and distinguish them from other forms of government:

- Nationalization of the economy, by which the state becomes the owner of the principal industries, determines prices and production, and establishes in advance the course of development.

- Nationalization of thought, which entails state control over education and thought, which is as a rule based upon an official theory that cannot be criticized.

- Repression of differing opinions, whose holders find themselves confronted with censorship, official boycott, and persecution.

- Organization of enthusiasm, which includes first of all the celebration of an ideology marked by rituals and mass demonstrations, but also by the creation of recreational social activities that distract people while cementing their sense of collective belonging. 
- Increasing bureaucratization, from the urge to organize the different sectors of life (society, economy, politics, etc.) thoroughly and incrementally to subtract independence from individuals.

- Strong military and paramilitary formations, by which order and absolute obedience are secured, the activities and also the private life of the people are controlled, and dissent or opposition is suppressed.

- Distrust in democracy, witnessed by the steady expression of doubts on its efficaciousness and by the acceptance of an alternative agency that gradually undermines open democratic procedures.

- Perception that order can be guaranteed only by the existence of an authoritarian power vested in the personality of an individual powerholder.

In Halévy's understanding these phenomena characterize modern tyranny as an autocratic regime exhibiting stability and durability. An era of tyrannies is then attained when tyrannies become numerous and effective and begin to seriously influence international politics as well as internal affairs of other states. Evidence for an era of tyrannies is particularly clear when still existing democracies are pushed into the defensive and face serious difficulties in justifying their system and in achieving consensus in its defense: "We should note that those countries with representative governments have become the timid countries, eager to protect a past that is dear to them, rather than to work for a future of which they are sure. Their attitude towards the arbitrary governments is the attitude of fear." 15

\section{Present Authoritarian Tendencies and their Counterweights}

In comparing the situation today with Halévy's time between the two

World Wars, it seems more appropriate to speak of authoritarian than 
of tyrannical tendencies. In most cases, leaders are selected through democratic elections. This, however, does not prevent powerholders from the possibility of reducing the spheres of individual freedom and limiting the forms of political opposition. They simultaneously stress the need for order and security, impose national or nationalistic values, and concentrate power in their own hands or in the hands of their affiliates. These tendencies also mark leaders at the head of populist movements and parties who intend to present an alternative way of governing their countries. If we carry the comparison with the era of tyrannies depicted by Halévy further, we can affirm that several populist leaders today are charismatic politicians aiming to concentrate in their hands power and decision-making, even though they show themselves more inclined than in the past to formally respect the law and democratic procedures. ${ }^{16}$ On the other hand, we must allow that at the present moment society offers several constraints that prevent gaining of tyrannical power or at least render it more difficult. As a matter of fact, the media provide political news and international visibility, and global diffusion through the new media facilitates circulation of pluralistic information. Therefore, a prevailing culture of democracy remains in politics, among the élites, and (at least officially) in the civic mentality. Agency departing from democratic canons is castigated, requires awkward justifications, and is as a rule publicly denied. Moreover, most states possess a strong autonomous juridical power. International courts can also play a major role. Since these too can be appealed to by single citizens and civic groups, they exercise some supervision over state management and government policies. Finally, increasing global interconnection has led to the creation and enhancement of supranational organizations and powers that exert pressure on individual states and declare their support of democratic and human rights-based values. 


\section{Centralization and the Risk of Over-organization}

If supranational powers contribute to guaranteeing respect for legality and to confirming democracy, nevertheless they also create new forms of distrust, which foster authoritarian and populist tendencies. In effect, supranational powers depend upon an increase in organization that widens the distance between such centers of power and the people. Furthermore, organization implies specialization and technocracy, with the result that scientists and experts are not seen any longer as impartial analysts, but on the contrary as part of an untrustworthy establishment. Such lack of trust then coincides with people's tendency to support populist leaders and movements that speak an everyday language and ostentatiously "attack" the aloof officers of state, taking the people's side. Distrustfulness and insecurity on the citizens' part are exacerbated by the more troubling side of globalization, which entails disquieting effects such as greater instability of standards of living, mass migration, and uncertainty about the groups and forces at play. In particular, people's fear is fed by their consciousness of the rise to power of transnational players and of the weakness of national states in confronting them. Toward reinstating national sovereignty and affirming priorities on a local basis, populist ideas are welcomed, especially by luckless or dispossessed individuals and by all who believe that they are at risk.

\section{A Near-War Condition?}

Certainly, it has to be recognized that, at least for most nations, the influence of war cannot be considered as a major conditioning factor nowadays as compared with the interwar past. However, economic competition and crises of a different order are increasingly perceived 
as a near-war condition; and the right to manage domestic economy "again" primarily for the national benefit is widely and intensely longed for. A sentiment of defeat also pervades some strata of the population who feel that they have forfeited their former better economic position and have lost their social-economic status. This generates a nostalgic attitude toward the past together with "angst" about the future, ${ }^{17}$ both accompanied by resentment toward and envy of other persons and groups. Under these circumstances, blame becomes a way of shifting discomfort and pain onto others, for it is directed especially against foreigners and the "Other," who are identified as enemies. This feeling of near-war conditions, though latent and emerging only intermittently, nevertheless affects one's everyday life and tends to strengthen authoritarian tendencies in society. ${ }^{18}$ First of all, it intensifies the search for an exclusive community, segregating those others and keeping Them apart, thereby securing the privileges and priorities of a closed Us. Concomitantly it deepens a conviction that security may have to be preferred to freedom. This preference reflects once more that uncertainty and instability in social life in important respects replicates the stressful conditions created by war. For the sake of security, ever more individuals appear to be ready incrementally to renounce civic rights and to tolerate the increasing control and interference in private life by the authorities, for whose supposed insufficiencies at state level they often compensate with self-organized monitoring groups. These entail the organization of enthusiasm, marked by mass meetings, continual communication, with largely exclusive exchange among the like-minded. All of this produces echo chamber effects, ${ }^{19}$ reinforcing the personal convictions of individuals and tending to push them to extremes, since it sharpens the sense of 
imminent danger and of the necessity of group activism in order to resist it.

\section{Against an Era of Tyrannies: The Enhancement of the Democratic Process}

In the light of such present authoritarian temptations, it would be a grave mistake to ignore people's underlying "angst" or play down its political potential. Their fears have a basis in growing social mobility and instability, the undeniable existence of which requires taking them seriously and conceiving new forms of political intervention to mitigate their anxieties. This implies forms of closer consultation with and involvement of those concerned. It can be accomplished by public meetings as well as by purposeful communication through the media. To the extent that fiscal realities make it possible, effective social policies in non-bureaucratic forms should be devised to meet citizens' more urgent demands adequately. In order to neutralize authoritarian trends with their risk of a new era of tyranny, a substantial challenge would be to "organize enthusiasm" in a democratic participatory way, such as would couple emotional allegiance with reasoned commitment. This can be achieved only by reinstating strong democracy that stresses the role of well-functioning parliaments and their pluralist membership, on the one hand, and on the other, creates multiple circles and forums that articulate proposals to convey to higher levels of authority. These outcomes require, apart from electoral campaigns and other manifestly political affairs, strengthening the contact between the people and the political-institutional élites in a steady, intentional way. Democratic leaders must be ready to amplify such efforts in cases of acute crises and urgent demands. Democracy can aspire to restore trust and security but must be close to the people and strong in its determination to give satisfactory responses to them. The 
more the political-institutional sphere is perceived to govern efficiently, i.e. to meet the needs of the people and to find practicable answers to pressing questions, the more democracy can successfully combat impulses toward authoritarian solutions that reduce personal freedom, foster non-democratic tendencies, and instill an attitude of uncritical acceptance and obedience.

\section{Notes}

\footnotetext{
${ }^{1}$ Cf. Raymond Aron, Démocratie et totalitarisme (Paris: Gallimard, 1965).

${ }^{2}$ Cf. Hannah Arendt, The Origins of Totalitarianism (New York: Harcourt, Brace, 1951).

${ }^{3}$ Élie Halévy, Correspondance et écrits de guerre (1914-1919), Euvres I (Paris: Les Belles Lettres, 2016), Letter to Xavier Léon, 26 November 1914, 43.

${ }^{4}$ Ibid., Letter to Xavier Léon, 27 October 1915, 113.

${ }^{5}$ Cf. François Furet, "Préface” to Élie Halévy, Correspondance (1891-1937) (Paris: Éditions de Fallois, 1996), 19-54, 44.

${ }^{6}$ Cf. Myrna Chase, Élie Halévy. An Intellectual Biography (New York: Columbia University Press, 1980), 165-66.
}

${ }^{7}$ Cf. Vincent Duclert, “Introduction” to Élie Halévy, L’Ère des tyrannies, Euvres II (Paris: Les Belles Lettres, 2016), 23-41, here $35 \mathrm{ff}$.

${ }^{8}$ Cf. Michèle Bo Bramsen, Portrait d'Élie Halévy (Amsterdam: Grüner, 1978), 323-25.

${ }^{9}$ Cf. Furet, "Préface", 29ff.

${ }^{10}$ Cf. Chase, Élie Halévy, 210.

${ }^{11}$ Cf. Roberto Vivarelli, "Élie Halévy e la guerra," in Élie Halévy e l'era delle tirannie, ed. Maurizio Griffo/Gaetano Quagliariello (Soveria Mannelli: Rubbettino, 2001), 279-98.

${ }^{12}$ Cf. Dino Cofrancesco, Europeismo e cultura (Genova: ECIG, 1981), 91.

${ }^{13}$ Cf. Élie Halévy, The Era of Tyrannies (New York: Anchor Books, 1965), $266 f$.

${ }^{14}$ Raymond Aron, "L'Ère des tyrannies d'Élie Halévy," Revue de Métaphysique et de Morale 46, no. 2 (1939): 283-307.

${ }^{15}$ Halévy, The Era of Tyrannies, 307.

${ }^{16}$ Cf. Jean-Claude Casanova, "Propos sur Élie Halévy," and Nicolas Bavarez, "Élie Halévy et l'Ère des Tyrannies, Socialisme, démocratie et tyrannie," in Élie Halévy et l'Ère des Tyrannies (Paris: Les Belles Lettres, 2019), 27-34, 237-48.

${ }^{17}$ Cornelia Koppetsch, Die Gesellschaft des Zorns (Bielefeld: transcript, 2019), 157ff.

${ }^{18}$ Cf. William Daves, Nervous States (London: Cape, 2018), 123ff.

${ }^{19}$ Cf. Eli Pariser, The Filter Bubble (New York: Penguin Group, 2011). 


\section{Appraising the Oldest 'Era of Tyrannies' (Toward a Tyrannology?)}

Victor Castellani

Department of Languages \& Literatures

University of Denver, CO, USA

What can we today learn from Archaic/Classical Greece? Cautions about ambitious current office-holders who may "bend" a democratic constitution? In 2005 appeared a collection of essays titled Confronting Tyranny. Ancient Lessons for Global Politics. ${ }^{1}$ Eight years later one of its contributors published Tyranny: $A$ New

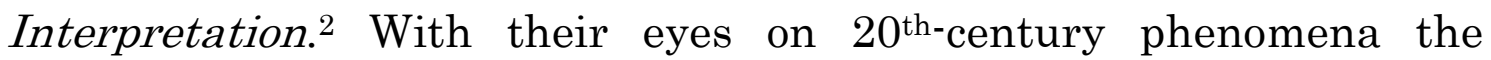
writers sometimes anachronize perceptions, judgments, and prescriptions. Here we step back and take a look back in ancient context.

Narrowly applied, turannis, "tyranny" in the $7^{\text {th }}$ and $6^{\text {th }}$ centuries BCE categorized rule by de facto monarchs who gained as much absolute, irresponsible power as was possible then otherwise than by legitimate inheritance in a kingly line. Instead they established primacy unconstitutionally and maintained it precariously, depending upon (1) flaunted force, e.g., armed bodyguards (like Aegisthus's at the end of Aeschylus' Agamemnon), (2) gratitude and trust of the governed, gained by benevolent rule, or (3) some combination of both.

Until late in Sophocles' famous tragedy, universally admired Oedipus is reckoned (as the play's Greek title says) a turannos. Believed not even to be native Theban but rather Corinthian, by national consensus he ascended the deceased, supposedly sonless King Laius of Thebes' throne. In fact, king Oedipus succeeded his father the late king, agnate descendant of city-founder Cadmus. The audience know all along (though his son does not) how Laius died and who killed him. 
According to the same poet's Antigone, Oedipus' maternal uncle (and brother-in-law!) Creon is elected general (stratēgos) and succeeds Oedipus' slain son Eteocles as ruler of Thebes. Creon, too, is turannos, as the script matter-of-factly calls him. However, when by our standards he turns "tyannical," this is no inevitable result of irregular succession. Indeed all three Athenian tragedians use the noun túrannos and the adjective turannikós with subtlety and intentionality that philologists often miss - and translators almost always.

Theban myth and Shakespeare's Malvolio agree: "Some are born great [Oedipus' fratricidal sons who cannot share legitimate kingship], some achieve greatness [Oedipus himself by solving a riddle and slaying a Sphinx], and some have greatness thrust upon them" [Creon, who takes charge of the city, his reluctance to rule notwithstanding].

Below we survey historical strongmen, many of them homegrown, who impose themselves upon city-states. ${ }^{3}$ In Archaic Greece some túrannoi did deserve the description "tyrannical." These men abused irresponsible power. Stereotypical "despots" (from a word denoting slave-owner) they treated like slaves subjects whose lives they spared yet constantly threatened, whose daughters and sons they raped, whose inherited or hard-won wealth they appropriated. In later Greek and Latinized as tyránnus, the title became a term of opprobrium, simplifying, simplistic. Sic semper tyrannis, more than one proud assassin has exclaimed! (That "tyranny" lies in the eye of a provoked beholder Abraham Lincoln's assassin John Wilkes Booth demonstrated when he shouted that famous Latin.)

Plato's Republic and Aristotle's Politics regard "turannís" as worst of government forms, even though Aristotle does makes distinctions among manifestations of it. 
In Book 8 of Republic (545c-570e) "Socrates" advances a detailed account of how best government, "aristocracy," exercise of power by the "truly best," deteriorates in successive, inexorable stages through "timocracy," control by persons with highest acknowledged social esteem, further downward via "plutocracy," alias "oligarchy," where those few with greatest material riches attain prevailing power, and then to democracy, "power to the people," leading to the worst government by the worst individuals, "tyrants" who manipulate the masses. ${ }^{4}$ Democracy, exercise of power by the demotic masses who claim not to be "best" but merely "equal" (Athenians revered isonomia," equality under law"), eventually elevates to supreme personal power a charismatic leader, perhaps one with military victories to his well-advertised credit. He will "Make [your city-state's name here] Great Again." He will "Drain the Swamp" of others' corruption that he may, for a time at least, conceal better than the government he overthrew did, even another tyrant's!

In Politics Book 5 Aristotle agrees with Plato that tyranny is the perverse but inevitable "end form" of democracy (1312b). However, he differentiates one sort of ruler who violently seizes sole power and maintains it by force or its threat from another kind who through specious excellence, by conspicuous largesse and benevolent rule, wins over a populace that do not perceive how he instrumentalizes virtue in order more gently to fleece them (1313a-1315b). Even mild, less blatant self-aggrandizing rule hardly conduces to long-term good. (Aristotle notes how founder-tyrants' ambition to gain legitimacy, to found a new hereditary monarchy, almost always fails after a generation or two.)

Poleis of Archaic Greece, independent city-state-societies, ranged in population from far smaller than the ten thousand that political philosophers believed to be their ideal size, up to hundreds of 
thousands. Larger and largest ones included both citizens with nominal exclusive rights and free non-citizen residents whom Athenians called metoikoi ("metics" in English).

Social stratification was unstable. So were values and moral principles, some of which all a city's habitants shared. Others belonged to single strata. All were in play, often interplay. Lower strata were vicariously impressed by compatriots' military achievements and victories at Panhellenic games, including ones by "tyrants," whereas the upper class craved opportunities to win personal glory, military or athletic, as merely their ancestral due. In peacetime they or their horses competed and won at Olympia, Delphi, et alibi. However, interlopers from propertied middling strata also aspired to do the like (and sometimes could).

To deny aristocrats, often fellow aristocrats, prestige, tyrants would monopolize generalship in warfare or delegate it very cautiously. For smaller poleis successful defense against aggressive neighbors, Greek or barbarian, was illustrious enough; for larger ones, conquest was its requisite. Occasionally a lieutenant replaced the tyrant himself or his son, never in such an amiable way as Roman emperor Nerva was succeeded by adoptive son Trajan, and Trajan's adoptee Hadrian by adopted Antoninus Pius.

Economic ambitions also differed. Urban lower classes wanted paid employment or orderly markets for artisan wares; farmers, lucrative outlets for surplus produce. Tyrants fostered all that. Before a money economy developed beginning in the late 600 s $\mathrm{BCE}$, wealth was in neither cash money nor proto-capital investment but in productive land. Athens' census measured status by annual yield of grain from arable land, whose fortunate inheritors deplored the enrichment of upstart rivals through industry and commerce. 
Nobles and commoners were alike interested in breeding. However, hoi oligoi, "the few," intermarried with peers from other lands, even occasionally with barbarian potentates or semi-barbarous Macedonians. Consequently they often displayed transnational solidary, helping fellow aristos in other lands to maintain control or, if lost by more or less leveling revolution, to regain it, sometimes from a populist "tyrant." Hoi polloi, in contrast, "the many," tended to be nationalist, nativist, even proto-racialist. Marrying cousins or neighbors, they monopolized civic privileges. The worst thing pedigreed nobles could do - as they sometimes did - was to hire foreign, even savage barbarian mercenaries to help keep the native masses down.

Overwhelmingly popular heads of Greek city-states, honest-togoodness "first citizens" or "champions of the common people," were therefore "tyrannical" and "tyrants" in the jaundiced view of nobles whose idea of proper government was aristocratic. Some "tyrants" regrettably brought peace and prosperity that permitted humbler-born citizens to become rich in the new silver currencies while depriving the warrior elite of glory. A few were constitutional reformers granted emergency dictatorial powers. ${ }^{5}$ Others were revolutionists who deposed legitimate kings or, more often, toppled oppressive oligarchs who had lost whatever deference their ancestors may once have earned.

Such new leaders might fill power vacuums provisionally, then, discovering that they enjoyed ruling, and clutch the reins of power. The majority, decisive "strong men," were by some criteria progressive, quasi-democratic in leadership. Their decrees and policies might be honestly directed toward well-being of the bulk of their citystates' population. Though Plato would hardly concede this, they might govern well. Peisistratus of Athens comes immediately to mind: 
though twice forced out of the city by aristocrats and their dependents, he was twice restored to primacy by popular will.

Most "tyrants" of antiquity were patriots, albeit rarely selfless ones. By victorious warfare, by diplomacy, and/or by economic development they boosted their cities' power and prosperity. Many opened their lands to immigration by those aforementioned metics, of whom some begged asylum, but most sought opportunity. All would benefit their adopted cities in many ways. Although as everywhere in ancient Greece except in new colonies, neither they nor their descendants could ever acquire citizenship, citizen patrons who welcomed them as partners in business or as engineers, artists, or teachers could provide personal security. Nationalist-nativists in larger city-states might have doubts about a "tyrannous" open-door policy, yet usually were content to reserve important advantages of citizenship for themselves while enjoying all that the foreigners brought.

Furthermore, tyrants promoted, even personally sponsored religious and broader cultural activities in which the entire citizen body participated. "Tyrannical" religious-cultic innovations were broadly inclusive. A few tyrants held traditional priesthoods. Much to the chagrin of defenders or would-be restorers of oligarchy, gods like Athena whose patronage the nobility formerly kept to themselves became patrons of the demmos; a belittled rustic cult like that of Dionysus became a national religion and cultural leveler. Peisistratus, about whom we know the most, made Panathenaea and City Dionysia into spectacular affairs, the pride and joy of proprietary Athenians. Other tyrants sponsored cult-related arts for public consumption, importing artists who lent Panhellenic glamour and prestige to a Sicyon, a Samos, or a Chios, for the blessing, enjoyment, and even specialized employment for homebodies. 
"Tyrants," for their part, used the masses and the masses used them. Inevitably they were resented by pretended patriots who had different, usually reactionary agendas. To divide demagogues' popular base, Athenian critics routinely alleged that they were no true-born citizens. ${ }^{6}$

As already indicated, "tyrannical" policies multiplied wealth in coin from enterprise and commerce, challenging old aristocracies' economic dominance. Tyrants' cultural enhancements glorified their cities as well as themselves. In short, from government 'of the people, by the few, for the few,' developed government 'of the people, by a strong man, for the majority.' Effective new leaders drew overwhelming support from both underclasses and the industrious and enterprising. In fact, more often than not "tyrants" were born noble yet played a game that the Romans, whose experience centuries later was comparable, would call popularis. ${ }^{7}$

Granted, no Greek adolescent would likely have said to himself, let alone to anyone else, "When I grow up I want to be tyrant here," unless perhaps he could add "just like Dad." On the other hand, of the catalogue of tyrants in ancient Aegean and Western Hellas no two were really alike, not even father and son. ${ }^{8}$

For example, mythologized father Cypselus of Corinth gained prominence as a generalissimo during victorious wars against Argos, along the way using command of the army to expel as traitors any who opposed him (including claimants to legitimate kingship from the ousted royal dynasty). Contrast his famous son Periander of Corinth. The heir's wisdom secured immense popularity. Periander's policies made Corinth the leading economic, commercial powerhouse of Greece in the late $600 \mathrm{~s} \mathrm{BCE}$, thanks to developed western and eastern ports flanking the Isthmus. Rapidly increasing wealth spread widely among citizens who evidently cared more about trade than about politics, 
more about piling up beautiful Corinthian silver staters that adverised Corinthian Athena and national hero Bellerophon's mount Pegasus than about morally dubious kerdos, a Greek word that is roughly rendered "amoral profit."

On the one hand, some holders of irregular rule were by their demerits true "tyrants" as we would apply the term, with all the stigma attached. Others, however, were "tyrannical" only according to political or philosophical opponents and/or in safe retrospect.

While Peisistratus was "tyrant" by traditional, pat classification, Solon before him and Pericles after were not. Athenians canonized Solon as a founder of democracy, like mythical hero-king Theseus! Pericles' Athenian admirer Thucydides inoculated him against such disrepute..$^{9}$ Note, however, that real "tyranny" at Athens was wielded by a narrow oligarchy of "Thirty Tyrants" at the end of the Peloponnesian War. Peisistratid Hippias became "tyrannical" only after his brother's murder.

Tyrants' restrained, benign exercise of "prevailing power" - Greek kratos as in dēmocratia and aristokratia - and excellent "leadership" something with "-archy" in it - here and there shines through generic condemnation of rulers who refused to play by the old rules that had held compatriots socio-politically down, economically and culturally back. Relatively few retained power by reigns of terror, but instead shrewdly plied reins of implicit power. "Olympian" orator and elected general Pericles, generally admired by his fellow citizens, could be confused with (obsolete in Aegean Greece) "tyrants" only as tendentiously as Socrates was with (contemporary) Sophists. "Tyrants" as such had a bad press back then and still have. However beneficial their regimes, they were never forgiven. However, they were hardy homogeneous. 
Dare we judge blue-blood statesman Pericles and "new man" industrialist Cleon alike as tyrant-minded? Both were effective orators who normally got their way in the Athenians' sovereign Assembly and were elected annually to the highest executive office, generalship, Pericles for decades, Cleon for a shorter time because of untimely death in battle. According to Thucydides both likened Athens' imperial hegemony over other Greek states to turannis! ${ }^{10}$

The two most recent U.S. presidents, Obama and Trump, were elected during perceived crises. Each has been accurately accused of unconstitutional overreach by executive order and of bypassing Congress as indolent or obstructive. However different their styles, each campaigned by what we may fairly describe as demagoguery. Each has been accused of being a tyrannical enemy of liberty! Should the world count both as belonging to a new "Era of Tyrants"? Are unconstitutional improvisers among other established or rising strongmen who are scattered today over Eurasia and elsewhere uniform in causation and character? Or does a Family Tyrannidae include a number of Genera - some of them long ago extinct, others extant - which in turn comprise distinct Species of actual or would-be "tyrants," past, present, and to come?

To devise specific sub- and even sub-sub-categories among dominant leaders, such as ancient Hellenes would compendiously call turannoi, we must differentiate them according to their stories and characters, then see whether many or any translate to our time:

1. Circumstances of accession to power: Exploiting a crisis or succeeding to father or other near relative or (with or without treachery) to a protector?

2. Opportunism: If beneficiary of crisis, what kind? War or external threat? Internal stasis (as the Greeks called acute 
internecine strife - civil war cold or hot)? "Legitimate" government's manifest corruption?

3. Respect for constitution and law: Working within them? Amending them? Ignoring them? A political reformist or revolutionary?

4. Economics: Notably concerned with primary productions, industry, trade? With culture, including public religion?

5. Foreign policy: Belligerent or pacific? Celebrating and enhancing the nation's glory and prestige, soft power in culture? Hard, in military might?

6. Nationalism: Historical revisionist? Nativist attitude toward foreigners within the community, whether established residents or new immigrants?

7. Persuasion: A rhētor, as the old Greeks called an active, vocal politician? In speeches and writings mitigates or exacerbates existing divisions in the nation, e.g. between/among ethnic groups and socio-economic strata?

8. Defense of personal primacy: Violent or politic? Addressing criticism? Threatening, intimidating, persecuting enemies, declared or suspected, short of "liquidation"?

9. Lifestyle: Exemplary, ordinary, or stereotypically scandalous?

10. And drawing a lesson from Herodotus' legend of Solon and Croesus, Finish: How does the ascendancy end? Including, where available, retrospective/posthumous reputation.

Answer these, at least above nos. 1-9, in assessing your own favorite latter day turannos. How does that person measure up - or down - by these timeless criteria? You will, of course, have to assign relative weight to each. 


\section{Notes}

${ }^{1}$ Toivo Koivukoski and D. E. Tabachnick, eds., Confronting Tyranny. Ancient Lessons for Global Politics (Lanham, MD: Rowan \& Littlefield, 2005).

${ }^{2}$ W. R. Newell, Tyranny: A New Interpretation (Cambridge: Cambridge University Press, 2013).

${ }^{3}$ I exclude primiinter pares of juntas and quislings like so-called "tyrant" Strattis of Chios, one among many whom suzerain Persian kings imposed on Greek cities in Ionia and elsewhere.

${ }^{4}$ This is amoral self-aggrandizing rule of any government in place, democratic or tyrannical, such as Thrasymachus posits in Book 1 (338c-339a).

${ }^{5}$ Prime example: Solon of Athens, one of the Seven Sages of Archaic Greece, who, however, seems never to have been called a tyrant. Himself well-born, he was an entrepreneur who came to believe that any free Athenian smart enough to succeed in commerce deserved a role in government. More on him below.

${ }^{6}$ Cleon of Athens is 'poster boy' for such slander. Reactionary comic playwright Aristophanes famously called the hated demagogue "Paphlagonian," from a faraway barbarous region in Anatolia. Euripides' Heracles dramatizes similar vilification. The play is set in Thebes, where the great Tirynthian hero grew up and married King Creon's daughter. In his absence a villainous usurper, not a true Theban but a Euboean from across the water, killed Creon and usurped monarchy, a vicious turannos whose name Lycus, "Wolf," befits him. In fact, the younger Athenian poet offers an untypical scenario, contrasted with what old Aeschylus did in Agamemnon. There usurper Aegisthus belongs to a line of royal descent parallel to his cousin and victim Agamemnon's. (Ironically, nobles often had pedigreed non-citizen mothers and wives.)

${ }^{7}$ Julius Caesar Dictator is prime example. His Patrician assassin Marcus Junius Brutus shouted the original Sic semper tyrannis after his "unkindest cut of all," then had EID MART inscribed on denarii struck to ay the anti-Caesarian army he lost at Philippi.

${ }^{8}$ A table with a list and diagnosis of better known "tyrants" is available from vastell@du.edu.

${ }^{9}$ Even Boeotian Plutarch, no lover of Athens, admired Solon, one of the Seven Sages, as his Solon makes clear, reporting (14.6) that Solon expressly rejected advice that, in a position to do so, he seize tyrannical power. Plutarch's Pericles is also mostly quite flattering. Neither Pericles' young contemporary Aristophanes nor in the next century Plato, though neither admired him, calls him "tyrant."

${ }^{10}$ Pericles at II.63.2, Cleon at III.37.2. 


\section{Who's Afraid of Globalization?}

Erik M. Vogt

Department of Philosophy, Trinity College, Hartford, CT, USA

\section{Globalization and Democracy in Jacques Rancière}

The term "globalization" has become a kind of generalized name for a supposedly quasi-inevitable facticity, that is, for the quasi-fateful predetermination of humanity's course. Moreover, globalization continues to figure primarily in terms of the globalization of capitalist economy that has caused not only the dismantling of the welfare state, of social benefits, and of social achievements, but has also engendered the diffusion of the sovereignty of the nation-state and, more broadly, a radical reorganization of contemporary societies that includes an enormous income and wealth redistribution from the bottom to the top. A model based on the capitalist market controls contemporary societies and alleged democratic processes comply with the needs and requirements of the market. Consequently, financial markets, banks and debt holders seem to determine exclusively politics, thereby assimilating politics to consensus.

Jacques Rancière subscribes to the view that globalization constitutes primarily the triumph of capitalist globalization and its redistribution of powers within that framework to such an extent that the world is increasingly governed in an ever more direct manner by the play between the movement of global capital and international organizations. In addition, this formation of a capitalist global economy has refashioned the relationships between states in that the states have become mutually dependent in this global economic system. According to Rancière, the global law of the market and of profit, that is, the solidification of a global economic logic of 
domination, defines the common world structures in terms of structures of necessity striving to exclude possibilities, contingencies, and choices, except the choice of the optimal administration of economic necessity.

While Rancière does not explicitly chart processes of globalization in other areas of contemporary societies such as science or culture, he analyses the implications of economic globalization attempting to suppress and render invisible the current possibilities of political that is, democratic - dissensus. It is in this context that he takes recourse to the term "consensual democracy" or "post-democracy." Post-democracy designates "the paradox that, in the name of democracy, emphasizes the consensual practice of effacing the forms of democratic action. Post-democracy is the government practice and conceptual legitimization of a democracy after the demos, a democracy that has eliminated the appearance, miscount, and dispute of the people and is thereby reducible to the sole interplay of state mechanisms and combinations of social energies and interests. Postdemocracy ... is an identifying mode, among institutional mechanisms and the allocation of the society's appropriate parts and shares, for making the subject and democracy's own action disappear. It is the practice and theory of what is appropriate with nothing left over for forms of the state and the state of social relations." Thus, consensual post-democracy constitutes "a certain regime of the perceptible: the regime in which the parties are presupposed as already given, their community established and the count of their speech identical to their linguistic performance. What consensus thus presupposes is the disappearance of any gap between a party to a dispute and a part of society. ... It is, in a word, the disappearance of politics."2 Rancière insists that consensual post-democracy should not be interpreted as a pragmatic version of democracy, but rather as the "negation of the 
democratic basis for politics: it desires to have well-identifiable groups with specific interests, aspirations, values and 'culture.."3 Incidentally, this quotation demonstrates that consensual post-democracy and the multiplication of differences and identities are not mutually exclusive, but rather seem to reinforce each other. That is to say: "The 'one' of consensus nourishes itself with the multiple - or, perhaps, with a certain idea of the multiple that allows itself to be objectified and counted. ... What consensualism rejects, on the other hand, is the multiple that functions as a supplement to the count and as a break in the auto-representational logic of society, that is, the supplementary multiple of political subjects" (97).

Consensual post-democracy denotes the globalization of capitalist economy, as well as the increasing appeal to juridical and scientific expertise functioning as immanent functional moments of postdemocracy's orientation toward (majority) consensus. Its main tendency consists in the extirpation of any conflictual scenes allowing for the possibility of political subjectivation: that is, for processes in which previously invisible, silenced, and uncounted individuals and groups articulate their respective demands for participating in the demos and challenge the existing regime of perception, speech, and thought. At the same time, Rancière notes that post-democracy is a "polemical concept with which to denounce the assimilation of democracy and consensus" and not "a description of a historical moment that supposedly succeeds the historical moment of democracy" (151). Rancière's rejection of the subsumption of politics under any kind of historical teleology that could form the basis for the all too common claim regarding the "end of politics" is indicative of the fact that neither the relationship between democracy and postdemocracy nor the logic of capitalist globalization represent irresistible and necessary historical forces. For this very reason, one 
cannot ascribe to economic globalization a univocal effect, but rather must grasp it in terms of manifold, ambivalent, and transformative processes and movements. In other words, the logic of economic globalization constitutes a contingent logic and it therefore does not represent the only referential reality. Rancière states: "Some want to see it as an opportunity for nomadic multitudes to explode the Empire. But we know that globalization has also prompted an equally powerful, and massive, return to identitarianism. ... In the states of 'Old Europe', however, the people has tended towards an extreme desubstantialization, a dissolution into weak figures of subjectivation (weak in gathering power)" (145). Although this is not the place to elaborate on the speculative identity of "weak," multicultural figures of subjectivation and of identitarianism, one can grasp the different figures of far-right populism currently traversing virtually all European countries as returns to the nation, that is, to some originary land, the land of the fathers and ancestors, as well as to an alleged common linguistic and cultural origin serving as birth place of a group of individuals. In a word, the different far-right populisms want to reestablish a figure of authentic national-cultural identity purified from all inauthentic ingredients. According to Rancière, one can render them intelligible as inherent spectral doubles of post-democracy employing an arsenal of mystifications aiming at the reduction of a complex political situation by reintroducing the opposition between friend and enemy. Furthermore, far-right populism must not be misunderstood as a site in which one could inscribe emancipatory projects; rather, the far-right populist temptation and its central tenet - that the people exists - must be rejected because its depoliticization or naturalization of politics renders the conflicts immanent to global capital in the reified vocabulary of an externalized opposition between unified people and external intruder. ${ }^{4}$ 
These many-voiced effects of capitalist globalization challenge the assumption that capitalist globalization is the only game in town that provides the relevant criteria for judging social reality because it alone prescribes the rules for signifying "objective" social reality. However, they indicate on the one hand that capitalist globalization presents itself as the only effective social reality demanding conformity and consensus. On the other hand, they also reveal that certain critical discourses of capitalist globalization often leave the reality of capitalist globalization unchallenged in that they continue, in their denunciation of commodity fetishism, consumerism, or individualism, to rely on the very terms providing the language and logic for discussing capitalist globalization as an unquestionable necessity. In other words, the effort to expose the global logic of commodification, consumerism etc. might only be the other and consensual side of the economic-political law of capitalist globalization.

It is this strange univocity of capitalist globalization and critique of commodification that Rancière identifies in Antonio Negri's and Michael Hardt's conception of the relation between Empire and multitude that, presenting itself as actualized communism, carries out the metapolitical identification of the economic with the political. Rancière reads Negri's and Hardt's stipulation that the scene of political subjectivation remains a mere ideological appearance, if one considers political subjectivation at a distance from the socioeconomic processes that are constitutive of the production of contemporary common material life, in terms of a revival of a certain Marxist metapolitics. More generally, Marxist metapolitics "has always regarded the scenes of political subjectivation that constitute the figures of the demos as subordinate and more or less illusory when compared to the anthropological and economic processes involved in the production of material life" (Dissenting Words, 107). Once the fusion of 
the Marxian labor-subject with a Spinozist notion of multitude is accomplished by Negri and Hardt, this subject "can then seem like the true interiority of imperialism's ubiquitous and decentralized reality, and as the unifying form of a political action disseminated across all the forms of life in which the power of the capitalist empire is exercised" (108). Rancière rejects this underlying co-extensivity of politics, life, and the economy and reads Negri's and Hardt's dubious affirmation in the context of globalized capital that is devoid of both any governmental or statist center and of any recognizable collective actor that could serve as reference point for political subjectivation. In other words, the notion of multitude represents Negri's and Hardt's problematic answer to the missing support for political subjectivation within the framework of capitalist globalization. It is problematic because it ultimately relies on an actualized version of the traditional Marxian economic schema, according to which the productive forces will necessarily burst asunder the shell enclosing the relations of production. In other words, Negri and Hardt repeat the Marxian claim that "the collective forces of humanity already exist in their objectification in the unilateral form of capitalist production. The only requirement, then, is to find a form for their collective and subjective reappropriation."5 Consequently, communism already "exists within, and thanks to, new forms of capitalist production." To be exact, "today communism is more actual, more effective inside of capitalism than ever before. It has to be demonstrated that it is actual both as the materiality of a common sensory world and as the accomplishment of an immaterial form of rationality - as the unity of that materiality and that immateriality." Negri and Hardt try to justify their argument by pointing to the contemporary shift in capitalism from the production of material goods to the production of immaterial services and modes of communication. In short, contemporary capitalist 
production's tendency toward immateriality is indicative of its departure from the traditional Marxian notions of commodity and fetishism; instead, it edges ever closer to the realization of "the global network construed as the sensory materiality of immaterial collective intelligence." Here is Rancière's succinct summary of Negri's and Hardt's actualization of communism within capitalist empire: "What contemporary capitalism essentially produces - rather than goods for private appropriation - is the network of human communication, in which production, consumption and exchange are no longer separate but join together in the same collective process. Consequently, the content of capitalist production starts to emerge through the capitalist form itself, a content which turns out to be the same as the communist power of cooperative immaterial labor" (77-78).

For Negri and Hardt, the shift within global capital from material labor producing in a centralized manner material objects to immaterial labor producing a vast decentralized domain of the common consisting of collective structures of knowledge, forms of (labor) cooperation, and communication engenders the immediate reversal of Empire into a democracy of multitude, in so far as the democracy of multitude is already contained within Empire. Since the products of immaterial labor are the (new) social relations themselves, immaterial production is directly biopolitical, that is, as Slavoj Žižek notes, it becomes directly the political production of society itself: "The wager of Hardt and Negri is that this directly socialized, immaterial production not only renders owners progressively superfluous ...; the producers also master the regulation of social space, since social relations (politics) is the stuff of their work. The way is thus open for 'absolute democracy', for the producers directly regulating their social relations without even the detour of democratic representation."6 Apart from the suspicion that the supposed immediate "political" 
relation between the Empire and multitude might actually amount to a depoliticization of politics in that politics is reduced to mere biopolitical administration, the claim that the decentralized and deterritorializing power of global capitalism producing directly the proliferation of the democratic multitude also has to take account of the following questions: Is the notion of the multitude "ruling itself" not "the ultimate capitalist fantasy, the fantasy of capitalism's selfrevolutionizing perpetual motion exploding freely when its inherent obstacle is removed? In other words, is not the capitalist form (the form of the appropriation of surplus-value) the necessary form, formal frame/condition, of the self-propelling productive movement?"7 Hardt's and Negri's argument for the possibility of a direct politicization of global capitalism is thus problematic because it neglects the fact that global capitalism seems to escape all immediate political holds; what is more, it seems to suggest that it is possible to simply bypass the issue of "constituting a global political stage" (Dissenting Words, 125). What is more, their notion of a democratic multitude as a socialized way of life is opposed to Rancière's own conception of democracy; for democracy is neither a regime nor a social way of life, but rather "the institution of politics itself, the system of forms of subjectivation through which any order of distribution of bodies into functions is undermined, thrown back on its contingency."8 It constitutes a break with any consensual harmony of doing, being, and saying and confronts its logic of equality with the logic of the consensual order. For Rancière, politics and democracy are nominations for conflictual processes by means of which orders of inequality are interrupted by new modes of political subjectivation that demand, in the name of equality, participation in the people and at the same time are cognizant that no community can ever represent the equality of the people. However, these conflictual processes of 
political subjectivation are never finally resolved or sublated but rather insist, since each reordering of society ends up in distributions and counts in the course of which new identities, exclusions, and hierarchies are formed. This can also explain Rancière's adherence to an anti-imperialist politics that, due also to the fractured scene of political confrontation today, can no longer simply rely on the capacity to universalize particular contradictions as general instances of dissensus, but must be mediated by "relations to states, bringing into play an inside and an outside" (Dissenting Words, 125). He explains: "I think that national mediation remains effective, yes, because it's there that the relation between a structure of inclusion and what it excludes plays itself out. ... So, I think that there are specific scenes of contradiction in confining some people while allowing others to circulate freely, but not one great nomadic movement of the multitude against Empire or one overarching relation between the system and its peripheries" (126). In other words, politics should neither be anchored to some form of identitarianism nor to some Marxist metapolitics operating with the opposition between the reality of global capitalism and the mere "appearance of national political scenes" (151). Instead, one should recognize the multiple current international and national struggles that, although one might not be able to synthesize them into one coherent politics, nonetheless "attack consensualist logic by illuminating the forms of exclusion it engenders: movements of the unemployed, of the sans-papiers (who are denied legal status and thus excluded from the 'free circulation' endorsed by the state) and, finally, movements that address international economic institutions" (98). Again, the separation of these different national and international scenes of political subjectivation "makes their unification into transversal forms of subjectivation close to impossible" (98). At the same time, they have successfully undermined 
- and exposed as contingent - the authority appealed to by different attempts to intellectually justify the effective reality of the consensualist order of global capital. There is no effective reality of the consensualist order; rather, it is a construction claiming the legitimacy of objectivity for itself by donning the sensory self-evidence of the supposedly natural, necessary, and inevitable order. Accordingly, the different current national and international scenes of political subjectivation harbor the following good news: "Politics is difficult today, but it is rethinkable: it is once again possible to separate politics, in principle, from the management of the flux of populations and goods" (98).

\section{Notes}

\footnotetext{
${ }^{1}$ Jacques Rancière, Disagreement: Politics and Philosophy, trans. Julie Rose (Minneapolis: University of Minnesota Press, 1999), 101-2.

${ }^{2}$ Rancière, Disagreement, 102.

${ }^{3}$ Emiliano Battista, Dissenting Words: Interviews with Jacques Rancière, ed. and trans. Emiliano Battista (London: Bloomsbury, 2017), 97. Hereafter page references are cited in the text.

${ }^{4}$ See Erik M. Vogt, "Europa: Politik der Gestalt und/oder Politik des Universalen?” in Bruchlinien Europas, ed. Gerhard Unterthurner and Erik M. Vogt (Vienna: Turia + Kant, 2016), 10-44.

5 Jacques Rancière, Dissensus: On Politics and Aesthetics, ed. and trans. Steven Corcoran (London: Continuum, 2010), 76-77. Hereafter page references are cited in the text.

${ }^{6}$ Slavoj Žižek, Organs Without Bodies: On Deleuze and Consequences (New York: Routledge, 2004), 196.

${ }^{7}$ Slavoj Žižek, The Parallax View (Cambridge, MA: The MIT Press, 2006), 263.

${ }^{8}$ Rancière, Disagreement, 101.
} 
Workshop 4:

Film, Culture and the Struggle for Democratic Governance

Chairs: Juan Tarancón and Elena Oliete-Aldea 


\section{The Globalism of Contemporary Jacobean Films: The Case of Emilio}

\section{Estévez's The Way}

Carmen Induráin

Universidad Pública de Navarra, Spain

\section{Abstract}

This paper examines the representation of personal crises and relationships in pilgrimage films along Saint James's Way. Concretely, it analyzes Jacobean films as a special case of atypical road movies set in Europe, across the Spanish-French border in the Pyrenees. Following a summary of filmic representations of Saint James's Way throughout the last century, their success and recurrent themes, this paper focuses on the elements that make Jacobean films global. Firstly, their function as promoters of country branding, in this case of both Galicia and Spain by means of this pilgrimage route and the celebrations of the Jacobean Years, in an attempt to attract not just European but also world tourism to Spain. Secondly, there is a corpus of films based on the personal experiences of international writers and filmmakers who were marked by their own Jacobean experience (e.g. Paulo Coelho, Hape Kerkeling, Laurence Boulting, and Hannes Stöhr). In addition, the transnational scope of the Camino de Santiago is seen in the range of nationalities of its filmography (mostly European), in its numerous co-productions and in the multiple languages heard in any given film. Likewise, the trope of pilgrimage has been framed within a wide variety of film genres. A further aspect that facilitates the globalization and transnationalization of the Jacobean theme is its tendency towards generic hybridity, within which the road movie is a staple reference genre. Thus, another major aim of this paper is to examine Jacobean cinema from a generic 
perspective as a special case within the road movie, a transnational genre par excellence.

As an illustration, Emilio Estévez's The Way (2010) both follows but also remarkably deviates from staple generic conventions in the road movie, like its exaltation of family values, its depiction of an old protagonist in a youth-oriented genre, especially of an American suffering from a personal crisis that makes him travel across Spain instead of across the United States and, surprisingly enough, doing so on foot, not by car.

This paper aims to examine the representation of personal crises and relationships in the era of globalization in pilgrimage films along Saint James's Way. More specifically, this paper analyzes Jacobean films as a special case of atypical road movies set in Europe, across the Spanish-French border in the Pyrenees. The focus of attention is especially the Jacobean films released after the outbreak of the economic crisis of 2008 and more concretely, Emilio Estevez's 2010 The Wayl El Camino.

I present a summary of the history of filmic representation of Saint James's Way from the year 1915 with the documentary Peregrinaciones Compostelanas to the year 2017 with another documentary: Aaron C. Leaman's Looking for Infinity: El Camino. My aim is to examine the production of Jacobean cinema, to analyze its generic hybridity, its representation of personal crises and especially the elements that make Jacobean films global.

In his 2008 compilation Cine Jacobeo: el Camino de Santiago en la pantalla, Ramón Herrera claims that "Jacobean cinema is a box office flop" (Herrera in Rojo). However, the production of Jacobean cinema has been very fruitful, as the 45 titles in the filmography of this paper 
show. Herrera catalogues more than 20 films made within half a century, between 1953 and 2007 .

This detailed corpus has been updated with 25 productions, 16 of them released from the year 2009 to 2017.

The production of films on Saint James's Way throughout the last century has been irregular, with a sharp standstill during the 1970s and 1980s and several peaks of production, much more prolific from 1993 onwards. In his book Peripheral Visions/Global Sounds: From Galicia to the World (2017), José Colmeiro highlights the beginning of the visibility of Galicia and of The Camino de Santiago abroad. He claims that "peripheral positions can lead to global visions" (32) and thus describes "a movement from the Atlantic to the global" (31). This movement started in 1993 with the first stellar celebrations of the Xacobeo around the Camino de Santiago, which "represented Galicia's international entrance into the culture of global spectacle" (9).

Indeed, these Camino films function as promoters of countrybranding, expanding the knowledge of both Galicia and Spain by means of this pilgrimage route and attracting not just European, but also world tourism in Spain. They present The Way as a cultural heritage route for modern pilgrims and tourists alike, so that this movement from the peripheral Atlantic to the World goes now both ways.

As for country-branding examples in Jacobean cinema, Rosanna Mestre-Pérez argues that the anime film Gisaku, "sold with highly positive results the Marca de País España in the Expo of Aichi, improving the perception of Spain in Japan, and promoting the most favorable aspects of its current reality" (2006). Likewise, Herrera describes Kevin Noland's Americano (2005) as "a film with an unusual promotional flavor of Spain with the lure of the Camino de Santiago" 
(2008, 119). Moreover, Colmeiro highlights Fernando Cortizo's $O$ Apostolo/The Apostle, 2012, as "evidence of the phenomenon of the renewal and repositioning of Santiago and Galicia in the new national European and world map" $(2017,86)$.

We also find a relevant corpus of biographical documentaries based on the personal experiences of international writers and filmmakers. Among these we find Paulo Coelho on the Road to Santiago (Monica Oien and Einar Matre, 2004), and The Pilgrim: Paulo Coelho's Best Story (Daniel Augusto, 2014). Similarly, a book by German comedian Hape Kerkeling, Ich Bin Dann Mal Weg, was adapted to the big screen in 2015 by Julia Von Heinz. Likewise, Within the Way Without, 2004, and One Day in Europe, 2005, present the Jacobean experiences of a British and a German director: Laurence Boulting and Hannes Stör, respectively (Herrera, 2008, 146).

In addition, the transnational scope of the Camino de Santiago is to be seen in the wide range of nationalities of the pilgrims and especially of its filmography (mostly European) and in its numerous coproductions. Although many of these films are Spanish, there are some French titles and there is a considerable number of German, Austrian, Brazilian and U.S. American Camino films as well. It is worth mentioning here the transnational symbol of the pilgrims' passport, stamped at every stop on its pilgrimage route.

Furthermore, the transnational element lies firstly in the variety of languages spoken in a given film (e.g. English-Spanish in Footprints, Portuguese Spanish in Onde Está a Felicidade/¿Dónde Está la Felicidad?), et cetera. And secondly, in the need to overcome the language barrier and communicate in a single language, given the multiculturalism inherent in Saint James's Way. 
A further aspect that facilitates the globalization and transnationalization of the Jacobean theme is its tendency towards generic hybridity, within which the road movie is a staple reference genre. Thus, we need to examine Jacobean cinema from a generic perspective as a special case within the road movie, bearing in mind the value of the "road movie as a transnational model" (Santiago García, 2016), the conception of what Duarte and Corrigan denominate "the global road movie" (2018).

Over the years, the pilgrimage trope of Santiago has been framed within a wide variety of film genres, namely documentaries, historical and epic films, adventure films, melodramas and even thrillers. More recently, we witness a significant trend towards the representation of the protagonists' personal crises and their conflict-ridden relationships in comedies and choral films.

We may mention the Spanish comedy Al Final del Camino (Roberto Santiago, 2009), the French Saint Jacques.... La Mecque (Coline Serreau, 2005), the Austrian Brüder III Auf Dem Jacobsweg by Wolfgang Mumberglr, 2006, and specially the German One Day in Europe, 2005 and Ich Bin Dann Mal Weg, 2015).

As for choral films we find: Gisaku, Saint Jacques... La Mecque, Walking the Camino: Six Ways to Santiago, Al Final del Camino, One Day in Europe and Footprints. We even find some special innovations: two Spanish animation films: Gisaku, a Japanese anime film and $O$ Apostolo/The Apostle (Fernando Cortizo, 2012), the first stop-motion $3 \mathrm{D}$ claymation film made in Spain.

However, genre-wise, we need to highlight two main issues: firstly, the all-pervading generic hybridity that exists in all these Jacobean films, if we follow Ryall's open concept of genre as "an effective and pertinent 
contextfor the reading of a film" $(1998,336)$." Or as Pye puts it: "as a context in which meaning is created $(1995,109)$.

And secondly, the presence of the road movie as a reference film genre, a staple in the generic hybridity all these pilgrimage films share. Eyerman and Löfgren go even further and speak about "the road movie as a film genre within a genre, a genre that could be called "the road-story" $(1995,54)$.

This paper focuses on a representative and recent Jacobean film that illustrates personal crises on the road in a transnational, multicultural context like The Camino de Santiago. The Way/El Camino is a Spanish-U.S. coproduction by the New York director, actor, script-writer and producer Emilio Estévez, with his father Martin Sheen in the male leading role. This project of the 2010 Xacobean Year, sponsored by the Xunta de Galicia, functioned as "a country-branding film" (Mestre-Pérez, 2006) to attract tourists to walk the Camino de Santiago and, as García claims, "it was targeted specially to a US American audience" (2010).

Let's watch now the film's trailer to get a feeling of this Camino film https://www.youtube.com/watch?v=6TH8u7ApHTs 2'24"

This is the film synopsis:

Tom Avery, a Californian ophthalmologist has had a strained relationship with his 40-year-old only son, Daniel, ever since the death of his wife. That strain is due to the differences in their outlooks on life: Daniel feels Tom is living a lie, while Tom feels Daniel has no focus. Their last argument was caused by Daniel's decision to quit his post-graduate studies to go and find himself while walking El Camino de Santiago as a pilgrim. Unfortunately, Daniel dies in an accident in the French Pyrenees on the first day of pilgrimage. Tom heads to Europe, has Daniel's body cremated, and as homage to him and in 
trying to understand his son's wishes, he decides to do the pilgrimage, spreading his ashes along the way. He takes this decision despite his old age, his lack of training, and being a lapsed Catholic himself. Along the way Tom meets various travel companions: a funny Dutch food-lover, a frustrated Irish writer, and a divorced Canadian, all of whom have their own personal crises on their backs and a great need to reorient their lives. They share numerous adventures, such as a night at a police station, the theft of Tom's rucksack, a gypsy party, and their escape from the crazy El Ramón's house, etc. Through walking, encounters and anecdotes along the Camino, they build a strong bond. Thanks to his pilgrimage Tom is reconciled with his son. In doing so, he finds his own personal redemption: he learns to choose his own life, not a well-off one back in the USA, but as the traveler his son wished to be, as we see him doing in the final scene in Morocco.

If we analyze The Way from a generic perspective, it is a mixture of comedy, drama and choral/multi-protagonist cinema that is often found in road movies. It maintains some core conventions of the average road movie, like the genre's narrative simplicity and linearity, since the journey is shot in chronological order. More significantly, it presents a journey of discovery that involves both significant changes in its protagonists and a bonding among them. Road movies usually put together mismatched characters, like The Way's four leading pilgrims, who get to know and like each other along the journey. This bonding that constitutes a central aspect of the road movie's subject matter is also seen in the two estranged men with a failed father-son relationship on a posthumous journey of discovery (Daniel appears to Tom several times in visions).

The road movie trip symbolizes the journey of life, and is sometimes associated with death. The Way belongs to these road movies in which the journey is triggered by death: an imminent one, as in The Straight 
Story, About Schmidt (2003), Nebraska (2013), and The Leisure Seeker (2017), or a real one, as in Last Orders (2001), Around the Bend (2004), and Saint Jacques.... La Mecque. The Way differs from the former in that Tom is not doing the Camino to achieve his own dream but his late son's. But as the gendarme tells Tom before departing: "you have to do the Camino for yourself." On arrival in Santiago, Tom is asked again why he did the pilgrimage and this time he answers that he thought he had to travel more, which shows his own personal transformation.

The portrayal of existential crises and of significant beautiful landscapes and settings are all staple elements in the charactercentered stories typical of the road genre. In these Jacobean films, Saint James's Way is not merely a group of film locations but a highly powerful setting. It isn't just a place but what De Certeau calls a space, "that which is effectively produced by movement, history and becoming" (1984). As happens in road movies, space, in this case the pilgrimage route and its varied locations from Saint Jean de Pied de Port in France to Santiago de Compostela, constitutes a significant element. The protagonists experience a communion with nature, for example on the nights of their sleeping rough (after Tom's fall into the river). These meaningful settings and encounters on the way function as key elements in the protagonists' metamorphosis, a major convention both in the road movie and in its Jacobean subgenre.

Atypically, The Way remarkably follows the generic exception of other silver road movies, such as About Schmidt, The Straight Story, Broken Flowers, The Leisure Seeker, and gives visibility and agency to an elderly protagonist, something still atypical in a traditionally youth-oriented genre (Sheen was already 70 years old when the film was shot). Secondly, like Everything is Illuminated (Liev Schreiber, 2005), Americano, and Footprints: El Camino de tu Vida, The Way 
atypically portrays an American citizen whose personal crisis makes him travel across Europe and not the other way around. As Burkhard Pohl argues, "the road movie is an international genre par excellence" (2007, 54), and in my opinion, all the more so in its Jacobean version. In addition, the film's director and its male lead, Estévez and Sheen, are American citizens, though of Spanish descent (Piñeiro, 2010).

As Carmen Lobo remarks, The Way is "a road movie without an automobile" (2010), which marks a gentle pace that is uncommon in the fast-moving road genre, as well as a longer journey and the absence of typical elements in the roadscape, like gas stations and motels. The Way's narrative path also deviates generically in that the protagonists reach their final destination.

Finally, another significant aspect which distinguishes The Way from both the average Jacobean film and from traditional road movies is its representation of the family. The Way depicts the journey a father takes for, and somehow with, his son (his appearances and his ashes). Lately, several foreign Camino comedies also celebrate the institution of the family: the French Saint Jacques.... La Mecque and the Austrian Brüder III Auf Dem Jacobsweg depict the personal conflict of three brothers who are finally reconciled with each other along their pilgrimage. Herrera also describes two documentaries as "family road movies' (2008,134), L'Enfant du Chemin: Naissance d'une Famille sur le Chemin de Saint-Jacques de Compostelle (Jean-François Castell) and El Camino de Santiago, No un Camino de Rosas (José Álvarez).

Although in 1997 Cohan and Hark claimed that "a road narrative responds to the breakdown of the family unit" (2), recent road cinema reaffirms the institution of the family and its values, as the following titles show: Around the Bend, Transamerica, Little Miss Sunshine 
and Nebraska. The Way follows this atypical but growing trend to confer greater relevance to a family, one that gets on the road due to some existential crisis and that remarkably includes an elderly member.

To conclude: the production of Jacobean cinema has been very varied and fruitful, especially in Jacobean years and in the last decade. Moreover, Camino films seem to be growing in popularity and to be playing a major role as promoters of country-branding.

As happens with contemporary road cinema, Jacobean films often illustrate personal crises in the era of globalization. In Camino films the transnational reach of Saint James's Way is reflected in the wide range of languages and nationalities of its protagonists and of its filmography and in its numerous co-productions. The hybridization of the Jacobean trope, conceived as a road-story, contributes to its globalization and transnationalization. Remarkably, we observe a current trend for comedies and choral Camino films, together with numerous documentaries, which can all be better read within the context of the road movie.

A detailed analysis of The Way from a generic perspective shows that this pilgrimage film follows the staple generic conventions in the road movie. As other Jacobean films, it is a "quest road movie" (Archer, $2016,2002,20)$ that recovers the convention of the journey as a life initiation experience. It presents the values of life as a physical and spiritual journey, whose end, death, triggers in this case a person's crisis and existential journey.

Jacobean cinema also depicts a journey towards the West, which stands for a better future and for personal rebirth. The characters' communion with nature and meaningful encounters along this lifechanging walk, together with the use of water as a symbol of rebirth 
gain great significance as are key elements in the travelers' metamorphosis-

However, The Way atypically deviates from traditional road movies in its depiction of non-Spanish characters on an existential journey across France and Spain. Secondly, it follows the more recent and growing trend of road movies that grant special visibility to an elderly protagonist, and celebrate the family, the conflicts of which triggered the protagonist's personal crisis and subsequent existential journey in the first place.

\section{Bibliography}

Archer, N. (2016). The Road Movie: In Search of Meaning. Nueva York: Wallflower Press.

Cohan, S. and Hark I. R., eds. (1997). The Road Movie Book. London and New York: Routledge. Colmeiro, J. (2017). Peripheral Visions/Global Sounds: From Galicia to the World. Liverpool: Liverpool University Press.

Duarte, J. and Corrigan, T. eds. (2018). The Global Road Movie: Alternative Journeys around the World. Intellectbooks

Eyerman, R. and Löfgren O. (1995). "Romancing the Road: Road Movies and Images of Mobility".

Theory, Culture and Society, vol 12, nº1, pp. 53-79.

García, B. P. (2010). "La cara más Yanqui del Camino de Santiago".

http://www.enclavedecine.com/2010/11/la-cara-mas-yanqui-del-camino-de-santiago-the-way-de-emilioestevez.html. 28 Nov 2010.

García Ochoa, S. (2016). "La road movie como modelo transnacional y su presencia en el cine español: marco metodológico y principales aportaciones". Boletín de Arte, $\mathrm{n}^{\mathrm{o}} 37$, pp. 77-88.

Herrera, R. (2008). Cine Jacobeo: el Camino de Santiago en la pantalla. Bilbao: La Cineclopedia.

Ediciones Mensajero.

http://www.todocaminosantiago.com/peliculas-sobre-el-camino-de-santiago/

Lobo, C. L. (2010). "The Way: Camino de Perfección". https://www.larazon.es/historico/2986-the-waycamino-de-perfeccion-QLLA_RAZON_343099

Mestre-Pérez, R. (2006). “Cine con marca de país: Gisaku redescubre España en Japón”. I Jornadas Internacionales sobre Cine y Turismo, CITur - Dep. de Teoría dels Llenguatges i Ciències de la Comunicació - Universitat de València Noviembre de 2006. http://www.uv.es/citur

Piñeiro, J. C. (2010). Entrevista a Martin Sheen: "Martin Sheen y Emilio Estévez: somos gallegos que nunca nos hemos ido pero que volvemos a casa". http://www.enclavedecine.com/2010/11/martin-sheenemilio-estevez-somos-gallegos-que-nunca-nos-hemos-ido-pero-que-volvemos-a-casa.html. 8 Nov 2010. Pohl, B. (2007). "Rutas transnacionales: la road movie en el cine español", Hispanic Research Journal, vol. $8, \mathrm{n}^{\mathrm{o}} 1$, pp. 53-68.

Pye, D. (1995). “Genre”. En Maltby y Craven, eds. Hollywood Cinema: An Introduction. Oxford: Blackwell. pp. 107-143.

Rojo G. D. (2010) "El Valle de las Espadas y La maldición del Cine Jacobeo". http://www.fernangonzalez.es/2010/11/el-valle-de-las-espadas-y-lamaldicion.html Ryall, T. 1998. "Genre and Hollywood". En Hill y Gibson, eds. The Oxford Guide to Film Studies. Oxford: Blackwell. pp. 327-338.

Travers, P. (2011). Review. The Way. Rolling Stone, $6^{\text {th }}$ October. https://www.rollingstone.com/movies/reviews/the-way-20111006 
Workshop 5:

From Polis to Nation to Global Community and Back Again Chair: Ann Ward 


\section{Nationalism and Globalism: A Canadian Perspective}

Leah Bradshaw

Brock University, Niagara Region

Ontario, Canada

George Grant was a Canadian political thinker with whom few outside the borders of Canada are familiar, but who was a towering figure in Canadian political thought throughout the period from 1965 to 1985. Most students in political science departments in Canada in these two decades had some familiarity with the works of George Grant, usually with his widely successful, polemical, and frankly cult-like little book Lament for a Nation. ${ }^{1}$ A lot of this short book devolves on disentangling the debacle of John Diefenbaker's tenure as Canada's Prime Minister. Diefenbaker was a Western Canadian, a populist, by all accounts (including Grant's) rather bumbling and unsophisticated, and deeply antipathetic to the influence of the United States on Canadian policy. Diefenbaker came to power on a huge majority, and within five years his party and his particular brand of nationalism was soundly defeated. What Diefenbaker is most remembered for in political circles is his stand against placing nuclear warheads by the United States on Canadian soil. Diefenbaker's defense of Canadian sovereignty, at the height of the Cuban missile crisis and in the midst of the Cold War, was interpreted by many as an act of disloyalty and bad faith regarding Canada's southern neighbor.

George Grant defends Diefenbaker strenuously in his Lament for a Nation: "Diefenbaker was accused of anti-Americanism, but he was surely being honest to his own past when he said that he thought of his policies as being pro-Canadian, not anti-American" (34). What exactly were Diefenbaker's 'pro-Canadian' sentiments? Grant 
identifies them as rooted in "a profound - if romantic-sense of historical continuity" (13). There was a vague loyalty to the Britishness of Canadian institutions. "The Britishness of Canada, according to Grant, "was more than economic. It was a tradition that stood in firm opposition to the Jeffersonian liberalism so dominant in the United States. By its nature this conservatism was not philosophically explicit, although it had shaped our institutions and had penetrated into the lives of generations of Canadians" (34). Canadian nationalism, for Grant, had had historically an intrinsic connection with British conservatism, and its "greater sense of order and restraint than freedom-loving republicanism would allow." It also meant a greater trust of the public good, a kind of collective responsibility that was categorically distinct from the state protection of individual freedoms or rights. "In our early expansions," Grant claimed, "this conservative nationalism expressed itself in the use of public control in the political and economic spheres. Our opening of the West differed from that of the United States, in that the law of the central government was used more extensively, and less reliance was placed on the free settler. Until recently, Canadians have been much more willing to use governmental control over economic life to protect the public good against private freedom" (70).

Order, restraint and public good: these are the three things that Grant comes back to again and again as the core commitments of Canadian nationalism. While Grant explicitly connects these commitments to British conservatism, there is also a sense in which Grant's affirmations of the public good lend themselves to being embraced by those on the left. And indeed, Lament for a Nation became a kind of 'little red book' for the nationalist, anti-American, socialist voices of the 1960s. Grant's endearment to the left in the 1960s in Canada is probably best captured in a series of televised exchanges that Grant 
had with Gad Horowitz. As Arthur Davis and Henry Roper characterize Horowitz, he was a figure of the left who had become prominent in Canadian academic and political circles because of his ideas on Canadian identity. Horowitz declared Grant to be "the prime example of the Canadian phenomenon of the 'red tory' at the 'highest level', a 'philosopher who combines elements of socialism and toryism so thoroughly integrated that it is impossible to say that he is a proponent of either one or the other." ${ }^{2}$ In one of these exchanges, Grant is up front about his socialist leanings. When Horowitz asks Grant how he would build a society that is better than that in the United States, Grant answers: "I would say that you have to move towards something like a socialist society in which the public good takes precedence over the individual right to be free . . . What I mean is a society in which the public good is much more emphasized against the rights of people to make money than it is now in the United States or in present-day Canada. I have no hesitation about that."3

The label red tory is one that stuck to George Grant, and to this day, the term survives in Canada as a depiction of someone who embodies both conservative (in the British tradition) and socialist predilections. But Grant himself did not like the assignation. In conversation with George Grant, David Cayley asked Grant what he thought of being called a red tory, and Grant replied: "it's not a term I like very much. ... but you know, if one goes into the public world, anybody can call you anything, and I think quite rightly. I'm not trying to stop them." When Cayley prods Grant further, asking if Brant's antipathy to this label was because Grant's concerns were always "related more to national survival than to some a priori ideological position," Grant responds: "of course."

If we take Grant at his word, the ideological poles of conservative and socialist meant far less to him that the matter of national identity. To 
preserve a national identity, Grant was pretty clear that you need to maintain the triad of 'goods' that were mentioned earlier: order, restraint and a sense of the public good. These goods could be at least partially sustained by conservative or socialist policies, but they emphatically could not be sustained by liberal ones.

In Lament for a Nation, Grant makes it clear that his book is a lament for something lost, not a call to action for preservation. Many of his readers, Gad Horowitz among them, did not read the book this way and regarded it as a manifesto for resistance to the American empire and capitalism. But Grant thought this was a losing battle. He did not think the nation of Canada could withstand the forces of what he called 'continentalism'. To the continentalists, he wrote, "democracy has not been interpreted solely in a political sense, but has been identified with social equality, contractual human relations, and the society open to all men, regardless of race or creed or class" (89). Continentalism, he claimed, requires that "nationalisms be overcome." "In moving to larger units of government, we are moving in the direction of world order. If Canadians refuse this, they are standing back from the vital job of building a peaceful world. After the horrors that nationalistic wars have inflicted on this century, how can one have sympathy for nationalism?” (89). 'Continentalism' for Grant was inseparable from the conviction that we are living in an age of progress, and he often iterated how difficult it is to argue with progress. "Has it not been in the age of progress that disease and overwork, hunger and poverty, have been drastically reduced? Those who criticize our age must at the same time contemplate pain, infant mortality, crop failures in isolated areas, and the sixteen- hour day." At the same time, though, Grant urged that we must think simultaneously about "the increasing outbreaks of impersonal ferocity, the banality of existence in technological society, the pursuit of 
expansion as an end in itself." Grant feared that the interference in nature, human and otherwise, by technological means, could in fact mean that man in his excessive pride was in danger of corrupting his verv being. "It is feasible to wonder whether modern assumptions may be basically inhuman" (94).

The theme of interconnectedness among liberalism, progress and technology was one that preoccupied Grant long after he wrote Lament for a Nation and was expanded in a series of essays collected into published volumes: Technology and Empire, English Speaking Justice, and Technology and Justice. In English-Speaking Justice, Grant examines the foundations of liberalism in the English-speaking tradition and expresses his concerns that what was most noble in that tradition has been corroded by the impetus toward progress and technological mastery. "Liberalism in its generic form," Grant writes, "is surely something that all decent men accept as good 'conservatives' included." Grant identifies an essential element of English-speaking justice that he regards as the noble core of liberalism: "the institutions of the English-speaking world at their best have been much more than a justification of progress in the mastery of human and non-human nature. They have affirmed that any regime to be called good, and any progress to be called good, must include liberty and consent." 5

However, the general tenor of this book is that liberalism thus defined does not have the strength, or the solidity of foundation, to resist its erosion by the more powerful impetus of technological advance. According to Grant, it is "in the heartlands of the English-speaking empire that the more fundamental facts appear which put into question the mutual interdependence of technological and liberal reason. The chief of these facts is that the development of technology is now increasingly directed toward the mastery of human beings. ... 
technology organizes a system which requires a massive apparatus of artisans concerned with the control of human beings. Such work as behavior modification, population control by abortion and genetic engineering are extreme examples."

The drive toward technological advance, and its connection to progress, is by definition, according to Grant, a universal directive, and one that eclipses any parochial loyalties to one's people or place. These universal directives are bolstered by the liberal language of rights, insofar as that language is strictly contractual, international and non-specific. Grant's friend and colleague Louis Greenspan wrote of English-Speaking Justice that "one of the primary dramas of ideas throughout the book is the tension between the growth of technology and a liberalism for which contractualism is becoming more and more central." Contractualism, Greenspan defines as "a system of relations between calculating self-interested individuals," and he notes wryly that "in such a conception, the basic loyalties to the state, loyalties that would make one ready to die for one's country, seem as inappropriate as the readiness to die for MacDonald's hamburgers."7 Greenspan's summary of Grant on the unravelling of liberalism helps us to see how starkly Grant contrasted liberalism with the kind of conservatism (red toryism?) that underscored Grant's lament for Canada. Liberalism as it has become entangled with the commitment to progress and married to technology abandons the three things that Grant thought were essential to a healthy national narrative: order, restraint and a sense of the public good.

We have established that while Grant embraced some elements of what we would term broadly conservatism and socialism, Grant himself rejected these labels. He regarded them as ideological, and he was not a man interested in attaching himself to abstract ideological concepts. But he consistently came back to this notion of the "love of 
one's own'. Liberalism has failed us, Grant thought, for a number of reasons, but at the heart of the matter is Grant's conviction that human beings do not become good or even better by attaching themselves to ideas like individual right. They become good, or better, by being habituated in communities of belonging. Whatever Grant may have maintained about his Lament for a Nation, specifically his consistent claims that this was not a call to action for a cause already lost, and despite his somewhat ambivalent stance toward the achievements of progress under liberalism, he never stopped coming back to his defense of the love of one's own. In an essay titled "Canadian Fate and Imperialism," Grant wrote: "man is by nature a political animal and to know that citizenship is an impossibility is to be cut off from one of the highest forms of life. To retreat from loyalty to one's own has the exhilaration of rebellion, but rebellion cannot be the basis for a whole life." ${ }^{8}$ For Grant "loyalty to one's own" is a basic human inclination, and furthermore, as he indicated, an inclination that is directly connected to one of the "highest forms of life." "Love of one's own" was for Grant, the foundation for genuine politics. At the end of Lament for a Nation, Grant declares: "I must dissociate myself from a common philosophic assumption. I do not identify necessity and goodness." The assimilation of Canada into the broader imperatives of progress, technological integration and universal norms did not for Grant make these thigs good. "A discussion of Canada's goodness must be separated from a discussion of its necessity" (87).

In Lament for a Nation, Grant professed great admiration for the French Canadians and their "deeply rooted culture." "The French Canadians had entered Confederation not to protect the rights of the individual but the rights of a nation" (22). Clearly, this French Canadian nationalism stood alongside, and not necessarily in tandem, with the British legacy that Grant admired. "The two original peoples, 
French and Catholic, British and Protestant, united precariously in their desire not to be part of the great Republic [the United States]; but their reasons were quite different. This union was precarious partly because the preponderant classes of British stock were determined that the Canadian nation should support the international policies of the British Empire, whereas the French were either indifferent or hostile to these policies" (23). For Grant, one of the great failures of Diefenbaker's regime was his inability, or unwillingness, to cultivate the support of Quebec. "The most bewildering aspect of Diefenbaker's nationalism was his failure to find effective FrenchCanadian colleagues. The keystone of a Canadian nation is the French fact; the slightest knowledge of history makes this platitudinous. English-speaking Canadians who desire the survival of their nation have to cooperate with those who seek the continuance of FrancoAmerican civilization. The failure of Diefenbaker to act on this maxim was his most tragic mistake" (20-21).

Much has transpired in Quebec and in Canada as a whole since Grant penned these words, and there is a lot one can say about whether "Franco-American civilization" has been able to resist the forces of what Grant termed 'continentalism'. Quebec remains a distinct society within Confederation, but the distinctiveness of it is complex and controversial. Grant is vague on the exact parameters of French Canadian solidarity, but obviously for him, this solidarity owed much originally to the hegemony of the Roman Catholic Church. To Catholics, Grant wrote, whatever their level of "sophistication," "virtue must be prior to freedom." "They will therefore build a society in which the right of the common good restrains the freedom of the individual. Quebec was not a society that would come to terms with the political philosophy of Thomas Jefferson or the New England capitalists" (75). At the time that Grant was writing Lament for a 
Nation, Quebec was undergoing what we call the "quiet revolution," moving from a Catholic, largely homogenous rural society to a more modern liberal, urban and cosmopolitan one. Grant recognized that "to run a modern economy, men must be trained in the new technology over human and non-human nature. Such training cannot be reconciled with French Canadian classical education” (78).

Grant understood that French Canadian nationalism was being transformed by the forces of modernization and those of secularism, but he still hung onto the localism of Quebec as a bright spot in the Canadian story. Again, in conversation with Gad Horowitz, Grant proclaimed: "there is in human nature a need to be rooted, but this doesn't say that technological society cannot destroy human nature, and can't destroy the need." Business corporations as well as universities, Grant tells Horowitz, make of us cosmopolitan freefloating agents. "The more advanced you get in technical skill in society, the more and more mobile you become. You are less rooted in a place and this seems to me to destroy the possibility of nationhood, because nations originally were institutions that grew up from a kind of love, not only of a particular place, but of the continuity of that place."9

The imperatives toward cosmopolitanism may be irresistible, but George Grant helps us understand why nationalisms nonetheless persist in a global, interrelated world. In liberal democratic, technological and progressive societies, our understandings of justice may be neglectful of some very basic human needs. If the need for belonging is as powerful as Grant claims it is, and if that need is consistently repressed by the forces of liberalism, continentalism and globalization, then we are likely to see more strident and insular defenses of the 'love of one's own'. 


\section{Notes}

${ }^{1}$ George Grant, Lament for a Nation (Montreal and Kingston, 2005, Carleton Library Series, McGillQueen's Press; first published in 1965). Hereafter page references are cited in the text.

${ }^{2}$ Arthur David and Henry Roper, Introduction to "Two Televised Conversations Between George Grant and Gad Horowitz," Canadian Broadcasting Corporation, February 7 and 14, 1966. Text reprinted in Arthur David and Henry Roper, eds., Collected Works of George Grant, Volume 3: 1960-1969 (Toronto: University of Toronto Press, 2005), 431.

${ }^{3}$ Arthur and Roper, Collected Works, Volume 3, 442.

${ }^{4}$ David Cayley, George Grant in Conversation (Toronto: House of Anansi Press, 1995), 103-4.

${ }^{5}$ George Grant, English-Speaking Justice (Toronto: House of Anansi Press, 1985; first published in 1974), 5

${ }^{6}$ Ibid., 9.

${ }^{7}$ Louis Greenspan, "The Unravelling of Liberalism," in George Grant and the Subversion of Modernity, ed. Arthur Davis (Toronto: University of Toronto Press, 1996), 210.

${ }^{8}$ George Grant, "Canadian Fate and Imperialism," in Technology and Empire (Toronto: House of Anansi Press, 1969), 77.

${ }^{9}$ Arthur and Roper, "Two Televised Conversations Between George Grant and Gad Horowitz," 439-40. 


\section{Nietzsche Against the Sovereign Individual in the Second Essay of the}

Genealogy

Matthew Dinan

St. Thomas University, Fredericton, NB, Canada

In the preface to On the Genealogy of Morals, Nietzsche describes a youthful scruple — "uninvited" "irresistible," almost like Socrates' "little voice," his daimōnion-against morality. This scruple, which Nietzsche also calls his "a priori," inspires his "first philosophical effort," in which he gives "honor to God" by making Him "the father of evil" (17). ${ }^{1}$ Nietzsche's a priori does not precipitate another Copernican revolution in philosophy, as God remains a fixed point: God is an evil God, but God all the same. Nietzsche recognizes this problem and asks: "Was that what my 'a priori' demanded of me? That new immoral, or at least unmoralistic 'a priori' and the alas! so antiKantian, enigmatic 'categorical imperative' which spoke through it and to which I have since listened more and more closely, and not merely listened?" (17). But how precisely is On the Genealogy of Morals an example of Nietzsche's "anti-Kantian, enigmatic 'categorical imperative?" In one way, it shows the "anti-Kantian" orientation of Nietzsche's thought by denying the rational basis of anti-egoist morality and casting it as an expression of the self-interest of certain factions in history. However, this paper argues that Nietzsche's engagement with Kant in the Genealogy is deeper than the difference between a groundwork and a genealogy.

Specifically, I argue that Kant's notion of moral autonomy-what Nietzsche calls the "sovereign individual"-is the subject of the second essay's critique. The sovereign individual is the peculiar species of self-punishment that emerges from Kantian liberalism, differing only 
in content from older ideas of guilt and bad conscience it is supposed to replace. The problem with the sovereign individual is not in the particular moral commitments Kantian liberals prefer, so much as the categorical and imperative character of the way they live out these commitments. Nietzsche's aim is thus to expose and alter the modern subject's tyrannical mode of relating herself to herself. I conclude this essay by briefly considering how Nietzsche's critique of the sovereign individual complicates the idea that Kantian cosmopolitanism can offer a straightforward alternative to the moral horizon of the sovereign nation-state.

\section{Groundwork for the Genealogy of Morals}

Strangely, scholars do not usually connect the sovereign individual described at the beginning of the second essay of On the Genealogy of Morals with the story Nietzsche subsequently tells about the origins of guilt and bad conscience. According to Owen, Nietzsche's goal in the essay is to make fewer of us "wantons" and to create "sovereign individuality" as a part of the coming of the overman. ${ }^{2}$ On the idea that the sovereign individual attempts complete control over future time as "the promise-making animal," Owen explains that Nietzsche praises the modern subject who can claim "a degree of prudence in their commitment-making activity" (99). This improbable view is shared by prominent Nietzsche scholars like Warren, Ansell-Pearson, White, and, surprisingly, Honig. ${ }^{3}$ On this reading, Nietzsche is friendly to liberal democracy and bullish on the Kantian substitution of the categorical imperative for the Christian notion of guilt. Following Hatab and Acampora, I think this is mistaken. ${ }^{4}$ As Hatab observes, "the sovereign individual names the modern ideal of rational autonomy, which is something Nietzsche critiques as a vestige of slave 
morality." Both Acampora and Hatab point to the Kantian provenance of the concept of modern rational autonomy, but do not expand their arguments beyond this observation. In what follows, this paper will make this connection and explore its implications. Before turning to the second essay of the Genealogy, I briefly show that Kant's Groundwork of the Metaphysics of Morals theorizes autonomy in the way Nietzsche describes.

The third formulation of the categorical imperative in the Groundwork appears to repeat many, if not all of, the elements of the first. The "formula of universal law" is simple and forceful in its articulation of the how one determines the moral duties that flow from the predicates of practical reason in Section I: "Act only in accordance with that maxim through which you can at the same time will that it become a universal law."' Whereas in his statement of the second formula-"the formula of humanity"-Kant follows the same procedure of showing its consistency with four universal duties as he does in the first, by the time he reaches the third formula, he cuts right to the chase. The socalled "formula of autonomy" emphasizes neither the universality nor the rationality of a moral law, but its provenance in the autonomous will: "...all maxims are to be repudiated that are inconsistent with the will's own giving of universal law. Hence the will is not merely subject to the law but subject to it in such a way that it must be viewed also as giving the law to itself." 7 The disinterestedness of the first version of the categorical imperative leaves it open to the criticism that its rationality is too abstract: why, after all, should I obey reason if it is not my own? Obedience to reason as a detached, objective principle might not much differ from an ethics of divine command, or a theory of natural law. The formula of autonomy stipulates the subjective participation of the good will in the categorical imperative to be as 
important as its rationality. The promise of the categorical imperative is that it at once unleashes and tames moral self-rule; it is enlightened and intrepid, but also safe. If we want to be moral, we have a responsibility to be autonomous, and vice-versa.

As in Kant's formulation in the Groundwork, we show our autonomy precisely through our capacity for moral responsibility. Indeed, responsibility is the prestige concept in the moral and political vocabulary of modern liberal democracy. To be charged with "irresponsibility" is an accusation often on par with vice or evil in times past. So when Nietzsche opens the second essay of the Genealogy by inquiring about the origin of the "animal with the right to make promises" or the animal "capable of promising," to jettison some of Kaufmann's infelicitous translation, ${ }^{8}$ he is not only in firmly Kantian territory, he is accessing a basic form of modern liberal thought. Nietzsche's "sovereign individual," who takes the place of the "animal capable of promising," is one who has achieved self-conscious mastery over the world and herself. She is, of course, "autonomous" and able to set a law for herself: she is held responsible for her own word without recourse to any other outside standard. She has the "privilege of responsibility, the consciousness of this rare freedom" (60). Responsibility is a privilege, not a burden, because the sovereign individual is aware of her power to make and fulfill commitments.

The sovereign individual's apparent autonomy is impressive; "quivering in every muscle" in delighted awareness of her selfsufficiency, she is "emancipated...the master of a free will" (59). The sovereign individual casts this free will imperially over the future with her promises, guaranteeing a specific chain of causes and effects. So what do we call the sovereign individual's awareness of her superiority over those who cannot make promises? her domination of 
future time - of fate? "The answer is beyond doubt: the sovereign [individual] calls it...conscience....the right to affirm oneself" (60). For a Kantian, conscience is nothing more than self-assertion: a clean conscience is self-justified self-assertion. But Nietzsche points out that "autonomous and moral are mutually exclusive." This seems obviously so: any system of morality requires submitting oneself to an outside standard. What then does it mean if that standard is self-fashioned? Like the Hobbesian sovereign, the sovereign individual makes and enforces the law. Nietzsche thus identifies something inconsistently "supramoral" in Kant. The third derivation of the categorical imperative shows it to be as much about willfulness as goodness, or rationality. The responsible subject is bold in her self-limitation; Nietzsche suggests that beneath the sober demeanour of the modern responsible subject lies a ferocious will to power.

As Nietzsche observes in one of his arch and powerful parentheses, our love of cruelty remains a barbarous atavism in modern philosophy: "(Even in good old Kant: the categorical imperative smells of cruelty)" (65). As a form of unflinching self-mastery, the categorical imperative has a "whiff" of something potentially unsavoury because it represents the full internalization of traditional morality while having the nerve to call itself autonomous and free. The categorical imperative, and the mode of moral reasoning it represents, is in deep continuity with the traditional understanding of the conscience. When Nietzsche's essay then pivots to explain the emergence of guilt and bad conscience, he is not describing an alternative to a salutary "sovereign individual," he is showing us, in a way, how we have become what we are, and why there is work to be done even after Kant. If Nietzsche is motivated by an anti-Kantian version of the categorical imperative, this categorical imperative seems aimed at exposing cruelty. 


\section{The Spectacle of Sovereignty}

The rest of the second essay unfolds the spectacular economy of guilt and punishment, which emerges from the moralization of the debtorcreditor relationship. Nietzsche traces the belief in an equivalence between an injury received and retributory pain from the original contractual relationship between creditor and debtor. The promise to repay was previously underwritten by the substitution of something dear for what was lost, but "above all" that the creditor could inflict "every sort of indignity and torture upon the body of the debtor" (64). This is not arithmetical justice, but the substitution of loss for pleasure. Such pleasure is psychologically complex; it is not only the pleasure that comes from the cruelty of violation, but from the "psychic sensation" of experiencing the "right of the master." The idea of conscience thus has its origins in cruelty; with dramatic flair Nietzsche says "its beginnings, more like the beginnings of everything great on earth are soaked in blood, thoroughly and for a long time."

Nietzsche then makes his case for human beings as the cruel animal. Thoroughly in the territory of early modern thinkers, who considered us rather more diffident than cruel, Nietzsche provides a not-at-allun-Hobbesian account of the origin of justice as something that emerges as "good will among parties of approximately equal power to come to terms with one another, to reach and understanding by means of a settlement" (71). So too, then, does the conjoint logic of the creditor-debtor relationship and the human delight in cruelty generate the sovereignty of the political community: "One lives in a community, one enjoys the advantages of a community...one dwells protected...from certain hostilities" (71). What happens when the pledge to obey the community is broken? "The community, the disappointed creditor, will get what repayment it can, one may depend 
upon that." The lawbreaker, Nietzsche observes, is "above all a breaker" - the fact of the transgression matters much more than the moral offense of a given crime. The "disappointed creditor" is predictably brutal, leading "the community to throw the debtor into the savage and outlaw state against which he has heretofore been protected." This cruelty is then celebrated in the manner of a war victory, the celebration of a "vae victis" (72). The increasing need for someone to witness this cruelty, to make a spectacle of it eventually leads to the idea of God, the ultimate spectator.

Due to a precipitous, forced socialization, humans became unable to externalize their desire for domination and are thereby forced to "turn inwards." The "soul" and "subjectivity" emerge through the "internalization" of our natural instincts, which are denied outward expression. The inhibited individual still feels the old pre-political instincts for freedom and cruelty, but, unable to discharge them, becomes tortured. He attempts to tame them and, in this way, "this fool, this yearning and desperate prisoner became the inventor of 'bad conscience" (85). Bad conscience is the spectacle of cruelty turned against itself, a self-torturing misunderstanding on the part of the suffering individual. No longer permitted to be cruel, nor to enjoy the spectacle of cruelty, our cruelty as it is turned against ourselves for every perceived imperfection. The sovereign individual becomes indebted to himself and is a rapacious creditor.

The prehistory of the sovereign individual-to tie the end of Nietzsche's essay back to the beginning-is consequently "soaked in blood thoroughly, and for a long time" (65). If we return to the notion of the animal capable of promising, can we not see that this is the animal who punishes herself in advance? Nietzsche recasts the responsible subject as a being who punishes himself before he ever 
commits a wrong; a promise means initiating a prolonged process of self-torture, it is a sort of preliminary guilt. Inasmuch as it indulges our desire for dominating the other and the self, we moreover enjoy this brand of suffering. Responsibility is self-indulgence of the desire for cruelty.

By the end of the second essay, the idea of conscience becomes unconscionable. Nietzsche turns the conscience against itself as we are made to feel guilty over the very fact that we feel guilt. He thus makes us feel complicit in-responsible for-the problems with the sovereign, responsible, individual. We are in fact indulging in the third derivation of the categorical imperative: we will our own autonomy. We sovereign individuals, Nietzsche suggests, "burn a 'No' into ourselves" with a "secret self-ravishment:" this is not simply the province of Christian scrupulousness, but an effect of the expectation of sovereign individuality. But a conscience thus compromised becomes an unreliable guide to right and wrong-it becomes, like the natural right tradition before it, a blunt instrument. Nietzsche's irresponsible crusade against the idea of responsibility has the very humane goal of ending our "conscience vivisection and self-torture." Nietzsche's humanity opposes Kantian cruelty by releasing us from the demands of radical autonomy.

\section{Facing the "Cold Monster"}

Nietzsche understandably foresees difficulty in a campaign against responsibility, because one will be forced to position oneself against the good themselves, the sovereign individuals: "What gives greater offense, what separates one more fundamentally, than to reveal something of the severity and respect with which one treats oneself?" (95). We do not want to be liberated from ourselves. The problem is 
then not necessarily any of the particular duties or laws relentlessly produced by the machinery of the categorical imperative; it is rather because it is categorical and imperative. We suffer from modern autonomy's unrelenting intensity: the self-imposed imperative toward self-rule. In puncturing the "severity and respect" with which we treat ourselves, Nietzschean immorality is not so much unethical as it is an attempt to give us permission to relax. Nietzsche's Zarathustra is sharply critical of the modern state, deriding it as a "new idol," and a "cold monster," and here he makes clear that this monstrosity exists within us, too. ${ }^{9}$ Having attempted, with the help of thinkers like Kant, to root out tyranny in institutional life, can we bear to pursue it within ourselves? Hasn't tyranny simply moved from the Leviathan without to the one within?

In current debates about sovereignty the choice is almost always framed as one between Kantian cosmopolitans who view national sovereignty as morally unjustifiable and nationalists who want to preserve the form of the nation state. Part of Nietzsche's work in the second essay of the Genealogy is to show that this is a false choice because insofar as cosmopolitans retain a conception of the self as sovereign, the logic remains unchanged, even as practical consequences seem very different. A sovereign state creates a border with an absolute outside. Just as any violation of the law is punished because it is a violation, so is any threat to sovereignty punished not on its merits, but because it threatens the absolute character of sovereignty itself. We might say the same about the sovereign individual, who is not only harsh with himself, but refuses most claims of community which might limit his sovereign individuality. The self then becomes the measure against which all potential claims are adjudicated, and any threat to that autonomy is considered 
unethical. The sovereign individual, moreover, reinscribes what we might call "sovereign logic" onto the character of the debate: the nationalist enemies are often treated with the same cold furor of the migrant or criminal on the "wrong" side of the authority of the state. Kantian cosmopolitanism is not an alternative to the logic of sovereignty; rather, it reinterprets and radicalizes it.

Nietzsche's critique of the sovereign individual thereby aims to implicate the good, modern autonomous individual in the very cruelty these individuals despise. The goal is to make Kantian rigour itself questionable. At the end of the essay Nietzsche therefore wonders aloud whether he is knocking an old ideal down or propping a new one up. In the case of sovereignty-at the level of the state and of the individual-it is perhaps enough to knock it down, as sovereignty is defined by its inability to abide competition or make exceptions. Nietzsche's "anti-Kantian" version of the categorical imperative would seem to entail an awareness of context, particularity, and perspective; its "immorality" comes not so much from an attempt to banish responsibility as to ask whether an account of the good can be good if it creates a tyrannical relationship of the self to the self. If we are serious about considering political forms beyond the nation state, Nietzsche points us in the direction of imagining, or recovering, a cheerful self capable of relinquishing sovereignty.

\section{Notes}

\footnotetext{
${ }^{1}$ Friedrich Nietzsche, On the Genealogy of Morals trans. Walter Kaufmann. Revised Edition (New York, Knopf Doubleday Publishing, 2010). This text is cited parenthetically throughout this essay.

${ }^{2}$ David Owen, Nietzsche's Genealogy of Morality (Montreal/Kingston, McGill-Queens University Press, 2007): 98-9.

${ }^{3}$ Mark Warren, Nietzsche and Political Thought (Cambridge, MA: MIT Press, 1988); Keith AnsellPearson, "Nietzsche: A Radical Challenge to Political Theory?” Radical Philosophy 54 (Spring 1990),
} 
10-18; Richard White, Nietzsche and the Problem of Sovereignty (Urbana, IL: University of Illinois Press, 1997); Bonnie Honig, Political Theory and the Displacement of Politics (Ithaca, NY: Cornell University Press, 1993): 47-9.

${ }^{4}$ Lawrence J. Hatab, Nietzsche's On the Genealogy of Morality: An Introduction (Cambridge, UK:

Cambridge University Press, 2008); Christa Davis Acampora, "On Sovereignty and Overhumanity: Why It Matters How We Read Nietzsche's Genealogy II.2” in Acampora, ed., Nietzsche's On the Genealogy of Morals: Critical Essays (Lanham, MD: Lexington Books): pp 147-161.

${ }^{5}$ Hatab, Nietzsche's Genealogy, 76.

${ }^{6}$ Immanuel Kant, Groundwork of the Metaphysics of Morals. trans. Mary Gregor (Cambridge, UK: Cambridge University Press, 1997): 31.

${ }^{7}$ Kant, Groundwork, 39.

${ }^{8}$ Acampora, "On Sovereignty and Overhumanity," 148-150.

${ }^{9}$ Friedrich Nietzsche, Thus Spoke Zarathustra, trans. Adrian Del Caro (Cambridge, UK, Cambridge University Press, 2006): 34-6. 


\section{Neither Patriot Nor Saint: The Theological Implications of Twain's Defense of Nationalism in Personal Recollections of Joan of Arc}

Bernard J. Dobski

Department of Political Science, Assumption College, Worcester, USA

In the preface to A Connecticut Yankee in King Arthur's Court, Mark Twain announces his intention to explore whether or not a providential deity unerringly selects a person of the requisite moral qualities to serve as the chief executive of a nation. Judging that such an investigation admits of at least two "tacks" and that the current effort, which adopts one of those "tacks," will not by itself settle the matter, Twain declares that he will pursue the remaining approach in his next book. ${ }^{1}$ The "tack" pursued in Connecticut Yankee focuses on the democratic individual par excellence, Hank Morgan and his desire to gain technological mastery over the material world. And it shows how the modern secular approach to science and government is itself rooted in a kind of piety in the faith of human reason to conquer chance. The religious impulse at work in both modern and premodern politics thus remains in need of exploration. It is to an exploration of this impulse that the promised next book, Personal Recollections of Joan of Arc, is dedicated, a work that Twain called his "best"2 and the product of his greatest labors. ${ }^{3}$

Interestingly, this novel, the last and longest fictional book finished by Twain, ties his earlier stated interest in the theological-political problem to the question of the modern nation, and the emergence of the French nation in particular. The book begins and ends with enthusiastic proclamations declaring Joan of Arc to be the avatar of modern nationalism, the embodiment of patriotism as such, and the deliverer of France from foreign control. In between such over-the-top 
praise, the novel tells in three Books the story of Joan's life, military career, trial and execution through the eyes and mouth of Joan's childhood companion Sieur Louis de Conte. ${ }^{4}$ Twain's choice of theme and his artistic treatment of his subject thus invites one to wonder what constitutes, in his view, the link between nationalism and providential politics. It is to an exploration of that link that the present essay is devoted.

Though rooted in a larger engagement with the novel, the treatment that follows is limited to the last third of the book, focused as it is on Joan's imprisonment, trial, and execution by the Catholic Church. I argue that this most widely ignored part of Twain's most widely ignored book presents Twain's critique of providential politics. Twain illustrates for the attentive reader the rational limits to any effort to provide a theological justification for a particular and exclusive nationalism. Book III does this in at least two ways. In the first case, it shows how Joan, the innocent victim of a wicked Church, is best seen as a political actor and not a saint, one armed with incredible talents that she uses to help engineer her martyrdom on behalf of French liberty. But Twain complicates the picture of Joan's secular patriotism in his own overlapping presentation of the Church's prosecution of the Maid. That presentation illuminates the costs to a particular providence of justifying rationally revelatory claims. This critical view of the Church's providential politics implicates Joan's patriotism insofar as she understands her particular defense of French freedom to be providential itself. But Twain is not Joan. His criticism of his heroine and the Church that prosecutes her shows that any effort to defend the particularity of a nation-state requires a rational engagement with human nature, one rooted in the dynamics of the human soul. Book III of Personal Recollections is thus 
indispensable to clarifying the authorial intention that links his two most political novels.

\section{The Historical Trial and Joan's Statesmanship}

Twain's narrative of Joan's imprisonment, trial, and execution is difficult to read. Long gone are the dramatic accounts of battlefield exploits, with Joan leading the charge, battle standard at her side, sweeping the enemies of France before her. Here the narrative pace slows, halted by treatments of church doctrine and byzantine legal questions. In the place of stories about Joan's great beauty and physical vitality, her meteoric political rise, or even the comical farce of the Paladin - the subjects of Books I and II - one finds a tragic tale in which our heroine, now captive to the Catholic Church, physically withers as she recedes from the view of the reader until she is consumed by flames. In a work lambasted for its boredom, this part is easily the most boring.

Part of that boredom stems from the fact that Book III presents itself as a historical reworking of this famous event. Twain claims in the novel's front-matter that he consulted nearly a dozen historical authorities for Personal Recollections, the bulk of which he used for the third and longest part of the novel. Moreover, Part III, which is almost exclusively devoted to Joan's trial is exceptional in that it can draw on official records in both Latin and French of what was said and done (and by whom) during the trial.

These records were not only widely circulated among literate Europeans of Joan's day, and thus available to an international public. They were also translated into English by the $19^{\text {th }}$ century and thus available to both Twain (who knew French) and his audience. Book III of Personal Recollections thus promises to be the most 
historically informed portion of a novel that makes every effort to appear historically grounded. And yet, despite this, despite Twain's manifest interest in history, and despite his great familiarity with the sources surrounding Joan's legend, Book III fails to live up to its promise of historical verisimilitude. Indeed, it commits numerous sins of omission and commission.

The effect of Twain's historical deviations and innovations is a portrait of a young girl unjustly martyred by the Church she loved and unfriended by the country she served. Such a portrait may be morally and politically salutary, but it is also demonstrably false. Given the extensive, detailed, and well-publicized record of Joan's trial, why would Twain have his narrator produce such an obviously falsifiable account of Joan's conviction and execution? One way to think about these changes is to note that Twain's presentation of Joan in Book III builds on the image of her that he has carefully sketched throughout the first two-thirds of the novel. Seen in light of that portrait, Joan's behavior during her trial and de Conte's hagiography of his childhoodfriend-turned-anointed-savior of France is better understood as the product of statecraft, a strategy intended by Joan to engineer her conviction and secure her legacy as a martyr worthy of immortal memory.

Once alerted to this interpretive approach to Joan's behavior throughout her trial, the reader is better positioned to appreciate the evidence that Twain strews throughout Book III, all of which makes it increasingly difficult for the reader to view her speeches and deeds here as anything other than the result of a prudential calculation distinct from grace. This reading of Joan's trial and execution suggests that the girl who raised the siege of Orleans at 17 years old was no mere martyr or pawn, no passive victim to powerful forces beyond her control. On the contrary, Joan seems every bit a partner in fostering 
and even engineering a trial that would become known for convicting and executing an innocent girl, a young patriot, and an innocent believer dedicated to serving God's commands. That such service should be in the name of French nationalism only serves to enhance her glory in the eyes of her fellow countrymen. And such an appearance is crucial to Joan's goal of restoring to France her freedom untarnished from all taint of illegitimacy. As someone willing to use the Church to serve her political goals, Joan appears less a saint and more the patriot par excellence - talented, fearless, far-sighted, ambitious - the kind that could lead her to being viewed by later generations as the avatar of modern, secular nationalism.

\section{The Church's Two-Pronged Assault on Joan}

Not content merely to highlight Joan's statecraft, Twain in Book III also makes curious use of the strategy employed by the Catholic Church against Joan. To be precise, de Conte's narrative of the Church's prosecutorial strategy selectively amplifies aspects of the historical case against Joan of Arc, focusing primarily on (1) her adoption of male attire, and (2) her claims to hear divine voices and experience visions of Michael the Archangel, St. Catherine, and St. Marguerite. The case against Joan eventually succeeds because she abjures and resumes female dress, only to relapse and recant immediately. Though the attack on Joan's voices yields less fruit for the Church, it does prompt the reader to wonder how one can justify rationally any particular claim to revelation. And in doing so it invites the reader to question the coherence of the kind of providential politics that Joan embodies. Understanding what ties together the strategies that Twain's narrator emphasizes, deepens the reader's critical appreciation of Joan's saintliness while showing her particular patriotic attachment to France to be no less "providential," and 
therefore every bit as open to rational challenge as her divine credentials. It thus prepares the reader to address more directly the question with which we began.

In Twain's presentation, the issue of Joan's cross-dressing looms much larger than in the historical case. As Linda Morris observes, in "Twain's version of the 'life' the matter of Joan's 'male attire' is the subject of interrogation twenty times - more than in his sources, more than in the official court record." 5 According to Morris, Joan's crossdressing, which occurs over "nearly two-thirds" of the novel,"6 constitutes "the one and only justification" for the Church's execution of the Maid. ${ }^{7}$ And why should this issue prove so central? According to de Conte, Joan's adoption of military attire, in the eyes of the Church, reflects an attempt by the Maid to rule over men and assume a command denied her sex (396);8 her example and her success implicitly challenge the natural moral and political order preserved by those conventional categories whose sharply defined contours were drawn in part by Scripture (Deut: 22:5; 1 Cor: 11:5-15) and by the Church. ${ }^{9}$

While the representatives of the Church militant defeat Joan on this issue, they do so by default. They appear to force Joan either to relapse and recant or to endure the forcible sacrifice of her virginity: in both cases, her execution is the likely result. Theirs is thus a hollow victory and no more vindicates the existence of particular discrete moral boundaries rooted in natural differences than it indicts Joan's defiance of such limits. Fortunately, Twain also invites us to evaluate the case against Joan in terms that he established earlier in the novel. Whereas the Maid of Orleans sought to nourish the spiritual longings of her countrymen, providing them through her speeches and deeds with "noble shads" that would make them free and independent, the Church's interrogation serves Joan a "poisoned fish" (370, 400-401), a 
strategy intended to return the "famishing soul" (403) of this captive girl to dependence on the Church militant.

For the Church to render Joan dependent on it requires nothing less than an attack on the freedom of Joan's natural intelligence, either by reducing it to inspiration alone (and thus the product of God's grace), or by revealing it to be nonsense (and thus in need of God's grace). As we have seen, Twain's presentation of Joan's trial, while not quite rejecting the possibility of divine inspiration as the source of Joan's greatness, nonetheless provides his readers an alternative to it and invites them to reflect on which ground, divine revelation or unassisted human reason, offers a more plausible explanation. To evaluate objectively the authority behind Joan's political prudence, one must evaluate more deeply her claims about the divine character of her mission. For the Church militant, proof of such divinity requires a rational demonstration whose contradictions they hope to expose.

As it turns out, however, the contradictions that the Church exposes are its own. These contradictions become most visible in the effort by the University of Paris to prove that Joan's voices were not from angels, but Belial, Satan, and Behemoth. According to de Conte, such an argument consumes itself. For if the Church truly wants to defeat Joan, then it must satisfy the same demands it makes of the Maid and supply a rational, and thus consistent and coherent, account of its own revelation, one superior to its rival. For without such an account, one that appealed to something common to all human beings, how else could the Church hope to persuade the "faithful" to adopt its account of revelation over and against any particular rival claim to divine inspiration? Indeed, it would be disarmed against statesmen, like Joan, who possess her understanding of the human roots of religious belief and her ambition to use that understanding to serve their political goals. For the Church to defend itself against this challenge it 
would need to relax its own insistence on the importance of particular revelatory political claims.

As the immediate sequel points out, the Church's ability to provide such an account is complicated by the tension between its religious commitments, which require that Joan's voices be condemned as satanic, and its political allegiance, which requires Joan's divine voices to be defenders of the English cause (not the French) and hence not satanic. Of course, such a contradiction is not mandated by revelation as such; there is nothing within revelation that would require these complicating political allegiances. But such a contradiction does seem a risk to all those religious claims that are explicitly providential and which aspire to justify a particular political or social order as evidence of God's involvement in the affairs of a particular human community.

For a rational account of Joan's French voices as satanic and those supporting the English as angelic to be persuasive, it would have to speak to its audience both in terms of and in reference to a good that is common to all human beings. It would require the Church to offer a rational account of human nature (which all humans could in principle understand) and the goods belonging to that nature (in which all human beings can in principle participate). And it would need to show how the particular (in this case the Church in England and not in France) embodies those universal goods. Conjugating the universal and particular, illuminating this particular articulation, requires a prudence that can see the universal in and through particulars, something that itself requires recognizing the importance of the particular, contingent, and discrete. Openness to the way the contingent manifests itself in the ordinary course of things means recognizing that some contingent particulars, such as a Christ-like Joan of Arc, might not easily reside within any available categories; 
such openness therefore requires that we relax the demand for categories - natural, moral, and political - that are always clear, permanent, and knowable. It is this demand that the example of Joan, a woman whose nature allows her to rule the empire of men and whose fluidity is symbolized by her transvestitism, most challenges.

But such a challenge proves to render vulnerable Joan's religious, and hence political, authority as well, at least insofar as it denies her recourse to a coherent and rational defense against any rival challenges that she in turn might face. Nor should one forget that while her example embodies a defiance of conventional limits and restraints, her political ambitions are in the service of restoring precisely those limits and restraints for France and for the French. Joan's transgression of religious and natural limits is undertaken on behalf of the integrity of other political limits. The question is whether Joan could provide a defense of French sovereignty and French liberty for Frenchmen that doesn't also in some decisive way speak to their good as human beings, a rhetorical move which would in principle open it to the English as well. Or is the good of a free France a particularly exclusive good, to be shared in and enjoyed by only those who are - somehow - determined to belong to France herself? If the former, then wherein lies the dignity of France such that it merits the particular blood and sacrifice of her citizens? If the latter, then how might Joan offer a rational defense of French liberty that speaks to their good as human beings? Joan's patriotic defense of French freedom thus confronts problems not unlike those confronting the providential politics of the Catholic Church. Though Joan's politics appear to aim at secular ends, the rootedness of her attachment to France as a particular human community blessed by God indicates that its origins can be found in a similar, problematic hopefulness that characterizes the believers in providential politics. 
Forced to offer a conclusion, one might be say then that Twain's presentation of Joan's trial seems to admit the possibility of divine revelation in principle while ruling out the possibility of that revelation rationally defending any particular political order. Given the link between the Church militant and Joan's patriotism, such a conclusion seems to cast a similar shadow over the rational defense of one's commitment to a particular community. Lest this seem to cast too gloomy a picture for the prospects of a rational defense of nationalism, one might note that Twain has his elderly protagonist dictate his recollections of Joan to his nephew in the year 1492. The emergence of Joan's story thus points to another possibility, one that hinges on the discovery of a new world with a new "science of politics"10 at its foundation.

\section{Notes}

\footnotetext{
${ }^{1}$ Mark Twain, A Connecticut Yankee in King Arthur's Court, ed. Allison R. Ensor. (New York: W.W. Norton, 1982), "Word of Explanation."

${ }^{2}$ Albert Bigelow Paine, Mark Twain: A Bibliography, vol. 2 (New York: Harper \& Bros., 1912), 1034.

${ }^{3}$ Letter by Mark Twain to H.H. Rogers, January 29, 1895 as quoted in Wilson Cary McWilliams, "Divine Right: Mark Twain's Joan of Arc," The Review of Politics 69 (2007): 332.

${ }^{4}$ Mark Twain, The Oxford Mark Twain: Personal Recollections of Joan of Arc, ed. Shelley Fisher Fishkin (New York: Oxford University Press, 1996). All parenthetical citations are to this edition of the novel.

${ }^{5}$ Linda Morris, A Gender Play in Mark Twain: Cross-Dressing and Transgression (Columbia: University of Missouri Press, 2007), 113.

${ }^{6}$ Ibid., 89, 90, 116.

${ }^{7}$ Ibid., 2.

${ }^{8}$ Thomas Maik, A Reexamination of Mark Twain's Joan of Arc (Lewiston: Edwin Mellen, 1992), 64.

${ }^{9}$ Morris, Gender Play, 106-7.

${ }^{10}$ Alexander Hamilton, John Jay, and James Madison, The Federalist, ed. George W. Carey and James McClellan (Indianapolis: Liberty Fund, 2001), 38.
} 


\section{Judith Hermann's Nichts als Gespenster: Globality, Ambient Romance and Identity Tourism}

Steven Joyce

Department of Germanic Languages and Literatures, The Ohio State University - Mansfield Campus, USA

When Judith Hermann published her second collection of short stories entitled Nichts als Gespenster (Nothing but Ghosts) in 2004, a number of critics cited her as an important if not controversial new voice in German literature. ${ }^{1}$ While Hermann's work has been variously praised for "its laconic yet elegiac style of writing" 2 and for its precise and poetic depiction of what one critic called her "Berlin slacker generation," it has also been criticized as little more than a series of Ich Geschichten (I stories) curiously bereft of references to place, nationality, history and current events. ${ }^{3}$ Moreover, her literary focus on the various ego-centered mini dramas that make up the seven stories in Nichts als Gespenster, reveals a kind of thematic insubstantiality and thinness of character that prompted critics to refer to the work as nicht sagend (saying nothing). In this regard the title of the work Nothing but Ghosts, is apt. ${ }^{4}$ Yet, there is another ghostly presence in the work which serves to explain Hermann's depiction of character and construction of plot in Nichts als Gespenster and that is the cultural and economic phenomenon of globalization.

While Hermann remains mostly tacit about the influence of globalization on the conception and creation of her work, she implies that globalization, as ghostly background presence, significantly alters the look and feel of her characters as well as serves to explain the weak interpersonal dynamics that characterize their circumscribed, personal dramas. Thus, Hermann's depiction of her disengaged and 
indulgent "slackers" as insubstantial specter-like European drifters in Nichts als Gespenster reveals the shaping influence that globalization has on the formation of the psyche and on the conception of self as a transactional entity. Two significant concepts that illustrate this effect are ambient romanticism and identity tourism. While Hermann does not address globalism per se in Nichts als Gespenster, she obliquely critiques what can be construed as its misshaping effect on the modern sensibility as depicted in her characters. ${ }^{5}$

Globalism, a not so recent economic and cultural phenomenon, owes its existence to a number of ideational predecessors including the Enlightenment, liberal democracy, and free market economic theory. ${ }^{6}$ It continues to evolve as an economic and cultural phenomenon under the aegis of emerging global multinational corporations, international political and regulatory agencies, and large banks. This ongoing evolution, however, is not without its critics. While benefitting many countries in many ways, globalism implies to a certain degree a kind of imperialistic influence that many European leaders oppose, pointing out that globalism has the deleterious effect of abrogating political, social and economic heterogeneity in favor of a global homogeneity that has become excessively bureaucratic, unabashedly imperialistic, and aggressively inimical to local and national culture and identity. ${ }^{7}$ Proponents of globalism and those institutions and political organizations supporting globalism point out, however, that the creation of such organizations after WWII such as the WTO, IMF, ECC that culminated in the European Community, has improved the economic standing of many countries while effectively staving off yet another internecine world conflict.

While this sketch of the current controversy surrounding globalization and its effect on liberal democracy is at best cursory, it does provide a backdrop to Judith Hermann's Nichts als Gespenster. ${ }^{8}$ This work 
unfolds in a social and economic milieu not only grounded in Enlightenment thought, democratic liberalism and free market economic theory but also committed to the high ideals of the welfare state as a place of economic privilege and social protections for all its citizens. ${ }^{9}$ Yet, many of Hermann's "privileged" characters find themselves in flight from the globalized and commodified welfare state for reasons which are not immediately apparent in Nichts als Gespenster. Indifference, boredom, and indulgence create an impermeable intellectual and psychological membrane that does not allow penetration by either thought or feeling. The various expressions of dissatisfaction rarely get beyond a meager and unfocussed distress call that goes unheard and keeps Hermann's characters firmly in the clutches of existential ennui. ${ }^{10}$ Rather than engage self, world and the other, her characters prefer to drift in a murk of undemanding sameness that allows them to move in slurpy, disengaged worlds of whiny needs, indifferent emotions and low-level intellectualism. Most of her characters prefer the distraction of global travel to the more difficult and complex work of establishing place and identity within their own countries. ${ }^{11}$ At bottom, their disengaged,

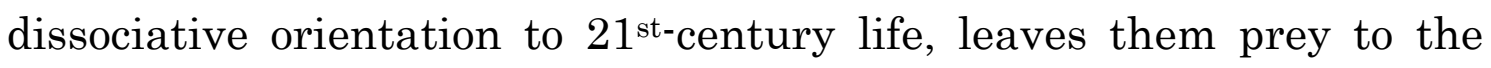
homogenizing pressures of globalization to which they respond by withdrawing into indifference, apathy, and egocentrism. As a result, Hermann's characters in Nichts als Gespenster are uniformly apolitical, a-historical, and a-national. They are, in effect, the aural equivalent of white noise, a collective human buzz in the background of society that unintentionally has marginalized and rendered irrelevant their unique voices. ${ }^{12}$

By deliberately emptying the text of much of its complex social, historical and political particularities, Hermann, opened herself to the criticism that Nichts als Gespenster was little more than another 
example of a transnational literature that aimed at accommodating the lowest common readership denominator while juicing sales in the international marketplace. ${ }^{13}$ While to a certain degree the "accessibility" of Nichts als Gespenster and its ostensible valorization of trite, soap-operatic conversation partially bears this out, Hermann sabotages this criticism by offering a hidden critique of the effects of globalization. While it appears that she has "globalized" her text by stripping it of its complexity, literary depth and national particularities, she has, in effect, created an "anti-transnational text" by insisting that the depiction of her characters and the substance of her plots are symptomatic of a cultural and economic force that has exerted a deforming influence both on the idea of romance and on travel and tourism. The result is what Emil Durkheim called anomie the breakdown of social bonds between an individual and the community accompanied by the fissuring of social identity.

The other argument that dispels criticism that Nichts als Gespenster is little more than an example of commercial transnational literature is the aesthetic contention that Hermann's use of language and construction of poetic tropes in bringing to life the characters of her ennui ridden generation, are aesthetic and intellectual as well as demanding, sophisticated, and complex. She depicts her a-national German millennials convincingly, capturing the rhythms and texture of their sensibility with poetic poignancy. This alone rescues Hermann's work from the criticism that it is merely another example of simplistic, dumbed-down, transnational literature.

If Judith Hermann's literary voice provides the sound of her generation and if she is unlike those writers referred to as nichtssagend (saying nothing), then what remains to examine is how her work succeeds as a new species of "romantic writing" and 
specifically how ambient romanticism and identity tourism influence this conception of modern romance.

Ambient romanticism as well as identity tourism represent a turn away from the conventional notions associated with love and travel. What brings these two phenomena together is a group of shared characteristics that appear as reactions to the contingencies of the modern global welfare state. First, albeit poetically, Hermann depicts characters on balance unable to express or feel profound emotion or complex sentiment. Second, while she depicts her characters as selfserving, egotistical, and vapid, she suggests that the reason for their ongoing sense of enervation and lack of identity is the homogenizing effects of globalization. Third, while Hermann intentionally excises references to current social, political or national events from the text of Nichts als Gespenster, she does so not by oversight but in order to depict the feeling of irrelevance and marginalization her characters experience in an increasingly globalized world. Fourth, the literary world of Nichts als Gespenster is a world transparently overshadowed by the phenomena of global commodification and homogenization, which slowly transforms everything in its purview into a transactional commodity.

Thus, these commodified avatars of human emotion and personal identity superimposed onto the more conventional forms of love and identity have a kind of paralyzing effect on Hermann's characters that makes them appear as if they were half-hearted, careless existentialists. Ambient romanticism, which reflects this developmentally recidivistic state, reimagines body as exotic place and emotion as sentient elsewhere, and both as objects of transaction. Thus, the search for love, the establishment of relationships, and the longing for identity come under the morphing influence of globalization and its concomitant commodification. The process yields 
what in German is called potenzierte Ungenügsamkeit (amplified dissatisfaction). Nearly all of Hermann's characters experience potenzierte Ungenügsamkeit to some degree as a result of being part of a global society that is economically advanced, socially progressive, and politically enlightened. Ironically, this society that guarantees the freie Entfaltung der Personlichkeit (the free unfolding of the personality), much like our own guarantees of "life, liberty and the pursuit of happiness' in the Declaration of Independence, reneges on the Enlightenment promises of fulfillment and dignity by commodifying them. The inference that the global economic political order in general aligned to the process of commodification in particular is responsible for the amplified dissatisfaction Hermann's characters experience in Nichts als Gespenster is central to the concept of ambient romanticism.

Already in the late 1700s the German Frühromantiks complained of the effect philistine commercialism was having on the sensibilities of poets and writers as well as on the German sensibility in general. The Schlegel brothers and Novalis responded to this cultural development by arguing for a kind of romanticism that would provide a corrective to the blandness and enervation brought on by an ever-increasing global preoccupation with commodification.

Hermann's characters negotiate the literary world of Nichts als Gespenster by transacting loneliness, longing, desire and facelessness in the mistaken belief that these very human characteristics can be acquired by means of aggressive acquisition and spatial occupation. Thus, they approach the logistics of love and identity as if colonizing the "other." They settle into the significance of the appropriated other by way of escape from potenzierte Ungenügsamkeit and by way of starting anew, shoring up their trailing inadequacies and their weakened sense of purpose and identity. Subsequently, these 
commodified, emotional encounters reveal themselves to be not only transactional but also evanescent. While Hermann's characters do not come close to uttering their romantic equivalents of "I am Heathcliff," they nonetheless struggle weakly to escape the enervated indifference and casual aimlessness that defines them as epigones, who remain ghostlike in their inability to take any kind of substantial form vis-à-vis a very real and problematic world. These "ghosts," like those encountered by Odysseus in Hades, do not know who they are nor can they recognize others for whom they are. Hermann's ghosts traffic in vague, wispy emotions and fictionalized notions of romance. The studied nonchalance and emotional exhaustion that characterizes these global travelers as they emigrate from their scrutable, ordered global societies to the undifferentiated worlds beyond their homelands further characterize the emerging cultural dystopia that sends them fleeing.

Ambient romanticism in its extreme form attests to a loss of nearly everything relating to the human experience - loss of identity, loss of love, loss of meaning, loss of purpose, and loss of transcendent magic. ${ }^{14} \mathrm{~A}$ similar sense of loss was already experienced by the early German romantics in the late 1700s. Frederick Beiser discussing the orientation of the German Frühromantiks points out that their aim was "to make [their] lives into a novel or poem so that they would regain meaning, mystery, and magic [which] they had lost in the fragmented modern world. ${ }^{15}$ The romantic poet Novalis provided the rallying call for the Frühromantic movement when he stated that the "world must be romanticized and restored to its plenary fullness and wonder."

Judith Hermann does not issue a rallying call as much as she whispers a warning. The romantic wasteland she chronicles as a place of drift, dissociation, and insubstantiality, is a place drained of magic 
and charm. The intersection of ambient romanticism and identity tourism occurs when Hermann's characters begin to see that the search for love is inextricably tied to the search for self and other. The overarching sense of emotional drift that comes to define her characters identifies them as first-world refugees, who flee security, prosperity and political stability for reasons of boredom, indifference, and vague longing. ${ }^{16}$ Yet, they do not seek a permanent home elsewhere. They flee homogenization and commodification and globalization more like angry juveniles looking to leave home than dispossessed refugees seeking a new homeland and a new life.

Hermann subdivides her first-world refugees into various groups of travelers. She identifies mass tourists, adventure travelers, secular pilgrims, emotional emigrants, and psychological refugees among her characters. The term "identity tourism" implies that the curious exoduses of her privileged first-world characters are symptoms of loss and confusion, on the serious side, and restlessness and boredom on the indulgent side. Identity tourism also implies appropriation and commodification as means to alleviate the amplified dissatisfaction that plagues their lives. Ultimately, however, it implies a return to a dominant culture, marking travel time and experience as mere interlude. ${ }^{17}$ Taken as a symptom of a subtle yet encompassing global malaise, the pursuit of identity tourism defines itself as a transactional activity that aims at a repatriation of romance and identity.

At the lowest level of identity tourism, travelers tend to leave their countries to relieve boredom rather than to seek a transformation of self by means of appropriating place and the other. At this level, travel itself is the alembic even though it has become fully commercialized and fully commodified. At the higher levels of identity tourism, complementation, redemption, and repatriation come into 
play, but subtly and quietly. While identity tourism at this level shares the goal of escape, the existential driver for this is the desire, even if imperfectly understood, to reclaim a sense of significance and relevance that is at once authentic, profound and redemptive. While many of Hermann's characters experience travel as artful wandering, they remain only peripherally aware of its higher aims and transformative possibilities. Many of them fuss solipsistically over their unresolved feelings of dissatisfaction and irrelevance, which exacerbates rather than alleviates their imperfectly expressed feelings of loneliness and facelessness. ${ }^{18}$

The transactional encounters that characterize most of the relationships in Nichts als Gespenster are as tepid and noncommittal as they are ephemeral. They attest to a transformational cultural phenomenon which exists as a sub-textual motif in Nichts als Gespenster. While globalization plays an inoculatory role in promoting many of the principles of the Enlightenment and liberal economic democracy, it also introduces the very malaise it was meant to alleviate. It does this by significantly altering the Enlightenment values upon which it is based and by substituting the uniformity of homogeneity for the uniqueness of heterogeneity. The presence and shaping influence of a global consumer culture, predicated on free market economic theory and liberal democratic principles is the transformative absent "presence" in Nichts als Gespenster. It is this shaping force that is largely responsible for the development of ambient romance, the transactional and exhausted, ghostly version of conventional romance, and identity tourism, the attempt at reclamation of self by means of complementation and appropriation of person and place. As textual features of Nichts als Gespenster, ambient romantism and identity tourism conceptually serve to shed light on the mood and mentality of the current generation of young 
European millennials. They also serve to support the assessment that Hermann's work will remain a literary achievement in capturing the sounds and rhythms of her millennial generation and in offering a sustained, albeit subtle critique of the emptying, homogenizing effect of globalization.

\section{Notes}

\footnotetext{
${ }^{1}$ Judith Hermann, Nichts als Gespenster (Frankfurt am Main: Fischer Verlag, 2004).

${ }^{2}$ Claudia Gremler, "Looking for Redemption in a Globalized North: Representations of the Arctic in Judith Hermann's Short Stories ‘Kaltblau' (Cold-Blue) and 'Die Liebe zu Ari Oskarsson' (Love for Ari Oskarsson)," Nordlit 23 (Tromsø, Norway: Humanistiske Fakultet, 2008), 119.

${ }^{3}$ Anke Biendarra, “Globlaization, Travel, and Identity: Judith Hermann and Gregor Hens," Gegenwartsliteratur: ein germanistisches Jahrbuch 5 (Tübigen: Stauffenburg, 2006), 236.

${ }^{4}$ See Thomas Borgstedt, "Wunschwelten: Judith Hermann und die Neuromantik der Gegewart," Gegenwartsliteratur: ein germanistisches Jahrbuch 5 (Tübigen: Stauffenburg, 2006), 207.

${ }^{5}$ Biendarra, "Globalization, Travel, and Identity,“ 236.

${ }^{6}$ Ibid., 233-34.
}

${ }^{7}$ See David N. Coury, "Beyond the National: Sarah Khan and the Globalization of German Literature," German Studies Review 30, no. 2 (2007): 244, where he states: “In cultural terms, it [globalism] signal's an individual's inevitable mediation with the hegemonic regime of commodification and consumption the either universalizes desires or particularizes traditions."

${ }^{8}$ See Michel Goodhart, "Democracy, Globalization, and the Problem of the State," Polity 33, no. 4 (2001): 529-32, for an extended discussion of the impact globalization has on democracy.

${ }^{9}$ Gremler, "Looking for Redemption," 120.

${ }^{10}$ See Biendarra, "Globalization, Travel, and Identity," 237, where she states: "Traveling is the prominent motif in Nichts als Gespenster [whose characters] . . engage in a day-to-day draft form of life that centers exclusively on private concerns."

${ }^{11}$ Beth Linklater, "Germany as Background. Global Concerns in Recent Women's Writing in German," in German Literature in the Age of Globalization, ed. Stuart Taberner (Birmingham: University of Birmingham Press, 2004), 67.

${ }^{12}$ See Biendarra, "Globalization, Travel, and Identity," 235, where she states: "All the narratives [in the works of Hermann and Hens] take place in settings that are marred by the influence of Western capitalism and its cultural homogeneity." 
${ }^{13}$ Sean Nam, "The Globalization of Literature," online review of The Global Novel by Adam Kirsch in The New Rambler, 2015.

${ }^{14}$ Frederick C. Beiser, The Romantic Imperative: The Concept of Early German Romanticism

(Cambridge, MA: Harvard University Press, 2003), 23-30.

${ }^{15}$ Beiser, The Romantic Imperative, 19.

${ }^{16}$ Karen Leeder, "Another Piece of the Past: Stories of a New German Identity," Oxford German Studies 33 (2004): 131.

${ }^{17}$ See Gremler, "Looking for Redemption,” 121, where she quotes Iris Radisch and Mila Ganeva, respectively, referring to the condition as 'tristesse globale' and to Hermann's characters as 'global flâneurs'.

${ }^{18}$ Gremler, "Looking for Redemption," 120. 


\section{Joyful Contests: Nietzsche and the Politics of Friendship}

\section{Paul Kirkland}

Carthage College, Kenosha, Wisconsin, USA

Aristotle famously writes that among friends there is no need for justice. The possibility of human bonds that are not tied to relationships of justice, and that remain perhaps beyond the scope of politics, emerges from this claim. This essay takes an approach to Nietzsche's political considerations that foregrounds his treatment of friendship, treating it in light of his critique of nationalism, the modern state, and universalism.

Nietzsche recommends his approach of gay science in the supplement to the book bearing that title to the "homeless" among Europeans today. While suggesting a bond among the detached, he highlights their separation from all political movements of the day. He makes clear that "we homeless ones" are not conservatives, liberals, progressives, or nationalists. In this effort to make space for those who do not fit existing political options, an important place for friendship emerges. Nietzsche announces that he offers a new view of what is shared in his definition of friendship as "not shared suffering (Mitlied) but shared joy (Mitfreude)" (HH 499).

After rejecting liberalism and conservatism, Nietzsche challenges humanitarianism, describing it as an "enamored impatience to approach in all honesty the whole of humanity with one's lust" (GS 377). Rather than allowing a sort of love that would be so radically unselective as to love all of humanity, and to harbor a desire for a kind of union with it, Nietzsche rejects the claims of humanitarians, 
providing a spur to consider the scope to which it is reasonable or desirable to extend one's affections and attachments. Nietzsche also argues that we "homeless ones" are "not nearly German enough... to advocate nationalism and race hatred" (GS 377). Neither nation nor humanity is an appropriate object of love and attachment.

Having rejected all such commitments and attachments, Nietzsche introduces "good Europeans" (GS 377) among whom he includes himself, distinguishing them from "European morality of today" (GS 380). Rather than preserving a tradition, these "good Europeans" seek "a freedom from everything 'European,' by which I mean the sum of the imperious value judgments that have become part of our flesh and blood" (GS 380). They will make use of their cultural heritage to seek new possibilities and to make way for new social forms.

\section{Things Called Love}

In considering social forms and human relations, Nietzsche treats many of the things that have been called love as forms of avarice. He describes love of neighbor as lust for new possession, love of knowledge as an insatiable imperialistic eros, and pity for the suffering as a form of conquest. The feeling of pity (Mitleid) involves something like the view that one can feel the suffering of another, and a benefactor wants to make the good of the beneficiary one's own, to make the life benefitted into one's own possession. In the case of sexual love, the desire for reciprocity in amorous relationships involves a desire for the complete possession of another, "unconditional power over the soul and the body of the beloved" (GS 14). The mistaken view of love as 
extending beyond egoism, Nietzsche suggests, is a result of the usage of those who do not possess but desire a beloved.

Nietzsche points to a possibility that goes beyond those love relationships in which two cling to one another:

Here and there on earth we may encounter a kind of continuation of love in which the possessive craving of two people for each other gives way to a new desire and lust for possession - a shared higher thirst for an ideal above them. But who knows such love? Who has experienced it? Its right name is friendship. (GS 14)

Two craving an ideal together makes possible friendship. When this experience is shared the connection is not reducible to the desire to possess the other either sexually or as their beneficiary. Insofar as each party brings something different to the thirst for the ideal, the friendship might open the way of sharing multiple perspectives.

\section{Valuing Enmity}

Those who can appreciate enmity and contest recognize the limitations of their own or any singular dominating view. When Nietzsche writes about "the spiritualization of enmity" (TI Morality 3), he sets "a profound appreciation of the value of having enemies" against those who seek "the destruction of ... enemies" (TI Morality 3). Using the church as his example of an institution that strives for the singularity that would result from such domination, he declares that "we immoralists and antiChristians" appreciate the value of the continued existence of the Church and value the endurance of enmity. Given the lack of a comprehensive position, a genuine enemy provides an 
alternative perspective, one that broadens one's view of life and demands acknowledgment of the limit of one's singular perspective.

Social relations and indeed "the natural condition of things" require honoring those who are equal (BGE 265). The honor and the "reverence" a noble man has for his enemies (GM 1.10) include an acknowledgement of limitations. Recognizing and seeking equal enemies involves awareness that one is not complete, and that recognizing the worth of another does not entail the loss of anything of oneself. Those who can appreciate the value of enmity do not view themselves as the same as their enemies, but rather they acknowledge a kind of equality in difference.

Nietzsche writes of the end of the age of spiritual tyrants ( $\mathrm{HH} \mathrm{261)}$ and the possibility that authority now "lies in the hands of the oligarchs of the spirit" whose members "recognize and acknowledge (erkennen und anerkennen) each other" (HH 261). In explaining this claim, he argues that the time of those who believe they "possess the absolute truth" can give way to a time in which spiritual authority is multiple. Those who assert authority, but not comprehensive authority, both recognize and compete with others who do the same. Taking Nietzsche's claims about enmity and recognition together, we see that he presents the possibility of multiplicity and contests rather than tyranny or peace. Contest that recognizes the opponent values the contest rather than expecting a victory that will end all conflict.

\section{Recognition, Pity, and Shared Joy}

Nietzsche's treatment of honor, enmity, and multiplicity reveal the outlines of a kind of recognition that remains consistent with 
maintaining difference, addressing a matter that has been of great concern in political theory. Many who have addressed the matter, including Charles Taylor, Jürgen Habermas, and Axel Honneth draw from a Hegelian conception of recognition and run in the direction of comprehensive reconciliation. ${ }^{1}$ In light of the difficulty of preserving genuine difference along with recognition, James Tully suggests that recognition theory is mistaken, suggesting a "more open-ended language of acknowledgment."2 Nietzsche's presentation of recognition and acknowledgement of enemies offers a resource for considering the possibility of esteem that does not involve consensus. By forgoing the demands of equality, Nietzsche's thought on modes of human relations, including friendship and enmity, focuses attention on the ways in which acknowledging others while retaining genuine differences might be possible. Nietzsche's contrast between pity (Mitleid) and shared joy (Mitfreude) addresses this dilemma in political theory.

Near the end of Part Four of The Gay Science, ${ }^{3}$ Nietzsche returns to the theme of pity, providing analysis of the emotion. In the first place, pity obliterates all that is distinct, and "strips away from the suffering of others whatever is distinctly personal" (GS 338). In this way, pity fails to recognize the other. Nietzsche shows the deep problems in the effort to extend dignity to others in an egalitarian manner. Those who attempt to benefit others, especially by removing their suffering, diminish their worth. The effort to benefit one who is suffering entails an effort to remove that suffering and thereby to remove what is distinct about the set of experiences that produce it. As Nietzsche understands overcoming and self-overcoming as the path to 
accomplishments and joys, he reminds his readers that one's own particular torment and difficulty is a part of any such path.

The failure to recognize what is distinct in the suffering of others leaves only the smallness that results in conflating distinctions among human beings and making a morality of the destruction of distinct paths. Nietzsche attributes the appeal of such a morality of pity to the difficulty of forging one's own way. The emotion of pity is rooted in a desire to eliminate the finitude that prevents one from suffering the death of another, but it does so through a drive to eliminate all that is distinct. The "religion of pity" that demands aid to others involves such self-annihilation.

War clarifies the way in which the morality of self-annihilation bears on political commitments. Nietzsche describes those who "Rapturously... throw themselves into the new danger of death because the sacrifice for the fatherland seems to them to offer the long desired permission - to dodge their goal; war offers them a detour to suicide, but a detour with a good conscience (GS 338). The willingness to sacrifice oneself in war is another form of self-annihilation that already lurks in dedicating one's life to a fatherland, subsuming one own life in that of the nation. If attachments to any political body or cause are nothing but self-annihilation, all social and political connections may lose any possible value. While radical isolation is not Nietzsche's final word on the matter, he surely does recommend against giving oneself over to any nation.

Rather than outlining political arrangements counter to those of the nation-state, Nietzsche goes so far as to advise, "Live in seclusion so that you can live for yourself. ... And the clamor of today, the noise of 
wars and revolutions should be a mere murmur for you (GS 338). Instead of losing oneself in the noise of the day, the political commitments of one's time, or the values of the age, Nietzsche counsels an effort to remove oneself from them like the homeless ones he describes in Part Five.

This admonition to resist pity entails a rejection of the kind of generalized love of humanity that produces universalist claims as well as the self-sacrifice involved in nationalism. Resisting both nationalism and humanitarianism, Nietzsche does not leave the matter by endorsing isolation. Instead he looks to friendship as a model in which genuine benefit to another is possible. Instead of obliterating oneself in generalized sacrifice or destroying all that is distinctive in the effort to remove suffering, one might attend to the distinct relations of friendship in which one may share not merely suffering, but joy. Nietzsche writes of the possibility of shared joy:

I want to make them bolder, more persevering, simpler, gayer (frölicher). I want to teach them what is understood by so few today, least of all by these preachers of pity - not shared suffering (Mitleid), but shared joy (die Mitfreude)! (GS 338)

As Nietzsche seeks to foster human relations of shared joy (Mitfreude), he offers an alternative to relations of pity (Mitleid). The analysis that leads up to this point shows pity (Mitleid) to entail the destruction of all that is distinct, both in self-sacrifice and the effort to subsume another's suffering. Where pity pulls one into one's own time and people, shared joy is possible where there is a something distinctive in the parties to such friendship. It operates not on collapsing the differences and debasing suffering by generalizing it, but rather on the 
overflowing capacity of joy that can be shared. Producing this sort of joy is the aim of Nietzsche's gay science, the announced aim of the book that makes laughter and gaiety an objective and an aid to knowing.

\section{Hospitality, Estrangement, and Elevation}

Nietzsche treats the possibility of relating to something new without destroying its difference in a reconsideration of the theme of learning love. Using the example of an unfamiliar melody for confronting something new, Nietzsche describes the need "to detect and distinguish it and delimit it as a separate life" (GS 334). Between recognizing its distinctness and appreciating the musical figure comes a period of toleration, in which the strangeness is fully recognized with patience. Only then can we become "used to it" after which "we wait for it," miss it, and, then "desire nothing better in the world than it and only it" (GS 334). Once one has had the patience to welcome the strange, "gradually, it sheds it veil and turns out to be a new and indescribable beauty. That is its thanks for our hospitality" (GS 334). Explicitly contrasting such patience and hospitality to his earlier treatment of lovers who want only surfaces (GS 59), he shows how beauty is revealed. He shows the benefits to learning and beauty gained from hospitality, rather than any moral insistence upon "respect" or "dignity." By contrast to his earlier treatments of things called love, he presents the possibility of a learned love that makes room for something that is genuinely other than oneself. In such learning one can move beyond one's own narrow ego and perhaps gain sufficient distance to learn to see what is familiar as strange. 
Along with acknowledging difference, a kind of estrangement is characteristic of relations of shared joy. The acknowledging of what is strange in another, and nonetheless a source of joy and overcoming, can assist the effort to gain distance from oneself. The richness of friendships that acknowledge particularity and share joy includes the capacity to move beyond oneself and one's own time in oneself. In writing of relations of shared joy, Nietzsche gives content to "we" homeless ones and the "good Europeans" who are too "traveled" and "untimely," to attach themselves to "petty politics," preferring to "live in mountains" apart from what dominates the age. Learned love and gaining distance from oneself link hospitality and estrangement as elements of a model for human relations that do not collapse differences. Combining welcoming the stranger and becoming a stranger, Nietzsche indicates an important role for hospitality. Rather than conditions driven by national or humanitarian attachments, those who can see the strange as such while appreciating its value shape conditions for friendship and for social relations built on joyful contest rather than domination.

The experience of welcoming the strange does not for Nietzsche entail losing oneself like those bound to national and humanitarian attachments. By recognizing one's own distinctiveness, one can appreciate the distinctive claims of others, for neither needs to be collapsed into something universal. Maintaining distinct human possibilities requires the contesting spirit that holds one's own against another even while acknowledging and appreciating the other. Only combining the two yields any genuine variety. 
The possibility of the sort of freedom gained through overcoming oneself is surely rare, and we should not expect to be able to transform institutional political relations into structures that serve such goals. Nonetheless, the relations of contest Nietzsche describes can allow the acknowledgment of the limits of one's particular attachments along with the value of struggle and overcoming. A politics of difference rooted in neither universal aspirations nor or tribal commitments could allow contests that do not expect conclusions. Instead of hopes for an end to all conflict, joyful contest allows one to embrace the reality of social and political relations, and thus more fully to appreciate life and the varied paths to joyful overcoming it entails.

Along with recognition and strangeness, relations of shared joy (Mitfreude) involve a kind of elevation, one that Nietzsche links to the possibility of knowledge and the project of a gay science. The "good Europeans" for whom he writes are not simply European rather than national in their commitments, they are also able to move beyond European morality and see it from a distance. Sharing the capacity for joy in overcoming the values of one's time serves the effort of gaining such distance. By seeing joyful overcoming in others who one recognizes as different, one is more capable of moving beyond oneself and what attaches oneself to the valuing dominant in one's time. To be able to overcome one's time in oneself, one has to be "very light" (GS 380). Earlier in the Gay Science, he attributes the capacity for such levity to the effects of art, which can help us to gain distance from ourselves and make us capable of "laughing over ourselves" (GS 107). As seeing oneself through the eyes of a work of art can allow us to look 
at ourselves from a distance, so also can friendship allow one to see oneself through the eyes of another.

Nietzsche writes of the lightness involved in gaining distance from oneself, "we need all exuberant, floating, dancing, mocking, childish, and blissful art lest we lose the freedom above things that our ideal demands of us" (GS 107). In shared joy, such levity is gained along with another, producing the lightness capable of climbing above oneself and beyond one's age. Nietzsche's project of producing a gay science requires an alliance between laughter and wisdom, in which levity allows distance for knowledge, distance gained through shared joy, the distance that makes it possible to get beyond the view of tragic moralists to a position from which one can appreciate "the eternal comedy of existence" (GS 1). The levity in friendship, capable of sharing joy rather than suffering, serves not only to increase knowledge but to make it possible to affirm the whole of life, including its difficulties and limitations, the aim Nietzsche expresses through the affirmation of the eternal return of the same. New social relations serve this goal, relations of shared joy that preserve distinction, recognize difference, enable distance, and elevate vision.

\section{Notes}

\footnotetext{
${ }^{1}$ See Charles Taylor, "The Politics of Recognition," in Multiculturalism: Examining the Politics of Recognition, ed. Amy Guttmann (Princeton, NJ: Princeton University Press, 1994); Axel Honneth, The Struggle for Recognition: The Moral Grammar of Social Conflicts (Cambridge, MA: MIT Press, 1996).

2 James Tully, Public Philosophy in a New Key (New York: Cambridge University Presss, 2008), 208.

${ }^{3}$ The original 1882 ending of the book.
} 
Global Enframing, Authentic History, Dasein: Thoughts on the "Preview" of Heidegger's Beiträge zur Philosophie (Contributions to Philosophy)

José Daniel Parra

Facultad de Gobierno y Relaciones Internacionales, Universidad Externado de Colombia, Bogotá, Colombia

Martin Heidegger's Contributions to Philosophy (Beiträge zur Philosophie $)^{1}$ offers a condensed meditation on the spiritual state of the modern epoch. This paper offers a series of remarks on the "Preview" of the Contributions in order to trace how the book's six "joinings" - echo, playing-forth, leap, grounding, the ones to come, and the last god - convey a hermeneutic contrast between "authentic history" and our seemingly "post-metaphysical" condition. Heidegger does not write the Contributions in order to analytically structure an argument. Rather, the text has a particular hermeneutic movement and rhythm that we will try to trace and account for. Heidegger seems to be writing this book, in the first place, as a sort of hypomnemata. The Contributions presents and reiterates a series of notions that aim to prepare the "transition" (Übergang) from the first beginning to the other beginning of philosophy.

The "matter" at issue in the Contributions to Philosophy is "the age of crossing from metaphysics to be-ing-historical thinking [seynsgeschichtliches Denken]" (3). Heidegger tells us that this movement implies a thinking "underway." Such authentic historical thinking is not the representational thought of subject/object cogitation, but rather a kind of process toward an essential transformation of the human from "rational animal" to Da-sein. The transit toward what Heidegger calls the "other beginning" is a 
crossing within the traced openness of history. He is referring to a history-making crossing, that is, perhaps, a very long sojourn. At the same time, the other beginning has the character of a decisive "intimation" (Ahnung). In this sojourn, the essential sway of be-ing manifests itself as "enowning" (Ereignis).

Theologically speaking, the intimation toward the other beginning hints at the "godding of the god of gods, from out of which Dasein's allotment to be-ing comes into its own, as grounding truth of be-ing." This new dispensation remains shrouded in mystery, however; it is a thinking-saying of philosophy that, apparently, does not describe, explain, proclaim, teach. Rather, the "saying" that intimates the other beginning sounds out as the essential swaying of be-ing. It also seems to have a spontaneous ring to it, for it is "not the purposeful activity of an individual, nor the limited calculation of a community" (4). The other beginning will, according to Heidegger, be communicated by way of momentous "hints," coming from what is most "question-worthy." Heidegger also signals his "post-structuralist" bent: the time of systems is over. We are experiencing a period of transition whereby "the time of re-building the essential shaping of beings has not yet arrived." The Contributions is therefore a "preparatory exercise" within an underlying transitional period. This unfolding, we are told, is a unique and singular epochal event: we don't have guidance from scholastic systems or doctrines which as such would evade the problematics of the Seinsfrage in our time of crossing.

The "other beginning" occurs in tandem with the Platonic-Aristotelian "first beginning" of philosophy. The origin of the "other beginning" seems to have an ambiguous character: it is both an Auseinandersetzung or "deciding encounter" with and a sublation of the "first beginning." As such, the Platonic-Aristotelian first beginning always remains there opening the way for the preparatory "transiting" 
thought: the founding projecting-open of the truth of be-ing as historical mindfulness. The Contributions prepares the transit: history (Geschichte) for Heidegger is the space-time of fundamental "decisions" that trace the crossing. The historicity of the "crossing" and the structure of Ereignis are laid out by Heidegger in the following set of interrelated historical moments:

(1) Echo or the resonance (Anklang) of the oblivion of be-ing in the age of machination. This produces the experience of "startled dismay" (Erschrenken) as the self-referential projection of modern humanity seems to be lacking ontological standards to "hold fast to Da-sein."

(2) Playing-forth or foreplay (Zuspiel): a paidia or paideia for gaining momentum toward the leap from the first beginning of classical Greek "wonder" toward the other beginning that, as yet, has no name.

(3) Leap (Sprung), which has a familiar ring to Kierkegaard's leap of faith: The leap occurs when the crossing from the Leitfrage of philosophy toward the Grundfrage is undergone by way of historical Dasein. Heidegger claims that "the self becomes its own in the leap."

(4) Grounding (Gründung) as the intimation of founding a new dispensation following the "leap": a new "freedom" of be-ing-historical thinking in poetic "law or song" (nomos).

(5) The ones to come (die Zukünftigen): "post-disenchanted" philosopher-poets of the future who are the custodians of the crossing.

(6) The last god (der letzte Gott): which still resonates in the hearts and minds of those who might witness and care for the truth of be-ing in the epoch of transition.

The historical structure of Ereignis begins with an echo or resonance of be-ing as not granting. Here the playing-forth of the question gains impulse from the first beginning (in wonder) which brings the other beginning (in startled dismay) into play; the mutual playing-forth - 
paidia or paideia - that is to say, possibly a kind of "liberal education," prepares the way for the "crossing" or "leap." A leap into the sphere of be-ing releases and therefore makes possible the other grounding of Da-sein. This foundational act is somehow allotted from be-ing. Grounding unfolds as the originating grounding of truth as the truth of be-ing in Da-sein.

Now, this "non-analytical" framework seems to establish the existential difference between a state of mind of those who live only in the present (and who, as thinkers, engage in philosophia perennis), and "those who are to come" or "those who are but once" whose philosophizing is attuned to the synchronicities and needs of be-inghistorical thinking (5). In order to shed light on the philosophical poles of the crossing, Heidegger introduces the difference between the Grundfrage and the Leitfrage of philosophy. Heidegger claims that the Grundfrage, the question of "the Ground," unfolds historically: it manifests "who we are" in accordance with our attunement to the Seinsfrage. The Leitfrage, on the other hand, manifests the dualistic question about beings: the "what is" question that structures phenomena in the categories and typologies of genus and species that sustain the epistemology of modern enframing. The Leitfrage for Heidegger is synonymous with "Platonism" and its legacy, that is: the binary set of distinctions of forms/shadows, ought/is, ideal/real, City of God/City of man, res cogitans/res extensa, noumenalphenomena, values/facts that in his account has framed the history of western onto-theological thought from Plato to Nietzsche.

For Heidegger, the dualism of "is and ought" is conceived now as the "open strife between earth and world" (6). It is in this context that the messengers of the truth of be-ing "go under," are enowned as potential founders, keeping their measure by their attunement to the essential swaying of be-ing. According to Heidegger, the act of founding is 
required by be-ing itself." Be-ing itself needs those who go under." Those who "go under" come "only once" and are the conveyors of "inceptual thinking."

The dynamics between the first and the other beginning are also characterized by Heidegger as a "playing-forth." Such educational spiel occurs in the historical context of the "echo" of be-ing in the distress produced by be-ing's silence. From such needfulness, a saturation point seems to be reached which prompts the "leap" into the quality of be-ing in order to "ground its truth." This, in turn, is a "preparation" for the "ones to come" and their mysterious relation to "the last god." The thinking-saying that follows is, however, neither a doctrine nor a common opinion. It contains a preliminary task "to retrieve man from the chaos of non-beings into the pliancy of a reserved creating of sites set up for the passing of the last god" (6). The "ones to come" are therefore learning and re-considering the art of contemplation.

Such a task, however, is faced with a relatively new sort of danger as man has become feeble for the custodianship of Da-sein in the age of mass society and global enframing. Heidegger poses the question of whether a sense of "shock of deep awe [Scheu]" might put man back into the grounding-attunement of reservedness "setting him up for $\mathrm{Da}^{-}$ sein" again. In other words, Heidegger seems to be experimenting with ways to transform our human perspective from a mere rational or calculative animal to let Da-sein emerge mindfully and trustfully into the truth of be-ing. Such emergence would ground the truth of beings and of man in a new foundational act. The Contributions prepares the movement for this post-calculative ontology, which, nevertheless, is still far ahead in the future. For now, we are told that "the first thing here remains to put be-ing into question." 
Asking the question of the truth of be-ing occurs for Heidegger in the mood of fundamental distress or needfulness. It is therefore a painful or non-superficial experience of pathein mathein that bears the "solitude of his highest hour." Unlike the "ontological difference" of Being and Time, enowning in the Contributions is conceived as the "temporal-spatial simultaneity of be-ing and beings" (10). This implies a shift from propositional to dispositional knowing - knowing as creating from higher attunement in alignment with the Seinsfrage, which produces the transformation from merely "existentiell" conditioning toward "Da-sein as measure." Such dispositional or transformational knowledge is a "turning around" or metanoia that clears and opens a new path of the history of be-ing.

It seems to follow that such a "leap into the metaxy or "in-between" lets "Da-sein spring forth" into the grounding of the truth of be-ing. The grounding-attunement of thinking in the "other beginning resonates as ... startled dismay" intimating a "deep awe" (11). A new aidos seems to be intimated in the silencing of the proximity of the last god. This is a historical moment of crossing, moving from the metaphysics of subjectivity to the truth of be-ing channeling the mystery of the Seinsfrage.

For Heidegger the grounding-attunement of the period of transition is one of "startled dismay" as contrasted to the "wonder" or "astonishment" (thaumazein) of the first beginning. Startled dismay means "returning from the ease of comportment of what is familiar to the openness of the rush of the self-sheltering" (11). Apparently, being has abandoned beings. ${ }^{2}$ Startled dismay seems to be a kind of "alienation," the realization that be-ing appears to have abandoned all "beings" withdrawing from them in our period of transition. In this context of overarching perplexity "reservedness" seems to become a needful practical virtue. 
Yet the refusal (Verweigerung) is ambiguous: it is also a preparation for "gifting." Reservedness therefore is a pre-disposition whereby refusal constitutes the foreground for the receptivity of the "gift" of thought. A kind of reticent reservedness is the style of thought at the origin of the other beginning. From this follows the centrality of silence, as well as the mindful attentiveness to signals, synchronicities, hints. Reservedness becomes the character of inceptual thinking and "midpoint" between startled dismay, deep awe, and the circumspect need for mindful reticence. Such reticence, according to Heidegger, does not mean evading beings, "but the opposite." It means a sense of simplicity in the "sheltering of truth."

Heidegger signals the reserved need to carefully cultivate, foster, and "give once again historical man a goal: namely, to become the founder and preserver of the truth of be-ing" (12). To be t/here - is to be in the attunement of care: care for the sake of be-ing, not merely the being of man but the be-ing of beings as a whole. Care, Heidegger reiterates, that is neither dogma, nor popular opinion. Care that is the opposite of acedia or spiritual laziness. The experience of the abandonment of being prepares the thoughtfully poetic decision to attend and tend to the call of care. Care is thus the character of Da-sein. Da-sein is now for Heidegger historically understood as "seeker, preserver, guardian, caretaker [...] In this reservedness Da-sein attunes itself to the stillness of the passing of the last god" (13). Apparently, gods pass (away) or withdraw, and return. Meanwhile, "situated creatively in this grounding-attunement of Da-sein, man becomes the guardian and caretaker of this stillness" (13). The meditative equanimity of Da-sein prepares an "inceptual mindfulness" from which genuine historical thinking may still unfold when the time is ripe. Seeking and finding of be-ing - and thus a "homecoming" - becomes the goal of inceptual thinking. Inceptual thinking rests outside the familiarity of "beings" 
and outside the determinations of current opinion. The key figure in this mode of inceptual thought is the poet who unpretentiously "veils the truth in image and thus bestows it to our view for keeping" (14). Heidegger contrasts the sense of historical "intimation" to calculative standardized reasoning. As such, authentic intimation "takes stock of the whole of temporality: the free-play of the time-space of the t/here" (16). Intimation shelters the thinking that deals with "crossing." This sort of thinking, Heidegger tells us, "must grow out of genuine knowing awareness of preservation of the truth of be-ing" (17). It is a "gifting" and a "deciding" in-between the apparently no-longer of the first beginning and the not-yet of the fulfillment of the other beginning. It prepares a decision that precedes the guardianship of man as founder of Dasein. Such guardianship is grounded on the "stillness of the passing of the last god." This is a meditative stillness from which the "going under" of Ereignis may be heeded.

\section{Notes}

\footnotetext{
${ }^{1}$ Martin Heidegger, Contributions to Philosophy (From Enowning), trans. Parvis Emad and Kenneth Maly (Indianapolis: Indiana University Press, 1999). References in the text are from this edition and hereafter are cited by page number. The Contributions are written in an intricate, non-analytical, aphoristic, and quite reiterative mode of composition. The book is composed of a "preview," six “joinings" and a final section titled "be-ing." The "preview" and the six "joinings" were written in 193637, and the last part "be-ing" (which is an attempt to "rethink" what was conveyed in the previous sections) was written in 1938. The book was composed during Heidegger's “middle period," but was published posthumously in the year 1989. One of the key developments of the text is the movement from the "ontological difference" of Being and Time toward an attempt of harmonizing or at least approximating the "ontological" and the "ontic" realms as the emergence of a qualifiedly non-dualistic historical unfolding. Such temporal attunement of the ontological-and-the-ontic in Da-sein Heidegger now describes with the word be-ing (Seyn).

${ }^{2}$ Plato, Statesman (269c7-d7).
} 


\section{To "Persuade Without Convincing": Rousseau as the Legislator of}

\section{Nature}

Emma Planinc

University of Notre Dame, Indiana, USA

In his Social Contract, Jean-Jacques Rousseau famously claims that any legitimate state requires a Legislator, or a Law-Giver: a figure of "superior intelligence" who is not of the state, but will supply its law. The Lawgiver is described as wielding a seemingly boundless power of "establish[ing] a people's institutions... [and] changing, so to speak, human nature; of transforming each individual..." (SC II.vii.191). To this great power, Rousseau adds a great difficulty: to achieve this transformation, the "effect would have to become the cause. The social spirit which ought to be the work of that institution, would have to preside over the institution itself, and men would have to be prior to the laws what they are to become through the laws. Hence, therefore, since the lawgiver can use neither force nor reasoning, he must of necessity have recourse to an authority of a different order which might be able to motivate without violence, and persuade without convincing" (SC II.vii.192-93).

This is a phrase ('persuade without convincing') that also appears in the Fourth Chapter of his Essay on the Origin of Languages. Rousseau writes 'Of the Distinctive Characteristics of the First Language' that 'it would persuade without convincing, and depict without arguing" (EoL IV, 256). ${ }^{1}$ Compared to the invocation of this phrase in the Social Contract, the addition of 'depicting' to the category of persuasive language is important here. He writes: "I do not doubt that if it first existed, the first language would have preserved certain original characteristics besides vocabulary and syntax which 
would distinguish it from all other languages. Not only would all the turns of phrase in this language have to be in images, sentiments, figures; but in its mechanical aspect it would have to answer to its primary aim, and convey to the ear as well as to the understanding the almost inescapable impressions of passion seeking to communicate itself" (EoL IV, 255). It is, according to Rousseau, the "passions that wrung the first voices," and the first language would not be "methodical or reasoned" but "lively and figurative" (EoL IV, 252). The first languages were those "of Poets," and they were "songlike and passionate before they were plain and methodical" (EoL IV, 253).

"As enlightenment spreads," Rousseau writes, "language changes in character; it becomes more precise and less passionate; it substitutes ideas for sentiments, it no longer speaks to the heart but to reason" (EoL II, 256). Putting this together, then, with the Social Contract, one can see a kind of dark Lawgiver figure emerging as the spectre of fascisms to come. He must speak to the heart and not reason in order to change human nature and form a political community, and must use a figurative mode of communication that "is not that of the truth" (EoL III, 254). Indeed, Rousseau writes in the Social Contract that the most important sort of law is that "which is not engraved on marble or bronze, but in the hearts of citizens; which is the genuine constitution of the state... I speak of morals, customs, and especially opinion [notice he does not say anything about truth] - a part of the laws... to which the great lawgiver attends in secret" (SC II.12.202-3). Rousseau wants the lawgiver to use language that moves you, which convincing would fail to do. There is something static about the presentation of argument, and even about being convinced of the truth. Many scholars have focused on the musical tones of the first language (Chris Kelly, Bryan Garsten, John Scott). I claim that all that can be said of music in this case can also be said of Rousseau's 
accounting of and for visual images: that they are prior, figurative, speak to the heart and the passions, and that they can move. This is drawn out of a source heavily employed by Rousseau in the Essay, and mentioned in the Social Contract - William Warburton's Divine Legation of Moses Demonstrated of 1738 (part of which was translated into French in 1744 as the Essai sur les hieroglyphs des Egyptiens and was a major influence on Condillac and the Encyclopédistes as well as Rousseau). By looking at this more closely, I hope to demonstrate that in privileging the imagistic as opposed to musical side of Rousseau's claims about the first language, one is able to tie the very images Rousseau employs in the Second Discourse to a persuasive power he sees himself harnessing to move us.

Rousseau claims the first language is figurative: "figurative language [langage figuré] arose first, proper [or literal]] meaning [le sens propre] was found last. Things were called by their true name only once they were seen in their genuine form. At first men spoke only poetry; only much later did it occur to anyone to reason" (EoL III, 253). To make clear what he means by this, Rousseau provides an example:

[A] savage meeting others will at first have been frightened. His fright will have made him see these men as larger and stronger than himself; he will have called them Giants. After much experience he will have recognized that since these supposed Giants are neither bigger nor stronger than he, their stature did not fit the idea he had initially attached to the word Giant. He will therefore invent another name common both to them and to himself, for example the name man, and he will restrict the name Giant to the false object that had struck him during his illusion. This is how the figurative word arises before the proper [or literal] word does, when passion holds our eyes spellbound 
and the first idea which it presents to us is not that of the truth. ... Since the illusory image presented by passion showed itself first, the language answering to it was invented first." (EoL III, 254)

Here then you can see that Rousseau is invoking the dichotomy of persuasion and truth to emphasize the manner in which the first language was linked to the passions, and was imagistic, or figurative, and here also mythic.

This example of Rousseau's links to the very first things said in the Essay about the first gestural modes of communication, which rely on sight, images, and visual communication. He writes that one must "consult ancient history" to see how men used to communicate via things and their figurations (EoL I, 249) and employs an example: "Darius waging war in Scythia receives from the King of Scythians a frog, a bird, a mouse, and five arrows: the Herald transmits his gift in silence and departs. This terrible harangue was understood, and Darius found nothing more urgent than to get back to his country as best he could. Substitute a letter for these signs, the more it threatens the less it frightens; it is mere bluster at which Darius would simply have laughed" (EoL I, 249). There is thus something original about communicating in the figurative, interpretive, and mythic mode. It is the aforementioned Warburton who cites the fable about Darius to demonstrate that the first language was a mode of expression in which "thoughts by action perfectly coincided with that of recording them by picture... [and that the purport of the story] was, we see, expressed by a composition of action and picture." 2

This forms the basis of Warburton's account of the origin of language, which is entirely imagistic. Focusing on hieroglyphs, Warburton claims that pictorial language corresponds to the communication of things, whereas alphabetical, or lettered, communication is always 
only the communication of words (Divine Legation IV, 402). The general history of writing is then "a gradual and easy descent from a picture to a letter." There is such a concurrence in the first forms of communications throughout history and across cultures, Warburton claims, that this "method of recording the thoughts, can never be supposed the effect of chance, imitation, or partial purposes; but must needs be the uniform voice of nature" (405). The first languages were "equivocal" (405), and were a mixed discourse "of words and actions," both insofar as the language moved people and communicated movement in its imagistic presentation of actions.

The originality of pictorial representation (as in hieroglyphs) maps for Warburton onto an argument about the originality of figurative expression more generally. The use of pictures to communicate came to be transformed into the use of fables, into parables, and finally into metaphorical relations. Examples abound, Warburton claims, to demonstrate that all "common people are always most given to speak in figures" and that figurative expression results from "gross conception[s] met with a warm imagination which delight[s] in painting strong and lively images" (445-46). ${ }^{3}$ Hieroglyphs were, Warburton wants to demonstrate, not initially a 'secret' and mysterious code, but part of a language that spoke to common people through imagistic communication - the "uniform voice of nature." This was thus, he claims, a common and "political alphabet" (440).

Like Warburton, Rousseau claims that the first language was one of "images" and "figures" (EoL, 255); it was figurative and its first expressions were tropes (EoL, 254). It was a kind of poetic living painting (this phrasing is borrowed from Jaucourt), or - in the words of Warburton - a "speaking hieroglyphic" that is the universal voice of nature. This is the language that can persuade without convincing; 
that can move - and move us - without requiring demonstration. But how? And to what end?

I will conclude with presenting an account of how Rousseau sees this imagistic persuasion functioning in his political theory. To remind us of the stakes of this consideration: it is Rousseau's claim in the Social Contract that the legitimate state must have a Lawgiver, or Legislator, who can persuade without convincing. This has led commentators to speculate about what this form of communication might look like: one which Rousseau claims speaks to the heart of the citizens, and is the secret occupation of the lawgiver. This form of persuasion will change human nature and transform each individual. It is, in fact, in this very section of the Social Contract that Rousseau cites Warburton in the main body of the text, concluding his discussion of the lawgiver by invoking Warburton's arguments about the usefulness of religion for politics (SC II.vii.193-94). The temptation here is to merely affiliate Rousseau's account of Lawgiving with Warburton's arguments about Moses himself (the subject of much of Warburton's volumes); but Warburton's own arguments about theological-religious power are grounded in his account of the imagistic origins of language.

I want to return here to the example Rousseau employs in the Essay to explain what he means in claiming that the first language would have been figurative. He presents us with an account of men who, when they did not understand what they saw as similar to them, called other men Giants. This is demonstrative not only of the original manner in which language was employed at the service of the passions (fear of others), but also of the fact that figurative language is original insofar as it is founded on difference. We provide figurations to ourselves of things that we do not understand, and that we do not see as similar to us. It is this capacity to imagine outside of ourselves that 
ties the origin of language to the origin of society for Rousseau. Figurative language is prior to other forms of communication precisely because our conceptions of those things outside of ourselves must begin as illusory images: they are mythic to our own understanding. To see things in their genuine form, Rousseau claims, we must begin with seeing them in images - and they present themselves to us as images of difference, representing our passions.

Rousseau claims in the Second Discourse that we have found ourselves in a position in which we no longer know ourselves: "the most useful and the least advanced of all human knowledge appears to me to be that of man; and I dare say that the inscription on the Temple of Delphi [know thyself] alone contained a precept more important and more difficult than all the hefty books of the moralists... Since all the progress of the human species continually moves it further from its primitive state, the more we accumulate new knowledge, the more we deprive ourselves of the means of acquiring the most important knowledge of all, and it is, in a sense, by dint of studying man that we have rendered ourselves incapable of knowing him" (SD 51-52). It is, thus, our reason, and our studying, for Rousseau that has made us incapable of knowing ourselves: we have become convinced that we know what is good for us, only to subject ourselves to miserable conditions and political inequalities. We must thus be persuaded that we do not know ourselves as well as we think we do. For this, Rousseau employs the very language of persuasion upon which he elaborates in the Essay on the Origin of Languages, inspired by Warburton's "lively images." Rousseau presents to us a living painting that communicates the universal voice of nature in its 'original': the image, or figuration, of natural man. Rousseau concludes the Second Discourse placing savage and civilized man in such stark contrast that he claims they "differ so much in the bottom 
of their hearts and inclinations that what constitutes the supreme happiness of the one would reduce the other to despair" (SD 116). "Original man" is our natural condition, and we can only be persuaded of this if we are presented with the illusory image of how different we are from ourselves.

This discourse, for Rousseau, can only serve to persuade if it does not attempt to convince. It is a corrective to the lack of poetic language in modernity, which Rousseau phrases too as a corrective akin to the damage done in Ancient Greece through the turn to philosophy and Sophistry (that is, reason and rhetoric): "in cultivating the art of convincing, the art of moving was lost" (EoL XIX, 296). Thus we are provided with an image of ourselves - as naturally free and equal that will move our hearts before it shapes our minds. To be persuaded without being convinced, then, is not a nefarious fascistic enterprise. It is at the foundation of coming to know who and what we are as linguistic and political (human) beings. Indeed we now hold as true and self-evident that we are free and equal, which according to (or because of) Rousseau we must acknowledge to be an image or figuration. Contrary to our condemning Rousseau's politics because of his seeming rejection of truth, however, we need to see that this same figurative foundation is precisely what gives it its power to inspire people to act: that it is an image of what we are not and what we would perhaps wish to be. The ground of the Social Contract, in its liberal iterations as well as in its fascistic ones, is a fable about the human being that has served to persuade and move people politically. For Rousseau we can only represent ourselves this way if we wish to seek our own origins; we are by nature only what we persuade ourselves to be. 


\section{Notes}

${ }^{1}$ Citations from the Essay on the Origin of Languages are from Jean-Jacques Rousseau, The Discourses and Other Early Political Writings, ed. Victor Gourevitch (Cambridge: Cambridge University Press, 2007 [1997]). The French has also been consulted. Hereafter cited in text as EoL. Rousseau claimed that the Essay was a long extract that he had pulled from the Second Discourse (SD), which was completed in 1754. Scholars feel comfortable placing the completion of the Essay at around the time of Emile's publication in 1762. I will agree with John Scott that regardless of the often debated discrepancies that exist between the tales told in the Essay and in the Second Discourse, "the essay belongs to the philosophical project of the Second Discourse" (Scott, "Rousseau and the Melodious Language of Freedom," Journal of Politics 59 (3) [1997]: 806).

${ }^{2}$ William Warburton, The Divine Legation of Moses Demonstrated, in The Works of the Right Reverend William Warburton (London: J. Nichols, 1788 [1738-41]), Volume IV, 409. As was previously discussed, Warburton's work on hieroglyphs was translated into French in 1744 by Léonard des Malpeines as the Essai sur les hiéroglyphes des Égyptiens. This was a translation of Volume IV. In all cases when I am citing the English I have consulted the French to confirm continuity; so too have I restricted myself to the portions that also appeared in French translation. If and when there is an addition or discrepancy (as above), I have noted it.

${ }^{3}$ Here too we have another coming together of picture and sound, when Warburton claims that sounds in primitive languages would "incite the idea of the thing, sometimes as its audible image, sometimes as its natural representative" (Divine Legation of Moses, vol. IV, 440; my emphasis). 


\section{A Few, But Really Determined Women and Men Can Make a Difference - Even Today: Lessons from Fiume after the Summer of 1919}

Haimo Schulz Meinen

Institute of Sociology, University of Hannover, Germany

\section{Introduction}

Can a "few, but really determined women and men really make a difference"? The lessons from Fiume (Adria) after the Summer of 1919, as this contribution was originally entitled, set out to deal with another aspect of forming a polis, city and nation, will tell us. I will follow the historical example before addressing the mobilization of modern determined people engaging in urban communities.

A hundred years ago, the Italian fin-de-siècle poet Gabriele D'Annunzio invented and powerfully illustrated how, after the summer of 1919, a city with a population of 40,000, enlarged by volunteers from the rest of Italy and hundreds of inspired people from abroad, was transformed by him into a a vibrant, thrilling multitude, partially turned into hippies, incited musically and by virtue of the use of free drugs, and became a politicalized commune and a precursor of several developments in the following 100 years. Heroic speeches from the balcony, rhythmic war cries, black shirts with skull and crossbones and specific salute forms as well as a very modern constitution of a republic were used to successfully create an allembracing feeling of difference. Everybody in the then occupied Fiume (today Rijeka, in Croatia) was urged to endorse the mission, his mission. Drawing on diverse elements of art, literature, political rhetoric, military talent and inventing modern propaganda, D'Annunzio with some colleagues set the path to what today has to be 
considered a mobilized public, which at least pretended to be a democratic republic. Being opposed to the then leading powers of the world turned out to be helpful in this effort of mobilization.

Situated on the hilly, sunny and bright Adriatic coast that opens to the southwest, the small harbor town of Fiume, with its many old imperial styled classical buildings with very high ceilings, had a vivid past as the Austrian imperial harbor St. Veit am Flaum, and a splendid future. 40,000 people, of whom maybe a small majority were Italian, some Austrian-Germans, and many Croatian speakers, inhabited it, the second free port declared by the Austrian emperor after Trieste in the 18th century. As such, "Fiume was a port of considerable strategic importance. By the time of the outbreak of the Great [First World] War, it was the major hub for the railroad lines leading to Belgrade, Prague, Budapest, and Zagreb, and was the natural outlet for commerce flowing between theses cities and the West." ${ }^{1}$ While today $90 \%$ of all products are shipped in containers, in the past, thousands of harbor men in Fiume had to lift goods by crane to unload the 8,000 ships per year (1913), products worth 650 million Kronen. Up until 1914, Fiume under the German name of "St. Veit am Flaum," was the most important harbor for the second largest (surface) power of Europe, the Habsburgian Empire of Austria and Hungary. 2,000 harbormasters not only had medical and retirement plans, but also flats and houses with views of the sea and a private toilet, a luxury that in Italy only thirty years later would become the standard.

I turn now to a summary of the D'Annunzian adventure in Fiume as told by Lucy Hughes-Hallet, who together with Michael A. Ledeen has led the English-language research on the topic.

“On September 12, 1919, Gabriele D'Annunzio together with 2500 deserted soldiers annexed the dalmatian harbor city of Fiume 
(Croatian: Rijeka). In a dramatic manor 'The Poet' intervened in the peace talks in Paris, where Italian representatives kept on trying in vain to make the confidential agreements from before the war a postwar reality. Italy had been promised territorial expansions on the Dalmatian coast. This was the moment an endless debauchment in Fiume started. A state of exception was in charge turning everything upside down: war, politics, law, the hearts and the sensations.

D'Annunzio would become Fiume's Duce and dictator, in defiance of all the Allied powers. Gabriele D'Annunzio was a man of vehement, but incoherent, political views. As the greatest Italian poet, in his own (and many others') estimation, since Dante, he was il Vate, the national bard. He was a spokesman for the irredentist movement, whose enthusiasts wished to regain all the territories which had once been, or so they claimed, Italian, and which had been left irredenti (unredeemed) when Italians liberated themselves from foreign rulers in the previous century. His overt aim in coming to Fiume had been to make the place, which had a large Italian population, a part of Italy. Within days of his arrival it became evident this aim was unrealistic. Rather than admitting defeat, D'Annunzio enlarged his vision of what his little fiefdom might be. It was not just a patch of disputed territory. He announced that he was creating a model city-state, one so politically innovative and so culturally brilliant that the whole drab, war-exhausted world would be dazzled by it. He called his Fiume a "searchlight radiant in the midst of an ocean of abjection." It was a sacred fire whose sparks, flying on the wind, would set the world alight. It was the "City of the Holocaust."

The place became a political laboratory. Socialists, anarchists, syndicalists, and some of those who had begun, earlier that year, to call themselves fascists, congregated there. Representatives of Sinn Fein and of nationalist groups from India and Egypt arrived, 
discreetly followed by British agents. Then there were the groups whose homeland was not of this earth: the Union of Free Spirits Tending Towards Perfection who met under a fig tree in the old town to talk about free love and the abolition of money, and YOGA, a kind of political-club-cum-street-gang described by one of its members as "an Island of the Blest in the infinite sea of history."

D'Annunzio's Fiume was a Land of Cockaigne, an extra-legitimate space where normal rules didn't apply. It was also a land of cocaine (fashionably carried in a little gold box in the waistcoat pocket). Deserters and adrenalin-starved war veterans alike sought a refuge there from the dreariness of economic depression and the tedium of peace. Drug dealers and prostitutes followed them into the city: one visitor reported he had never known sex so cheap. So did aristocratic dilettantes, runaway teenagers, poets and poetry lovers from all over the Western world.

Fiume in 1919 was as magnetic to an international confraternity of discontented idealists as San Francisco's Haight-Ashbury would be in 1968; but, unlike the hippies, D’Annunzio's followers intended to make war as well as love. They formed a combustible mix. Every foreign office in Europe posted agents in Fiume, anxiously watching what D'Annunzio was up to. Journalists crammed the hotels. D'Annunzio was already a bestselling novelist, a revered poet, and a dramatist whose premieres were attended by royalty and triggered riots. Now he boasted that in Fiume he was making an artwork whose materials were human lives. Fiume's public life was a non-stop street-theatre performance. One observer likened life in the city to an endless fourteenth of July: 'Songs, dances, rockets, fireworks, speeches. Eloquence! Eloquence! Eloquence!' [...] For over a year it suited none of the great powers to bestir themselves to eject him, but when, eventually, an Italian warship arrived in the harbor and bombarded 
his headquarters, he capitulated after a five-day fight. But for the duration of his command, Fiume was - precisely as he had intended it should be - the stage for an extraordinary real-life drama with a cast of thousands and a worldwide audience, one in which some of the darkest themes of the next half-century's history were announced." An important role was played by Guido Keller (1893-1929), the closest friend of D'Annunzio, who died in a car accident. Prior to his death, and in a state of depression, he had requested permission from Mussolini to be exiled to China or to South America as he didn't feel needed anymore. ${ }^{3}$

"The second paragraph of the new constitution stated: "The Republic of Carnaro is a direct democracy that has productive labor as its base and the largest possible functional and local autonomy as its governing principle. It confirms, therefore, the collective sovereignty of all citizens, without regard to sex, race, language, class, or religion; but it recognizes major rights to the producers and decentralizes the power of the state as much as possible, in order to assure the harmonious blending of the elements that form it."

Using the Fiuman adventure for a thought experiment can perhaps throw light on recent forms of political units. If we focus on how a small group of people intentionally changed the politics of a region for quite some time and successfully opposed all leading world powers for 20 months, we can learn a great deal.

What does "determined" mean? It can mean the following: survivors and families of the victims of the February 14, 2018, shooting at Marjory Stoneman Douglas High School in Parkland, Florida. Together, they called for changes that would prevent a similar tragedy from recurring. They confronted their lawmakers. They rallied others to their cause. And then they took to the streets of Washington, DC, to 
put on the March For Our Lives and make impassioned pleas for reform and declare, "Never Again."

Gun safety advocates say their success is perhaps best illustrated by the legislation passed in different states across the country last year: 137 new gun safety bills have been signed into law enacted by both Republican and Democratic legislators in 32 states and Washington, DC, according to a year-end report by the Giffords Law Center to Prevent Gun Violence. ${ }^{4}$ Among them: Emma Gonzàlez, from Parkland, Florida, born in 1999, and Naomi Wadler, from Washington DC, born in 2007. To them I will add Greta Thunberg, from Stockholm/Sweden, born in 2003; Carola Rackete, from Germany, born in 1988. And Edward Abbey, from Indiana, Pennsylvania, 1927-1989. In my thought experiment, I will put these four girls and women together with the old seasonal park ranger and author Edward Abbey into the scene of Fiume, as a modernized and more feminine Rat Pack, in memory of the five guys around Frank Sinatra in Las Vegas shows in the 1960s (Sinatra, Dean Martin, Sammy Davis junior, Joey Bishop and Peter Lawford).

Captain Carola Rackete from Germany, like D’Annunzio exactly 100 years before, opposed the commands of the Italian government and contributed to raising an opposition that finally led to a movement called "Sardines," rallying the courts and places in Italy against rightwing populism in Italy. ${ }^{5}$ "By the way in which she triggered in less than half a week so many donations for her organization Sea Watch, which helps drowning migrants, that her organization could have bought several new vessels. ${ }^{6}$ She confronted Matteo Salvini, Minister of the Interior and since 2013 party chairman of the right-wing Lega, who has called her a 'rich and spoiled communist'."7 Rackete was released when an "Italian judge ruled ... that Carola Rackete had not broken the law when she refused to obey warships attempting to keep 
her away from docking on the Italian island of Lampedusa last weekend. Rackete had defied an order from Rome that blocks migrant ships from coming ashore when she brought 40 migrants aboard the Sea-Watch vessel into port." "It wasn't an act of violence, but only one of disobedience," Rackete told Italian newspaper Corriere della Sera in an interview... "The situation was desperate ... my goal was only to bring exhausted and desperate people to shore." "I know what I'm risking," Rackete said at the time. ${ }^{8}$ Later in 2019 , she published a book, "Acting instead of Hope: Calling to the Last Generation."

American gun-control-activist Emma Gonzalez, whose "We call it B.S." speech has made it into a 2019-Madonna song ("I rise"), powerfully opposed U.S .President Donald Trump and the even more powerful arms lobby National Rifles Association, NRA. Gonzales, as a student survivor of the February 14, 2018, shooting at Marjory Stoneman Douglas High School in Parkland, Florida, publicly revealed that the U.S. President had been paid by the arms lobby. "Emma Gonzalez's name was trending on Twitter for much of the afternoon as she took on President Trump, the National Rifle Association, politicians and every argument against tightening gun laws, starting a chant of "shame on you!" in the crowd of hundreds at the rally in Fort Lauderdale, Florida. The deaths of 17 students and faculty at Marjory Stoneman Douglas High School in Parkland, Forida, on Wednesday has started the familiar debate on gun laws after a mass shooting but what's different is students are leading the charge and becoming a powerful voice." 10

Gonzalez recalled a core democratic principle of the people who are left alone by their representatives and take action into their own hands: "Every single person up here today, all these people should be home grieving. But instead we are up here standing together because if all our government and President can do is send thoughts and 
prayers, then it's time for victims to be the change that we need to see."11

Naomi Wadler, born in 2007, added in her memorable speech in Washington D.C. at the March For Our Lives on March 25, 2018, in front of an audience of more than 100,000 against racial discrimination, 12 "To honor the girls, the women of color who are murdered at disproportionate rates in this nation."13

The success of Greta Thunberg (b. 2003) in 2018 and 2019, named "Person of the Year 2019" by Time magazine, is hardly comprehensible without this previous rally of US-American teenagers. ${ }^{14}$ Thunberg, who stopped going to school on Fridays in autumn 2018, and demonstrated in front of the Swedish Parliament calling for action against climate change, soon had thousands of followers all around the globe.

And finally, author, novelist, and essayist Edward Abbey (1927-1989) is the only male and dead person in this selection. But as having provoked much of the Deep Ecology Movement whose impact on modern traditional economic growth politics ${ }^{15}$ hasn't been fully understood, ${ }^{16}$ I judge him to be one of the precursors of climate activism, civil disobedience, mistrust of government and empowerment of the marginalized: "The duty of a patriot is to protect his country from its government." "Power is always dangerous. Power attracts the worst and corrupts the best." "Abbey preached against trashing the planet, "but with a raffish panache that unsolemnizes his jeremiads." 17

Now imagine Gonzalez, Wadler, Rackete, Thunberg, and Abbey appearing on the balcony of Fiume's governmental palace. Rackete pretty soon will be adopted by D'Annunzio's action secretary Guido Keller and his bureau for hand strikes, "Ufficio colpi di mano," in the 
section of the "Uscocchi," pirates on the Mediterranean that were harvesting vessels to deliver food and weapons for the people in Fiume.

Gonzalez, Wadler, and Thunberg will take classes on rhetoric with D'Annunzio. Gonzalez ("Shame on you!," "We call it B.S.!") and Thunberg ("How dare you!") will discuss chants. Wadler will draw to the League of Fiume where, like in an alternative United Nations, the league of the oppressed and marginalized peoples act for the benefit of others. Each of them will get a baseball club, keep it at hand and show it to D'Annunzio to prevent false ideas. Abbey, in turn, will walk with Keller and his eagle, naked or with clothes, to investigate the countryside.

The crowd will roam every day, enjoy the music of the bands walking by, listen to the speeches and build up a true urban republic where music, art, culture, and respect will guarantee the rights of all citizens.

\section{Notes}

\footnotetext{
${ }^{1}$ Michael A. Ledeen, The First Duce: D'Annunzio at Fiume (Baltimore, MD: Johns Hopkins University Press, 1977), 17.

${ }^{2}$ Lucy Hughes-Hallett, The Pike: Gabriele D'Annunzio - Poet, Seducer, and Preacher of War (London: Anchor, 2014), 4-5.

${ }^{3}$ Bettina Vogel-Walter, "Guido Keller - Mystiker des Futurismus," in Hans Ulrich Gumbrecht (Hrsg.), Der Dichter als Kommandant. D'Annunzio erobert Fiume, (München: Wilhelm Fink, 1996), 117-32, 132. ${ }^{4}$ https://giffords.org/blog/2019/12/year-end-trendwatch-states-surpass-previous-years-progress-in-2019blog/; (accessed 24/12/2019).

${ }^{5}$ https://www.nytimes.com/2019/12/14/world/europe/italy-sardines-salvini.html (accessed 24/12/2019).

${ }^{6}$ Malene Gürgen, Patricia Hecht, Nina Horaczek, Christian Jakob, Sabine am Orde, Angriff auf Europa. Die Internationale des Rechtspopulismus (Berlin: Christoph Links Verlag, 2019), 244.

${ }^{7}$ https://www.thelocal.it/20190705/sea-watch-captain-carola-rackete-sue-matteo-salvini-defamation-italy; (accessed 24/12/2019).
} 
${ }^{8}$ https://edition.cnn.com/2019/07/02/europe/carola-rackete-released-migrant-ship-italy-intl/index.html; (accessed 24/12/2019).

${ }^{9}$ German captain of rescue ship Sea Watch 3 and Extinction Rebellion activist Carola Rackete attended a news conference to introduce her book Handeln statt hoffen: Aufruf an die letzte Generation (Acting instead of hope: Calling to the last generation) in Berlin, October 30, 2019.

https://pictures.reuters.com/archive/GERMANY-RACKETE—RC1DE186E480.html; (accessed 24/12/2019).

${ }^{10} \mathrm{https} / /$ eu.usatoday.com/story/news/2018/02/17/student-emma-gonzalez-school-shooting-givespassionate-speech-against-g/348357002/; (accessed 24/12/2019).

${ }^{11}$ Sarah Lerner, ed., Parkland Speaks: Survivors from Marjory Stoneman Douglas Share their Stories (New York: Penguin Random House, 2019).

${ }^{12} \mathrm{https}$ //www.washingtonpost.com/local/march-for-our-lives-huge-crowds-gather-for-rally-against-gunviolence-in-nations-capital/2018/03/24/4121b100-2f7d-11e8-b0b0-f706877db618_story.html; (accessed 24/12/2019).

13 "I am here today to represent Hadiya Pendleton. I am here today to represent Taiyania Thompson who, at just 16, was shot dead in her home here in Washington DC. I am here today to acknowledge and represent the African American girls whose stories don't make the front page of every national newspaper, whose stories don't lead on the evening news. I represent the African American women who are victims of gun violence, who are simply statistics instead of vibrant, beautiful girls full of potential." https://amysmartgirls.com/read-naomi-wadlers-11-yrs-full-speech-from-march-for-our-lives-dce729940f30be; (accessed 24/12/2019).

${ }^{14}$ Carolyn Kormann, "The Pure Spirit of Greta Thunberg is the Perfect Antidote to Donald Trump," The New Yorker, 13/12/2019, https://www.newyorker.com/news/news-desk/the-pure-spirit-of-greta-thunbergis-the-perfect-antidote-to-donald-trump; (accessed 24/12/2019).

${ }^{15}$ Haimo Schulz Meinen, "Einstellungen Jugendlicher zur Natur. Chancen der Deep ecology als Millenarismus" (Attitudes of youths towards nature: Chances of deep ecology as Millenialism) (MA diss., University of Hannover, Germany, 1995).

16 "The theoretical and practical contributions of deep ecology to today's Green politics are apparent in the groups such as Earth First!, as well as movements such as Extinction Rebellion." Peter Newell, "Deep Ecology,” in Global Green Politics (Cambridge: Cambridge University Press, 2020), 43-48, 46.

${ }^{17}$ Lawrence Buell, The Environmental Imagination:Thoreau, Nature Writing, and the Formation of American Culture (Cambridge, MA: Harvard University Press, 1995), 300, quoted in Paul Lindholdt, Rage Against the Machine: Edward Abbey and the Neo-Luddite Thought, in Peter Quigley, Coyote in the Maze: Tracking Edward Abbey in a World of Words (Salt Lake City: The University of Utah Press , 1998). 


\section{Rootedness and National Identity in the 21st Century}

Luma Simms

Ethics and Public Policy Center, Washington, DC, USA

\section{Introduction}

Historically, the thing known as national identity - what makes one nation different from another and creates solidarity between a people that they can be called a people - is attachment to several elements: common history, place, that is, land, culture, language, religion, traditions, civilizational memory, a variety of institutions particular to that nation, and more often than not, blood, that is, ancestry. Unity over form of government - that is, a "social contract," or as John Jay put it in Federalist Number 2, "attach[ment] to the same principles of government"1 - has not historically been a defining element of national identity in itself. More often than not, the other elements of shared identity are what allows a people to form, submit to - or endure - their government.

But is attachment to the same principles of government itself enough to hold people together? Does unity over a form of government rise to what we have hitherto defined as national identity? Could it be that we can have different languages, different religions, different values, different ideas of what is right and wrong, what is good or bad for society, and still be a nation as long as we are attached to the same principles of government? And does this way of looking at it not imply that the intellect, and an assent to an idea, takes precedence over every other element of human attachment? That is, that ideas rationality - are superior to all other qualities of the human person? That is a question for another essay I hope to get to in the future. 


\section{Identity Crisis}

The recent populist movements in Europe, the United States, and elsewhere in the West, indicate at the very least, a discontent with the status quo style of governing, that is, they are discontented with their politicians answering "yes" to that question that I just raised when they sense in their very lives that that is not enough. At the heart of this national and international disquiet is an existential homelessness; people don't know who they are, to whom and where they belong - this is an identity crisis that is experienced both individually, as people themselves are having an identity crisis, and collectively. Here I want to focus on national identity and rootedness, for there are those who want to erase them, and those who long to reespouse them.

National identity eroded in conjunction with the growth of democratic society that supplanted the elements of the traditional society. As nations grew and developed towards their democratic ideals, they shed the traditional and historic ways of how humans function in a society.

Alexis de Tocqueville in his magnum opus, Democracy in America, devotes most of of Volume 2 to demonstrate the differences between a democratic society and what he calls the "aristocratic society," what I call here traditional society. We will trace what has increased and what has decreased in democratic societies according to Tocqueville's predictions. And we will see that the deterioration of the elements which constitute national identity (and individual identity as well) have caused the sense of rootlessness in those societies, and that this has been lubricated through the weakening and supplanting of traditional society by late-stage democratic society. 
What has increased is the atomization of society driven by an increase in individualism (these in turn have increased mobility and a restive spirit); we have also seen an increase in what Tocqueville calls extreme equality, what today we call radical egalitarianism, as well as unlimited liberty. These work against rootedness and identity. They do so because as the characteristics of late-stage democracy increase, they decrease the characteristics of the traditional society such as the strong and meaningful hierarchical structures of institutions, loyalty and obligation, unchosen relationships, parental authority and the value of the family, common customs and culture, attachment to physical geographical places, the value of, and attachment to, religious institutions. It is these elements of the traditional society that contribute to rootedness and identity.

In traditional societies people are linked by the bonds of loyalty and obligation, that is, unchosen bonds come before chosen bonds; people depend on one another. Roles are expected and respected: husband, wife, mother, father, son, daughter, grandfather, grandmother, teacher, priest, Rabbi, and so on. These are all unchosen organic relationships, and in a traditional society they engender loyalty and obligations.

Because of their mutual reliance and connection, people are bound to each other and are conscious of their ancestors and descendants, and man "willingly does his duty by both," writes Tocqueville, "sacrific[ing] his personal enjoyments for beings who no longer exist or who do not yet exist." In a traditional society, "a man almost always knows his ancestors and respects them; he believes he already perceives his great-grandsons and he loves them." That kind of vision affects a man's actions in the moment. "Aristocracy had made of all citizens a long chain that went from the peasant up to the king; democracy breaks the chain and sets each link apart," he writes. "Men who live in aristocratic centuries [traditional societies for our purposes] are 
therefore almost always bound in a tight manner to something that is placed outside of them, and they are often disposed to forget themselves." 2

Contra the democratic society where man does not forget himself, but rather by excessive egotism is rendered unmoored, isolated, and lonely - untethered from his past, and (barring some personal choice) unconcerned for his progeny. Tocqueville tells us that, "amidst the continual movement that reigns in the heart of a democratic society, the bond that unites generations is relaxed or broken; each man easily loses track of the ideas of his ancestors or scarcely worries about them" (483).

\section{Equality and Individualism}

This happens in a democratic society for several reasons, but Tocqueville tells us that there are two primary driving engines that debase the value of family ties and make it easier to loosen family bonds, as well as bonds between the citizens of a society: equality and individualism. Equality makes it so that "each man seeks his belief in himself," while individualism makes a man turn "all his sentiments toward himself alone" (482). These of course are ultimately driven by an unchecked democratic spirit which sets the locus of authority over what is the truth and what is not the truth in the individual human person; not an authority outside the self. Thus the locus of all authority rests in the self.

Contrasting individualism with plain old selfishness, Tocqueville writes: "Individualism is a recent expression arising from a new idea. Our fathers knew only selfishness." And he continues: "individualism proceeds from an erroneous judgment rather than a depraved sentiment. It has its source in the defects of the mind" (482). 
Furthermore, "individualism at first dries up only the source of public virtues; but in the long term it attacks and destroys all the others and will finally be absorbed in selfishness." "Selfishness is a vice as old as the world. It scarcely belongs more to one form of society than to another"; while "Individualism is of democratic origin, and it threatens to develop as conditions become equal" (483). And these two qualities - individualism and extreme equality - in combination, become toxic to family, religion and the entire society.

The primary driver against hierarchy, differentiation, and exclusion three crucial elements of strong institutions - is the insatiable desire for equality. Tocqueville discusses the ardent love for equality in democratic societies, and points out that it is even greater than the love for freedom:

Democratic peoples love equality at all times, but in certain periods, they press the passion they feel for it to delirium. This happens at the moment when the old social hierarchy, long threatened, is finally destroyed after a last internecine struggle, and the barriers that separated citizens are finally overturned. Then men rush at equality as at a conquest, and they become attached to it as to a precious good someone wants to rob them of. The passion for equality penetrates all parts of the human heart; there it spreads and fills it entirely. Do not say to men that in giving themselves over so blindly to an exclusive passion, they compromise their dearest interests; they are deaf. Do not show them that freedom escapes from their hands while they are looking elsewhere; they are blind, or rather they perceive only one good in the whole universe worth longing for. (481) 
Driven by this insatiable desire for equality, coupled with unchecked individualism, democratic man destroys the very associations he needs to form his identity, understand himself, and the world around him. All these forces work against one another. People are isolated and disengaged, their soul has needs and craves formation, but the very presuppositions they live under work against the very institutions that could give these souls what they need. "This sort of equality," Simone Weil wrote, "if allowed full play by itself, can make social life fluid to the point of decomposing it."3

Attachment to the land is yet another element democratic society has diminished. Alexis de Tocqueville reminds us that: "In aristocratic peoples, families remain in the same state for centuries, and often in the same place" (483). Why? Because traditional societies value rootedness, they are historically minded and remember that the human person flourishes when he is known, when he knows who he is, and to whom and where he belongs. "Know thyself" the ancient Greeks warned and inscribed on the temple portal at Delphi. Tocqueville writes this of Americans:

In the United States, a man carefully builds a dwelling in which to pass his declining years, and he sells it while the roof is being laid; he plants a garden and he rents it out just as he was going to taste its fruits; he clears a field and he leaves to others the care of harvesting its crops. He embraces a profession and quits it. He settles in a place from which he departs soon after so as to take his changing desires elsewhere. Should his private affairs give him some respite, he immediately plunges into the whirlwind of politics. And when toward the end of a year filled with work some leisure still remains to him, he carries his restive curiosity here and there within the vast limits of the United States. He will thus go five hundred leagues in a few 
days in order better to distract himself from his happiness.... This spectacle is, however, as old as the world; what is new is to see a whole people show it. (512)

Why did this happen to a whole people? For several reasons, Tocqueville writes: "The taste of material enjoyments," the result of a heart bent on "the goods of this world," is a man who is "always in a hurry," his soul is kept "in a sort of unceasing trepidation that brings him to change his designs and his peace at every moment." This sets up the overall cultural climate of the land. He continues, "if a social state in which law or custom no longer keeps anyone in his place is joined to the taste for material well-being, this too greatly excites further restiveness of spirit: one will then see men change course continuously for fear of missing the shortest road that would lead them to happiness" (512).

Many in the modern world turn up their noses at the idea of attachment to land or the obligation to stay in one place; we do so because we discount the need of the human soul for geographic roots. And we have so reduced the idea of national identity to fascist ideology, that we can no longer see clearly all the elements a person needs to live harmoniously in this world.

\section{Rootedness}

The link, the tether between the elements which constitute identity, and identity as such, is rootedness. And yet modern man boasts that he has transcended the need for roots. But we have not, as we see from the disquiet of people throughout the West.

"To be rooted is perhaps the most important and least recognized need of the human soul... Every human being needs to have multiple roots. It is necessary for him to draw well nigh the whole of his moral, 
intellectual, and spiritual life by way of the environment of which he forms a natural part," ${ }^{4}$ so wrote Simone Weil. I see rootedness as something due to every human being, as part of their human dignity. Without it, man is cut off from the very elements which make him who he is - his identity.

What is rootedness? Rootedness - think of the roots that shoot out from a plant and embed themselves into the soil; they multiply to such a degree that there comes a point where it's difficult to distinguish between the multiplicity of roots and the soil. And when a plant is plucked up and replanted, often the roots are left behind, and the plant may or may not grow well in the new soil. Hence rootedness is the combination of bonds (like all those roots that plunge themselves into the soil and grow and multiply) that attach the person to his or her environment: family, religion, culture, language, physical land, and heritage. There are other elements as well like music and dance which we usually think of under the rubric of culture. And in our modern arrogance we have forgotten that the variety of soils are not always interchangeable, there is a fittingness.

Hannah Arendt, Simone Weil and others bemoaned the mass uprootedness due to war during the early part of the $20^{\text {th }}$ century. Exacerbated by globalization, the disease of uprootedness is in a malignant state across our world today in the $21^{\text {st }}$ century. Echoing Tocqueville, Weil writes that "there are two poisons at work spreading this disease." One of them is money. "Money destroys human roots where it is able to penetrate, by turning desire for gain into the sole motive."5 Recall from above Tocqueville's warnings about man attaching himself to the goods of this world, to which he adds: "the taste for material enjoyments must be considered as the first source of this secret restiveness revealed in the actions of Americans and of the inconstancy of which they give daily examples" (512). When we 
combine a heart bent on the goods of this world, the primacy of the individual, and a societal structure which makes it easy for the individual to get up and move, we find the acute state of the disease of uprootedness.

The second poison spreading the disease of uprootedness that Simone Weil mentions is modern education. She sees in it a stifling and restrictive culture of education, "influenced by technical science, very strongly tinged with pragmatism, extremely broken up by specialization, entirely deprived of both contact with this world and, at the same time, of any window opening on to the world beyond." 6 In short, it is an education untethered from the metaphysical. This kind of education fills the student with facts but severs him from his surroundings, thereby uprooting him.

Weil also addresses the way the disease of uprootedness affects the working class, she writes:

Although they have remained geographically stationary, they have been morally uprooted, banished and then reinstated, as it were on sufferance, in the form of industrial brawn. Unemployment, is of course, an uprootedness raised to the second power...There is something woefully wrong with the health of a social system, when a peasant tills the soil with the feeling that if he is a peasant, it is because he wasn't intelligent enough to become a schoolteacher. ${ }^{7}$

"To be uprooted," Hannah Arendt writes in The Origins of Totalitarianism, "means to have no place in the world, recognized and guaranteed by others." 8 That place includes, but is not limited to geography. But by virtue of roots, Simone Weil writes, we have "real, active and natural participation in the life of a community which preserves in living shape certain particular treasures of the past and 
certain particular expectations for the future." ${ }^{\circ}$ But losing the elements of the traditional society - a common history, place, culture, language, religion, traditions, civilizational memory, and institutions results not only in the breakdown of our political and social institutions, but in the uprootedness of the individual or of an entire people. The elements I laid out above provide the very conditions for this participation, but without them, a person is deprived of participating in the life of the community. Uprootedness is that deprivation.

Tocqueville believed, and I'm too convinced, that only religion and family, as institutions, and as elements of traditional society, can make democracy sustainable. In the encyclical Centesimus Annus, Pope John Paul II wrote:

Authentic democracy is possible only in a State ruled by law and on the basis of a correct conception of the human person... Nowadays there is a tendency to claim that agnosticism and skeptical relativism are the philosophy and the basic attitude which corresponds to democratic forms of political life... It must be observed in this regard that if there is no ultimate truth to guide and direct political activity, then ideas and convictions can easily be manipulated for reasons of power. As history demonstrates, a democracy without values easily turns into open or thinly disguised totalitarianism. ${ }^{10}$

The spirit of democracy, unchecked by religious and familial loyalty and obligation, isolates, unmoors and uproots a people. Men of democratic society, unbounded by elements of traditional society, atomized and lonely, feel themselves to be superfluous, and fall into melancholy and madness. In this late-stage democracy, man's ability to act as a citizen breaks down, and "the man will get the better of the 
citizen."11 Having arrived at this state of isolation, loneliness, uprootedness, and superfluousness - the four essential conditions of totalitarianism according to Arendt - and too fatigued to rule themselves, men will ask to be ruled. Arendt writes, "What prepares men for totalitarian domination in the non-totalitarian world is the fact that loneliness, once a borderline experience usually suffered in certain marginal social conditions like old age, has become an everyday experience of the ever-growing masses of our century." 12

We see that national identity receded and the disease of uprootedness spread as the traditional society was supplanted by the democratic society. This uprootedness was driven by an increase in the following elements of the democratic society: atomization driven by individualism, extreme equality, and unlimited liberty. This has happened in direct relation to the decrease in the following elements of the traditional society: hierarchical structures in the institutions of society, loyalty and obligations, unchosen relationships and their value, parental authority and the value of the family, common customs and culture, attachment to physical geographical places, the value of and attachment to religious institutions. So the increase in one drives the decrease in the other, and the decrease of the elements of the traditional society further increases the elements of the democratic society. How do we get national identity back in the $21^{\text {st }}$ century? By getting rootedness back. And how do we get rootedness back? By thickening the elements of the traditional society that work against isolation and loneliness. Every fight for identity, personal or national, is a push against the forces of totalitarianism. The goal is not so that we can return to some bygone age. As Tocqueville wrote, the "democratic revolution... is an irresistible fact against which it would be neither desirable nor wise to struggle" (400). The goal instead is to 
get at a more moderate mix of the two - one better suited for the wellbeing of the human person.

\section{Note}

${ }^{1}$ John Jay, Federalist No. 2, The Federalist Papers (New York: Signet Classics, 2003), 32.

2 Alexis de Tocqueville, Democracy in America, trans. Harvey Mansfield and Delba Winthrop (Chicago: The University of Chicago Press, 2002), 483; hereafter page references are cited in the text.

${ }^{3}$ Simone Weil, The Need for Roots: Prelude to a Declaration of Duties Towards Mankind (New York: Routledge, 2002), 17.

${ }^{4}$ Weil, The Need for Roots, 43.

${ }^{5}$ Ibid., 44

${ }^{6}$ Ibid., 45.

${ }^{7}$ Ibid., 45-47.

${ }^{8}$ Hannah Arendt, The Origins of Totalitarianism (New York: Harcourt, 1985), 475.

${ }^{9}$ Weil, The Need for Roots, 43.

${ }^{10}$ Pope John Paul II, Centesimus Annus (Boston, MA: Pauline Books \& Media, 1991), 67.

${ }^{11}$ J. Hector St. John de Crèvecoeur, Letters from an American Farmer (New York: Dover, 2005), 140.

${ }^{12}$ Arendt, The Origins of Totalitarianism, 478. 
The Bayeux Tapestry: Nationalism before Nations and Globes Marlene K. Sokolon

Department of Political Science, Concordia University, Montréal, Québec, Canada

Contemporary media is full of images depicting the rising tension between the demand to protect "pure" national identities and the opposing view that nations are diverse communities. Debates stress issues of border integrity, citizenship law, and international agreements; yet, nationalism is embedded in the idea of shared history, language, and culture. For this reason, investigating how art can be a "powerful vehicle of cultural memory" is important for understanding nationalistic debates. ${ }^{1}$ Cultural artifacts also provide a unique approach because they offer a multiplicity of meanings that do not expect their audience "to choose one of these [perspectives] as alone correct, but rather to grasp and preserve [several]."2 This paper focuses on an early example of cultural nationalism: the Bayeux Tapestry. Although usually perceived as Norman propaganda, the Tapestry suggests multiple interpretations that undermine this straightforward perspective. ${ }^{3}$ It also reveals the need to remember and reflect on the violence of our political founding. As such, the Tapestry's greatest legacy may be its vision of the plasticity necessary in forging and maintaining the bonds of community identity.

\section{The Bayeux Tapestry}

The Bayeux Tapestry is not really a tapestry, but an embroidered lined strip approximately seventy meters long and fifty centimetres high. ${ }^{4}$ The middle section recounts the main narrative of the events leading to, and during, the Battle of Hastings. It begins with Harold's 
story: his meeting with Edward the Confessor, the journey to Normandy, his ransom by William, and the famous depiction of his oath. A dejected Harold returns to England, but after Edward's death, he is crowned King. At this point, the story shifts to William. After learning of Harold's coronation, William orders a fleet of ships and sails for England where his troops loot the locals and they eat a last supper. The last third of the Tapestry depicts the battle on October 14, 1066. Dressed in elaborately detailed armour, the Norman archers and knights fight the English forces. When all appears lost for William, he rallies his troops and Harold dies.

Although many scholars believe the Tapestry originally ended with an image of William enthroned, it now ends abruptly with the Normans in pursuit of fleeing English. Above and below this main story are borders similar to medieval manuscripts that depict a colorful bestiary of real and imagined animals, trees, plants, symbols, and people farming and hunting. The Tapestry first appears in historical record in the Bayeux Cathedral treasury in 1476. Although previously assumed to be commissioned by William's wife Matilda, most scholars now believe it was made for his half-brother Odo. ${ }^{5}$ Based on the artistic conventions of the iconography, the Tapestry likely was crafted sometime between 1070-75. ${ }^{6}$ Although nothing is known of its intended first audience, the Tapestry is a snapshot of the ideas of nascent nation-building.

\section{Ambiguity I: The Story of Harold and William}

The most crucial events leading up to and during the Battle of Hasting often lack information that leaves the meaning ambiguous. It is possible original viewers knew how to interpret each image. Some ambiguous features may also simply reflect the designer's lack of 
knowledge, especially of private conversations. Yet, many of the images appear deliberately ambiguous. This approach presents a multiplicity of meanings that allows both Normans and Anglo-Saxons to see in the Tapestry their own interpretations of events without requiring a single coherent story presented as the truth. ${ }^{7}$

The first ambiguous scene is the opening image of King Edward sitting on his throne touching an Anglo-Saxon knight. This gesture could represent Edward's intention that Harold offer the throne to William of Normandy. ${ }^{8}$ Yet, by 1064, Edward was losing his powerstruggle with the powerful Harold Godwinson, which makes it unlikely the Earl would undertake such a mission. Another possible interpretation is that Edward is indicating Harold should be careful in his quest to obtain the release of a younger brother and nephew held hostage by William. The captions on the Tapestry are no help: the first states: "King Edward;" and the second proclaims: "[w]herein, Harold, Duke of the English and his soldiers ride on to Bosham."

The famous oath scene also appears purposefully ambiguous. The caption on the Tapestry notes: "[w]hereby Harold made a promise to Duke William." Although French interpreters see this oath as the central event of Harold's journey, they disagree as to the content or where such an oath took place. ${ }^{9}$ William of Poitiers suggests Harold took an oath to act as William's advocate at Bonneville-sur-Touques; other sources place it in Rouen. The Tapestry identifies the location at Bayeux. ${ }^{10}$ Significantly, Anglo-Saxon sources never mention an oath and later sources stress that, as a prisoner, Harold could not swear fealty. The plot also thickens when Harold returns to England. Again, the caption only indicates "he [Harold] came to King Edward." Yet, Harold's posture is telling: with arched shoulders, bowed head, and beseeching arms, he is the epitome of failure. From the English 
perspective, if his mission was to offer the crown to William, then Harold should be confident at his success.

Another example of ambiguity concerns Edward's death which disrupts the normal left to right chronology. ${ }^{11}$ The first image, as the caption indicates, is Edward's shrouded body being carried for burial. Immediately following, a top-down divided image depicts Edward's dying and death. In the upper portion, a reclining Edward speaks to four followers, but we do not know what was said; in the lower portion, a dying Edward is accompanied by a priest and the caption: "[a]nd here, he died." Thus, the action really rotates in a clockwise circle from the image at the top, to his death below, and then backwards towards the funeral procession. This problematic scene may reflect the description in the Life of King Edward which indicates four people in attendance: his wife Edith, Harold, Archbishop Stigand, and the palace steward. ${ }^{12}$ If this is the case, then Edward's last words to Harold were: "I commend this woman and all the kingdom to your protection."13 This interpretation challenges the legitimacy of William's subsequent attack, especially since the next scene shows the Lords of the Witan giving Harold the crown with the caption pronouncing him "king."14 Other interpretations dispute Harold's claim. ${ }^{15}$ The unusual chronology, for example, could symbolize Harold's manipulation of a deathbed inheritance as something madeup after Edward was already dead. Certainly, the ominous star indicates some impropriety.

A final example is that of Harold's death. A caption written over the image of two dying Anglo-Saxons states: "[h]ere King Harold was killed." Above the first man, who is shot in the eye with an arrow, is written "Harold"; below the words "was killed," a second man falls beneath a mounted knight who hacks at his leg. The question is which man is Harold? One widely repeated story of Hastings is that Harold 
was shot in the eye with an arrow; thus, Harold must be the first man. This story, however, has been critiqued as too convenient, since blinding was a divine punishment for oath-breakers. ${ }^{16}$ French sources suggest four Norman knights attacked Harold on William's orders: Harold was pierced with a lance, beheaded, disembowelled, and his leg (a possible euphemism for his private parts) was cut off. ${ }^{17}$ From this perspective, Harold is the second man falling beneath a Norman knight. ${ }^{18}$ The confusion surrounding Harold's death is significant for assessing the Tapestry's potential message. If Harold is killed by an anonymous archer, he was punished by God as an oath-breaker and William is the legitimate king. ${ }^{19}$ In contrast, if Harold is the second man deliberately slaughtered by a Norman knight, the image reveals the lawlessness and ruthlessness of the invasion. ${ }^{20}$

Importantly, Harold is central to all the most crucial ambiguities in the Tapestry. In several instances, the ambiguity is due to the lack of content of what was said. Importantly, the Tapestry does provide crucial information in other instances. It notes William's inspirational speech to his troops: "to fight bravely with wisdom and courage against the English army." Or, clearly indicates that "[h]ere they [the Witan] give Harold the king's crown." Other captions carefully record unimportant information: "they drag the ships to the sea" or "here they cook meat." Thus, the Tapestry could have added crucial details, such as "here Edward sent Harold to offer the crown to William" in the opening scene. In Edward's death scene, instead of "here, in his bed, Edward speaks to his followers," it could have said something like: "here Edward grants Harold the crown," or "here Edward reminds Harold of his oath." 21 Thus, the ambiguity surrounding Harold appears intentional.

Such ambiguity could be easily explained, if the Tapestry was created during the reconciliatory period prior to the Anglo-Saxon revolts in 
1069. However, since a pre-1069 timeline is unrealistic for the manufacture of the Tapestry, such deliberate ambiguity was crafted during the later tumultuous period of Norman consolidation. Although such ambiguity may appear to embolden such rebellions, such nuances challenge the interpretation that the Tapestry is merely a biased celebration of William's victory. In contrast, this almost 1000-year old artwork stresses the importance of raising multiple meanings and possible interpretations. It also underscores the importance of rejecting a narrow caricature of the "enemy" and the value of an openness to diverse meanings of crucial events in the creation of common identity.

\section{Ambiguity II: On the Borders}

Beyond the main story of Harold and William, the upper and lower borders are filled with various symbols, animals, plants, and people. Some figures appear random and repetitive decoration; yet, other figures appear to offer a commentary on the central story. On the border above William receiving Harold, for example, there are two peacocks: one, like William, is standing with his tail down; the other, in a similar stance to Harold, has his tail up in full display of plumage. ${ }^{22}$ Out of the literally hundreds of little figures, one series stands out: immediately below the scene where Harold is ransomed, there begins a series of ordinary men doing ordinary things, such as farming, hunting, and having sex. Similar to the main story, these images provoke diverse interpretations, but one possibility is that these ordinary people are reminders of the human cost underlying the grand narratives we tell of shared political identity.

The series of ordinary men begins with depictions of agriculture and hunting: two men ploughing with a donkey; a man sowing grain; 
another harrowing with a horse attached to a harness; and a man using a slingshot to hunt for birds. This series is interrupted with two rosters facing outward, then continues with a series of hunting scenes: a man with a sword and baited bear; a stag hunt with two men and their hunting dogs. Directly below the moment where Harold is taken to William, there is an erotic image: a naked man reaching for a naked woman who bashfully covers herself. This series depicts typical medieval motifs as well as unique images of technological innovations. $^{23}$ The two men ploughing use a newly invented mouldboard plough and the man harrowing is the first visual representation of this tool. In contrast, the man hunting birds is almost an identical copy of an illustration in a Canterbury manuscript. ${ }^{24}$ One noticeable difference is that the Canterbury manuscript depicts a man with long hair and a beard, but the Tapestry's sling-shot hunter as well as his agrarian companions are clean-shaven Normans with short hair. Thus, like contemporary film "split-screen," the Normans on the lower border may depict an alternative story happening simultaneously to the main drama above. Just before two main characters have high ranking discussions and their adventure in Brittany, we have several people going about their daily lives filled with activities of farming, hunting, and sex.

Importantly, these two storylines intersect. In some instances, the images in the border appear to suggest a commentary on the main events. After a few images of birds, the amorous couple is followed by two more naked men: the first man is inexplicably working with a broad ax and a second man reaching upward to a mysterious woman labelled Alfgifu. ${ }^{25}$ One theory suggests the second naked man is an allusion to a scandal involving a female relative of Harold; as another Godwinson oath-breaker, her crime reinforces the righteousness of William's invasion. In another example, on the top border immediately 
before the battle commences: two naked women open their arms to mustached Anglo-Saxon men. As these women are less modest than their earlier Norman counterpart, this image might imply loose AngloSaxon morals on the night before battle.

Second, the lives of ordinary men and women do not appear in isolation but populate the grand narrative as a supporting cast of rowers, spies, guards, servants, refugees, and soldiers. We see a crowd cheering on Harold as king and it is ordinary men who prepare for William's war by cutting down trees and making boats filled with provisions. Once in England, they loot supplies and cook the Norman last supper. Soldiers also set an Anglo-Saxon woman's house on fire. Although this pillaging and looting is not belabored in the Tapestry, the fleeing woman and her child is an understated reminder of the impact of the Norman invasion on the local population. ${ }^{26}$

After the battle begins, the distinction between the borders and the main story simply blurs. The many Norman archers eventually overrun the bottom border. ${ }^{27}$ Previously the reserve of beasts and ordinary men, it is now littered with the dead: hacked to pieces or simply pieces - heads, trunks, arms, and legs. The dead are no longer distinguishable, but include knights and housecarls, horses, archers, and many featureless men stripped of their armor. No longer identifiable as Norman or Anglo-Saxon, knight or commoner, these bodies are a reminder that death is the great leveller. William may defeat Harold, but the foundation of his new nation builds on this foundation of death and destruction.

\section{Conclusion}

Although the Tapestry may have ended with a balancing portrait of enthroned William, it is more prosaic to think the Tapestry ends as it 
has come down to posterity. William will be crowned king, but the story continues with uprisings, invasions, and so forth into history. If the Tapestry is propaganda, it is not a one-sided celebration of William's victory but presents the legitimacy of his claim in an ambiguous light. It reveals that grand stories of kings happen simultaneously with and affect ordinary people. Thus, the Tapestry presents more than a single linear story of victory; instead, as a visual artform, it encompasses a multiplicity of meanings, perspectives, and interpretations. Thus, if the Tapestry is a "weaving together" 28 of a new nation, then its ambiguity reveals such construction requires the flexibility to accommodate differing viewpoints and new perspectives of the events.

\section{Notes}

\footnotetext{
${ }^{1}$ R. Howard Bloch, A Needle in the Right Hand of God (New York: Random House, 2006), 17.

2 Israel Scheffler, "Pictorial Ambiguity," The Journal of Aesthetics and Art Criticism 47 (2) (1989): 113. See Judith Farr Tormey and Alan Tormey, “Art and Ambiguity,” Leonardo 16, 3, Special Issue: Psychology and the Arts (1983).

${ }^{3}$ For Napoleon and Hilter's use of the Tapestry as propaganda see Carola Hicks, The Bayeux Tapestry (London: Vintage/Random House, 2007), 105-15; 205-51.

${ }^{4}$ Pierre Boulet and Francois Neveux, The Bayeux Tapestry (Lille-Rennes: Editions Ouest-France, 2015), 2-5; Sylvette Lemagnen, La Tapisserie De Bayeaux, trans. Heather Inglis (Bayeux: OREP Editions, 2015), 12-17.

${ }^{5}$ Odo was the Bishop of Bayeux and became the Earl of Kent, which included Canterbury where the Tapestry likely was crafted. Pierre Bouet and Francois Neveux, La Tapisserie De Bayeux (Aix-enProvence-Lille-Rennes: Editions Ouest-France, 2013), 193-96.

${ }^{6}$ Boulet and Neveux, The Bayeux Tapestry, 3; Hicks, The Bayeux Tapestry, 38; Lemagnen, La Tapisserie De Bayeaux, 13-14.

${ }^{7}$ Bloch, A Needle in the Right Hand of God, 46-7; Stephen D. White, "Is the Bayeux Embroidery a Record of Events?," in The Bayeux Tapestry and Its Context, ed. Elizabeth Carson Pastan and Stephen D. White (Woodbridge: Boydell Press, 2014), 33-58.

${ }^{8}$ This version is found in William of Jumièges and William of Poitiers. David Douglas, "Edward the Confessor, Duke William of Normandy, and the English Succession," The English Historical Review 68 (1953): 269.
} 
${ }^{9}$ Eric John, "Edward the Confessor and the Norman Succession," The English Historical Review 94 (1979): 371; Victoria Thompson, "Kingship-in-Death in the Bayeux Tapestry," Reading Medieval Studies 25 (1999).

${ }^{10}$ Marc Morris, The Norman Conquest (London: Random House, 2013), 4.

${ }^{11}$ Thompson, "Kingship-in-Death in the Bayeux Tapestry," 113.

${ }^{12}$ George Garnett, "Coronation and Propaganda," Transactions of the Royal Historical Society 36 (1986);

Richard M. Koch, "Sacred Threads," Peregrinations 2 (4) (2009): 157-60.

${ }^{13}$ As quoted in Morris, The Norman Conquest, 134.

${ }^{14}$ Garnett, "Coronation and Propaganda," 98-99.

${ }^{15}$ John, "Edward the Confessor and the Norman Succession."

${ }^{16}$ This image of the man hit in the eye may be a nineteenth century reconstruction as an earlier drawing shows this figure throwing a spear. Foys Martin K, "Pulling the Arrow Out," in The Bayeux Tapestry, ed. Martin K. Foys, Karen Eileen Overbey, and Dan Terkla (Suffolk: Boydell Press, 2016).

${ }^{17}$ As quoted in Morris, The Norman Conquest, 185-87.

${ }^{18}$ The doubling of images might depict continuous action with Harold first shot in the eye and then stuck by the knight. See Boulet and Neveux, The Bayeux Tapestry, 18; Lemagnen, La Tapisserie De Bayeaux, 134-35.

${ }^{19}$ C. R. Dodwell, “The Bayeux Tapestry and the French Secular Epic,” The Burlington Magazine 108 (1966): 554-57.

${ }^{20}$ Morris, The Norman Conquest, 183-88: Carl I. Hammer, "Harold in Normandy," in Studies in Medievalism XII, ed. Tom Shippey and Martin Arnold (Boydell and Brewer, 2003).

${ }^{21}$ Thompson, "Kingship-in-Death in the Bayeux Tapestry," 114.

${ }^{22}$ Lemagnen, La Tapisserie De Bayeaux, 46-47.

${ }^{23}$ Bouet and Neveux, La Tapisserie De Bayeux, 23.

${ }^{24}$ The British Library, Cotton Claudius B. IV. in Bouet and Neveux, La Tapisserie De Bayeux, 23, $192-$ 93.

${ }^{25}$ Karen Rose Matthews, "Nudity in the Margins," in Naked before God, ed. Benjamin C. Withers and Jonathan Wilcox (Charleston: West Virginia University Press, 2003), 138-61.

${ }^{26}$ Morris, The Norman Conquest, 166-83.

${ }^{27}$ Madeline H. Caviness, “'The Simple Perception of Matter' and the Representation of Narrative, Ca. 1180-1280," Gesta 30 (1) (1991): 49-50.

${ }^{28}$ Bloch, A Needle in the Right Hand of God, 17. 


\section{"Forced to be free": Nationalism and the Hijab Controversy in France}

Ann Ward

Department of Political Science, Baylor University, Texas, USA

The hijab, or Muslim headscarf that covers completely the hair of women and girls, is becoming more visible in political debate in the West. In the United States in January 2019, Congress, after 181 years, voted 234 to 197 to change their rule banning the wearing of headgear on the floor of the House in order to seat representative Ilhan Omar while wearing her hijab. As the hijab is becoming more acceptable and increasingly a sign of one's progressive political commitments in the U.S., other parts of the world are moving in the opposite direction. In 2004, France extended the ban on wearing the hijab to pupils in French public schools, teachers having been prohibited from wearing religious symbols in the classroom since 1884. The French government also clarified in this same 2004 law that all employees in state buildings were banned from wearing the hijab. It has recently extended the ban on the hijab in the public sector workplace to the private sector workplace, upheld by the European Court of Justice in 2017. The European Court, unlike the U.S. Supreme Court, decided that the prohibition of wearing the hijab in private sector workplaces did not constitute discrimination.

In this paper I explore the hijab controversy in France through an analysis of Cecile Laborde's Critical Republicanism: The Hijab Controversy and Political Philosophy. Laborde argues that hostility to the hijab in France results from a particular interpretation of the republican principle of laicite. Under this interpretation, the state is justified in compelling French citizens to prioritize their homogeneous and therefore rational public identity as citizens, over against their private and therefore sub-rational identity as Muslims, Christians or 
Jews, men or women. Although this is more commonly viewed by Laborde and others as a rejection of civic multiculturalism, I argue that the ban can also be understood as a rejection of cosmopolitanism or a certain concept of "global citizenship." As such it is (a largely unspoken) assertion of nationalism; it requires citizens to be "French first," as it were, or to be citizens of France rather than of the world.

\section{Laicite as a Political Principle}

In Critical Republicanism, Cecile Laborde, who opposes the measure, investigates how France got to the law promulgated on March 15, 2004, that banned the wearing of the hijab in state schools. Prohibiting in primary and secondary schools "the wearing of signs or clothes through which pupils ostensibly express a religious preference," while technically covering Jewish yarmulkes and large Christian crosses, the law is aimed at the Muslim headscarf. ${ }^{1}$ It is intended to put an end to the fifteen-year long "hijab controversy" in France that started in the autumn of 1989 in Creil when two girls came to class wearing the Muslim headdress. To understand the ban, Laborde argues, requires reflection on the French principle of laicite, which is the French republican interpretation of the requirements necessary for the liberal ideal of religious freedom to be achieved (32). From what Laborde terms the "official republican" - heretofore simply republican - point of view, the minimal requirement for laicite or religious freedom is state neutrality or a neutral public sphere. Moreover, as Laborde notes, French republicans have a much more expansive understanding of the public sphere than traditional political "liberals" (32). "Public service" in France can include postal services, public transportation, public libraries, doctor's offices, and state schools, taking in up to five million public service providers across the country. 
As a political principle, laicite for French republicans has three components: separation of church and state, religious freedom, and equal citizenship. The first component, separation, has its legal framework in the 1905 Law of Separation between Church and State. Article 1 states: "The Republic ensures freedom of conscience. It guarantees the free exercise of religions," and Article 2 states: "It neither recognizes nor subsidizes any religion" (33). Laborde explains that the 1905 Law of Separation replaced the "Concordat" which, since 1801, had recognized Catholicism as "the religion of the great majority of the French" (35). Conferring many benefits to the Roman Catholic Church - for instance the free use by Catholics of state-owned churches and the near monopoly over primary education - unavailable to other "recognized religions" such as Protestantism and Judaism, these benefits were withdrawn in 1905 when "recognized religions" were abolished and all religious institutions vis-à-vis the sate were put on an equal plane (35).

The second component of laicite, religious freedom, requires that the state refrain from interfering in religious affairs such that religion be allowed to flourish in the private sphere without public interference. Equal citizenship, the third component, holds that the moral equality between believers of all faiths vis-à-vis the state is made possible by the state's refusal to give preference to one religion over another (34, 35). Laborde argues that this latter principle is distinct from and much more than the principle of religious freedom. Unlimited religious freedom, Laborde notes, is consistent with state preference for one religion; the Anglican Church in England is established while complete religious freedom is simultaneously extended to all citizens, similar to the position of the Catholic Church in France under the Concordat (35). Laicite, however, grounded by the 1905 Law, places all 
religious institutions and faiths on an equal plane, or endorses what political liberals would call religious pluralism.

Laborde argues that laicite, or state neutrality in France after 1905, embraces religious pluralism in its refusal to give preference to one religion over another. I would argue, however, that the French republican view of state neutrality, as described by Laborde, actually goes much further than the embrace of religious pluralism, revealing key differences with the American understanding of the requirements for religious freedom as embodied in the First Amendment of the U.S. Constitution. For French republicans, state neutrality requires not simply separating the state from preference for one particular religion over another, as in the American understanding, but separating the state from "religion as such." A state separated from religion as such, or "neutral by ignorance - vis-à-vis the respective claims of believers and non-believers," is what Laborde calls an "agnostic" state, yet what Americans would call an "atheist" state (36). State neutrality in France, in other words, means that the state is secular and not simply non-sectarian as in the American understanding. Such a purely secular public morality assumes no need for "transcendental foundations," and produces what Laborde terms the "naked public square," by which she means a public space bereft of any religious expressions or symbols whatsoever, even of a non-sectarian nature (36, 37). Examples of the "naked public square" in France are communal cemeteries "secularized" in the 1880s, with religious signs such as crosses removed from tombstones. Another example is the French state's prohibition against collecting statistics about racial origins or religious affiliation, with the result that it is very hard to get an accurate figure of just how many Catholics, Protestants, Jews, Muslims and other religiously affiliated persons are in the country. 
The French state, in other words, does not recognize the existence of “minorities," including religious minorities (37).

Perhaps the most significant example of the "naked public square" in terms of how French republicanism differs from American republicanism in its understanding of the requirements for religious freedom, is that in France representatives of the state, or public service providers, must refrain from expressions of religious faith. Laborde explains that for French republicans, equal respect for citizens, meaning that no citizen is discriminated against on the basis of religion, requires that state actors show outward signs of neutrality; they must not simply be neutral but must be seen to be neutral (48). This entails what the French call a "devoir de reserve," or an obligation of restraint on public actors; in order to show equal respect to all citizens or users of public services, providers of public services must not express or display any sign of "religious allegiance" as such, even of a non-sectarian nature (48). Thus, whereas in America it is believed, in accordance with the First Amendment, that religious liberty requires freedom of expression, in France, in accordance with republican laicite, it is believed that religious liberty requires restraints on expression, on the part of both public actors and, with the ban on the hijab, citizens or receivers of public services as well.

\section{Laicite and Public Identity}

The "naked public square," Laborde argues, reflects a laicite that seeks to have citizens embrace a robust and "homogeneous public identity" that transcends more particular religious, cultural or class loyalties (41). It wants citizens to think and say, "I am French," meaning republican - being "French" is not politically neutral - rather than "I am Catholic, Jewish or Muslim," white or black, male or female, rich or poor. To embrace this civic identity requires an 
autonomous public sphere protected from interference by particular loyalties, identities or groups. Moreover, for republicans, the state school is the primary vehicle for creating the homogeneous public identity that laicite intends French citizens to adopt.

The political mission of the state school, republicans believe, requires strict religious neutrality, reflected in the 1884 Educational Laws (50). Examples of such neutrality in state schools are the removal of all religious signs, such as crosses, from classrooms, and importantly, teachers must strictly refrain from endorsing or criticizing religious values (50). Teachers are understood as "public servants" who must embody the laicite doctrine of state neutrality, which requires, as noted above, a "devoir de reserve" or restraint on religious expression. The religious neutrality of the state school, Laborde explains, allows republicans to conceive of the school as a "sanctuary" from divisive sectarian-moral divisions that threaten to tear civil society apart (51).

\section{The Ban on the Hijab}

The 1884 Educational Laws require strict neutrality or restraints on expression on the part of teachers understood as public servants or providers of public services. The 2004 law banning the wearing of the Muslim headscarf in state schools enacted a significant innovation to the 1884 laws. The 2004 law, Laborde explains, requires neutrality or restraints on expression not just from teachers but students as well; not just from the providers of a public service but also from their "receivers" (53). The problem with this innovation, Laborde argues, is that students themselves, or "receivers" of state services such as education, are not state actors and thus in no way can be understood as representing the neutrality of the state (53). Thus, Laborde reflects on how France came to the 2004 ban which sought to restrain the religious expression of students as well teachers. 
The "hijab controversy," as noted above, began in 1989 in Creil when two girls arrived in school wearing the headscarf. In 1994, Education Minister Francois Bayrou issued a directive that stated the hijab is an "ostentatious" religious symbol - the hijab itself is a form of "proselytism" - and as such it constitutes religious discrimination that defeats the schools' mission of "integration" and homogeneous "identity formation" (52-53). How can the hijab itself be a form of religious discrimination? According to Laborde, for French republicans, religious signs separate or divide students from each other; they separate believers from non-believers, Muslims from nonMuslims, "good" Muslims from "bad" Muslims, men from women (54). As such, religious signs infringe upon the "difference-blind equality" between all students that the school is to maintain (54). Moreover, tolerating the hijab would create a special exemption from the obligation of restraint otherwise required from other believers, who must refrain from wearing such items as yarmulkes or crosses.

Bayrou's directive singling out the hijab as an ostentatious religious symbol that constitutes discrimination laid the groundwork for the four premises Laborde identifies as underlying the 2004 ban. The fourth and most important premise, I would argue, of the 2004 ban is that the wearing of the Muslim headscarf undermines the religious freedom of others who are not wearers (54). As Laborde describes it, this premise points to a key difference in the way that French republicans and American political liberals understand religious liberty. According to the fourth premise, the argument proceeds as follows: children in primary and secondary school are at a "vulnerable" age, and if exposed to the "ostentatious" religious behavior of others, such as wearing the hijab, the freedom of conscience of these vulnerable children may be infringed (54). This line of thought is very different from the American understanding of the "free exercise" 
clause of the First Amendment. The "free exercise" clause is usually understood as protecting the freedom of conscience and expression of the person engaging in the religious behavior, in this case the wearer of the hijab, against opposition. In France, by contrast, it appears that laicite principles seek to protect the freedom of conscience and expression of the person not engaging in the religious behavior - in this case those who are not wearing the hijab - against those who are. What does it mean to protect the freedom of conscience of those persons not engaging in the contested religious behavior? Out of Laborde's description of the official republican understanding of laicite and the premises that underlie the ban on the hijab, I would reconstruct something like the following line of argument I believe French republicans are making. First, if the hijab is tolerated in public schools, non-wearers are made to feel that their religious beliefs and values are defective. For instance, girls not wearing the hijab are implicitly pointed to as immoral because they are not showing due modesty as girls should. Likewise, boys whose mothers and sisters do not wear the hijab are made to feel that the female members of their family are immoral. All this even though the parents of these children are taxpayers whose taxes support the public school. The second problem, given that the hijab itself is a form of proselytism, is the problem of conversion. For instance, a parent sends their non-Muslim daughter to school, a "sanctuary" that they believe is religiously neutral, and being consistently exposed to the headscarf by her friends, she converts to Islam. Isn't this a violation of her and her parents' freedom of conscience? The headscarf had an undue influence because there were no other religious symbols in the school to compete with it.

If I am correct that in imposing the 2004 ban on the hijab in state schools, French republicans are following some such line of thinking 
as I sketch above, important questions present themselves: Are French republicans worried about French children becoming Muslim? If so, are they not implicitly acknowledging a problem with laicite and enforced state neutrality or secularism in public schools? If you empty public schools of all religious symbols and expressions from the country's past - in France's case Catholic symbols - creating the socalled "naked public square," will children and youth be drawn to the only religious symbols that they $d o$ see - the hijab - and the religion it symbolizes, Islam? Moreover, isn't this an underhand acknowledgment by French republicans that children and youth naturally seek transcendence - beyond their homogeneous public identity - and will be drawn to that - Islam - that offers it to them? Isn't it an acknowledgement, in other words, that the state cannot suppress the soul completely?

\section{Nationalism and the Rejection of Cosmopolitanism}

Laborde, who associates herself with a "critical republicanism" in opposition to the "official republicanism" she sees behind the 2004 ban on the hijab in state schools, commonly addresses the ban as a rejection not just of religious expression in the public square on the part of official republicanism, but of civic multiculturalism as well (61$63,72-73,80,83)$. Official republicans reject cultural diversity in the public square, Laborde argues, because such diversity mitigates the homogeneous public identity that they believe laicite guides the citizen body in France to achieve.

I would argue, however, that the ban is not simply a rejection of civic multiculturalism, but of cosmopolitanism or of "global citizenship" as well. What is meant by "global citizenship" in this context? Laborde herself and other "critical republicans," I believe, have a concept of it even if they do not explicitly term it as such. This comes out most 
clearly in Laborde's admittedly unorthodox proposal from the critical laicite perspective, that the contemporary French state provide public subsidies for the building of mosques (94).

Laborde begins to explain this proposed exception to the 1905 Separation Law by arguing that Catholic Christianity in France has, "benefited from favorable treatment by the state," such that "the (roughly) equal opportunity to practise Islam" requires that these benefits be "corrected or compensated for." What does Laborde mean when she claims Catholic Christianity has received favorable treatment by the French state that Muslims in France must be compensated for?

Laborde argues that fundamental to religious freedom is "the availability of suitable places of worship," and notes that, "Scholars agree that the establishment and maintenance of a place of worship is part of the fundamental rights of religious freedom enjoyed by everyone in Europe" (94). Given this fundamental right of "free exercise" combined with the fact that Muslims in France are demographically significant yet economically poor, an exception to the principle of separation should be made, and the French state should subsidize the building and maintaining of mosques for the Muslim community under its jurisdiction (94).

It is in this sense that Laborde and critical republicans have a concept of "global citizenship": any individual or religious group living at any time in history and located anywhere on the globe has, in theory, claims against or is owed rights from the French state, such as the right to the "free exercise" of their religion which requires the maintenance of their places of worship. In practice, however, these individuals and groups - or citizens as such or always in potentia, as it were - can only claim their rights when they or their descendants arrive in the territory under the control of the French state, and when 
they do the French state must make retroactive recompense, as it were, to these new arrivals. It is also in this sense that I think official republicans, who oppose the public subsidy to mosques and tolerating the hijab in the public square, are making a nationalist assertion against this concept of "global citizenship."

\section{Notes}

${ }^{1}$ Cecile Laborde, Critical Republicanism: The Hijab Controversy and Political Philosophy (Oxford: Oxford University Press, 2008), 32. Hereafter page references are cited in the text. 


\section{Glocalism and Democracy in James Tully's Critique of Cosmopolitanism and Imperialism}

Lee Ward

Department of Political Science, Baylor University, Texas, USA

In the age of Brexit and Trump the critique of cosmopolitanism from the political right has received much more attention in the media and in academia than cosmopolitanism's critics on the left. The zeitgeist of this new era of anti-cosmopolitanism seems to be coeval with the looming presence of renewed nationalism and right-wing populism with its major concerns being the weakening of the claims of national sovereignty and territoriality, fears about the demographic and cultural impact of migration and immigration, and a penchant for volkish authoritarian politics. The prevailing belief in our time, then, is that the ascendant political forces are coming from the antiestablishment right wing, which derives much of its ideological, even spiritual, strength from a deep ambivalence, and often outright hostility, toward supranational organizations, international treaties, and cosmopolitan values.

But just a few short years prior to 2016 it was a very different story. In the summer of 2010, it was the left-wing critics of globalization who garnered the world media spotlight with large and well-coordinated demonstrations, led by politically astute and technologically savvy activists. At that time, it was Greek trade unions calling a general strike to oppose European Union imposed austerity measures and it was the mass arrest of "black bloc" G-20 protestors battling police in the streets of Toronto that seemed to challenge complacent assumptions about the new global world order. Indeed, in some respects in the lead up to the events of 2016 in the United States and 
the United Kingdom, the anti-globalization, anti-cosmopolitan left and right found common cause, as can be seen for instance in the opposition to the Trans-Pacific Partnership in the United States in 2015-16 led by Donald Trump in the Republican Party and by Senators Bernie Sanders and Elizabeth Warren among the Democrats. Likewise, the complex politics of the Brexit debate in the United Kingdom revealed similar ambivalent attitudes toward the European Union shared by the right-wing populist Nigel Farage's United Kingdom Independence Party and the hard-left labourites led by Jeremy Corbyn.

This paper re-examines the theoretical foundations of the critique of cosmopolitanism from the political left by reflecting upon one of the preeminent progressive political theorists in the English-speaking world today, Canadian thinker James Tully. Central to Tully's effort to fashion a new more engaged and truly democratic political theory, which he terms "public philosophy," is his assault upon the universalist tendencies of Enlightenment rationalism embodied in Immanuel Kant's cosmopolitan philosophy. For Tully, the Kantian cosmopolitan ideal provided philosophical justification for the vast network of both formal and informal structures of imperial domination that over several centuries deterritorialized socio-economic and political spaces through a system of international law and free trade.

Today this Janus-faced phenomenon of globalization means both that citizens can more effectively organize at the local and global levels to resist Kantian cosmopolitanism-inspired imperialism, even while institutions of global governance such as the World Trade Organization (WTO), the United Nations (UN), and the International Monetary Fund (IMF), as well as multinational corporations, govern informally over the global relations of inequality inherited from the colonial period. In contrast to the "constrained" system of 
representative constitutional government that he associates with the western idea of citizenship and rule of law, Tully presents his conception of "glocal citizenship" as an alternative model for a globalized, de-imperialized era in which the "extensive" practices of genuine democracy can emerge from networks of local groups resisting oppression and inequality.

\section{Democracy as Public Philosophy}

James Tully's critique of liberal constitutionalism is an important element of his larger philosophical project to establish a more robust account of democracy as the hallmark of a new public philosophy for the twenty-first century. Central to this new public philosophy is Tully's effort to reconcile democratic theory and practice through the identification and promotion of certain "practices of civic freedom." 1 The actual content of these practices of civic freedom will vary due to the diverse circumstances and local contexts in which these practices arise and develop, but Tully insists that his idea of democracy is recognizable as much, or more, by what it is not, as opposed to any specific substantive institutional features. That is to say, Tully's conception of democracy amounts to a rejection of what he takes to be "elite" political theory. Traditional elite political theory is more constrained than democratic pubic philosophy because it forecloses a wide range of discursive possibilities for constructive dialogue. Elite political theory assumes causal processes and universal norms that determine the citizen's field of activity, even as it presupposes certain "canonical preconditions" that supply background knowledge to democratic institutions (8-9). But how precisely does Tully's democratic public philosophy differ in practice from traditional elite political theory? 
The first obvious difference relates to Tully's insistence that a truly democratic public philosophy will build from the grassroots up and avoid all forms of grand theoretical meta-narratives by looking instead to theorizing about observable practices that inform "strategies of freedom" befitting democratic citizens. Another point of departure from traditional political theory is Tully's endorsement of agonistical principles embedded into the practices of civic freedom. By the call "to act differently," Tully encourages democrats to embrace a spirit of disruption and civil disobedience, while his secular faith in "a world without end" enjoins a practically endless drive for constant negotiation, re-negotiation and dialogue. For Tully, "acting differently" in a dialogical mode grounded on an abiding confidence in never ending conversation, also means that democratic political theory must focus on what appears to be contingent, as well as on the particular aspects of political life that the laws or formal constitutions do not adequately describe. Indeed, echoing Richard Rorty, one of his philosophical inspirations, Tully affirms that every citizen in a democracy is or can become a philosopher because by rejecting elite political theory we no longer believe that the theorist must assume "a position above the demos" (4). With this, Tully strives to replace the influential Enlightenment model of disembodied reason.

The second relation between Tully's idea of democracy and diverse civic practices is his tendency to employ history as an instrument of critique. Tully views history as a critical tool against the universalizing tendencies of Enlightenment thought insofar as history contains a liberating power that combats intellectual and normative homogeneity or the "unity" imposed by western rationalism. Tully's assumption is that past customs were generally more organic and consensual than contemporary practices built around a legal philosophy of individual rights and private property. Legitimacy as 
such is not determined by an objective standard of right, but by a regime's capacity to encourage certain beneficial political practices and the positive public sentiments toward the government. This involves a full-throated rejection of the traditional western ideas of constituent power and representation such as the "decisive moment" of nation-building and the Rousseauian semi-mythical Legislator figure. Tully's use of history aims to cast light on these western ideas designed to hide their particularity and produce the appearance of reflecting universal rules.

It is Tully's contention that contemporary world politics is still largely structured by five hundred years of inherited imperial relations. While the postcolonial era is not marked by the same direct colonization and occupation as in the prior past imperial age, Tully claims that western imperialism continues to dominate the developing world through informal means of international capital and global institutions such as the IMF, the World Bank and the UN. For Tully, globalization is in some respects profoundly antagonistic to democracy as it locks nations into uneven, hierarchical networks that deterritorialize socio-economic and political space and produce structures of dependence and control (58-59). Yet Tully also sees democratic possibilities in globalization as communications technology and greater consciousness of international links among groups and places allows political actors and public philosophers to effectively organize at local and global levels. But before we can appreciate Tully's complex attitude toward the Janus-faced phenomena of globalization, we need to consider in more detail his rejection of the Kant-inspired idea of liberal cosmopolitanism. 


\section{Kant's Cosmopolitan-Imperial Legacy}

Immanuel Kant's Perpetual Peace: A Philosophical Sketch is, in Tully's view, the seminal text in liberal cosmopolitan imperialism. The intersection between cosmopolitanism, imperialism and representative democracy is the Kantian ideal of the republican state at the center of a rule-based system of international law that culminates in a league of nations or "pacific federation." ${ }^{2}$ Needless to say, Kant's idea of the modern representative government is profoundly European, deriving as it does from the Westphalian model of a centrally organized sovereign state - that unique product of the political and religious conflicts of early modern western Europe. The Kantian concept of the state and the Kantian ideal of a rule-based global order are historically and intellectually intertwined, according to Tully, in the ideology of European imperialism: the imperialist impulse contained within what Tully identifies as the "historical idea of Europe" (17). Kant assumed the cultural superiority of Europe and saw in the modern republican state the furthest stage in national development and representative government. As Tully observes, not coincidentally the most rapid expansion of European imperial conquest occurred in the period immediately following the publication of Kant's writings. Kant's cosmopolitanism, then, emerged at least in part as a philosophical justification for the imperialist drives of the European great powers.

For our purposes, the central question appears to be: Is Kant's idea of republican government and global order compatible with Tully's idea of democracy? Tully does not understand democracy primarily as a set of representative institutions designed to promote majority-rule. Embedded in this idea of representation is a series of restrictive practices that are formal, legal, hierarchical, and tend toward the perpetuation of structural inequalities both domestically and 
internationally. The internationally restrictive practices derive from a system of international law designed to promote great power interests and enforced through international institutions such as the IMF, WTO and the UN that impair and undermine self-government in the postcolonial states. This condition generates two kinds of related problems today. First, Tully recognizes a diversion and dispersal of political power within decolonized states that produces weaker political institutions relative to regulative regimes imposed by international institutions such as the IMF and the World Bank. Second, Tully identifies the decline of democratic deliberation in traditional representative institutions as witnessed in voter apathy, powerful special interests and prerogatives of judicial elites. $\mathrm{He}$ traces the causes of these conditions back to the original Kantian model of representative government, which he suggests promoted a highly restricted conception of democracy.

Tully's conclusion is that inequality and restrictive political practices are intrinsic to Kantian cosmopolitan democracy. Tully is skeptical about the "end of sovereignty" thesis advanced by some observers of globalization, but he agrees that globalization skews discussion of democracy away from local practices of civic freedom negatively towards the big picture formal criteria of international political development. For this reason, Tully determines that it is hard to see how the current stratified state system can be the basis for a truly non-imperial alternative, especially if ideas of self-determination and representative government are always determined by the western powers (60-63). The true democratic alternative to Kant's cosmopolitan democracy would be a political vision that promoted and supported the extensive practices of civic freedom central to Tully's democratic political philosophy. 


\section{The European Union as an Alternative to Cosmopolitan Imperialism}

Tully recognizes that the contemporary idea of Europe is more constitutionally and culturally diverse than what Kant envisioned two centuries ago. But is the European Union - arguably the epitome of European identity today - a unique state form that provides an alternative model to formal and informal western imperialism? There is clearly much that Tully admires about the European Union, especially the diverse conceptions of citizenship, multicultural practices and innovative integrative transnational institutions that by and large do not impair the self-government capacities of the constituent national and regional parts. Indeed, on the level of practice, Tully sees an "invisible form of democratic integration" at work in everyday activities that are not normally picked up in theory, for example in the activities of ecological and refugee groups or cultural associations and regional governments (226). This is not to suggest that Tully is unaware of the criticism that the EU suffers from a "democratic deficit," according to which technocratic elites in Brussels and Strasbourg make rules and regulations out of touch from the reality of life and actual concerns of European peoples still organized under national governments. He clearly does recognize this problem but his solution is not abandoning the European project, but rather Tully claims that if this invisible form of integration were to be made more prominent in the official institutions of the EU, it would be a "new and different form of association" (226).

Tully's major conclusion based upon his observations of the EU is that diverse democratic societies cannot be held together by a definitive single set of institutions, procedures and norms because these place limits on democratic negotiations precisely where disagreement is likely to arise in diverse societies (230). The result of the Brexit Referendum in 2016 in this sense, confirms Tully's recognition of the 
vast conceptual challenges confronting the $\mathrm{EU}$ as it struggles to negotiate among distinct, and often competing, claims of civic identity and political self-determination. But the promise, as well as the limits, to the EU's non-restricted approach lies in the capacity to avoid "seeing like a state" by learning to appreciate the vast field of unorganized practical arts of integration among citizens of diverse states (240). Despite the palpable promise for democratic practices in the multinational and multicultural EU, Tully also, however, recognizes structural limits on the degree of economic and foreign policy integration possible. Moreover, while the EU model of consensual and self-limiting practices is laudable, these practices do not provide a complete response to the depth of the legacy of imperialism. Indeed, for Tully it is difficult to see how the current stratified state system, of which the EU remains a part, can be the basis for a genuinely non-imperial alternative model of government. The limits of the EU model are similar in this respect to the inadequacy of postcolonial theory, which Tully identifies as problematic because it still retains categories of colonial power and subalterns that operate within the logic of informal imperialism. Thus, to this extent, the EU is not a complete alternative for Kantian cosmopolitanism because it may have a limited role of application to similarly situated countries with similar political traditions and cultures as is the case of Europe. For Tully, the more daunting, and hitherto more elusive, task is to democratize the entire global order.

\section{Glocalism vs Cosmopolitanism}

Glocalism is the term that Tully employs to describe a radically democratic alternative to the Kantian-inspired cosmopolitan imperial political order. Originally coined by sociologist Roland Robertson in the mid-1990s to characterize the occurrence of both universalizing 
and particularizing tendencies in the globalization process, ${ }^{3}$ Tully draws upon the aspect of glocalism that he believes reflects the struggle for democracy in the extensive sense that involves bringing globalized civic practices under the democratic control of the participants (300-308).

Tully identifies several main elements that characterize the glocal strategies of freedom including the development of civic practices outside of traditional representative institutions that are derived from, or at least compatible with, local particular conditions. Tully envisions the glocal approach as a remedy for the problem of traditional representative institutions that he believes are inadequate precisely because they typically lack proportionality and do not truly represent marginalized groups (300-301). The structural character of glocalized institutions will, of course, vary, but Tully views the primary moral energy of glocalism deriving from its focus on conflicts at the interstices of local and global issues such as the environmental impact of multinational corporations in developing countries or opposition to high-profile international projects such as the XLKeystone Pipeline designed to transport Alberta oilsands to refineries in the United States. Disputes such as these provide an opportunity for bringing international actors into dialogue with grassroots organizations. But Tully insists that glocalism requires replacing the traditional rule of law approach, according to which matters are definitively "settled" in courts (typically favoring powerful interests), with a model of confrontation, disturbance, negotiation and further ongoing negotiation and further consultation: "world without end." Ultimately, the techniques of resistance that Tully associates with glocalism have the goal of permanently redressing power imbalances by establishing durable networks that provide oversight for any resolution (305). 
Tully presupposes that cosmopolitanism largely reinforces structures of hegemony and inequality by promoting "a form of global cosmopolitan citizenship for official NGOs and multinational corporations; low-intensity citizenship for dependent elites of the former colonies; the dispossession or marginalization of local citizenship and governance; [and] the subordination of local economies and polities to global corporations and trade regimes" (301). Glocalism, on the other hand, provides an alternative model of citizenship that signifies embedded diversity. It is this globalized conception of diverse citizenship that Tully is confident "has the capacity to overcome imperialism and bring a democratic world into being" (243).

James Tully's critique of liberal cosmopolitan imperialism does not, however, in the final analysis deny the central historical fact that cosmopolitanism has made a glocalized democratic future both necessary and possible. Perhaps in a parallel introspective process the political theorist and democratic citizen of the future will likewise need to reflect upon the rarefied vision of a cosmopolitan global order in order to return again with clear eyes and fresh energy to truly experience the world where we now are.

\section{Notes}

\footnotetext{
${ }^{1}$ James Tully, Political Philosophy in a New Key, Vol 2: Imperialism and Civic Freedom (Cambridge: Cambridge University Press, 2008), 4. Hereafter page numbers are cited in the text.

${ }^{2}$ Immanuel Kant, "Perpetual Peace: A Philosophical Sketch," in Kant Political Writings, ed. Hans Reiss (Cambridge: Cambridge University Press, 1991), 104-5.

${ }^{3}$ Roland Robertson, "Globalization as a Problem," in The Globalization Reader, ed. Frank J. Lechner and John Boli, $5^{\text {th }}$ ed. (Oxford: Wiley-Blackwell, 2015), 86-93.
} 
Workshop 6

Historical Memory in a Global World

Chair: Boris Gubman 


\section{Arthur Danto on Historical Narrative: Between Past and Present Carina Anufrieva \\ Tver State University, Russia}

\section{Introduction}

Arthur Danto (1924-2013) is associated with the development of one of the most significant theories of historical narrative within the AngloAmerican analytical philosophy of history. ${ }^{1} \mathrm{He}$ believed that the correlation between past and present in the context of narration should be regarded as one of the principal issues of the epistemology of history. Trying to imagine the specifics of knowledge of the past, he assumes that the past is characterized by particular kinds of epistemological, logical and linguistic procedures of its fixation, which are closely bound together and are largely different from disciplines that capture their object in a purely synchronous dimension. In contrast to the theorists of continental European philosophy, who turned to the problems of historical knowledge, Danto remained throughout his career a supporter of analytical methodology which, in his opinion, allows in a clear rational and logical form to give a description of any problem, not only scientific, but also of a practical nature to the world. At the same time, his doctrine of historical narration integrally included many of the ideas of pragmatism and presentist historiography.

\section{The Instrumental Character of Historical Knowledge and Historical} Experience

Danto, by his own admission, was initially influenced by the ideas and methodological tools of logical positivism, and adopted many of the provisions of the philosophy of Ernest Nagel. Addressing the issues of 
historical knowledge, he accepted and synthesized within the boundaries of his narrative studies a model of the historical explanation of Karl Popper and Carl Hempel. In his writings, he constantly refers to Ludwig Wittgenstein, to Gilbert Ryle's "descriptive metaphysics," and to W. V. O. Quine's and Donald Davidson's ideas. At the same time, Danto was attracted by the ideas of pragmatism of Sidney Hook. Among the classics of pragmatism, his special interest was aroused by the works of C. S. Pierce, John Dewey, C. I. Lewis, and Chalres A. Beard and other supporters of presentist historiography. In his understanding, their ideas were quite in tune with the "perspectivism" of Nietzsche's philosophy of knowledge and close to his philosophical aspirations. Perhaps, in light of the influence of pragmatism, one should also understand Danto's enthusiasm for the post-positivist theory of Thomas Kuhn in the late period of his work. Dealing with the specifics of the historical narrative, he discovered the depths of Khum's constructions in his theory of paradigms of knowledge, which implied the plurality and historicity of correlative worlds.

Danto believed that his network of narrative ideas about history is in principle consistent with a realistic cognitive setup, suggesting a reference to a certain reality of the past, which is unthinkable beyond the correlation with the present moment. The reality of history, represented by the narrative, turns out to be a given chain of events occurring in the flow of time. This kind of realism, by definition, contains a significant dose of critical and constructivist principles, as it initially assumes that the narrative is created by the efforts of the subject's imagination. At the same time, following the logical-positivist approach, Danto identifies the meaning of the sentences that make up the narrative, and their truth value with the possibility of verification. ${ }^{2}$ If this definition of meaning is to be accepted on the 
basis of verification, the question remains, he emphasizes, as to how this is done with respect to the meanings of time-bound sentences. In short, the question is: what experience allows us to verify our claims about a past that no longer exists. This problem, according to Danto, is fundamentally analyzed in the works of C.I. Lewis and of representatives of pragmatism in general. In its format, it is necessary to determine the importance of the temporary form of the proposition in its difference from the content expressed in it. Kant also stressed that time is not given in experience but constitutes a form and a prerequisite for such experience. The problem, in Danto's opinion, lies in the focus of Wittgenstein's attention, when in the Tractatus LogicoPhilosophicus he examines the difference between a proposition's form of expression and its content. Pragmatism tries to include all reality in an experience that is inseparable from language. Danto believes that it would be logical to argue that the forms of time in the final instance should not be considered as part of the proposition. These forms, in his opinion, can be interpreted as an expression of the fact that a certain statement may appear at the present moment, in the past, or in the future, as true. In this regard, Danto considers it correct to say that the very possibility of various true evaluations of sentences expresses the way of human existence in time. However, there is still the dilemma of meaningfulness and verifiability of historical events: fundamentally significant events cannot always be empirically confirmed even by potential witnesses in time, because of the operational unverifiability of many phenomena (for example, the beginning of the Renaissance).

According to Danto, the significance of the assumption of reality fixed by sentences about the past can be interpreted in an instrumentalist way. The past, recorded in sentences that Danto defines as associated with the process of narration and the expression of the temporal 
connection of the sequence of events, is important for the organization of the experience of the present. While openly noting that he uses Dewey's philosophical platform, Danto simultaneously claims the novelty of his own approach, emphasizing his priority in the instrumentalist interpretation of historical judgments. ${ }^{3}$ At the same time, he believes that historical narrative judgments are similar in instrumental terms to the theoretical propositions of the sciences, mainly modeling natural processes on a synchronous plane. The theory maintains its ability to be not only pragmatically useful but also true in its content. A similar property can, according to Danto, be considered as inherent to narrative sentences that can be a pragmatically useful form of organization of the experience of the present and at the same time carry true content.

Judgments about the past, Danto believes, bear the possibility of historical relativism. In this connection, he considered Charles Beard's presentist views that were associated with the statement on the impossibility of an unbiased reading of the evidence of the past. ${ }^{4} \mathrm{We}$ can agree that considering something as evidence already presupposes the knowledge that it should support certain statements. Evidence is sought at the present moment for reinforcement of a certain judgment about the past associated with the event under the consideration. The ability to connect the present with the past, in Danto's opinion, constitutes a historical attitude to the world. The lack of knowledge about history can make it difficult to see in the historic relics what they represent, reducing them simply to a kind of corporeal entities. That is why words "from the language of time" cannot be translated using a dictionary "neutral in respect of time." The very idea of the past is really born together with the development of language, many predicates of which point to the past. Danto believes that there is no experience that is independent of time, and this kind of statement 
seems to be supported by the realities of the existence of language. ${ }^{5}$ He corrects Beard by saying that not only does the present affect the perception of the past, but that the past also affects our perception of the present. In Beard's reasoning, according to Danto's remark, many important characteristics of historical knowledge are highlighted, but this fact should not - and again we can agree with him - testify to a greater relativity of knowledge of the past than in the sciences of nature.

Beard's understanding of the sciences of nature in the spirit of objectivism is the starting point of presentism's hyper-relative interpretation of history. Danto rightly evaluates Beard's Baconian interpretation of science as incapable of creating an unbiased view of the study of natural phenomena. ${ }^{6}$ Danto is very close not only to Beard's approach but also to Nietzschean perspectivism, but he justifiably sees no reason to oppose history and the science of nature on the basis of the "degree" of their ability to relativize the results of the cognitive process. Relativity is their common feature, but it is presented in a special version in the narrative way of organizing historical knowledge.

Organization of Historical Narrative: The Connection between the Past and the Present

Historical narrative as a way of comprehending and representing the diachronic reality of the past is significantly different from the comprehension of natural phenomena. Following Benedetto Croce, Danto distinguishes between history and chronicle. However, his understanding of their dissimilarity is different from Croce's version. For Croce, the chronicle is a fixation of what happened during a certain period, whereas history is a vision of a significant chain of 
events in the light of the tasks of the present. ${ }^{7}$ Noting that the distinction of the chronicle as a "simple narrative" about what happened and a significant narrative about some chain of events chosen by the narrator is not meaningless, Danto simultaneously emphasizes that this is still a distinction within a historical narrative. A historical narration, as Danto correctly points out, should not only report events, describe them in the order in which they occurred, and explain them, although these characteristics are among the necessary ones. To be called a narrative, it must also have another necessary feature that proves the sufficiency of the above-mentioned properties: a complete description of a certain set of significant events selected by the historian according to the chosen criteria.

Entering again into a controversy with Beard, Danto says that no historical narrative in fact is able to and should give a description of all the events that belong to the studied period, indicated by the problem of research. To demand such completeness would be as absurd as to suggest to a hypothetical landscape painter to include in the picture of the landscape everything that is potentially available to his visual perception in a particular situation. If so, it is hardly possible to rigidly oppose the chronicle and a significant story about the events of the past, as they can be contrasted only as a simple and more advanced historical narrative.

William Walsh believed that the chronicle only records the course of events of interest to us, while the significant narrative also assumes their explanation. From the point of view of Danto, this distinction is not meaningless, but it is worth remembering that both types of narratives produce a selection of events in the light of the chosen criteria for their construction. As for the method of selecting the events that constitute the narrative, according to Danto, it may be formed on the basis of multiple empirical, theoretical, and value 
grounds that are chosen by historians. ${ }^{8}$ These preferences can condition various scenarios of the organization of a meaningful narrative.

Discussing the narrative structure of historical knowledge, Danto notes that its specificity is expressed in sentences that capture the knowledge of the past. "Their most general characteristic is that they refer to at least two time-separated events though they only describe (are only about) the earliest event to which they refer." 9 This means that in the end, narrative sentences contain a certain correlation between the events that are considered by the narrator in the time perspective. In this regard, he argues that Pierce's opinion in his letter to Lady Welby assumes the completeness and immutability of the past as opposed to the openness of the future. Summarizing his approach, Danto emphasizes that the characteristic feature of narrative sentences is always their reference to later events, considered from the point of view of the present. Thus, for example, even the seemingly simple statement contained in the sentence "The Thirty years' war began in 1618" carries information about the duration of this war, and therefore refers indirectly to the time of its completion, involving retrospective optics of vision of this important event. This brings us back to Danto's conviction that the past is always revealed in the narrative through the prism of the present.

Narrativity, according to Danto's correct remark, turns out to be impossible with the assumption of an "absolute chronicle" existence, which would have the ability to display the fullness of the event that occurred in the past. Indeed, if we assume that the historian is able to capture in absolute synchrony all the facets of the "screened" events of his study, it turns out that his story "falls" out of the flow of time and tells about the potentially postulated completeness of the phenomena. In order to find the narration material selection perspective, we need 
to turn to a certain point in time unobtainable in the absolute moment of eternity. Of course, the choice of the basis of the description automatically returns to what was in time beyond the postulated moment of synchrony, incompatible with history as such. In general, the "connection" to time is dictated by the inevitable reference to what happened after the moment of synchrony. Thus, we are forced to discard the opportunity to present the "absolute chronicle," and, therefore, restore to its rights the idea of narrativity as a constant relationship between the events of the past and present. Thus Danto's formulation of the question is quite consonant with Pierce's idea of an unlimited semiosis.

The realization of the contradiction between the ideal picture of the narrative construction and the historical paradigm of the practice of history came to Danto as a result of reading Kuhn's major work, The Structure of Scientific Revolutions, and then familiarization with the works of Michel Foucault devoted to the history of scientific knowledge and discursive formations in their diachronic change. This is the reason why he started speaking about the decline and decomposition of the analytical philosophy of history. "Kuhn advanced a view of history so powerful that, rather than being an applied science, as Hempel holds history to be, history came to be the matrix for viewing all the sciences." 10 This "overnight" approach, as stated by Danto, has become a kind of philosophical fashion, demanding to analyze science in the perspective of history rather than logic. Recognition of the importance of the paradigmality of historical knowledge in fact would require translation of the consideration of the narrative's nature from the standpoint of the study of specific areas and schools of historiography with their inherent ways of theoretical conceptualization and schematization of the studied processes, multilevel principles, nomological generalizations, types of explanations, 
rooted in meta-theoretic assumptions. Especially, of course, this kind of "change of reference points" would have to be accompanied by the study of the role of philosophical and ideological components of the theoretical layer of narrative. This theme is only briefly outlined at the end of Danto's professional career as the next step in the development of his theory of historical narrative, but it does not receive full development in his own constructions, stimulating the search of other theorists of analytical orientation. The next step he made in a number of his interviews was the declaration that historical narratives should be understood as deeply rooted in the existence in time of human beings.

\section{Conclusion}

Danto offered a profound analysis of the relationship between narrativity and historical time. His attention was focused on the sentences giving the description of the past and constituting on the basis of productive historical imagination a narrative as a certain totality that covers particular set of the events in their time succession. The past fixed in sentences that Danto defines as dependent on the process of narrative-making and the expression of the temporal integrity of an event sequence turn out to be important for organizing the present experience. He corrects Beard, saying that not only the present affects the perception of the past, but the past has an impact on our perception of the present. Openly admitting the use of Dewey's philosophical strategy here, Danto at the same time emphasizes the novelty of his own approach. He believes that the priority of the instrumentalist interpretation of historical judgments belongs to him. 
The fact that Danto in the later period of his career realized the contradiction between the ideal picture of narrative construction and the historical paradigmality of history practice was a result of his familiarization with T. Kuhn's opus magnum and then with M. Foucault's works dedicated to the history of scientific knowledge and discourse formations in their diachronic succession. The evolution of Danto's narrativist theory shows the inexhaustible influence of pragmatism. At the same time, his emphasis on the existential origin of the past events reading in the light of the contemporary situation justifies F. Ankersmit's opinion that Danto's narrative philosophical interpretation should be classified as belonging to "analytical hermeneutics."

\section{Notes}

\footnotetext{
${ }^{1}$ Frank R. Ankersmit, "Danto, History, and the Tragedy of Human Existence," in Action, Art, History. Engagement with Arthur Danto, ed. Daniel Hurwitz and Michael Kelly (New York: Columbia University Press, 2007), 175-89.

${ }^{2}$ Arthur C. Danto, Narration and Knowledge (New York: Columbia University Press, 2007), 60-61.

${ }^{3}$ Ibid., 81 .

${ }^{4}$ Charles A. Beard, 'Written History as an Act of Faith,” The American Historical Review 39, no. 2 (1933): 219-31.

5 Arthur C. Danto, “Narrative Sentences,”,History and Theory 2, no. 2 (1962): 167.

${ }^{6}$ Danto, Narration and Knowledge, 110.

${ }^{7}$ Benedetto Croce, Theory and History of Historiography (London: The Ballantyne Press, 1921), 11-26.

${ }^{8}$ Danto, Narration and Knowledge, 132-36.

${ }^{9}$ Danto, "Narrative Sentences," 146.

${ }^{10}$ Arthur C. Danto, "The Decline and Fall of the Analytical Philosophy of History," in A New Philosophy of History, ed. Frank Ankersmit and Hans Kellner (Chicago, IL: University of Chicago Press, 1995), 72.
} 


\section{New Horizons of History and Historical Memory Relations in the Age of Globalization}

Gubman Boris

Tver State University, Russia

\section{Introduction}

Historical memory can be considered as a set of narratively formed ideas about history shared by a certain community of people at some point in time and employed for the goal of self-identification. Historical memory, on the one hand, appears as a certain axiologically colored picture of the development dynamics of a people or a nation in time, and on the other hand, as a set of ideas mediating diverse intersubjective connections in the present - interaction practices, social structures and institutions. By virtue of these aspects, historical memory is understood as an instrument of political power legitimation. It is therefore precisely history as the professional knowledge of the past that has a close yet contradictory relationship with historical memory. Their rapport is invaded by the interests of the power mechanism that dominates society and often seeks to transform history as knowledge into a mythological or deological product that is necessary for strengthening its own symbolic resources. Characteristically, the situation of globalization leaves its ineffaceable imprint on the nature of the production and transmission of historical memory, the immanent reflection of historians about their own field of knowledge and its relationship with the formation of historical memory. 


\section{Historical Memory in the Context of Personal and Collective Experience}

Memory is an undoubted ingredient of the integrity of the experience of human beings and of collective communities. It communicates a historical dimension to personal and collective experience. When approached analytically, the experience of the person conditioned by an existential source is presented as a complete fusion of their worldperception, world-understanding, ways and orientations of activity, united together by the awareness of their own "I." The acquisition of personal identity - the image of the "I" - as a result of the life journey that took place in time sets the basis for the constitution of personal experience. Contrary to the purely empirical interpretation of experience, its formation is manifested as a fusion of sensory, emotional, rational, cognitive, volitional and practical components, subordinated to the purpose of constructing the image of the "I" that is able to maintain its identity through active interaction with the world. Memory organizes the experience of a person, tracing the trajectory of their existence in time. It allows you to connect the images of personal existence in the past and the present into a single whole in the light of openness to the future. St. Augustine realized the unity of memory, direct contemplation and expectation as modes of the soul's existence characterizing the trinity of time dimensions. Considering the flow of mental time in its integrity, continuity and striving forward, he perceived simultaneously the existence of its three facets, emphasizing the primacy of the present in relation to the past and the future. Many important aspects of the formal organization of the relationship between memory and subjective time as the most important prerequisite for its functioning were reflexively described by I. Kant and E. Husserl. The fundamental ontology of M. Heidegger revealed the importance of the understanding of the problem of memory from 
the perspective of its existential foundations. The "Metaphysics of finality," which takes as its starting point the fact of "Verworfenheit" of a human being in the world, suggests that his existence is unthinkable outside the rapid flow of time. The history of mankind and the possibility of historiography are rooted in the historicity of "Dasein." Viewed from this perspective, memory, P. Ricoeur believes, is the ability not only to provide a reflexive self-identity of the individual, but also inevitably to acquire a cultural and historical dimension, inscribing a person in the world in its synchronous and diachronic dimensions. ${ }^{1}$ It should thus be understood as a basis for the interweaving of individual and cultural-historical experience, which is the property of human communities.

The world of culture is a kind of symbolic reservoir of collective experience, nourishing individual experience. In the synchronous dimension, it is objectified in a variety of forms that have a specific structural ordering and objective embodiment associated with the established stereotypes of activity and hierarchy of values. The semantic content of the world of culture exists in a state of perpetual transformation and development. The acquisition of the cultural world's meaningful contents and simultaneously the production of its new phenomena are two parallel processes produced by collective praxis. The diversity of cultural worlds reveals the pluralism of forms of experience of the subjects involved in their milieu. Cultural worlds have a tendency to maintain self-identity, just as a person seeks and clarifies the image of their own "I." Individual and cultural experiences are complementary, they participate in the creation of each other. Cultures are open to each other through the possibility of dialogical translation of their own experience, and this process can hardly be represented today in a linear-progressive way in the spirit of G.W.F. Hegel or K. Marx. Rather, it is similar to the "garden of 
forking paths" (J.L. Borges), or to a computer catalog, "rhizomatic" and subordinated to the synergetic version of the generation of the new.

Historical memory ensures the existence of a diachronic dimension of experience shared by the subjects of a particular culture. It is a product of the perception of the past in the mass consciousness, and is created by the efforts not only of professional historians but also of the makers of the epic works, various genres of fiction, performances, films, television series, and works of art about the past. In short, historical memory is by no means an academic narrative about what happened at a certain point in the past. It acts as "our past," demanded in the name of solving contemporary problems and predicting the future. It is on the basis of historical memory that cultural identity arises.

Historical experience, in the light of H.-G. Gadamer's theory of "effective history," should be understood as the result of the subject's involvement in the events taking place in history. Experience may be defined through categories of faith, understanding, and play. Faith, in Gadamer's opinion, presupposes a preliminary understanding of events presented as propositional knowledge in the form of "forejudgments" contained in the cultural tradition. Indeed, if we take a judgment as an elementary "cell" of knowledge and interpret it as a belief possessing truth status and potential verifiability, then it is obvious that it is based on the already existing "fore-knowledge" that allows us to make it. Understanding is born within the boundaries of the hermeneutic circle, the expansion of which is achieved through a constant "merging of the horizons" of the past and the present, as well as incessant questioning. The game is also associated with the unpredictability of the event, which demands consideration and a response on the part of the subjects involved in it. ${ }^{2}$ Eventfulness 
should be considered as a moment dictating the unpredictability of the expansion of the field of historical experience, its openness.

The effect of merging the time horizon of past and present experience gives rise to the need for historical memory. The present constantly addresses its questions to the past in search of the origins of the contemporary state of society and culture. Paradoxically, the past can also raise questions that need to be answered in the present. Questions arising from the present are born in the context of intersubjective relations within the boundaries of different cultural worlds. They are the result of a polylogue going both within and between individual cultural worlds. In view of this issue, productively represented in the works of H.-G. Gadamer, R. Kozelleck, H. R. Jauss, P. Ricoeur and other authors, one can say that the dynamics of the portrayal of different contemporary cultural worlds determines the conditions for setting questions addressed to the past.

\section{Historiography and Historical Memory}

Historical memory and history as a specific academic discipline have a common ontological source - the existence of man in time. They both use the narrative form of comprehension and representation of the past. Narrative as a way of understanding history, unlike the theoretical constructions, for example, of natural science, portrays different periods of history in their connection with the present. This applies equally to both artistic versions of the narrative and to the practice of history as an academic discipline. The story about the past always presupposes the vision of its fragment in the context of history as an integral unity, even with a targeted focus on the totality of the events of the past that directly or indirectly excite interest today. Even the crisis of classical philosophy of the history of modernity and 
the attempts to reject general theories of historical development are unable to completely remove the question of how histories of different periods, peoples, and countries fit into the format of the universal human history. Individual stories that become the property of the community of professional historians or a wider audience under the influence of the popular presentation of academic knowledge, as well as artistic, figurative interpretations, one way or another always claim the scale and significance that is established in the perspective of history as an integral whole.

I. Kant rightly emphasized the regulative significance of the idea of universal history that allows for grasping the diversity of events happening in time in the perspective of their unity. However, his vision of the idea of universal history was marked by the conviction of the steady triumph of the process of theoretical and practical reason. It anticipated Hegel's approach to the idea of universal history not only as a regulative tool for its understanding, but also as a constitutive basis for "making" socio-cultural reality. R. G. Collingwood, who was a neo-Hegelian, did not share his teacher's progressive optimism, but considered it necessary to recognize the role of the a priori idea of history inherent in human consciousness as a universal prerequisite for historical thinking. ${ }^{3}$ Indeed, the understanding of particular histories becomes possible on the background of a universal history, which, of course, can be interpreted in different ways. Contemporary history, which has reached the highest degree of universality of human relations, powerfully reminds us of this circumstance. In this regard, the very situation of Dasein presence in the flux of time, always surpassing specific narratives, gives rise to the desire to include particular stories in the unity of history, which is open and unpredictable. ${ }^{4}$ Thus the understanding of 
history is based on different conceptual strategies and ontological assumptions that are subjected to change in the course of time.

Historical memory differs from academic historiography in the way of its "appropriation" of the historical past, although they are inextricably interrelated. Of course, since historiography and historical memory both rely on the phenomenon of connection between the past and the present, they can mutually cooperate. However, it is historical memory that claims to "appropriate" the past for the purpose of the practical development of the present state of affairs in the interests of a certain community. It is this kind of attitude towards the past that allows us to qualify it as "our past."5 Organizing the experience of the community, historical memory affects the present and serves as the basis for projecting the future. Due to this, historical memory is focused primarily on the national-cultural moment of "our past" by its value-colored appropriation of experience. History, on the contrary, even if it is focused on the comprehension of the national past, claims a certain distance from the practical use of its data thus protecting the academic character of its own image. At the same time, it should be noted that the image of the craft of a professional historian has changed significantly under the influence of the "criticism of historical reason," and, in particular, contemporary narrativist theories.

Having assimilated many ideas from the philosophy of life, neoKantianism, existential hermeneutics, various versions of analytical philosophy, poststructuralism and other trends that contributed to the "criticism of historical reason," representatives of the Anglo-American analytical philosophy of history and continental hermeneutics developed the theory of narration, showing the fundamental relationship and difference between artistic and historical narrative. The narrative appeared in this perspective as existing simultaneously 
with the synchronous-theoretical and philosophical-categorical forms of knowledge as a specific type of understanding of the world and of human existence.

Already on the level of building an elementary historical sentence, the historical event receives semantic content that depends on subsequent events and their connection with the present (A. Danto). ${ }^{6}$ The historical narrative is a certain chain of events, which are deployed step by step by the power of the imagination of the author, requiring the reader's attention (W. B. Gallie) and, in the final instance, appearing as some reflexively constituted integrity (L. O. Mink). If individual historical propositions are verifiable from the point of view of their truth content, the narrative as an integral unity cannot be evaluated as true or false, because it selectively contains events chosen by its author and portrayed by cause-and-effect relationships. At the same time, it turns out that the historical narrative, whether by its appeal to a certain idea or the intrigues of its narrative composition, is largely similar to the literary narrative (L. O. Mink, H. White, P. Veyne, H. Kellner, etc.). In the end, as Ricoeur rightly believes, all these features of the historical narrative are rooted in Dasein presence in the world M. Heidegger spoke about. Following H.G. Gadamer in his interpretation of the dynamics of historical experience, Ricoeur showed that the coming of the unforeseen event of the present entails the need to respond to it through the prism of the language of tradition. This is the inexhaustible source of a variety of narratives about the past, related to the present. The historian, reproducing the worlds of the past, portrays them in the world of his narration addressed to the world of the reader. At the same time, it is obvious that historiography can be oriented in different ways: it can serve the discourse of power uncritically or challenge it, calling for revision of the picture of historical memory. Both of these possibilities 
of history were implemented in various ways in the past and are being embodied in the present context of globalization.

\section{Conclusion: Historical Memory in the Global World}

Globalization, uniting the planetary community, carries out this effect on the basis of previously existing and new media. A unified information space, which is the result and condition of globalization, brings with it new opportunities for the formation of historical memory, but, at the same time, it does not lead to the formation of a standardized picture of historical reality. On the contrary, a polylogue of various nationally colored and media-based pictures of historical memory is produced.

In the era of globalization, the power mechanisms of national-states actively use media to ensure the effective functioning of historical memory. Significant historical sources and studies, from historically focused works of fine art, literature, cinema (especially documentary films), records of lectures of professional historians in electronic archives, are today available through a network of libraries, museums and the Internet (H. Lübbe). Socio-cultural space as a whole has reached museum dimensions (A. Malraux, G. Vattimo). P. Nora offers in this regard his diagnosis of the collapse of the organically existing society based on the history of national identity and the formation of the politics of memory, designed in the era of the triumph of the present and the oblivion of the past, that should revive society's connection with tradition. He correlates the politics of memory with the professional work of historians with "places of memory" helping to restore the connection of the past with the present and the future through remembrance. It is natural that, at the same time, images of historical memory in the service of power, and, first and foremost, in 
the interests of national states, are considered primarily in their social-mythological and ideological functions. In the global media space, there is a radical confrontation of different pictures of historical memory associated with political alliances and conflicts.

At the same time, the media space in the era of globalization creates quite productive grounds for the critical and reflective work of professional historians. This effect is produced, first of all, thanks to the contacts with a global audience in the media and Internet environment: not only lecture courses of historians, but also interviews with them on topical issues, video broadcasts of professional discussions, seminars and conferences allow them to convey their point of view on a particular subject to a significant number of interested people (P.J. Beck). ${ }^{7}$ Popularizers of historical knowledge, like, for instance, S. Schama or E. Radzinsky, are able to gain the popularity of media stars. The search for correct and reasonable representations of historical events in narratives often results in confrontations of professional historians with the official ideas and versions of historical memory. The latter are often, as shown, for example, by P. Nora, shaken by critical-reflective reasoning. 8 The idea of history, which is most consonant with modernity in the interpretation of R. D. Collingwood, appears in its polyphonic version as a call for the unending search for a vision of the integrity of the past in the horizon of the present and its problems. It is the key to the transformation of historical knowledge and, therefore, in the final analysis, of historical memory, which ultimately determines the dynamics of socio-cultural change. 


\section{Notes}

${ }^{1}$ Paul Ricouer, Temps et récit III. Le temps raconté (Paris: Editions du Seuille, 1985), 358.

${ }^{2}$ Hans-Georg Gadamer, Philosophical Hermeneutics (Berkeley: University of California, 1976), 53.

${ }^{3}$ Robin George Collingwood, The Idea of History. Revised Edition with Lectures, 1926-1928 (Oxford: Oxford University Press, 1994), 356.

${ }^{4}$ Martin Heidegger, Sein und Zeit (Tübingen: Max Niemeyer Verlag, 1986), 375.

${ }^{5}$ Hyden White, The Practical Past (Evanston: Northwestern University Press, 2014), xiii-xiv.

${ }^{6}$ Arthur C. Danto, Narration and Knowledge (New York: Columbia University Press, 2007), 167.

${ }^{7}$ Peter J. Beck, Presenting History (New York: Palgrave Macmillan, 2012), 303-4.

${ }^{8}$ Pierre Nora, "Between Memory and History: Les Lieux de Mémoire," Special Issue: Memory and Counter-Memory, Representations, no. 26 (Spring 1989): 7-24. 


\section{Representations of the Chuvash People's National Narrative Erbina Nikitina and Gennadiy Trifonov \\ Cheboksary Cooperative Institute, Chuvashia Republic, Russia}

\section{Introduction}

One of the conditions for preserving a people's national character and tradition is the representation of its history and culture in its national (ethnic) or national-state narrative. A national narrative is a story about the significant events in the life of a people that define its existence and constitute an important part of its national identity. The national-state narrative includes the linear history of the nationstate, in which the state is united with the people (nation) and represented as a single whole.

Such a narrative is the basis for social interaction and translation of experience, and also highlights significant ethno-cultural elements. ${ }^{1}$ As a socially oriented form of knowledge, the national narrative reconstructs the people's past in accordance with the current needs of society, and thus exercises control over the people's social memory. ${ }^{2}$ The process of forming the content of the national-state narrative is often contradictory. On the one hand, the narrative sets the basic parameters of the worldview and an adequate image of the past, which are supported by the people's historical consciousness (as expressed through its folklore, literature, journalism, visual arts). On the other hand, by using the national narrative, the current government can impose on society the what it sees as the "necessary" history for its own political and economic intersts and aims (through the official media and the celebration of memorable dates, the revision of educational and reference books on national history, etc.). Since the creation of a nation's identity begins with school, the "memory policy" 
is in the direct interest of the state, whose task includes the upbringing of loyal citizens. ${ }^{3}$

As a result of the development of information technologies (especially the internet and digital media), not only professional historians, philologists and linguists have the opportunity to express their views on the past, but also nonprofessional historians, history buffs, publicists, and bloggers. And it is the latter who are mostly the authors of modern national narratives. Their works (unlike most scientific works) are aimed at a wide audience and are accessible and easy to understand and thus have a higher degree of effectiveness.

In the European historiography of the 20th century, the national-state narrative was "the main instrument of compilation into the public consciousness of the British, Germans, French, Russians, etc. of the ideas about the special value of their own state, which has followed a long and difficult path during its construction."4 The Chuvash narrative ${ }^{5}$ the first samples of which appeared in the 19 th century (Spiridon Mikhailov, Ivan Yakovlev, Nikolai Nikolsky and others), should have been built on this principle. However, since the modern Chuvash people never had state independence in the full meaning of the word (in 2020 the 100th anniversary of the Chuvash autonomy within the framework of the Russian state will be celebrated), the Chuvash narrative in the 20th century did not rise to the level of a national-state narrative. Obviously, this will not happen in the 21st century either: in 2012, the Constitution of the Chuvash Republic lost the status word "state" in the definition of the Chuvash Republic. In this regard, the modern Chuvash narrative is still being built on the peripeteias of the "long-suffering fate" of the Chuvash people and the biographies of its outstanding personalities.

The modern Chuvash national narrative is based on classic theses: a story about the origins of the people (the search for the "golden age"), 
the fate of warlords and national heroes, and a description of the ancestral lands and territories inhabited by the Chuvash people. ${ }^{6}$ It also includes the origins and characteristics of the people's religious beliefs, the roots and conditions for the preservation of the national language, folklore and culture, the stages of development of the national movement, the functioning of the national media. The elaboration on these elements in the national narrative reveals the level of development of national self-awareness, the level of ethnic well-being and the specificity of ethnic mentality as an ethno-social matrix of behavior, thinking and communication.

\section{The Origin of the People}

Since the myth of origins is a central element in the identification and integration of a people, the Chuvash people, who have been in the shadows of history for centuries ${ }^{7}$ diligently seek their "golden age" either in Mesopotamia and Central Asia, or in the Volga Bulgaria. The fact that the Chuvash people are descendants of the Volga Bulgars was first announced by the Russian historian Vasiliy Tatishchev, who knew the Volga region from his own experience. In his work "Russian History from the Most Ancient Times," he wrote multiple times about "Chuvashs, ancient Bulgars" and "remaining Bulgarian peoples,

Chuvashs." However, in the 20th century the issue of the Bulgarian origins of the Chuvash people was politicized due to the fact that a reference to the Volga Bulgars was also included in the history of the Volga Tatars.

\section{National Heroes}

The key figure in the modern Chuvash narrative is the educator Ivan Yakovlev, who lived at the turn of the 19th century. The Chuvash 
State Pedagogical University bears his name; many museums and monuments in the capital of the Chuvash Republic, the city of Cheboksary, are dedicated to him.

Yakovlev sought the symbiosis of the Chuvash and Russian worlds with the introduction of Orthodoxy into the Chuvash culture approved by the authorities. This credo is at the center of his Testament to the Chuvash People, which today is one of the most cited texts in the national narrative, primarily due to its endorsement by the official authorities of the Chuvash Republic. Yakovlev's words "Believe in Russia, love her, and she will be your mother" were the leitmotif during the celebration of his 170th anniversary in 2018.

Besides Ivan Yakovlev, the Chuvash revere the Civil War commander Vasiliy Chapaev and Soviet astronaut No. 3 Andriyan Nikolaev as their national heroes. Their names are continually broadcast in the ethnic media.

\section{The Territory of the Chuvash Region}

The most popular topic on this point in the Chuvash national narrative is the proposal of the leader of the young Soviet state Vladimir Lenin in 1920 to form the Chuvash Republic with the capital in the city of Simbirsk, which the chairman of the Chuvash regional executive committee, Daniil Elmen, refused for unknown reasons.

Historian Sergei Shcherbakov from Cheboksary believes this to be an artificially created myth, according to which in 1920 Lenin made the offer to Elmen regarding the capital city three times. ${ }^{8}$ However, he immediately quotes a brochure published by the Presidium of the Chuvash Autonomous Region: "The question of the formation of the Chuvash Autonomous Soviet Socialist Republic with a center in the city of Simbirsk was first raised by V.I. Lenin at a meeting of the 
Council of People's Commissars, when the question of organizing the Chuvash region was discussed."9 This question still remains open and, moreover, attractive from the point of view of exaggerating the legend of the great possibilities that the great people had once missed.

\section{Religion}

In the European national-state narratives, Christianity was always positioned as one of the most important features that determined the national spirit of their peoples. ${ }^{10}$ The Chuvash people in their national narrative translate the hypothesis of the Zoroastrian roots of their ethnic religion. Specialists who studied the Chuvash ethnic religion (Alexander Trofimov, Anton Salmin, Vitaliy Stanyal and others) represent the Chuvash traditional faith as a developed independent religious system, which contains traces of the Sumero-Akkadian, Hurrian, Judaic-Khazar, Arab-Islamic and Slavic-Christian culture. Alexander Trofimov insists that "the ancestors of the Chuvash were in the midst of developed civilizations, creating rich cultural values. Zoroastrianism was their religion."11

One of the main postulates in the Chuvash ethnic religion, as in the Avesta, is the dualism and cyclicality in the development of the world. ${ }^{12}$ The Chuvash prayers reflect Avestan formulas of idioms, principles of versification, names of gods and spirits.

\section{National Language}

The role of language as a factor in the formation of national identity and of folklore as an expression of an ethnic culture cannot be overestimated. Currently, the national Chuvash narrative emphasizes the fact that the Chuvash language is the only living representative of the Bulgarian group of Turkic languages. The topic of preserving, 
relaying and social functioning of the native language has been particularly relevant for the past three decades. It had special pungency in 2018, when the Federal Law "On Education in the Russian Federation" was amended, according to which school education in the native languages of the peoples of the Russian Federation and the state languages of the republics of the Russian Federation was made a matter of choice on the basis of an application from parents of schoolchildren. ${ }^{13}$

As for the future of Chuvash language, the collective interview of Cheboksary philologists, journalists and teachers reflecting on the the prestige of the Chuvash language published under the title "Chuvash will last no more than 50 years?" can be considered indicative. ${ }^{14}$ The forecasts of specialists in the field of language are pessimistic.

\section{National Movement}

The first wave of the national movement came to the Chuvash with the popular revolution of 1905. A group of educated Chuvash politicians (Timofey Khuri, Gavriil Alyunov, Dmitriy Petrov-Uman, Nikolay Nikolskiy, Agafya Gavrilova) led a wide propaganda campaign of populist ideas. The second massive upsurge in the national movement was caused by the revolutions of 1917, the preparations for the elections to the All-Russian Constituent Assembly, and the formation of autonomy.

For the modern Chuvash narrative and national consciousness, the activities of the non-profit organization Chuvash National Congress, established in 1992, are of vital importance. The founder of the congress, philologist and local historian Vitaliy Stanyal notes: "The local branches and national-cultural autonomies of the diaspora have shown enviable persistence in protecting their spiritual and national 
interests."15 The Chuvash people of Bashkortostan, Tatarstan, Ulyanovsk, Leningrad, Moscow, Krasnoyarsk, Samara and other regions managed to quickly organize themselves and establish stable activities among the population. Meetings of Chuvash nationalcultural autonomies are conducted in many other regions in Russia and the rest of the world (USA, Germany, France) as well.

\section{National Media}

The conditions for the mass distribution of narratives throughout Russia existed only in the 1930s, and this effort was associated with the mass elimination of illiteracy and the introduction of compulsory school education. But in the national narrative of the Chuvash on this topic there is an important argument that refers to the beginning of the 20th century, namely, to the foundation of the first socio-political newspaper published in the Chuvash language in 1906. The Khypar, seen as the "peasant Chuvash newspaper," can be considered a mass medium because it was a powerful tool for informing and educating the Chuvash masses, a mouthpiece for propaganda and relaying the national narrative.

By founding the Khypar, its first editor-in-chief Professor Nikolay Nikolskiy brought the Chuvash people to the forefront, since other indigenous peoples of the Volga region had no national newspapers. In 2017, the Volga Internet site "Idel.Realii," in the framework of the rubric "Volga region 100 years ago," published materials from the Khypar of 1917 (translated into Russian). This public attention to the hundred-year-old Chuvash newspaper has become an important part of the modern national narrative of the Chuvash. 


\section{Conclusion}

A national narrative cannot be separated from a people's ethnic mentality, understood as the generally accepted patterns of thinking, behavior and communication that enable the development of a collective self-identify. The peculiarity of the ethnic mentality reflects the peculiarities of the socio-political status of the people, which is formed in the process of the historical development of the nation and is recorded in the national narrative.

In our opinion, the main idea of the national Chuvash narrative in modern Chuvash historiography is most adequately expressed in Austrian historian Andreas Kappeler's book, Die Tschuwaschen. Ein Volk im Schatten der Geschichte (Chuvashs: People in the shadow of history). ${ }^{16}$ Kappeler writes that throughout the history of the Russian state, the Chuvash people were in the shadow not only of the Russian, but also of the Tatar people. This is reflected in the mentality of modern Chuvashs: while having an ancient history, a unique language and a rich culture, the Chuvashs are forced to realize and accept that they, nevertheless, are in the shadow of peoples who due to historical, socio-political and geographical factors are ahead of them in the areas of population size, ethno-cultural demand, state independence and financial well-being.

Collective memory is quite selective, and the national narrative mainly broadcasts those moments from the past of the people that contribute to its normal positive ethnic identification in the present. In any national narrative, the prospect of the development of history must necessarily be present. The history of the nation should be constructed in the form of "a continuous line directed, most likely, to infinity and showing an upward movement, continuous development, despite possible recessions and failures." 17 Narratives associated with the actualization of the mortality of a nation as a community, ${ }^{18}$ 
existing since the beginning of the 20th century in the form of the rhetorical question "Does the Chuvash people have a future?" (Guri Komissarov-Vander), were supported only by a certain part of the Chuvash intelligentsia (Mikhail Sespel, Boris Chindykov). On the whole, death and depression did not become the leading line in either the modern Chuvash identity or the modern Chuvash narrative.

In the 20th century, the narratives of small indigenous groups in Russia successfully fit into the grand narrative of a large nationalstate community - the Soviet and post-Soviet Russian people. At critical moments in history, small nations, along with Russians, came to the defense of the united Fatherland (for example, during the years of the Civil and Great Patriotic Wars), and these heroic events had a noticeable effect on the conflict-free infusion of many ethnic narratives into a single national-state narrative of a multinational country. However, against the backdrop of globalization, these positive trends are gradually being leveled. At first, this was due to the forced unification of the intellectual space and the revival of the negative trends of Russian nationalism since the 2000s. Secondly, the Chuvash identity, as well as the identity of all the small peoples of Russia and other countries, nowadays faces challenges of adaptation to the Internet world, which involves the withering away of traditional identities and their gradual migration into virtual space. ${ }^{19}$

The new Chuvash narrative adequately reflects the position of the people in the structure of the Russian Federation (lack of statehood and political independence, the threat of the disappearance of the national language and culture, the unattainability of the region's financial well-being, etc.), but at the same time, it outlines ways out of the current situation so as not to lose hope in the original development of the culture based on traditional foundations. Often found in modern Chuvash fiction and journalistic literature, the old saying "Chuvash 
will disappear then the world will disappear," translated by the national intelligentsia, most likely, on an intuitive level, has a huge positive potential. This worldview and sociocultural orientation to the relative "eternity" of their own nation passes from the national narrative to the ethnic mentality. This will allow the Chuvash people in the near future to preserve their ethno-cultural "anchors" in the era of globalization and integration of the peoples of the world.

\section{Notes}

\footnotetext{
${ }^{1}$ I.V. Aleshanova, "Narrative as a Cultural Model," Bulletin of the Novosibirsk State University, Linguistics and Intercultural Communication Series, vol. 4, no. 1 (2006): 42.

${ }^{2}$ S.I. Malovichko, “National-State Narrative as a Kind of Socially Oriented Historiography, ”Bulletin of St. Petersburg University, series 2, no. 4 (2015): 127.
}

${ }^{3}$ Nations and Ethnicity in the Humanities. Ethnic, Protonational and National Narratives: Formation and Representation, ed. O.H. Daudova and S.E. Fedorova (St. Petersburg: Aletheia, 2017), 13.

${ }^{4}$ Malovichko, "National-State Narrative," 132.

${ }^{5}$ According to the 2010 All-Russian Census, the Chuvash people are the fifth most numerous population in the Russian Federation.

${ }^{6}$ Daudova and Fedorova, Nations and Ethnicity in the Humanities, 5.

${ }^{7}$ Andreas Kappeler, Die Tschuwaschen. Ein Volk im Schatten der Geschichte (Köln-Weimar-Wien: Böhlau Verlag, 2016), 33.

${ }^{8}$ Ersubay Yangarov, "What Brought Chuvash and Jews Closer in 1917? And Could Ulyanovsk Become the Capital of Big Chuvashia,” Idel.Realii 27 (October, 2017). Retrieved from https://www.idelreal.org/amp/chuvashi-i-evrei-1917-revolution/28820648.html.

${ }^{9}$ Ibid.

${ }^{10}$ Malovichko, "National-State Narrative," 131.

${ }^{11}$ A.A. Trofimov, Zoroastrianism: Suvar-Bulgarian and Chuvash Folk Culture (Cheboksary: ChGIGN, 2009), 3.

${ }^{12}$ V.P. Stanyal, “Chuvash Folk Religion Sardash,” Society. State. Religion (Cheboksary: ChGIGN, 2002), 96.

${ }^{13}$ On Amendments to Articles 11 and 14 of the Federal Law "On Education in the Russian Federation," Federal Law, N 317-FZ (2018). Retrieved from http://www.consultant.ru/document/cons_doc_LAW_304090.

${ }^{14}$ Ersubay Yangarov, “Chuvash will last no more than 50 years?”,Idel.Realii 20 (February, 2017). Retrieved from https://www.idelreal.org/a/28317621.html (accessed June 10, 2018). 
${ }^{15}$ Chuvash National Congress: 1992-2017. Documents and Materials, ed. A.P. Leontiev (Cheboksary: Publishing House "Free Poetry," 2017), 347.

${ }^{16}$ Kappeler, Die Tschuwaschen. Ein Volk, 10.

${ }^{17}$ G.B. Gutner, "National Narrative and National Responsibility," Ethical Thought, vol. 17, no. 1 (2017): 102.

${ }^{18}$ M.V. Kirchanov, "Narratives of Wilěm in the Discourse of the Chuvash (post) Modern Literature," Special Issue of the Russian Journal of Nationalism Studies no. 1-2 (2015): 9.

${ }^{19}$ Ibid., 58, 63. 


\section{Dominick LaCapra: Trauma and the Politics of Memory}

Vera Potamskaya

Tver State Technical University, Russia

\section{Introduction}

The politics of memory is an activity aimed at producing images of the past in the contemporary context through various verbal and visual means. It can be used to actualize a particular image of the past. It is included in the wider context of symbolic policies, the purpose of which is to produce mass-consumed images that increase the degree of consolidation and minimize political risks.

In the case of politics of memory, we are talking about collective memory. Maurice Halbwachs introduced this concept to the study of social reality in the $1920 \mathrm{~s}$. According to him, memory is socially determined. On the personal level, memory is the outcome of socialization and is impossible without a social context. Both individual and collective memory coexist in the intersubjective communication space. Collective memory is strongly associated with a particular subject and cannot be transferred to anyone else. So, collective memory is a special form of the "presence of the past" (traditions, "concepts," "school knowledge," "symbols," etc.) and is formed in the depths of social institutions and bodies (family, school, religion, class). ${ }^{1}$

Aleida Assmann's interpretation of cultural memory was largely based on Halbwachs's theory. A new relationship between the past and the future, proclaimed within the framework of cultural memory implies not only recognizing the impact of the past on the present and the future, but also a reassessment of the past in the light of the current state of our knowledge. ${ }^{2}$ 
From the point of view of cultural memory, the past serves not only as a subject of knowledge that can be handed over to the archive, but also as a parameter of human experience, memories, feelings and identity. ${ }^{3}$ Cultural memory plays a significant role in the politics of identity. It is based on a connection with history and the principle of a voluntary and conscious choice of collective affiliation. Thus an essential element of identity is the awareness of belonging to history. Identity is not just a stable, imaginative structure that retains its stability. It arises only in the present thanks to the choice that determines its character local, cultural, national, transnational. The construction of identity can be based on the policy of self-affirmation, which is a uniquely positive construction of national identity, building a narrative of continuity with episodes demonstrating the greatness, significance, and past of a nation. Another strategy can be named the policy of repentance. It involves the recognition of crimes committed in the past and is based on breaking and changing. ${ }^{4}$

Contemporary intellectual historians have demonstrated the existence of an ideological dimension in all historical texts, which is connected to the engagement of historians, the inability to eliminate the historian's subjectivity from the text, and the constructivist nature of historical knowledge. An important feature of the assertion of the history of memory is its transformation into an important component of the collective representations of the group which always depend on the present. In this sense, any memory of history is the politics of using the past in the present.

\section{The Theory of Memory}

The theory of memory is based on a special relationship between time, identity, and culture. In this scholarly field, the past does not die, but 
rather serves the cause of disputes and disagreements focused on memory and oblivion. The past may be approached as the area related to claims, confessions and accusations, as the subject of appropriation and rejection. According to the theory of memory, the past depends on the changing views and needs of people living in the present. In other words, the past as such does not exist at all, but it can always be retrieved, presented and saved only by means of certain objects, ideas, representations and performances within the framework of certain interpretations. ${ }^{5}$

According to Dominick LaCapra, memory is one of the key elements in the process of understanding the past. On the one hand, memory raises questions about the history of current issues which are explored with a certain degree of emotionality and characteristic values. On the other hand, historians critically examine memory and prepare it for working through. LaCapra distinguishes between two approaches to the interpretation of memory. In the first instance, memory is crucial because it is what history must define itself against, whether happily or sadly. Memory, in brief, becomes the antithesis or "other" of history. In the second instance, memory's importance stems from its putative position as the ground or essence of history. Memory is then understood as basically the same as history or at least as history's matrix and muse. The first tendency often leads to a neo-positivist understanding of history as a dry and sober matter of fact and analysis and to a suspicion of memory as inherently uncritical and close to myth. "Memory not only plays tricks; it is purportedly constituted by its tricks, which make it intrinsically unreliable as a historical source. The second tendency induces a fictionalizing if not mythologizing idea of history that is insensitive to the tricks memory plays and to the reasons for those tricks." 6 So, we can speak of the binary nature of history and memory. History is evaluated in 
accordance with memory, and simultaneously memory is accessed in cooperation with history.

According to LaCapra, Pierre Nora's approach to memory is a simple neutralization of trauma and an insufficient basis for a critical attempt to working-through someone's implications during the research process. For Nora, memory and history are far from being synonymous, they are essentially opposites ${ }^{7}$ LaCapra, in turn, argues that memory is not identical to history, but at the same time is not opposed to it. Memory is an essential source for history. Even in its falsifications, memory can be informative from the position of the anxious perception and assimilation of what happened to participants in events and those born later at the same time. Moreover, a critical approach to memory is important in attempts to determine what deserves to be preserved as an existing tradition in history and what needs to be avoided. ${ }^{8}$

History, in turn, explores memory from a critical position and determines what is empirically correct or has a different status. As soon as the story loses contact with memory, it turns into "dead" problems that don't arouse an evaluative and emotional interest. The past itself is an integral part of culture, human existence, individual reflection and collective identity. This applies not only to the positively evaluated events of the past which are fixed in traditional narratives and serve as the basis of collective self-consciousness. Also mass political mobilization can be carried out through it. This also applies to the negative experiences of individual or collective suffering which remain unsaid for a long time in the form of trauma or guilt.

The breaks of historical continuity are not only accompanied by the rejection of the past, at the same time they generate an increased interest in the restoration of the past. For people who have experienced traumatic events, they are not a thing of the past. They 
remain relevant to the present not only because of the pathological impact, but due to their ethical nature.

\section{Trauma and Memory}

Trauma, which leads to the reconfiguration of historical experience and disrupts the relations between fundamental historical links of past, present and future, is the focal point of LaCapra's theory of historical memory. Memory is significant in the context of delayed recognition of traumatic series of events in recent history. Traumatic events have a tremendous impact not only on the victim, but also on all those who were in contact with the traumatic reality. Trauma entails collapses and ruptures in memory that destroy continuity with the past thus produce a threat to identity and a possibility of subsequent identity destruction. ${ }^{9}$

According to LaCapra, it's important to distinguish between structural and historical traumas. Structural trauma is a condition of possibility which generates potential for trauma and empirical forms of historical trauma. Historical trauma correlates to concrete historical events and significant losses, for example, the Holocaust, the apartheid regime, the atomic bombing of Hiroshima and Nagasaki. Such traumas can be a cause of identity disruption as well as a basis for identity construction. ${ }^{10}$

The use of narrative is one way of representing trauma. Its beginning should be interpreted as the supposed source designed as a version of full or intact presence. The middle of the narrative should portray a loss of this original state as a result of misfortunes or disasters. The end of the narrative should describe a restoration of this state, at least at the level of deep understanding. Similarly, historical narration is a story that is always organized as some kind of integral unity 
describing the historian's chosen chain of events of the past correlated with the moment of the present, in which the author of the story lives. ${ }^{11}$ In this regard, the linguistic turn has had a significant influence on LaCapra, although the interpretation of the narration problem as a central one for grasping the nature of history is estimated by him as quite controversial. He recognizes the importance of narrative as a social practice, but notes that a linguistic turn should not be identified only with a narrative turn. And it is less insightful to try to reduce non-narrative genres (essays, lyrics, statistical analysis, polemics, parody, satire, dialogue) to narrative as a putative "urtext." Similar statements are based on an overly general concept of narrative. ${ }^{12}$

Psychoanalysis, which draws LaCapra's special attention, represents other non-binary analytic discernible processes of experiencing trauma: "acting out" and "working through."13 In acting out the subject is characterized by a mimetic approach to the past expressed in its renewal as fully present, rather than simply represented in memory and narration. Working through makes even trauma possible in the process of self-identification, implying a different dimension of performance, and interrelation with the past when its difference with the present is recognized. LaCapra considers mourning and memory in the context of working through. Mourning enacts a specific performative attitude to the fact that is simultaneously fixed and from which it undertakes a partial departure, allowing a critical judgment of what happened and the possibility of including trauma in the processes of self-identification. ${ }^{14}$ Memory works as a tool for remembering mistakes and erroneous actions, as a critical avoidance of the least desirable elements of the past, and it appears as an attempt to honor other details of the past or to make them the basis for constructive actions in the future. 


\section{Testimonies, Memory, and Trauma}

Testimony of surviving witnesses takes on special meaning in the context of memory and trauma. It is a prevalent genre that emphasizes the problems of interaction between the actual and the fictional. The famous French historian A. Vivierka has called the modern period an era of testimony and witnessing. Other researchers, such as Geoffrey Hartman and Aleida Assmann, characterize testimony as a newly-created genre, which distinguishes the modern era. Giving testimony involves the attempt to address or give an account of the experience one has had oneself and through which one has lived. In a sense, one might understand giving testimony as the fallible attempt to verbalize or otherwise articulate bearing witness. Testimony is itself both threatened and somehow authenticated or validated insofar as it bears the marks of, while not being utterly consumed and distorted by, the symptomatic effects of trauma. But testimony shades into various kinds of commentary on experience and the events it involved. A survivor who gives testimony may also produce various kinds of commentary and even have testimony influenced or shaped by commentary and by exposure to the media or signifying practice such a films, novels, or histories, on the level both of construing events and of templates for narratives or interpretations. ${ }^{15}$

Testimonies become the preferred way to access past and traumatic events. They provide insight into life experience and its verbal and non-verbal transference. The testimony and witnessing brings together the ethical working-through of the past underestimated by positivistoriented historians in the witnessing and exaggerated by researchers in relation to testimony. Testimonies are one of the most important sources in the framework of powerful movements for the emancipation 
of social groups, each of which required its remembrance and its recognition by the nation. Gradually, the "national memory" began to be crowded out by group memory.

At the state level, decisions concerning memory politics are usually made in close connection with the interests of various groups of civil society, as well as by intellectuals. They are also determined by the dynamics of historical research that supplies new materials. The politics of memory is more than just the formation and consolidation of a normative or dogmatic worldview, because it involves the transfer of all sorts of memories and experiences, as well as the search for forgotten facts and traces of rejected alternatives. Historical politics also implies the formation of identity. The individual pages of history are used during the construction, maintenance and reproduction of an identity. The specific features for each of the countries are the same: events, personalities, "places of memory" and individual symbols borrowed from the national culture.

\section{Conclusion}

History and memory are connected with each other, and they coexist mutually correcting one another. According to the established consensus, the memorial culture is blind without historical scholarly knowledge, and history is empty without interaction with memory.

Memory, trauma, and history have a close relationship. First, memory is important in the context of deferring recognition of the significant traumatic series of events in recent history. Traumatic events have a tremendous impact not only on the victim but also on those who have been in contact with the traumatic event: the collaborator, the witness, as well as those born later. Trauma entails breaks and ruptures in memory that destroy the length of the past, putting 


\section{identity at risk and even creating opportunities for its subsequent destruction.}

\section{Notes}

\footnotetext{
${ }^{1}$ Maurice Halbwachs, La Mémoire collective (Paris: Albin Michel, coll. Bibliothèque de l'évolution de l'humanité, 1997).

${ }^{2}$ Aleida Assmann, Cultural Memory and Western Civilization: Functions, Media, Archives (Cambridge: Cambridge University Press, 2012).

${ }^{3}$ Jan Assmann, Das kulturelle Gedächtnis. Schrift, Erinnerung und politische Identität in frühen Hochkulturen (München: C.H. Beck, 1992).

${ }^{4}$ Aleida Assman, Ist die Zeit aus den Fugen? Aufstieg und Fall des Zeitregimes der Moderne (München:
} Hanser, 2013), 186-88.

5 Ibid., 198.

${ }^{6}$ Dominick LaCapra, History and Memory after Auschwitz (Ithaca, NY: Cornell University Press, 1998), $16-17$.

${ }^{7}$ Pierre Nora, Realms of Memory: The Construction of the French Past (New York: Columbia University Press, 1998).

${ }^{8}$ LaCapra, History and Memory after Auschwitz, 19-20.

${ }^{9}$ Ibid., 9 .

${ }^{10}$ Dominick LaCapra, “Trauma, Absence, Loss,” Critical Inquiry, vol. 25, no. 4 (1999): 696-727.

${ }^{11}$ Boris L. Gubman, “A.C. Danto and P. Ricœur: Narrative as a Tool of Historical Knowledge,” Russian Journal of Philosophical Sciences = Filosofskie nauki 10 (2018): 147.

${ }^{12}$ Dominick LaCapra, History and Its Limits: Human, Animal, Violence (Ithaca, NY: Cornell University Press, 2009), 195-220.

${ }^{13}$ LaCapra, History and Memory after Auschwitz, 9.

${ }^{14}$ Ibid., 183-84.

${ }^{15}$ LaCapra, History and Its Limits, 60-61. 


\section{Workshop 7}

Language and Nationality: Between Globalization and

Localization; and Journalism, the Media and the Viability of Democracies

Chair: Ruvik Rosenthal 
The Struggle for Spanish Identity in the Press Coverage of the Third Reich, 1930-1936

Kenneth Alarcón Negy

Department of History, University of North Carolina at Chapel Hill, USA

When Nazi Germany withdrew from the League of Nations at the end of 1933, the Spanish Falangist newspaper, F.E., defended its distant neighbor's controversial decision and drew connections to the political and social problems of Spain's Second Republic (1931-36). "For us," argued F.E., "a nation has no higher right than to what it earns each day. Rights are like bread: one must conquer and earn it daily." Possibly for literary effect based on the similarity of the Spanish words "fuerza" and "esfuerzo," the newspaper claimed that "rights are not strength, but effort. And there are nations that reject bread, [reject] rights! They become archaeological museums . . . that was Greece, that was Cordoban Islam, and that is becoming Spain if we don't decide to 'break those urns.' Germany broke them." ${ }^{\prime}$ Basing its reasoning on the principle of social Darwinism, F.E. argued that the Third Reich was justified in its actions because it was fighting for what it deserved in comparison to lethargic nations like Spain. From the perspective of the Spanish fascists, Germany was to be a role model for other nations wishing to regain strength and power.

As this example illustrates, Spain during the 1930s was in search of a new identity. It was becoming increasingly clear that its new democratic system was leading to further discontent and tension among Spain's different political factions. Politicians, writers, scholars, and journalists alike engaged in the discourse surrounding the Second Republic's perceived ills. Just as members of the left 
romanticized democracy and its defense by means of its choice of words (for example, the Republic was referred to by many of its supporters as "the pretty girl"), so too did members of the right make use of poetic language in order to sway readers to oppose democracy. Right-wing reporting on events in the Third Reich in particular exemplifies the extent to which conservative Spaniards hoped to find a new political and social model for their nation. The rhetoric in a few examples taken from $A B C$, the monarchist paper that still exists today, as well as some of the Falangist newspapers of the 1930s, provides insight into the mentalities of Spanish right-wing writers hoping to draw lessons from the Nazi case for the treatment of Spain's troubles.

For the purpose of comparison, it is worth briefly addressing the tone in Spanish coverage of the Nazi Party prior to the latter's full accession to power in 1933. When the Nazis surprisingly won enough votes in the German Reichstag elections of 1930 to become Germany's second largest party, $A B C$ did little outside of straightforward reporting. Its only opinionated piece for several days came in a critique of the party's full name: the National Socialist German Workers Party. $A B C$ commented on the irony of Nazism being "ultranationalist" and "violently anti-Semitic and xenophobic," while at the same time being, or wishing to be, socialist and "in some ways almost communist." One of its writers expanded on this confusion, stating:

If the nationalists coincide in part with the communists with respect to worker vindication, the former are [also] in agreement with the extreme right with respect to foreign policy. What for Hitler is a national struggle is for the socialists an international proletarian fight against the capitalist and imperialist powers; but the result is the same. $^{2}$ 
Coverage of the subsequent elections in 1932, during which the Nazi Party gained the majority of parliamentary seats mirrored the previous dispassionate tone. Even Hitler's appointment as Chancellor in 1933 did little to alter the relatively straightforward accounts of German affairs presented in $A B C$.

It was only with the infamous Reichstag fire, in which an arson attempt on the German parliament was blamed on a supposed leftist conspiracy, that the Spanish paper decided that the situation in Germany had become significant enough to send someone on site instead of merely transmitting second-hand reports from news agencies such as United Press as before. César González-Ruano and Eugenio Montes soon thereafter were dispatched to Berlin. On behalf of $A B C$, they would write some of the paper's most romanticized and positive opinion pieces on Nazi Germany.

González-Ruano's reporting in Potsdam at the first Reichstag session held after the fire, for example, demonstrates the extent of his admiration for Nazi Germany or at least the fact that he had adopted its symbolic language. In describing the importance of Potsdam to the German identity, he relied on the metaphor of the nation as a German soldier wearing a military uniform. He called Potsdam the "highest and most illustrious award that Germany could have placed on its Prussian military lapel," while dismissing Weimar as the stain on its uniform. González-Ruano also referred to Potsdam as the capital of the "spirit of Germania" and the only aspect of Germany that did not surrender during the "fourteen Marxist years," again referring to the Weimar Republic. After further complimenting the sight of the German soldiers at the event, González-Ruano ended his article by stating that it was a mistake on the part of non-Germans to assume that the Nazis had seized power. It was clear to him that it was the German people who had placed them in their ruling position. ${ }^{3}$ This 
and other $A B C$ articles exhibit the increasing attention and positive rhetoric dedicated to the Third Reich.

The original Spanish fascist newspaper El Fascio, which was published around the same time, made even clearer the newfound inspiration being drawn from Germany in certain Spanish circles. One article offered an attempt at defining fascist doctrine for a Spanish context. Its author called vaguely for "making the [Spanish] nation great again . . . by projecting onto the future the secret of a great past," thereby appealing to emotion rather than reasoned argumentation. ${ }^{4}$ In comparing Spain to Fascist Italy and the Third Reich, the writer emphasized the importance of establishing Spanish fascism as an even greater version of the ideology, because, unlike the particular cases of Italy and Germany, the Spanish variant would be based on the spreading of Catholicism and therefore universally accessible. What is significant here is that, even with certain members of the Spanish radical right already asserting the need to move away from a purely German solution to Spain's troubles, the Spanish right was nonetheless inspired by the newfound rise of the fascists in Germany. Aside from the fact that the fascist newspaper was published roughly a month after Hitler's appointment as chancellor, it is also noteworthy that the Spanish fascist party, the Falange Española, was only established in 1933, some ten years after Mussolini's March on Rome.

The following year, in the reinvented fascist newspaper called F.E., Spanish fascists published an anonymous article titled "Germany: Nazis and Jews." 5 F.E. began by declaring that "the most characteristic distinction of German fascism is without a doubt: 'anti-Semitism." This distinguished it from both the Italian and Spanish versions. F.E. clarified for readers that there was indeed a "Jewish problem," but that, "for Spain, [it] has not been nor will ever be one of race, but [one] 
of faith." As proof, the newspaper pointed to "the ease and joy with which traditionalists, also called the 'right,' admit into their bosom enemy people ... who are later friends as soon as they commit a simple act of faith. Spain tolerates the convert very easily . . without ever looking at the color of the skin, the shape of the nose or the ears." $F . E$. went even further to emphasize the Spanish lack of racism by calling the "supposed Latin race" a false and pedantic conception. Addressing the celebration of Columbus Day, which in Spanish traditionally refers to a celebration of the Spanish/Latin race, the periodical wrote "our paradoxical 'Fiesta de la Raza' . . means the opposite in reality. Spain mixed with all the races with no racist or unitary sense and with no prejudice." As an explanation for this, it suggested that this characteristic stemmed from religion, since "the essence of Catholicism is anti-racist." Nonetheless, despite the imaginary significance of the Jewish problem for the Nazis, F.E. admired Hitler for being "an Aryan-Hero," a "Teutonic knight," and a "medieval knight" fighting against his enemies. ${ }^{6}$ This article exemplifies the willingness of the Spanish fascists to criticize or dismiss aspects of the German case in order to develop a particular version of fascism better suited for their own nation while at the same time still viewing the Nazis as potential role models for the process of national rebirth.

The summer of 1934 set Spain and Germany on seemingly opposite trajectories. Turmoil in Spain grew significantly with the failure of the conservative republican government to satisfy any of the Spanish factions on either side of the ideological spectrum. Leftist groups throughout Spain increased their protests and threats to revolt if members of the CEDA, a radical Catholic coalition, were admitted into the government cabinet, and both radical left and right groups began violently expressing their discontent toward each other. In contrast, 
the Nazi government was able to establish a certain level of stability in Germany. Responding to increasing Nazi aggression toward groups such as Jews and communists, as well as a continued push for socialist revolution from party radicals in the S.A., the Nazi paramilitary unit, Hitler chose to restrain the party's more radical impulses for political expediency. At the end of June 1934, Hitler conducted a purge of many S.A. members, having them and other rival politicians murdered in what was later called the "Röhm Putsch" or the "Night of the Long Knives." This was done under the pretense that Ernst Röhm, the S.A. captain, and other S.A. members were planning on overthrowing Hitler and taking control of power.

$A B C$ s writers accepted the official narrative with no sign of doubt or skepticism and instead came to the defense of the Third Reich. In the July 4issue of its newspaper for example, $A B C$ devoted a full tenpages to the glorification of Germany, including a photo on its frontcover and a six-page spread found outside of the normal international news section. Within those pages, Eugenio Montes and César González-Ruano offered romanticized literary narratives as a way to explain the political and social situation in Germany to Spanish readers.

González-Ruano provided the Greek myth of Orestes as a parallel to the so-called Röhm-Putsch. In the Greek story, when he was still a baby, Orestes' father Agamemnon went away to war, and during this time his wife took a new lover. Upon Agamemnon's return, she concocted a plot with her paramour to murder her husband. When Orestes grew older, he was compelled by the Oracle of Delphi to avenge his father's death and he therefore killed both his mother and her lover. In González-Ruano's retelling of the story, Hitler played the "just [justo] and enlightened" role of Orestes, and Röhm took the part of the familial figure that betrays him. Hitler, also referred to directly 
by the writer as Orestes, was forced to kill Röhm as vengeance for his betrayal. González-Ruano argued that this retelling would resonate with Spanish readers because of their sensitive "latinicity" for myths. ${ }^{7}$ Immediately following this literary piece was an article by Eugenio Montes defending National Socialism's successes in establishing order and peace within Germany. He argued that the Nazis had gained the general approval of the German public and thereby created a unified nation. The socialists, who he compared to the lost city of Atlantis, had been totally submerged (presumably by the wave of Nazi fascism) or remained only in isolated islands. Montes additionally claimed that previous communists had become S.A. members. In this way, the Nazis had "imposed a vital reaction to tame and contain [that] violent collision of [those] destructive forces." Montes highlighted the transformation of the previously rebellious Marxists into S.A. members, who exemplified the values of uniformity, discipline, and subservience to the state as a sign of Nazi success. He thus offered the German model as a solution to Spain's similar problem of radicalism on the left. ${ }^{8}$ Altogether, these articles most explicitly exhibit the growing fanaticism and admiration of Nazi Germany from the right-wing newspaper and represent perhaps the pinnacle of its enthusiasm.

Spanish coverage of the two other main events in the Nazi timeline from that summer, the Dollfuss assassination and the death of German President Paul von Hindenburg, highlight, however, the slowly shifting attitudes of Spanish conservatives away from the Nazi model, a trend that would last at least for the remaining lifespan of the Second Republic. In the specific case of Hindenburg's passing, the successful military general had reluctantly appointed Hitler as chancellor with the hope that the latter could be controlled from behind the scenes. Since he was the main figure capable of limiting 
the chancellor's power, Hindenburg's death created a new opportunity for Hitler to combine the positions of chancellor and president into a single dictatorial position as Führer of the Reich.

Yet despite Hitler's success in finally completing his establishment as dictator, this was not highlighted in $A B C$ s opinion pieces. Instead, the conservative newspaper found a more noteworthy figure in Hindenburg. An article published the day after his death exemplified $A B C$ s difficulty in deciding which aspect of Hindenburg's character and life it admired more. "If he had disappeared before 1914" either by remaining in retirement or because the Second World War had not taken place, "countless people would [still] know his name." The paper listed his military consciousness, bravery, and sternness on the level of a paternal figure as characteristics making him the ideal Prussian soldier. As German president, he "had been both a constitutional and impeccable head of state, which no one could deny." His death meant that "Germany [had lost] its most prestigious son who had saved it many times from the most difficult situations." Further, Hindenburg had effectively transformed himself from "glorious military leader of war" to "herald of peace" as leader of the Weimar Republic. The article ended with a lamentation for his death, writing poetically that "Spain bows to the memory of the most grand of the Germans and accompanies this friend nation with sincere sentiment in its profound pain."9

Ramiro de Maetzu, the editor of the Maurrasian journal for the radical right Acción Española, held up Hindenburg's traditionalism, subservience, and anti-Marxist actions as his most valuable characteristics. In his view, Hindenburg had been "a rock," "the only thing fixed in a fluctuating world." He clarified that Hindenburg's willingness to serve his nation was the result of having grown up in a monarchy, given that such a system "educat[ed] men in the spirit of 
service." Democracies, on the other hand, "encourage [people] to be free, to be masters" and therefore, when they are permitted to do what they want, they do not serve at all. ${ }^{10}$ In this sense, Maetzu and many of the other contributors to $A B C$ implicitly turned away from the Nazi model in favor of another German figure better exemplifying the Spanish right-wing values of military service, obedience, traditionalism, and so on.

Reporting on the Third Reich in the final two years of the Second Republic would continue this trend by paying less attention to events in Germany and downplaying the significance of the Nazi party or ideology to perceived German victories. Eugenio Montes, in his typical poetic and flowery style, heaped praise on Germany after the 1935 Saar plebiscite, for example, in which the interwar mandate voted overwhelmingly to rejoin Germany and not France. Montes made clear, however, that this was not so much a sign of Nazi support but of love for the "Patria." 1

Overall, the Spanish right was actively looking for new solutions to the perceived problems associated with the democratic character of the Second Republic. Their search was not limited to domestic ideas, but extended beyond Spanish borders. They latched on, at least partially, to Germany as a possible model upon which they could seize for inspiration in their pursuit of a return to monarchy and dictatorial rule. Only laterally can a relatively precise timeline be developed for the underlying turn away from German fascism: it was in the events of 1934 in which Spanish onlookers were forced to implicitly compare German Nazis with more traditional, conservative Germans that this shift occurred.

In an appendix to 1984, George Orwell, perhaps drawing on the ideas of Ludwig Wittgenstein, effectively demonstrated the extent to which the manipulation of language could affect and limit ideas. This was 
certainly the case of some of the propagandistic writings of the Spanish right during the Second Republic, hoping to influence readers with a reliance on emotionally charged, literary writing in discussing Nazi German developments. The particularities of their language also, however, provide a key to unlocking their own mentalities and intentions in trying to overcome democracy.

\section{Notes}

\footnotetext{
1 "Vida fascista: Alemania," F.E., December 7, 1933, 8.

2 "Las elecciones generales en Alemania: Importante triunfo de los partidos extremos," $A B C$, September $16,1930,21$.
}

3 “ $A B C$ en Berlin: El Reichstag se ha reunido en Potsdam, ciudad simbólica de las glorias prusianas. Discursos de Hindenburg e Hitler. La ceremonia religiosa y la primera session," $A B C$, March 22, 1933, 31.

4 "Hacer de nuevo grande a un pueblo que lo ha sido ya significa proyectar sobre un porvenir- desde el presente-el secreto de un pasado genial."

${ }^{5}$ José Antonio Primo de Rivera argued along a similar line and may have even been the article's anonymous writer. See Michael Seidman, The Victorious Counterrevolution (Madison, Wisconsin: The University of Wisconsin Press, 2011), 197.

6 “Vida fascista: Alemania: Nazis y Judíos,” F.E., January 11, 1934, 8.

7 “[N]uestra latinidad sensible al mito.” César González-Ruano, "El Gesto,” ABC, July 4, 1934, 4-5.

${ }^{8}$ Eugenio Montes, “ABC en Berlín: Lo que va de ayer a hoy,” $A B C$, July 4, 1934, 6-7.

9 “Semblanza del mariscal-presidente: El estadista," ABC, August 3, 1934, 17.

${ }^{10}$ Ramiro de Maetzu, "Hindenburg," ABC, August 9, 1934, 4-5.

${ }^{11}$ Eugenio Montes, "La fecha de hoy es un gran día para el Saar y Alemania: $A B C$ en el Saar," $A B C$, January 13, 1935, 33. 


\section{The "Non-Ideaist" View of Humanity in J.G. Hamann, J.G. Herder, and Eugen Rosenstock-Huessy}

Wayne Cristaudo

Charles Darwin University, NT, Australia

That ideas provide a vantage point for illuminating what our names are imperfectly seeking to identify was argued by Plato in the Cratylus. There he repeated and developed the attack on the sophists and their "methods" (especially the etymological derivation of names), which played a major role in various dialogues in which he advanced an epistemology and ontology that demonstrated not only that Aristophanes' equation of philosophy and sophistry was false, but that the poets, orators, statesmen, and sophists were themselves members of a common family, all dealing in shadow realities, and all lacking any method for arriving at the truth, including the most important truth of all, the nature of the good. Although, Aristotle's emphasis upon structures and his theory of fourfold causation raised fundamental objections to Plato's epistemology and ontology, and although he also reconciled philosophy with poetry and rhetoric, the cleavage between ideas (now deprived of existence in a beyond) and names was left essentially untouched.

One all-important consequence of this was that philosophy could fairly be summed up to tread the path of what Locke called "the way of ideas" and which Thomas Reid criticized from the vantage point of "common sense." The purpose of the "way of ideas" was to enable philosophers a point of view provided by philosophically defensible ideas, from which the world could be properly espied. Hence that vantage point required an idea or cluster of ideas which formed a paradigm: they served as a model, either in fitting our data into a 
defensible, demonstrable and predictable mode of knowing, or in making our very selves and judgments conform ethically by living up to a standard (like Socrates in Plato's dialogues) or principles serving as what Kant calls a "typic." The idea(s) upon which the paradigm is erected becomes the unquestionable basis for thought. I call this "ideaism," though it shares affinities with what Franz Rosenzweig called "ism"-thinking. Ultimately it is of no matter whether this ground is material (as in Marx's historical materialism, or in physicalist materialism) or ideal in origin. Indeed, Hegel made the compelling argument that all materialism is idealism because all predications are necessarily formed out of knowledge, which is itself impossible without thinking (and hence logic). However, Hegel's insight has generally been overlooked. In large part this was because even if we must concede that Hegel's claim that the sciences are grounded in rational principles is compelling, we simply cannot know everything (the Absolute Idea), or what Herder called the "All" (a term also taken up by Schelling and Rosenzweig). Although Hegel's defence of Absolute idealism is no longer seriously defended by philosophers, the fact remains that "ideaism" remains commonplace within philosophy. That is, philosophers still mainly proceed from a known essence, essential condition, i.e. absolute idea or set of ideas, and hence proceed from a "know-all" position. Elsewhere I have argued in detail that the metaphysics of the "new science" through to Kant, Hegel, the post-Hegelians, analytic philosophy, Heidegger and Husserl and the anti-domination philosophers, who have become so influential in shaping our public narratives in the West, are all ideaist. ${ }^{1}$ There are, however, a group of philosophers who propose a more anthropological and historically attuned philosophy in which language, specifically the importance of names, returns to challenge the supremacy of ideas, and whom I identify as "anti-ideaist" They 
include Hamann, Herder and Rosenstock-Huessy. Let me state from the outset, that I do not see that the problem of ideaism is due to referring and deferring to ideas, because we do indeed draw upon ideas when we discuss, but in thinking that we can elevate ourselves above reality by way of (philosophical) ideas, or that our ideas are always adequate when we identify specific events and features of reality, which we name before we have adequate and exhaustive explanations about their nature.

Although it was Plato who first introduced the "idea," philosophy took on an entirely new significance in the modern world. The great metaphysical shift which is commonly identified as the commencement of modern philosophy was inaugurated with Descartes's attempt to develop a philosophy of correct understanding. What exactly was involved in that understanding, the precise nature of nature, and the requisite metaphysics for making sense of our understanding and the world of experience was debated among all the major philosophers: Hobbes, Spinoza, Locke, Leibniz, Berkeley, and Malebranche. Kant's work was the grandest attempt to synthesise the new philosophy into a system of metaphysics. We will return to Kant, but it was David Hume, whose discussion of causality inspired Kant, who argued that philosophy had failed to account for "common-life." The best we can achieve with our ideas, he argued, is probable belief. Thomas Reid, his contemporary, mounted a full scale critique on "the way of ideas" by appealing to the importance of social life and language as inescapable conditions of thought, including philosophical thought. Kant himself ignored the insights about sociality and language that were so important to Reid, primarily because he, like the other philosophers mentioned, equated experience and nature, and hence the scientific understanding of the natural world became the ground whose metaphysical base had to be explained. Thus his 
transcendental critique would commence with the a priori conditions of "experience," which were in fact the a priori conditions of "nature." Two of Kant's contemporaries, J.G. Hamann and J.G. Herder, not only admired Reid and Hume, but developed their argument that sociality, history, and language had to be incorporated into any philosophical thinking that was not blinded by modern metaphysics. They knew they had a precursor in Vico, who had argued that the "new science" should be grounded in a philological reading of history. Both also believed that Hume's great service had been to make belief and faith a condition of being in the world. For Hamann, especially, this was central to his argument that Enlightenment philosophy was not only predicated on metaphysics, but that the metaphysics was itself a kind of idolatry, resting on a faith in ideas, "a mere verbal image which you have deified through a more than poetic license into a real person." 2 While Hamann was an important inspiration for Herder, there were important differences between them. Perhaps the greatest difference had to do with their view of language. Herder's Treatise on the Origin of Language provided a naturalistic explanation of language, while Hamann saw language as a miracle of the continuity of creation, rather than an "object of study:" we speak as we think and hence we are never able to 'get on top' of language. Hamann's trenchant criticisms of his friend's work left Herder crestfallen. Nevertheless both agreed that language cannot be seen as a mere "tool" of thought but is essential to how and what we think. Another important difference was in their respective assessments of metaphysics. Whereas Hamann had little more than contempt for metaphysics, Herder was not only attracted to metaphysics, but drew upon Leibniz, first and foremost, as well as on Spinoza, Shaftesbury, Locke and many others. Herder was not only devoted to learning about everything, but to seeing everything, including philosophy, as 
contributing to the greater project of humanity. At the same time, he was humble enough to recognize that the task of complete knowledge was beyond him. His debt to Hamann lay in accepting his hermeneutical notion of truth as incarnation in a community (for Hamann the truth of the Christian community). Herder expanded this to seeing the entire history of the human race not only in hermeneutical terms, but providentially. He saw each people, in its own way, as contributing to the greatness of the one human race. There was no escaping the fact that through benign and malign encounters - discoveries, colonialism, wars, trade etc. - the human race consisted of a multiplicity of peoples and traditions. For him the purpose of our knowledge was to help create a greater peace in which the very best of human achievements could be pooled into the great history of the human race. But this required a readiness to learn from each other, and not simply to elevate the European way of life above all others.

The role of philosophy in Herder's search for the mutual recognition and learning from each other's cultures (i.e. a dialogical disposition) was to provide the principles for exploring humanity's creative achievements. He thus delved into areas that were not Hamann's concerns, and his interest in metaphysics was bound up with the methodological issues of studying the encounters of ages, traditions and cultures. Herder argued against the danger of taking even some of the achievements of his time, such as the modern form of republican government, as something that should be spread universally.

Although he was not opposed to appealing to "ideas," Herder's procedure was one in which the pre-philosophical, personal and cultural feelings and sentiments took primacy.

What was important was not the reconciliation of ancient and modern philosophy, but the reversion to the primacy of the living (active force) 
over the dead (pre-organic matter). Similarly, Herder, whose view of knowledge was both deeply opposed to Kant and heavily derivative from Leibniz, took feeling as a kind of knowledge.

In general, Herder's Leibnizian development goes hand in hand with his emphasis upon the unity of our feeling and thinking and knowing, and hence too of the interaction between the part and whole, the individual and community, and on the socially and historically accrued knowledge and faith. But note, unlike the Hegelian "Idea," for Herder not only is all knowledge developmental, it is more importantly only ever partially understood. Hence there is no system as such and no need to entangle oneself in the Hegelian substantiation of reason. Put simply, we are in the position of needing to learn more about our past and the past of others as well as to reciprocally negotiate the kind of future we will make together, in the knowledge that our understanding of the world is always limited and partial, but subject to expansion through encounter and dialogue. So, while Herder had some influence in the $19^{\text {th }}$ century, his hermeneutically, developmental and philosophical anthropological orientation remained outside the philosophical mainstream.

In everyday life a community's "ideas" develop in all manner of ways: they are rarely the result of philosophical reflection. They emerge as named responses to encounters and events, and thus names are emphasized consistently by Herder (as indeed they are in Hamann). When we look at ideas as being first and foremost names, we take into account the trial and error in the naming process. Even more so than Herder, Eugen Rosenstock-Huessy wrote at length on the role of names in our world-making.

Although dialogue is more implicit than explicit in Herder, Rosenstock-Huessy belongs to the group of "speech thinkers" that also included Fritz Ebner and Martin Buber (whom Rosenzweig also 
designated as "new thinkers"). The distinctive feature about "speech thinkers" is not merely that they see language/speech (in German Sprache covers both senses) as inseparable from (social) thinking, but that speech itself and hence thinking cannot be adequately grasped if broken down into the subject/object distinction, as if the central task of language was to accurately describe the world the subject perceives (e.g., as it is for Plato, Locke, Kant and others). The latter view overlooks the fact that language is the means of calling and responding, oath-making and pact-making, affirmation and negation, declaration and behest and so forth. Thus the question of the meeting of perception and object is but one feature of our world-making. We live in the worlds we do because we make them with and through speech. Thus for speech thinkers, reflection is a moment within a greater concatenation of social actions. Closely related to the matter of speech is time, not in the mechanical sense but as living growth, enveloped by the plurality of times as manifest in the forms of life that come into being and persist through the adaptations and engagements of their members. Further, the way we deal with time is intrinsically bound up with speech and grammar. We are able to recollect what occurs in time and transfer our recollections so that they may continue to activate future generations, whose lives are conducted via their own projects (what Rosenstock-Huessy called prejects). Recollections and valuations of the past and prejections of the future, necessity and possibility, our sense of veneration and shame, interpenetrate, and we are implicated in this interpenetration. Just as the words and names we draw upon form the social subconscious, our accumulated past, with numerous forces still active in our language and institutions and mores, our grammar facilitates the integration of our communal responsiveness. 
In Applied Sciences of the Soul, Rosenstock-Huessy argued that the philosophical disposition tended to favour the indicative and optative moods. The former gave the illusion of essences by taking the present as formed by the past (and hence as knowable). Apart from Parmenides' elevation of Being, this was most conspicuous in the initial Socratic question ti estin? (what is $\mathrm{x}$ ?), and hence the Socratic legacy, which became the modality of Western philosophical questioning. But insofar as the ti estin? is undertaken not only to grasp the nature of something but to incorporate that knowledge for improving our condition (hence the primacy of the good in Plato, or some such other cognate such as freedom, or equality or communism etc.), the subjunctive mood expresses a possibility which the philosopher would like to help bring about. The combination of the dominance of these two moods ultimately lent itself to the key feature of ideaism: that what we will and what we identify can be actualised in the real.

We should also pause upon what Rosenstock-Huessy sees as the philosophical deformation of the most fundamental form of social formation, the imperative. He argues that the child must be commanded not only for the child's earliest orientation but for a community's survival and reproduction. It was Kant, of course, who having seen the entirety of human action as subordinate to free-moral action, made the categorical imperative the basis of human freedom and morality. The subjunctive nevertheless remains what must first be processed before the specific imperative finds formulation. This is also indicative of the elevated role that consciousness necessarily plays in philosophy: we make reality conform to the idea. So by contrast to the philosophers' imperative, the imperatives of parents and even legislators lack the clarity and precision of the philosophical point of view. This is because a community and its survival are 
predicated on a range of actions and roles which are not exhaustively known, which do not fold into clear and distinct ideas, but which are nevertheless held together by an array of intangible and unknown specifications. At certain moments the imperative is called upon "don't put your hand in the fire," "collect the firewood," etc.

Closely related is another point Rosenstock-Huessy makes much of: Events will always overtake us, and to think that we just need to better perfect our ideas in order to have the world conform to them is simply to further dig the grave we wish to escape from. This by no means discounts the fact that action is intrinsic to our condition, but what an action means and what it becomes through its expansions, circulations, adaptations, and, even, incubations means that we and are our world are, to use a theological term, revelations. So in the thought of Herder and Rosenstock-Huessy another theological term, "providence," features heavily - for (only) God (who as Baudelaire once said "is the only being who does not need to exist in order to rule") knows what will become of what we do. Providential history of Heilsgeschichte, both defended by Herder and Rosenstock-Huessy, is predicated upon providence overrunning our intentions, and hence a deferral to providence is a concession to our finitude when it comes to improvement over time. That is, in appealing to providence we are also acknowledging what we do not see, and do not and cannot know, when the interweaving of human actions and events, over time, leads to a more convivial reality. For Rosenstock-Huessy what comes out of revolution may well be a blessing for the future provided by the tremendous suffering of generations, as ways of life are torn out of existence, and no longer form any contribution to the future. It is important to distinguish, though, between a collective uprising leading to social breakdown, as in France and Russia, and the ideas fostered by elites to give these uprisings social and political meaning 
in the institutional transformations the revolutionary elite imposes. When those impositions instantiate ideas and processes within institutions that gain sufficient social support a new chapter in the human story commences. But instantiation has a life of its own, involving the to-and-froing of respondents and is never merely the mind's imprint upon the world. Change and transformation, responsiveness, and the vast extent of our not knowing the "All" and not knowing what any action will generate once unleashed, all of this flies in the face of ideaism, and suggests why a more provisional, compromising, dialogical disposition is essential to philosophical improvement. And I emphasize, as Rosenzweig put it, that reason is something we deploy in the world.

The Enlightenment's elevation of the understanding over the imagination was an attempt not only to extinguish the fires of panicked and crazed imaginations, but to revisit experiences and rename them in accordance with the "law" (natural and then moral). That also meant revisiting and renaming the contingencies that people had previously held sacred and reconsidering which contingencies were to be incorporated into an emancipated world. However, the specific contingencies that communities venerate and incorporate into their authoritative narratives and appeals are intrinsic to the powers of the past that push us (which RosenstockHuessy calls our trajects) and the powers of the future we take guidance from and attempt to realize (prejects). The subject/object dichotomy of the Enlightenment had originally replaced history with nature, only then to introduce a theory of history which would conform to the ideas of our telling it. Closely related to this was the idea of historical progress and the view of history as having a meaning in which superstition would be discarded and enlightened emancipation follow. Certain features of human experience do indeed lend 
themselves to the human story being one of "development": the two most obvious are technological discoveries and their social deployment, and, more generally, socioeconomic complexity. But the problem with telling history as a "progressive" narrative is something that the Romantics and later anthropologists highlighted, following in the tracks of Vico and Herder by taking culture, and hence the spiritual life of the collective, seriously. In addition, modern problems of anomie, alienation, and social fragmentation and isolation, with their accompanying spiritual despair and "mental health" ailments, were all rightly seen as connected to the destruction of community. The concept of "culture" became the counter-concept of progress, and since Montaigne and even more so, Rousseau, the modern is equally pulled by nostalgic and romantic cultural narratives (generally of indigenous and non-Western "cultures") and "progress." But to speak of "culture" is really to speak of values that have been generated out of contingencies, practices, and appeals of collectives. That these are evident in the very different spirits and historical events that have directed communities in such different ways is often interpreted philosophically as the problem of relativism, which becomes an obstacle to rational moral argument. The term relativism is itself part of an ideaist vocabulary, and its significance as an obstacle to philosophy is a recurrent theme in Plato. Commonly it is taken to mean that different appeals make rational criticism of absolute claims impossible. Herder has often been criticized for being a relativist, which is not accurate. However, while contingencies and different historical trajectories are intrinsic for understanding dialogical disputants, the value of the dialogical lies in identifying the different contingencies and motivations informing different perspectives. We then each try to understand the terms of difference, but that does not mean that those terms and hence foundational appeals are beyond 
discussion. Vico had pointed out that the lawcourt provides the original institutional precondition for philosophy, which is to say that philosophy treats dispute as if it were akin to legal reasoning and the appeal to the kind of evidence which would enable a correct decision between disputing parties. Life, however, is not like a lawcourt and disputation may not result in a satisfactory resolve, yet this is no less the case between philosophers, one only has to consider how incapable the analytic tradition has proven to be when it comes to ultimate answers from metaphysics to ethics to aesthetics and beyond. And just as the associations and appeals that trigger personal interest and responses to a problem of philosophy cannot overcome that problem, so it is when different collectives appeal to different ultimate values. But we can always track the developments, trajectories and scopes of such appeals and contingencies for dialogical purposes. That we are historical beings does not mean that there are no basic conditions of social solidarity. So even when the core appeals seem to remain constant new perturbations occur along with the new discursive penumbra that do not necessarily involve new names coming into circulation. New names carry new "freights" of other possibilities, leading to new narrative formulations and emphases. Again, transformation is thrust even on groups which wish to remain anchored to their foundations and narrative certainties, and their sense of pride and shame that binds them as a collective.

Apart from new names, pride and shame are basic components of social formation, solidarity, and peace-making. That the triggers of shame may differ between groups does not imply that shame is not common. Herein lies philosophy's strength - its ability to detect general "ideas" by virtue of its "abstracting" capacity - provided it does not completely "take flight" from the world and remains one more component in our world-making. In the West the ideaist nature of the 
normative components of dialogue all too often oversimplifies historical experience, and may lead to what Rosenstock-Huessy saw as the danger of "social amnesia." The view of history as an emancipative history has led to a gross oversimplified division of the world into oppressors and oppressed, and an overwhelming feeling of shame in the Western past (its colonialism and imperialism, the slave trade, etc.), the correlate of which is pride in ideaist moral certainties. NonWestern people are more and more often folded into the ideaist antidomination narrative, which weakens the prospect of a dialogue built on shared knowledge. Although philosophy in conjunction with historical knowledge should alert us to such dangers, philosophy has tended to exacerbate this condition. Examples such as ignorance of the non-Western slave trade, and the treatment of women outside the West, abound. Further, this leads to a situation in which the values that are alien to the Western modern trajectory are little understood or simply unseen, which makes dialogue impossible. The balance of shame and an understanding of the realities other peoples have had to deal with can only be achieved by an empathetic expansion that requires ever greater historical and geographical knowledge, and hermeneutical attunement, which makes our values more provisional and open rather than principled and closed.

I will close by drawing upon two other insights of Rosenstock-Huessy. The first involves the idea of social time. Throughout I have spoken of "cultures" and referred to the importance culture plays in Herder's thought. However, it is not only important to acknowledge that cultures are continually being contested, and even more so as migration flows and sheer contact between peoples expands, but that they are as temporal as "regional/spatial" complexes. Further, insofar as creative acts by founders, not only of peoples but of projects and new ways of life, including professions and other "doings" are the 
incarnation of a social type and are socially replicated, a culture may be said to contain many (social)times within it: a monk, a nun, a physicist, an actor, a banker is each an incarnation of some more foundational act and its replication. The great revolutions were invariably due to a type demanding more power (and meeting resistance) in a constellation in which it had previously not "overly mattered." In this all important respect the problem of conversableness is, as Rosenstock-Huessy puts, a matter of distemporaries becoming contemporaries. In the main, this is a problem that has escaped the purview of ideaist philosophies, which now generally appeal to such abstractions as oppressor and oppressed, a dyad that inevitably sets up a kind of axiomatic normative application that in turn oversimplifies the nature of the problem of social and cultural cohabitation. Only by having a good grasp of our past will we be able to better "see" our contemporary situation and the requirements for a future concord.

Closely related to this is the importance of human suffering. Rosenstock-Huessy argued that sociology as a discipline emerged as a response to the problem of suffering and took this as essential to its undertaking, though he also saw that the one of the earliest sociologists, Saint-Simon had recognized that sociology emerged in a cultural context and was intended to develop further in a secular way the sentiments and values Christianity had cultivated. And I do think that, while many religions may be seen as responses to suffering, especially Buddhism, it was the Christian tradition (itself drawing vastly upon its own Jewish heritage, one of the first people to make love of neighbour a divine command; and the Mohists in China also took love as the fundamental principle for driving action) that attempted a worldly historical and institutional transformation based on fraternal compassion. The desire to overcome suffering is also 
discernible within the Marxist-socialist-anti-domination philosophies and identity politics. However, its modern philosophical forms mitigate against the universal aspect of suffering, by virtue of the polarities that are established, which end up negating the suffering of those who are seen as "unjust" or exploitative. And hence they have all too often committed the same "sins" as the Church: they participate in persecution and in so doing undo the very empathy that gives them "legitimacy."

Although we may have many ideas about the nature and causes of suffering, it is too opaque, too intricate, too big, so to speak, to make it an ideaist principle. We may well see love (and compassion) as the predisposition which best helps us consider each other as suffering beings. To turn to Rosenstock-Huessy again, he argued that suffering humanity is ever implicated within the spaces and times of the objective world, our subjective responses, our trajects and prejects, and that if we really wish to understand anything human we will be better prepared if we see it through what he called "the cross of reality." He also accepted the divine command of loving God and the neighbour, though he was aware that the very name of God had lost its power for most Western moderns. This was a decision of faith. He recognized that different collectives have been formed by different faiths, and even argued that the world now is such that understanding each other's faiths has the potential to expand the experiences which the different religions of the past had cultivated. Thus he argued that Judaism, Christianity, Buddhism and Taoism could each learn from each other to form another cross in which the paths of their respective founders could be seen as meeting in a manner that better opened us up to the nature of the real. Rosenstock-Huessy also argued that knowledge of the experiences of tribes, and ancient empires was essential for understanding the trajects within which we remain. Yet 
our post-Enlightenment "ideas" of other traditions are ever in flux, subject to adaptation and coming into or out of existence.

Ultimately, philosophy's greatness does not lie in any of the ideaist dictates, but in its opening up a number of vistas, principles and questions for organizing our thoughts. Yet it is the strange and revelatory and ever-shifting nature of circumstance and encounter, of the creative capacities we have in making our world, the traditions and future prospects and goals - all that is bound up with human speaking and thinking and action - that should be the materials within which philosophy works.

\section{Notes}

\footnotetext{
${ }^{1}$ Wayne Cristaudo, Idolizing the Idea: A Critical History of Modern Philosophy (Lanham, MD: Lexington Books, 2019).

2 Hamann, "Neue Apologie des Buchstabens h von ihm selbst," in Hamann's Schriften, ed. Herausgegeben von Friedrich Roth and Vierter Theil (Berlin: C. Reimer, 1823), 145. This is my translation.
} 


\section{The Spread of Chinese Films in Italy}

Beibei Guan

Harbin Institute of Technology, Shenzhen, China

Since the establishment of diplomatic relations with China in 1970, Italy has always maintained good relations with China. Exchanges between the two countries in the cultural field have also become increasingly frequent since 2004, when the two countries launched a comprehensive strategic partnership. For the Chinese government, the effective dissemination of Chinese films in Italy is seen as an opportunity not only to promote the cultural exchange between China and Italy, but also to help shape the image of China in Italy and even in Europe, which, as can be gauged by the overseas box office success of Chinese films in recent years, is an important source of revenue for the Chinese economy. ${ }^{1}$

\section{Academic and Professional Studies of Chinese Film in Italy}

European and North American studies of Chinese cinema commenced in the 1950s. The first-English monograph on the subject was Alan P. Liu's Chinese Film Industry under Communism. ${ }^{2}$ Although from the 1950 s to the 1980 s studies were relatively few, almost from the beginning Italy played an important role in the reception of Chinese films. International Film Festivals held in Italy led to two seminal publications on the subject: Contemporary Chinese Film and Performance, published during the 14th International New Film Festival (Fano, 1978), and Film: Chinese Film Essays and Studies published at the International Film Festival in Turin (Ireno, 1982). These studies include not only research on the history and 
development of Chinese films, but also more detailed articles on their sociological, cultural, and political interpretation. Both books are indicative of the importance Italian filmmakers and audiences attach to Chinese films. ${ }^{3}$

Although the total number of Italian publications on Chinese cinema is lower than that published by other Western countries such as France, Britain and the United States, in terms of quality the studies by Italian film curators, critics, professors and Orientalists have played a very important role in enhancing the Western interest and understanding of Chinese cinema in Europe.

What had commenced as an interest by those directly involved in the film industry - filmmakers and critics - had by the turn of the 21st century expanded to the academy, particularly in the fields of China or Asian Studies. We can also note two general tendencies in academic works on Chinese cinema:4 The first tends to place Chinese films in the broader context of Asian films and centers on the evolution of a Chinese films in different periods. This approach is exhibited in Far East Film Studies, 1980s to the Present, by Professor Dario Tomasi, an authority on European Oriental Film Studies, as well as in the work of leading Italian film scholar Matco Dalla Gassa (Turin, 2010) which discusses mainland and Hong Kong and Taiwan films.

The second, as illustrated by the Hong Kong Film Dictionary 19792004, co-authored by film critics G. A. Nazzarro and A. Tagliacozzo (Coedi, 2005), tends to take the development and main characteristics of Hong Kong films as the major topic of Chinese film research. It is also worth mentioning that Italian professional film magazines, such as Ciak, Sentieri Selvaggi, Nonsolo Cinema and other journals also publish information and research on Chinese films. ${ }^{5}$ 


\section{Chinese Films and Their Italian Audience}

The importance of Chinese films in Italy can broadly be divided into three categories: (1) Commercial movies with martial arts themes; (2) Hong Kong and Taiwan films, comedies, and dramas; and (3) Representative works of famous directors.

With respect to Hong Kong films, it was the Kung Fu films, conveying the virtues of martial arts culture, such as Tangshan Brother and Death Game made in the 1970s and 1980s, and starring Bruce Lee and Jackie Chan, respectively, that became extremely popular in Italy. Martial arts commercial films originally opened the "golden age" of the dissemination of Chinese films in Italy. The production of these films is expensive, and the overseas distribution is professional and largescale. For example, films such as Golden Armour in the City, Ambush on all Sides, and Crouching Tiger, Hidden Dragon have also been very successful in the Italian market, establishing the "Chinese style" in the Italian film. ${ }^{6}$ In addition to the commercial martial arts blockbusters, several Hong Kong light comedies have also been popular in Italy. The themes of such films are often related to food. For example, Eating and Drinking Men and Women, directed by Li An, and Magic Kitchen, starring Zheng Xiuwen and Andy Lau, also set off a Chinese wave in Italian film theaters.

Some of the early Taiwanese films that were popular in Italy focused more on social relationships and problems, in a manner not altogether dissimilar from Italian social realism of the post-World War 2 period. This is evident in the works of the two film masters, Yang Dechang and Hou Xiaoxian, who are described by Dario Thomasi in Asian Film as "the originators of new Taiwanese films. The former focuses on the 
urban bourgeoisie, while the latter is more interested in rural life and the historical development of Taiwan." Another important Taiwanese film was Hou Xiaoxian's City of Sadness, who won the Golden Lion Award for Best Film at the 46th Venice International Film Festival, thereby becoming the Festival's first Chinese winner of the Golden Lion.

The third category includes representative works of famous directors that mainly focus on Chinese mainland films. Whether it is the representative works of the fifth generation of directors, such as Zhang Yimou's Not One Less, My Father and Mother, Tian Zhuang's Spring of a Small City, Chen Kaige's With You, etc., or the successful works of the sixth generation of directors, such as Li Yu's This Summer and Jia Zhangke's Good Man in the Three Gorges, etc., have been critically well received in Italy. One should also not underestimate the importance of Zhang Yimou's The Red Lantern, winner of the Silver Lion Award for Best Film at the 1991 Venice Film Festival, which remains one of the most popular Chinese films amongst Italian cinema audiences. It was a "break-out" film for "mainland" Chinese filmmakers insofar as prior to that, and up until the last decade of the $20^{\text {th }}$ century, the appreciation of Chinese films was generally confined to the film festival circuit, and thus did not really enter the Italian market. Also important was Zhang Yimou's commercial blockbuster of 2002, Hero, which was a huge box-office hit in Italy.

\section{Chinese Films at Italian Film Festivals}

It is perhaps no exaggeration to state that Italy has been the "blessed land" of Chinese films in Europe insofar as Italian International Film Festivals are concerned, in promoting the global spread of Chinese 
films. For it was originally the appearance of Chinese films in these prestigious festivals that provided an important launching pad for Chinese films to enter the Italian market by attracting the attention of the global media and fans. I have already mention Zhang Yimou's Red Lantern winning the Golden Lion Award. He also won the same Award for Not One Less, while in 2006, the sixth-generation Chinese director Jia Zhangke once again won the Golden Lion Award with Good Man in the Three Gorges.

In recent years, Chinese documentaries have also been shown and well received in the Italian film festivals. In 2015, Zhao Liang's Behemoth, the only Chinese shortlisted film, won the "Green Drop Award" in the "sustainable development and ecological balance" unit of the Venice Film Festival. The Oriental Film Festival in Turin in 2016 also brought new Chinese films, especially science fiction films, onto the screen. The purpose of the festival was to enhance the Sino-Italian friendship and mutual understanding, through Sino-Italian art and cultural exchange.

In addition, Chinese films have also received much recognition in the Far East Film Festival in Udine, Italy, the largest Asian Film Festival in Europe. Chinese "mainland" films such as Peacock, Nothing Happily, and the Hong Kong film Detective received numerous awards, while Hong Kong director Xu Guanwen won the "Golden Mulberry Lifetime Achievement Award." These honors not only fully reflect the strength of Chinese films in Asia, but also show that Chinese films have achieved international success.

Chinese films have also done very well at other "local film festivals" in Italy. In 2011, for example, the Chinese animated film Dream to Sands City won top prize of the long-animated film competition unit, the 
Platinum Land Award in the Bologna Future Film Festival. And since 2011, at the Confucius Institute in Pisa, the Chinese Film Festival has been held as scheduled every year. Again, this festival provides a platform for expressing Chinese culture and injects new vitality into Chinese films in Italian cities.

\section{The Spread of Chinese Gilms in Italy}

Under the general trend of globalization, the cultural soft power of a country has become an important indicator of its national strength, and since the film industry is an important part of the cultural industry it too is an indicator of China's soft power.

Film is also the most international product among cultural products. A large part of its success consists in its form, which allows the audience to cross cultural gaps through images, voice, light, music, narration, and a range of triggering mechanisms to facilitate intuitive grasps of complex narration. As a result, film has become an important tool for cultural exchange between countries. A country's film can be said to be its name card. Thus, the spread of Chinese films in Italy has played an important role in the spread of Chinese culture. Nevertheless, although China's economic and technological strength is developing rapidly, the development of its cultural industry is relatively backward.

\section{The Current Situation of Chinese Film Dissemination in Italy}

Although there are many forms of film, the development of Chinese film tends to be unique. Further, most contemporary Chinese films are either historical dramas or comedies. The historical films usually draw upon complex background materials and thus have unique cultural 
elements. This can make them inaccessible to an overseas audience whose own cultural triggers have little in common with more traditional Chinese values and cultural protocols. Thus, Chinese films face a number of obstacles in their attempt to expand their international market.

\section{Conceptual Differences}

One major difference between Chinese and Italian films is the overt didacticism of the former. Chinese films tend to reflect the protracted nature and style of its educational system. Thus, Chinese films often have a preaching style, which may be difficult or even repellent for non-Chinese audiences who have their own socioeconomic, political, and cultural/national traditions.

\section{Difficulties in the Investment and Financing Process}

The investment and financing that Chinese films receive are insufficient. At present, European films are generally funded by their governments, and are as high as $70 \%$. With the help of tax rebates and other relevant preferential policies, such funding can reach as high as $80 \%$. In Britain, where subsidies are lower, it can also reach up to 50\%. Thus, China needs to formulate reasonable policies in line with its national conditions, and in considering its cultural strategy via film, it should take into account the investment and financing policies of Europe, America, Japan, South Korea and other countries.

For international film production and marketing, China has to formulate and adopt corresponding policies and measures which meet international market standards. For Chinese-foreign co-produced films, this means paying attention to certain legal conceptions that 
usually have no place in China. Thus, the value for market share and the larger aim of cultural "soft power" that co-production can bring must be weighed against domestic practices and concerns, which ultimately hold back these objectives. The purpose of cooperation should be based on the principle of fairness, mutual benefit and reciprocity, and strengthening of cultural exchanges, which requires a comprehensive platform and the formulation of joint projects through the government.

In recent years, domestic venture capital has been important in the development of the Chinese film industry, and a number of banks and creative companies have emerged to share the risks and benefits of financing films. This in turn requires that the Chinese government provide a legally sound and relatively secure financial system to facilitate and promote the development of the film industry.

In spite of relative success of Chinese films in the Italian market, Chinese film production and film companies still need to go some way to meet international standards, and the Chinese films industry is still a relatively closed system, and hence nowhere near as internationally competitive as they could be.

\section{Competition Strategies of Chinese Films in the Italian Market}

If the Chinese films industry is to expand, it must be more international, and it must be easier for foreign audiences to understand the connotations of Chinese culture. In the case of Italy, this requires Chinese filmmakers who undertake joint ventures with Italian filmmakers to pay particular attention to the combination of Chinese cultural connotations and Italian expressions when shooting films, so that a genuine "dialogue" between Chinese films and their 
foreign audience may transpire. That is to say that Chinese filmmakers must produce films that are not only unique and good enough in the Chinese context but films that can develop a more international perspective. China may well be suspicious of many Western mores, but if it wishes to use film as a vehicle of cultural exchange, cooperation and mutual understanding of values - if, that is, it seeks a successful cultural penetration and economic advancement for its film industry - it cannot afford to be insular in its choice of the style or content of the cinematic stories it develops.

\section{Conclusion}

Chinese films have made considerable inroads into the international market. The combination of critical and academic interest, films festivals, commercial success, and joint ventures, which we have focused on in the Italian context are part of the larger international context in which China is seeking to export its culture. In this respect, in order to succeed, film companies and related units must continue to make full use of various channels such as film festivals, film exhibitions, large scale promotions, and to initiate replays of Chinese films, so as to increase the influence of Chinese films in Italy, and gradually increase the market share in the Italian market. At the same time, it is necessary to explore business opportunities and communication channels outside the screen, such as the development of film related books, models, commemorative badges, and so forth, with Chinese cinema as the backbone for developing multiple branches to create a three-dimensional communication platform for spreading Chinese film culture. 


\section{Notes}

\footnotetext{
${ }^{1}$ Huang Huilin, Yang Di, Wang Xin, and Yang Zhuofan, "A Study on the Impact of Chinese Films on the Spread of Chinese Culture in Europe: A Survey Report on Chinese Films in Europe in 2018," Beijing: Journal of Communication University of China 41 (2019): 1- 6.

2 Alan P. Liu, "Chinese Film Industry under Communism” (Bejing: Peking University, 1950).

${ }^{3}$ Liu Shi, "The International Way of Chinese Films, Based on the Investigation of Chinese Films in Three International Film Festivals in Europe since 1990," Beijing: Journal of Cultural and Educational Materials Z1 (2017): 194- 97.

${ }^{4}$ Ding Jinyang, "Presentation of the Chinese Cultural Scene in Award-winning Inland Films at the Three Major European Film Festivals" (Qingdao: Shandong University Press, 2017).

${ }^{5}$ Wang Yuliang, "Cross-border, Recognition and Interaction" (Shanghai: Shanghai University Press, 2017).

${ }^{6}$ Ye Yili, "Three Major European Film Festivals and Chinese Mainland Art Films" (Chongqing: Chongqing Technology and Business University Press, 2016).
} 


\section{The Bible and the Zionist Lexicon}

Ruvik Rosenthal

The Open University of Israel, Israel

From its very inception, the banner raised by Zionism, the Jewish national movement, was clear and simple: to become a nation, the Jews must return to the land of Israel, the biblical homeland. The aim of the Zionists was thus to redress the split between the Jews as a nation and the land, Israel, a split that had lasted for 2,000 years during the Diaspora. In 1881 Eliezer Ben-Yehuda declared in his article "A Burning Question" that this split had become a threefold split - separating the nation (the Jews), the land (Israel), and the language (Hebrew). In his "A Letter to Ben-Yehuda," he responded to Peretz Smolenskin's view of the problem by stating that "The Hebrew language didn't die powerless: it died by the death of the nation and will live by the revival of the nation!"

The Hebrew revival project began to bear fruit at the beginning of the twentieth century and encompassed all aspects of the language. Modern Hebrew, as this revival is usually referred to, is firmly based on Biblical Hebrew. Furthermore, the Bible provided a rich resource for the terms and ideas required by the Zionist leaders and writers. Many of these terms outline the historical and ideological map that links the new Zionist ethos to its Biblical origins.

The name of the movement, Zionut, "the Zionist movement," is toponymic. Zion appears 154 times in the Bible, 4 times as the name of a fortress conquered by King David, to the south of Mount Moriah near Jerusalem. As the use of the term "Zion" increased, it also became the term used to refer to Jerusalem, and later on the name of the entire land of Israel. Zion is the symbolic land, the idea embedded 
in the "promised land," to which the Jews prayed and yearned to return to throughout the long centuries of exile. Zion's symbolic status recurs in many biblical verses, as, for example, in Isaiah: "For Zion's sake will I not hold my peace, and for Jerusalem's sake I will not rest" (Isaiah 62:1). It is often personified: Zion sings and is merry; it sometimes grieves, when abandoned by God; at times it mocks, at other times it rests from action. The phrase "the daughter of Zion" elevates and magnifies its status beyond its geographical location: "What thing shall I liken to thee, O daughter of Jerusalem? What shall I equal to thee, that I may comfort thee, $\mathrm{O}$ virgin daughter of Zion?" (Lamentations 2:13).

The direct link between the Biblical Zion and its modern usage is manifested in the names of several of the Jewish national movements that sprang up in Europe and America during the nineteenth century: Lovers of Zion, the Zion Brotherhood, Sons of Zion, Return to Zion and so forth. In 1882 dozens of these movements formed a federation called Hibat Zion - literally, "fondness for Zion." Although the federation did not last, it inspired the Jewish-Austrian intellectual Nathan Birnbaum to coin the German term Zionismus. This, in turn, was translated by the founder of the Zionist movement, Theodor Binyamin Ze'ev Herzl, into the Hebrew term Zionut. The whole process of founding the national movement and realizing its ideals is known today as "the Zionist Project."

In their attempts to define the Jews as an ethnic group, the founding fathers of Zionism considered a range of words and phrases. What they needed were words that correlated with the terms used by other European national movements at the time. They thus considered three biblical words: 'am, umma, le-om. In the Bible these words are part of the same semantic field. Sometimes they seem synonyms: "Harken unto me, my people, and give ear unto me, O my nation" 
(Isaiah 51:4). The word 'am refers to a member of the family, the brother of the father. In its extended meaning it refers to a large gathering of people, a crowd; and by a further extension it refers to an ethnic group. The word umma, which appears only twice in the Bible, denotes a tribe: "twelve princes according to their nations" (Genesis $25: 16)$.

Why, then, was the choice among these three terms so crucial? The choice of the word has to do with the core Zionist idea. The selfperception of the Jews before the national awakening was as an 'am, in the sense of the shared cultural, historical and religious bonds that unite Jews all over the world. A Jew could identify himself as part of one people ('am), the Jewish people, and at the same time as part of another nation (le-om), like the German nation. The novel idea, initiated by Zionism, was that the Jews would become autonomous and have their own national territory, and thus belong to the same 'am and the same le-om. But this change required a new term besides 'am, for which the Bible offered two options: le-om and umma. A similar distinction can be found in German: Volk means many people and an ethnic group; Nation is parallel to le-om. In English there is a similar distinction: people versus nation.

However, the choice between le-om and umma was not clear-cut. Both terms are used today as synonyms, yet with subtle distinctions. Le-om functions as the unifying term of the sovereign ethnic entity, as in the phrase medinat le-om - a nation-state, the adjective le-umi, national, and the general term le-ummiyut - nationality. Umma preserves the mythical and unifying aspect of the nation and thus bridges 'am and le-om. The leaders and intellectuals of the Zionist movement often used umma, referring to it as a living creature, a living soul.

The dream of the Zionists and their followers was, as noted, to return to the Land of Israel - eretz Israel. The phrase eretz Israel appears 
only 11 times in the Bible, as in 1 Samuel: "Now there was no smith found throughout all the land of Israel" (1 Samuel 13:19). The inspirational force of the term appears later, as in Ezekiel: "In the visions of God brought he me into the land of Israel" (Ezekiel 40:2). The use of the phrase became more prevalent in the writings of Chazal (acronym for 'Our Sages, may their memory be blessed'), and in medieval Hebrew, as a result of the Jews living in distant lands, faraway from the Promised Land.

The political discourse following the Six-Day War of 1967 gave rise to a new term eretz Israel ha-shelema, the whole of Israel. ${ }^{1}$ An earlier nostalgic term, which preceded the war, was "the good old land of Israel." In one of Naomi Shemer's most popular songs, "At the Nahal Outpost in Sinai," she writes: "In the Nahal outpost in Sinai, I could not believe my eyes; suddenly I found in a corner the old land of Israel, the lost land of Israel, the beautiful and forgotten." 2 This term also refers to "the songs of Eretz Israel," the songs that were written and sung in the early decades of the state.

The vision of the Return (shiva) appears in several Biblical verses, including the root shuv, as, for example, in Jeremiah: "And there is hope in thine end, saith the LORD, that thy children shall come again to their own border" (Jeremiah 31:16). It stands opposed to the idea of exile, gola and galut, which are synonyms. The repeated experience of going into exile and remaining in exile over the centuries strengthened the identification of the Jews with similar stories from the Bible. This enabled them to feel a close and intense attachment to their ancestors who thousands of years earlier, like them, had lived under foreign rule, without sovereignty.

The term kibbutz galuyot - the ingathering of the exiles - originated in the Talmud: "Gathering the diaspora is great as the day of creation" (Pesachim 88:1). Another phrase that figures in the story of return in 
the Zionist agenda is Aliyah la-aretz - literally, 'coming up to the land'. The verbal phrase is 'ala artza. The origin of the phrase is Biblical: "from the day that the children of Israel came up out of the land of Egypt" (Judges 19:30). The mirror-image of Aliyah is yeridah'going down', the verbal phrase being yarad me-he-aretz - went down from the land (of Israel). This phrase derives from the Israelites' voluntary exile in Egypt: "but Jacob and his children went down into Egypt" (Joshua 24:4). Yerida carries negative connotations regarding those who voluntarily leave the land of Israel.

In 1948, with the declaration of independence and creation of the state of Israel, the Zionist ideal of the return to the land was institutionalized and legitimated by "The Law of Return" - hok hashvut, the right of every Jew in the world to come to Israel and become a citizen. The name of the law was inspired by the words of the Prophet Amos, which included the word shevut, return: "And I will bring again the captivity of my people of Israel, and they shall build the waste cities, and inhabit them" (Amos 9:14). Like the Jews returning to their land, the Palestinians too claim that they are entitled to "the right of return [to Palestine]" - zechut ha-shiva. The similarity between the Jewish law and its Arabic parallels is clear: Kanun (law) il-auda, versus hak (right, close to hok, law, in Hebrew) il-auda.

The founders of the Zionist project not only encouraged the Jews to emigrate to Israel but called on them to build new towns and villages, to cultivate the land and develop its industry. The agenda set down by the leaders of the Aliyah was a combination of socialist and nationalist ideas. The keyword in the process of settling the land was kibbush conquest. The root k.b.sh. appears 14 times in the Bible in the forms of kal and niph'al, but only once in pi'el, kibbesh: "that he had dedicated of all nations which he subdued" (2 Samuel 8:11). In his article "A 
Land Given," Israel's first prime minister, David Ben Gurion, who had declared the foundation of the state, dwelt on the negative connotations of conquest - kibbush:... "Not by money or rights but by our labor the land would be conquered...Israel will be ours when we shall be the workers and guardians...."

The creation of new settlements was the heart of the Zionist conquest of work. The main root in this national effort is y.sh.b, which appears 815 times in the Bible. Some of its uses refer to the physical act of 'sitting down'. Other uses serve as a metaphor for ruling: Yet in most of its uses it refers to inhabitants, a family, a tribe or a people inhabiting a specific location, and these are generally in the kal stem: Thus the term hityashvut came to refer to the whole project of settling the land of Israel, a task that was championed by Ben Gurion who saw it as the central task of Zionism.

The synonym of hityashvut is hitnachalut, though its use was marginal in the early Zionist discourse. This seems odd. The verb hitnachel, 'inherited', appears in the Bible in the sense of settling Canaan: "And ye shall divide the land by lot for an inheritance among your families" (Numbers 33:54). After the 1967 war, the use of the verb hitnachel gradually came to refer specifically to the settlements in the West Bank and the Gaza Strip.

The vanguard of the Zionist conquest of work, those who had to physically carry it out, were called by three different names: oved (laborer), po'el (worker), and halutz (pioneer). Halutz conveyed the mythical dimension of the conquest of work. The word appears 17 in the Bible, mostly referring to military activity, and in some cases to religious rites. Halutz is mostly a soldier, bearing weapons. In six of its appearances halutz denotes the soldier who goes in front of the army, the vanguard: "The LORD your God hath given you this land to 
possess it: ye shall pass over armed before your brethren the children of Israel, all that are meet for the war" (Deuteronomy 3:18).

The Zionist lexicon presented here, is, of course, incomplete. Biblical words and phrases pervade every aspect of the Zionist discourse. Words like Moledet (homeland), phrases like mi-sho'ah li-tekuma (from Holocaust to rising to statehood/resurrection), the names of the first Zionist moshavot (urban settlements) and many other words and terms show how deeply rooted the leaders and thinkers of the Zionist project were in the language of the Bible. Finally, while the Zionist ideology is the subject of ongoing debate in Israel's ever-changing reality, it is the language itself that continues to preserve its fundamental raison d'être - to build a Jewish state in the land of Israel, the land of the Bible.

\section{Notes}

\footnotetext{
${ }^{1}$ It first appeared in the movement's manifesto on September 22, 1967.

${ }^{2}$ Shiron.net. http://bit.ly/2GMEb1D.
} 
Workshop 8:

Nationalisms and Democracies: Theory, History, Literature, Culture

Chair: Mark Gelber 


\section{Workshop 9:}

Necessity vs. Progress: The 'Use Value' of Ancient Greek Drama Chair: Heinz-Uwe Haus 


\section{Prometheus: The Power of Fire}

Claudine Elnécavé

Department of Theater, University of Haifa, Israel

The aim of this paper is to try to answer the question: What would have been our world without Prometheus?

In order to answer this question, we have to know first who Prometheus is. His name is usually translated as "forethought" or "foresight." There are several versions of the Prometheus myth, and this study will be based on the two ancient sources of Hesiod and Aeschylus. Hesiod gave the first version of the myth in Theogony Works and Days, and it also appears in the Greek tragedy Prometheus Bound, which is traditionally attributed to Aeschylus, the $5^{\text {th-century }}$ $\mathrm{BC}$ playwright.

In Aeschylus' play, Prometheus defies Zeus by stealing fire from the gods and giving it to mankind. "I gave them intelligence, I made them masters of their own thought." Prometheus is seen as the benefactor of mankind, the creator of art and science. Prometheus' gift of fire gave mankind the ability for technical progress. Because of Prometheus' transgression, Zeus sentenced him to eternal torment. He was bound to a rock where each day an eagle was sent to feed on his liver which would then grow back.

It is interesting to note that this particular myth is a source of creative inspiration for some of the greatests poets such as Byron, Shelly, and authors such as Mary Shelly in Frankenstein or the modern Prometheus, Goethe in Faust, musicians from Beethoven to Ex-Machina, artists such as Pierro Di Cosimo, Rubens, philosophers, scientists and even science-fiction writers such as Ridley Scott.

The 2,800-year-old myth has had an amazing longevity: we find references to the myth in our everyday life, and the question is why? 
In fact, Prometheus represents Knowledge, which, as an old saying says is Power. In order to understand the fascination of the myth, I will focus on three main themes: Liver, Fire, and the Rock to demonstrate the relevance of the Titan called Prometheus to the $21^{\text {st }}$ century.

The Liver: Paul Rubens among many artists, in Prometheus Bound, paints a powerful scene depicting an enchained Prometheus writhing in the foreground with an eagle pecking at his exposed liver. Zeus' punishment, the eagle eating Prometheus' liver, which is restored every day, is an uncommon occurrence in the literature of myths. It raises the question why the liver? Had the ancient Greeks some knowledge about the liver's amazing capacity to self-repair? In order to answer this question, we have to understand the symbolic significance of the liver. For the ancient Greeks, the liver, according to Hesiod, was the symbol of the soul and intelligence. In Aeschylus, the eagle came every other day allowing a full day for recovery. This full day for recovery may prove their knowledge of the liver's capacity of self-repair. It is interesting to note that Prometheus' punishment fascinated the scientific community, especially those who study hepatic diseases.

Fire: In Aeschylus' Prometheus Bound, Prometheus stole the fire from Zeus and gave it to man. By giving them the gift of fire he gave them the ability to develop themselves in many ways, from technology to art: as Albert Camus wrote "Prometheus is the one who loved man and gave them fire and liberty, technology and art." In order to understand the importance of Prometheus' gift, we have to investigate the ambivalent nature of fire which on one hand is a positive power. Many cultures view fire as a symbol of wisdom and knowledge. Fire represents creativity, curiosity, imagination, and it is the source of all forms of technology. The inscription carved in the red granite wall of 
the statue of Prometheus at the Rockefeller Center in New York reads: "Prometheus teacher in Every Art Brought the Fire that Hath Proved to Mortals a Means to Mighty Ends." Thus Fire is energy through which human beings are able to exercise greater power to improve their life; but on the other hand, we must not forget that it is a stolen gift with a negative disastrous, destructive power. I am referring to the nuclear bombing of Hiroshima and Nagasaki. According to a legend, Godzilla, an enormous destructive sea monster, was awakened and empowered by nuclear radiation. Godzilla is a metaphor for nuclear weapons. The bombing of Hiroshima and Nagasaki is still very much part of Japanese consciousness. Nuclear power is as important to humanity as fire. In the USSR post-Soviet Union, a nuclear power plant was considered a safe and cheap energy source. So for us, technological development is the "New Prometheus" which provides us with the "gift" of nuclear fusion. Ironically, though, if we remember that Prometheus was caught and tortured by the gods and that nuclear fusion destroyed everything around Chernobyl in a nuclear holocaust.

The Rock: Fire is a bond between Prometheus and his creation. Man and makers are interchangeable. This bond places scientists as creators, as they are involved in the race for more technological power. This race gives them the illusion of being in a divine dimension. They dream of becoming gods but they do not know how to control this power or the consequences of their actions. The Promethean spirit lives on in their ambition to improve science and technology without limits. They are bound to a rock called technology, unable to stop their eternal search for innovations. This search puts humanity in danger because we seem to have lost control over our own inventions. We have entered a world of man versus the machine. 


\section{Notes}

${ }^{1}$ Aeschylus, Promethus Bound, trans. J. Scully and C. J. Hermigtom (Oxford: Oxford University Press, 1971), 630.

${ }^{2}$ Paul Rubens, Prometheus Bound (1618).

${ }^{3}$ Albert Camus, Lyrical and Critical Essays, trans. Ellen Conroy Kenedy (New York: Alfred A. Knopf, 1969), 138

${ }^{4}$ At chto.org/en/Prometheus-symbol-of-young-pripyat/. 


\section{Brecht's "Use Value" and Aristotle's "Artistic Proofs" \\ Heinz-Uwe Haus}

University of Delaware, USA

1. When I met Karolos Koun for the first time, ${ }^{1}$ we both tried to introduce ourselves by presenting our views on common professional subjects. I remember that Koun listened to my re-reading (I called it "decoding") of Brecht, using the experiences I just had with the first Cypriot Brecht production ever, The Caucasian Chalk Circle, ${ }^{2}$ and that he described his experiments with popular roots in Ancient Greek theater traditions. It was then, when I started to explain the functional "use value" of Brechtian theater tools to underline that the aesthetic of the THOK production was not the result of a style, but the challenge of traditional local viewing habits. Since Koun was not familiar with the term "use value" (Gebrauchswert), because very few non-dramatic texts of Brecht had been translated into Greek, and an ideological simplification of Brecht's terminology ("epic theatre," "alienation") had a more confusing than theatricality enabling effect, he immediately looked for a connection to Aristotle. He started to give me a lecture about Logos, Pathos, Ethos, which he called "artistic proofs," a term I found very expressive and precise. Koun, the master of Ancient Greek comedy, laid bare a sociology of character, which was not only relatable to Brecht's model, but covered basics of theater making. We agreed that a speech act performed on stage is not predicated on the actor that performs it but is attributed to a character in a (fictional) world. I could not agree more, that as the whole, this fictional world should be seen as a rhetorical attempt to shatter the rooted values of the contemporary audience. At that first meeting, a few days before Christmas 1975, with Koun in his small office at his Art Theater in Athens, we contemplated the ability of the 
director to look out for means of persuasion in a given situation, making rhetoric applicable in all fields, not just politics.

2. In Ancient Greece, the earliest mention of oratorical skill occurs in Homer's Iliad, where heroes like Achilles, Hector, and Odysseus were honored for their ability to advise and exhort their peers and followers (the laosor army) in wise and appropriate action. With the rise of the democratic polis, the skill of speaking was adapted to the needs of the public and political life of cities in Ancient Greece, much of which revolved around the use of oratory as the medium through which political and judicial decisions were made, and through which philosophical ideas were developed and disseminated. Language ability was referred to as logon techner "skill with arguments" or "verbal artistry." Throughout European history, rhetoric has concerned itself with persuasion in public and political settings such as assemblies and courts. Because of its associations with democratic institutions, rhetoric is commonly said to flourish in open and democratic societies with rights of free speech, free assembly, and political enfranchisement for some portion of the population. Those who classify rhetoric as a civic art believe that rhetoric has the power to shape communities, form the character of citizens and greatly impact civic life.

Rhetoric was viewed as a civic art by several of the Ancient philosophers. Aristotle and Isocrates were two of the first to see rhetoric in this light. In his work, Antidosis, Isocrates states, "we have come together and founded cities and made laws and invented arts; and, generally speaking, there is no institution devised by man which the power of speech has not helped us to establish." 3 With this statement he argues that rhetoric is a fundamental part of civic life in every society and that it has been necessary in the foundation of all aspects of society. He further argues that rhetoric, although it cannot 
be taught to just anyone, is capable of shaping the character of man. He writes, "I do think that the study of political discourse can help more than any other thing to stimulate and form such qualities of character."

Aristotle, writing several years after Isocrates, supported many of his arguments for rhetoric as a civic art. According to Aristotle, our perception of a speaker's or writer's character influences how believable or convincing we find what that person has to say. This projected character is called the speaker's or writer's ethos. We are naturally more likely to be persuaded by a person who, we think, has personal warmth, consideration of others, a good mind and solid education. Often, we know something of the character of speakers and writers ahead of time. They come with a reputation or extrinsic ethos. People whose education, experience, and previous performances qualify them to speak on a certain issue earn the special extrinsic ethos. Their "character" creates the authority. But whether or not we know anything about the speaker or writer ahead of time, the actual text we hear or read, the way it is written or spoken and what it says, always conveys an impression of the author's character. This impression created by the text itself is the intrinsic ethos.

Representatives of the modern history of democracy are determined by such structures and attitudes. We remember "with malice toward none" and "we having nothing to fear" and "tear down this wall" because the words embodied the essential Lincoln, Roosevelt, and Reagan, respectively. Obama's Nobel Prize speech cannot be summed up in a similarly pithy quotation. Taken all in all, though, it is likely to endure because it is the testament of a man whose tragic view on the world is deeply and authentically held. Obama may well become the first US-president since Lincoln to lead his nation in a running meditation on the ways and means of fate. 
In the founding text of Western ethical philosophy, The Nicomachean Ethics, Aristotle defines ethics as the formation of good character through the practice of moral virtue, where moral virtue is thought not to come naturally but to require cultivation, training and repetition, like learning to play a musical instrument. Eventually, the practice of virtue becomes second nature, becomes habit: "moral or ethical virtue is the product of habit (ethos), and has indeed derived its name... from that word" (Aristotle 33). Significantly, Aristotle rejects Plato's "idea of good" as the basis of ethics, instead orienting the practice of virtue towards the attainment of happiness (Aristotle 8-14).

In the Christian era, ethics loses its focus on the self and its happiness and becomes a matter of self-renunciation and submission to external law. ${ }^{4}$ The emphasis shifts from character and habit to decision and act. Good conduct becomes a question of choice, where at every turn the fate of the eternal soul hangs in the balance: "Christian ethics is a drama of autonomous decision-making, a theme that dovetails neatly into modern pragmatic liberalism."5 Hence Kant's categorical imperative, which seeks to ground Christian submission to the law on the more universal and incontrovertible 'foundation of Reason itself': "Act only according to that maxim by which you can at the same time will that it should become a universal law."6

For the Athenian audience, historicizing their own mythological past was a means of re-evaluating its "use value" for their actual needs as a community re-writing pre-historic stories leads directly to the dynamic social exchange of the drama onstage and the drama of life outside the theatron, the "seeing place." The temporal exigencies of a dramatic performance are ad hoc playgrounds, engaging questions of moral, political, and religious authority, where each and every moment of the performance is significant and yet unrecoverable. The 
dramaturgy is always strictly the same: a known series of incidents that precipitates a crisis and brings the meaning of the protagonist's actions into focus and has to be judged for the polis's policymaking. Aristotle, we know, called this crisis the peripeteia, or reversal, and argued that it should be accompanied by an act of anagnorisis, or recognition, in which the character responds to the change.

3. As contemporary readers of Greek tragedy, we may feel that we face different truths than did the Greek audiences twenty-five hundred years ago. How, then, do we create meaning from these plays? How do we reconcile the tensions which exist between the fictional images of life the Greeks presented and the ongoing reality of our own lives? One way to begin is to identify particular areas in which the view of life implied in Greek tragedy differs from our own. The discovery that it is possible to look at life through entirely new eyes is in itself a kind of meaning which drama has to offer. ${ }^{7}$ This was made possible in Ancient Greek dramaturgy by the conjunction of two ingenious devices: imprinting of images on matter and mediation of language.

The imprinting of images on matter created a specific kind of iconic signifier, coupling image and matter, which is perceptible and thus communicable. The mediation of language enabled both control over iconic signifies and formalization of imagistic syntax - thus lending a high degree of articulation that is clearly discerned in the imagistic/iconic performing arts.

The goal of scripted Pathos and staged Ethos is to persuade the audience that the presented ideas are valid, or more valid than someone else's. Aristotle's categories of pathos, ethos and logos were in ancient times and are still today basic categories of social communication and depend on the interests they serve. Over the past 
century, people studying rhetoric have tended to enlarge its object domain beyond speech texts. A wider interpretation of rhetoric as identification broadened the scope from strategic and overt political persuasion to the more implicit tactics of identification found in an immense range of sources. Here a few examples of different aspects:

- "The personality of the orator outweighs the issues." (John Leopold)

- "I'm not a doctor, but I play one on TV." (1960s TV commercial for Excedrin)

- "If Aristotle's study of pathos is a psychology of emotion, then his treatment of ethos amounts to a sociology of character. It is not simply a how-to guide to establishing one's credibility with an audience, but rather it is a careful study of what Athenians consider to be the qualities of a trustworthy individual."(James Herrick,) The History and Theory of Rhetoric. Allyn and Bacon, 2001)

- "If, in my low moments, in word, deed or attitude, through some error of temper, taste, or tone, I have caused anyone discomfort, created pain, or revived someone's fears, that was not my truest self. If there were occasions when my grape turned into a raisin or my joy bell lost its resonance, please forgive me. Charge it to my head and not to my heart. My head-so limited in its finitude: my heart, which is boundless in its love for the human family. I am not a perfect servant. I am a public servant doing my best against the odds." (Jesse Jackson, Democratic National Convention Keynote Address,1984)

These quotations illustrate what Koun and I called in our conversation "producing iconic replicas of verbal and nonverbal acts," when we compared the rhetoric of Brecht's Azdak with that of Ancient 
Athens' Pericles. Both forms of rhetorical persuasion seek to make possible the kind of knowledge that might lead not to catharsis but to an interventionist critique. And something else I remember from our discussion. We saw structural similarities in the Ancient Greek's and in Brecht's drama: their investigative nature allows us to know on behalf of, and in excess of the character's own social and psychological specificity. Instead of simply indexing "objective reality" in an attempt to uncover the real as something independent of social and political subjectivity, theater making has developed from its very beginning an approach that dialogically structures reality into representation, invites a disrobing gaze, encourages understanding, and even implies the possibility of intervention. The question was and is always: how to re-read the given texts for a changing history.

Reality is the model for theater making. The rise and presence of Barack Hussein Obama in U.S. politics is such an example. It was the Narrative - Obama's life and telling of it - that produced the Obama presidency. Many if not most of the key moments were speeches: Chicago in 2002, Boston in 2004, Philadelphia and Denver in 2008. The crafting of this story was always a joint Obama-Axelrod enterprise. At the president's address to the nation (in front of both Houses) both "authors" unveiled a new chapter in the saga. The story telling goes like this: Our hero has been attacked by all the evil creatures in Washington and vows to tame them, either by his charm or with his bare hands. He promises to create jobs, cut the deficit, cut more taxes (but raise them on the rich), and finally redeem this promise to end the corrupt, insipid, and selfish ways of the capital.

In the House chamber, and on TV, it worked. Obama was forceful and shrewd, amiable, and reasonable. He commanded the room (except for the stone-faced members of the Supreme Court) with ease. Judging from the instant polls that night, the public loved it. As a piece of 
political stagecraft, it impressed. But in the cold light of day, people do have a "but" - in fact more than one.

The address sometimes seemed more about Obama himself than about the country. At times it was not so much his thought on the state of the Union as it was his thoughts on the state of the presidency, and on our (the spectator's) view on him. "Now, I am not naive," the president said. "I never thought that the mere fact of my election would usher in peace, harmony, and some post-partisan era." ${ }^{8}$ And later: "I have never suggested that change would be easy, or that I can do it alone." Then, in the closing flourish: "I don't quit." A comedian's comment: You'd better not, you have a four-year contract!

In the post-Oprah age, Americans not only accept but also even demand this kind of intimate, almost confessional style in political leaders and public figures. Most Americans like Obama as a person, and most want him to succeed as a president. But he has to remember that he is supposed to be a character in our story - not the other way around.

Unlike his perfectly paced memoirs, Obama's presidency is not a narrative whose plot he can dictate, or even control. It is not a Euripides tragedy or a James Cameron movie or a bildungsroman. It is an accretion of actions, decisions, and confrontations - some of them unexpected and unwelcome - in the real world. Reality, especially the bureaucratic and governmental one, resists the smooth-flowing hero story, and it is annoyingly prosaic. At this point even Obama's supporters no longer yearn for a superhero. As one critic wrote after the address: "The country will settle for a competent administration, and it isn't clear that this is one" (Howard Fineman, The New Yorker, January 18, 2010, p. 20). 
4. The Tragic Hero of Ancient Greek drama is not an ideal but a warning, and the warning is addressed not to an aristocratic audience, i.e. other potentially heroic individuals, but to the demos, i.e. the collective chorus.

The conflict in Greek tragedy reveals forces to which both mortals and gods are subject. Recognition in Greek tragedy takes place at human and cosmic levels. At the human level, one character discovers the true identity of another. Recognition at the cosmic level is tied in with the final resolution of the conflict between human striving and the forces of denial. The Greeks believed in a universal principle which reconciled the forces of creation and destruction. They called it Moira, translated variously as Fate, or Necessity. To the modern mind, Necessity is an unfamiliar idea. We believe, instead, in progress - the idea that we can assert ourselves unconditionally and that, some day in the future, we will triumph once and for all over the forces of denial. The fascination in reading Greek tragedy, however, is in reading it as if we believed that our being cannot be asserted unconditionally, and that we occupy a small place in an immense universe in which all things, even the immortal gods, are subject to the one force, Necessity. It is the recognition of Necessity, in one form or another, that finally resolves the conflict in Greek tragedy.

Through witnessing the fall of the tragic hero from happiness to misery, the chorus learns that the Homeric hero is not the ideal man they should try to imitate or admire. On the contrary, the strong man is tempted by his strength into becoming the impious man whom the gods punish, for the gods are not gods because they are ideally strong but because they are ideally just. Their strength is only the instrument by which they enforce their justice.

The ideal man whom every member of the democracy should try to become is not the aristocratic heroic individual but the moderate law- 
abiding citizen who does not want to be stronger and more glorious than everybody else.

Anthony Trollope once argued that tragedy was embodied in a blind giant, a creature haunted by the memory of his former power. ${ }^{9}$ In the 1930s, Reinhold Niebuhr said, "The history of mankind is a perennial tragedy; for the highest ideals which the individual may project are ideals which he can never realize in social and collective terms."10

It is this last insight that informs Obama's thinking: tragedy as the acceptance of the fact that the world will never fully confirm our wishes, and that even the noblest human efforts will fall short of our highest aspirations. "We must begin by acknowledging the hard truth that we will not eradicate violence in our lifetimes," Obama said in Oslo; "there will be times when nations - acting individually or in concert - will find the use of force not only necessary but morally justified... I face the world as it is and cannot stand idle in the face of threats to the American people. For make no mistake: evil does exist in the world... To say that force is sometimes necessary is not a call to cynicism - it is a recognition of history, the imperfections of man and the limits of reason."11

Politicians tend not to speak this way. It is more fun to inspire than to warn. By focusing on antagonistic contradictions, the speaker's rhetoric determines what constitutes truth, and therefore, what is beyond question and debate. The deliberation and decision-making are - as in the theater - audience centered. Obviously, the logos alienates the pathos and ethos of the prize acceptance ceremony. The characters of Ancient Greek plays are all about warning and the limits of reason. The observations of their actions rely on the spectator's reasonable judgement. 
Our first view of Oedipus the King is of a man in the public eye, a beloved king who is sought by his people. The matching of the large group against the single figure provides the scenic background for the developing interplay between the public and the private domain. This visual relationship between the 'solitary' standing figure and the prostrate assembly is immediately reinforced in a particular and striking way: "Children..." This, the first word of the tragedy, Oedipus addresses to young and old alike. On the other hand, it is a natural expression of the role which the presence of the suppliants confers upon him. He is the leader, the protector, the patriarch. On the other hand, there is the real father, the polluted one, who at the end is compelled to relinquish the daughters born of his own incest. The image of the father is the instant link between the external political circumstance and the lurking family horror. Oedipus' relationship with his "children" begins and ends the drama.

5. Ancient Greek characters undertake extreme, audacious objectives and pursue them relentlessly, to the point of catastrophe. Their actions help the community to face its fear of the implacable power of Necessity and inspire pity for the suffering which they must undergo in the process. If we empathize with the protagonist, we can vicariously test our own powers of truth-facing and survival. But aside from the ongoing speculations about reversal and recognition and the functioning of catharsis or the impact the emotional pressures of the tragic actions may have on the audience, it is almost certain that the most provoking theatrical invention, which replaced the earlier choral dancing and revelry and is known from Aristophanes' plays, was the parabasis, the choral ode that was delivered to the audience and addressed political issues. The need to replace older viewing habits through "thinking capable of intervention" is thus not an invention of 
the twentieth-century theater revolution: it was already a basic element in the development of the social function of the theater in Ancient Greece.

Modern readers are sometimes tempted to skip choral passages, but to the Greek audience the odes were a crucial part of the play. The chorus represents the community's Elders, who, in the fictional theater world, are deeply concerned with the fate of their city. They also perform the priestly function of speaking for and to the gods in the real world of the audience. Aristophanes expressed the Greek perception of the chorus when he wrote:

There is no function more noble than that

of the god-touched Chorus

Teaching the City in Song.

This tradition of spiritual teaching in Greek tragedy is centered in the choral odes. The chorus is partly encircled by the audience to provide maximum contact in those moments when the drama "speaks the truth for the improvement of the city."

The stagecraft and tragic conception of Ancient Greek drama are always united by the idea of vision. The exploitation of children for example to evoke pathos is supposed to be Euripidean. Yet in two of seven plays, the Ajax and Oedipus the King, Sophocles employs just such an effect. And this is not to mention the heart-rending separation and reunion of the two daughters in the Oedipus at Colonus. Enormity confronts innocence, terrible knowledge, silent incomprehension. And how important is this scene in Oedipus the King: it comes last and it is that against which the beginning is measured. From success to ruin, from authority to impotence, from kingship to beggary, the reversal worked out by the whole play is very much a visual demonstration. Moreover, the scene of final pathos is but the climax of a long display 
of horror and suffering. The emergence of Oedipus, stumbling and self-mutilated, introduces a sight which is with us until the end of the play, no shorter "a spectacle of horror" than the sight of Pentheus' impaled head in the Bacchae of Euripides.

Remember the display of Oedipus' suffering that comes to its climax with the arrival of his two daughters. He has begged Creon to be allowed to touch and hold them. Already he is contradicting the whole purpose of the self-mutilation: his hands are to be his eyes (1469-70). The generosity of Creon is immediately substantiated, an unquestioned thing. Oedipus hears their sobs, he gropes for them, and they come and cling to their father: "O children." With this repeated echo of the opening spectacle the reversal is brought home with crushing power, the tableaux of exaltation set against the tableaux of ruin. As the crowd was silent so now are the daughters. Here, at last, is the real father with the real children. He stoops down, bringing his bloody sockets level with his children's gaze: "Come here, come to these hands of mine, hands of your brother, hands of your father, which made these once bright eyes to see in this way - his, who neither seeing nor knowing was seen (ephanten) to become your father by her from whom he himself was born. For you also I weep since I have no power to see you, when I think of the bitter life in the future" (1480-7).

The whole visual meaning of his fate is condensed into this, the final formulation of the play's controlling imagery. Still there is the seeing and the being seen. After showing himself to Thebes, he shows himself to the silence of the children and horror turns to pity. The hands which so tenderly hold them are the hands which are imbued with the blind and the knowing abominations which he has done to himself. But, above all, they are the hands that "see": he "feels" the horror he has created and again in his blindness he speaks of "seeing," which at 
this point is not the fulfilment of his first anguished purpose, the physical assault, but a new kind of inner vision.

From a theater-making point of view the visual imagery is simply one feature of the whole pattern of "reflexion" which is built into Oedipus' manner of speaking. One has to draw attention to the characters' often emphatic mention of "hands" in the prologue and throughout the play. For the hand that will average the murder (107) is the same as the hand of the murderer, the hand which will in fact be used against himself in the self-mutilation (cf. 139-40, 231, 266, 810-11, 821-2, 996, 1329-35, 1481-3). And perhaps, as Gould suggests, there are gestures of the hand to accompany the verbal reference. ${ }^{12}$ But whatever form of theatrical narration is used, pathos and ethos appear always as a unit: verbal and non`verbal.

6. Lee Breuer says it best: "The writing down of words and music creates only a body. Performance brings to life the soul."13 The soul is the territory for the "artistic proof of any theater making. The Ancient Greeks used the same word for "alive" as for "ensouled." Soul and aliveness were synonymous, both are conceptually linked in spiritual thinking.

The Gospel at Colonus (1983) is an oratorio set in a black Pentecostal service, in which Greek myth replaces a Biblical story. It is sung, acted, and preached by the characters of the "play"- Preacher, Pastor, Evangelist - who take the roles of the oratorio-Oedipus, Theseus, Antigone. The preaching addresses the audience directly in rhetorical styles ranging from the intimate to the musically "tuned" chant. Choir serves as onstage congregation and responds throughout. Organ underscores sermon and scene. Breuer, the author, describes the work as follows: "As was the classic Greek performance, the Pentecostal 
service is a communal catharsis which forges religious, cultural and political bonds. Should not the living experience teach us something of the historical one?... Music is our ministry. The living heritage of Africa's oral culture, informing Christianity, is the power of the Pentecostal service. 'Music' means preaching and responding and moving and testifying as well as the playing of instruments and the singing of, songs. Would not the oral culture of the Homeric age have similarly informed the theater of Sophocles?"14

The Rev. Earl F. Miller, who performed the role of Pastor Theseus in the Broadway production, describes in a lecture, delivered at the Yale School of Drama in 1986, the specific way of storytelling in this production: "In black preaching the preacher has to get outside of himself, or in church language, let the spirit take control. In order for the people to judge the preacher's call to the ministry authentic, at some point in the sermon he has to lose his cool because he is not supposed to be in charge anyway. Black preaching is body and soul. Black preaching like religion is holistic. It engages the whole person. One of the clear things we can say is that the black religious experience is not just a meeting of the minds. It is an encounter with the living God. When we first started serving God, we did not serve him with our words, we did not serve him with our ideas, we danced him. We praised him with our whole being." 15

Lee Breuer's lyrics and Bob Telson's music translated the spirit of the original into the spirit of a different language and context. Their work uses the idea of reimagining in a striking and original way. Remembering the Five Blind Boys of Alabama, to mention only one of the musical groups, it is obvious what in practical terms scripted pathos and staged ethos can mean for the present theater making.

As in my talk with Koun nearly 45 years ago, the question is always how to find a storytelling which has "use value" for the present. In our 
discussion about Azdak and Pericles we considered it very practical that there is no important action that is separated from the words; "the poetry is the action." The action is a necessary unity of speech and movement: "acted speech"; and where there are minor actions that are separate these again are prescribed by the form as a whole, which is fully realized in the words, written for known performance conditions.

The purpose of a basic attitude like this is, Koun and I agreed:

- to make the spectator a critical observer who like the protagonist on stage must make decisions (to modify or control instinct and will).

- to explore the social determination of the individual, showing the historical nature of human misfortune, the changeable order of nature, and the tragic hero's role (warning) for the demos (collective chorus).

- to find out why self-examination was vital for the Ancient Greek ideals, and why unexamined life revealed the need for order, proportion, and restraint.

- to focus on the process, not the outcome of the events.

And that is Brechtian as well as it is Aristotelian!

\section{Notes:}

\footnotetext{
${ }^{1}$ Karolos Koun (1908-1987), who founded in 1942 the experimental Art Theater in Athens, was famous for his stagings of ancient Greek drama, especially the comedies of Aristophanes. He introduced to Greek audience avant-garde European playwrights such as Bertolt Brecht, Luigi Pirandello, Jean Genet, F. Lorca, and Eugene lonesco.

${ }^{2}$ The Caucasian Chalk Circle by Bertolt Brecht, Prologue adapted by Christakis Georghiou, Music by George Kotsonis, Cypriot Premiere 4 October 1975, directed by Heinz-Uwe Haus

${ }^{3}$ Aristotle, Poetics, in S. H. Butcher, ed. and trans., Aristotle's Theory of Poetry and Fine Art (New York: Dover; 1951); Aristotle, The Art of Rhetoric, trans. H. C. Lawson-Tancred (London: Penguin Books 1991); Aristotle, The Nicomachean Ethics, trans. Harris Rackham. Ware (Wordsworth Editions,
} 
1996); Isocrates, Against the Sophists, in Isocrates with an English Translation in Three Volumes, trans. George Norlin (London: William Heinemann, 1980).

${ }^{4}$ Michel Foucault, "Technologies of the Self," in Ethics: Subjectivity and Truth, in Essential Works of Foucault, 1954-1984, Vol. 1, ed. Paul Rabinow (New York: New Press, 2006), 223-252.

${ }^{5}$ Russel Smith, Beckett and Ethics (London: Continuum, 2008).

${ }^{6}$ Immanuel Kant, Critique of Practical Reason and Other Writings in Moral Philosophy, ed. and trans. Lewis White Beck (Chicago: University of Chicago Press, 1949).

${ }^{7}$ Heinz-Uwe Haus, Re-Reading of Ancient Greek Theater Texts (Nicosia: Cyclos, 2005).

${ }^{8}$ Remarks of President Barack Obama - As Prepared for Delivery. Address to Joint Session of Congress, 24 February 2010; http://www.whitehouse.gov/.

${ }^{9}$ Anthony Trollope (1815-1882), English novelist of the Victorian era, critiques generally acknowledge the sweeping satire The Way We Live Now (1875) as his masterpiece. In all, Trollope wrote forty-seven novels, as well as dozens of short stories.

${ }^{10}$ Reinhold Niebuhr (1892-1971), German-American theologian and commentator on public affairs. He attacked utopianism as useless for dealing with reality, writing in The Children of Light and the Children of Darkness (1944): “Man's capacity for justice makes democracy possible; but man's inclination to injustice makes democracy necessary." His influence has been acknowledged by such recent leaders of American policy as Jimmy Carter, Madeleine Albright, Hillary Clinton, and Barack Obama, as well as John McCain.

${ }^{11}$ Full text of Obama's Nobel Peace Prize speech, 10 December 2009, White House-msnbc.com

${ }^{12}$ Thomas Gould, ed., Oedipus the King (Englewood Cliffs, NJ: Prentice Hall, 1970), 9.

${ }^{13}$ Lee Breuer, The Gospel at Colonus (New York: Theater Communications Group), xv.

${ }^{14}$ Ibid., ix.

${ }^{15}$ Earl F. Miller, in Lee Breuer, The Gospel at Colonus, xiii-xiv. 
Workshop 10:

Philosophies and Pedagogies of Inclusion and Exclusion

Chairs: Marianna Papastephanou and Torill Strand 


\section{Affected But Not Heard: Democratic Iterations and the Restricted Language of Human Rights}

Inga Bostad

Department of Education, University of Oslo, Norway

How can we be responsible citizens of the world, and take on responsibility for other human beings? If, as Seyla Benhabib argues, ${ }^{1}$ democracy is not possible without borders, and cosmopolitanism is not possible without some kind of autonomy, how should an individual's rights be defended if they are neither a citizen nor belong to a place?

Further, what follows from the much-debated position that such and related ethical dilemmas and questions occur when morality is no longer universal? Benhabib defends a non-essentialist, nonreductionist democratic rationale, while at the same time leaving it open as to how the normative foundations should liberate those affected but who are not heard.

In this presentation, I reflect on the different philosophical dilemmas that may arise through Benhabib's mediation strategy, between moral universalism and ethical particularism. Let me start with the solution Benhabib offers us: we need to bring back some kind of dialogical universalism. This is a strategy for an ongoing mediation between judicial, political, and moral norms, and the argument is based on the premise that the right to be recognized and protected as having the right to have rights, that is, to be a legal person ${ }^{2}$ belongs to all human beings. Moreover, this is not strictly a political nor a judicial right, but rather a moral norm.

A Habermasian solution could be that, through a critical analysis of power relations - for instance, permitting Muslim women to wear face veils in public, and arguing for their right to do so - one would, in a 
liberating moment, make the other (the "opponent") see the force of the argument or the practice, and then either alter or reiterate the norms in use. This, ultimately, would affect the rights of inclusion.

Along with the third generation of the Frankfurt School, Benhabib together with Nancy Fraser and Axel Honneth, among others - is also known for criticizing the ideals of an open communicative community that emphasizes arguments and demands rationality and objectivity, and instead of recognizing power distribution and vulnerability, underlining that all theorizing is situated: to have our universal rights as well as insights, we have to be de-centered.

What first comes to my mind is: who are we? Who is included in the "we," and who is excluded? Does this mediation strategy imply some kind of guardianship between the ones engaging in the dialogical universalism and the ones being represented, or is it primarily a more or less abstract, idealized, interpersonal, and interdependent model of relating to each other?

I will not go into the long process of identifying the dilemmas between, and trying to clarify, the old versus the new, Western versus nonWestern, and cosmopolitanism. Rather, I look at Benhabib's efforts and arguments regarding moral universalism and ethical particularism as a combination, not a reduction or a dogmatic rule of moral and legal rights in light of the concept "democratic iteration"3 or, in my own words, how to make democracies governed by the rights of majorities commit to universal rights adjusted by the local, national, and global plurality of human lives.

Benhabib's argument is that we need a cosmopolitanism "without illusion (...) to use the public law documents and human rights covenants without utopian fanfare (...), claiming rights across borders in a series of interlocking democratic iterations, and reinventions and 
reappropriations of valuable norms (....." 4 That is, we need creative and courageous actions.

Benhabib asks whether cosmopolitans are dead souls, with their "privileged attitude of globe-trotting and world-hugging elites, removed from the concerns of ordinary citizens." ${ }^{5}$ In response to her own question, Benhabib writes that it is instead "a field of unresolved contrasts: between particularistic attachments and universalist aspirations; between the multiplicity of human laws and the ideal of a rational order that would be common to all humans; and between belief in the unity of mankind and the healthy agonism and antagonism generated by human diversity." 6

Benhabib's question then becomes: how can we, today, combine legal and political norms with moral standards? ${ }^{7}$ She attempts to bring together different sources of global norms - neither just legal, nor just moral - with the understanding that, even if you lose your citizenship, we are still committed to each other.

In a 2011 interview with Gomez-Muller and Rockhill, ${ }^{8}$ Benhabib stated that throughout her academic work, she has struggled and engaged with one issue, and that is how to legitimize a normative theory using arguments from either a post-Kantian or a left-Hegelian tradition.

In this presentation, I focus on Benhabib's book Another Cosmopolitanism, published in 2011. As I see it, this book is still highly relevant, and pinpoints some of the most complex moral and political agendas of current arguments in the debate on European human rights policies, of the status of democracy and migration, and inclusion and exclusion. That said, Benbabib offers few solutions or practical tools, leaving us instead with some concepts and paradoxes to help us understand why we fail to be responsible for/act responsible 
towards the most vulnerable - those without a legal status - and to secure the basic human rights of those affected but not heard.

Born in 1950 in Istanbul, Benhabib's own life is colored by having both an Eastern background and that of a Westerner (as an American), and by her return to her secular Jewish upbringing and her subsequent experience of belonging to a minority.

In Another Cosmopolitanism, Benhabib engages in a conversation with Hannah Arendt and Karl Jaspers - illustrating, as I see it, that philosophy is primarily about participating in a dialogue with other philosophers, talking about and examining their world-views and use of concepts, and trying to reintroduce them to enlighten our own point of view.

Philosophy originates from actual happenings in our everyday life that is, according to Dewey, experience (or acknowledged experience) is the starting point for philosophical questions and engagements. In Another Cosmopolitanism, Benhabib combines these two perspectives of the significance of philosophy: arguing from her own experience of belonging to a minority, investigating and reinventing more or less useful concepts of being part of a larger philosophical community. Benhabib's philosophical argument seems to consist largely of counterarguments to understand and protect the real lives of those who are not protected by the existing legal frameworks of European states. Her clear feminist perspective is expressed by her emphasis on the bodily embeddedness of the refugees traveling through Europe, and of the Muslim women in France and Germany whose wearing of face veils expresses "rights in action." This highlights the fundamental issues of today regarding international commitments through concrete examples of paperless refugees, and their citizenship and participation in democracy. 
Even though Benhabib's motivation is the unfair treatment and troubled lives of refugees - and of Muslim women in French and German cities, in particular - she continues a rather abstract human rights rhetoric that, in my opinion, not only fails to move or have an impact on the current discourse and political debate, but also ignores the alienation of the human rights language itself.

Michael Ignatieff (a Canadian academic, historian, and former politician) argues that it is essential for the language surrounding human rights today be a "language of gifts," which to his mind is contextualized, selective, and contingent to the situation: that is, nonuniversal. The language of human rights, however, is universal and un-conditional. ${ }^{9}$ The argument that follows is that giving gifts or being grateful to every human being is impossible. On the other hand, a language of human rights commits the individual to humanity, as such - independent of their background, identity, and situatedness which is the essence of universality. Accordingly, human rights discourse and debates appear to be both abstract and alienating. As Ignatieff sees it, it is the specific individual whom we tolerate and to whom we give gifts and gratitude. This is especially significant with regards to refugees, as illustrated by countries like Canada that have a solidarity and openness towards refugees while at the same time framing it as hospitality: "To some, we give gifts, and we welcome you." The language of human rights is doing the opposite, however: "We are all alike in rights and duties." Still, we need to justify and regard human rights as the ideal of dignity for all and rights belonging to all human beings.

Now, I want to turn to Benhabib's concept of "iteration," a key concept in her argument regarding the transforming of our understanding of being a citizen - and in my opinion, it is a fruitful one. Iteration is more broadly a kind of repetition, however, in Benhabib's argument, 
she uses the term "democratic iteration" so as to bring to the fore those who are affected but not heard, like the French girls wearing face veils." 10 When we repeat a word or a concept (or an argument, I would add) we never make a copy, but always a variation. According to Benhabib, every repetition alters the meaning and adds something to it, that is, there is no original source or principle; this form of democratic repetition also transforms what is perceived as valid in existing jurisdiction or the sovereignty of the state as an authoritative source. The word "iteration" is well-known in computing and data technology, as well as mathematics and law, where repeating a process is intended to approach a goal or result. Each repetition of the process is used as the starting point for the next iteration as a means of obtaining successively closer approximations to the solution of a problem.

Or, to put it differently: whether one holds it to be a clear answer to the authority of moral and legal norms, it is something that must be negotiated. And as an extension of this: with regards to the refugee on the run and the Muslim women wearing face veils in public, as well as the isolated farmer in the north of Norway, how may they be heard and how may they negotiate and form these ongoing democratic iterations?

In an essay from 1971, Derrida introduces the word "iteration" in the philosophy of language as the strategy to reveal differences dismissed by a closed theoretical identity. ${ }^{11}$ Elements of a discourse or a sign have to be repeatable or citable to "work" at all. For Derrida, there is only "text" because there is iteration. The term iteration derives from the Sanskrit adjective itara, which means "other" and "different," and which holds the potential to break with its preceding context.

That iterability allows a sign to distract from its context, to confuse and go beyond its context and to repeat itself in another context, is 
exemplified in the European media's rhetoric with its metaphors of a "stream," "wave," and "flood" of refugees. In 2015, David Cameron spoke of a "swarm of people coming across the Mediterranean" as something unavoidable, a natural phenomenon one must be protected against. To break with such a context has proven extremely hard, creating new contexts and thus casting a grey light on the more optimistic project of both Derrida and Benhabib.

Thus, iterability is a limited repetition of cultural norms. Moreover, according to Judith Butler, this repetition is observed by others, and imitated. Rather than choosing what behaviors to imitate, people imitate the performances of others who have the same discursive label. ${ }^{12}$ The process of iteration occurs constantly, with Facebook as one example. One study found that Facebook users tend to assume group-based identities, avoiding self-descriptions. Inclusion produces an appeal to the user's friends as well as other Facebook-users. ${ }^{13}$

Again drawing on Butler, we see that "performativity must be understood not as a singular or deliberate 'act' but, rather, as the reiterative and citational practice by which discourse produces the effects that it names."14 Hence, we need to distinguish between democratic iteration as a descriptive concept (that is, imitating or repeating our understanding and use of words like "citizen" as part of modern democracies) and a normative concept (that is, transforming and creating new contexts of a concept by repeating, reformulating, and rearticulating it, as in lawmaking processes).

In his book Liberalism and Social Action, Dewey criticizes the claim that individuality is something ready-made and objective, and argues instead that individuality is something that must be developed and seen as a process and a continuation that is relational and dependent on resources provided by a sound democracy. ${ }^{15}$ The concept of democratic iteration may then open our eyes to the social and 
systemic, as a shared practice we take over by imitating and repeating, in discourse as well as nonverbally. This, then, pinpoints the dilemma: Are we transforming to be more homogeneous or to be liberated, unique, and free? Here, I also see a connection to subjectivity as - following Dewey - something in constant change, and the negotiation of rights in modern democracies.

I will conclude by returning to Benhabib, but first I want to take a quick detour to visit Søren Kierkegaard, as I see Kierkegaard's Repetition, ${ }^{16}$ as an even more profound reflection on the concept of iteration, primarily as an existential concept, the book opens with a reference to Greek philosophy: For the Greeks, recognition was a form of remembrance, but in recent philosophy, according to Kierkegaard, this has been replaced by, or developed into, a basic view of life as a whole, seeing repetition and remembrance against life's impermanence. One could say that remembrance, as Kierkegaard describes it, makes one uncomfortable, whilst repetition opens one up. Thinking, dreaming, feeling, longing for something that has been and can never be repeated, is a fact of life, while acting or doing the same, again, in a new way, is the only way forward. "Memory has the great advantage that it begins with loss," writes Kierkegaard, “(...) therefore it has nothing to lose." Remembrance is a way of holding on to the past, history, and identity, while repetition or iteration becomes the existential condition of life that encapsulates the paradox of living. In other words, everything repeats itself while nothing is the same,"17 and preserving something is therefore ambiguous.

According to Kierkegaard, it is through the concept of repetition that experiences can be understood philosophically, that is, in light of philosophical concepts. At the same time, repeating an action is impossible: everything happens within a time frame, and remembering something is also coloring something, subtracting from 
and adding to it. Reflecting on concepts such as remembrance and repetition also detaches experiences from history and makes it a human existential, whether in text or in reality, through an action that unites us as humans. In Kierkegaard's understanding repetitions require both courage and seriousness: Here, it is about the double movement in giving something up but at the same time getting something back from the world.

There is also a form of dialectics in Benhabib's text: placing the ideal of democratic iteration at the center makes us aware of the fact that law-making processes are about abandoning discrimination, adding new insights regarding the lives of those without rights, and continuously synthesizing new creations of rights and meanings for institutions and processes.

Conversations about moral and legal rights go beyond national boundaries and target all of humanity, as, according to Benhabib, "we are all potential participants in such conversations of justification."18 At the same time, there are situations that do not invite such conversations, as Benhabib is aware of. Thus, let me conclude with Benhabib and her appeal to us, which presents itself as a kind of imperative: democracy must be flexible, and it requires a continuous discussion to get people involved.

Benhabib's concrete universalism thus exceeds the distinction between the concrete and the universal: because we are all different, in different situations, there is something specific about our situation, which is linked to our life; at the same time, however, there is something universal, in that we are humans and our common humanity binds us together. 


\section{Notes}

\footnotetext{
${ }^{1}$ Seyla Benhabib, The Rights of Others (Cambridge: Cambridge University Press, 2004), 14.

${ }^{2}$ Seyla Benhabib, Another Cosmopolitanism (New York: Oxford University Press, 2006), 19.

${ }^{3}$ Ibid., 45, 80.

${ }^{4}$ Seyla Benhabib, Dignity in Adversity: Human Rights in Troubled Times (Cambridge: Polity Press, 2011), 188.

${ }^{5}$ Ibid., 1.

${ }^{6}$ Ibid., 188.

${ }^{7}$ Before we go on, I will make a short remark on the need to distinguish between state law (that is, the rights and rules between citizens within the state) and international law (that is, the rights and rules between states).

${ }^{8}$ Alfredo Gomez-Muller and Gabriel Rockhill, "Concrete Universality and Critical Social Theory," in Politics of Culture and the Spirit of Critique: Dialogues, ed. Gabriel Rockhill and Alfredo Gomez-Muller (New York: Columbia University Press, 2011), 48-65, cited from Seyla Benhabib, Et annet verdensborgerskap [Another Cosmopolitanism] (Oslo: Cappelen, 2011), 11.

${ }^{9}$ Michael Ignatieff, "Human Rights, Global Ethics, and the Ordinary Virtues," Ethics \& International Affairs 31, no. 1 (2017): 3-16. doi:10.1017/S0892679416000629.

${ }^{10}$ Benhabib, Another Cosmopolitanism, 56.

${ }^{11}$ Jacques Derrida, "Signature Event Context," in The Rhetorical Tradition: Readings from Classical Times to the Present, trans. Samuel Weber and Jeffrey Mehlman, ed. Patricia Bizzell and Bruce Herzberg, 2d ed. (Boston, MA: Bedford/St. Martin's, 2001), 1475-90.

${ }^{12}$ Judith Butler, Bodies That Matter: On the Discursive Limits of "Sex" (New York: Routledge, 1993).

${ }^{13}$ Zhao Grasmuck, Sherri Grasmuck, and Jason Martin, "Identity Construction on Facebook: Digital Empowerment in Anchored Relationships," Computers in Human Behavior 24, no. 5(2008):1816-36.

${ }^{14}$ Butler understands gender performativity to be a repetitive act that perpetually reproduces itself: Your gender is constructed through your own repetitive performance of gender. Judith Butler, Excitable Speech: Politics of the Performative (New York: Routledge, 1997).

${ }^{15}$ John Dewey, Liberalism and Social Action (New York: Minton Balch Book, 1935).

${ }^{16}$ Repetition is an 1843 book by Søren Kierkegaard, published under the pseudonym Constantin Constantius, originally titled, Gentagelsen. Et Fors $\phi$ g i den Experimenterende Psychologi af Constantin Constantius, trans. Walter Lowrie (C.A. Reitzel's, Printed by Biance Luno Press, 1941).

${ }^{17}$ Søren Kierkegaard, Gjentakelsen (SolumBokvennen AS, Norge, 2009), my translation.

${ }^{18}$ Benhabib, The Rights of Others, 14.
} 


\section{A Janus-Faced Democracy: On the Autoimmune Condition in the Body of Politics}

Mark Debono

Department of Systems of Knowledge, University of Malta Junior College, Malta

This paper revisits one of the main concerns of the late Jacques Derrida, namely, how the autoimmune condition affects the political sovereignty of the democratic body of politics. In keeping with its biological implications, the protective sense of immunity will be utilised to explore whether the immune condition gives rise to a dual vision of politics. Throughout the paper, the trope of Janus as the deity whose two faces looked in opposite directions will be deployed to illustrate this dual vision of politics as an attack/defence system. This illustration advances the argument by offering insight into how Janus-faced politics consolidate the state's sovereignty particularly in the exceptional instances of when the state decides who lives or dies, who or what is included in the set of the viable or not. Socrates' example of capital punishment is utilised as a springboard to analyse how the level of protection in the community appears to strengthen the attack/defence position implied by the immune condition. A critique will be made of how this divisive strategy contributes to the friend/enemy distinction. As a contrasting point, this paper demonstrates how in the case of political autoimmunity, the difference between friend and enemy is mitigated. The reason for this is that through the autoimmune condition, the political turns foreign to itself. The referencing to the examples of the 9/11 events and European populism will illustrate how these phenomena damage internally the democratic fabric. The last section of this paper reimagines the survival of politics and our democratic heritage by reassessing how 
autoimmunity makes the body of democracy ill. It is in the light of this illness that the concluding part examines whether democracy has lost its sovereign authority to control its own body and that of others. All the steps of this paper are here taken indicatively and cannot be fully unpacked for reason of space. Therefore, their deeper relevance to the issue of inclusions and exclusions, which is the topic of this workshop, will remain somewhat cryptic and undeveloped.

\section{The Juridical and Pathological Basis of a Janus-Faced Democracy}

The basis for "immunology" results from the operation of "defense mechanisms which can establish a state of immunity against infection (Latin immunitas, freedom from)."1 This preliminary emphasis on immunity as a body exempt from infection opens the discussion in Roberto Esposito's work on how immunity operates in the political body. Esposito points to a gradational development of protection, one which culminates in the instance when the political "immunizes itself by instituting sovereign power." 2 As Esposito remarks, the state justifies the power of its sovereignty by a neutralising effect, one which brings an "organism to a condition that simultaneously negates or reduces its power to expand." 3 The capital punishment of Socrates serves to actualize the discussion on the above point regarding political immunity from the perspective of the exceptional condition of sovereignty.

In his Apology, ${ }^{4}$ Plato covers the proceedings of the jury that accused Socrates of wrongdoing, and ultimately condemned him to death. For the jury, Socrates was no more than an impious person who introduced new divinities to the polis and a thinker who utilised his dialectical method to corrupt the minds of the young. The perception of Socrates as a "terror-inspiring" figure and his death penalty raise 
questions as to whether sovereigns can have an exceptional "selfauthorizing power" 6 to decide on the execution of individuals. Matthias Fritsch recalls how in the Seminars, Jacques Derrida reminded them that when states abolish the death penalty, the "sovereign states will [still] reserve the right to kill perceived enemies, whether citizens or not, even if they abolish legal putting to death."7 In contrast to the juridical implications of immunity, Donna Haraway reviews the immune condition from a pathological perspective. For Haraway, the issue of immunity stems from a "plan for meaningful action to construct and maintain the boundaries for what may count as self and other in the crucial realms of the normal and the pathological." Haraway's remark on the "self" can be applied to the community's decision to raise its level of protection to classify individuals as normal or pathological. This disproportionate use of defence mechanisms can be traced to how Aristotle conceived the structure of power relations in his political organisation. In the opening lines of his Politics, Aristotle lays down the groundwork for the nature and purpose of the polis: "first, that every city [polis] is a species of association, and secondly, that all associations come into being for the sake of some good." 9 At first sight, Aristotle's reasoning on how people form associations to develop and share things together portrays politics as a seemingly healthy activity.

In the Eudemian Ethics, Aristotle qualifies the criteria of "likemindedness and good will" 10 for citizens to reap the political benefits of their community. This balanced equation between consensus and political friendship gives rise to the development of a Janus-faced politics, one whose two-fold optics is based on the distinction between "friend" and "enemy" (the "unfriendly one" as implied by inimicus which is the Latin word for enemy). Against this impasse, Derrida and other thinkers have earnestly explored the issue of whether there can 
be alternative political formations beyond the limit of Janus-faced politics. The next section explores how the autoimmune condition in democratic power can mitigate the adverse effects of the friend/enemy distinction in its various redemptive and perverse forms.

\section{Political Autoimmunity}

The Oxford Dictionary of Biochemistry and Molecular Biology defines autoimmunity as "a state of immunological reactivity against constituents of the subject's own tissues." 11 The following paragraphs adopt this biological meaning of autoimmunity to review whether the 9/11 events in the United States and the issue of populism in Europe are effects of an autoimmune condition. While political immunity positions the enemy on the outside of the democratic process, the review of the 9/11 episodes and European populism from the perspective of political autoimmunity allows one to view these happenings as reactions that harm the democratic fabric internally.

What also supports this position is Jacques Derrida's interpretation of autoimmunity as a condition of "immunity of the autos itself: it consists not only in compromising oneself [s'auto entamer] but in compromising the self, the autos - and thus ipseity." 12 The 9/11 events and European populism have undoubtedly weakened the democratic ability to define itself in terms of how the power of the people determines its governing body.

\section{The Case of the 9/11 Events}

The rational response of democracy to the $9 / 11$ events presented a symmetrical picture of the conflicts between the global forces. One side of the world was depicted as "normal and civilised" and the other side was shown as "abnormal and radicalised." This division between 
two equal sides recalls the powerful effect of the friend/enemy distinction implied in Janus-faced politics. Unfortunately, in this vein, the academic side also produced a number of well-argued scholarly works. These works attempted to interpret the anxiety that followed the $9 / 11$ events from a rational perspective. Can, for example, the following claim on radicalization as a "radical religious ideology [which] has been conceived as a kind of virus infecting those with whom it comes into contact, either by itself or in combination with psychological processes"13 mitigate the sense of mourning of what Toni Morrison calls "the September dead"?14 Though the seminal production of these evaluations carries some validity, yet they still reflect a deficit in the philosophical responses to terror, to its nuances and to its genealogies.

Marianna Papastephanou argues that these "deficits of philosophy as an entry point for investigating terror should not be dissociated from deficits of philosophical conceptions of what should count as cosmopolitan and patriotic and deficits of political imagination in examining terror-producing, remote realities." 15 She disagrees that this deficit is remedied when we think of terrorology as a discourse and a process that can be "reduced to contractarian matters such as the trade-off of individual liberty and personal security of the citizen." 16 No adequate narrative can fill the philosophical lacunae of theorizing the notions that surround events such as the 9/11 as well as what traspired before it and beyond it.

The narratives on the 9/11 events are in some way postscript remarks, texts written after the damage of the events had been noted. Such a description fits into the line of thinking which perceives the autoimmune condition as a process that is noticed after the body suffers collateral damage. The rhetoric of the "war on terrorism" justified the attack on the enemy while consolidating the tactics of the 
Janus-faced democracy. It is this sad scenario, in my view, that Papastephanou problematises as an advertised product with a "there is no alternative (TINA)"17 label. She tackles this slogan of irremediability from the perspective of political imagination and its lack. After the 9/11 events, the "enemy" had again to be summoned to face the sovereign's exceptional decision as to who should live or die. But this time, the employment of the strategy of "war" raises questions on whether such tactics have weakened the political hegemony of the sovereign indefinitely. The next section proceeds to discuss this line of thinking on the reversal of democratic sovereignty. To discuss this point, it considers the example of European populism to explore whether it is still fitting to speak of democracy in terms of the people's determining say to direct their communities politically.

\section{European Populism}

In The Other Heading, ${ }^{18}$ Derrida presses the issue of the rift that Europe caused by its obsession to leave the sovereign mark of its democracy on the countries it desired to colonise while, at the same time, creating a democratic deficit in its own countries. This failure by democratic governments to answer people's demands brings a shift to the concept of democracy as it points directly to a disruption of the connection between "people" and "power." While some have interpreted this disruption as a phenomenon happening "outside" the democratic body, the next section presents a view which speaks on the disconnection between "people" and "power" as an autoimmune

process which happens "inside" the democratic body. Evidently, the "inside" versus "outside" is yet another possibility of formulating what is included and what is excluded.

For example, Benjamin Arditi refers to the point made by Margaret 
Canovan about populism as "an appeal to 'the people' against both the established structure of power and dominant ideas and values of the society" 19 as a shadow cast from the democratic body. Shadows, as in art, are external shapes, remaining outside, not included in the main body, and are produced between the light falling on the body and the surface. Unlike Canovan's perception of populism as an external phenomenon, Arditi perceives populism as an internal phenomenon which can bring about the downfall of democracy itself. He remarks that "populism can be a dimension of representation and a mode of participation lodged in the rougher edges of democracy, but also something more disturbing, as it can thrive in political democracies while it morphs into democracy's nemesis." ${ }^{20}$ By this last phrase, Arditi draws attention to how populism acts like an autoimmune process which damages democratic sovereignty internally.

\section{Conclusion}

It is difficult for democracy to bracket the logic of its authority because, as Derrida notes, the nature of "sovereignty is round; it is a rounding off." 21 Ironically, today, the cyclical patterns of democracy are noticed again through its frantic attempt to idolise the remains of its sovereignty. William Mitchell illustrates this point by referring to the idols of our time like "the monumentalisation of $9 / 11$, the fetishistic concept of terrorism, the mythic cultural icon of immunity as homeland security." 22 The picture of a shattered democracy resonates through Nietzsche's griefing expression on why we cannot have twilight on our idols.

Democracy seems to have its own idols so far as these serve their purpose of anesthesising people from the trauma of the dissolution of

power. The idols, also, represent the excess of the effacement of the 
democratic body where the collective community turns anonymous in the global forces that control the world. What would the sovereign power of democracy look like when its people have no face? So far, the review of the democratic power relations from the perspective of autoimmunity has positioned the connection between "power" and "people" at the crossroad of a decision-making process. At this stage, democracy can take different paths. One of them is to respond to its responsibilities by the "injunction as absolute urgency" 23 on the redirection of Aristotle's plot of political likemindedness. The 9/11 events and the rise of populism in Europe, as events that required immediate political action, have profoundly changed the political landscape revealing and exacerbating older asymmetries while producing new ones. This imbalance in democratic power relations serves as a reminder that every time politics actualises again the exceptional character of its sovereignty, it will also be closing the people's future indefinitely effecting ever new modalities of inclusions and exclusions.

\section{Notes}

\footnotetext{
${ }^{1}$ Ivan M. Roitt and Peter J. Delves, Roitt's Essential Immunology, 10th ed. (Massachusetts: Blackwell Science, 2004), chapter $1,1$.

${ }^{2}$ Timothy Campbell, “'Bios', Immunity, Life: The Thought of Roberto Esposito,” Diacritics 36 (2) (2006): 2-22, 5 .

${ }^{3}$ Roberto Esposito, Bíos: Biopolitics and Philosophy (Minneapolis: University of Minnesota Press, 2008), 46.

${ }^{4}$ Plato: Euthyphro, Apology, Crito, Phaedo, Phaedrus, trans. Harold N. Fowler (Cambridge: Harvard University Press, 2005).

${ }^{5}$ Friedrich W. Nietzsche, Philosophy in the Tragic Age of the Greeks, trans. Marianne Cowann (Washington: Regenery Publishing, 1994), 34.

${ }^{6}$ Matthias Fritsch, "Derrida on the Death Penalty," The Southern Journal of Philosophy 50 (2012): 56-73, 66.

${ }^{7}$ Fritsch, "Derrida on the Death Penalty," 68.
} 
${ }^{8}$ Donna J. Haraway, Simians, Cyborgs, and Women - The Reinvention of Nature (New York: Routledge, 1991), 204.

${ }^{9}$ Aristotle: Politics, trans. Ernest Barker and intr. Richard F. Stalley (Oxford: Oxford University Press, 1998), 7.

${ }^{10}$ Aristotle: Eudemian Ethics, trans. and ed. Brad Inwood and Raphael Woolf (Cambridge: Cambridge University Press, 2013), 138.

${ }^{11}$ Anthony Smith et al., The Oxford Dictionary of Biochemistry and Molecular Biology (Oxford: Oxford University Press, 2000), 56.

${ }^{12}$ Jacques Derrida, Rogues - Two Essays on Reason, trans. Pascale-Anne Brault and Michael B. Naas (Stanford, CA: Stanford University Press, 2005), 45.

${ }^{13}$ Arun Kudnani, “Radicalisation: The Journey of a Concept," Institute of Race Relations 54 (2) (2012): $3-25,21$.

${ }^{14}$ Toni Morrison, "The Dead of September 11," in The Source of Self-Regard-Selected Essays, Speeches, and Meditations (New York: Alfred A. Knopf, 2019), 3-4, 3.

${ }^{15}$ Marianna Papastephanou, "Terror(ology) in the Time of 'Cosmopolitanism'," Knowledge Cultures 6 (3) (2018): 7-27, 8.

${ }^{16}$ Ibid., 16.

${ }^{17}$ Ibid., 19.

${ }^{18}$ Jacques Derrida, The Other Heading, trans. Pascale-Anne Brault and intr. Michael B. Naas (Bloomington: Indiana University Press, 1992).

${ }^{19}$ Margaret Canovan, "Trust the People! Populism and the Two Faces of Democracy," Political Studies 47 (1) (1999): 2-16, 3.

${ }^{20}$ Benjamin Arditi, "Populism as a Spectre of Democracy: A Response to Canovan," Political Studies 52 (2004): 135-43, 143.

${ }^{21}$ Derrida, Rouges, 13.

${ }^{22}$ William John Thomas Mitchell, "Picturing Terror: Derrida's Autoimmunity," in The Late Derrida (Chicago: The Uiversity of Chicago Press, 2007), 59-72, 72.

${ }^{23}$ Derrida, Rouges, 29. 


\title{
Identity versus Alterity and Inclusion versus Exclusion:
}

\section{Unavoidable Dipoles?}

Kalli Drousioti

Independent Scholar, Limassol, Cyprus

\begin{abstract}
In this paper, I clarify the connection of political practices of inclusion and exclusion with the issue of incriminating Otherness. If we attribute an ontological status to incriminating Otherness, we end up with a legitimization of various political exclusions and/or of assimilation. Moreover, we establish a rigid dichotomy between inclusion and exclusion, which presupposes, I argue, the ontologization of the 'Self versus Otherness' dipole. These implications of the theorization of identity's construction along incriminatoryontological lines escape the attention of many thinkers who are otherwise interested in inclusivist politics. Therefore, this paper will take up constructionist approaches of incrimination as an example of a theorization of "identity 'versus' alterity" that allows such implications. My first step is briefly to clarify the notion of inclusion. Then I present some constructionist approaches to identity, which maintain that identity presupposes an external enemy in order to be constructed. I explain how this position establishes a rigid dichotomy between Self and Otherness and by implication between inclusion and exclusion. Along such dichotomous lines, exclusion and assimilation are legitimized, and important nuances of identity and inclusion are bypassed.
\end{abstract}




\section{Introduction}

The dichotomy of inclusion and exclusion is predominant in the relevant literature. This seems justifiable because inclusion presupposes the acceptance of the "Other", her incorporation into the "We", whilst exclusion presupposes that the "Other" cannot belong to the "We". The latter is, at times, legitimized on grounds of the Other having being incriminated or demonized. For instance, some constructionist approaches to identity conceptualize the "I" as inherently incriminatory of an otherness. By attributing an ontological status to identity operations of incriminating Otherness, they run the risks of legitimizing exclusion and/or assimilation and of establishing a rigid dichotomy between identity and alterity, and, by implication, between inclusion and exclusion. Thus employed, these binary oppositions have had various political operations and have raised several questions (see, for instance, Papastephanou1). Are these dichotomies unavoidable? Are there not any possibilities of getting away from the drastic choice that these dichotomies entail? In other words, is it part of an inescapable social ontology that we are somebody's Others or that we are some Others' Others so that this othering will give us grounds to exclude them? To tackle these questions indicatively in this work-in-progress, I present some constructionist interpretations of the notion of scapegoating as an example of perceiving incrimination as the ontological result of identity construction. Despite their inclusivist intentions, such approaches extrapolate that exclusion is unavoidable. In so doing, they thus indirectly legitimize exclusions of a kind as an inevitable outcome of being. I conclude that, if we are to avoid such pitfalls, we have to consider the inclusion-exclusion dichotomy and the Self-Other relationship differently. 


\section{Inclusion: What Is It About, or What Should It Be About?}

The term "inclusion" has become fashionable in recent academic, educational and other discourses. "It comes from the Latin includere which interestingly means to 'shut in', to 'shut something up', to 'confine.".2 As a concept, inclusion "suggests that nobody is excluded."3 Nobody is excluded either from schooling (educational inclusion), or from society, local and global (social inclusion). To put it otherwise, inclusion aims to provide "many opportunities and spaces for citizens and residents to take part in the cultural and political affairs of the community." 4

Thus defined, inclusion (educational and social) is widely acknowledged as a desirable status of education and society and it must be given high priority. However, some risks become noticeable when inclusion is (naively) perceived as the desirable endpoint of schooling and society. Amongst other things and regarding migration, Marianna Papastephanou points out that we account for movement in an undifferentiated and hegemonic manner; we are so doing, she claims, by supposing that all that the other wants and needs is to be included in our dream world; and, worst, that all we owe to her is to make room for her in our dreamlands. When we fail to differentiate our accounts of movement, we get entrapped in a narcissist assumption that our ethico-political debts to others is merely to share our "idealized locality" with them. ${ }^{5}$ In other words:

believing to inhabit the advanced space of promise and possibility, many Europeans utopianize their locality as an appealing Promised Land and fail to realize that, to some immigrants, coming to Europe is a necessity, not an option. If those immigrants could stay home, some of them may have preferred to do so rather than flee. Hence, instead of expecting from Europeans just to open Europe as a Land promised to the 
"other", many non-Europeans would expect those measures that would enhance their capability of free choice of residency. ${ }^{6}$

By seeing inclusion in a new, more nuanced light, not only do we become aware of hegemonic and narcissistic stances towards otherness, but we also avoid considering inclusion and exclusion as being necessarily in a dichotomous relationship: If we assume that inclusion and exclusion constitute an unavoidable dipole, then we end up conceiving inclusion of the Other as the utmost good for her. ${ }^{7}$ As a result, we Eurocentrically overlook the possibility that the Other's expectations may not involve a desired de-territorializing from her own space and, thus, exclusion or inclusion may not be applicable or exhaustive of ethico-political normativity.

The example of migration invites the questions: why did the Other have to flee her country? What (historical and other) responsibilities the Western Self has for others' misfortune or lack of existential choice? ${ }^{8}$ How should affluent countries belonging in the set designated "Western spatiality" (so deconstructible and problematic, yet simultaneously so persistent and pertinent as a socio-political category) deal with global problems that burden others? Tackling these questions might be helpful for shedding new light on our debts to otherness, a task which is more complicated and challenging than the facile and convenient assertion that all we owe to alterity is to make room for her allows us to see. ${ }^{9}$ Thinking this through to its implications explains why inclusion should not be perceived as a clearcut and simple notion in a dichotomous relationship with exclusion. ${ }^{10}$ Let me present in the next section another important operation of the conceptualization of the relationship between inclusion and exclusion as unavoidably dichotomous. This dichotomy mirrors (and simultaneously perpetuates) the problematic assumption that there is 
an inherent sharp contrast between Self and alterity - an assumption that is detectable in constructionist accounts of scapegoating.

\section{Self versus Otherness (and Inclusion versus Exclusion) in and through Social Constructionism}

The theorization of inclusion as a clear-cut, un-nuanced notion (simplistically perceived as the desirable endpoint of society and schooling) chimes, I argue, with the problematic theorization of identity as by definition exclusivist and, possibly, derives from it. Some constructionist, incriminatory, approaches to identity can serve as an example of how the "inclusion versus exclusion" dichotomy reflects and also reproduces the "Self versus Otherness" dipole.

The assertion that identities are in an oppositional and negative relationship is underpinned by the compelling argument that identity is constructed and formulated through its difference with an ever shifting otherness, which entails the impossibility of obtaining a full identity. And an otherness must supposedly be blamed for this impossibility/failure. William E. Connolly, who conceives identity as constructed, explains the relationship between identity and difference as follows:

the paradoxical element in the relation of identity to difference is that we cannot dispense with personal and collective identities, but the multiple drives to stamp truth upon those identities function to convert differences into otherness and otherness into scapegoats created and maintained to secure the appearance of a true identity. To possess a true identity is to be false to difference, while to be true to difference is to sacrifice the promise of a true identity. ${ }^{11}$ (emphasis added) 
And he continues: "The other is sacrificed so that the self can project an infantile image of self-identity, national unity, and the human condition."12 Connolly's position entails that identity presupposes an otherness to be contrasted to. We need an (incriminated) otherness to obtain identity and retrospectively, we are Others' Others. This assertion not only renders identity unavoidably exclusivist, but it also legitimizes, indirectly and unwittingly, exclusion as the unavoidable result of identification.

Similarly, Yannis Stavrakakis maintains that identity goes hand in hand with the practice of othering and with incrimination. He argues that: Even relatively stable identity formations, when encountering a dislocatory event, when entering a state of crisis or a "critical juncture," often lose the appearance of stability and fullness. Under such conditions they can only attempt to retain their hegemonic status by blaming someone else, even a previously friendly out-group. Far from being a mere matter of (un)reflexivity and symbolic rearrangement, identity construction - this process of managing the semblance of a stable and complete identity - ultimately depends on the ability of a discourse to explain (and/or mask) its lack of fullness and completeness. This is why scapegoating, the sinister type of difference as exclusion and demonization, always remains a real possibility inscribed at the core of any identity claim. ${ }^{13}$

Stavrakakis also argues that "the need for the structural position of the anti-figure remains constant (...). Nobody is excluded from being stigmatized." 14 Thus, although he conceives of identity as constructed, Stavrakakis asserts that identity is inherently incriminatory of an otherness.

In the same vein, Jacob Torfing's constructionist conception of identity ends up incriminating identity constitution and legitimizing exclusion, since he also reads identity as inherently incriminatory of an 
otherness. For instance, Torfing maintains that "the homogenization and substantialization of the nation can only be obtained in and through the discursive construction of 'enemies of the nation,' which are simultaneously outside and inside the nation." 15 And he continues: "The role of the hegemonic project of nationalism is (...) to provide the empty signifier of the nation, which symbolizes an absent fullness, with a precise substantive content that people can identify with." 16 Thus, the sweeping incrimination of identity in Torfing's approach narrows down to national identity.

The main position of the above-mentioned constructionist approaches to identity is that identity needs an alterity to be contrasted to. If identity is to be established as such, an incriminated/ demonized Other must be found. Hence, such approaches construct a rigid dichotomy between Self and alterity. This dichotomy, I argue, chimes with or perhaps even produces the dichotomy between inclusion and exclusion. For instance, Connolly claims that democratic agonism "insists that one significant way to support human dignity is to cultivate agonistic respect between interlocking and contending constituencies." 17 "Connolly's argumentation is developed along the polarity identity/difference with the ethical sting being a recognition of Otherness." 18 Thus, Connolly reduces the Self-Other relationship issue to respect toward, and acknowledgement of, otherness. Within his approach, there are only two options regarding our stance toward otherness: we will be either exclusivist or inclusivist yet in an assimilative manner; it seems that there is nothing in between inclusion and exclusion.

The dichotomy between inclusion and exclusion and their un-nuanced conceptualization is apparent in Stavrakakis' work too. Stavrakakis simplistically holds that inclusion presupposes a certain exclusion, that is to say a signification of the limits of political reality. Social 
groups, for example, tend to define themselves through exclusion, by comparing themselves to "strangers". But how are these strangers defined? One crucial element is the lack of communication. ${ }^{19}$

Thus, Stavrakakis discards any nuance of the notions of inclusion and exclusion. Furthermore, Stavrakakis attributes an ontoanthropological status to exclusion: "Only the exclusion of this real can guarantee the stability of our reality. Our reality can be real only if the real outside reality is negated, attributed to the Other who somehow stole it from us." 20 By perceiving exclusion as the unavoidable result of our tendency to conceal reality's contingency, Stavrakakis considers exclusion a social ontology and he understands inclusion and exclusion as clear-cut and simple notions.

The dichotomy between inclusion and exclusion, established by the "Self versus Other" dipole, emerges in Torfing's perspective too. Torfing suggests that "rather than seeking to dissolve political conflicts and antagonisms within the framework of a consensual, deliberative democracy, we should aim to find ways of making social antagonisms compatible with pluralist democracy. The trick is to turn antagonism into agonism." ${ }^{21}$ And citing Mouffe's positions, he opines that "within such an agonistic democracy, enemies would not be destroyed, but rather turned into adversaries whose politics we might disagree with, but whose existence would be legitimate and should be tolerated." 22 Thus, in Torfing's approach inclusion and exclusion are simplistically perceived as clear-cut, un-nuanced notions: different political identities (which are constituents of democracy) are mutually exclusive (due to their difference), yet in an agonistic, rather than antagonistic, manner: they tolerate and recognize otherness. However our relationship with alterity is not reducible to tolerance or recognition: what about our debts to, and empathy with, others and their misfortunes? 


\section{Conclusion}

The dichotomy between the Self and the Other goes hand in hand with the dichotomy between inclusion and exclusion. As a result, inclusion more often than not ends up in expectations or presuppositions of assimilation. In the case of the migrant Other, this is confirmed by our facile assumption that the Other is quite eager to be included; that the Other, similar as she supposedly is to us, finds appealing, and would like to be included in, our "dream-world". In a nutshell, within a framework that takes the Self to be in an oppositional relation to the Other, if we are to include the other, ironically, we have to efface her otherness.

Regrettably, on the basis of such dichotomous thinking, we understand inclusion, exclusion, and identities as clear-cut and simple notions. This blocks us from exploiting nuanced (re)conceptualizations of identity and inclusion and from going beyond the assumption that the relationship between the Self and the Other is exhausted in (desirable) inclusion versus (undesirable) exclusion. On the contrary, by grasping the intricacies of the notions of identity and inclusion and of their correlation, we may become more capable of empathizing with alterity, e.g. of apprehending that the migrant Other is in some cases forced to leave her country. And this provides a strong challenge to the Western Self (which the relevant literature has glossed over to a great extent): what (historical and other) responsibilities she has for others' misfortune or lack of existential choice, ${ }^{23}$ and under what circumstances the migrant is perhaps forced to leave her country. ${ }^{24} \mathrm{In}$ a nutshell, if the Western Self is wholeheartedly willing to help the migrant Other, she might have to consider her debt to alterity differently and step out of the box of self-convenience and selfcongratulation. 


\section{Notes}

\footnotetext{
${ }^{1}$ Marianna Papastephanou, "Inclusion in Education and in Public Debates on Education,” Beijing International Review of Education 1 (June 2019): 303-23.

2 Ibid., 306.

${ }^{3}$ Linda Dunne, “Discourses of Inclusion: A Critique," Power and Education 1 (March 2009): 12.

${ }^{4}$ Robin Richardson, quoted in Margaret Reynolds, "Education for Inclusion, Teacher Education and the Teacher Training Agency Standards,” Journal of In-Service Education 27 (2001): 466.

${ }^{5}$ Marianna Papastephanou, “Cosmopolitan Dice Recast,” Educational Philosophy and Theory 49 (2017): 1338-50.

${ }^{6}$ Marianna Papastephanou, "Why Cosmopolitanism Needs Rethinking," in The Palgrave Handbook of Global Citizenship and Education, ed. Ian Davies, Li-Ching Ho, Dina Kiwan, Carla L. Peck, Andrew Peterson, Edda Sant, and Yusef Waghid (London: Palgrave Macmillan, 2018), 189.

${ }^{7}$ Papastephanou, Inclusion in Education and in Public Debates on Education, 312.

${ }^{8}$ Papastephanou, “Cosmopolitan Dice Recast."

${ }^{9}$ Ibid.

${ }^{10}$ Papastephanou, "Inclusion in Education and in Public Debates on Education."

${ }^{11}$ William E. Connolly, Identity/Difference: Democratic Negotiations of Political Paradox (Minneapolis: University of Minnesota Press, 1991), 67.

${ }^{12}$ Ibid., 101.

${ }^{13}$ Yannis Stavrakakis, The Lacanian Left: Psychoanalysis, Theory, Politics (Edinburgh: Edinburgh University Press, 2007), 195.

${ }^{14}$ Yiannis Stavrakakis, Lacan and the Political (London: Routledge, 1999), 105.

${ }^{15}$ Jacob Torfing, New Theories of Discourse: Laclau, Mouffe and Žižek (Brighton: G \& G Editorial, 1999), 191

${ }^{16}$ Ibid., 195.

${ }^{17}$ Connolly, Identity/Difference, $\mathrm{x}$.

${ }^{18}$ Stavrakakis, Lacan and the Political, 139.

${ }^{19}$ Ibid., 80.

${ }^{20}$ Ibid.

${ }^{21}$ Torfing, New Theories of Discourse, 255.

${ }^{22}$ Ibid.

${ }^{23}$ Papastephanou, "Cosmopolitan Dice Recast."

${ }^{24}$ Ibid
} 


\section{Who can teach what none have learned?" Pedagogies of Inclusion and Exclusion in Thomas Hobbes' Behemoth}

Giorgos Kataliakos

Department of Education, University of Cyprus, Cyprus

\section{Introduction}

The notion of inclusion has met growing popularity among scholars who work in a variety of relevant theoretical disciplines from political decisionism and exceptionalism to migrants' integration and feminist theory. For instance, Georgio Agamben has, in further expanding Carl Schmitt's decisionistic account of the sovereign as "he who decides on the exception," famously suggested that in today's world nobody can be seen as excluded from emergency conditions decided by governments in order to face possible dangers, coming from internal enemies or foreign factors, that tend to shake the very foundations of Western democracies. ${ }^{2}$ Etienne Balibar and Immanuel Wallerstein have, regarding the issue of migrants' inclusion in contemporary Western societies, pointed to the present tendency of reducing "every social 'problem' to a problem being posed by the fact of the presence of 'immigrants' or, at least, as being aggravated by their presence."3 They detect that all the dimensions of social pathologies are reduced to one social problem, namely, the precarious migrant condition, and this poses a great challenge for current democratic procedures and institutions. ${ }^{4}$ In a similar tone, Sylvia Federici depicts the problematic of inclusion from a feminist point of view, arguing that "migrant women do the most of the work needed for the reproduction of the work-force in industrialized countries, especially in Europe and the U.S.," ${ }^{5}$ and that migrant women should also enjoy equal working 
rights and benefits as all native populations in industrialized countries. ${ }^{6}$

Many of these arguments are credible as such, yet, we should avoid uncritical and sweeping overgeneralizations on inclusion and exclusion simply because they meet wide acceptance and growing applicability. In my view, and following Marianna Papastephanou's elaboration on inclusion, the question of who is included into what and in what sense should definitely be of concern since it reveals a much more complicated understanding of what inclusion might mean and of its various implications. ${ }^{7}$

In this regard, my presentation draws attention to the early modern philosopher Thomas Hobbes and explores how inclusion and exclusion operate in his writings on the English civil war in Behemoth. Hobbes remains a powerful influence in philosophy and politics to this day and his anthropological, epistemic and political concerns relate to aspects of inclusion and exclusion that are worthy of further investigation.

Hobbes' book Behemoth, which is one of his most underestimated works compared to his famous Leviathan and to his less famous De Cive, enables, I argue, a much more nuanced and complicated reading of political operations of inclusion than those which dominate academic research today. Hobbes makes inclusion operative in Behemoth at a point in the theatrical dialogue between the teacher and the student where the latter is educated by the former on the proper meaning and signification of the word "justice" and the subsequent mistreatment of the term by people who Hobbes believed had betrayed the authority of the king. As this episode unfolds, Hobbes maintains an attitude towards British possessions in Scotland that could pass today as inclusivist at first sight. And he constantly blames intellectuals and universities for allowing seditious education 
to become disseminated across British political space. In other words, Hobbes accuses intellectuals principally of harboring and cultivating seditious beliefs and tendencies toward self-exclusion from the British polity. Peoples' liberation becomes, for Hobbes, a politically repugnant self-exclusion and his inclusivism turns out to be an argument in favour of stability and preservation of the imperial state.

In what follows, I analyze my argument further by addressing Hobbes' inclusivist and exclusivist attitudes towards British possessions and also by underlining some literary strategies that Hobbes followed for making his position sound.

\section{Inclusion and Exclusion in Hobbes}

In Behemoth, which discusses the civil wars in England, Hobbes gives ample evidence of his overarching devotion to the English gentry of his times as well as to the numerous potentialities arising from the possible re-education of this class to the principles designed by Hobbes to guarantee peace and stability within a commonwealth. He goes about this by expressing his great disappointment by the inability of this class to offer consistent support to the King against his many rivals. Though "the gentry" for Hobbes expressed the most educated kind of people, thoroughly equipped with the right sort of manners, they nevertheless proved weak and incapable to defend the interests of their own class and, by extension, of their motherland England. Due to the dissemination of what Hobbes himself defined as seditious political doctrines and pernicious educational material all around England, people started having democratic inspirations that questioned the monarchical state of the king. Along with this uncontrolled dissemination, processes were set in motion by which the 
king's capability to maintain control of the British possessions in Ireland, Scotland and Wales was also challenged.

Hobbes' treatment of the British possessions in Scotland, Ireland and Wales and the implications this matter raises for his political theory as a whole and beyond, is a subject that remains partly unclear and understudied in the relevant literature. Daniel J. Kapust and Brandon P. Turner merely touch upon this issue in their attempt to link the rhetoric of liberty to dominion in Hobbes' thought. ${ }^{8}$ Maximilian Jaede, despite discussing Hobbes' expressed worries concerning the difficulties faced by the sovereign to maintain control over occupied lands soon after a successful invasion, never discusses Hobbes' own politics concerning British possessions and the colonial elements in his political thought. 9 This inattention is caused by a number of reasons, methodological, philosophical and educational, which, I believe, limit the scope of critical revaluation of Hobbes' contested republicanism and the various implications of this matter for reframing a contemporary concept of "the political." Interesting as this issue may seem, it certainly goes beyond the scope of this presentation which is to explore the imperial operations of inclusion in Hobbes as found in a passage from his analysis of the civil war in England during the years 1641-1660.

\section{Inclusion}

From the early beginning of Hobbes' directed dialogue between the teacher (A) and the student (B), his general intentions become evident through a particularly self-referencing and authoritative manner. Hints like "I am now in a narration, not in a disputation" 10 or "Truly I do not know; I cannot enter into other men's thoughts" are indications of the overall tension and anxiety that Hobbes felt in his whole course 
of writing history. Hobbes, in the disguise of the teacher, expresses his intention to provide clear and straightforward answers to controversial opinions raised by the student. In one indicative encounter between the two, related to the troubles of Scotland during the civil war, the student appears curious enough to learn why Scots and English are not "united into one people" 11 since they both talk the same language and obey the same king. In this regard, he brings up the case of Rome as a past example of an empire that gave the right to all subjected nations and populations to call themselves Romans and to feel "protected from the contumelies of other nations where they resided." 12

Right at this point, Hobbes defends an attitude that can pass in our contemporary terms as thoroughly inclusivist towards Scotland arguing that "Scotch have now as many privileges in England as any nation had in Rome";13 to prove that this is indeed the case, he refers to the Scots' inalienable right given by the king to buy property wherever in England they deemed possible. Despite Hobbes' obvious denial to go any further in Ancient Rome's "empire" structure and social composition, he insists that Scots should feel somehow pleased with their status, since they enjoy equality and protection along with all the subjects in the commonwealth.

Yet Hobbes seems unsatisfied with his example of Ancient Rome and brings another, that of "the provinces of France," presumably, as a more up to date example of how Scots should ideally feel as an inextricable part of the English commonwealth which at the same time enjoys parliamentary and constitutional independence. Attention to how Hobbes shifts his scope toward a case that he believes likely to convince the reader reveals his insistence to further strengthen inclusivist attitudes towards British possessions.

When the student rhetorically wonders: 
"Those Romans, when any of them were in Rome, had their voice in the making of laws." 14

He receives by the teacher the immediate answer:

"And the Scotch have their Parliaments, wherein their assent is required to the laws there made, which is as good. Have not many of the provinces of France their several parliaments and several constitutions? And yet they are all equally natural subjects of the king of France. And therefore for my part I think they were mistaken, both English and Scotch, in calling one another foreigners." 15

Through this statement Hobbes seems overeager to point out that Scots have a political say in the whole process of decision making that reflects their status as citizens of equal rights and dignity as the English citizenry. Hence Scots, according to Hobbes, should be regarded as native citizens belonging to the English commonwealth since they enjoy equal rights and protection, but they should keep a form of autonomy in calling themselves Scots and not English citizens properly speaking. This slight distinction demarcates Hobbes' own understanding of inclusion, which is certainly very interesting, if we think that Hobbes is widely regarded as a strong and indisputable supporter of absolute monarchy. This established and widely accepted opinion among Hobbesian scholars and beyond, namely that of Hobbes being an indisputable supporter of absolute monarchy, may be challenged through this example and many others that point to a more nuanced, complicated aspect of his thought and indicate his preparedness to accept qualifications of monarchy for the sake of preservation and reproduction of the imperial state.

I therefore suggest here that Hobbes may not have been an adamant supporter of monarchy per se but rather a defender of everlasting and durable government that guarantees equal protection for all citizens 
under the sovereign rule. His insistence that the English gentry had gone astray and that this class should be definitely educated and reeducated under his command if it is to maintain in power comes across through the student's own words thus:

"I am therefore of your opinion... that we shall never have a lasting peace [till] the Nobility and Gentry know, that the Liberty of a State is not an exemption from the Laws of their own country, whether made by an Assemblyor by a Monarch, but an exemption from the constraint and insolence of their Neighbours." 16

Here Hobbes clearly addresses the gentry as the only legitimate receiver of his political views and recommendations. Educating the common people on the rules of sovereign power was pointless for Hobbes, since the later "have been, and always will be, ignorant of their duty to the public"17. The liberty of a State is a task that has to be taught explicitly to the elite class and can be prescribed either by an assembly or by a monarch, a statement that testifies to Hobbes' chief devotion to the English gentry and to his belief that this class is the only one capable of controlling and reproducing the political regime of his times. Hobbes was in favour of the monarchical state of the king inter alia because the latter managed by that time to maintain peace between all included populations residing in the English Commonwealth. The matter of civil war pose a great risk for Britain in losing control over British possessions in Scotland, Ireland and Wales and this, for Hobbes, could prove devastating, in the long run, for the ever-presence of a powerful British State.

\section{Exclusion}

But who is to be blamed, according to Hobbes, for this unforeseen miseducation of the gentry, which, to an extent, sparked beliefs and 
tendencies toward self-exclusion from the British polity? This question brings us to the second point I wish to raise concerning Hobbes' insistence to renounce the teaching of certain philosophical and political doctrines that to him encouraged students to turn against their legitimate sovereign. These doctrines were the writings of Ancient Greek and Roman philosophers like Aristotle, Seneca and Cicero whose teachings Hobbes considered dangerous mainly for two reasons: (a) these philosophers failed, according to Hobbes, to work out clear meanings and definitions concerning the stability and the formation of a commonwealth, a fact that to him caused great confusion to the masses of readers, including schoolmasters and academics; (b) the latter, who were trained to teach these doctrines to the masses of students, became attached to this kind of doctrines that suggested alternative forms of government, and this was enough reason for sparking tendencies toward self-exclusion from the British polity.

According to Hobbes, schoolmasters and academics not only motivated groups of citizens to take arms against the king, but were also chiefly responsible for planting wrong ideas in peoples' minds and souls. These groups of educated people residing and teaching at the English Universities indulged in scholasticism, which, in Hobbes' mind, articulated Aristotle's already absurd and "repugnant" 18 philosophical ideas in a rather obscure manner that further resulted in what he calls "insignificant speech and meaningless language." As Hobbes repeatedly notes in Leviathan, the Universities were not at all teaching philosophy, but, instead, "Aristotelity,"19 and "have been to their nation as the wooden horse was for the Trojans." 20

The problem of education for Hobbes and his proposal for reforming the universities lays at the very center of his political thought and is a matter worthy of further attention as to its various implications. For, 
he believes that nothing is capable to guarantee everlasting peace unless all the subjects of the commonwealth get comprehensive instruction on his proposed civic science. But, while suggesting the reeducation of the entire population to his civic science, he proves exclusivist in attributing "ignorance" and "difficulty of being taught" 1 (what he defines as indocibility or amatheia) to some people, while addressing the gentry as the only agent educated enough to comprehend his teachings. ${ }^{22}$ Hobbes' urgent need to name who should be included and who should be excluded from his relevant teachings, points to his decisiveness to further develop conservative mechanisms of control that will alone prevent civil conflict and disorder in the future. In one such occasion, in Behemoth, Hobbes gives lessons on the proper meaning and signification of the word "justice" and why this cannot be "rightly" taught to the masses of what he calls "ignorant people." What is particularly striking in this episode is that the role of the teacher and the student suddenly takes a different turn, in the sense that it is the student now giving rhetorical answers to the teacher's insistent questions. Soon after the student positions himself against common people as being restlessly ignorant of their true duty to the public, this telling dialogue follows:

Teacher: Why may not men be taught their duty, that is, the science of just and unjust, as divers other sciences have been taught, from true principles and evident demonstration; and much more easily than any of those preachers and democratical gentlemen could teach rebellion and treason?

Student: But who can teach what none have learned? Or, if any man hath been so singular, as to have studied the science of justice and equity; how can he teach it safely, when it is against the interest of those that are in possession of the power to hurt him? 
This dialogical discrepancy reveals Hobbes' rhetorical tactics of pushing his argument to the limits through both the teacher's and the student's positions. Hobbes' effort to convince a specific audience, namely the gentry, that justice and equality can only be established through his true definitions and evident demonstration presupposes the re-education and realignment of schoolmasters to his proposed civil doctrine as found in Leviathan. Moving my argument a step further, what I suggest is that "the re-education of the educated" comes at a high risk for Hobbes, since he seems ready to challenge the validity of philosophical-political ideas, like sovereignty and the constitution of the body politic, that to him formed the ground for developing his own political theory. What I have tried to point out throughout my presentation is a more complicated understanding of both inclusion and exclusion as indicated in Hobbes' philosophy and theory of the State. Going back to the roots of modern political thought and specifically through the example of Hobbes, we can see that both inclusion and exclusion served as conservative mechanisms of control and as technologies for the reproduction of the political regime of his times. The inclusion of Scots as indisputable part of the United Kingdom during the troubled period of civil war, along with the renouncement of the teaching of certain philosophical and political doctrines, constitute two operations set forth by Hobbes that, to him, ensure the persistence and ever-presence of a powerful State. The need to underline implications and applications of Hobbes' operations of inclusion and exclusion and its relevance to education and contemporary politics is a project under study that I wish to further explore in the near future. 


\section{Notes}

${ }^{1}$ Carl Schmitt, Political Theology, trans. George Schwab (Chicago: The University of Chicago Press, 2005), 5.

${ }^{2}$ Giorgio Agamben, State of Exception, trans. Kevin Attell (Chicago: The University of Chicago Press, 2005), $2,3$.

${ }^{3}$ Etienne Balibar and Immanuel Wallerstein, trans. Chris Turner, Race, Nation, Class: Ambiguous Identities (London: Verso, 1988), 219-20.

${ }^{4}$ Ibid., 219-20.

${ }^{5}$ Silvia Federici, "Women, Reproduction and Globalization," Économie mondialisée et identités de genre (Institute Publications, 2002), 58. Available at: <http://books.openedition.org/iheid/6171>. ISBN: 9782940503780. DOI: $10.4000 /$.

${ }^{6}$ Ibid., 58 .

${ }^{7}$ Marianna Papastephanou, "Inclusion in Education and in Public Debates on Education," Beijing International Review of Education 1 (2) (2019): 5.

${ }^{8}$ Daniel J. Kapust and Brandon P. Turner, "Democratical Gentlemen and the Lust for Mastery: Status, Ambition, and the Language of Liberty in Hobbes's Political Thought," Political Theory 4 (4) (2013): 665.

${ }^{9}$ Maximilian Jaede, "Nature and Artifice in Hobbes's International Political Thought," Hobbes Studies 28 (2015): 31-32.

${ }^{10}$ Thomas Hobbes, Behemoth, Vol. VI, The English Works of Thomas Hobbes of Malmesbury, ed. Sir William Molesworth (London: John Bohn, 1839-45; Reprinted, Routledge/Thoemmes Press, 1997), 115.

${ }^{11}$ Ibid., 128.

${ }^{12}$ Ibid.

${ }^{13}$ Ibid.

${ }^{14}$ Ibid., 129.

${ }^{15} \mathrm{Ibid}$

${ }^{16}$ Ibid., 148.

${ }^{17}$ Ibid., 133.

${ }^{18}$ Thomas Hobbes, Leviathan, Vol. III, Part I-II, The English Works of Thomas Hobbes, 523.

${ }^{19}$ Ibid.

${ }^{20}$ Hobbes, Behemoth, Vol. VI, The English Works of Thomas Hobbes, 133.

${ }^{21}$ Thomas Hobbes, Elements of Law, Vol. IV, The English Works of Thomas Hobbes, 30.

${ }^{22}$ Ibid., 30. 


\section{The Inclusive Qualities of the Homeric Concept of Daimôn beyond the Dipole of the One and the Many}

Eleni Katsiai, Marianna Papastephanou, and Mary KoutseliniIoannides

Department of Education, University of Cyprus, Cyprus

\section{Introduction}

Inclusion has typically been examined in political philosophy and in various educational studies as a notion that concerns expanded membership into social categories and groups. Acknowledging diversity and welcoming otherness have also been associated with increased sensitivity to people's hopes for, or claims of, belonging. "Inclusive" is an adjective of normative import that is mostly attributed to societies, institutions or political formations which are open, hospitable and attentive to ever greater numbers of people. ${ }^{1}$ But "inclusive," "inclusion" and "inclusivity" have hardly been explored as to their broader relevance and applicability to worldviews, ontologies and theologies of diverse societies.

True, the Western metaphysical tendencies to homogenize the world and to reduce it to Oneness have been criticized time and again, and efforts have been made to elaborate either a reason whose unity includes all its manifestations (pace Habermas) or, along more postmodern lines, to discard all claims to unity in favor of anarchic and disunited pluralism. And it is also true that philosophical longings for ontological reductions of the Many to the One have been associated with the political effects of creating "no counts," that is, of excluding alterity from social ontology (Badiou), and of producing unevenness in distributions of the sensible (Rancière) and worldviews that hierarchize existence (Haraway). But the question about "how 
such worldviews, ontologies and theologies illustrate and cultivate inclusive mentalities" and the question about "whether richer, moral plural and diverse cosmic forces are represented, in fact, included, in accounts of being" largely remain in penumbra. Worse, because Western metaphysics stands accused of favoring the One over the Many and this is often pinned down to ancient Greek culture as the cradle of Western civilization, the ancient Greek world is typically and uniformly charged with initiating the metaphysics of Oneness.

In this paper, we claim that such ontological accounts, which downplay plurality, exclude alterity and privilege the One, are, in our view, wrongly attributed to the ancient Greek world as a whole and themselves reflect a reductive tendency toward uniform and onedimensional readings of the ancient world. Thus, such charges of the ancient world attest more to the persistence of totalizing modern metaphysics of the One (one explanation, one element elevated to dominance by silencing other elements) in current theorizations of antiquity than to a kind of omnipresence and transhistoricity of exclusivist totality in Greek cultural metaphysics. We offer a different approach to this issue by retrieving a notion of ancient Greek culture that contests the hegemonic reason that homogenizes the ancient and the modern world as concerns unity and plurality. We discuss the above questions by narrowing their scope down to how the ancient Greek pantheon included a different, itself more inclusive, relationship of the One and the Many in its cosmology. To illustrate our argument we focus on the Homeric figure of the daimôn as both a unified/unifying concept (that, though singular and comprehensive, is not totalizing) and a metaphor for the coexistence of diverse deified powers that infiltrate cosmic and human structures.

But, before we proceed, a caveat is required: we are not arguing that all world-understandings in Greek antiquity were inclusive, plural 
and porous. It is indisputable that the ancient social ontology suffered from blatant exclusions and "no-counts" - with women and slaves being the paramount example from modernity to the present. What we dispute, however, is the generalization of exclusivism to a wholesale and uncomplicated feature of the ancient world, to a principle by which the ancient world organized and distributed a uniform and totalizing conception of the real.

\section{The Homeric World and its Metaphysics}

In the metaphysics of the Homeric world we encounter a complex interplay of the One and the Many where unity and plurality intersect, instead of being poles of a binary opposition. The Homeric daimôn serves as an illustration of figures and divine forces that pervade nature, cosmic order and human constructions.

Given the character of Homeric religion and the composition of the Homeric world as an amalgam of different powers, scholars emphasize that, unlike other peoples in the Mediterranean and in the Middle East, the Greeks had a polytheist religion of a peculiar nature. ${ }^{2}$ This polytheist religion struck many modern thinkers as both disorganized and disunited. This feature was attributed to the primitive and sheer distance between man and gods; the related explanation elaborated on a Platonic insight (Symp. 203), as Plato was the first to articulate the distinction that "god and man do not mix," hence a world containing beings of such radical distance could not be united and ordered without a prior hierarchization of entities. Thus, the hierarchy of beings that is indeed characteristic of Greek antiquity was interpreted in modernity as a sign of a bipolar, two-world metaphysics where humans and gods (despite anthropomorphism) occupied distinctive 
and exclusive positions with no intermediate ontology and no crossings of clearly demarcated boundaries.

What was thus overlooked and set aside as of no major interest was the fact that Greek polytheism included a variety of other entities, superhuman and mysterious, which were functioning on their own and in ways independent from those of the gods and the mortals. More specifically, in the epic pantheon, together with the gods, winds, rivers, Eos (dawn), Erinyes (the deities of guilt) and Eileithyia (the deity of birth) - to give only indicative examples - are also venerated, representing forces that do not fall squarely within modern ossified categories of the human and the superhuman. Various collective divine powers were also part of, and constantly erupting in, this world. They were worshipped collectively in a variety of local forms (the Graces, the Muses, and the Nymphs, which were invisible and "indissociable)." 3 Various personifications were found in the epics as well. They represented harmful demonological powers. They did not belong to the set of gods [e.g. Phobos (fear), Deimos (terror), Eris (discord), Ossa (rumor) or Ate (infatuation, folly and its punishment, which are sent by the gods]. ${ }^{4}$ Behind the gods on Olympus, and over them, "a dark indeterminate force is at work, in the face of which Zeus himself is impotent: Moira" (fate). ${ }^{5}$ The Greeks also recognized the existence of "mysterious forms of divine powers, both beneficent and maleficent, with the capacity to intervene in human affairs."

However, despite this plurality that complicates the neat categorization of beings into gods and mortals and makes the natural world acquire a strong representation in metaphysics as a co-player in the cosmic order rather than as a passive, "still" material on which gods and humans act, the complex ancient Greek religious system was not totally un-organized. In the eyes of many modern thinkers who saw order only in simplicity and stability, the Homeric world appeared 
as in total and potential chaos. This impression was strengthened by the fact that Homer did not have a unified conception, qua reduction to the One, of the world that he was describing. Also, he had no unified conception of the human body and no concept denoting the psychic whole. Nor did he have any notion that could possibly correspond and be associated with the word we use today to denote a "soul" capable of making entirely independent, autonomous decisions. ${ }^{7}$ Had he had such notions, Homer would most certainly have applied some sort of stable and permanent structure to his world. But, the fluid world of Homer required no such structure to justify its existence or to maintain its collective qualities of preservation, reproduction and resilience in time. The Homeric world had all these qualities by obtaining a kind of unity different from its modern conception, one that emerged from the complex synergy of all its ontological levels. It was more an aesthetic order, a cosmos, an expression of wonder rather than a strictly disciplining, unchangeable and obsessive structure of permanent exclusions and strategic inclusions for the sake of control.

How the Homeric world order was reflected in Greek religion has been explored in related literature ${ }^{8}$ and, in fact, we have enough evidence of the Greek gods being organized into a vast family tree, which explained how each took his or her place in the structure of the pantheon, where some were presented as older or younger, higher or lower in rank, and tied to natural domains. We are also aware of Zeus as the father and the highest of all gods, who was responsible for establishing order in the divine pantheon; he was making sure that each god and every divine power occupied its own domain and was preserved in its own and personalized activities. Ken Dowden once described the Homeric world as a "remarkably varied and yet unified amalgam." ${ }^{9}$ 


\section{The Daimôn as a Mediating and Organizing Force}

Let us now qualify Dowden's statement by illustrating, through the notion of the daimôn, how the Homeric world emerges as a coherent pluriverse rather than as a unified whole or as a single-principle universe. The presence of daimôns in epic poetry is, as we explain below, such that it renders daimôn a tool of thought of significant contribution in maintaining and also in reinforcing the organization of the Homeric world. For, the daimôn's main and significant quality as a complex "receptacle" contributes to the existence of a system of organization that is different from blatantly and downright univocal, hierarchical systems that reduce the Many to the One.

First, let us clarify that daimôn denotes a specific but un-named superhuman agent; or a named god or goddess; or a collective divine force; or a chthonic power; or an unaccountable strain in mortal behavior. Thus, as a term, daimôn has as its intrinsic quality a conceptual elasticity that reflects inclusive diversity, and, at the same time, a point of convergence of its associated concepts. The term's mysterious nature constitutes a link between daimôn as an unspecified supernatural power, collective gods, specific gods, chthonic powers and mortals. The notion of daimôn is, therefore, a conceptual device that contributes to Homer's representation of forces within and beyond human control and understanding. The daimôn's role is, amongst other things, that of an "identifiable sign" of the inexplicable and the mysterious against the background of the combined interaction of gods and human beings.

So far, scholars have perceived the denotative and conceptual diversity of daimôn as a problem. There have been various, often 
unsuccessful, and generally reductive attempts to reconcile these different semantic contents of daimôn $n^{10}$ in a way that unity and conceptual uniformity become privileged. What is thus obscured and even lost is that diversity, far from being a problem, is, in fact, an enabling and significant acknowledgement of the richness and plurality of worldliness (to adapt Hannah Arendt's term here); the "demonic world" manages to remain a coherent and structured world because of the links that it creates between the variously given components of its complex setting. The presence of daimôn helps Homer maintain a unique yet multifaceted universe, thus a coherent pluriverse, within the epic world with no need of any static and eternal Absolute that would empty reality (the human included) of all empowering transcendent elements within diverse forms of nature.

Consequently, the Homeric usage of the term demonstrates that daimôn's associations with all of the previously mentioned entities, which in fact are part of its composite character, make it a "complex," "controversial" and even "polyvalent" term, but in no way a "problematic" one.

What's more, we propose that we see the mysterious nature of daimôn as working like an incision, in mathematical terms, linking together various ensembles; the one main ensemble resembles daimôn and the other, peripheral ones remind us of the rest of the supernatural powers. ${ }^{11}$ As a unified concept, daimôn enables the various entities of the supernatural to be organized and still maintain their diversity in the context of the same universe of Homeric divinities. In fact, as it happens with Hesiod's use of daimôn too, ${ }^{12}$ we encounter the daimônic ensemble as a heterotopia, that is, as a smaller and much more structured world placed within the larger confines of the Homeric world. All of the diverse entities that already belong to the bigger picture of the Homeric world appear to be incorporated and to 
be brought together under the "demonic world" before they are even situated in the larger spectrum of the Homeric world. ${ }^{13}$ Consequently, this is also how daimôn as a sign of the mysterious allows us to gain knowledge of the mysterious aspect of things, and this is also how daimôn as a tool of thought allows us to know that, in fact, the mysterious can not only be organized, but can also offer a new form of structure to the world of the epics. When thought through, the comprehensive notion of daimôn reveals that, although the Homeric world is poetic rather than historical, it merits as close a study as any real society. As a society on which the characteristics of a real society may be projected, we may conclude that the Homeric world is a complex society formed by many diversities, but not without structure, just as the analysis of the daimôn as a concept that encapsulates One and Many demonstrates.

\section{Conclusion}

We have argued in this presentation that, as part of the universe of Homeric divinities and as a reference of the divine, the daimôn acquires and maintains an intricate, complex and diverse character. Controversial and polyvalent, the multiple conceptual contents of daimôn accommodate all sorts of divine, mortal and superhuman characteristics. At this point, the question "why does Homer become the best framework for a treatment of daimôn as a term of diversities?" would be pertinent and valid. The answer is that because, without romanticizing or sanitizing it, without raising it to a paradigmatic, utopian vision of included diversity, the Homeric world nevertheless provides, through the constitutive function of its notion of daimôn, rich material for considering the complexities of inclusions and exclusions at a discursive ${ }^{14}$ and at an ontological level. We are dealing with a world, as it is depicted in the epics, that is composed of 
a variety of powers, with the divine taking a variety of forms and names and whose natural and human aspects are suffused with divine manifestations and presence.

We hope to have demonstrated or, at least, indicated how the Homeric usage of daimôn includes a number of diversities which are connected by their common mysterious power. This is important, we have argued, not only because daimôn as a point of convergence is what keeps together all these diverse entities (i.e. specific gods, fate, Zeus and other divine entities) in a world that is not uniform and univocal (though is nevertheless a coherent world), but also because it associates daimôn with a positive function: it exemplifies a relationship between the One and the Many at an ontological level that differs from unitary and homogenizing modern logics and logistics that turn nature into an object on which a superior and exceptionalist humankind acts in unrestrained and profit-seeking ways. It also points to a concomitant social ontology that is, in principle, neither reductive nor exclusionary of membership. The diversity of character, or what scholars perceived as the "problem of daimôn," instead of revealing a supposed weakness or failure, offers us the opportunity to see how Homer values knowledge or awareness (even if or when it is humanly unattainable) of that part of worldly experience that remained "unknown" and merely assumed. This concerns the various aspects of the superhuman "other," all that transcends human power and has been named the mysterious and inexplicable. The term daimôn is a useful verbal device (on grounds of its quality as an organizing idea of a number of components) that allows the "beyond" of human capacity and control, the transcendence whose presence is felt within immanence rather than ousted to an epekeina, to be organized and to be expressed, maintaining its 


\section{diversity under the polymorphic, but still within the structured world of the epics.}

\section{Notes}

\footnotetext{
${ }^{1}$ Marianna Papastephanou, "Inclusion in Education and in Public Debates on Education,” Beijing International Review of Education 1, no. 2-3 (2019): 1-22.

${ }^{2}$ Louise Bruit Zaidman and Pauline Schmitt Pantel, Religion in the Ancient Greek City, trans. Paul Cartledge (Cambridge: Cambridge University Press, 1992), 176f.

${ }^{3}$ Ibid.

${ }^{4}$ Constantine A. Trypanis, The Homeric Epics, trans. William Phelps (Warminster: Aris and Phillips,
} 1977), 93.

${ }^{5}$ Ibid. See also Il. 2.209-213, where Zeus consults Moira about her will and he is forced to abandon Hector, who ultimately faces death, in the battle. Cf. Hugh Lloyd-Jones, The Justice of Zeus (Berkeley: University of California Press, 1971).

${ }^{6}$ Zaidman and Pantel, Religion in the Ancient Greek City, 178f. Cf. Jennifer Larson, Ancient Greek Cults: A Guide (New York: Routledge, 2007), 1f.

${ }^{7}$ This is part of the more general idea that, according to Snell, Homer does not realize that decisions of will/impulses/emotions have their origin in the human being, but instead, that they are inextricably linked with gods who act mentally on the agent/ human and over whom the human has no control. See further Bruno Snell, The Discovery of the Mind, trans. Thomas G. Rosenmeyer (New York: Harper \& Row, 1982), 22, 30f.

${ }^{8}$ Ken Dowden, “Olympian Gods, Olympian Pantheon,” in A Companion to Greek Religion, ed. Daniel Ogden (Oxford: Blackwell Publishing, 2007), 44-45.

${ }^{9}$ Ibid., 48.

${ }^{10}$ See further Odysseus Tsagarakis, Natureand Background of Major Concepts of Divine Power in Homer (Amsterdam: B. R. Grüner, 1977); Gilbert François, Le Polythéisme et l'Emploi au Singulier des Mots $\Theta E O \Sigma, \triangle A I M \Omega N$ : Dans la Littérature Grecque D’ Homère a Plato (Paris: Les Belles Lettres, 1957); Bernard B. Dietrich, Death, Fate and the Gods: The Development of a Religious Idea in Greek Popular Belief and in Homer (London: Athlone Press, 1965); Martin P. Nilsson, A History of Greek Religion (New York: Norton, 1964); Walter Burkert, Greek Religion, trans. John Raffan (Oxford: Blackwell Publishing Ltd and Harvard University Press, 1985); Frederick E. Brenk, "In the Light of the Moon: Demonology in the Early Imperial Period,” Aufstiegund Niedergang der römischenWelt, 2.16 .3 (1986): 2068-2145.

${ }^{11}$ See Appendix II.

${ }^{12}$ Marianna Papastephanou, "Hesiod the Cosmopolitan: Utopian and Dystopian Discourse and EthicoPolitical Education," Ethics and Education 3, no. 2 (2008): 89-105.

${ }^{13}$ See Appendix I, Diagram B.

${ }^{14}$ Papastephanou, "Inclusion in Education and in Public Debates on Education." 


\section{Inclusion, Self-Exclusion, and Public Debates on Teachers and}

\section{Education ${ }^{1}$}

Marianna Papastephanou

Department of Education, University of Cyprus, Cyprus

Inclusion is valued in educational studies today. Discourses of inclusion evoke a humanist perspective on a right to membership in just about any collectivity or activity that may attract social agents. The act of including becomes the foremost token or credential of political correctness and sensitivity. It is assumed that, if we cultivate inclusion of any possible other within our communities, debates, institutions and practices, we respect alterity and fulfill our ethicopolitical obligations towards others. We thus surpass older developmental stages of humanity and advance toward new desirable states of political organization, leaving behind all those backward elements of society that effect discrimination and marginalization. In other words, inclusion is invested with a modernist passion for the new and the redemptive that, supposedly, brings about liberation from pathologies. Inclusion has thus obtained the status of a utopianized endpoint, a set destination of educational ventures.

The term "inclusion" exerts remarkable rhetorical power in current education and in public debates. Using the word "inclusion" sometimes operates in ways that benefit the user, granting them a favorable moral image. By declaring their commitment to inclusive talk and through vehement, verbal renunciation of exclusion, educationists and policy makers give credentials of progressivism and concern for otherness. Regardless of intentions or regardless of awareness of inclusion-use effects, the educationist thus obtains their own inclusion in the community of researchers worthy of the name. Likewise, 
administrators and politicians establish a positive public image that secures them membership, i.e., inclusion, in the category of progressive and democratic leaders. This operation of safe and protected progressive self-descriptions, which deep down benefits the social agent rather than exposing them to thought-provocation, is accompanied by a paradoxical and as yet unnoticed implication: the obsessive and facile attachment to inclusion results in various exclusions.

Inclusion is seen, and even glorified, as prerogative; but, in some cases, this entails major political complicities. I do not argue that inclusion is undesirable or that people should be excluded from public debates. I vehemently reject exclusivist practices by which some agents are silenced or left out. Nor am I saying that because inclusion plays a part in current academic and extra-mural distributions of power (e.g. securing academic visibility and citability, creating new agents of policy shaping, etc.) this is enough for discrediting it normatively. I argue that, though vital, inclusion cannot cover the whole ground of political-educational normativity and should not be utopianized. Its ambiguities should be acknowledged and researched. When uncritically exaggerated, inclusion is promoted at the high cost of neglecting other normative tasks; of discursively excluding other notions and challenges of selfhood; and, ultimately, of putting a full stop at politics too soon, as if all that politics has to accomplish is just to assist the inclusion of people to whatever the hosting frame might be. Thus, I target uncritical and unqualified glorifications of inclusion. Inclusion is a concept of the modern European vocabulary, dating back to the $17^{\text {th }}$ century. It comes from the Latin includere which interestingly means to "shut in," to "shut something up" and to "confine." In its current meaning, "inclusion" refers to an addition or annexation to a group or set, and, more commonly, to the act of adding 
or annexing to a group anything external or foreign. ${ }^{3}$ In academia, inclusion is mostly employed when the other to be included has been a subject or collectivity whose rightful membership within a totality has long been either neglected or disputed and blocked.

At first sight, inclusion and its antonym, exclusion, appear as logical and mathematical relations of set and subsets. A set has subsets, sets and subsets have members; membership in a set or in a subset is based on criteria and rules of relevance or commonality. For sets and subsets to exist, something must inevitably be excluded from them. But such relations become politicized when numbers matter, when numerical relations reflect a social ontology (who counts, who is of essence, who remains invisible, who is thought to inhabit a space rightfully, etc.) and are associated with conditions of membership, treatment of otherness and outlook on what passes as the "strange" and the "unusual." Geometrically, inclusion could be depicted with being within a circle, something which is not devoid of social symbolisms and political connotations. Consider, for instance, membership in circles and aspirations to join specific circles: we find references to developing countries joining the circle of the civilized countries even in John Dewey. ${ }^{4}$

In my view, inclusion operates at two intersecting and overlapping levels, a discursive and a material level: something may be included in theoretical and conceptual works, in discourses and specific idioms, in researches and deliberation. Related theoretical and research questions are then formulated: reforms and new recommendations also revolve around an idea or a topic meriting discursive inclusion. But, more commonly, we associate inclusion with being accepted to participate in activities and practices and to join groups, communities, states, etc., in actual life and with material, direct, measurable or immeasurable consequences for one's life. ${ }^{5}$ 
In some cases, membership in debates/discourses is accompanied with the material effects of the power that the newly added member has. Discursive inclusion may paradoxically entail that the new voice silences all other voices, if the new member enjoys special social status, symbolic capital and distinction in a valued social domain. Power over a collectivity may not quite or not always derive from the force of the better argument during the collectivity's deliberations and democratic decision-making. Some of the influence that a new inclusion (qua addition) in a set exerts is either because what is being said is consumable and easily heard or because it reproduces widely disseminated and established views that go down well in resonating with familiar and popular ideological positions on a topic (ultra rightwing populism is a case in point).

Discursive or embodied ("real life," so to speak), inclusion is an act, a practice. But it is also an ethico-political term; it has both descriptive and normative functions. Like exclusion, inclusion demarcates the degree of permeability of a structure and the possibility of a person's or an idea's positioning within or outside the structure. Such descriptions often comprise normative language concerning whether inclusion rather than exclusion should be the case. Furthermore, regardless of how we speak about inclusions and exclusions and of whether we are aware of them, inclusions and exclusions are also realities for some and longings for others. Some people long to be included within a valued circle or totality, whilst others, often already members of the desired totality, long for the exclusion of the aspiring candidates for membership. Even in cases where people are open to otherness, the risk of including only those who are not cumbersome, dangerous or radically different, in other words, the risk of including merely the same, is not easily staved off. Inclusion is not unconditional and, from the moment that conditions are set, all sorts 
of issues emerge as to who has the power - communicative and institutional - to define the terms and conditions of membership and participation. In some cases, there should be normative criteria of membership and expectations from the prospective new member, even confrontational, dialogical engagement with the other. Awareness of this (e.g., are there not criteria for teacher appointment?) complicates lukewarm, abstract celebrations of inclusion understood as offering a safe haven of disengaged acceptance to just any alterity. Keeping one too safe, protecting people or groups from one another, not making demands on the other is, in my view, a subtle form of racism. It is so because it amounts to considering the other incapable of the justice that you deem yourself capable of.

A relevant though rarely asked question is: inclusion of who into what? Many people seem to assume that the utmost good for a person is to be included. Those who assume so without asking the "into what" question forget that, since Hegel's vision of the Absolute as the spirit's return to an undifferentiated unity (for what was this, other than a frightening prospect of an inclusion absorbing and annihilating diversity?), we may no longer turn an innocent, unsuspecting eye to pleas for all-encompassing, all-embracing, seemingly benevolent treatments of alterity. Inclusion does not entail acknowledging the value of difference and exerting generosity, kindness, hospitality, open-mindedness and various ethical, political and intellectual virtues.

Those who are more aware of dangers of romanticizing the inclusion into an unchanged or unchallenged host totality still presuppose - as I see it - that the utmost good for a person is to be included and, by implication, the worst thing is to be excluded. It is especially so, if the host totality is considered a transformative and worthy one (that is, if the "into what" question has been answered in rosy terms for the host 
collectivity). In making such assumptions about the subject aspiring to be included, educationists, public personae and policy makers contribute to the promotion of the social interpellation to be included. Simultaneously, they fail to give due attention to self-exclusion, to withdrawal and conscious retreat as a virtue and as a potentially valuable political stance. One may not want to be included 6 in a way of life, in a dialogue or in a community or process, for various reasons. Some such reasons may not only make sense but even problematize the obsession with belonging, with not being left out or with not lagging behind.

Still, withdrawal should not be romanticized either. Self-exclusion may sometimes result from operations of "othering" those who constitute members of a totality. The self may narcissistically exaggerate their distance from the totality and their difference from its members to find precisely self-vindication in the dark depiction of such a collective otherness. A subject can find safety and reproduce their own comfort zones when included and, sometimes, even when excluded or self-excluded. The entrapment in the "inclusion-exclusion" dichotomy and the limitation of politics to such stakes block insight into a normativity that cannot be channeled into the "inclusion versus exclusion" preoccupations. Ultimately, they block awareness of a relationality that is more demanding on both sides, the totality and the singularity joining it, and that invites or requires those unsettling and destabilizing experiences that shake the ego and draw you into something better.

I argue, then, that the questioning of inclusion exclusively from the perspective of what exclusions may accompany inclusion or come in as a side- or after-effect still operates within the confines of the "inclusion/exclusion" and "insider/outsider" dichotomy, as if the worst thing that can happen in life is to be either subtly or blatantly 
excluded. By implication, it is not surprising that, in the diagnostics of current global pathologies, the metaphor of gate-keeping emerges as the major problem that the Western researcher can notice and appreciate in today's world.

In fact, the academic popularity of inclusion excludes a whole family of other normative terms (thus, it fails at the level of discursive inclusion). Other normativities (international right, redistribution of wealth, egalitarianism, educational offset of uneven cultural capital effects) no longer receive due attention; or, when they are included in discourses, they are approached through the framework of inclusion, as if they were mere cognates of it. I object to the reduction of political vision to merely including otherness because this reduction results in failure to consider more concrete and material political measures such as environmental policies on grounds of non-anthropocentric ideality, settlement of damages of global conflicts on grounds of pending historical ethico-political debts, global redistribution of wealth on grounds of justice beyond self-congratulatory framings of charity and aid, etc. Also, inclusivist politics fails to cultivate daily awareness of issues which, had they been known or declared as problems of global and environmental justice, they would have constituted higher political demands than simply enlarging the numbers of "we."

Implications of hegemonic framings of inclusion can be drawn from public discourses (politicians' statements and interventions, party politics on education, media and educational policy texts), that is, from "social practices that represent social realities in particular ways, and construct particular social positions." They are public "in that they are constructed in, and circulate within, the public sphere." 7 The context of public debates on education involves the fact that "the 21st century is a media-saturated world" in which the media, notably television and Internet, are "central to public life." ${ }^{\circ}$ Within such a 
context, the public interest in education has been expressed with unprecedented passion: "there have never before been such blistering media commentaries and such highly politicized battles about teacher education as those that have dominated the public discourse and fueled legislative reforms" in recent years. ${ }^{9}$ This holds true not just regarding national public debates but also regarding the European context, which has its own specificity and presents particular challenges to inclusion and participation in public opinion shaping. For, "the mass media public sphere on which European political communication relies even more than national political communication is a highly competitive environment in which actors compete for limited public visibility, resonance and legitimacy."10 However, debates on educational matters are more than Europeanized. They are, indeed, globalized. Public debates about education abound and have been prominent worldwide.

Inclusion in public debates is seemingly unconditional, democratic and unrestricted by specialization, as more and more non-educationists such as economists, administrators, politicians, media personae and think tanks feel entitled to speak (and take such a liberty) about the "trials" of education and the "deficits" of teacher performance. But, if we "read" the whole issue in more awareness of ambiguities of inclusivity, we will realize that the realities underneath public interest in education are more complex. In my view, relevant interrogations of possible future research on education should include questions such as: what is excluded from public debates or initiatives? Who is included in public discourse? Who is publically though tacitly granted investigative force? And, who has true discursive influence on issues of education?

The public interest in education - an interest that may be otherwise well-meant and welcome - is nevertheless strongly influenced by 
claim-making power. The latter is diversified and involves "strategic action in the public sphere." Diverse interests are expressed when various actors exert public communicative power through their purposive, open articulationof political demands, criticisms, calls to action or recommendations. "Which actors are most effective in making their mark on public debates" 11 relates to the issue about who wants to be included and who manages to turn communicative power into institutional power most effectively in relation to educational stakes. Further evidence shows that the Europeanisation of public debates exacerbates these power differentials. Concerning education, this makes us suspect that the actors who manage to cross the boundaries of national public spheres are not those who are actively involved in educational theory and practice. Indeed, as evidence proves, the true boundary crossers are "overwhelmingly core executive actors such as heads of government and cabinet ministers." 12 Educators and their union representatives make 9 per cent of the purely national claims on education (i.e., the issue field "where they are strong") against 5 per cent of Europeanized claims on education. ${ }^{13}$ Thus, educators "are extremely weakly represented in Europeanized public debates."14 "Government and executive actors are by far the most important beneficiaries of the Europeanisation of public debates compared to legislative and party actors, and even more so compared to civil society actors" 15 such as educators.

Unqualified inclusion of various agents, fora, international organizations and think tanks in public discussions on education has legitimized new distributions of communicative power that are far from fair or balanced. This is not merely about inclusion deficits in public debates that could be remedied by more inclusion. Inclusion concerns the question about the frequency with which some issues and interested social agents pass the selection filters of the public sphere 
and make their mark on public debates. There may be various practical and applied-politics means of enhancing the voice of civil society actors who are currently "clearly the least able to profit from the opening up of Europeanised discursive spaces."16 But that's not my point. "Which actors populate the Europeanised public sphere"17 is, from my perspective, an example of how inclusion relates to the discursive relevance and to self-exclusion as a virtue. Hence, the issue I raise is that, apart from considering more inclusion or empowerment of the voice of people inhabiting specialized fields, there should be another challenge to education. People (especially those who have $e x$ officio more discursive influence, namely, politicians, executives, media actors, etc, though less knowledge about educational matters) should be educated about the importance of self-exclusion on grounds of discursive relevance or of pause for thought and of the self-restraint that enables one's harkening to the specialist's voice.

Unqualified and unrestrained inclusion has led to the emergence of a new set of agents, a new particularist community, those who use the benefit of being overrepresented in public debates sweepingly to criticize educators (the underrepresented in public claims-making). Little self-restraint or pause for thought is noticed when social agents who know too little about education nevertheless feel entitle to speak about it and make judgments or recommendations that shape and direct public opinion. The limits of their own field are, to them, the limits of the world.

A temporary self-exclusion from public discourses, a kind of pause for thought, may facilitate engagement with dialogue as a will- and opinion-formative medium rather than as a vehicle for promoting ideologically imbued, competing agendas. The entrapment in the framework of "inclusion versus exclusion" obscures a perception of varying political responsibilities in the plural and of virtues such as 
self-restraint. Though admirable (and, sadly, as yet unmet), the urge/exhortation to include is not exhaustive of human responsibilities. As too minimal a demand, and when not accompanied with any other ethico-political expectations, inclusion operates in politically soporific ways.

\section{Notes}

\footnotetext{
${ }^{1}$ A much longer version of this paper has been published as: Marianna Papastephanou, "Inclusion in Education and in Public Debates on Education,” Beijing International Review of Education 1 (2019): 303-
} 23.

${ }^{2}$ See, for instance, the Online Etymological Dictionary, https://www.etymonline.com/word/inclusion

${ }^{3}$ https://dictionary.cambridge.org/dictionary/english/inclusion

${ }^{4}$ Dewey employed precisely this vocabulary of civilizing mission in support of a development that would make a foreign nation eventually merit inclusion in the "civilized world." See Marianna Papastephanou, “Genocide, Diversity, and John Dewey's Progressive Education,” Metaphilosophy 47 (2016): 627-55, and Marianna Papastephanou, "Learning by Undoing, Democracy and Education, and John Dewey, the Colonial Traveler," Education Sciences 7 (2017): 20-33.

${ }^{5}$ That is to say, in the more common use of inclusion as a cherished educational aim and as andisputed political value with specific effects on communicative and institutionalized power.

${ }^{6}$ I mean, by invitation or by obligation or by necessity.

${ }^{7}$ Sue Thomas, "Teachers and Public Engagement: An Argument for Rethinking Teacher Professionalism to Challenge Deficit Discourses in the Public Sphere," Discourse: Studies in the Cultural Politics of Education 32 (2011): 371-82, 372.

${ }^{8}$ Ibid.

${ }^{9}$ Marilyn Cochran-Smith and Mary Kim Fries, "Sticks, Stones, and Ideology: The Discourse of Reform in Teacher Education," Educational Researcher 30 (2001): 3-15, 3.

${ }^{10}$ Ruud Koopmans, "Who Inhabits the European Public Sphere? Winners and Losers, Supporters and Opponents in Europeanised Political Debates," European Journal of Political Research 46 (2007): 183 210, 205.

${ }^{11}$ Ibid., 194.

12 Ibid., 196.

${ }^{13}$ Ibid., 200.

${ }^{14}$ Ibid., 183.

${ }^{15}$ Ibid., 183.

${ }^{16}$ Ibid., 199.

${ }^{17}$ Ibid., 200. 


\section{Rosi Braidotti on the Exclusion of the Female Subject}

Christos Pavlides

Department of Education, University of Cyprus, Cyprus

\section{Introduction}

In this paper, I focus on the terms "exclusion" and "female subject." I study how the term female subject, theorized through Rosi Braidotti's ideas, has experienced a variety of exclusions. Feminism maintains that the female subject does not enjoy all human rights inter alia because the female subject has always been confined to the private sphere. The exclusion of the female subject has been a reality and for this reason feminism emerged as a movement that has been struggling to change the values attributed to, and the representations made of, "woman" over the long course of patriarchal history as well as in the deeper, lived time of one's own identity. Therefore, subjectivity and identity are considered to be a primary base for the development of the female/feminist subject.

According to Braidotti, the voices of women are buried under the words of another subject, under the very words of a man. This is one of the many faces of exclusion that women have undergone, since female voices are left out and cannot be heard in a world where the words of a male subject are hegemonic. The dominant view of subjectivity refers to the obsessive and problematic habit of elevating masculinity or some abstract masculinity to the status of the subject prope This results in an irresistible and highly effective phallocentrism, ${ }^{1}$ understood as every discourse asserting the sovereignty of the phallus as a symbol of power and authority. Feminist theory marks the dis-identification of women/female subjects from phallologocentrism, ${ }^{2}$ and, by working on this term, Braidotti combines 
the concepts of phallo-centrism and logocentrism, as discussed by Lacan and Derrida respectively, ${ }^{3}$ to promote a contestation of patriarchy and a deconstructive critique of language.

The central Braidottian aim is to create points of exit from phallologocentric structures and premises. Braidotti argues for an understanding of feminism as the interruption of the existing political order from the outside in the name of equality. This urges us to see that there are opportunities to make society open to feminism and so to transcend and challenge the exclusions of the existing order of society. ${ }^{4}$ The interruption of the androcentric political order will combat exclusions and bring the ideal of gender equality closer to real situations. But as I explain in the next section, this ideality does not operate exclusively at the level of material, societal conditions of women's life. It is also operative at the discursive level of feminine/feminist disruption of the philosophical patriarchal order. According to Marianna Papastephanou, "there are two intersecting and overlapping levels at which inclusion operates, a discursive and a material: something may be included in theoretical and conceptual works, in discourses and specific idioms, in researches and deliberation." 5 Therefore, in this paper, I explore how Braidotti's engagement with the positioning of women in philosophy illustrates the investigative significance of perceiving exclusions not just at the material but also at the discursive level.

\section{Philosophy as a Diachronic Machine of Exclusion}

Braidotti sees the institution of philosophy today as a power device that enforces the sanctimonious sacredness of certain texts: the texts of the great philosophical tradition - all male, all white, all Eurocentric. ${ }^{6}$ For Braidotti, it is time for feminists to get rid of the 
"anxiety of influence" of the masters, to break out of paralyzing structures of an academic style that has turned philosophy into a machine of intimidation and exclusion. ${ }^{7}$ Braidotti defends feminism as philosophy and revalues all that women have thought and contributed to the life of the mind, in spite of the belligerent opposition of the established institutions. She condemns the historical role of traditional philosophy as an institution that has theorized and practiced the oppression, exclusion, and symbolic disqualification of women $^{8}$ and contributed to the exclusion of the female subject. Braidotti upholds a distinction between thinking and philosophizing and she lays all the emphasis on a passion for inventing new forms of thought, which far outweighs her attachment to the discipline of philosophy and its codified modes of thought. ${ }^{9}$ Therefore, some of the opportunities for opening up society to the movement of feminism pass through the retrieval of voices that patriarchy had silenced in the history of thought.

\section{The Female Subject in the Position of "Other" in the Field of Philosophy}

Analyzing feminist theory in the 1990s, Braidotti concludes that the tendency then was to conflate the masculine viewpoint with the general, "human" standpoint, and, thereby to confine the feminine to the structural position of the "other." Thus, the masculine qua human is taken as the "norm" and the feminine qua other is seen as marking the "difference." The corollary of this definition is that the burden of sexual difference falls upon women, marking them off as the second sex, or the structural "other," whereas men are marked by the imperative of carrying the universal. The symbolic division of labor between the sexes, which the term gender helps to explain, is 
the system set up by phallogocentrism, which is the inner logic of patriarchy. This system has simply come to be the powerful foundation of a society in which we are all constructed as either men or women by certain symbolic, semiotic, and material conditions. ${ }^{10}$ Philosophy permitted the masculine to mark the human and the feminine to mark the other and thus enabled the exclusion of the female subject in its field.

At the discursive level philosophy functions as a terrain of the diachronic exclusion of the female subject by continually margializing the female voice. But such exclusion is not easily perceived when in current political, cultural and academic discourses the inclusionexclusion dichotomy is typically examined mainly at the surface level of concrete and active participation of women in practical and material interventions. As Papastephanou points out, "more commonly, we talk about inclusion when someone is accepted to participate in activities and practices and to join groups, communities, states, etc., in actual life and with material, direct, measurable or immeasurable consequences for one's life. This second, more material, level of relevance of inclusion has become a mainstream concern in educational studies"11 to the neglect of deeper exclusions whose relation to abstract thought makes them not as immediately visible as feminism would hope.

Braidotti mainly explores the exclusion of the female subject in philosophy. She studies specifically Michèle Le Doeuff's work, which focuses on what the "phallocratic point of view consists in. It comprises the idea that there is only one sex, the other half of the sky being emasculated. The phallocentric point of view: an ideological justification of the exclusion of women from valorized domains of society, and a project for maintaining all forms of social domination of 
women, maintaining their inferiority."12 Braidotti points out that Le Doeuff pursues the issue through an analysis of the function of that other myth, the image of women that philosophy yields, which is overthrown only by doing without the logocentric/phallocratic imaginary. In fact, women's presence in philosophy only ever serves as a pretext, to the point of one's having to ask: 'When a philosopher is talking about women, what exactly is he talking about?"13 Le Doeuff emphasizes the paradox which simultaneously obliterates sexual difference and exacerbates the sexual specificity of the feminine. Everything about women is sexualized, with the exception of her own sexuality. This equivocation leads to a "double bind" which simultaneously makes a dark continent out of women's bodies, and a problem of female sexuality, by sexually overdetermining them. Woman is so much the sign of sexedness that she loses her own libidinal corporeality in the process of becoming the incarnation of sex. As Le Doeuff concludes, such systematic forgetting of sexual difference through the process of constructing this image of the feminine is essential to the philosophical stance. ${ }^{14}$

Braidotti's critical discussion of Le Doeuff's illuminates the former's position on the matter of philosophical exclusion. Braidotti claims that it logically follows that the exclusion of the other, above all, that of woman, is not a sign of negativity; for thought creates what it excludes, and simultaneously creates itself in what it represses: "As it is essential that it [the other] is repressed, it never stops separating itself from it, closing, becoming insular." 15 On the basis of the indivisibility of Reason and its others, Le Doeuff reclaims the status of thought for these mythical images which, however devalued, are still essential to the progress of self-validation of philosophy. Although she only uses Marxist vocabulary to denounce the masters' oppression of the slaves, she does take up its schema of dialectical 
opposition. Drawing on psychoanalysis, she suggests that what is excluded or unsaid creates a shadow zone, a zone of indeterminacy within the circle of the light of reason. ${ }^{16}$ The zone of indeterminacy is a step toward exclusion. Braidotti believes that Le Doeuff refuses to assimilate women and femininity to silence, negativity, and the repressed. Firstly, because if the theoretical silence of women did correspond to the place assigned to them in discourse, that of the image reflected by theoretical Reason, it could not translate any form of essential truth about women. It would function as a masculine principle of self-validation: that someone is incapable of thinking philosophically is comforting in that it suggests that philosophy is capable of something. ${ }^{17}$ This is because this exclusion is much more a crucial moment in the development of discourse than the final distancing of the other. Traditionally barred from the exercise of philosophy, women have been condemned to theoretical silence; more exactly, they shelter in philosophy's silence, thanks to which the voice of others may be heard. ${ }^{18}$

More precisely, it seems to Braidotti that philosophy does not stem from a properly 'masculine rationality', but rather, that it often infers a misogynist imaginary in trying to be more than it is. It is trying to make rationalization operate beyond its limits. ${ }^{19}$ Le Doeuff sees in the phallocentric nature of philosophy the (false) product of a false consciousness, rather than the 'true' discourse of a consciousness which lies about women. She thus validates philosophical consciousness while also condemning its endemic phallocentrism and locating it in precise historical conditions. Faithful to the premise of historical materialism which ties the history of ideas to their sociopolitical context, she condemns philosophy's collusion with political power: historically, philosophy has served to train the young for power. As a parallel to this, thanks to the changes which have 
disrupted the order of Knowledge, notably the deconstructions of rationality accomplished by modern philosophy, it is now possible to free Reason from its links with Power. ${ }^{20}$

Again for Braidotti, one of the aims of Le Doeuff's work has been to think rationality in terms other than those of the hegemonic mode. In Le Doeuff's work, we do not find any attempt to define the feminine. Her rejection of the masculine-rational couple, based on a historical study of reason and the modalities of thought it has assumed, is evidence of resistance to essentialism. The logic of the oppression of women is therefore inscribed in a political and theoretical dynamic. The "liberation" of women's theoretical voices, which is inconceivable without their socio-political liberation, will come about thanks to changes within Reason. ${ }^{21}$ Reason will liberate their life in the present and the future.

\section{Philosophy as a Discursive Power on the Way to the Inclusion of the Feminist Subject}

Women were excluded from the philosophical discourse more than from all other kinds of knowledge, and Braidotti indeed sees "philosophy as requiring mechanisms of exclusion and domination as part of its standard practices. Philosophy is a hegemonic discipline whose historical task has been to legislate among possible forms of knowledge, codifying certain modes of thinking that become legitimated as scientifically acceptable. Philosophy is all about discursive power." 22 Consequently, in her view, which is influenced by Foucault, philosophy creates itself through what it excludes as much as through what it asserts; it asserts its values through the exclusion of many - women, nonwives, non-learned, etc. ${ }^{23}$ The structural necessity of the pejorative others, the "slaves" of philosophy who 
stand in a specular relation to the philosophical utterance, makes Braidotti doubt "the theoretical capacity, let alone the moral and political willingness, of this discipline to act in a nonhegemonic and non-exclusionary manner." 24 What is also at stake is the legacy of critical theory and its attempt to separate philosophy from instrumental reason. ${ }^{25}$ Following Adrienne Rich, Braidotti believes that the redefinition of the female feminist subject starts with the revaluation of the bodily roots of subjectivity, rejecting the traditional vision of the knowing subject as universal, neutral, and consequently gender-free. ${ }^{26}$

Braidotti claims that by accepting De Beauvoir's axiom that one is not born a woman but rather one becomes a woman, feminists concentrated on showing that woman was constituted and produced by established social norms which made her into man's eternal mirror. Femininity, that huge masquerade, is fabricated by man as he pleases, and has no biological basis. Woman - and femininity - cannot be defined anatomically, or as the function of some physical specification: the sole basis of identification of women, and therefore the only constant enabling them to form a political group, is the fact of their oppression by man. The rejection of any biological specification, which is necessary for claims that sexual difference is social rather than "natural," led to the rejection of all difference as marking inferiority and therefore oppression. By identifying the progress of subjectification with material subjection - and therefore oppression - this phase of feminism underlined that women's "difference" is constructed on the basis of the signifying position that man has monopolized. Masculine power presents itself as the norm, and on that basis, classes, measures, and judges women, who are therefore eternally "different" according to the yardstick of the idea of humanity as incorporated in man. This kind of feminist position, 
based on the struggle for equality between the sexes, confines the notion of "difference" to the ranks of an essentialist or deterministic concept, a mark of inferiority for those to whom it is applied. ${ }^{27}$ Thus feminists have to struggle against phallo-logocentrism, that is, every discourse aimed at maintaining the sovereignty of the phallus as a symbol of power and authority.

\section{Conclusion}

Braidotti believes that what the feminism of sexual difference wants to free in women is also their desire for freedom, justice, selfaccomplishment, and well-being. This political process is forward looking, not nostalgic: it does not glorify the feminine, but rather works toward its actualization or empowerment as a political project of affirmation of alternative female subjectivities. It aims to bring to representation that which phallogocentrism declares unrepresentable and thus to do justice to what women feminists, in their great diversity, have already become. ${ }^{28}$ Also, Braidotti hopes that the poststructuralist generation of feminists (and herself) can just as easily make the transition towards the new. She hopes they will be able to negotiate the change that such a jump would require, while coping with the challenges of their changing times. In the post-humanist era of dissolving subjectivities and crumbling certainties, she hopes that feminist subjects will assert the positivity of the difference that feminism makes, while recognizing the fragility of what is commonly called "civilization," the network of multiply-differentiated and therefore interrelating subjects, functioning on a consensual basis. ${ }^{29}$ Braidotti hopes that they "can reconcile the lightness of the new era with the heaviness of a female genealogy which produces the uncomfortable awareness that, however molecular, this is still a 
man's word." She hopes they shall "be able to think multiplicity and lightness, speed and difference but also to carry the burden of their luggage: on the one hand the historical memory of oppression, on the other the weight of feminist epistemology, feminist ethics and feminist politics. Most of all, Braidotti hopes the female feminists can carry this historical burden." In her words, "like the acrobats they have had to become, may they jump long and jump high, and still land on their own two feet."30

\section{Notes}

${ }^{1}$ Rosi Braidotti, Nomadic Subjects: Embodiment and Sexual Difference in Contemporary Feminist Theory, trans. A. Sifaki, O. Tsiakalou, ed. A. Sifaki (Athens: Nissos, 2014), 171.

${ }^{2}$ Rosi Braidotti, "Embodiment, Sexual Difference, and the Nomadic Subject” Hypatia 8 (1) (1993): 2.

${ }^{3}$ Phallo(lo)gocentrism, ed. E. Mitsi, Student Interdisciplinary Postgraduate Program of Lexicography Studies. http://www.fylopedia.uoa.gr/index.php?title, accessed 15 June 2019.

${ }^{4}$ Braidotti, "Embodiment, Sexual Difference, and the Nomadic Subject," 11.

${ }^{5}$ Marianna Papastephanou, "Inclusion in Education and in Public Debates on Education,” Beijing International Review of Education 1 (2) (2019): 5.

${ }^{6}$ Braidotti, "Embodiment, Sexual Difference, and the Nomadic Subject," 2.

${ }^{7}$ Deleuze 1975 and 1977 in Braidotti, "Embodiment, Sexual Difference, and the Nomadic Subject," 2.

${ }^{8}$ Braidotti, "Embodiment, Sexual Difference, and the Nomadic Subject," 4.

${ }^{9}$ Ibid.

${ }^{10}$ Rosi Braidotti, Nomadic Subjects: Embodiment and Sexual Difference in Contemporary Feminist Theory, 2d ed. (New York: Columbia University Press, 2011), 143.

${ }^{11}$ Papastephanou, "Inclusion in Education and in Public Debates on Education," 5.

${ }^{12}$ Rosi Braidotti, Patterns of Dissonance, trans. E. Guild (Cambridge: Polity Press, 1996), 193.

${ }^{13}$ Ibid., 193-94.

${ }^{14}$ Ibid., 194.

${ }^{15}$ Ibid.

${ }^{16}$ Ibid.

${ }^{17}$ Ibid., 194-95.

${ }^{18}$ Ibid., 195.

${ }^{19}$ Ibid.

${ }^{20}$ Ibid., 195-96. 
${ }^{21}$ Ibid., 196.

${ }^{22}$ Braidotti, "Embodiment, Sexual Difference, and the Nomadic Subject," 5.

${ }^{23}$ Ibid.

${ }^{24}$ Ibid.

${ }^{25}$ Ibid.

${ }^{26}$ Ibid., 6-7.

${ }^{27}$ Braidotti, Patterns of Dissonance, 127-28.

${ }^{28}$ Braidotti, Nomadic Subjects: Embodiment and Sexual Difference, 2d ed., 107.

${ }^{29}$ Braidotti, Patterns of Dissonance, 284.

${ }^{30}$ Ibid. 


\section{Marginality and the Insignificance of Choice ${ }^{1}$}

Daniele Santoro

Centre for Ethics, Politics, and Society, ILCH, University of Minho, Portugal

"Nobody but a beggar chooses to depend chiefly upon the benevolence of his fellow-citizens."

- Adam Smith, The Wealth of Nations, I.ii.2.

\section{Introduction}

Adam Smith was a man of his age. Despite the wisdom in describing the principles of moral approbation underlying the science of human nature, ${ }^{2}$ he shared with his contemporaries the belief that marginal people "chose" to depend on the benevolence of others. The picture evoked resembles a Dickensian portrait of the beggars, prostitutes, and barefoot children that populated the streets of Great Britain during the early stages of the Industrial Revolution - those we imagine imploring for a penny, or worse offering their body or labor for meager pay. The same portrait, sadly, is still common among us today. The perception that laziness is the main cause of economic inequality, and therefore of poverty and marginality, is still widespread in Anglo-American culture, and just a bit less so in Europe and the rest of the world. ${ }^{3}$ But even where poverty is not believed to be caused by moral weakness, there is still an unspoken belief that poverty is a form of weakness that calls for condescendence. What is at stake in these attitudes of judgment or condescendence is the incapacity to see that poverty, inequality, and marginality are not just a consequence of a given distribution of resources, opportunities, wealth or income, but that they are also deeply affected by the quality 
of social relationships, that sense of respect that comes with treating others as equals, or the lack thereof. For, when social relationships are exacerbated by gross inequality, the worst-off are also subjected to hierarchies of power, esteem, and status. The debate on social egalitarian relationships ${ }^{4}$ has rightly insisted on exclusion as a consequence of social inequality, but has overlooked the fact that exclusion is part of a more general and persistent phenomenon of marginality in every social system based on inequalities of wealth and status. While marginality is a proper object of sociological analysis, philosophers have failed to recognize its moral and political value. I am not suggesting that philosophers should be engaged in defining the conditions for the emergence of marginality but that they can help clarify the concept of marginality in ways that do justice to the reality of such a phenomenon. My attempt in this brief note is to contribute to this work of clarification. I will start with a working definition of marginality and clarify what I think is the nexus between marginality and exclusion. I will then move on to elaborate on exclusion as a matter of choice. The main claim is that the concept of marginality, as it is used in the European and American public discourse, relies upon a specific conception of choice as a resolute act of the will. However, if we frame marginality in these terms, we miss the crucial point that marginal subjects are indifferent to the language of choice, for they do not attach significance to the very capacity of making a choice.

I characterize marginality as the permanent condition of individuals or groups who do not play any socially recognized productive role in a social system and are therefore excluded from the economy of credibility that regulates social hierarchies. Marginal groups may include ethnic or other minorities cursed with stigmas and prejudice or more fluid communities such as migrants and refugees. Marginal individuals living outside communities may include homeless people, 
sex workers, persons affected by mental health issues, the elderly as well as people with disabilities left without supporting structures. Marginality usually affects individuals belonging to more than one single category, whose common condition is their vulnerability and social isolation. The list, of course, is not exhaustive. Classification of groups or individuals as marginal can change over time and place, although certain categories are exposed more than others to social exclusion.

Now, we say that marginal people are excluded from relevant social relationships, but what does this mean exactly? In general, exclusion recalls the image of a spatial configuration between center and periphery, or between in and out. Community marginals (the homeless, the elderly poor, sex-workers) are usually excluded in this spatial sense, sometimes even segregated (for instance, when they are institutionalized). In this sense, community marginals share the same fate as those in exile or as migrants (who literally reside outside a territory).

There is more, however, in the idea of marginality than what the spatial image conveys. Marginalized groups are also excluded in the more specific sense that they are considered not to be part of a cooperative social system. They are excluded from what we may call the economy of esteem ${ }^{5}$ that regulates the attribution of social status in society. Whether such a condition is coerced or chosen to some extent, is a more nuanced aspect of marginality that the spatial image does not capture. Let's explore this.

\section{The Resolute Model}

Choices have value when they can affect our prospects of achieving something we value. Realizing a life-plan, accomplishing a task, 
whether self-regarding or other-regarding, all involve making choices at different steps. ${ }^{6}$ A common way of conceptualizing existential choices of these sort is as a node in a forking path. This image has both a philosophical and a literary attraction, as it conveys a representation of life as a branching tree of possible worlds, where choices made at each node actualize one of the paths. T. S. Eliot expressed this image in the Four Quartets: "What might have been is an abstraction / Remaining a perpetual possibility / Only in a world of speculation. / What might have been and what has been / Point to one end, which is always present."

Since these choices are nodes in a branching tree unfolding into the future, they are represented as both ineluctable and irremediable decisions about which path to take. In virtue of this crucial significance, they are conceived as willful deliberations. We may call "resolute" this model of the condition of choice. The resolute model is grounded in a conception of agency as a unity across time, i.e., in the presumption that at each node in the forking path, there is a self exercising a power of decision over which path to walk. In the resolute model, life appears as a continuous flow in which agents exercise control over their actions and strive to contain the effects of events that they do not control. Life is thus the temporal dimension in which agency unfolds its deeds. One may think of such a unity along the lines of the Kantian idea of a transcendental unity of the self, or as a deeper psychological fact that preserves the continuity of the self across time. In either case, the model embeds one feature that is relevant to our discussion. This is the idea that the value attached to the capacity of making choices gives value to the choices one makes. It is this deep fact about our agency that gives the agent a sense of selfworth through the practical realization of mundane deeds.

The resolute model gives shape to a liberal conception of the 
autonomous person that has the full moral and cognitive powers to realize life-plans in accordance with their will in a cooperative system in which their efforts and achievements are recognized by their peers. This is, for instance, according to John Rawls, the conception of moral personhood in a society where social institutions act according to principles of justice. It is not my intention to criticize this view. I rather suggest considering the model of choice as a standard of evaluation for social inclusion in a liberal-democratic society. If we use this model as a standard, marginals fail as full agents under the most important feature of the model, the value they are able to attach to their choices.

\section{The Insignificance of Choice}

In order to address the significance of choice in conditions of marginality, we should note that the resolute model fails to distinguish between valuing choices, for instance, by attaching utility to opportunities, and valuing one's ability to make choices based on those opportunities. ${ }^{7}$

The resolute model holds that one's ability to make choices - having control over one's life plans - confers values on the choices one makes. But, along with this, there is a second dimension of choice: in the ordinary circumstances of socially integrated members, for a person to have the ability to make choices is conducive to realizing, through opportunities, the goals and life plans she values. This view is often associated with the belief that effort contributes to turning opportunities into achievements. Thus, valuing one's choices confers value to one's ability to make choices. It is the mutual reinforcement between choices and ability that provides the ground for attributing moral value to agency. Agents are full members of an economy of 
credibility that can claim deserts and hold responsibility for their actions. For marginal subjects, such a system of reinforcement is broken. This can happen for several reasons: deprived of opportunities, choices become less relevant, and marginal subjects lose confidence in their power of making choices that are effective in achieving their goals and promoting their well-being more generally. As a consequence, also the belief that effort increases the likelihood of achievement loses its grip. While still capable of making choices in a narrow sense of the term, marginal subjects lose their sense of being able to influence their lives, thus becoming indifferent to their ability to make choices. As this attitude toward self-concern becomes more rooted over time, marginal subjects are increasingly more resistant even to policies designed to increase their opportunity set. Once agency no longer carries any value, no real opportunity can hail this loss.

We may call 'the significance of choice' the view that agency is morally valuable. Marginality is the condition in which such a capacity, not just what is chosen, loses significance. Marginality is, in other words, harm to the very capacity for moral agency. An example of the lost significance of choice is what we may call 'bound to fail' attitudes. They consist in the expectation that a life-plan is doomed to fail, thus leading to self-blame when the failure inevitably occurs. Attitudes of this sort manifest themselves in avoiding to engage in any activity whose goal a person expects not to be able to achieve. 'Bound to fail' attitudes are not a psychological condition that falls upon someone, but presuppose voluntariness. A person adopts a 'bound to fail' attitude and does not simply suffer from it. Moreover, 'bound to fail' attitudes are eminently social: they arise from a condition of disadvantage in valuing opportunities required to achieve a planned goal, which lies outside the person's control. 
The distinction I have drawn between making a particular choice and valuing one's capacity to make a choice can help to explain the rationale of 'bound to fail' attitudes. An agent who is able to make a choice normally prefers certain options over others in his opportunity set. The agent acts rationally if he satisfies his strongest preference. However, sometimes people are indifferent with regard to the opportunities they have: they become unable to assign value to their opportunities and cannot rank their preferences. This is what happens when expected failure becomes predominant at important nodes in the forking paths of life. In cases of this sort, what they choose, or if they choose at all, does not make any difference to their value system, and from that perspective, it is hard to see why it would be irrational for them to choose by tossing a coin. Thus, choices lose significance for them.

If we assume that the characterization I gave of the 'bound to fail' attitudes is correct, at least as a hypothesis, then we realize why 'bound to fail' attitudes may lead marginalization even in the presence of progressive policies that try to mitigate inequality of opportunities. Consider, for instance, policies that grant more extensive access to better education through affirmative action or 'no child left behind' programs. These policies often frame the problem as a matter of access to opportunities. The idea of many egalitarian theorists in the liberal-democratic tradition is that an educational system promotes fair equality of opportunity, that is - as Rawls put it - "equal prospects of achievement and culture for those similarly motivated and endowed." ${ }^{\circ}$ Nevertheless, progressive policies inspired by this ideal of justice can hardly alleviate the expected failure and lack of self-respect suffered by certain minorities and social groups due to the general condition of their social life, be it poverty, prejudice, or other factors. 
Since the expectation of failure undermines effort and motivation, even a system of generally trustworthy institutions (that promote fair equality of educational opportunities) falls short of addressing the expectation of failure, because they address the wrong issue: it is not the lack of opportunities for educational goods that matters, but the attitudes towards those goods. Thus, it can happen that even within a democratic education system that, in principle, promotes equality, students from disadvantaged or low-income backgrounds would still misrecognize their conditions of failure as their fault, and in doing so, bash their sense of self-worth.

I have framed this brief analysis as an exercise in the moral psychology of marginality. By moral psychology, I refer to the set of attitudes of regret and resentment, guilt and failure, self-exclusion, and lack of self-respect, that marginal subjects develop in response to how they are treated by social institutions. I do not have the time here to elaborate further on the moral psychology of marginality. I just want to remark that the moral psychology of 'bound to fail' attitudes shows - or can help to show at least - how the self-perception of unworthiness may turn choices into chances. When choices lose their significance, because they do not make a difference in our chances to achieve our goals, the capacity itself of making a choice loses its value.

\section{Conclusion}

I have argued that marginality is a condition in which subjects lose their sense of being able to influence their life course through opportunity and effort, thus becoming indifferent to their capacity to make choices. The lost significance of choice contributes to explain two aspects of marginality as a stable feature of hierarchical societies. First is the internalized attitude of disempowerment as unworthiness 
that is common in marginalized groups (often as a pathological condition of pervasive depression). Second, the fact that marginal subjects live outside the economy of esteem and credibility of social hierarchies in which responsibility for achievements is the common currency of status attribution.

I want to conclude by coming back to the image of choice as a resolute act of will. A consequence of the attitude that making choices has no significance is that life appears as unstructured, thus lacking that unity the resolute model presupposes for agency. When such a capacity loses its significance, also the capacity of exercising control over one's life is undermined as a consequence. Not only the burden of events falls onto a life in disarray, for their effects on the person cannot be contained anymore, but the confidence itself of giving a direction to one's life by acting purposefully vanishes, leaving behind only the residual power to act out of necessity. By undermining the significance of choice, marginality thus deprives people of the value of their agency as moral persons.

\section{Notes}

\footnotetext{
1 This contribution is part of a broader collaboration with Manohar Kumar on epistemic injustice and the significance of choice. I wish to thank Marianna Papastephanou and Torill Strand for inviting me to present part of this work to the workshop on 'Philosophies and Pedagogies of Inclusion and Exclusion' at ISSEI 2019, and the audience for a fruitful discussion.

${ }^{2}$ See Adam Smith, A Theory of Moral Sentiments [1759] (Penguin Classics, 2010).

${ }^{3}$ See, for instance, Pete Dorey, “A Poverty of Imagination: Blaming the Poor for Inequality,” The Political Quarterly 81 (3) (2010): 333-43; Bruce Stokes, "Is Laziness the Cause of Economic Inequality?",Foreign Policy, October 22, 2014. https://foreignpolicy.com/2014/10/22/is-laziness-thecause-of-economic-inequality/ (accessed 1 December 2019); Volpato, Le radici psicologiche dell'ineguaglianza (Roma-Bari: Laterza, 2019), 113-22.

${ }^{4}$ Some crucial contributions to social egalitarianism include: Elizabeth Anderson, "What Is the Point of Equality? Ethics, 109 (1999): 287-337; Carina Fourie, Fabian Schuppert, and Ivo Wallim-Helmer, eds., Social Equality. On What It Means to Be Equals (Oxford: Oxford University Press, 2015); Martin
} 
O’Neill, “What Should Egalitarians Believe?” Philosophy \& Public Affairs 36 (2008): 119-56; Samuel, Scheffler, "What is Egalitarianism?" Philosophy \& Public Affairs 31 (1) (2003): 5-39; Richard Wilkinson and Kate Pickett, The Spirit Level: Why Greater Equality Makes Societies Stronger (London:

Bloomsbury, 2009).

${ }^{5}$ See Geoffrey Brennan and Philip Pettit, The Economy of Esteem. An Essay on Civil and Political Society (Oxford: Oxford University Press, 2005); Miranda Fricker, Epistemic Injustice: Power and the Ethics of Knowing (Oxford: Oxford University Press, 2007), chapter 2.

${ }^{6}$ Here I am not referring to choices of trivial substance - for instance, whether one should prefer to wear a blue or a black-tie at a dinner party - but to choices that set people of paths of life: educational choices, looking for a job (or quitting it), following a vocation, having a family, children, and so on.

${ }^{7}$ Tim Scanlon gave a seminal contribution to this topic in his 1986 Tanner Lectures. See Thomas Scanlon, "The Significance of Choice," in The Tanner Lectures on Human Values, ed. Sterling M. McMurrin, vol. 8 (University of Utah Press, 1988): 149-216. For a discussion of the significance of choice for self-respect, see also Eszter Kollar and Daniele Santoro, "Not by Bread Alone: Inequality, Relative Deprivation, and Self-Respect,” Philosophical Topics 40 (1) (2012): 79-96.

${ }^{8}$ John Rawls, A Theory of Justice, 2d ed. (Cambridge, MA: Harvard University Press, 1999), 63. 


\section{"We are striking because we have done our homework": Two Perspectives on Contemporary Youths' Emerging Ethical- Political Awareness}

Torill Strand

Department of EducationUniversity of Oslo, Norway

\section{Introduction}

In this paper, I use the ongoing Global Strike for Climate Change as a starting point in an exploration of the German philosopher Axel Honneth's and the French philosopher Alain Badiou's distinct ways of thinking ethical-political formation ${ }^{1}$ of and for the present. My aim is to compare and contrast Honneth's political theory of recognition with Badiou's ontological position as I ask; what may generate these youths' emerging ethical-political awareness?

This spring, hundreds of thousands of students from around the world have walked out of their classrooms in a call for more action to fight climate change. On May 24, 2019, crowds of youths were flooding the streets of 1,851 cities worldwide, from Sydney to Berlin, from Bangkok to New Delhi, Oslo, and London. ${ }^{2}$ These young people, that have no voting rights, want to escape their "no-count" position in regard to future policies on climate change. "For way too long, the politicians and the people in power have gotten away with not doing anything to fight the climate crisis, but we will make sure that they will not get away with it any longer. We are striking because we have done our homework and they have not," Greta Thunberg, a 16-year old Swedish activist, said. ${ }^{3}$

My question here is to what degree Honneth and Badiou offer productive perspectives on the historical and ontological conditions generating these youths' emerging ethical-political awareness. My 
focus is not so much the tangible aspects of the strikes, but rather that which comes before these youth's ethical-political awareness. How should we think the historical and ontological conditions that create such an emerging awareness?

In the first part of this paper, I adopt Honneth's political theory of recognition to read the driving force beyond the youths' political engagement. Next, I explore how Badiou's philosophical system conceptualizes the youths' emerging ethical-political awareness. In the third and last part, I compare and contrast Honneth's and Badiou's positions while asking to what degree they help to theorize the formation of contemporary youths' ethical-political awareness.

\section{Axel Honneth's Political Theory of Recognition}

With his political theory of recognition, Axel Honneth (b. 1949) offers a perspective on the moral infrastructure of society. In his first book, coauthored with Hans Joas, Honneth promoted a "historical anthropological" position, arguing that human beings are fundamentally intersubjective. ${ }^{4}$ In the book The Struggle for Recognition, which is a key to his political theory, he returns to this position. ${ }^{5}$ He here develops his theory through a close reading of Hegel, and next reconstructs and substantiates it with the help of Donald Winnicott's object-relations theory and George Herbart Mead's social psychology. However, Hegel offers the basic model of recognition. Let me explain: in Chapter 4 of his Phenomenology of Spirit, Hegel demonstrates the ways in which my self-consciousness is born out of intersubjective relations. ${ }^{6}$ Hegel's argument is that my self-awareness cannot exist in terms of an awareness of external, objective reality only. If so, I have to limit myself from my own existence as part of this reality. My self-awareness can neither exist in 
terms of an awareness of my own existence only. If so, the distinction between me and the world would completely collapse in "a frozen tautology: I equals I." Rather, my self-consciousness emerges as soon as I realize that the world contains other independent selves. Because at that very moment I start to see myself through the eyes of the other as "a separate moment." In this way, my self-consciousness is essentially inter-subjective, which means that my awareness of myself as an independent individual exists only in relation to other independent selves. This creates a desire, a driving force to be seen, understood, and confirmed by others as an independent individual. This is a desire for recognition. Because, as Hegel says, "Selfconsciousness is in and for itself, in that it is in and for another, meaning that it only exists as recognized." It is exactly this insight that is the background for Honneth's description of the lifelong and never-ending struggle for recognition as a process of education (Bildungsreise).

Again, I should underline that Honneth's theory of recognition goes beyond a psychological perspective on the human condition as he grounds his concept of recognition in a historical anthropology, or that which Jean Paul Deranty refers to as "a philosophical anthropology of practical intersubjectivity." ${ }^{8}$ Honneth describes the struggle for recognition as an ontological phenomenon, that is, a phenomenon characteristic of people's way of being in the world.

This insight raises the question: should we envision the youths' emerging ethical-political engagement as an ontological struggle for recognition?

When Honneth portrays this struggle as a process of ethical-political formation, ${ }^{9}$ he reads Hegel's phenomenology in light of Hegel's philosophy of right. ${ }^{10}$ In doing so, he develops a perspective on the ways in which the struggle for recognition plays out when 
encountering social institutions. Honneth differentiates his concept of recognition within three spheres - the private, the legal, and the solidary - each of which represents different ontogenetic steps in relation to the ethical-political formation of the individual.

When the struggle for recognition plays out within the private sphere, as in love, friendship or the affective relationship between parent and child, the struggle is about emotional attention. The work of education here is about being able to leave the emotional symbiosis and develop self-confidence. When the struggle for recognition takes place within the legal sphere, in which individuals relate to each other as independent subjects who can say "yes" or "no" to any deal of transaction, the struggle is about cognitive respect and social integrity. The work of education here is about self-respect. When the struggle for recognition takes place within the sphere of solidarity, as in cultural, political, or work-related communities, the struggle is about social appreciation. The work of education here is about selfesteem and dignity. Each separate sphere of recognition cannot alone form the basis of a fully realized self-awareness. Nevertheless, the affective love relationship stands out because it lays the ground for intersubjective relations.

Honneth's theory of recognition relates to a Hegelian philosophy of mind, which conceives reality as socially constructed in mutual recognition. This branch of philosophy of mind uses Hegel to explain processes that are as constitutive of the individual and the social as of the area of the normative and epistemic: "I know that the credibility of my assessments depends on you being able to join them." In other words, recognition is not only vital in generating and maintaining a person's identity. Recognition also points to a fundamental normative attitude: "Recognizing someone is letting her have a normative 
status... that implies making a moral choice, committing, and taking on responsibilities."11

Consequently, we are moving towards a vital aspect of Honneth's political theory of recognition. Namely, how the theory may throw light on the formation of people's social and political engagements. ${ }^{12}$ As Honneth says, "Any negative emotional reaction that is part of the experience of disregarded recognition requirements, gives the affected subject the opportunity to acknowledge the alleged injustice and make it a motivation for political resistance."13 Thus, Honneth's political theory of recognition seems to offer an illumination of social and political resistance, including the emerging ethical-political awareness among youths worldwide.

\section{Alain Badiou's Philosophy}

Following Alain Badiou (b. 1937), the Global Strike for Climate Change is a political event. First, because it addresses an issue that at every moment concerns people all over the world. Second, because it summons and reveals the endless character of the situation. Third, because it puts the state - in both the ontological and historical senses of the term - at a distance by assigning a measure to its superpower. ${ }^{14}$ For Badiou, an "event" is a conceptualization of a possibility for change. So, let us take a closer look at how he thinks this possibility.

Despite the fact that Badiou has not written extensively on education, the pedagogical theme is vital, constitutive, and ongoing throughout his work. He is an outspoken critic of the analytic and postmodern schools of thought as he strongly promotes the prospects of what he calls "an education by truths." 15 The task of philosophy, he claims, is to think these truths, which emerge from and pursue gradual transformations of particular situations. Badiou's concern is not an 
education by the state, since such an education would simply just perpetuate, replicate, or reproduce the norms, laws, procedures, and worldviews already contained by the situation. An education by truths, by contrast, is a transformative, open-ended, and ongoing process instituted by an exception, a radical rupture, an event. An education by truths does not follow any curriculum or pre-established methods in its promotion of ontological awareness, curiosity, and search for non-knowledge. A pertinent question is thus to what degree Badiou's idea of an "education by truths" illuminates the emerging and global ethical-political awareness among contemporary youths. So, let us look into how Badiou's key concepts constitute a model of thinking such an education.

Truths, to Badiou, are existential, ongoing, and open-ended ontological operations that emerge from an event. Truths do not belong to any epistemic category: truths do not belong to philosophy, but rather to the world that they emerge from and are a part of. However, truths are immanent exceptions. They depend on the world while concurrently moving beyond the world as they reveal or unfold something entirely new, something that we cannot grasp or apprehend by the already established categories of the discourse. Nevertheless, truths, or truth-procedures, gradually transform the discourse, or the world in which they appear. Education, for Badiou, is a formation generated by these truths.

For Badiou, truths are truths of worlds. A world should be conceived both in its being and in its appearing: "The world is the place in which objects appear. Or the 'world' designates one of the logics of appearing."16 However, a world is indistinguishable from the operation of thought that created it. Consequently, for Badiou there are no significant distinctions between our thoughts and the world. A vital distinction, however, is rather between pure being qua being and 
the unified presentation of being, which is a world. Pure and inconsistent being - being qua being - remains unthought-of. Here is the very key to Badiou's philosophy: There is an irreducible and apparently illogical gap between being qua being and the world. Let me explain: Our operations of thought are not being. Being qua being is, for Badiou, the uncounted, pure, and inconsistent multiple. This pure, non-self-identical and inconsistent multiplicity is a unique set to which nothing belongs. Badiou thus speaks of a void, a gap between a world and being qua being. As being qua being remains unthought-of, it seems pertinent to question the possibility to move beyond any given world to get a glimpse of pure and inconsistent being. So how does Badiou conceptualize the potential of radical transformations of any given world?

Again, for Badiou an event is a conceptualization of the possibility of change. The event is unexpected and unpredictable, something that vanishes and disappears. Nevertheless, it unfolds truth-procedures that bring to pass instituted outlooks, knowledge, and opinions. An event will never appear sensible in the light of everyday rules of life since it strikes a radically different logic. An event is an ontological "impossibility." It is both situated and something that goes beyond the situation: on the one hand, the condition for an event to happen is a lack - a situated void - around which an abundance of outlooks, knowledge and opinions circulate. On the other hand, the event carries a potential for radical novelty, a deep-seated change, a radically different logic that implies that it is impossible to continue to practice, let us say a field of politics, in the same way as earlier.

Badiou holds that truths are the real stuff of philosophy, the object of thought. The subject is a process that gradually unfolds these truths, or the significance of an event. In fact, a subject is a sequence of operations that takes place under specific conditions, and which 
produces a synthetic effect or novelty. A subject, for Badiou, is thus a philosophical category, and must never be confused with a social agent, a human being, or an invariable transcendental function. The subject is rather a diligent process involving a number of elements, such as intervention, fidelity, and forcing. It addresses the whole situation and unfolds the infinity of the truths exposed by the event. It is "a forced exception," 17 a sequence of subtractions from any conception of the situation or the world. In other words, the subject goes beyond any given as it gradually constructs the truth-processes that may or may not emerge from an event. The pedagogical theme, in Badiou, is that which opens up for an encounter between these truths and the philosophical practice that thinks them. In short, Badiou's first philosophy offers some tools for a philosophical thinking, and also a strengthening of, the educative truth-procedures emerging from the ongoing global strikes for climate change.

\section{Thinking Ethical-Political Education}

In short, Axel Honneth's political theory of recognition conceptualizes contemporary youths' emerging ethical-political awareness as a struggle for recognition; while Alain Badiou may help to conceptualize this emerging awareness as an education by truths. To compare and contrast their distinct philosophical positions, however, it seems useful to look at their separate ontological positions; distinct theories of the subject; and dissimilar conceptualizations of change. In doing so, we may better understand their contrasting ways of thinking ethical-political education.

Axel Honneth grounds his ontological position in a historical anthropology, claiming, "In every historical epoch, individual, particular anticipations of expanded recognition relations accumulate 
into a system of normative demands." 18 For Alain Badiou, on the other hand, mathematical set theory is the appropriate discourse on being. In the introduction to his first book on logic, he writes; "The entire history of rational thought appeared to me to be illuminated once one assumed the hypothesis that mathematics, far from being a game without object, draws the exceptional severity of its law from being bound to support the discourse of ontology." 19 Resulting from these different ontological positions, the subject is for Honneth the individual, social being, while the subject for Badiou is thought in motion; a process that gradually unfolds truths. Moreover, Honneth holds a Hegelian, dialectical model of change, while for Badiou change is instituted by a sudden, unexpected, and unpredictable event.

For Honneth, ethical-political formation happens through a self/other awareness. The motivation is a continuous struggle for recognition that "goes in the direction of ever-greater liberation of individuality, increasing personal autonomy," an active citizenship and deep-felt solidarity. For Badiou, ethical-political formation is an education by truths that operates through a subtraction from the state of the situation and proposes a different direction as regards to the true life. Badiou underlines, however, that the pedagogical effect of such truthprocedures is conditioned by the way in which philosophy identifies, articulates, and affirms these truths. Education is thus part of a triadic knot: condition - philosophy - education. Badiou's notion of education has therefore a distinct form, very different from the forms inscribed in and represented by contemporary discourses on education, as he calls for the philosophical identification and affirmation of truths.

So, what is there to learn from Honneth's and Badiou's ways of thinking ethical-political formation of and for the present? First, the ways in which they both calls for an ontological awareness is 
intriguing. Despite their distinct philosophical positions, Honneth and Badiou both invite a conscientious philosophical sensitivity in regard to the youths' everyday experience. Next, they both hold a critical outlook in the sense that they stress an ethical-political formation that cultivates an autonomous, free, and critical consciousness among the next generation. For Honneth, the task of ethical-political formation is 'to equip the 'generalized other' with a 'common good' that puts everyone in the same position to understand his or her value for the community without restricting the autonomous realization of his or her self."20 For Badiou, an education by truths transforms the thinking subject and proposes a different direction in regard to the true life. ${ }^{21}$ Consequently, Honneth and Badiou both avoid the hegemonic position of a neo-liberal discourse that pictures education as a fruitful tool to promote skills that would help the youths to survive in a global knowledge economy. To them, education is closer to continual ethical-political and formative processes that open up to a rooted mindfulness.

\section{Notes}

\footnotetext{
${ }^{1}$ I here use the term "formation" to designate Bildung; an ongoing and general process of ethical-political education.

${ }^{2}$ School Strike for Climate. https://en.wikipedia.org/wiki/School_strike_for_the_climate.

${ }^{3}$ Greta Thunberg. https://en.wikiquote.org/wiki/Greta_Thunberg.

${ }^{4}$ Axel Honneth and Hans Joas, Social Action and Human Nature (Cambridge: Cambridge University Press, 1988).

5 Axel Honneth, The Struggle for Recognition (Cambridge: Polity Press, 1994),

${ }^{6}$ Georg Wilhelm Friedrich Hegel, The Phenomenology of Spirit (Oxford: Oxford University Press, 2018).

${ }^{7}$ Hegel, The Phenomenology of Spirit.

${ }^{8}$ Jean Paul Deranty, Beyond Communication: A Critical Study of Axel Honneth's Social Philosophy (Leiden: Brill, 2009).

${ }^{9}$ Bildung.
} 
${ }^{10}$ Georg Wilhelm Friedrich Hegel, System of Ethical Life (New York: State University of New York Press, 1979).

${ }^{11}$ Robert Brandom, "The Structure of Desire and Recognition," Philosophy and Social Criticism 33 (1) (2007): 127-50.

${ }^{12}$ Mattias Iser, Recognition, in The Stanford Encyclopedia of Philosophy, ed. E. N. Zalta. https://plato.stanford.edu/archives/fall2013/entries/recognition.

${ }^{13}$ Honneth, Struggle for Recognition, 14.

${ }^{14}$ Alain Badiou, Metapolitics (New York: Verso, 2005).

${ }^{15}$ Alain Badiou, Handbook of Inaesthetics (Stanford, CA: Stanford University Press, 2005).

${ }^{16}$ Alain Badiou, Logics of Worlds: Being and Event II (London: Continuum, 2009).

${ }^{17}$ Alain Badiou, Theory of the Subject (London: Continuum, 2009).

${ }^{18}$ Honneth, Struggle for Recognition.

${ }^{19}$ Alain Badiou, Being and Event (London: Continuum, 2005).

${ }^{20}$ Honneth, Struggle for Recognition.

${ }^{21}$ Alain Badiou, The True Life (Cambridge: Polity, 2017). 
Workshop 11:

Social Work in Uncertain Times

Chairs: Cecilia Serrano Martínez and Domingo Carbonero 


\section{Challenges in the Context of Uncertainty: Implications for Diversity}

\section{Management in Spain}

Cecilia Serrano-Martínez and Domingo Carbonero Muñoz

Social Work and Social Services Area, Law Department, University of La Rioja, Spain

\section{Introduction}

As a consequence of the convergence of socioeconomic and political changes, to which protection systems must adapt, new realities arise in the context of uncertainty that call into question the concepts of subject and community. This article aims to highlight the impact of social changes on diversity management in Spain, as well as the challenges facing community intervention from the perspective of applied social sciences. Community actions include examples of success based on social cohesion, cooperation, and the active participation of citizens as sponsors of diversity management and intervention measures within the community.

\section{The Development of Subjects and Citizens within the Community in the Context of Uncertainty}

As a consequence of the convergence of socioeconomic and political changes, to which protection systems must adapt in order to respond to new realities, several concepts need to be taken into account in order to obtain a better understanding and analysis of uncertainty generated by change. In order to understand changing contexts in a more comprehensive way, the following aspects need to be considered as attributes associated with the transformation of social, political, artistic, and scientific life': (1) the revolutionary role of the event; (2) its interference; (3) the impact of the change; and (4) the effects of the 
crisis. All of the aforementioned have an impact on the way we live and assimilate social life.

In the case of Spain, society owes its origins to so-called traditional values. As a result, two of its most significant features are the weight of the family in providing assistance and the impact of intergenerational transmission of poverty. ${ }^{2}$ According to Eurostat data, Spain has the fourth highest Intergenerational Transmission of Poverty Rate in the EU. ${ }^{3}$ However, signs of change can be seen in certain areas such as the effect of the decline of the traditional family model, and the need for new social policies linked to diversity management. Nevertheless, other aspects relating to this context are unemployment and insecurity, making Spain the country with the second highest unemployment rate and highest rate of people living in households with very low work intensity. ${ }^{4}$ Nevertheless, the protection of young people can be explained by family dynamics. Within the European context, Spain is characterized, inter alia, by an aboveaverage age of young people leaving home; above-average early school leaving rates; above-average rates of young people neither in employment nor in education, and an above-average unemployment and long-term unemployment rates. ${ }^{5}$

In essence, Europe is built on a set of political, economic and social rights that began taking shape in the mid-1940s. However, Spain evolved independently from the rest of Europe and only as a political subject in the mid to late-1970s, which delayed its incorporation as a member of the European welfare states. ${ }^{6}$ However, on its incorporation, there was an immediate change in the concept of the subject. ${ }^{7}$ A process of individualization began, characterized by the "corrosion and slow disintegration of the concept of citizenship." 8 This implied the exaltation of private interests to the detriment of public interests and placed the very concept of community, which would 
become characterized as fragile and ephemeral, on a lower plane. Community has traditionally been associated with the presence of a group of individuals in a specific geographical area, which, in turn, gives rise to a feeling of belonging. Analyzing the foundational principles of diverse cultures, the concept of identity has been linked to legitimacy and filiation, which is based on the exclusion of the other. $^{9}$

From a functional perspective, various prototypical types of solidarity have been described over the years. Émile Durkheim initiated a tradition in sociology linked to community and social cohesion studies. ${ }^{10}$ His distinction between mechanical and organic solidarity refers to the differences between traditional and modern societies. In the same vein, authors such as Robert Merton and Talcott Parsons explored issues such as the formation of communities and deviant population groups. Parson argued that there is a link between social control mechanisms and deviant behavior. ${ }^{11}$ In turn, Merton argued that deviant subcultures are linked to shared values and the distribution of resources. ${ }^{12}$

From a cultural perspective, researchers have taken a more in-depth look at the emic vision of community bonds. For example, Georg Simmel examined a specific type of interdependence in his definition of "the poor." 13 Specifically, the bonds of interdependence created between social groups receiving assistance and those not, with a focus on status and social image. This perspective was primarily adopted by the Chicago School and theories on the culture of poverty. ${ }^{14}$ With respect to marginal groups, the latter attempt to offer explanations from the social actors themselves that offer insights into values, beliefs, behaviors, and norms located on the margins of mainstream culture. 
As for the concept of citizenship, the starting point should be the integration of the concept's singularities, given that individuals are the result of a progressive differentiation in the individualization process itself. ${ }^{15}$ Regarding the imaginary of community, in the current logic of changing societies, it would be more appropriate to link the concept with the term "tribe" in the broadest sense. In one of the classic definitions of community, Natalio Kisnerman refers to it as a "system of social relations in a defined space, integrated on the basis of shared interests and needs." 16 Similarly, Ezequiel Ander-Egg alludes to a group of people who interact with each other and perceive themselves as a social unit in a determined geographical area. These components share functions, objectives, and a sense of belonging. ${ }^{17}$

\section{Characteristics of Geographical Vulnerability in Spanish Society}

If the distinguishing features of community are placed within the confluence of changes, diversities, and hybrids, then the idea of "tribe" would be associated with a combination of inclusive relationships: that is, the coming together of multiple identities that meet in the same time-space that comprises a diverse and heterogeneous group of individuals. In Spain, neighborhoods are diverse, with areas of action implemented in numerous cities according to their multicultural composition and problems of sociodemographic, socioeconomic, residential, and subjective vulnerability. ${ }^{18}$ Given this diversity, an "Atlas of Vulnerability" has been created to study the patterns of vulnerable areas. ${ }^{19}$

(a) Demographic pattern. In this regard, it should be noted that the evolution of population growth indicates an increase in foreign nationals from $3.8 \%$ to $11.25 \%$ overall. This means that $48.54 \%$ of Spanish areas have a population consisting of 
over $5.6 \%$ foreign nationals. In turn, there has also been an increase in the number of children with foreign nationality from $3.06 \%$ to $12.09 \%$ in the two most recent population censuses. Thus $22.84 \%$ of areas have over $13.9 \%$ children with foreign nationality. Other demographic realities indicate the weight of the over-75 years old who comprise $8.71 \%$ of the population. However, there are $24.18 \%$ of areas in which over $16.3 \%$ of the population consists of individuals over 75 .

(b) Socioeconomic vulnerability. The growth in the unemployment rate can be observed in the 2001 (14.20\%) and 2011 (29.63\%) censuses, with $18.84 \%$ of areas with rates higher than $30 \%$ of the population unemployed in the latter period. Similarly, youth unemployment rates have also shown an increase from $19.98 \%$ to $44.81 \%$. Currently, there are $20.24 \%$ of areas with youth unemployment rates higher than $42.3 \%$. Lastly, the growth of unskilled labor has increased from $12.20 \%$ to $18.90 \%$, with $20.08 \%$ of areas with more than $17.8 \%$ of the population employed in unskilled labor.

(c) Residential vulnerability. Around $6.99 \%$ of housing is in a dilapidated, poor or merely tolerable state, with at least $16.01 \%$ of areas with over $15.9 \%$ of housing in this condition. In addition, $9.47 \%$ of the housing were built before 1940 . The 2011 census reflects $15.15 \%$ of areas with more than $25.51 \%$ of housing prior to this date.

(d) Subjective perception and vulnerability. Data is only available for the period of 2001. First, $22.74 \%$ of the population perceives crime as a problem in their environment, with $40.17 \%$ of areas and over $20.6 \%$ of the 
population perceiving crime as a problem. Second, 37.40\% of the population perceives a lack of green spaces, with $40.07 \%$ of areas and over $39.8 \%$ affected. Third, $14.72 \%$ highlight the problem of poor communication, with $40 \%$ of areas and at least $11.1 \%$ of the population identifying this problem. Fourth, pollution problems affect $19.89 \%$, and there are $40.15 \%$ of areas of in which more than $19 \%$ of the population is affected. And lastly, $31.18 \%$ perceive problems of environmental noise pollution, and there are $40.18 \%$ of areas in which more than $33.7 \%$ of the population is affected.

For more than a decade, community actions have been implemented to intervene in neighborhood geographic vulnerability. In Spain, examples of such interventions can be found in the neighborhoods of Casco Histórico and Delicias in Zaragoza, Cañada Real and San Cristóbal de los Ángeles in Madrid, Ciudat Vella and el Raval in Barcelona, and the Polígono Sur in Seville. Specific actions were implemented in these neighborhoods using proposals for community action defined by Marco Marchioni, which proved to be particularly beneficial inasmuch as he proposes the interrelation of four elements: territory, population, demands, and resources. ${ }^{20}$ For community action to have an optimum effect, social participation is paramount. In this regard, obtaining consensus for participative development implies considering all the parts that comprise the complex group of social relations. Equally, from a community action perspective, it is important not to ignore the diversity of possible alternatives in order to include everyone in the sustainable development process. ${ }^{21}$ 


\section{Challenges and Critical Proposals in the Framework of Community Intervention}

In a context marked by rapid social, economic and political change, the roles of modernity and of the individual become apparent when it comes to creating new ways of responding to and coping with the phenomenon of social acceleration, characterized by the speed of social dynamics and "task overload" typical of the modern world and the break with the past. ${ }^{22}$ In turn, this context is framed within a more globalized context, which "has not managed to reduce poverty, but neither to guarantee stability." 23 These changes suggest a "new form of modern slavery [that] is inexorably manifested in the dictatorship of haste, in the obligation to adapt to an accelerated perception of reality and to the belief in a dynamic of unlimited progress." 24

In response to this dynamic, new trends and lifestyles have emerged such as the Slow Movement, which advocates modifying our fast pace of life in favor of social welfare and degrowth. This entails a reasonable use of resources and the environment, and moderate consumption. ${ }^{25}$ However, in this debate, there are elements that have accentuated the problem, such as weak protection systems, job destruction, the inadequate distribution of wealth, the crisis of the welfare state, etc.

As a result, there has been an increase in old and new social risks relating to the growth of in-work poverty rates, problems of inequality, the emergence of new demands linked to the conciliation of family life, care dependency, and intercultural coexistence. The historical data compiled by Eurostat indicates an overall increase of in-work poverty rates in Europe, ${ }^{26}$ with Spain figuring as one of the countries with the highest rates for 2004-2018; albeit, rates that are above $10 \%$ were only observed from 2008 onwards. In contrast, the Gini index has remained stable for the EU and Spain alike. However, the results from the data 
for 2009-2017 point to Spain as one of the countries with the highest poverty and in-work-poverty rates for the period. ${ }^{27}$ In contrast to the EU-28, Spain has a lower per capita social expenditure for social policies as a whole. With the exception of per capita expenditure on unemployment, Spain has lower expenditure on family and children, housing, and health and pensions. ${ }^{28}$

In the period 2008-2017, per capita social spending increased in Spain and in the EU-28 in general, but by the end of the period differences began to emerge. In Spain, the only increase observed was in per capita expenditure for old-age pensions. However, while other items showed an increase in the EU-28 as a whole, they showed a decrease in Spain; giving rise to an increase in differences in social spending.

Social capital is a fundamental factor in the assessment of new challenges as it directly impacts the community, which, in turn, "is essential for the creation and maintenance of civil society." ${ }^{29}$ In the case of Spain, there are currently various projects linked to community intervention, such as the Community and Intercultural Intervention Project, managed by the private foundation La Caixa, which is deployed in neighborhoods with a high level of multiculturalism and social diversity. This same entity offers a community social accompaniment program aimed at the elderly in situations of loneliness, under the slogan "Always Accompanied." Similarly, more and more "cohousing" initiatives are materializing in Spain. These initiatives were created with the idea of sharing living spaces and gaining services and companionship. Other initiatives have also emerged that promote the use of a circular economy in order to guarantee an efficient use of resources; an example is the Foundation for the Circular Economy. ${ }^{30}$ These examples aim to guarantee sustainability, inclusion and coexistence in communities that have suffered the devastating effects of capitalism. In this regard, 
it is vital to establish the logic of cooperation in contrast to that of competition and individualism. We need to look for tangible objectives and to rethink the challenges that the reality of uncertainty creates, in order to propose solutions based on the multiple capacities and resources available to us. ${ }^{31}$

\section{Conclusions}

In order to understand changing contexts in a more comprehensive way, we need to take into account the impact of crises, changes in social models, and the traditional values that have influenced and shaped Spanish society. We also need to consider the diversities that form part of community social life, which, in turn, change old models and create new ways of situating oneself in the community.

The decline of the traditional family model and the need for new social policies linked to diversity management, together with other aspects such as unemployment and insecurity, pose new management challenges for the development of Spain's social and economic policies. Social cohesion and coexistence are the ultimate goals in the process of community intervention, given that they respond to the diversities of geographical areas and the needs and demands of Spain's heterogeneous population.

Among the many challenges that the social protection system faces in terms of community intervention, the following need to be considered: ensuring active citizen participation and including the entire group of complex social relations in community action, and taking into account all the possible alternatives in a sustainable development process for everyone. In short, what the examples cited in this article have in common is the promotion of sustainability, inclusion and coexistence. Consequently, our proposal for diversity management is to include 
actions based on cooperation as opposed to competition. To be successfully implemented, the proposed approach should be combined with the multiple capacities available to citizens so as to facilitate a high level of social participation.

\section{Notes}

\footnotetext{
${ }^{1}$ Robert Nisbet, El problema del cambio social (Madrid: Alianza, 1979), 1.

2 Maurizio Ferrera, "The Southern Model of Welfare in Social Europe," Journal of European Social

Policy, 1 (1996): 17-37; Gosta Esping Andersen, Fundamentos sociales de las economías postindustriales
} (Barcelona: Ariel, 2000).

${ }^{3}$ Eurostat (2011), Low Educated Parents by their Descendants' Highest Level of Education, Age Group 25-59, https://ec.europa.eu/eurostat/statistics-

explained/index.php?title=File:Low_educated_parents_by_their_descendants_highest_level_of_educatio n,_age_group_25-59,_2011_.png (accessed 9/10/2019).

${ }^{4}$ Eurostat (2019a), Ad-Hoc-Modules, https://ec.europa.eu/eurostat/web/income-and-livingconditions/data/ad-hoc-modules (accessed 17/10/2019).

${ }^{5}$ Eurostat (2019b), Youth-Overbiew, database, https://ec.europa.eu/eurostat/web/youth/data/database, (accessed 9/10/2019).

6 T. H. Marshall and Tom Bottomore, Ciudadanía y clase social (Madrid: Alianza Editorial. Colección Ciencias Sociales, 2007); Luis Moreno and A. M. Guillén Rodríguez, "La europeización del bienestar social en España, ”in España 2015: Situación Social, ed. Cristóbal Torres Albero (Madrid: Centro de Investigaciones Sociológicas (CIS), 2015); Ana Marta Guillén and Gregorio Rodríguez Cabrero,

"Evolución del estado de bienestar en España," in España 2015: Situación Social, ed. Cristobal Torres

Albero (Madrid: Centro de Investigaciones Sociológicas (CIS), 2015).

${ }^{7}$ Ana María Fernández, Las lógicas colectivas. Imaginarios, cuerpos y multiplicidades (Buenos Aires: Biblos, 2007).

${ }^{8}$ Zygmunt Bauman, Modernidad líquida (México: Fondo de cultura económica, 2012), 42.

${ }^{9}$ Édouard Glissant, Introducción a una poética de lo diverso (Barcelona: Ediciones del Bronce, 2002).

10 Émile Durkheim, Las formas elementales de la vida religiosa (Madrid: Akal, 1982).

11 Talcott Parsons, La conducta desviada y mecanismos de control social (Madrid: Revista de Occidente, 1976).

12 Robert Merton, Teoría y Estructura Social (Madrid: Fondo de Cultura Económica, 1964).

${ }^{13}$ Georg Simmel, Les pauvres (Paris: Presses Universitaires de France (PUF), 1998).

${ }^{14}$ Larissa Adler de Lomitz, ¿Cómo sobreviven los marginados? (México: Siglo XXI, 1963); 
Ernest W. Burgess, "The Growth of the City: An Introduction to a Research Project," in Urban Ecology, ed. John M. Marzluff et al. (Boston: Springer, 2008), 71-78.

${ }^{15}$ Paolo Virno, Gramática de la multitud. Para un análisis de las formas de vida contemporáneas (Madrid: Traficantes de Sueños, 2003).

${ }^{16}$ Natalio Kisnerman, Teoría y práctica del trabajo social (Buenos Aires: Humanitas, 1990), 33.

${ }^{17}$ Ezequiel Ander Egg, Metodología y práctica del desarrollo de la comunidad (Buenos Aires: Humanitas, 1993).

${ }^{18}$ Fundación La Caixa, Proyectos de Intervención Comunitaria e intercultural (2019), https://obrasociallacaixa.org/es/pobreza-accion-social/interculturalidad-y-cohesionsocial/proyecto-de-intervencion-comunitaria-intercultural/que-hacemos; https://obrasociallacaixa.org/es/pobreza-accion-social/interculturalidad-y-cohesionsocial/proyecto-de-intervencion-comunitaria-intercultural/claves-del-proyecto, and https://obrasociallacaixa.org/es/pobreza-accion-social/personas-mayores/siempreacompanados (accessed 31/10/2019). INE (2019) Atlas de distribución de renta de los hogares (2019), inhttps://www.ine.es/experimental/experimental.htm (accessed 17/10/2019).

${ }^{19}$ Ministerio de Fomento., Atlas de vulnerabilidad urbana (2019) https://www.fomento.gob.es/areas-deactividad/arquitectura-vivienda-y-suelo/urbanismo-y-politica-de-suelo/observatorio-de-la-vulnerabilidadurbana/atlas-de-la-vulnerabilidad-urbana/atlas-de-las-vulnerabilidad-urbana-en-españa (accessed 17/10/2019).

${ }^{20}$ Marco Marchioni, “Organización y desarrollo de la comunidad: la intervención comunitaria en las nuevas condiciones sociales," in "Programas de animación sociocultural," ed. María Luisa Sarrate (Madrid: UNED, 2002), 455-82.

${ }^{21}$ Tomas Villasante, Las Democracias Participativas (Madrid: Hoac, 1995).

${ }^{22}$ Josetxo Beriain, Aceleración y tiranía del presente. Metamorfosis en las estructuras temporales de la modernidad (México: Anthropos, 2008).

${ }^{23}$ Joseph E. Stiglitz, El malestar en la globalización (Madrid: Taurus, 2002), 30.

${ }^{24}$ Ibid., 175.

${ }^{25}$ Serge Latouche, Decrecimiento y Postdesarrollo (Barcelona: El Viejo Topo, 2003).

${ }^{26}$ Eurostat (2019c), In-work Poverty in the EU, https://ec.europa.eu/eurostat/web/products-eurostatnews/-/DDN-20180316-1 (accessed 9/10/2019).

${ }^{27}$ Eurostat (2019d), Gini Coefficient of Equivalised Disposable Income - EU-SILC Survey, http://appsso.eurostat.ec.europa.eu/nui/show.do?dataset=ilc_di12\&lang=en (accessed 23/10/2019).

${ }^{28}$ Eurostat (2019e), Social Protection Expenditure, https://ec.europa.eu/eurostat/data/database (accessed 23/10/2019). 
${ }^{29}$ Félix Requena Santos, Redes sociales y sociedad civil (Madrid: CIS, 2008), 61.

${ }^{30}$ Fundación economía circular, http://economiacircular.org (accessed 31/10/2019).

${ }^{31}$ Amartya Sen, “A Sociological Approach to Measurement of Poverty: A Reply to Professor Peter Townsend," Oxford: Oxford Economic Paper 37 (1985): 669-76; Amartya Sen, Nuevo Examen de la desigualdad (Madrid: Alianza, 1996). 
Workshop 12:

Some Considerations Concerning a New Ethics of Warning Chair: Gesine Palmer 


\section{From Warning to Stigma: The Danger of Purity in Today's Europe Frank Hahn \\ Berlin, Germany}

When I read the title of Gesine Palmers' workshop - "Global Warning" - it was immediately clear to me that she wanted to warn against a certain form of warning. This paradox, implicit in the title, attracted me, and so I began to look critically at what kind of different forms of warning I would find. These deliberations had a more associative character, which led me into different fields concerning Europe's past and present as well as philosophy and literature. In the next half hour I will present to you some of these deliberations as loose fragments, which nonetheless are somehow interrelated, and which are more questions to stimulate further research than given answers or fixed assertions. I will present my thoughts in eight points.

\section{Point One: Warning and War}

In English, the word "war" is contained in the word "warning." Is the warning the first step towards war? Or is the warning meant to prevent war at the last minute? The famous Cold War doctrine "Launch on warning" stood for a policy of giving the order for a nuclear strike in advance in case the radar screen or other sensors would warn against already launched hostile missiles. The risk of a fake alert was rather high. This is only an example of how thin the line between warning, threat and attack could be. We are advised to look precisely at these phenomena, when looking at those not so rare authoritarian and hyper-narcissistic state leaders, be it in the past or the present. As we can see in an exemplary way with somebody like Trump, the incalculability seems to become a principle of governing - 
what remains calculable are warnings, threats and accusations of the others, and all of that works as an effective means of intimidation. It is playing with fire, where the line between warning and war is becoming thinner and thinner.

\section{Point Two: Intimidation among So-Called Friends}

Also associates, members of one's own club, of a party, a community or an academic circle must be intimidated from time to time, at least according to the club or party leaders. Such a leader usually warns or reminds the "ordinary member," better not to meet or to be seen with Mr. So-and-So. This could be harmful for the reputation or the career. This kind of warning has a twofold aim: to draw clear borders between "us" and the others and to demand complete loyalty to this "us." At the same time, the one who warns underscores with his warning who the boss is. His power depends not the least on his knowledge about the supposed secrets of Mr. So-and-So, about which the naive ordinary member does not know anything. The warning becomes a mechanism of knowledge, power, intimidation and demand of loyalty.

\section{Point Three: Warning and Education towards Hyper-Morality}

These mechanisms are often covered with objective necessities, socalled facts or political ideologies, in the disguise of rational science. These days we hear warnings of all kinds: warnings against migrants, climate change, against wrong nutrition, right-wing or left-wing populism, nationalism etc. It seems also that these warnings are spread with the intonation of "all or nothing," served with the corresponding doomsday fantasies. They are meant to serve logically the pattern of moral indignation, or support, as it is said sometimes, of a new form of hyper-morality. This reaches deeply into daily life and 
pops up around the question of what is permitted and what is not. Is it still allowed to listen to songs of Michael Jackson, although he is accused of child abuse? Can we after the MeToo-Debate still go to see a film by Harvey Weinstein or Roman Polanski? Are we to be forced to take down paintings by Emil Nolde, after it turned out that he was a convinced Nazi? Or other questions: what, according to ecological viewpoints, is forbidden to eat or to wear, can I still use airplanes etc? All these questions are legitimate and can be posed from time to time. But as soon as a system of moral judgment of behavior arises here, combined with moral and later even factual control and supervision of one's behavior, we may find ourselves faster than we thought in a problematic either-or-thinking or Friend-enemy-scheme. And finally, in a rather uncozy society of permanent attempts to educate each other. An example from Berlin: a former journalist of Der Spiegel was celebrating his $65^{\text {th }}$ birthday. The guy recently disturbed the public by some right-wing and Islamophobic bragging. And so the so-called public was looking a little bit closer, who would attend his birthday party. There were some right-wingers, but also old friends, who had no political intention, but found themselves on a "Guest list of horror," published by a daily newspaper. That was a warning: don't go to the birthday party of a renegade. Hyper-morality in everyday life - and so the circle of power, intimidation and loyalty is kept running. In a recent newspaper commentary, it was written:

Moral clarity and purity in all questions of daily life, from nutrition and sexuality to death - once an attitude among religious and conservative circles, is in the meantime spreading among non-conservative circles of an educated left -liberal milieu. For instance a study of the US based Institute "Predictwise" about the geographic ranking of intolerance recently showed, that the highest degree of intolerance is not 
found in republican strongholds of the Midwest or Texas, but in the area of Boston. Here live rather educated mostly democratic voters, but they are not experiencing political diversity, because $90 \%$ of the neighbourhood is politically, culturally and ethnically homogenous. ${ }^{1}$

\section{Point Four: Homogeneity, Purity, Stigma, Scar}

The right-wing nationalist vice chairman of the government in Italy, Matteo Salvini, reproduces the archaic pattern of purity and fear of impurity or defilement, when he warns that migrants spread contagious diseases. And he further warns that whoever is touching them, will himself or herself become sick and unclean. Pictures of leprous people of former centuries become vivid again. A rather disturbing example for it is the so-called Identitarian movement in Europe today. It seems as if the "pre-ethical notion of blemish or brand" (as Paul Ricoeur called it) is having a renaissance today. This is quite important, because according to Ricoeur the category of brand or blemish was much later turned into the notion of sin and guilt: while the blemish or the brand is something which is given by nature, guilt is connected at least to a certain deed, for which the person however free and conscious he or she may be - has made a personal decision and can take responsibility. Contrary to that, the impurity and the blemish are so to speak written into the body. Nothing can change it, no appeal to improve, no resocialization, no cultural integration - the only answer is banishment or annihilation. Polish thinker Zygmunt Bauman therefore has, as I think, in enormous clarity described the motive of the Nazis to commit the Holocaust: he said that the aim was to create a perfect society, the utopia of total purity, and the political actors of the Holocaust had seen themselves in the tradition of gardening and medicine -people whose task it was 
to erase weeds and rushes. It is very important to listen extremely carefully which kind of warnings are spread today by whom. Whoever deviates from a supposed pure or healthy norm is marked as the impure. Since ancient times society has used different means to mark those who violate the norm. They are called certain names, they are labeled or they are tacked with a brand or scar, so that they can always be recognized as the impure or the blemished. Today we speak less about the scar, but more about a stigma that somebody bears. That there is a certain and important correlation between both has been excellently elaborated by French author Hélène Cixous in her sampling of texts under the title "Stigmata." ${ }^{2}$ he follows the word etymologically in different languages, the sting in English, der Stich in German - in any case stigma signifies a wound, which is inflicted upon the body. With that injury something is taken away from the body, and later some fibrous tissue grows over the wound, which then constitutes a scar that is added to the body of the now marked person. But this scar is the result of the sting; the mark of the scar is not written into the body from birth or by nature, but is the result of an injury, of a stigma. First somebody is wounded, then he is marked, and then somebody warns against him.

\section{Point Five: Stigmas and Scars in Today's Europe}

Somehow I have the impression that this correlation or dialectic between stigma and scar is reflected in the warnings that some member states of the European Union raise against each other these days. For many generations we have had a north-south and west-east divide inside Europe, concerning the cultural perception that expresses itself as manifest feelings of superiority and inferiority. It has a long history of stigmata and scars, which I cannot go into here. A very visible example right now are the warnings between West and 
East. The West warns against the East for not appreciating the "European values," and the East warns against the West for betraying the "European values." Viktor Orban is quoted as saying: "27 years ago we here in Central Europe believed that Europe would be our future; today we sense that we are the future of Europe."

That sounds like a disappointed love affair, or at least as a big offence. How could that happen? Has the West nourished wrong expectations and by that betrayed the East? Was the East willing to be betrayed? Has the East nourished the illusion of a picture of Europe which was never congruent with the reality? Was that the result of pure desperation, because the West seemed to be the only partner offering herself? A kind of last minute panic? I do not want to stretch the love allegory too much, but isn't it a paradox that both sides make the same claim, namely to be the only one defending and preserving the European values, while obviously having totally different assumptions, what these values would be? It seems, as if both parties have a clear idea of the purity of these European values. I will leave aside the question what these values could be and how purely or impurely they are realized, and will rather look at the study of Iwan Krastev, a Bulgarian politologist, who published a lot about the developments in Eastern Europe since 1989.

In his booklet Explaining Eastern Europe he starts the analysis with the statement that the revolution of 1989 did not bring forward any new idea, but that the eastern part of Europe finally wanted to become "normal," i.e., like the western part. And so the East began a policy of imitation. The West, of course, supported this with all kinds of promises. But such a policy of imitation can only fail, because it deepens an asymmetric relationship, based not on an equal partnership, but on the dynamic of superiority and inferiority - and 
that at all levels: economic, moral, and cultural. Krastev writes (I quote):

The imitator's life inescapably produces feelings of inadequacy, inferiority, dependency, lost identity, and involuntary insincerity. Indeed, the futile struggle to create a truly credible copy of an idealized model involves a never-ending torment of self-criticism if not self-contempt. What makes imitation so irksome is not only the implicit assumption that the mimic is somehow morally and humanly inferior to the model. It also entails the assumption that Central and Eastern Europe's copycat nations accept the West's right to evaluate their success or failure at living up to Western standards. In this sense, imitation comes to feel like a loss of sovereignty. Thus the rise of authoritarian chauvinism and xenophobia in Central and Eastern Europe has its roots not in political theory, but in political psychology. It reflects a deepseated disgust at the post-1989 "imitation imperative," with all its demeaning and humiliating implications. The origins of the region's current illiberalism are emotional and pre-ideological, rooted in rebellion at the humiliations that must necessarily accompany a project requiring acknowledgment of a foreign culture as superior to one's own. Illiberalism in a strictly theoretical sense, then, is largely a cover story. It lends a patina of intellectual respectability to a desire, widely shared at a visceral level, to shake off the colonial dependency implicit in the very project of Westernization. ${ }^{3}$

The partner who feels himself and is seen by the other as inferior will never have a chance to equalize with the imitated one. There will remain a permanent gap - experienced as a stigma. The so-called inferiors will be for the so-called superiors always a little bit lazy, unorderly and uncultivated. The hopeless effort of imitation with all 
the stigmata creates offences - and out of that grows the rebellion. The whole history is then turned around and sounds like this: "We will not any longer try to copy you, and therefore it does not make sense that you look at us as inferior or failed copies of yourselves!" Such a sentence, according to Krastev, is an expression of the attempt to gain back national self-esteem. (In Western Germany there were similar tendencies in the 1960s expressed as Anti-Americanism, but because of the incredible crimes of Nazi Germany the way towards a populist and rough nationalist kind of self-esteem was closed. That is a big difference in respect to the Eastern European nations today. It would nonetheless be worthwhile to use this experience for a new kind of dialogue towards the East.)

It is interesting to read again, on the actual background, the books and papers of Polish Nobel Prize winner Czesław Miłosz from the 1950s. Already at that time imitation was an issue, but with a different emphasis. In his book The Captive Mind from 1953, Miłosz writes that the typical Eastern European views the typical American as rather dumb and uncultivated, and that mainly because these typical Americans seemed to be completely unable to get into the spirit of the Eastern Europeans. And inside Europe, the educated Pole, Czech or Hungarian knew a lot about Holland, Belgium or France, but not vice versa, the Western Europeans knew almost nothing about Poland, Hungary or Czechoslovakia. That was experienced in the East on the one hand as an offence, but on the other as a revalorization of their own cultural education. Therefore there was no reason to imitate the West. Even the Eastern European technicians and workers were in the meantime so much better trained to cope with their Western counterparts, according to Miłosz, and in the field of literature or music there was no reason to feel inferior. And so he resumes: "Why should the paintings of present day French painters, which are 
created in a country without any dynamics, be imitated in Warsaw or Prague? We must cure ourselves from that kind of mimic... that may have been justified, as long as French or Belgian or British capital was invested in mines, industrial companies or railways in the East, where at the same time the Western books, the films and the fashion were dragged in here." ${ }^{4}$ But the problem Miłosz saw was that the East, just liberated from the ban of the West, now came under the thumb of a new metropole (Moscow). And there was an order to imitate that new regime, because any search for new, peculiar ways would be interpreted as Titoism. And at the same time the forced imitation of Russia for a certain while even strengthened the self-confidence of the Eastern Europeans. I quote:

Russia always disdained the coddled western culture as decadent and bourgeois, and that has become stronger after the revolution. The eastern Europeans would like to imitate this Russian selfassurance and cure themselves from the bad habit of the parrot but on the other side the eastern European understands very well that he will be always condemned by Moscow as a cosmopolite, and therefore the East Europeans leer at the West, and then we are disappointed, that from there this certain something is not coming, which we are waiting for. ${ }^{5}$

One could follow these lines further and further. They demonstrate the high complexity of East-West relations in history, which is rarely understood today, but all these almost crazy dialectical moves back and forth, which Miłosz describes, have to be taken into account up until today, if we want really to understand the pre-history of offences, stigmata and scars. In the case of Poland it goes back at least to the period of the so-called divisions and the final extinction of Poland at the end of the $18^{\text {th }}$ century. In 1918 Poland experienced a national rebirth, but under what pain? At the same time the year 1918 marked 
a period of traumatic experience for the majority of eastern and south eastern central Europe, when the Austro-Hungarian monarchy collapsed, because now the principle of national homogeneity became predominant, where as before many different languages, cultures, religions and ethnicities had lived together. And then 25 years later,for a second time these areas went through a policy of "ethnic cleansing" by Nazi Germany, leading to the ethnic homogeneity prevailing until today.

These two waves of homogenization or purification, as a result of war and genocide in the area of central Europe, constitute, according to Krastev, a basic background for the reaction of these countries to the challenge posed by migrants and refugees. Krastev warns us against rather quickly attributing labels to the Eastern Europeans. Not all of them are already racists, when they are scared by immigrants and refugees. He underscores again and again two aspects to better understand this phenomenon: the first is related to the emigration of people from their own countries. Since 1990 Eastern Europe as a whole has lost between $20 \%$ and $30 \%$ of their population through emigration to Western Europe. The inflow of people from the Middle East, Central Asia or Africa is not hailed as a possibility to stop the population drain, but is perceived as an offence and a threat, not least because people are reminded of the wound that the migration of their own people had opened. And as an answer to this offence and threat one takes as a defense line the idea of ethnic homogeneity or purity, which was completely unusual for Central Europe 100 years ago, but since then the people in the East have gone through nothing else but this process of ethnic purification. 


\section{Point Six: Homogeneity (and Purity?) in European Ideas}

The question indeed is: how far is this obsession with purity or homogeneity a mark of European modernity that is not confined to the Eastern part? Was it not even the other way round, that this obsession was an "invention" of the West? Today there are many critical voices about the ideals of 1789. The call in the French Revolution for Liberté, Egalité, Fraternité sounds good and is understood as the foundation of human rights. But at the same time these slogans could be read also in a different way, as they became indeed the source of violence and submission by revolutionary France. You here in Spain were among the first victims. The war against Spain of $1808 / 09$ is a vivid reminder of Europe through the paintings of Goya (who was born near Saragossa). How come that out of nice ideas suppression, violence and war erupt? Perhaps there is an ugly inside to the outside of any idea or vice versa an ugly outside to a nice inside. Apart from the fact that pure ideas function often as a mere object of abstract thought, which demands a form of adoration, the words Egalité and Fraternité already show this other ugly side in the language. One of the most profound critics of the ideas of Egalité and Fraternité was Hannah Arendt, who cannot be suspected of refuting humanist principles or diminishing the importance of human rights. But as a German Jew she had a very fine nose to smell the very fine differences. In the idea of Egalité she heard or smelled the danger of the pressure of assimilation, out of which an intolerance would emerge against any difference and a collectivist subject would dominate. She warned (another aspect of warning) that in the notion of Egalité and Fraternité the tendency towards social and cultural homogeneity was already installed. The German Jews were, since the Enlightenment, persuaded or forced to assimilate into German society. As it became clear that even liberal, secular, and bourgeois Jews maintained a 
sense of difference and otherness, the supposed well-meaning and polite variant of assimilation pressure turned into a hateful antiSemitism, according to Arendt. This otherness became a stigma, and the Fraternite turned the political into family relations: that meant, if Fraternité, then all should become as we are - the next step away from political arguments was towards those of biology, leading finally to blood gang and race affiliation.

But long before that revolutionary France understood herself as the universal center of reason around 1800, French as the language of clarté, and out of that purity of reason and language the policy of a colonial and imperial mission for spreading universal reason led to violence, war and slavery. Out of nice ideas grew the obsession of purity. Of course, also the repeated opposition against the imperialist and colonialist rule erupted from inside Europe, as the philosophy of critique shows, which especially Jewish thinkers, some of them in the footsteps of Immanuel Kant, elaborated. And so today, it is an open question in which direction Europe is moving - towards purity and homogeneity or the assertion and appreciation of particularities and differences (of course, without giving up certain universals, but this is another complex issue).

\section{Point Seven: Literature and Stigma/Scar - Part I}

Are there ways to escape the circle of stigma, scar and warnings? It is difficult to imagine how whole nations can undergo therapy or that this may even happen mutually. But there is literature! We have narrations - maybe the most universal we have, because everybody has his or her story. We only have to be prepared to listen. Hélène Cixous writes in the preface of Stigmata that for her writing means a flight in the face of the intolerable: "But not only a flight in order to 
save one's own skin, as the French idiom says. In fleeing, the flight saves the trace of what it flees. This is why they flee: to maintain the horror unforgettable....the literature in me wants to maintain and reanimate traces." ${ }^{6}$ What is literature for her? It is the multilinguality and the ambiguity of every word, the poetic use of language. The poetic language keeps the power of resistance, the possibility to escape the nail, the sword, the knife, the axe, which threaten man with death and immobility. I quote: "The first and best ally in the evasion (of threats) is the poetic use of language. If only we listen, a language speaks several languages at once, and runs with a single word in opposite directions....Language's tricks are the allies of the artist, who goes into resistance or exile. Joyce said this a hundred years ago and Montaigne five hundred. Every language artist is an artist of the struggle against the condemnation of death." And she underscores, that sentences and words always lead somewhere, where we did not expect, neither the reader nor the author: "The incalculable is the text's promise and taste of triumph." 8 The incalculable as the opposite to the scar, which fixates its bearer, which makes him or her calculable? Cixous would not be Cixous, if she would not play also here with the word, and so she says: "All literature is scary."9

\section{Point Eight: Literature and Stigma/Scar - Part II}

All literature is scary - for whom? For the reader? For the author? In any case the author needs for his writing a great deal of fearlessness, because, as Maurice Blanchot said, writing means dying. That can be read in many different directions, but at least one can say that any author who reaches deep into the heart of the reader is writing for his life or as if it would be a question of life and death. 
In this respect writers should be in a special way prepared also to talk fearlessly to those whom most people would avoid talking to conspiracy theorists, fanatics, racists and all those who put out loud and shrill warnings. Would it not be marvelous, if we could succeed to break the circle of scar, stigma and warnings? If writers, according to Hélène Cixous, are those who can hear and speak in one language the voice of other languages, then they would be suited, I think, to go fearless to the fanatical warners, talk to them not with the attitude of knowing and arguing for right or wrong, but of listening and asking questions and of giving them a chance to stumble over themselves, i.e. to stumble over the rest of the human in them.

I offer two examples. First: the recently deceased Israeli author Amos Oz. One of his books, which came out recently, has the title Dear Zealots. Obviously it deals mainly with the Israeli-Palestinian conflict. $\mathrm{Oz}$ tells about an encounter between a writer and a taxi driver. The driver suddenly says: "We must kill all Arabs, then we will have peace." The writer does not react with moral indignation, but asks "We must kill them? Who exactly is this 'we'? Who is supposed to do it? The police, the firemen or the physicians with white coats and syringes?" The driver is getting nervous, but answers finally: "One has to distribute the task in a just way. Each Jewish man should kill some Arabs." "Alright," says the writer, "let's assume, you are ordered into a house with several floors. You go from door to door and ring the bell and ask politely "Are you by chance an Arab?" Who answers with yes, is shot. After you have killed all the people in the house, you hear a baby crying on the highest floor. What will you do? Go upstairs and shoot the baby?" For a while it is silent in the car, the driver is thinking heavily, and finally he says: "Listen, you are really a cruel man."10 
My second example: an author living near Berlin, who grew up in the former GDR, has written a novel about the period of the change of 1989. Now she is touring the countryside of the East with reading events. You have to imagine the situation there -depopulation, closed schools, closed pubs, closed libraries. The reading event sometimes takes place in a bakery, because there is no public room. Between 25\% and $40 \%$ of the people there give their vote to right-wing or even rightwing extremist parties. Migration is a big issue, and most people are strongly against those coming from outside, be it Syria or Afghanistan or Africa. She, the author, is nonetheless not only reading, but mainly listening - and in that role she creates experiences that are not reported in the media. For instance: in one village there were two Afghan families with their children. The presence of these Afghan children prevented the closing of the school, which would have been unavoidable otherwise because there would have been two fewer pupils. Now, since the Afghan families saved the school, they were suddenly welcomed in the little village in Eastern Germany and have become an integral part of the neighborhood life there. This happened in a village, where the inhabitants bear the label Racists. Maybe they are, but at the same time it is true that in a safe situation, where there is a possibility of real listening with open ears, other facets can come to the surface.

Is this all a severe warning against warnings of all kinds? But should we not warn against the warning against the warning? Is there not in each and every warning some sign of fear, some attempt to control, to educate, to stigmatize and to purify? Maybe. At the same time sometimes it is good to have a friend who warns us, when we are blind in front of an abyss. And so, each word spreads rather impurely in many different and even opposite directions. 


\section{Notes}

1 “Die Moralisierung des Alltags" (The moralization of everyday Life), Der Tagesspiegel 17 March 2019.

${ }^{2}$ Hélène Cixous, Stigmata: Escaping Texts (Abingdon, UK: Routledge, 1998).

${ }^{3}$ Ivan Krastev and Stephen Holmes, "Explaining Eastern Europe: Imitation and its Discontents," Journal of Democracy, vol. 29, no. (2018): 118-19. https://www.journalofdemocracy.org/articles/explainingeastern-europe-imitation-and-its-discontents- $2 /$.

${ }^{4}$ Czesław Miłosz; Verführtes Denken (The Captive Mind) (Berlin: Suhrkamp, 1974), 57 (my translation).

${ }^{5}$ Ibid., 8.

${ }^{6}$ Cixous, Stigmata, Preface, x 1.

${ }^{7}$ Ibid.

${ }^{8}$ Ibid., $\times 2$.

${ }^{9}$ Ibid.

${ }^{10}$ Amos Oz, Liebe Fanatiker - DreiPlädoyers (DearZealots: Letters from a Divided Land) (Berlin: Suhrkamp Verlag, 2018), 37-38 (my translation). 


\section{Structural Violence in Society: An Anchor Point for Anti-democratic Movements}

Reinhard Hildebrandt

Berlin, Germany

blog: rghildebrandt-analyse-forum.com

In 1969, the Norwegian peace researcher Johan Galtung extended the classic definition of violence by including the concept of structural violence. The concept does not consider "the destructive action of an offender or group of offenders" but rather the type of violence which acts systemically, curtailing basic human needs in such a way that individuals cannot develop their full potential. This broad definition does not attribute violence to real players. Acting anonymously, it undermines all values, standards, institutions, and discourses, as well as processes which are constitutive of the structures of a precise social system.

The purpose of Galtung's approach is to altogether eliminate structural violence in systems of interaction. Unfortunately, this method conceals the possibility of disclosing the inevitability of structural violence in every social system. This necessitates an analysis of the quantum of structural violence that could pose a threat to the survival of society as a whole or, on the other hand, may even help preserve it.

\section{Structural Violence Committed by Hegemonic Formations}

To begin with, the term "discursive formation" needs to be defined: it is a specific mode of thinking and analyzing regularities in the field of investigation, which could later be extended to the areas of law,

economics, administration, culture and public discussion. Other 
participants in the discourse are invited to articulate their differing or concurring standpoints as discursive formations that flow into the discussion.

The existence of subordination in a given society is not equivalent to the presence of structural violence. If antagonistic relationships were to emerge from relationships of subordination, then the hegemonic side would

- either justify the existing relationship of subordination and mitigate, or even totally eliminate, the reason for discontentment by using a corresponding discursive formation,

- or permit structural violence by using exclusively discursive formations which serve the preservation of the challenged relationship of subordination.

Hegemonic formations prefer the last alternative in avoiding the direct controversy with the resisting discursive formations or in completely interrupting the democratic discourse. Discursive formations not taking part in the actual controversy are treated, according to their possible potential of resistance, as to be subordinated, suppressed or not to be taken into account for a long time.

\section{The State's Right of Intervention to Preserve the Structured Whole as a Result of its Monopoly on Violence}

What is perceived as "society" and "the State" is an articulated whole, which is continually in a state of emergence. It is the sediment resulting from conflicting individual or associated autonomous entities. In the course of their checkered conflict they evolve into discursive and hegemonic formations which, depending on their 
individual manifestations, are rendered capable of a wide range of practices.

In such an articulated whole, the State, in its ambition to preserve this whole, is neither a key focus nor a pivotal node. In its selfpreservation, the State is also subject to the general horizon of change. The process by which the State adequately reconciles the contradiction between its efforts at self-preservation and its other activities occurs, as does the entire process of transformation, within the framework of a comprehensive discourse. From this unifying perspective, the autonomous entities appear as fragmented elements.

The wide range of state interventions includes:

- the support of rising hegemonic formations over existing ones;

- the constant exploration of limits and latitudes for hegemonic formations;

- mediation (with or without the state resorting to its monopoly on violence);

- keeping open the realm of infinite discursivity to activate or reactivate floating elements.

State interventions can only become effective if the State preserves its autonomy vis-a-vis hegemonic formations. Neither at the level of institutions nor on a personal level should the State permit its interventions, aimed at preserving the existence of the articulated whole, to be mistaken for hegemonic formations' scope of action. In such a scenario, it either becomes an appendage of these formations or the prime promoter of their acts of suppression. In the first case, the State proves to be helpless against the structural violence of high-level hegemonic formations. In the second, the State legitimizes structural violence, denies the transformation from subordination to suppression and decides what kind of physical or psychological violence would be 
required to keep those suppressed by structural violence under control.

\section{Conservative Justification of Structural Violence}

3.1 Moeller van den Brucks: The "Conservative Revolution" (1923)

The point of departure for conservative justification is the determination of autonomous entities into which the underlying substance of the universal life-stream is directly dissolved. According to Moeller van den Brucks, something "eternal" resides in this most humble form "which will be always restored and to which each evolution/performance will return." The human being figures as an autonomous entity with a "non-changeable" nature; as a living force, he emerges from the substance which is to him "a static, intrinsic world-order, inviolable by the human intellect." According to Hans Freyer (1926), demanding the "conservative revolution," the moment of the unchangeable nature of man is inconceivable without the second moment: "the active none," the driving force, the continual restoration of the original status in a purifying process, "the transformation of the finite into the infinite, into something constant, eternal" (cited by Richard Herzinger, Frankfurter Rundschau, 12.02.94). Hans Freyer extended Möller van den Brucks' ideas. He propounds a disruption produced by the human mind, a disruption in the original harmony between the unchangeable nature of the autonomous entity (the human being) and the intrinsic order of the world and implies a tendency to return to the lost ideal state. He further argues: since the last excluded class (the working-class) was integrated into society during the Proletarian Revolution of the $19^{\text {th }}$ century, and the struggle of partisan interests transformed itself into the necessity for compromise, there emerged from within the now emergent "industrial society" an integral whole: "the people." 
Freyer declares the people - this "organic entity" - to be the "historical subject" of the "right-wing revolution." To the treason of the spirit against life, the people react through the treason of the spirit against the spirit (Ernst Jünger), while re-establishing the original harmony. According to Freyer, "the people constitute the purport and meaning that merge into the world of industrial society, the vital core around which the resources of the industrial system are centralized ...." In a "total revolution" the people give rise to the "total state," which will "liberate itself from society"; and both together - the "people" and their "state" - would integrate in an organic manner all the technical possibilities produced by the industrial revolution, utilizing them for the very first time for the welfare of the whole. In his "Dynamismus," Richard Herzinger sums up Freyer's ideas with a critique: The ideal of an organic community seems to be the necessary and unavoidable result of the objective historical movement. Indeed, a more emphatic justification and glorification of structural violence can hardly be conceived.

In the final period of the Weimar Republic, those ideas became effective. The embittered confrontation between the discursive formations to obtain hegemony, to shape the structured whole including the competition for the various claims of universality focused on the legitimation principles, resulted in the fact, that the far right-wing hegemonic formation began to dominate all the others.

From the perspective of the formation that emerged victorious - the Nazi Party (NSDAP) - all the other formations without differentiation belonged to the hegemonized camp, although some of them had to be involved - for a certain period of time and to a no inconsiderable extent - in the task of governance. Likewise, the State too was regarded merely as an instrument of support for hegemonic action at the highest level; consequently, it was hindered from exploring the 
range of flexibility open to hegemonic formations competing for the top spot, in an effort to preserve the structured whole.

Even during the transition period from democracy to the absolute rule of the NSDAP, the State was not able to either form chains of equivalence with those in the second or third rungs to undermine the hegemonic formation claiming absolute supremacy, or assert its claim to authentic interpretation of the principles of legitimation. Ultimately, the dominant hegemonic formation - the National Socialist Workers' Party - gained absolute control, established the total State under its rule, broke all resistance using every means at its disposal and demanded total submission in thought and action from all those subordinated.

Herbert Wehner's study of national socialism, undertaken in 1942/43, showed that the Nazi Party used its name to pretend to be a successful synthesis of two radically opposed streams of ideas (Die Zeit, 25.02.94): Under the label "national" there appeared all those discursive formations which after the First World War declared "their overt or covert enmity towards political movements committed to peaceful re-construction as a mark of national consciousness." Bearing the label "socialist" combined with "national," the party gathered into its fold floating elements, which tended towards the labor movement. In adopting the term "German Socialism" it even offered sections of the middle class and the entrepreneurs scope for identification. The term "German" was targeted at Germans living outside Germany's borders; it tried to create a sense of togetherness even among subject positions far removed from the party.

According to Wehner the term "worker" has always carried a particular emphasis. The Nazi Party was not to be one among many bourgeois parties, not just another electoral party, but a workers' party that extended support to the many who were uprooted and 
disillusioned after World War I, elevating them to "German workers" who were to be distinct from their international counterparts who were regarded as stateless. The question "Are we not all workers?" turned the focus on the emergence of a new type of human being, who appeared in Ernst Jünger's article "Der Arbeiter. Herrschaft und Gestalt" (1932). This new being was a mix between a human industrial-robot and a hi-tech fighter. Going beyond "bourgeois liberty," he was to create a new world, an "organic construction" in which man and technology would once again merge with the eternal laws of "life" (Herzinger, ibid.) The term "party" in the Nazi Party's nomenclature was meant to connote a "people's community" in which the individual was not only to feel safe but also secure from conflicts of interest that could flare up again, as in the past. The "Führer" would ensure that the elite did not rise above the people, and from the ranks of the people there would emerge, from all levels of the popular movement, a plethora of 'mini fuehrers' who would remain faithfully loyal to Hitler.

Reducing the autonomous elements to limbs of a community, thereby subordinating the rights of the individual to the authority of the "Führer," dispensed with the universality of law as legitimation for rule, thereby duly subordinating it to the wisdom and benevolence of the Führer as a new basis for legitimation. Many-faced in its original avatar, the Nazi Party - following the assumption and remodeling of state power - came to increasingly incorporate those formations which had at first worked together with the Nazis, but were then forced into total subordination:

- German national circles (involving industry and large landowners of nobility);

- army generals (Reichswehr); 
- supporters of the empire and some members of the House of Hohenzollern;

- politicians and persons of influence from the Catholic Center Party.

This fusion of highest-ranked formations and the State - planned for a "thousand" years - collapsed in just twelve. Which meant accepting the finality of the coming-into-being and passing away of the structured whole.

Even after the collapse of the Nazi dictatorship, Carl Schmitt, one of Hitler's spiritual guides, neither regretted nor admitted his political mistakes. For him, there was no ' $\mathrm{I}$ ' that could have been held accountable, or it had simply died somewhere along the way. In the place of the splintered 'I', Schmitt proposed the "pure identity" of his "Self," which excluded the contaminating "Other." On the same lines, "unalloyed power" had to exclude all heterogeneity. "Every real democracy had not only to treat the equal as equal but that which was not equal was not to be treated as equal" - thus wrote Schmitt in his treatise "Geistesgeschichtliche Lage des heutigen Parlamentarismus" ("The intellectual history of present-day parliamentarism"). In the journal Glossarium published in November 1947, Schmitt exonerated himself thus: "In God's eyes the future has already come to pass and what confronts us as the present is like the ray of light from a distant star, long since extinguished ... Thus, justice in the divine world-order means ignoring what we perceive as our present. When God allowed the murder of hundreds of thousands of Jews, he at the same time discerned the revenge they would take against Germany, and what $\mathrm{He}$ sees in revenge-seekers today will be experienced by man in another unexpected present." (Thomas Asheuer, loc. cit) 
3.2 The Contradiction between popular sovereignty and rule of law In general, we can say that preserving things worth retaining rigidly against the spirit of the time will cause structural violence and suppression. According to Hans Maier, the State is on the one hand an instrument of general interest, and on the other hand the core area to guarantee freedom and justice; this differentiation is not only a neutral one but privileges those hegemonic formations which tend to preserve the articulated whole in the name of legal certainty and peace. There is no "order in itself" and what of the chaos is regulated or seems to be regulated is not a question of chance. The demand to realize justice needs to be examined by the question: "if justice only depends on its normativity or on the objective of its practical validity" (Rainer Wahl). Nobody doubts the necessity of pursuing and punishing crimes (e.g. murder) when it comes to individual and social damage. But there are certain crimes - e.g. economic crimes - which are less pursued because of the chronic lack of personnel in the prosecution authorities. The unspecific demand to pursue crimes is not very credible.

Maier considers "unfamiliarity with pluralism and parties" as a "conservative" waste-product. At the beginning of the $20^{\text {th }}$ century, Max Weber was convinced that democracy can only be successful by having a "charismatic leader." Politics is decided just by the few, therefore parties should be organized as a group of followers. Adenauer, who thought the Germans incapable of democracy, tried to bridge the maturation gap until they acquired a democratic consciousness by a "chancellor democracy." "He counted on the citizens' voluntary subordination under a leading spiritual elite, namely "those who are initiated" (Botho Strauß). In 2019, in view of a lot of parallel political crises, those ideas were once again in fashion according to a serious comment in Der Tagesspiegel (23 June 2019). 
Maier as an "enlightened conservative" cultivates the traditional constitutionality and uses it as a necessary counterforce against the daily struggles and activities. In his constitutional patriotism he refers particularly to the "key traditions of liberty," for instance the "common man and his history, estate grounded and early parliamentary traditions like the Hanseatic League, the bourgeoisie of the cities" and the "specific German tradition of natural law and freedom and human rights." He considers the principle of popular sovereignty - all power emanates from the people - through the lense of those traditions of liberty. In declaring those traditions as referential, they were no longer the foundation of popular sovereignty but got the power of command over it - as shown in the restrictive decision of the federal constitutional court concerning the women's right to abortion. In the same way, Maier recommends strengthening, though avoiding national pathos, the sense of belonging to the German nation and to use the power to define this pattern of identification in a conservative way. Maier distinguishes conservative tendencies defending rigidly established rights and prerogatives from those which are capable to adapt these rights to the evolution of society.

\subsection{Niklas Luhmann's theory of power}

Hans Maier's criterion of evolution corresponds to an aspect of structural violence which we find in Luhmann's "right of the society" and which is unfolding the indelible core of structural violence. In the condition of unlimited flexibility between those who are hegemonizing and those who are hegemonized, both sides adapt their expectations without delay and create a peaceful situation of superiority and subordination. If, according to Hegel, the extent of subordination requested by the master is always congruent to the extent of his care 
towards the slave, and the slave's desire for being recognized, sheltered and thanked, coincides with the master's behavior, each sort of suppression or structural violence is excluded. Antagonistic discursive formations have no chance to come into existence. A complete balance between them will also be realized, if the hegemonizing ones and the hegemonized are no longer interested in developing their power. Of course, such a society free from domination, depicted in many utopic scenarios, exists without structural violence. But for the moment, there is, and perhaps there will never be neither such a condition of unlimited flexibility nor the exclusion of heteronomy, and consequently, we have to reckon with structural violence.

To Luhmann, structural violence is not a topic of vital concern. According to him, power is created by "constellations of interaction" (Luhmann, 1988: Power, 14).

As a pure game with distributed and financed roles the duplication exclusively serves the conservation of power. Structure only evolves when progressive groups periodically alternate with conservative ones (i.e., by elections in a parliamentary democracy or by disputes over the orientations within the ruling party). Luhmann's ideas of the structural role of time show how high-ranged hegemonic formations try to organize an adequate ensemble of social and state-owned institutions, in which their "visions of the future" become legal and those of the other formations become illegal. This is the origin of structural violence. It will only come into effect if established rights and prerogatives will be preserved against the time or against the resistance of those who feel oppressed" (Luhmann, 14). 


\section{Social Politics under the Condition of Globalization}

In 1995, Hans-Olaf Henkel, former president of the federal association of German industry, expressed the following warning: "The discussion of social politics is more and more unbalanced." There is too much reflection about how to fairly distribute the social product and too little on how the increase it. He demanded: "In the future, not the dividing but the baking of a much greater cake should be the first aim of responsible politics." For him and his combatants like Hilmar Kopper (former boss of Deutsche Bank) or Klaus Murmann (former president of the employers' federal association), the national quota as well as the expenditure quota were too high, social expenditures exceeded investments and the total expenditure for social means irresponsibly increased up to $3 \%$ of the GDP.

All demands were disguised in the following wording: The social net should adapt to the narrower financial margin and should be reoriented. The strengthening of individual responsibility and the private provision should be the leading idea, which meant to consequently dismantle social security. There is a need for more markets and more competition. Behind those demands, there was the desire to reinforce high ranged hegemonic formations against the lower ranged ones. Otherwise the breakdown of the social fundaments was to be feared. During a conference in March 1995, André Leysen (member of the East-German privatization agency) changed the French Revolution slogan from "Liberty, Equality, Fraternity" to "Liberty, Equality, Affordability."

All these declarations meant that the entrepreneurs expected the State to accept a higher level of structural violence in preserving social freedoms and the articulated whole by supporting high ranged hegemonic formations. The State faced a turning point, 
- either it equated the preservation of the articulated whole with the well-being of the world-wide hegemonic formations and subordinated the lifespan of the articulated whole to that of the hegemonic formations,

- or it opened up the borders of the articulated whole beyond those of the nations.

In the first case, the State would lose its autonomy towards the hegemonic formations: that means that it helplessly justifies all forms of structural violence emanating from them (instead of restricting it) in denying the change from subordination to suppression and determines itself which forms of physical or psychological violence would be used to keep pressure on the hegemonized ones. In both scenarios, the State would have no resistance against the hegemonic formations, the articulated whole would perish with them, e.g., in an extensive financial crisis. In the second case, hegemonic formations should create formations in the field of discourse institutionalizing a State which would fit in the borders of a new articulated whole. For these formations, the autonomy of this State would be sacrosanct; like all the other autonomous unities, they would have to submit to this state. Once, the European Union acted in this way, but in recent times, it has been called into doubt; e.g., the decision of Great Britain to leave the EU or the desire of some East-European members to change the balance of powers between legislative, executive, and judicative in favor of the executive.

In the 2000s, both options were on the agenda. The EU-summit at Lisbon developed a strategy to transform the EU into the most competitive and dynamic economic region of the world. Innovation and social cohesion were to be the engines of this strategy. To make this effective more supra-state institutions would have been necessary. This is not what happened. All attempts to build such institutions 
failed. The focus on the well-being of the world-wide hegemonic formations resulted in the neo-liberal economy plans. In 1997, first the British Premier Tony Blair propagated the concept of "new labor." In 2003, the German government with Gerhard Schröder as chancellor followed this concept (Agenda 2010) and introduced an essential reconstruction of the German social system and the labor market. In the following period, Germany became world champion in export and came up with less and less unemployment but - in the EU - it now appeared with other states at the top of the list in the domain of low wages and precarious employment.

4.1 Very effective formations: The German new social market economy initiative (Initiative Neue Soziale Marktwirtschaft)

In October 2000, the employers' association Gesamtmetall launched the new social market economy initiative (INSM) because of the widespread massive resistance against the "new economy" offered by the German population and by the social-democratic and green government in office since 1998. Already at that time, Mr. Breuer, head of Deutsche Bank, and Tietmeyer, director of the federal German Reserve Bank explained to the new government, that from now on, it had to accept the financial capital as the leading rule. Soon after the government takeover, Gehard Schröder as chancellor turned away from the civil society orientated policy. The strategy against neoliberalism changed from delaying tactics to adjustment to USAmerican conditions, insistently required by the INSM. According to the prescription "to prevent things getting worse" the government reduced the civil society orientated discourse to the following slogan: "more responsibility for the individual," thereby it cooperated with the ideas of INSM. 
The famous and well-known management consultant, Roland Berger, and the president of Altana AG, Dr. Nikolaus Schweikart, both "ambassadors" of INSM, gave advice to chancellor Schröder on economics. They followed the slogan of Hans Werner Busch "to get the necessity of reforms into the citizens' heads, to inform them - from our point of view - what has to be done." (Busch, main executive director of Gesamtmetall). While the INSM tried to make a big plus in focusing on the motto "it is social to create new employment" and avoided attacking the labor unions directly, the latter came into an unbridgeable conflict with the red-green government.

After the stricter labor laws (Hartz-Gesetze) became effective in 2005, the Monday demonstrations of the years 1989/90 were revived by the growing discontent of the population. The German government was in a difficult situation, comparable with that of the conservative French government which in 2006 eliminated completely the notice period of young professionals. While in France excessive protests of students, unemployed young people, labor unions and left-wing politicians against these welfare cuts forced the government to completely $f$ withdraw those measures, the German government succeeded in neutralizing the impact force of the Monday demonstrations. Instead of violent protests in French cities, the German population fell into a desperate mood; anti-social measures were accepted and the long-term unemployed as well as pupils lost their motivation to get ahead. In both societies, the national administrations tried to fight against the collapse of social cohesion.

Harald Schumann, a German journalist, declared in 2005 before the German elections: "Millions of citizens have lost confidence in democracy, because they realize that their representatives redistribute the gains of the reforms only to the privileged while all the others have to pay on top" (Tagesspiegel, 5.3.2005). The party of 
the non-voters reached the top, while the popular and the small parties lagged behind. Unlike in France, there were no social riots, because the German government corresponded largely to the requirements of a hegemonic formation. But the growing social passivity and the political disinterest of great parts of the population triggered a negative democratic evolution, which has now produced a more than $10 \%$ support of the right-wing party "Alternative für Deutschland" (AFD).

Earlier than presumed, the economic situation changed to the disadvantage of INSM: investments turned to another direction. When companies dislocated production branches in lower-cost regions, they had to decide after a while if they should entirely disappear from the former market and transfer their production abroad, or if they should invest again in their original country so that the gap of the technical level between the transferred branches and those at home did not become too wide. For those branches which were - for technical reasons - not transferable, adjustment processes were inevitable. In fact, many German production facilities placed once again investments in their country and increasing orders caused increasing demands for the traditional suppliers of the main companies. The lifecycle of hegemonic formations is subject to their own process of creation and disappearance. As finite structures, they are marked by transience.

From the perspective of the initiators, the hegemonic formation is successful when it is able to realize within the field of discourse all the objectives, strategies, and tactics in the most efficient way. Nevertheless, the actors recognize neither the mismatch between the multitude of alternatives and the limited number of those they are conscious of, nor the possible variety of arrangements which the articulated whole offers, nor the undetected path of transience. Even 
the best financial and intellectual support cannot bridge this mismatch, which is even worsened by the lack of time when decisions are to be taken. The vigorous collision between advocators of the INSM on one hand and supporters of the purchasing power parity theory on the other hand proved the deep difference between them in organizing society, in placing the individual in it and in accepting structural violence. On the surface, there was controversy between representatives of the liberal market and the advocates of state dirigisme, neo-conservatives against supporters of Keynes, defenders of liberalism against defenders of the individual, propagandists of more individual responsibility against protectors of the non-privileged, top performers against beneficiaries, supporters of globalization and those who are against it. Genuinely, two questions had to be answered:

1. To what extent can structural violence be imposed by the privileged in order to preserve their power against the underprivileged without damaging the social cohesion and the democratic structure of society?

2. What is the State's task in this controversy? Which of the sides will it serve more? Is the State able to keep neutrality towards both sides in preserving the amorphous counterpart?

Many East-European countries, which, after the end of the cold war, joined the EU, were entirely caught into the suction of neo-liberalism, and were used as extended workbenches without any options to develop autonomous industry branches. South-European countries, particularly Greece, were subject to the pressure of the reformorientated EU countries, which dictated severe conditions in order to diminish their public debts (especially the loan repayments of private banks). Severe social cuts increased the unemployment rate and forced qualified young people to leave their country. EU- and worldwide acting companies succeeded more and more in playing off the 
countries against each other. They themselves appeared and still appear as financially well-off hegemonic formations to support the national companies in their resistance against international competition, in their desire to be backed by national subsidies and by the cuts of social benefits. If this strategy is successful in one country, it will be used in another country and increase the discontent with the high-costs of international pressures.

\subsection{The financial crisis and its consequences}

In 2008, the financial crisis started in the USA, stimulated by a massive budget deficit, which had been growing for a long time, and a high exchange deficit, which gave a blow to American self-perception. It undermined the position of the American dollar as the world's reserve currency. The EU had already tried to challenge it by the creation of the Euro in order to disconnect itself from the US-dollar and to place the Euro as a new reserve currency in addition to the dollar.

When the financial crisis became more and more obvious, banks did not trust each other anymore, the politicians' confidence in banks eroded drastically as well as the public's confidence in the financial system. The public criticized in particular the illegitimate and undemocratic methods which had come more and more into practice. For a long time, the American governments did not accept the ideas that followed Geoffrey Underhill's proposals. They expressed their incomprehension when the Europeans desired to reform the International Monetary Fund.

Geoffrey Underhill had urged the USA to give up their de facto veto position in the IMF; according to him it should be changed against a reduced EU veto so that nobody could claim a veto. Even when the 
crisis came to a dramatic turning point and some countries tried to leave the "hotel capital mobility" of the IMF, the USA stuck to their right of veto. Their privileged status $(16.77 \%$ of the voting rights within the IMF) allowed them to get into debts without limits. No other member country of the Bretton Woods Treaty enjoyed and still enjoys the same advantage.

Even China as the biggest creditor and the EU as the most important competitor of the USA on the world markets did not take essential measures against this situation. China even tried to bypass the negative consequences of the weakening dollar by transferring the Chinese monetary reserves from the US-dollar to the Euro and by replacing Chinese interest accounts by investments in US banks and investment funds like Blackstone. Blackstone is one of the most important American investors and calls itself as the world-wide leading financial and asset manager. Even if the EU created the Euro as a challenge against the US dollar, it did not succeed to replace it as the settlement currency for oil, natural gas, and high-quality products like airplanes.

Despite the bank-managers' resistance to their disempowerment by the State, it became necessary to change the old system of banking rules by a new one. But up to now, this has happened only on a small scale.

Globalization and digitalization had reached such a level that they limited the autonomy of States to preserve the amorphous counterpart. The world-wide tech-companies, which cannot be bypassed because of their level of digitalization, are not only able to play off the individual states against each other but to put economic and political pressure on them in order to keep their profit margins high. The lifestyle produced by those companies corresponds perfectly to the ideas of the INSM regarding a higher level of individual 
responsibility. Taking into consideration the circumstances under which start-ups work - easy-going working atmosphere, flat hierarchies, non-regular working hours, constant availability, relatively low wages, low age-assurance - and the dangers they confront - to be purchased by big companies - we realize to what an extent structural power affects the individual. The unresolved consequences of the 2008 banking crisis and the dangers of a new, deeper one were and still are at the expense of taxpayers, and have an impact on people with little or average earnings. In all, every single process created a growing income imbalance in Germany: the risk of poverty increased from $11 \%$ in the nineties to $15.8 \%$ in 2017 . In addition, the complex topic of the migration crisis has divided German society between winners and losers.

This poverty line is faster and faster approaching mainstream society. The particularities of some regions aggravate this problem: for instance, the Ruhr area and many parts of the East-German countries, which had undergone massive deindustrialization, suffer from the image of being the losing side. That means that the greater the structural violence towards those parts of the population, the more the functioning of democracy is threatened. While in 2010, German citizens turned away from politics because of their disappointment, today they are open to the ideas of the right-wing or extreme right movements or parties, which try to convince them they will solve their problems but are pursuing in a rather clever way a pure market orientated policy. These discursive formations use fear against receiving any more migrants or refugees, which they pop up as a "calculated undermining of the German people." According to them a policy of isolation would solve all the problems of the disadvantaged. A comparable mechanism is in place in other European countries as 
shown by the British desire to leave the EU and the electoral success of the Italian right-wing party.

\section{Summary: The State as the Engine of Social Development}

Real people do not correspond to the "homo oeconomicus", and the real market situation is not comparable to the mathematical model of the market. The ideal market situation does not exist in reality. Mathematics cannot represent reality in an appropriate way. This means that politics should deny the self-regulation of market forces. The stronger the market participants grow in placing orders and demands, the more the State should intervene in the market's activities. Its standard should not be the market's self-healing capacities but the preservation of the amorphous counterpart by democratic means. The State should follow its assigned executive rules of power. This logic is also used by the representatives of companies or banks. Consequently, Joseph Stiglitz, the well-known American economist, invites the State to preserve democratic structures and to act in favor of the general social welfare. More than in his analysis, the failure of the State should be emphasized. Its activities should not be oriented towards the economic self-healing capacities but towards the conservation of democracy. The State along with the market will be the gravedigger of democracy.

State activity should always focus on conserving the articulated whole: the autonomous unity split up into various elements which construct the enormous building of the multitude of discursive and hegemonic formations produced by their articulatory practices. Each state which plays off the conservation of the articulated whole against the single autonomous unity eliminates not only the existential basis of both, but enables an unlimited extent of structural violence. As long 
as the State functions as the engine of social transformation, the impact on the development of the individual should be the benchmark for the extent of structural violence. Which extent seems permissible and which not, is to be fought out between the discursive formations in the field of unlimited discourse. It is irrelevant if the impact refers only to the non-autonomous unities or to those participating in the various discursive and hegemonic formations, or beyond this to the underprivileged or even to the invariable substance of the life stream. The individual as self-creating, singular, and free in the development of its elements, can only be achieved by a broad participation in communication and political decision. (Paolo Flores D'Arcais quoted in Frankfurter Rundschau, 16.5.95). By its non-negotiable diversity, the best way for the individual would be to take part in power symmetrically, at least this would be a perspective. But at the same time, the individual as a physical unity, capable of communication, is split up into moments which belong to discursive formations and into those which are still floating. As a part of discursive and hegemonic formations it consolidates the ensemble of relatively stable social forms. As an "enormously changeable," "self-defining" animal (Richard Rorty), the individual will disrupt these forms again and again. Its singularity can be explained by the specific mixture of both components, different from one individual to the other. To keep open this mixture for all individuals on the occasion of social transformation processes marks the frontier of structural violence. Self-development, considered as a powerful private autonomy, which had replaced the priority of politics, goes beyond the "one-sidedness of the possessive individualism."

Worldviews, in themselves reasonable, acting together, against each other and mixed up, do not obey the rationality of a supra worldview; they represent a further differentiation of the self-sustaining 
autonomous entities. This differentiation goes beyond the pluralism of the market and the self-interested possessive atomism. The originally "romantic development of a further dimension of personal diversity, the rehabilitation of the apolitical and unreasonable idiot, the stubborn child, of the poetry, the private irony" has become "the real source of the new" (ibid). National transformation politics justified by a supposedly superior rationality should not cover up the diverse desire to be different. Disputing the border lines between the legal spheres of public and private life is, on the contrary, fueling the development. At the same time the visible differentiations show the way to transformation with a minimum of structural violence.

The national self-sustaining activity, reduced to smaller articulated wholes, is losing its significance for those hegemonic formations which partially represent the counterpart of the worldwide whole. Their small-scale development projects get into contradiction conflict with those acting within a worldwide scale. These projects cannot be detected as such because of the uncoordinated interspersion of national projects. The indirectly acting worldwide projects appear as a superior potency creating higher structural violence in the subordinated societies. The loss of employment, the increasing level of poverty among the old, and unaffordable rents are the consequences.

This self-sustaining activity could be shaped in another way if there were transnational entities - established beneath the level of a world state - which develop strategies to influence the larger articulated whole. If and when there will be a world state and if such a development will be desirable, is yet to be clarified. For the time being, a world state exists only virtually in the form of the UN and other commissions which try to realize a global governance. In reality, the international situation unfortunately tends towards the opposite direction. From this perspective, we have to fight with all the findings 
of this analysis for the conservation and the real democratization of the European Union. 


\section{The Franco-German Relations: A Shining Example of International Understanding or a Myth?}

Simone Lück-Hildebrandt

Berlin, Germany

\section{France and Germany: One Origin, Two Countries, Enmity for Centuries}

To begin with, we have to consider that, about 1200 years ago, France and Germany arose from one country: the Kingdom of the Franks. Shortly after the death of Charlemagne, the existence of this kingdom was called into doubt, its division by his three sons were inevitable; on the other hand, the Oaths of Strasbourg are not only a document representing the genesis of the French and German language but they proved their mutual recognition as equals. At least with the beginning of the religious wars this mutual recognition failed. During the Thirty Years' War, France as a catholic country battled alongside of the protestant Swedish country to bring the Holy Roman Empire of German nations to its knees. Since then, the characteristics of French politics are marked by the fear of a German nation too big for the middle of Europe. Frederick II, head of the ambitious Prussian kingdom, was very interested in French culture (he invited Voltaire to his castle Sanssouci at Potsdam), but there was no revival of the old mutual recognition due to the geopolitical situation in Europe.

The French Revolution: A turning point in the history of FrenchGerman relations?

Even if the Revolution caused euphoria amongst German intellectuals, the constant negative factor of this relationship did not change. On the contrary, Napoleon's conquest of Europe provoked the 
Liberation Wars. In trying to create a unified Germany at the same time, the grounds for national sentiments was prepared - national sentiments, which refer to cultural identity as well as a deep

antipathy against everything coming from France. The Prussian/Franco-German War of $1870 / 71$ sealed the traditional enmity (Erbfeindschaft) between France and Germany.

This long era of mutual deathly destruction between the two countries ended with the First and Second World War, during which the German Reich twice attacked the French nation and occupied it from 1940 to 1944. In light of this disastrous development, the thousandyear relationship of the two countries is a reminder of the story of Abel and Cain.

\section{The Genesis of the French-German Friendship after 1945}

A Bumpy Start: the European Coal and Steal Community (ECEC) (1951), the European Economic Community (EEC) (1957), the ElyséeTreaty (1963) = France as a Guardian of West-Germany's Integration in the Western Community

Even though France, as a conquered country, did not participate in the important conferences of a New World Order, it was invited - by the recommendation of Churchill - to take part in the occupation of Germany; the Saar and parts of the Rhineland as well as two sectors in Berlin became French occupation territories. In contrast to the American and British, the French occupation forces tended more towards the ideas of vengeance and behaved therefore more rigidly. Only after the American and British fusion of their zones (aimed at the reconstruction of Western Germany) became effective, the French were ready to join the two others. 
In the same way, Jean Monnet and Robert Schumann, the forerunners of European unification, supported the integration of Germany not because of a sense of friendship but because of the necessity to contain in time West Germany's recovery by the subsidies of the Marshall Plan. The European integration policy was inspired by the desire to attach the Federal Republic of Germany as much as possible to the West. Paris was conscious of the fact that its integration in the EEC meant at the same time the reinforcement of the division of Germany. As the French political scientist Henri Ménudier remarked, with reference to Germany's desire to reunite: "A reunited Germany as Member of the EEC would have a hegemonic position in the Community. An EEC without the German partner would tend to insignificance. France and the other member states do not want a reunification and consider this goal as unrealistic" (cf. R. Hildebrandt, Die deutsche Frage).

Nevertheless, the first step towards a Franco-German reconciliation was made by the creation of the ECEC and later on the EEC. But the essential momentum of the reconciliation took place when Charles de Gaulle and Konrad Adenauer signed in 1963 the Elysée Treaty, which was two years after the construction of the Berlin wall, when the French were sure that Germany in the heart of Europe would be weak for years. Along with the Elysée Treaty the Franco-German Youth Office was founded. This was a most important component of the Franco-German friendship, which developed into a sort of "skyscraper" of a multitude of exchanges, projects, and cultural activities bringing together particularly German and French youth as well as other partners. We will talk about this later on.

Until 1989/90, the elites' expectations concerning the Franco-German friendship were complementary: 
- as the French, in return for their offer of reconciliation, required subordination from the Germans, they let them feel their status as an occupation power, only less than after 1945. "The [the French] observed very strictly the responsibilities of the FourPower-Status as well as the consequences on West-Germany's policy" (cf. op. R. Hildebrandt).

- as the Germans showed submission, unbeknownst to the French, they disregarded them and tried to follow their own strategy.

The respective "transatlantic relationships" have their place in this interplay. The US as the leading power played an important role for West-Germany. By the time of the Berlin Blockade, the Marshall Plan and the defense of West-Berlin against Soviet ambitions, the US and the "American way of life" were deeply rooted in the Germans' hearts. The Franco-German friendship had difficulty in finding its own place. On the other hand, France was also able to play the American card against the Federal Republic, even if it externally demonstrated independency towards the US. For instance, after the fall of the Berlin wall, President Mitterrand ensured Mr. Genscher, former minister of foreign affairs, to accept German unification but required in return the support of the European unification process. To the French, the US hegemony seemed to be less dangerous than a united Germany. The Franco-West-German tandem of the past appeared not to be efficient enough to keep the German question under control. To resolve this question, it would be necessary to tie a new security net (in accordance with Frankfurter Rundschau, 04/27/1990).

\section{1989/90: The End of History or "old wine in new bottles"?}

As a primary means of protection against instability, Mitterrand approved the reform of NATO. France, "as an ally of the US," would 
cooperate in the foundation of a European axis which would also include Germany. It became obvious that the upcoming unification of Germany would necessitate closer ties between the West Europeans and intensive cooperation with the US. After his visit in the United States (in April 1990), Mitterrand believed that the US should have a key position in European security questions and therefore, necessarily, would have to station American soldiers in Europe and in Germany (cf. R. Hildebrandt).

\section{The change in hierarchy between France and Germany}

After the collapse of the Eastern bloc, France and Germany's positions changed. France's dominant behavior from the time of the Cold War gradually transformed in favor of Germany. The French demand to introduce the Euro in certain European countries, among them Germany, was grounded in the hope of eliminating the German mark as a European reserve currency and of opening up the economic space of France. The opposite development took place: Germany was able to create further markets and extended workbenches by integrating the GDR in German territory and the Eastern countries in the EU. The steep rise of the German export industry up until this point, to the disadvantage of all the other European countries, transformed Germany into a central "player" in the EU. And at least, since the Greek financial crisis, the same transformation took place in the political sphere. It seemed that Germany considered itself to be the leader of the northern European countries and France of the southern European countries. This meant that the Franco-German duo was situated in opposed camps which did not help the cooperation between them. On the other hand, close ties remained in managing the Ukraine crisis, in preserving the Nuclear Agreement with Iran and the INF contract. Due to Germany's longstanding economic weight 
and its growing political role, the French became deeply insecure and the relations between the two nations became more complicated.

Macron, a politician with European ambitions; Merkel and Scholz, politicians who put on the brakes

France's unfavorable situation changed with the presidency of Emmanuel Macron in 2017. His attempt to develop new dynamics and to restore France's role in the EU increased French self-confidence towards Germany. But the more the Germans delayed Macron's proposals (the foundation of a European community of solidarity, the creation of a financial transactions tax and a general digital tax, the foundation of a European defense community) the more pressure there was at home because of the intended reform program. The movement of the "gilets jaunes" decreased his approval rates and the European election placed him behind Le Pen.

With regard to Brexit, France followed a stricter agenda than Germany, but the German politicians prevailed. Therefore the question when and under which conditions the British would leave the EU remained open. The EU-reform steps required by Macron were pushed further and further into the background. Consequently, the Franco-German relationship suffered because of the long list of unpleasant events, although a renewal of the Elysée Treaty was signed at the beginning of 2019 in Aachen. Regarding the present relations from a bird's eye perspective, we have to admit that the Franco-German engine is sputtering. 


\section{Is There Really a Franco-German Friendship?}

\section{Latent connective currents}

Why, in the light of the above problems, do we continue to talk of a Franco-German friendship? Concerning the economic cooperation, there are similar problems if we think of Airbus or Arte. Is this friendship a phantom to which we like to refer, but which is only useful for soapbox speeches?

Concerning my following remarks, there is one important condition: on the one hand, I acknowledge the problems between the French and the Germans; yet on the other hand, I am so closely tied to French civilization that this part of my paper offers a very personal view.

Because France and Germany emanated from one kingdom, it is understandable that there must be a deep-rooted friendship, which we do not fully appreciate. Of course, there are reciprocal relations concerning culture, craftmanship and civilization in general, which we can see. The shock triggered in Germany by the recent fire of NotreDame Cathedral (15 April 2019) and by the terrorist attacks in several places in France, illustrates this friendship. The fact that those at the German royal courts spoke French, that French architecture, manners and fashion were decisive, can once again be explained by political and economic developments; it had, nevertheless, important effects on German thinking and behavior.

The potential of influence vice versa is less dominant. Even so, it is important to music and philosophy. All the currently notable French philosophers (Maurice Merleau-Ponty, JacquesDerrida, Michel Foucault, Jean-Luc Nancy, Edgar Morin, Hélène Cixous) refer to Hegel, Nietzsche, Heidegger, Husserl; they mastered of course the German language. The influence of German fashion is limited to Lagerfeld, an important name in Paris. There are some actors and 
movie directors who influenced French society: Marlene Dietrich, Romy Schneider and Wim Wenders.

In accordance with their critical position towards Germany, Dietrich and Schneider left the country. Germany only recognized the two artists after their death. Wim Wenders' movie The Sky above Berlin fascinated the French public by its resemblance to the "nouvelle vague" and its mystical staging of the divided city of Berlin. Otherwise, there is no big influence of current German literature, movies, and music on France. It is rare for German novels to be translated into French. During the last few years, the Cannes film festival has not invited German movies and the German hip-hop scene is not well known in France. It is true that the city of Berlin has become the ideal place of longing for young French people (belonging to the left-wing intellectuals), who want to build their life in Berlin in order to avoid the more centralistic French society. But even these ideas, which are naturally incomplete, concentrate on a certain French social class, which has nothing to do with the average population. The reason for the Franco-German friendship remains unknown.

\section{The every-day Franco-German friendship}

The two world wars - a connecting element?

It seems to be an apparent paradox, but the two world wars brought the ordinary people of both countries closer to each other. Who does not know the various stories?

- the French and German soldiers who sang Christmas carols together in their respective trenches during the First World War; 
- the possible hospitable reception of the French forced laborers who often replaced the German head of the family during the Second World War.

There are many stories of love or friendship in those difficult times, which we can read in novels or see in movies (two examples: Hiroshima, mon amour; Frantz).

Both of my parents, who stayed in France (my mother as a typist in Paris, my father as a soldier in Paris and on the Atlantic coast, not at the Front) transmitted such a fantastic image of this country and its people, that since childhood I have had deep feelings towards it. France is my second homeland. And vice versa, there are the same personal experiences: the singer-songwriter Corinne Douarre, who came to Berlin in the nineties to learn more about her grandfather (forced laborer in Plauen/Sachsen). Her songs about her feelings and experiences in Germany are very emotional.

Exchange projects for 9 million young people since 1963. The FrancoGerman Youth Office: The engine for reconciliation and mutual understanding Exchange

The desire, emanating from those dark days, to create mutual freedom and reconciliation so as to overcome the harm done to each other contributes to the success of this youth office. Since the beginning, there have been 9 million exchanges of pupils and children as well as young adults and teachers between both countries. There are more and more different projects (in sport, dance, and professional training) including those who have fewer chances because of where they come from.

Particularly in the last few years, these projects have not only focused on the two countries but were opened up to third parties, particularly 
in Eastern Europe. In Berlin, we have the advantage of having a second Franco-German institution - the Centre Français (located in the North of Berlin) - supporting the Youth Office in all sort of projects. It is especially important to know that for those projects, the knowledge of the other language is not at all a condition, but at the same time, it is the participation which guarantees the interest to learn the other language. Coaches and interpreters are ready to help and to propose language animation. In realizing the first step towards the Other, it is not the language that plays the important role, but it always results in the opening up to the Other. When my husband's parents met a former French forced laborer and his wife, they did not understand each other but it was their warmth of heart, their intuition that daily life demands the same attitude in coping with difficulties, that solidified their friendship throughout their lives. To do things together, to cope with difficulties together and create a basis to guarantee peaceful cooperation. The 56 years of Franco-German relations is the best example of this, despite the recurring difficulties.

Franco-German Relations: A myth, not to be revealed but, under a realistic perspective, to be cultivated

In view of the reality, it is at any rate correct to consider the FrancoGerman friendship a myth. But we should absolutely cultivate this myth and have confidence in it. In this way, we will come - despite all sort of backlashes - a little bit closer to it ... but we will never realize it. This means that instead of global warning, a clear analysis of the power relations in Europe, the knowledge about what has been reached, what is to be preserved, and the hope of what has to be done - would be helpful in courageously encountering the future. 


\section{Some Considerations Concerning a New Ethics of Warning}

Gesine Palmer

Berlin, Germany

www.gesine-palmer.de

Warning is a strange speech act. It does things to those who are being warned as well as to those who are being warned against. It stirs up fear, and often a will to act. It can be used truthfully, with good intentions, and it can be used fraudulently. It can be spread out of a misjudgment of any situation, and it can be very reasonably used in order to prevent serious harm. Because of its own power and the powers it is intertwined with, the very act of warning can and sometimes must be warned against. In times of aftershock, which might partly be explained by an alarmism of sorts, I wish to pose the question: do we need a new ethics of warning?

\section{Why Ethics?}

But why ethics? Why not begin with a phenomenology of warning, with a psychology or similar approaches? Should we not rather follow Niklas Luhmann, who in his famous little text entitled "Paradigm Lost," did nothing less than suggest that ethics should warn from morality itself. ${ }^{1}$

According to Luhmann, ethics tries to strengthen the moral code of explaining society rather than the truth code, which is supposed to be the relevant code for sociology. As a sociologist, Luhmann wants to make clear that society as such cannot properly be described in terms of the moral code, but only as the system that is to be taken as a given in order for moral distinctions to be drawn. Claiming that the morals of a society might, e.g., draw the lines of moral acceptability between those who protect the environment and those who do not, Luhmann 
says: of course there are lots of possibilities for moral communication in any given society - and lots of values to be referred to. But of an ethics it is to be demanded that it should reflect the structures of society, before recommending any given moral or even morality as such. ${ }^{2}$ And he thinks that the moral code cannot do so, for being too simplistic. This is why he warns against relapsing into an ethical discussion that only reiterates the moral categories it is supposed to analyze.

Luhmann himself, however, admits that warning is a very paradoxical activity. It aims - at its best, I would add - at proving itself wrong and making itself superfluous. So, maybe, even his warning against using the moral code will prove to be superfluous, when, this time, we get it right and do not ignore the systemic presuppositions in social reality?

\section{Alarmism and the Truth Code}

A particular type of warning bothers us today. Alarmed by the beginning and end of the War against Iraq in 2003, which was justified by false warnings, we have become alert to false alarmism. Obviously, the real danger in this case was not the weapons Iraq was supposed to hold - which turned out not to exist - but rather the willingness of Western politicians to use plain lies in order to wage a war that served the interests of some, but further fueled a permanent crisis for the masses in the Middle East. Sure, Saddam was a dictator, and therefore the war did not only serve the economic interests of a limited group of Western players. It also released some people from Saddam's hold. The cost, however, was high. Once again, the American experience with Germany in 1945 could not be repeated. The time when there was one rogue state which had to be brought down in a tough war, undergo a regime change under the friendly 
supervision of the victorious powers, and then slowly be turned into a loyal ally, if ever this was a proper description, seemed to be over.

When these days the tensions between the US and Iran are growing, we are alarmed, but are less sure concerning the identity of the aggressor. Could it not again be a fraud made up to intensify the dire situation and to begin a war at last? Have we not been watching for quite a long time now the growing influence of people who cannot wait to give up on democracy under the pretense of strengthening the Western position in the rude worldwide power game?

In fact, there are many warnings in Western society which are definitely not used in order to become superfluous. If fraudulent warners suggest that, e.g., liberal laws concerning homosexual marriage will lead to a decline of culture and social bonding in general, we get the message. Instead of being irritated by the things the warners want us to be cautious against, we would rather think: these warnings are set up in order to justify an ongoing oppression of sexual diversity. If a government suggests that a foreign government has weapons of mass destruction with which "they" want to dominate and destroy "us" - we immediately think of 2003. So, in these cases, we will most probably become alerted in another direction: we will carefully watch how far they are willing to go in order to achieve what we consider "a false alarm."

On the other hand: if many of us warn that global warming will come with disastrous consequences for the entire globe - we certainly hope to change the minds of many people. We want to see it be taken seriously. Only then can we hope to prevent the bad vision we paint from becoming reality.

In general, when talking about "alarmism," we speak about warnings that are intentionally used as instruments to misguide people and 
peoples in order to direct their attitudes by creating an atmosphere of permanent threat. But how are we to discern between one or the other use of warning? Could it not be that the $\mathrm{CO}_{2}$ panic only serves the purpose of the producers of technology for electric cars? Could it not be that another country really intends to dominate us? How could we, using the truth code, achieve a status of fact knowledge that would render us resilient against false warnings?

Luhmann is right in insisting upon science to be founded on the truth code. Yet how we decide to act after having the facts straight to the best of our knowledge in the respective situation will still and always remain a question of the moral code, irreducible to any question of the truth code.

\section{The Paradox of Science-Based Societies}

In the systematic frame of the truth code it can be stated: as a species, homo sapiens shares the twofold activity of warning with other beings. Some soft and vulnerable creatures by their very nature strangely indicate that they have much more powers than they really have. Birds actively try to allure predators away from their nests by making much noise about alleged dangers elsewhere. In other situations, they warn each other by similar noises against real dangers. However, the moveable systemic order of rules, which Luhmann's system theory only transferred from the realm of biology into the realm of sociology, seems to be analyzable by the human mind alone. Yet, up to now, nobody can clearly state how far the mind can really transcend its own limits and look at its presuppositions from outside. One attempt to cross the line, however, has been, from ancient times until today, the human habit of sacrificing. In sacrificing the person or group who does it, seem to prove stronger than the alleged instinctive coercion to 
survive or to breed offspring. In sacrifice the human being kills her/his darlings - for the sake of an alleged greater goal.

The story of science is, in one respect, a story of enlightenment against useless and superstitious sacrifices. On the other hand, the history of science itself is being told as a story of sacrifices: Scientists sacrifice greatly in order to gain better knowledge and better conditions of life. The enlightened mind will question the tradition of sacrificing a newborn child in order to make a new house last and invent something more practical instead. But almost every progress in rationalization of this or another kind was punished by society in the beginning - by victimizing the respective pioneers into sacrificing much too much, even life itself.

The earliest protesters against superstitious sacrificing were at the same time the earliest representatives of "global warning": the prophets. For some decades now, they have been acknowledged as predecessors of enlightenment. ${ }^{3}$ Looked at from a sociological perspective, they are representatives of the recurring pattern that to each and every established ruler of any society, there has always been an intellectual counterpower. In prophetic traditions, we can often observe a very smart and realistic analysis of circumstances. Far from being mere magicians and believers in wonders or pretenders to supernatural knowledge, they combined sharp moral judgement with clear-sighted estimations of probable developments and the good intention of warning before it is too late (warning in order to prevent the thing warned against from happening). Whether the mystified Cassandra in Greece or the equally mystified Biblical prophets - a strong combination of historical, political, and moral wisdom characterizes the reported figures and the texts ascribed to them. To replace a flattering and superstitious worldview by more realistic 
views, however, is in itself a moral demand in the first place. We are not regularly aware of this fact.

In our times, we usually think that our striving for an always better knowledge of nature, including our own nature, is only threatened by religiously motivated reactionary forces. But there are also intrinsic dangers, as to which Nobel Prize winner in physic, Robert B. Laughlin, warns us in The Crime of Reason and the Closing of the Scientific Mind. Discussing cases of forbidden knowledge from antiquity until today, Laughlin concludes: despite what we might think, the times of forbidden knowledge do not lie only in the far past nor in the remote societies of religious reaction. Beginning with Socrates, whose descriptions of matters of nature and society were feared to be dangerous for the state (with the well-known consequences for the philosopher), Laughlin informs us about many similar cases of knowledge that is considered dangerous in the modern Western world: the clearest case is that of the Princetonian John Phillips, a smart student who in 1977 just for the sake of it, with no more help than publicly accessible information and his own smart brain, found out how to build a little atomic bomb and stored a model of it in his own college room. He presented his studies as a qualification-work, and, of course, shocked the public and the national security agencies. ${ }^{4}$

This case exposes the fundamental paradox of democratic societies that consider themselves to be founded on the "truth code" rather than on the "moral code," claiming, for instance, that you would not want to enter an airplane constructed by people who qualify as true believers in the right values but by engineers who are experts in their field (Laughlin, 74). These will, of course, appreciate students like Phillips very much. As Laughlin states, universities are erected especially to produce people like this guy with a strong intrinsic motivation to find 
out the truth of this or that matter. On the other hand, when it comes to real dangerous knowledge, we would rather prevent a broader public from achieving it. ${ }^{5}$ On the one hand, society depends for all its developing capacities on the freedom of knowledge - one of the fundamental achievements of all the complex institutions in democracy that have no small part in bringing the technological superiority of the Western world. On the other hand, the more danger there is for knowledge to get into the wrong hands, being stolen by spies of authoritarian regimes and given away by individuals who find some reason (good or bad) to act as traitors of state secrets - the more alarmed societies might tend to say: just forbid to even think about it. ${ }^{6}$ What follows from this is the devastating question: has the scientific mind been its own undoing?

\section{An Additional Problem}

The truism that scientific progress is no guarantee at all for moral progress does not begin nor end with the most advanced scientific achievements. A recent case in Germany demonstrates how even comparatively simple jobs like that of a nurse in a hospital would have to be overseen at an unmanageable level in order to definitely prevent deadly abuse: No hospital can function without nurses knowing how to dose and distribute all kinds of medications. But any crazy or just immoral individual can use this comparatively simple knowledge for mass murder. Hence, warning (and with it the transmission of knowledge) is needed. This is not only true concerning the administration of medication, it can even apply to psychology: you can use it in order to try and help people whose souls suffer, but you can also use it in order to break people, as often happens in different contexts: sectarian religious communities, investigations done by

police or secret services. Even if institutions install all sorts of 
precautions to make sure their knowledge is used for the benefit of those who trust them - they cannot guarantee that there is no abusive subject among their staff.

Democracies are supposed to handle this problem by education. We are supposed to trust people who have gained a certain kind of education - and people in responsible positions are supposed to act trustworthy. In order to prevent untrustworthy people from gaining access to power and sensible knowledge, we try to find ever new reliable criteria for reasonable warning. As the reliability of persons is supposed to be rooted in their minds and souls, it is only natural that in enlightened societies scientific psychology is expected to help our judgement.

However, in addition to its principle abusability, which it shares with other sciences, psychology has one weakness which is at the same time the strength of all democratic development: the autonomy and the essential unpredictability of the human mind. In a way, this problem sheds a bright light on the scientific problem in knowledgebased societies: the theoretically unlimited progress of knowledge is confronted with the very existence of the ethical, the moral code, in the foundations and ultimate desires of the human mind. Up to this day, the most advanced psychological prognostics concerning one allegedly "paranoid" individual is degraded to the status of astrological prognostics if it turns out that the respective person is in fact persecuted by hideous actors. Not every conspiration theory is pathological, nor is real persecution a guarantee that a person has not become paranoid. In democratic and authoritarian states alike, secret services work on the basis of conspirations, and investigators work on the basis of conspiration theories in order to find out who has done what in a given criminal case. In every judgement about your own or some other's state of mind there is, therefore, a moral and emotional 
element that cannot be ruled out, even if you translate your judgement into an algorithm.

Of course, a well applied psychological theory can help to release people suffering from anxieties that have no foundation in reality etc. But what can it do regarding the problem of warning? In the best case, the ideal case in an ideal world, it could help "us" - all those in society who need to discern rational from alarmistic or crazy warning - to form a sober judgement concerning the question "who's speaking"! Under this assumption many people these days wish that their psychological polemics against the present POTUS (Donald Trump) and his state of mind might finally be accepted as "psychological facts." But would that be good? Let us check the other side, an alleged worst case to most of us: Greta Thunberg warns against some things that are considered to be a real danger by the overwhelming majority of scientists. But because she herself is being warned against as psychologically unreliable, would we ignore the warning and lock her up instead?

People who warned against real dangers, but failed, have suffered similar fates throughout human history. When their warning failed and the events that they had warned against occurred - the warners, who suffered serious losses during their lifetime, become elevated in hindsight as prophets. Had the warning been successful, however, and hence the threatening mischief prevented, as it well might have been in many cases - would this have led to a sense of gratitude towards the warner? To the contrary: the successful warner who against all probability made society change its ways and became a leading figure for a critical amount of time - is not only superfluous after the success: He or she is often supposed to be dangerous by those who earn benefit from the fruits of the success. ${ }^{7}$ Why so? 
A person who has been able to change the minds of many, for reasons that are not entirely understandable by these very people, might be able to change their minds again. And this is something we do not like if things go well. Hence people warn others from the (maybe dangerous) warner who had once helped them out of danger.

Wilhelm Reich, a critical psychoanalyst - whose theories other psychoanalysts warned were dangerous - himself warned that we should not believe too much in psychoanalysis. He claimed that concerning the accuracy of their social observations and emotional truth, the judgement of "schizoid" outsiders like Ibsen and Nietzsche was felt to be superior to that of the "homo normalis" by everyone. ${ }^{8}$ Yet only democratic societies, with their fundamental interest in freedom of opinion, freedom of information and freedom of the press, limit in principle (though regrettably not in every single case) the consequences for the individual holding deviant opinions and/or leading a life that does not look mainstream - as long as no law is transgressed and no other citizen of the same society harmed.

\section{New Dangers, New Warnings, New Dangers of Warning}

Staying with Nietzsche for a minute, we may quickly introduce the phenomenon of self-fulfilling prophecy.

Den Verwegnen

hüte Dich zu warnen!

Um der Warnung willen

läuft er in jeden Abgrund noch. ${ }^{9}$

Although addressing only the adventurous one, Nietzsche takes into overt consideration the effects that warning as such may have. The phenomenon of the self-fulfilling prophecy, a warning that perhaps wants to prevent the things it warns against but in actual reality 
leads to the very events it warns against, was first introduced into economic theory by Otto Neurath in 1911, and into sociology, with a full-fledged theory, by Robert King Merton in 1948. The basic definition goes: "The self-fulfilling prophecy is, in the beginning, a false definition of the situation evoking a new behavior which makes the original false conception come true. This specious validity of the self-fulfilling prophecy perpetuates a reign of error. For the prophet will cite the actual course of events as proof that he was right from the very beginning." 10 Psychology has put it to the test through many experiments, of which certainly one of the most interesting is the Robert Rosenthal experiment in school. It has also been tested in medicine under the name of "placebo-effect." But what do we make of it when warning is at stake? Are we to withhold warning from a real danger in order not to bring it about? Is the very fact that everybody talks about the shrinking of social democratic parties a factor in the real decline of these parties? Is the very warning we spread because of the rise of fascist movements helping them in their march?

The question is no less difficult than the one concerning dangerous knowledge. As long as we cannot control all effects of warning on the individual or the collective mind - and who would even wish to be able to do so? - there will always remain a conflict between the responsibility to warn others from real dangers and the possibility that this very warning might lead to the effect it is meant to prevent. This problem, which seems to have already been known by the authors of classical myth and tragedy, might stay with us, whether rumors of all kinds spread by hearsay or by the internet.

\section{Conclusion}

When Niklas Luhmann wants ethics to warn against morals, he himself argues in an ethical or even moral way: he says, "ethics 
should." And as brilliantly smart as he undoubtedly was, even Luhmann could not escape the tricky construction of our human mind, in which you can never think entirely inside the binary system of description or prescription. His concept of the analytical task of science caused him to demand that ethics should position itself also in relation to the system of the "truth-code." Whereas all sorts of ethical considerations usually already work with insights they claim to have gained by this very code: In the debate on climate change no warning will ever be uttered or accepted without recourse to scientific knowledge; on the other hand, no scientific program will ever gain financial support without describing its possible outcomes in terms of what is morally "good or bad."

As to an ethics of warning, it should be stated: If we knew (in the realm of true and false) whether a warning was intended to make itself superfluous, we could easily judge what to make of it. But often we cannot know. What we can know, however, is how to relate to warnings of uncertain origin and intention, and how to act ourselves as potential warners:

1. Do not bear false witness. This is still a good moral principle and translates into: do not launch false warnings.

2. Do not believe false warnings. Do not panic. Trust your own judgement and keep yourself informed.

Warning: This is not a new ethics of warning. It is only an attempt to pose the problem.

\section{Notes}

\footnotetext{
${ }^{1}$ Niklas Luhmann, Paradigm Lost: Über die ethische Reflexion der Moral (Frankfurt a. M.: Suhrkamp 1990), 41. He claims that ethical thought comes in waves and provokes reactions on a regular base: "Die nächste Welle kommt pünktlich. Zu Beginn der 80er Jahre füllen nach langer Abstinenz plötzlich wieder Ethikvorlesungen die Vorlesungsverzeichnisse der Universitäten. Der Neukantianismus nimmt sich auch
} 
dieser ,praktischen“ Fragen an, nicht ohne heftige Immunreaktionen im Stile Nietzsches auszulösen” (15f).

2 "Wenn Ethik eine Reflexionstheorie der Moral sein soll ..., muss sie sich selbst an den Code der Moral binden... Von einer Ethik sollte man aber verlangen können, dass sie die Strukturen des Gesellschaftssystems mitreflektiert, wenn sie der Moral ein Gütezeugnis oder auch nur eine Unbedenklichkeitsbescheinigung ausstellt.... Angesichts dieser Sachlage ist es vielleicht die vordringlichste Aufgabe der Ethik, vor Moral zu warnen.” (Luhmann, Paradigm Lost, 37-41).

${ }^{3}$ Still one of the most important essays to this subject: Albrecht Dihle, "Aufklärung in der Antike?," in Die Vernunft und ihr Gott, ed. Enno Rudolph (Stuttgart: Klett-Cotta 1992), 13-32.

${ }^{4}$ Robert B. Laughlin, Das Verbrechen der Vernunft. Betrug an der Wissensgesellschaft. Aus dem Englischen von Michael Bischoff (Frankfurt a. Main: Suhrkamp 2008), 72ff.

${ }^{5}$ Nuclear power is almost romantic compared to easily accessible biological knowledge. When I was writing this paper, German police, following a hint from American secret services, just uncovered the plan of a Germany-based couple connected with ISIS, to cause a major catastrophe by using a special derivate of Rizinus for the production of dangerous pollution in the underground. In this case, close observation and timely warning prevented the intended act of terror.

${ }^{6}$ One remarkable topos in Laughlin's argument is Gresham's Law, according to which "junk-knowledge" always wins over real knowledge. Cf. Laughlin, Verbrechen, 120.

${ }^{7}$ A hint at the story of Joan of Arc, to name but one famous instance, which does not 1:1 fit in, might do here as an illustration.

${ }^{8}$ Wilhelm Reich, Charakteranalyse (Frankfurt a. M.: Fischer 1973) (Kapitel übersetzt von Karl H. Bönner), 401.

${ }^{9}$ Friedrich Nietzsche, Bruchstücke zu den Dionysos-Dithyramben 70.

${ }^{10}$ Robert K. Merton, “The Self-fulfilling Prophecy,” The Antioch Review, Jg. 8 (1948): S. 193-210. 
Workshop 13:

Subjectivism and Globalism: The Metaphysical Self in the PostTruth Era between Now and Tomorrow

Chair: Theodor Damian 
Relativism: The Erosion of Objectivity. The Truth is in the "Eye" of the Beholder

Theodor Damian

Metropolitan College of New York, USA

\section{Preliminaries in Identity}

The issue of identity has an ontological character. That is why it cannot be uprooted. When problems arise in relation to identity in one's life, often that is classified as a mental illness, such as schizophrenia. Personal identity is, generally speaking, based on kinship by blood and culture, shared history, sense of belonging and language.

Language is particularly important for identity because it shapes one's conscience and it builds the sense of belonging and thus it builds loyalty to a group, a community, or a nation. What Karl Deutsch says about community can be applied to the nation as well. A community, he writes, is "a socially standardized system of symbols which is a language" that allows for "an integrated pattern or configuration of communicating, remembering and acting." 1

When we communicate, in conscious and unconscious ways, we communicate who we are, which is like making ourselves accessible to others, or even more, like giving ourselves to others, and this is a synergetic work, divine and human, because we give what we have received from God. Speaking about the ontological dimension of our identity, writer Patricia Snow explains that "God alone has the power to confer identity and individuality on human beings." ${ }^{2}$ So, when, in communication, we give, we give from what we have received from God. 
If the personal identity is a gift, so is the cultural and national identity. One cannot be asked to give it away.

When Jonah Goldberg writes that our mission today is to forget about cultural identity and to promote diversity, ${ }^{3}$ he ignores the ontological character of identity, as culture and identity are fundamental existential features, and confuses diversity of identities with diversity as a mixture of elements with no given shape and character. He also opposes identity to diversity as if there could not be distinct individuality within diversity.

\section{Nation and Nationalism}

A nation is based on the "unity of kinship, language and traditions, on the sense of mutual belonging and belonging to a group, a feeling that is strengthened by the duration and durability of the respective group or kin on the same territory."

As columnist Max Fisher heard in his travels across Europe last year, in the context of the consolidation of the political right in many places, identity is the foundation of a group's unity; and national identity, in particular, which is often associated with hard-won national sovereignty, which is based on a strong natural human desire to belong, to feel safe, cannot be easily transcended, as it is rooted in popular culture and built into the international order, ${ }^{5}$ and more than anything else, in people's conscience.

Nationalism is like patriotism then: a strong attachment, a special love for the group that one is part of, with its values, history and other characteristics.

Personal and national identity is cultivated and developed through knowledge of one's family tree, history, experiences; this education begins at home and lasts for one's entire life. Knowing one's history 
and the history of one's country is as imperative as knowing of any other school subject such as math and grammar for any educated person.

Nationalism also implies that one assumes the past. Yet one cannot assume it only in its possible negative aspects, but also in its positive features and accomplishments that make one proud to belong to it. Nationalism being related to identity and identity to values that often are understood as sacrosanct, such as religion, ancestors, tradition, fatherland or motherland, is considered a value in itself, a source of pride and dignity. This type of understanding is clearly different from chauvinistic nationalism that implies discrimination against other groups or nations.

As celebrated Father Constantin Galeriu from Romania said, "Just the way a human being accumulates in his memory a certain life experience based on which he shapes his personality, so are the nations rooted in their own tradition which is reflected in their specific characteristics at personal and community levels."6 Explaining that nations are part of the divine order and not simply the result of human making, Fr. Galeriu insists that "there is no pure, unconditional humanity; there is only humanity incorporated in nations" (ibid.).

Consequently, to be part of a nation and then to love it, is just a normal and natural thing. Yet that is not how everybody thinks. In his article "How Liberals Can Reclaim Nationalism," in The New York Times, Yasha Mounk asserts that "there is nothing natural about the idea of a nation. Its modern form took shape as a result of deliberate political choices and the construction of elaborate myths." 7 Two things must be observed here: first, nationalism, in particular when it is criticized, does not refer to modern history, when empires fell and 
nations emerged gaining sovereignty. The love of one's group, tribe, nation, is much older than the time when the term "nation" came to designate groups and tribes. Second, national cultures that give us specific identities can be seen as obstacles only when one wants to invade and conquer them, and today that can be done not with arms and armies like in the past but in many more subtle, powerful, sophisticated and dangerous ways. Therefore, nationalism, inasmuch as it does not degenerate into chauvinism, should be viewed as a virtue, not as a vice, because, as Gilbert Meilaender and Peter Meilaender write, national cultures "are the very fabric out of which we construct meaningful lives."

One can ask the question: what is wrong with tendencies to love and maintain national identity even in situations where alongside a majority live minority groups? Should one stop loving one's country because of minority groups that co-habit there peacefully? Would it be right for white minorities in typically black nations in Africa, for instance, to try to change their culture and values? The colonists did just that in the sixteenth century in Latin America and elsewhere, and that was a tragedy! In other words, the minorities should not dictate what values a majority has to adopt as long as the majority allows the minority to live by its own values.

How polarized the world has become about the issue of nationalism is evident in statements by leading personalities of leading nations in our time, such as President Emmanuel Macron of France and President Donald Trump of the United States. According to Macron "patriotism is the exact opposite of nationalism; nationalism, which implies care for ourselves first, for our interest, is a betrayal of patriotism,"9 thus implying that patriotism is care and love of others first. This seems ironic since by "others" the French President certainly means foreigners, in the context of the current migration of 
foreigners to Europe. And exactly opposite to his assumption, patriotism, meaning love of the father, one's fatherland, one's ancestors, is what Macron seems to understand by nationalism.

The identification between nationalism and patriotism was emphatically stated by U.S. President Donald Trump: "You know what I am? I am a nationalist, ok? I am a nationalist. Nationalist. Use that word. Use that word! A total nationalist in the true sense. I am somebody who loves our country," he exclaimed at a political rally in Houston, Texas. ${ }^{10}$ President Trump's emphatic declaration does come in the context where the love of one's country and nation is considered by many masters of suspicion as an infraction, and soon, the promoters of a certain type of globalism will be asking for it to be punished.

This type of manipulation of the meaning of the two terms, nationalism and patriotism, as writer Daniel Corbu notes, represents an attempt to reverse established values, to create and promote a programmatic confusion, a dangerous attack on the fundamental value of identity. ${ }^{11}$

Europe, for one, should become a union of nations, a unity in diversity; it "should not be denationalized," as "the degradation of traditional values and the suppression of patriotism" represent a serious threat, according to Tomio Okamura. ${ }^{12}$

It is the cultivation of an awareness of the irreducibility of the human spirit, of freedom and of values that gives a person and a nation dignity and power.

\section{Borders and Identity}

Cultural diversity needs to be seen as a blessing, not as a threat. Yet it implies borders, first in people's minds, as diversity implies identity, 
and second, as geographical borders. When Patricia Snow writes that we live in a world of "porous boundaries and blended identities"13 that does not mean one can generalize. Yes, porous boundaries in some places, and more rigid boundaries in others. We still do not travel the world visa-free. And the expression "blended identities" should be taken in the relative sense. First of all, what is a blended identity? One being a Russian-American? St. Paul was a Roman Jew. Cosmopolitanism is not a modern invention. We need only think of Athens, Ephesus, Jerusalem. In their article "Fences and neighbors," Gilbert and Peter Meilaender provide a strong theological analysis of the issue of borders and nations. Citing the examples of nations and borders existing in the Old Testament based on God's will and order, and of St. Paul's speech at the Areopagus in Athens (Acts 17), the authors argue that in order to be good citizens of the world, we need to learn to be good citizens in our smaller worlds which are our nations. They write: "We would do an injustice to our humanity if we had no sense of special obligation to those closely connected to us by nature and history." 14 And what is more difficult to observe is that "even the most important fences serve, in the providence of God, not as barriers to shared life, but as invitations" (24).

And invitations imply good neighborly relationships, mutual respect and good will. That is the basis of one being open to guests. But if one finds one's house invaded, occupied, and the owner will be forced to change his habits and lifestyle because of the uninvited stranger, that will not lead to peace.

Trying to argue against borders, political theorist Joseph Carens says that "borders have guards and the guards have guns" (22). Yes, that is true, yet that does not mean conflict unless one does not respect somebody else's territory, possessions, values, person, and community 
the way one wants to be respected by others: Respect makes guns unnecessary.

Jonah Goldberg asserts that we live in a borderless world already and what we need to do is not to defend old country borders, but the borders of civility and human rights. ${ }^{15}$ Goldberg is wrong first of all because of his generalizations. We do not live in a borderless world. Unless he means communication through satellites. But not even then. This assumption is just rhetorical in order to say that we need to watch other types of borders, like shifting attention from what happens at the traditional geographical borders of our world to something else, like 'don't mind about invasions; 'think of civility'. Yet, watching our geographical borders does not impede actions to improve civility and human rights in the world, regardless of the type of borders.

In what he says it is evident that Goldberg refers to the waves of migration to Europe of people from Middle Eastern and African countries, migration that is often defined on the basis of human rights. Yet human rights have to be applied to the local population as well, to those who want or do not want the migrants. Uprooting the newcomers from their cultures will not help them integrate in the new systems and a sense of "injustice" and of marginalization on their part would be in many ways inevitable. The Yellow Vests movement in France is a telling example.

Maybe the countries that are the destinations of these migrants can do something together like creating safe havens in areas where migrants are coming from or improving the political and economic conditions in those countries.

Goldberg suggests that one can leave the door of one's family house open for anybody to come in and take things as needed for as long as 
the owner is concerned with militating for civility and human rights. Nobody will do that, not even he who advises it. Yet, there is a paradox and an irony about those who preach globalization in the sense in which Goldberg does. R. R. Reno describes it: "Thought needs to be given to the ways in which globalism disenfranchises ordinary people and empowers the technocratic elite. It's an interesting paradox that the most ardent supporters of a 'borderless world' live in gated communities, don't mingle with others on public transportation, and channel their children toward a narrow set of elite educational institutions."16

\section{The Post-truth Era}

We have never lived in a more confusing and distorted world order than the current one where to lie is ordered and rewarded, where blatant individualistic behavior is becoming a virtue, and where fake news are constantly invading our brains.

William Davis calls this type of world and time the "post-truth" era. It is actually where the world order is the world disorder. ${ }^{17}$ The time when the absolute values used to cohabitate in harmony with the relative values, when the moral absolutes represented a last resort in decision making, standard of conduct or relational and existential dilemmas, is gone. What we witness today is the relativization of the absolute or the absolutization of the relative.

The relativization of absolute values is described by David Brooks in the following terms in an article about the cultivation of lies: "You have to find your own truth. This is the privatization of meaning. It's not up to the schools to teach a coherent set of moral values or a society. Everybody chooses his or her values. Come up with your own answers to the life's ultimate questions." 18 This is what in fact leads to 
moral confusion and to losing the sense of purpose and direction in life.

In fact, the moral absolutes that build character, strength, and a clear sense of purpose come from "values that are created and passed down by strong, self-confident communities and institutions. People absorb their values by submitting to communities and institutions and taking part in the conversations that take place within them" (ibid.).

But that seems to be history now. And history, as an element that strengthens personal and national identity is dismissed by the new preachers of a certain type of globalism.

In his book Suicide of the West: How the Rebirth of Tribalism, Populism, Nationalism and Identity Politics Is Destroying American Democracy, Jonah Goldberg deplores the "decadence and dysfunction of today's public discourse" and prophesizes that we are "standing at the end of history." 19 Goldberg might be right that we stand at the end of history, but certainly not because of the personal and national identity issues. On the contrary, that might be due to the intention to suppress identity and plunge the world into an amorphous mass, through the manipulation of meaning, the normalization of lies, the globalization of disloyalty. As Steven A. Long recognizes, we live "in a time of widespread blindness toward the truth." 20

The reversal of the moral order of the world is evident, for example, in the fact that "once controversial issues like divorce, sexuality, moderate drug use and the evergreen mistake of cursing on a hot mic are no longer fatal for political careers. Character issues still pose a threat, yet Mr. Trump faced an array of them - from dishonesty and extramarital behavior to alleged abuse of women - and he won the presidency," writes Lisa Lerer, reporting that what used to be a disqualifier for a high public function seems not to count anymore. In 
fact, "refusing to admit any missteps may be the best path to rally support." The strategy used in the post-truth era works as follows: "Never apologize, always play offense, attack the 'fake news,' and finally distract from the issue by kick-starting a new controversy." 21 One recognizes Trump in this picture, and how confused the value system in America, but also in the world, has become.

\section{Conclusion}

In a permissive society, as Robert Bellah et al. in their book Habits of the Heart: Individualism and Commitment in American Life call our society, where everything is possible and is allowed, for as long as one knows how to lobby for a certain interest, and how to manipulate the system and, sometimes, people's minds, the relativization of values is not a surprise. Moral absolutes seem to be gone. This is how the confusion begins. And confusion is the appropriate context one needs to create in order to change the order, to reinterpret, or deliberately misinterpret concepts, notions, and definitions to advance one's interest. Objectivity has become a historical and theoretical notion. Like beauty, the truth is in the eye of the beholder, of the one who has the power and the means to manipulate in order to convince. This becomes a sort of bellum omnium contra omnes, the war of all against all, where those with fewer scruples will win.

What do we need in such a situation? We need to return to or reinvent moral structures, or, to use a stronger term, moral absolutes. 


\section{Notes}

${ }^{1}$ Quoted in Paul Stock, "Towards a Language of 'Europe': History, Rhetoric, Community,” The European Legacy 22, no. 5-6 (2017): 648.

${ }^{2}$ Patricia Snow, “Empathy Is Not Charity,” First Things 276 (2017): 45.

${ }^{3}$ See R. R. Reno, "You Better Like It," First Things 286 (2018): 49.

${ }^{4}$ Theodor Damian, "Nationalism and Patriotism in Eminescu" [in Romanian], Vatra Veche 124 (2019): 6.

${ }^{5}$ Max Fisher, "Borders, Nationalism and the Fight for a Unified Europe," The New York Times (July 7 , 2018), A7.

${ }^{6}$ See Răzvan Codrescu, "Nation and National Church" [in Romanian], Certitudinea II/26 (2018): 2.

${ }^{7}$ Yasha Mounk, "How Liberals Can Reclaim Nationalism," The New York Times, International edition, (March 5, 2018), 1.

${ }^{8}$ Gilbert Meilaender and Peter Meilaender, "Fences and Neighbors," First Things 285 (2018): 23.

${ }^{9}$ See Peter Baker, "Trump Bashes Macron and Defends Decision to Skip Cemetery Visit," The New York Times (November 14, 2018), A6.

${ }^{10}$ Peter Baker, “'You know what I am? I'm a nationalist'," The New York Times (October 24, 2018), A12-13.

${ }^{11}$ Daniel Corbu, "Romania 100 or on Globalism, Nationalism and National Identity" [in Romanian], Feedback XV/9-10 (2018): 2.

${ }^{12}$ See Philip J. Heijmans and Hana de Goeij, "Protests Greet Far Right Leaders," The New York Times (December 17, 2017), A4.

${ }^{13}$ Snow, "Empathy Is Not Charity," 44.

${ }^{14}$ Meilaender and Meilaender, "Fences and Neighbors," 21-22.

${ }^{15}$ Reno, "You Better Like It," 49.

${ }^{16}$ R. R. Reno, “Getting Augustine Wrong: Globalism vs. Nationalism,” First Things (2017): 6.

${ }^{17}$ William Davies, "The Age of the Post-truth Politics," The New York Times (August 24, 2016), opinion section.

${ }^{18}$ David Brooks, "Five Lies Our Culture Tells Us," The New York Times (April 16, 2019), A25.

${ }^{19}$ See Reno, "You Better Like It," 47.

${ }^{20}$ Steven A. Long, “Magisterial Irresponsibility,” First Things 286 (2018): 45.

${ }^{21}$ Lisa Lerer, "Do Character Issues Matter in the Age of Trump? Democrats Will Find Out," The New York Times (December 5, 2018), A20. 


\section{Against Immorality}

\section{Michael Manfé}

Department of Multimedia Art, University of Applied Sciences

Salzburg, Austria

Moral versus immoral - great cinema from the very beginning. We turned to one and wished death to the other. But as the proverb goes: Those who are dead live longer. Morality was mortal, while immorality seemed to be immortal. Speechless, we stopped talking about immorality, and over time we forgot the difference between immorality and morality. This is the starting point for reflection on the term immorality. To move confidently between morality and immorality and to experience their difference means to infiltrate a gap and thus, to experience the distinction between humanity and inhumanity. Why? To not dissolve in your own infirmity and to survive in the feeling described by Jacques Derrida: "One wants to live as much as possible, to save oneself, to persevere, and to cultivate all these things which, though infinitely greater and more powerful than oneself, nonetheless form a part of this little 'me' that they exceed on all sides. To ask me to renounce what formed me, what I've loved so much, what has been my law, is to ask me to die."1

Here, a basic problem arises: immorality has always shaped the human being. It seems as if immorality has become a constitutive element in the history of humankind. What if we love immorality? It requires a revolution to grasp this. Perhaps, as I once formulated, we either need a revolution of conscience ${ }^{2}$ or go even further and ask: do we have to face and immerse impuissance ${ }^{3}$ in order to emerge as human beings? Indeed, to become humane we must break the law. This does not imply we ignore the law. In Derrida's words, we need a 
"disobedience with regard to some legislative provision in the name of a better or higher law." "Such a law would show consideration for the complexity of the issues. Regarding our topic, it would bring the immoral behavior out of balance.

The moral foundation of power is visible, as Jacques Rancière wrote in The Ignorant Schoolmaster. ${ }^{5}$ But what is the moral basis of human beings? We are all outlawed, we are all criminals and murderers at the bottom of our hearts, writes Henry Miller. This, in fact, is to be recognized, and this is quite a moral basis of people: "It is not our business to get after the murderers, but to get after the murderer which exists in each and every one of us. And I mean by murder the supreme kind which consists in murdering the spirit." 6

An emancipated community is a community of narrators and translators. ${ }^{7}$ So, the idea is to talk about immorality, visualize it, and by doing so, make it mortal. But what words can we use to describe the immoral? Which form or which forms does it adopt? It often acts in disguise. Our goal is to pin down the immoral so that it is stabilized by the shackles of the language and thereby domesticate it. Maybe it retreats. But we do not yet know whether its withdrawal is desirable. What if the immoral needs to stay in the world? What if we have to admit that we need the immoral, like a piece of dry bread that completes the onion soup? But what does the peculiar term immorality capture, and how does it delimit itself to related words such as amoral? ${ }^{8}$ If someone is amoral, they override morality. However, they are to be held accountable for the fact that they are ignorant about morality or have never encountered it. Those who move beyond the moral concepts direct their behavior against the prevailing moral concepts and overrule the moral principles. Those people are (still) devoid of moral principles, and are considered to lack morality. An example would be infants. In brief, there is a lack of 
understanding of moral norms, and the sense of right or wrong of such norms is only moderate, sometimes barely noticeable. Amoral can also mean that someone is not affected by basic moral norms established in a law firm. For example, an amoral person may follow the patterns of the apolitic or asexual. There is a fine line between right and wrong, and in many cases it is impossible to distinguish between the two. Within the concept of immorality, this limit does not exist, because immorality is already behind the (moral) limit and thus assessable. In immorality, moral laws are deliberately rejected. The conscious or the knowledgeable action is added. People act immorally when they ignore traditional moral laws. Thus, immorality is an appearance. Immorality indicates that moral standards are not maintained. An immoral person agrees to actions that are contrary to the traditional moral norms of a society. If one wishes to summarize immorality it could be as follows: morally corrupted, extravagant, self-indulgent, stunted, dissolute, malicious, vicious, vile, sinful, wicked, without scruple, reprehensible. The amoralist fails, the immoralist deliberately misses. The immoralist literally walks over dead bodies, is ruthless to other people, and puts moral principles in the background. The immoralist lacks loving gestures. Needless to say, the measurement of the room is undesirable, because it might point the way to leave the enslavement of man.

Questions about immorality often provoke violent discussions. The immorality in humans seems to represent the shadows, whose existence is denied, because their connotations are not flattering. Is there even an act of pedagogy required to subdue the immoral in us and to overcome the principle of stultification? ${ }^{9}$ Jacques Rancière refers to the interrupted or non-occurring process of emancipation of the human individual and points out that what stupefies people is not the lack of instruction, but the belief in the inferiority of their 
intelligence. With regard to the distinction between morality, immorality, amorality, or the difference between good and evil, stultification seems widespread, but the retreat to possible inferiority is simply unacceptable.

No matter how uncomfortable and difficult it might be to consider immorality, no ethics should presume to exclude any part of human behavior. It can certainly be unbearable to look at the immoral, because it takes place in the background of people's knowledge. But it is an inherent part of the human being and requires our attention. Even if it overwhelms us, we still have to master it. At this point, I would like to invite you to take a closer look at the French philosopher Louis Althusser. The mentally ill Althusser killed his wife. What is interesting is not the act of murder but the way he was treated afterwards. By looking at those incidents, we might come closer to answering the question, why it is so important to confront ourselves with immoral behavior. We are not exempt from it.

Lebenstot, a word that Louis Althusser takes up in his wonderful text The Future Lasts Forever, ${ }^{10}$ is the starting point. From here I want to fathom the immoral. I still want to force it to emerge. Then, only if I cling firmly to it, preventing it from disappearing behind the corners, its path will cast a shadow that is long enough to be pursued: the immoral must be prevented from blurring the evidence. With Lebenstot, Althusser addresses the fact that a so-called mentally ill or a madman is considered to have a lifelong sickness. These people (Lebenstote) have to endure their fateful internment "forever." By this attitude, I refer to our silent approval, we welcome the pleasant coldness of public opinion, and we support a human disaster that we only experience when we are looking at ourselves. A life in isolation or in the silence of the asylum that cannot be left is deadly for people. These people cannot express themselves publicly, they are included in 
the balance of the disappeared, the so-called disparus (Michael Foucault). For those thus affected, this is a strange state of affairs, which also lasts a lifetime, because the Lebenstote remain in the state of the disappeared, they are neither dead nor alive, not yet buried, but without work, says Michel Foucault.

The public feel a dull fear towards the people who are called Lebenstote (the disparus), and this implies the shameful assumption of a lifelong guilt of disparus. But these people disappear just as much as criminals disappear by internment. Maybe they stay hidden for a while; however, their existence is not over yet, because they live on. But they exist limitlessly, because they can return - and then? The question could be avoided if there could be a definite end of existence to the disappeared (or criminals) - we know that in some places nowadays this is still possible. We also know that enough historical examples have been documented to prevent the existence of those disappeared.

But what does Louis Althusser condemn? The answer is not surprising. The French philosopher vehemently rejects the annulment of the legal personality of a Lebenstote and the concomitant refusal of any general public. The general public deprives the affected persons, and this robbery affects their humanity. At this point, we have to ask about present-day disappearances. We have to look (or search) for those whose legal personality we have annulled ourselves. This search refers to the old and the sick, the people born without a voice, the women, the slaves, those who are sent on the way to disappearance. At the moment, we live at a time characterized by an ecstasy of communication, but we have to accept that it is also characterized by an ecstasy of the disappeared.

Horrifying dramas remain unrecognized and dormant far below. Those who find words and can give shape to the idea of the 
unthinkable keep silent or whisper their explanations in the dark. It is a darkness that does not reveal words to the public and that triggers the impossibility of understanding or extends the spiral of incomprehension. Lifelong internment is not an option for a human life, because it offers no prospects, and thus alternatives must be worked out, especially since the number of the disappeared is daily increasing. There are various reasons for this, and it is impossible to draw up a complete list.

Louis Althusser wanted to air the oppressive gravestone that weighed on him. For Althusser, the procedure is the gravestone; public death and silence are the same, since he tried to dislodge the gravestone himself. At this point, we should remember why Althusser was called a Lebenstoter. He suffered from delusions. They struck him and often corresponded to reality. After he strangled his wife he was admitted to the psychiatric clinic Sainte-Anne. His student Étienne Balibar vividly summarized the events after the murder. He portrayed the conditions of the admission as normal, which meant above all one thing: legal conformity. In a complex process, first in the clinics, then outside, it was up to Althusser's students and friends and, of course, up to him to reflect on what had happened. Balibar says that the murder incident was not a mishap, accident, or coincidence. The psychiatrists in this case were, in his view, biased and developed theories that he himself could not believe, even though he knew they existed in the psychiatric textbooks. However, it is not contradictory for Balibar that the act did break something. Although Althusser had killed his wife, which is of course unacceptable, he retained the essential characteristics of his personality. By this Balibar meant that even after killing his wife, Althusser kept the same traits that had characterized him before, like those of a vital interlocutor or attentive listener. The same person produced himself more or less again. 
Balibar concludef that this man was still his friend, even after this terrible deed. He was still there, and they could continue doing things together, even think together. Althusser remained himself. The killing did not change him.

The general public saw this differently. The public opinion, influenced by a particular section of the press, was clear and did not distinguish between the acute but temporary phases of madness and the fateful mental illness. The madman is easily considered a mental patient, and to be mentally ill of course means to be ill for life. Consequently, it also means that this human being can be interned for a lifetime. Even two years after his release from psychiatric custody, Althusser remained a disappeared person for the public, who knew his name. Since the case was closed, he could not rehabilitate himself (as far as this is possible after such an act). Even if the abatement of action helped, Althusser considered it doubtful, because under this gravestone of the abatement, of silence, and of public death, he was forced to survive and to learn to live again. Althusser aired his gravestone himself. How? By writing down his story.

But now it is up to us to lift the stones from the mass graves. Without naming the immoral, however, we will not succeed. We must also understand that people have fallen into a lie and, according to the French Nobel Prize winner André Gide, they prefer the pleasant to the true. We are called upon to shake our bourgeois existence, perhaps even bring it to collapse, to mature as human beings, or in other words, to become living troublemakers. Living means, in this sense, to fathom the truth, to escape the lie. If the attainment of the utopian goal of freedom is suspected behind it, the better it is. The thesis that immorality makes freedom impossible is worthy of discussion, but I write for the confirmation of this thesis and to deconstruct the immoral. Of course, we can free ourselves from immorality. The 
question we face confronts us with the space of experience of freedom. Can we preserve the state of freedom once we have experienced it? André Gide, who was brought up in a strict puritanical manner and who wholeheartedly supported the individual's freedom from the church, conventions, and morality, demands our attention. If we follow his thoughts in The Immoralist, the door to the immoral opens up, and we find ourselves trapped in the interplay between immorality and morality, between freedom and bondage, between life and death. It seems as if we have to become poets. ${ }^{11}$ For Gide, the poet does not get excited about the gruesome extent of death. The poet confidently transforms everything in long stringy wool by his very own sense of touch. Poets will, in this sense, constantly grope and intervene to give a contour to the living world. They will dive into the depths of the soul in order to be richly loaded or to reappear with a spark of clarity. Poets name the necessary change or rigorously take matters into their own hands in order to experience the mismatches as mismatches - to achieve what the literate René Char calls future. He writes that for every collapse of the evidence, the poet responds with a volley of future.

André Gide wrote against the massification of people. The great convulsions that brought cultural change are, at first sight, the result of significant historical events. An attentive investigation of these events, however, reveals that the true cause is a profound change in people's views. And at this point, André Gide's thoughts about immorality become clearer: a dictatorial world order does not necessarily need a dictator.

Maybe now it becomes clearer. I am trying to pick up the immoral, where it deprives individuals of their uniqueness, and the incorporation of literary texts also involves the desire to sketch a clearer image. The sound and clarity of the bestial at the center of our 
world might be considered untouchable. But if they are untouchable, we should at least enclose them with idioms, as did the Emmurés, the walled-in, seeking the nearness to God, embedded in a ring of rocks to prevent any escape and entry. Inside these walls, the immoral are left on their own with no masses to help them. Only speech is able to overcome the wall, and when the wall increases, the hurdle between morality and immorality gains volume. This volume leaves immorality in its own prison and keeps the rest of the world from being dead. We should not forget that being dead has populated everyday life.

In his essay About the Fatigue, Austrian writer Peter Handke speaks of the fatigue of satiety. ${ }^{12}$ It makes sensory experiences impossible: satiety makes you numb. Handke observed this fatigue among citizens (today we would probably say among those considered elites). At present, the fatigue of satiety seems to dominate a big part of the world. Within its protection, the immoral can settle unhindered. In the other part of this world, the projection of a world without fatigue dominates. It is the projection of a vanishing point, and it is veiled so that when this place of longing is actually reached, the projection breaks down into its elements, and the time of tiredness also occupies these people. And the era of satiety? It remains an illusion, and the fleetingness of the endless looping of projections feeds the belief in one utopia: a life without fatigue in a better place.

The immoral will disappear if we love much more than we are loved, if we stop being voyeurs of suffering without taking any part, and if we name the great shame of the earth and end the enjoyment of the immoral. People are not bad, but people act immorally, and that is indeed bad. Immoral action is not only bad but is also a real threat to all coexistence. When people go into voluntary exile, when they retire, and turn their backs on the environment, the amoral keeps an open door, because it conceals the awareness of wrongdoing. Immoral 
actions close the door, and to open it again becomes very difficult, because being immoral always means that these people have knowledge about their actions. We have allowed the violence of the social world to overpower us in the same way that it overwhelmed our fathers, mothers, grandfathers, grandmothers, and many more. It is time to drive the laughter out of the immoral and face the truth - as the poets tried to do.

\section{Notes}

\footnotetext{
${ }^{1}$ Jacques Derrida, Learning to Live Finally: The Last Interview (New York: Melville House, 2007), 2930 .

${ }^{2}$ Michael Manfé, Revolutionen des Gewissens (Hamburg: Avinus, 2015).

${ }^{3}$ Michael Manfé, Ohnmacht (Hamburg: Avinus, 2016).

${ }^{4}$ Derrida, Learning to Live Finally, 43.

${ }^{5}$ Jacques Rancière, The Ignorant Schoolmaster: Five Lessons in Intellectual Emancipation (Redwood City, CA: Stanford University Press, 1991), 37.

${ }^{6}$ Henry Miller, Stand Still Like the Hummingbird (New York: New Directions, 1962), 87.

${ }^{7}$ Jacques Rancière, The Emancipated Spectator (New York: Verso, 2011), 33.

${ }^{8}$ Michael Manfé, Das Immoralische (Hamburg: Avinus, 2017).

${ }^{9}$ Rancière, The Ignorant Schoolmaster.

${ }^{10}$ Louis Althusser, The Future Lasts Forever: A Memoir (New York: The New Press, 1995).

${ }^{11}$ André Gide, The Immoralist (London: Penguin Classics, 2000).

${ }^{12}$ Peter Handke, Versuch über die Müdigkeit (Frankfurt am Main: Suhrkamp, 1992).
} 


\section{La identidad nacional rumana en la poesía de Mihai Eminescu}

Anca Sîrghie

Alma Mater University, Sibiu, Romania

Motto: "La Patria es el fruto de decenas de generaciones y pertenece a otras decenas de generaciones venideras..."

- Mihai Eminescu

Tal como está situado, en la frontera del Este de Europa donde fue "custodiado" por los grandes imperios en una dramática evolución a través del tiempo, el pueblo rumano, en el siglo XIX, llamado el siglo de la constitución de las naciones, tuvo la oportunidad de empezar el proceso de unificación de las provincias en las que la historia lo había dividido sin cesar. Sin caer en la trampa de las opiniones subjetivas y míticas, empecé esta investigación desde la hipótesis según la cual el poeta Mihai Eminescu, que murió hace 130 años, formó su propia convicción sobre la identidad y la unidad del pueblo rumano durante sus peregrinaciones por las provincias de Rumania, a partir de la "dulce" Bucovina y la rica Moldavia' y su "tercera hermana," Besarabia, y recorriendo la Transilvania y el Banat antes de establecerse por un período en Valaquia, la "pequeña” Rumania; esta convicción está reflejada no sólo en el conjunto de sus artículos de prensa, sino también en sus poemas, ya desde sus primeras poesías. Eminescu, como habitante de Bucovina, vivió en carne propia la inclusión de Transilvania en el Imperio Austro-Húngaro en 1867, luego el momento del sacudir el yugo otomano por parte de Rumanía, en la Guerra de Independencia de 1877-1878, y no cesó de hacer campaña para una Rumanía Grande que recordara la Dacia de los antepasados. Vamos a contradecir la idea de que Eminescu haya sido un romántico soñador, encerrado en una torre de marfil para meditar 
sobre el porqué de la existencia, porque de hecho, era un poeta con hondos sentimientos patrióticos, con una importante actitud cívica que siempre acompañó al periodista comprometido políticamente que trataba los álgidos problemas de su pueblo.

\section{I. ¿Qué sentido le daba el poeta a la palabra "Rumanía"?}

Hemos meditado sobre el sentido del nombre de su pueblo, RUMANO, en la concepción de Eminescu y, de allí, sobre el nombre de RUMANÍA en aquellos tiempos en que esos conceptos eran atestiguados, pero de manera no oficial, aunque se habían usado anteriormente. ${ }^{2}$ Se sabe que a iniciativas del príncipe Al. I. Cuza, en la primera Asamblea general después de la Unión, se dio el nombre de "Rumanía" a los dos países unificados, lo que aparece en el primer artículo de la Constitución del 1 de julio de $1866 .^{3}$

Sin ambargo, Eminescu confería un significado mucho más amplio a la palabra "Rumanía" en su poema Qué deseo yo para ti, dulce Rumanía, concebido justamente en aquel momento histórico; vamos a ver cómo define él su país: ¿Qué deseo yo para ti, dulce Rumaníal Mi país de gloria, mi país de añoranza? En efecto, este país tan soñado por los rumanos abarcaba también las provincias robadas en aquel momento, en la segunda mitad del siglo XIX. Sin duda que el adolescente genial no hace referencia solamente a los dos Principados rumanos, Moldavia y Valaquia, porque en el poema, él reflexiona en la suerte de su pueblo por entero. Al escribir los versos Que diga al mundo entero la bandera tricolor/ Que diga qué es el pueblo grande, el rumano, el poeta está creando una visión orgánica, amplia, que se encontrará también en las poesías A las armas y Doina, lo que constituye un filón de gran relevancia para la afirmación de la identidad nacional. 
El hecho de que no se ha guardado el manuscrito del poema ${ }^{4} Q u e ́$ deseo yo para ti, dulce Rumanía no disminuye en nada su importancia. Este poema, definitorio para sus comienzos de poeta, es una muestra de actitud política que guardará durante toda su vida como poeta y como ciudadano, según lo prueban todos sus versos y sus artículos.

Tenemos que observar que justamente este poema, de un patriotismo arrollador, no fue seleccionado para el libro "Poesías" de 1884 por Titu Maiorescu, lo que demuestra que el gran crítico no intuyó ni su significado ideológico, ni su valor artístico. Maiorescu destacó el interés para los versos de los comienzos de Eminescu en esta "Antología inicial," creada por un "deber literario," para "hacer más asequibles para los amantes de literatura todos los escritos poéticos, inclusive los del comienzo (n.s.) de un autor que fue bendecido con el don de convertir en realidad su hondo sentimiento y los más altos pensamientos en una belleza de formas cuyo encanto otorga nueva vida al idioma rumano." 5 Estamos delante de una grave omisión, en nuestra opinión, al lado de Constantin Noica, que se permitía una ironía al referirse a la selección maioresciana, apreciando que "para Maiorescu, la poesía de Eminescu se reducía al libro publicado por él. Con 90 poesías - más o menos - Eminescu penetraba bruscamente en el absoluto rumano. ¿El resto? El resto le pareció a Maiorescu inadecuado o, en todo caso, ensayos fracasados, empeño de investigador o - al fin de cuentas - un material que hay que dejar de lado, posiblemente en el cajón que había recibido de Slavici. Puede que ni siquiera miró con atención en aquel cajón.”” 


\section{La visión integradora del poeta sobre su patria}

La palabra "patria" aparece en los versos escritos en Blaj en 1866, el año de su debut, y titulados Desde el extranjero en los cuales el alma del poeta "llora" porlos dulces campos de la patria, por sus llanuras sonrientes. Los versos de la poesía A Bucovina atestiguan el punto de partida de su patriotismo, a partir de una visión geopolítica: Nunca olvidaré, dulce Bucovinal Tu genio romántico, los montes de luz/ Los valles en flor/ Los ríos saltando entre altos peñascos/ Las aguas brillando en blancos diamantes (...). He aquí el espacio-raíz de su patria, formado por las montañas, aguas y llanuras que va a sostener todo su universo poético ulterior. ${ }^{7}$ A partir de su "dulce" patria como terruño natal, Eminescu transfiere este epíteto, por una extensión geopolítica, a su "dulce Rumanía," en el poema-declaración de su fe patriótica.

Con el ardiente deseo de descubrir la esencia de lo rumano, Eminescu recorría Transilvania, y sus biógrafos insistieron sobre su deseo de llegar a Blaj, donde "amaneció el sol de la rumanidad." Se ha constatado la manera simbólica en la que, irguiéndose en el carruaje que llegaba a Hula, en las colinas de Blaj, se sacó el sombrero y lo agitó, pronunciando palabras que quedaron en la historia: "Te saludo con todo mi corazón, Roma-pequeña. Gracias Señor, que me has ayudado a verla." ${ }^{\circ}$ Este momento pasó en 1866, cuando el adolescente ya había demostrado su honda comprensión para la estrecha relación que había entre las provincias rumanas, y su dolor era provocado por el hecho de que algunas de ellas estaban sometidas a algunos imperios.

He aquí por qué, en su poesía $A$ las armas, el verbo movilizador recibe acentos tajantes, reivindicativos en la descripción del amplio panorama de las provincias rumanas sometidas por los extranjeros. El poeta empieza por pedir la liberación de su tierna Besarabia, 
"nuestra hermana pequeña" que gime bajo el látigo ruso, mientras a que los húngaros, ocupantes de Transilvania, se les prepara una respuesta adecuada cuando "nuestro brazo os iba a machucar." El poema termina con el grito $A$ las armas, ihermanos rumanos! $\mathrm{Al}$ hacer referencia a su terruño natal, la antítesis entre el pasado grandioso y el presente esclavizado le inspira la personificación: $Y$ tú, querida Bucovina/ Diamante en la corona de Esteban/ Llegaste como esclava en el harén/ En manos sucias... El llamamiento a las armas está en contra de todos los invasores del la llanura miorítica - judíos, tártaros, polacos - por los cuales el poeta no tiene ni tolerancia, ni perdón. Escrita con la llama de un sentimiento patriótico incandescente, la poesía $A$ las armas prueba que en su conciencia no hay diferencia entre los rumanos de las diferentes provincias históricas rumanas. ${ }^{9}$

Eminescu vivía de manera intuitiva la transformación del pueblo en una nación mientras la nación rumana despertaba políticamente, organizándose en un Estado moderno que estaba luchando para afirmar su identidad. A pesar de la separación política, el pueblo rumano manifestaba su unión lingüística, de sangre y destino.

\section{La forma exponencial de una conciencia nacional ardiente}

La definición que Eminescu dio al pueblo rumano no deja lugar a dudas, puesto que sus términos son superlativos: "Valiente en las guerras, laborioso y honrado en tiempos de paz, diciendo siempre la verdad, bromista y sereno, justo y caritativo como un niño, el pueblo rumano no es capaz ni de traición, ni de infamias" 10 .

En realidad, Eminescu tenía una visión integradora de su pueblo, tal como lo demuestra la poesía Doina, en la cual, en versos motivadores lamenta al suerte de los co-nacionales de Besarabia, Bucovina y 
Transilvania. La forma inversa del verbo "quejarse" adquiere un fuerte impacto y muestra que el poeta hizo suyos los dolores de todos los rumanos: De la Nistru pân' la Tisal Tot românu' plânsu-mi-s'a ("Desde Nistru hasta Tisa / Todo rumano se me ha quejado"). El poeta tiene un espíritu justiciero y responsable. El peligro del enajenar la tierra ancestral heredada de los antepasados dacios amenaza la misma condición de existencia de su pueblo. Su conciencia lo mantiene atento al dolor del pueblo, y por eso exclama: “Ay, del pobre rumano mío!/ Retrocede tal cangrejo/ Ni le anda, ni intenta/ Ni le es otoñootoño,/ El verano no es suyo,/ Extraño queda en la casa suya" (traducción libre). Los más importantes períodos del calendario agrario perdieron su significado, porque durante el otoño el campesino ya no recoge los frutos de la tierra para sí mismo, sino para los extranjeros a los cuales les llegan todas las riquezas. Es una realidad intolerable para la conciencia profundamente rumana del poeta, que expresa en su poesía Doina, en versos cortos, faltos de metáforas embellecedoras. Es aquí donde aparece su fe política en nombre de la cual exalta a erradicar a los extranjeros invasores de las provincias históricas de Rumanía. De manera simbólica, el poeta recurre al ejemplo histórico del Gran Esteban, al que pide la salvación del pueblo en una célebre invocación retórica.

Enamorado de la historia, Eminescu eligió figuras de príncipes destacados, como la de Mircea el Viejo con su época de victorias heroicas como imagen antitética para su virulento panfleto político de la Carta III-ra, donde creó la más brillante lección de historia nacional de toda la literatura rumana. Con un preludio de la imagen del sueño legendario de ascensión del Imperio otomano, vuelto realidad, la confrontación de "en Rovine, en las campos" del sultán Baiazid el Relámpago y el viejo Mircea, príncipe de Valaquia, lleva a la filosofía política de los rumanos: ¿Yo? Defiendo mi pobreza, mis menesteres y 
mi pueblo... (...)/ No tenemos huestes, pero el amor al terruño es un muro/ que no se espanta ante tu fama de hombre duro!"

La evocada lucha de Rovine probará que los turcos no entendieron de qué tipo de aliados hablaba Mircea: de los bosques de robles, de las aguas, de "todo lo que se mueve en este país," añadido al valor y gallardía de los luchadores rumanos. El cuadro dinámico de la lucha tiene una apertura panorámica, marcada por el ritmo interior de los versos que describen al propio Mircea impulsando a sus hombres con su ejemplo personal: "Tal diluvio que anega, cual un mar atormentado (...), y "el granizo de acero" empuja hacia el Danubio a los paganos esparcidos...

\section{Algunas conclusiones concernientes al nacionalismo de Eminescu}

Al considerar los poemas como Doina, o A las armas desde la perspectiva del presente postdecembrista, momento cuando estas fueron repuestas en circulación, el primer ataque anti-Eminescu que A. Grama emprendió en 1891 parece totalmente equivocado, y puede ser explicado o bien por ignorancia, o bien por mala voluntad, tal como con justa razón había comentado también D. Murarașu. ${ }^{11}$

Eliade veía en Eminescu al teórico por excelencia de la rumanidad y del nacionalismo rumano. ${ }^{12}$ Mucho se escribió sobre el así llamado nacionalismo xenófobo de Eminescu, pero ni sus artículos, ni sus poesías como Doina o $A$ las armas pueden ser entendidos sin colocarlos en el contexto político de la época y sin cierta objetividad en la interpretación. Sólo así podemos atestiguar la autenticidad del nacionalismo que Mihai Eminescu vivió con toda su alma y lo expresó a través de su arma - la palabra. "El sentimiento de la imperfección del mundo" - observa Bianca Osnaga - viene de la conciencia del regreso y de la degradación de la patria, del carácter perecedero, de la 
insuficiente fuerza de oponerse a lo malo, a la enajenación, a la soledad, de la constatación de cierta insensibilidad y mezquindad del prójimo. La conciencia de sí mismo del poeta - comprometido, indignado - desde Los jóvenes corruptos hasta Lascartas es esencialmente heroica: su verbo tiende a marcar la posteridad, restaurar el mundo, a partir de la convicción de que este es perfectible. ${ }^{13}$ Convencido de que puede enderezar el mundo a través de la llama de su palabra, Eminescu daba a sus contemporáneos y a la posteridad, en la Carta III-ra, una incomparable lección de historia nacional. Al principio, en el manuscrito 2282, la segunda parte del poema se titulaba "La Patria y los patriotas" - y prueba que el pensamiento del poeta giraba en el torno del patriotismo: ES que de patria, de virtud no habla el liberal/ ipuedes creer su vida limpia cual el cristal?

La idea de nacionalidad no se detiene en el momento presente, porque Eminescu piensa también en las generaciones venideras. "En el pasado, se nos impuso una historia, en el futuro, que la hagamos nosotros, ${ }^{14}$ es una de sus convicciones más firmes, que pueden ser relacionadas como mensaje de Qué te deseo yo, dulce Rumanía, A las armas y Doina.

C. Noica matizó de una manera interesantísima la idea de la Gran Unificación cuando visitó Sibiu, respectivamente Transilvania "desde donde vinieron todas las Fundaciones" e hizo constar que por el documento de $1^{\circ}$ de Diciembre de 1918 jel antiguo Reino rumano se pegó a Transilvania! ¿Sabéis dónde se vio esto mejor? Primero lo vi en aquello que sucedía en el arco de los Cárpatos, en Valaquia y también en Moldavia, pues vi pastores transilvanos por todas partes, y vi esto sobre todo en las palabras. En las palabras... Y estas fundaciones de las palabras me hicieron comprender que la Patria Madre está aquí."15 
No es por casualidad que ve Noica en Eminescu, además del gran poeta del pueblo, un educador muy importante.

En efecto, estamos leyendo incluso hoy en día, a principios del siglo XXI, la poesía patriótica y los artículos firmados por Eminescu y encontramos debates sobre los problemas que todavía nos están preocupando, lo que nos hace considerar a este gran creador de vocablos rumanos, nuestro contemporáneo.

Reconocemos en Eminescu el calibrador del pensamiento lírico rumano, y por eso cabe recordar la opinión de C. Noica sobre él: LoS árboles no crecen hasta el cielo. Tampoco nosotros podemos crecer más allá de nuestra medida. Y nuestra medida es Eminescu. No vamos a crecer más. Pero hasta allá, hay que crecer. Porque el alma debe ser nutrida como la tierra. Y si no nos nutrimos de Eminescu... nos quedaremos siempre hambrientos. ${ }^{16}$

El concepto de patria es una realidad sustancial, constantemente afirmado en la creación poética y en los artículos de Eminescu, que están dialogando sobre este tema como vasos comunicantes. En la literatura rumana, el modelo de Eminescu fue seguido, en la línea del nacionalismo, por poetas como George Coșbuc, Aron Cotruș, Ioan Alexandru, Vasile Militaru etc. que dieron una amplia extensión al tema patriótico, pero no lograron igualar la ejemplaridad artística eminesciana.

\section{Notes}

\footnotetext{
${ }^{1}$ En el Mss. de la Academia Rumana 2258, folio 190 se encuentra la exclamación de Eminescu, “¡Ay, Moldavia, madre, madre!” que atestigua la pertenencia básica de esta provincia a Rumanía.

${ }^{2}$ El historiador de Banat Ioan Hațegan emprendió una investigación por la cual comprobó que en la prensa, poco antes de la revolución de 1848, Rumanía significaba el único país neolatino vigente que unificaba a todos los descendientes del Imperio Romano del Oriente, ya que estaba rodeado únicamente por pueblos eslavos.
} 
${ }^{3}$ Grigore Ioniță estudió la cuestión y puso de evidencia que en las Asambleas ad-hoc de 7 y 8 de octubre de 1857 se pedía la unificación en un sólo Estado llamado Rumanía, pero la petición fue rechazada por las Grandes Potencias durante la Convención de París de 1858, imponiéndose que se guardara la denominación de "Los Principados unidos de Moldavia y Valaquia." Pero al 1 de julio de 1866 fue promulgada la Constitución, en la que aparece "Rumanía."

${ }^{4}$ Verse Perpessicius, en M. Eminescu, Obras, II edición (Bucarest: Ed. Minerva, 1973), 266.

${ }^{5}$ Titu Maiorescu /Prólogo/, M. Eminescu, Poesías (Bucarest: Ed. de la Librería SOCEC\& Comp., 1884),

II. Su aversión declarada para la injerencia de lo político en la literatura explica esta omisión por lo que el crítico dejaba fuera del universo poético de Eminescu esta perla del patriotismo rumano.

${ }^{6}$ C. Noica, Introducción al milagro de Eminescu (Bucarest: Ed. Humanitas, 1992), 69.

${ }^{7}$ En calidad de redactor al periódico El Tiempo, Eminescu trataba, a partir de documentos históricos, la suerte de Bucovina, parte integrada forzosamente a Austria, y también la suerte de Besarabia, que es "pedazo de nuestra patria ancestral, es la herencia del infeliz y dividido pueblo rumano," citado M. Eminescu, Obras, ed. I. Crețu, vol. II, 286.

${ }^{8}$ En 1864, 1865, 1866, 1868 se encontraba a Sibiu, pero también lo encontramos a Brasov, Alba Iulia, Blaj etc., andando con compañías de teatro por todo el espacio rumano de Transilvania.

${ }^{9}$ La relación de Eminescu como poeta y sobre todo periodista con todas las provincias rumanas se convirtieron en investigaciones serias en los principios del siglo XX, y gracias a I. Scurtu, I. Duma, I. Ornea, E. Dăianu, R. I. Sbiera etc.

${ }^{10}$ M. Eminescu, Mss., La Academia Rumana, 2257.

${ }^{11}$ D. Murărașu, El nacionalismo de Eminescu (Brasov: Ed. Elida y Etios, 2000), 4.

${ }^{12}$ Ibíd.

${ }^{13}$ Bianca Osnaga, La conciencia trágica eminesciana (Cluj-Napoca: Ed. Eikon, 2014), 243.

${ }^{14}$ M. Eminescu, Obras, tomo IX (Bucarest: Ed. Academiei, 1980), 443.

${ }^{15}$ C. Noica, Introducción al milagro eminesciano (Bucarest: Ed. Humanitas, 1992), 78.

${ }^{16}$ Citado Th. Damian, "Nacionalismo y patriotismo en Eminescu," Ardealul literar 1-2 (2019). 


\section{Goalball y perspectivismo: una aproximación multinaturalista al}

deporte inclusivo

Carlos García Grados

Universidad del País Vasco, Bilbao, Spain

\section{Introducción}

Esta comunicación está basada en un trabajo de campo etnográfico intensivo que realicé en el contexto del País Vasco (España) acerca de un deporte para personas ciegas llamado Goalball. Concretamente, el equipo de Goalball Itxaropena, perteneciente a la Asociación Alavesa de Personas con Baja Visión, ha sido el grupo de personas junto a las que he podido conocer e investigar el Goalball que se denomina inclusivo, esto es, una modalidad en donde personas con y sin discapacidad visual juegan de manera conjunta.

Aunque por regla general las federaciones locales, nacionales e internacionales que regulan este deporte no permiten la participación de personas sin discapacidad visual en las competiciones oficiales, el equipo de Itxaropena siempre ha entrenado con jugadores videntes y ha promovido eventos competitivos de Goalball inclusivo. Un ejemplo de ello es la actual organización de la primera liga de Goalball inclusivo de España que tendrá lugar en Vitoria a partir del mes de noviembre de 2019. La principal finalidad de la asociación y del equipo con esta práctica deportiva es eliminar la segregación y la exclusión que enfrentan las personas con discapacidad visual y las personas videntes en el Goalball institucionalizado o federado y contribuir así, de manera general, al fomento de una sociedad más inclusiva.

Partiendo de este trabajo etnográfico, el propósito principal de esta comunicación será reflexionar acerca de las implicaciones políticas que tiene la práctica de Goalball inclusivo de Itxaropena en relación a la 
concepción de la ceguera. Como trataré más adelante, la determinación de llevar a cabo dicha práctica implica la resistencia frente al sistema de ordenamiento social capacitista basado en la dictomía capacidad/discapacidad, la transformación del ideal humano occidental y la lucha por el reconocimiento de la diversidad corporal como principio para el trato de igualdad entre los sujetos.

Para ello, la aproximación teórica al contexto etnográfico de partida tendrá lugar desde el giro corporal de las ciencias sociales en general y de los estudios de la discapacidad en particular. Es decir, desde la consideración del cuerpo como un sujeto agentivo socio-cultural de primer orden y no meramente como un objeto de índole natural y presocial excluido de la reflexión y la política. Específicamente, la aproximación tendrá lugar desde la Teoría Crip elaborada por Robert McRuer ${ }^{1}$ y, como refleja el título de la comunicación, desde el marco antropológico perspectivista y multinaturalista amerindio propuesto por Eduardo Viveiros de Castro². Volveré sobre el encuadre teórico más adelante. Ahora es momento de presentar brevemente el Goalball.

\section{El Goalball}

Este deporte fue inventado en 1946, tras la II Guerra Mundial, por el doctor alemán Hanz Lorenzen y el doctor austriaco Sepp Reindle con el objetivo de rehabilitar soldados ciegos del ejercito nazi. Desde 1976, es un deporte paralímpico. El Goalball se juega en una pista de 18 metros de largo por 9 de ancho. En cada fondo de la pista hay ubicada una portería que posee una altura de 1,30 metros y abarca todo el ancho de la pista, es decir, 9 metros. El campo se divide en dos áreas para cada equipo y en un área neutral central que ningún jugador o jugadora debe invadir en el transcurso del juego. En este deporte se enfrentan dos equipos compuestos por tres jugadoras o jugadores y la 
dinámica del juego consiste en atacar la portería contraria lanzando un balón con cascabeles y defender la portería propia alternativamente. El lanzamiento debe realizarse a ras de suelo y la defensa se realiza interceptando la trayectoria del balón con cualquier parte del cuerpo. Todas las líneas que componen el campo disponen en su interior de una cuerda que permite la orientación de las y los jugadores a través del tacto. Los objetos fundamentales en este deporte son el balón sonoro y unas gafas opacas que ponen a todas y todos los participantes en situación de ceguera. Estos objetos son la clave para entender la posibilidad de que personas videntes puedan jugar y por tanto una de las claves de su potencialidad como práctica inclusiva.

A pesar de la posibilidad de ser una modalidad de deporte inclusivo, como ya he advertido, las diferentes federaciones que lo regulan solo admiten la participación de personas diagnosticadas y certificadas médicamente como ciegas. Esto sucede así tanto en competiciones oficiales del País Vasco, como en las competiciones oficiales españolas y europeas y en los Juegos Paralímpicos. Debo señalar que todas estas federaciones tienen explícitamente un discurso a favor de la inclusión social de las personas con discapacidad, sin embargo no lo llevan a la práctica en el contexto de la competición deportiva. Este hecho contradictorio no lo es tanto si lo analizamos en el marco de la Teoría Crip.

\section{Crip Theory}

El término "crip" procede de la palabra inglesa "cripple," que se traduce principalmente al castellano como "tullido" y que es utilizada como insulto para las personas con diversidad funcional. Sin embargo, como sucede con el término "queer," los sujetos estigmatizados se han 
apropiado del insulto para neutralizarlo y poner en evidencia la construcción socio-cultural de la normalidad corporal. La Teoría Crip emerge en primer lugar frente al enfoque médico-rehabilitador de la discapacidad, en donde ésta es considerada como un problema biológico individual físico, cognitivo o sensorial que se desvía del cuerpo normal o capaz y, por tanto, el sujeto debe someterse a una rehabilitación para asimilarse a dicho cuerpo normativo y reinsertarse así en la sociedad. En segundo lugar, esta teoría responde a la insatisfacción que ha producido el enfoque social de la discapacidad al olvidar o dejar de lado la corporalidad para la reflexión y la lucha política por la integración. En el modelo social se considera que la discapacidad es el resultado de las barreras físicas, ideológicas y simbólicas que impone la sociedad a aquellos cuerpos que son deficientes, sin embargo la propia deficiencia corporal no se cuestiona y su definición continúa en manos de la biomedicina. Precisamente, la Teoría Crip cuestiona tanto la deficiencia como la discapacidad. Tal y como plantea McRuer, en una sociedad capacitista la capacidad es un ideal normativo obligatorio ${ }^{3}$. La capacidad es un acto corporal performativo que atiende a unos cánones culturales que son tanto orgánicos como funcionales. Es decir, el cuerpo humano debe tener un conjunto de características anatomo-fisiológicas, cognitivas y sensoriales determinadas y, además, tal y como pone de relieve el paradigma de la diversidad funcional, debe llevar a cabo sus capacidades de un modo concreto. Por ello, para sostener el sistema capacitista que ordena jerárquicamente a los sujetos es necesario crear la ficción de unos cuerpos naturalmente capaces y otros con discapacidad. Es aquí donde se halla la lógica de la segregación y la exclusión de las personas ciegas y videntes en el Goalball. Para reproducir cuerpos capaces y discapacitados, estos cuerpos no deben mezclarse debido al riesgo de que puedan ser (con)fundidos. Esto es 
precisamente lo que provoca la práctica del Goalball inclusivo. La mezcolanza de cuerpos diversos en este deporte permite la comparación entre los mismos, rompiéndose así la dicotomía entre cuerpos con y sin discapacidad visual que perpetúa negativamente la ceguera como una deficiencia y la videncia como una capacidad normal del cuerpo. En el terreno de un deporte que pone a todo el mundo en situación de ceguera, los jugadores videntes de Itxaropena han aprendido las limitaciones de no ver, pero también de las nuevas habilidades que posibilita, lo que significa haber aprendido a reconocer al mismo tiempo habilidades nuevas y limitaciones de sus propios cuerpos que las personas con ceguera no reconocen. Estos jugadores se asombran por ejemplo de la habilidad de las personas ciegas para discernir entre sonidos simultáneos o de la velocidad a la que pueden escuchar los asistentes de sus teléfonos móviles, habilidades que según ellos, a través de la práctica de este deporte, se han traducido en una mejora de su capacidad de concentración.

Las personas crip han dejado por tanto de pensar y experimentar sus cuerpos en referencia a la norma que las cataloga como anormales, enfermas, deficientes y discapacitadas, para ensalzar su agentividad y reivindicar así sus experiencias encarnadas como una manera diferente y creativa de conocer y estar en el mundo y como un modo de resistencia y lucha política frente a la norma y, en definitiva, como un modo de transformación socio-cultural. Sin embargo, como señalan José Ángel Bergua y Laura Moya, la Teoría Crip adolece aún de experiencia dada la "falta de tradición de trato reflexivo y político" con el cuerpo en occidente 4 . Por ello he aceptado la propuesta de estos autores de buscar inspiración en el protagonismo corporal amerindio para el análisis del Goalball inclusivo y profundizar así en sus implicaciones políticas. 


\section{Goalball Inclusivo, Perspectivismo y Multinaturalismo}

El perspectivismo, como lo define Viveiros de Castro, es "una concepción, común a muchos pueblos [amerindios], según la cual el mundo está habitado por diferentes especies de sujetos o personas, humanas y no-humanas, que lo aprehenden desde puntos de vista distintos"5. Pero aquí el punto de vista no hace referencia a aquella representación cultural del mundo que pertenece a un espíritu particular, sino a una perspectiva natural que pertenece a un cuerpo concreto. Como señaló Philippe Descola, los pueblos amerindios son animistas, ya que conceden la condición humana a otros seres como los animales, es decir, atribuyen "a los no-humanos [...] una interioridad idéntica a la suya"6. Por lo tanto, dado que la humanidad es un atributo universal derivado de la capacidad de ocupar un punto de vista, la estrategia de los amerindios para constituir su subjetividad consiste en distinguirse, frente al resto de cuerpos, como un cuerpo particularmente humano. Así, mientras que en occidente existe una continuidad física exterior y una discontinuidad espiritual interior entre los seres, lo que Descolá denominó como ontología naturalista ${ }^{7}$, entre los pueblos amerindios existe por el contrario una continuidad espiritual interior y una discontinuidad física exterior. En occidente, lo universal es la naturaleza y lo particular son las diferentes culturas. Por ello, con el propósito de convivir con la diversidad cultural humana, se ha implementado como política relativista el multiculturalismo. Sin embargo, en los pueblos amerindios lo universal es la cultura y lo particular son las múltiples naturalezas existentes. Así, con la finalidad de convivir con la diversidad natural de sujetos o personas humanas y no-humanas, se ha implementado como política perspectivista el multinaturalismo.

Derivado de tales cosmologías, como han señalado Bergua y Moya, el problema fundamental en occidente ha consistido en cómo unir las 
diferentes almas o espíritus que consideramos distanciados los unos de los otros. Para resolverlo, dicen estos autores, se han levantado grandes edificios intelectuales para justificar lo colectivo a través de cosas como el "contrato social". Sin embargo, el problema fundamental para los amerindios reside en cómo poner en comunicación la multiplicidad de cuerpos, lo que en este caso podríamos decir que ha dado lugar a edificios corporales que justifican lo individual a través de prácticas como el "chamanismo." Precisamente, la práctica de Goalball inclusivo que impulsa Itxaropena es postoccidental, ya que no trata de poner en comunicación espíritus interiores para su mutuo entendimiento, sino diferentes naturalezas exteriores, es decir, cuerpos con y sin ceguera. El resultado de ello, como ya he advertido en el caso de los jugadores videntes del equipo, es la experiencia y el aprendizaje del mundo de la ceguera del que el cuerpo ciego es punto de vista, lo que conlleva el reconocimiento de otras formas humanas de ser y estar en el mundo.

La lucha por la inclusión social y cultural ha sido una constante en el movimiento de las personas con discapacidad. A partir de los años $70 \mathrm{y}$ hasta los años 90, el paradigma social de la discapacidad se erigió como el enfoque más adecuado para lograr tal propósito. Como ya me he referido anteriormente, la estrategia de lucha fue poner el acento en la sociedad como barrera y no en la corporalidad de los sujetos, así como identificarse con una minoría cultural oprimida que reclamaba el reconocimiento de su humanidad y ciudadanía apelando a los Derechos Humanos. Sin embargo, esta estrategia política de corte multiculturalista se ha enfrentado a serías dificultades para avanzar hacia la inclusión social. Concretamente se ha enfrentado a los problemas derivados de la ontología naturalista. Posicionarse identitariamente como una minoría cultural conlleva asumir implícitamente la existencia de múltiples culturas y de una 
naturaleza universal o de un mundo común para todos lo seres. Esta naturaleza común, definida fundamentalmente por la ciencia positiva, manifiesta un conjunto cerrado de características al que deben adaptarse para sobrevivir los seres que lo habitan. Esto implica que el ser humano como especie debe poseer igualmente un conjunto cerrado de características orgánicas y funcionales básicas que le permita dicha adaptación. Por ello, en una sociedad capacitista, aquel individuo de la especie humana que no cumpla con los estándares corporales definidos por la ciencia sufrirá simultáneamente una devaluación de su condición humana. Tal y como sugiere el movimiento crip, la lucha por lograr encajar en tal concepción de lo humano no parece entonces una estrategia fructuosa para alcanzar la plena inclusión social.

Por el contrario, el empeño de Itxaropena en el Goalball inclusivo no persigue entroncar a las personas con discapacidad visual en la concepción occidental de lo humano, sino que provoca su apertura y transformación. Los componentes con discapacidad visual de Itxaropena dan por sentada su condición humana, pero para su reconocimiento han optado por el uso del Goalball como un medio de comunicación entre diferentes naturalezas que demuestre la agentividad y la subjetividad de los cuerpos ciegos. Itxaropena emplea el Goalball como un puente de comunicación entre cuerpos diversos para que las personas videntes puedan experimentar el mundo que emerge desde los cuerpos ciegos. Al igual que los chamanes amerindios usan ropas animales para desplazarse por el cosmos, las gafas opacas y el balón con cascabeles son instrumentos que permiten a las y los jugadores experimentar las habilidades que definen al cuerpo ciego. Por lo tanto, dicho cuerpo deja de ser así una relación defectuosa con la naturaleza o el mundo único que determina la ciencia. El cuerpo ciego deja de ser una deficiencia respecto al cuerpo normativo capaz 
para postularse como una forma natural más que puede adquirir lo humano.

La práctica de Goalball inclusivo de Itxaropena implica por tanto la disolución de la dicotomía capacidad/discapacidad al ponerse en cuestión el ideal de cuerpo capaz hegemónico de nuestros contextos sociales y culturales capacitistas. En definitiva, mediante esta práctica, se discute la idea sobre la especie Homo sapiens que acota lo humano en nuestra ontología naturalista al proponer el cuerpo ciego como otra forma humanamente posible de habitar el mundo. Todo ello supone un gesto posthumano mas efectivo para el desarrollo de unas sociedades más inclusivas, en donde el derecho a la divergencia de naturalezas sea el principio rector de la igualdad humana como condición.

\section{Notes}

\footnotetext{
${ }^{1}$ Robert McRuer, Crip Theory: Cultural Signs of Queerness and Disability (New York: New York University Press, 2006).

2 Eduardo Viveiros de Castro, "Perspectivismo y Multinaturalismo en la América Indígena," en Tierra Adentro: Territorio Indígena y Percepción del Entorno, Alexandre Surrallés y Pedro García Hierro, eds. (Lima, Perú: Alejandro Parellada, IWGIA, 2004), 37-80.

${ }^{3}$ McRuer, Crip Theory: Cultural Signs of Queerness and Disability.

4 José Ángel Bergua Amores y Laura Moya, "Creatividad corporal. Perspectivismo y movimiento crip," Imagonautas 10 (2017): 29-50.

${ }^{5}$ Viveiros de Castro, "Perspectivismo y Multinaturalismo en la América Indígena," 37.

${ }^{6}$ Philippe Descola, Más allá de Naturaleza y Cultura (Buenos Aires: Amorrortu, 2012), 199.

${ }^{7}$ bid, 190 .

${ }^{8}$ Bergua Amores y Moya, "Creatividad corporal. Perspectivismo y movimiento crip,” 42.
} 
Workshop 14:

The Post-Secular Condition: Democracy and the Return of Religion

Chairs: Rita Šerpytytė and Tomas Sodeika 


\section{Post-Secular and Post-Democratic India: A Study of the Digital \\ Dissolution of the State}

Rianka Roy

Department of Sociology, University of Connecticut, USA

\section{Introduction}

There are nine major religions in India, and hundreds of local religions. In a way, India has never been truly secular by definition. The Constitution of the country grants citizens the right to practice any religion of their choice. However, India now witnesses a stark presence of religion-based violence. The ruling right-wing government now seeks legal means to establish a Hindu state, abandoning the principles of tolerance. ${ }^{1}$ It uses the digital propaganda machinery to disseminate its Hindutva ideology.

This paper studies the status of contemporary Indian democracy and polity, and argues that in the digital era, the state exists in a postsecular and post-democratic form. Linear transition from modernism to post-modernism is neither absolute nor unidirectional. Even after nations and communities undergo postmodern transformations, it is possible for them to return to the political formulations of modernity. My paper examines this relapse in India, and contends that the unprecedented expanse of digital communication is responsible for the rise of religious intolerance and sectarianism.

\section{Secular Nation and Digital India}

After two centuries of colonial experience and intense anti-colonial struggle against the British Empire, India achieved its independence in 1947. The Constitution drafted in 1950, identified India as a secular democracy. One aim of the Constitution was to establish homogeneity 
in the very diverse cultural, linguistic and religious communities. The regional monarchs in various Indian provinces had to be brought under the unifying rubric of nation and nationhood.

Partha Chatterjee writes that the process of nations being born or coming into being constitutes critical discourses in postcolonial studies. ${ }^{2}$ In such discourses it is evident that in the Indian context, it is nearly impossible to implement secularism. Secularism in India emerged in governance as an anti-colonial stance of the elite, paradoxically being borrowed from European modernity and the theories of nationhood. ${ }^{3}$ This hegemonic concept of a territorialised nation is a legacy of European modernity. It is not a native concept to India.

What the nationalist elite intellectuals like Mahatma Gandhi and Jawaharlal Nehru in India presented in the idea of secularism was the principle of toleration. During the struggle for freedom, Mahatma Gandhi embraced followers from all religious communities, and wrote extensively against sectarianism and casteism. However, the articulation of his anti-colonial and secular discourse involved Hindu rituals. 4 This paternalistic "toleration" of minority communities continued even after independence. Ironically, secularism thus meant the elision of the characteristic diversity of the country and the acknowledgment of the Hindu majority.

Despite its secular status, India has always been divided by complex intersections of religion, class and caste. Since the pre-colonial times, India was a conglomeration of communities, tribes and princely states. These linguistic and cultural fissures could not be erased overnight by the external imposition of a European convention of nationhood. In the nineteenth century, the British colonial forces were cautious of the robust anti-colonial spirit among the natives, were reluctant to directly intervene in modernising the state through religious 
reformation. Wary of native antagonism, the colonizers left religious practices and personal law to the discretion of indigenous religious bodies. However, before and especially after independence, the state, despite being a declared secular entity, attempted to modernise the nation, and ended up intervening in religious affairs in the spirit of reformation. The secular state still intervenes in religious matters, but shows it as social and economic ventures. This reformation, Chatterjee claims, marks the crucial shift from "the legal authority of the (colonial) state to the moral authority of the (national) community."5

After independence, the state prepared for religious reformation with a bid to form a homogeneous idea of the nation and to bring the princely states under the sovereign power of the state. At that time, conflict arose between religious bodies and the state about legislation. The state, while being "neutral" and secular, took over the personal law, which had hitherto been at the discretion of religious bodies. It encountered resistance from religious bodies which largely saw it as political interference. The same tussle continues even now. In 2019, the nation witnessed an acrimonious battle between the Supreme Court and the Karnataka Temple Association regarding women's right to enter the Sabarimala Temple. ${ }^{6}$

Timothy Brennan writes about the adoption of the modern concept of nationhood in postcolonial societies, and their disturbing prevalence. Brennan notes that nations come into existence in public perception and imagination through hegemonic political discourses, media reports, historiography and dialogues, about uniformity and unity. ${ }^{7}$ Homi K. Bhabha, too, explains how nations are written into existence. He writes, "Nations, like narratives, lose their origins in the myths of time and only fully realise their horizons in the mind's eye." With the 
"traditions of political thought and literary language" the "impossible unity of the nation as a symbolic force" is represented. ${ }^{8}$

How do the digital media contribute to this nationalist discourse? Brennan states that media and communication in the twentieth century have caused the "massification" of the literate audience. ${ }^{9}$ As a result, it creates urgency in the circulation and consumption of narratives. This creates instant national heroes and instant patriotism. Nothing can illustrate this attribute of urgency better than digital media which have greatly expedited the production, circulation and consumption of nationalistic narratives.

Social media has globally opened up spaces for the exchange of ideas. Political discourses are now formed on social media. Citizens participate in debates and dialogues online. Ideally, this should have eliminated bigoted notions about religion and class. However, the reverse seems to have transpired. The political climate in India now is deeply divisive. The Hindutva politics of hatred and communalism with its regressive ideas on class, caste and gender has risen to alarming heights.

Chatterjee explained in 1994 that the Hindu Right in India, like the German Nazi party, does not discredit secularism per se. It mocks supporters of secularism as "pseudo-seculars" while projecting itself as a proponent of a unified state. Chatterjee claimed that the Hindu Right "often seeks to mobilise on its behalf the will of an interventionist modernising state" and creates "in the name of 'national culture', a homogenised content to the notion of citizenship." 10 It does not want to abrogate the secular status, but asserts its legal power to persecute the minority. ${ }^{11}$ But over the years the Hindu Right has gained enough force to unequivocally undermine the principles of secularism, and now demands the formation of a Hindu state. Right-wing social media trolls mock secular citizens as 
"sickulars." While the Hindu Right still seeks to establish the interventionist state and a homogenised culture based on religion, paradoxically the state and its attributes like secularism, democracy and security, struggle to retain their modern form. At this juncture, digital intervention constructs new paradigms of nation, secularism and citizenship.

\section{Digital Media for Sectarian Propaganda}

Digital media has played a significant role in provoking sectarianism and precipitating the decline of secularism in India. Disinformation on social media spreads bigotry and hatred. Political parties in India have "Information Technology Cells" for that purpose. The ease of putting together digital content has ushered in the perils of "posttruth." Social media disinformation on religion has reached such epidemic proportions that mob lynching, murders and communal riots on the basis of disinformation have become regular affairs in the last few years. The formation of a modern and secular nation has always been a matter of social and legislative adjustments as per the norms of the majority, not universal human rights. On social media this same majoritarian principle determines the content guidelines and access regulation. The community guidelines clearly indicate that if the majority of users accept even unethical content, it can exist on the networks. It is not a coincidence then that the extremist groups and political parties rely heavily on social media for their propaganda.

All social media users have the same level of access. The sites allow users to post content irrespective of class, caste, gender and religion. Apparently, this generates a utopic scope for democratic political engagement. However, the actual picture is quite unpleasant. The poor level of literacy and digital literacy results in the uncritical 
reception of disinformation among average Indian citizens. This certainly does not mean that religious intolerance and communal bigotry depend entirely on illiteracy; but, the digital circulation of disinformation meets hardly any resistance or critique when the audience has no means to verify the facts.

The unverifiability of digital content is also a result of the excess of information available on social media. It is not possible for ordinary social media users, without research instruments and adequate digital resources, to check facts. In India, media groups like AltNews and The Wire provide thorough reports on disinformation, but not many social media users in India are able to access these repositories due to their low literacy levels.

On social media, narratives are formed not only textually, but also with the aid of visuals. Fabricated images and videos are easy to produce, and they are powerful instruments for the dissemination of false narratives. Even the illiterate audience can consume these images, needing no textual support. Images in which political leaders are shown as incarnations of Hindu gods, or in which the opposition is literally demonised, in the iconography of "Bharat Mata" where the nation is presented as a goddess, and morphed images showing Muslims perpetrating violence are absurd yet widely-used content that has triggered communal violence in recent times. Even counterdiscourses resort to disinformation and to the facetious humour of memes, and thus legitimise this form of digital dialogues.

In the country that still grapples with the divisive nature of castes and religions, in which superstitions are deep-rooted in many communities, religious intolerance cannot be so easily eradicated. Secularism turns out to be the weakest defence against it, and at times even the reason behind it. Ashish Nandy writes about the two forms of religious discourses in India - one sees religion as faith, and 
the other shows religion as ideology. Secularism subscribes to the latter. India used secularism as an ideology while establishing itself as a modern nation state, and thus reinforced religion as ideology. Its impact is visible now - from Hinduism as faith, the political pivot has shifted to Hindutva ideology, which tries to do away with secularism. ${ }^{12}$ Secularism may have been borrowed from the colonial machinery, but the culturally disparate nation attributed new meanings to it, especially aided by digital technology. Chopra contends that the use of technology, and especially the internet, is a vital instrument of Hindutva nationalism, which he identifies as "technocultural nationalism." "Technocultural nationalism" enables the right-wing government to assert the identity of "a culturally distinct and strong Hindu civilization that is simultaneously a technologically and economically power state in the globalized world."13

Chatterjee notes that in India there is no native term for the word "secular." The word "dharmanirapekshata" is a literal translation of the English word. ${ }^{14}$ This absence of an indigenous vocabulary related to secularism and the awkward translation betrays the discomfort of Indian society to implement the western mode of secularism with the absolute neutrality of the state. Therefore, in the Indian context, the definition of secularism is ambiguous. In the same way, on social media, meanings of certain expressions are far from definitive. Their implications are ambiguous. Semantic evolution in terms like "friendship," "social/society," “community," "privacy," and "security" do not follow their traditional definitions. This means, for ambivalent and communally provocative remarks made on social media, it is easy for political outfits to choose any convenient meaning possible, to escape responsibility for disharmony and riots.

Virtual communities accommodate as many voices as possible, because this generates profit for digital companies. The consequent 
pluralism of social media dialogues apparently engenders discourses of post-secularism and post-democracy, beyond the linearity and singularity of modern theories of state. However, when political bodies use social media, they utilise the collective force rather than the individualistic capacity of digital citizens. The use of identical neologism with hashtags - "presstitutes," "sickular," "urban naxal" facilitates communal and political homogenisation - the first step to dividing the masses. The sheer volume of big data and the game of numbers are used to indicate the popularity of political parties, in the same way as social media companies sell their popularity on the basis of the number of users.

This polarization of digital masses is theoretically similar to the use of binary choices in social media communication. The habit of online culture is making social media users uncritically accept binaries even in their social and political choices. This reinstates the polarization of modernity, from which postmodernism had apparently liberated states and citizens. Postmodernism rejects binaries and definitiveness of modernist grand narratives. It accommodates pluralism and uncertainty, and advocates multiculturalism and globalism. However, the digital era, despite its postmodernist potential through global expanse and transnational communication, espouses technical binaries and reinforces ideological binaries. Thus, it generates postsecular and post-democratic nations and societies. The habit of viewing society and presenting the self through digital binaries invokes religious binaries as well. Divisive politics simply uses the constitution of digital communication as an instrument to deepen its ideology. 


\section{Conclusion: Digital Enterprises in the Dissolution of States}

It is a positivist idea to hold only digital technology accountable for the crisis of nation states and the rise of religious intolerance. However, the political economy of social media companies truly panders to sectarian forces of nationalism. The lack of accountability of social media companies is one of the reasons that lets bigotry thrive. With arbitrary community standards and content guidelines, sites like Facebook and Twitter allow users to indiscriminately post hateful content.

The question that emerges is: does the rise of sectarianism as well as anti-secular sentiments indicate the dissolution of the nation and its integrity? It certainty undermines the principle of nationhood where national identity is contingent on the elusive concept of homogeneity. However, the resounding demand to reinstate communal and geopolitical division (India versus Pakistan, Hindu versus Muslim) does not threaten sovereignty; rather, the sovereign reasserts its hegemony through communal binaries using digital tools.

Chatterjee contends that involvement of the state in religion undermines the constitutional principles of equality, neutrality and freedom. However, religious discrimination and intolerance does not indicate the decline of the state, because within the existing mode of secularism in India, discrimination is already a criterion. ${ }^{15} \mathrm{I}$ find that the decline of the state happens in other ways now. The gradual deterritorialization of nation states due to digital globalism has prompted states to reinforce their territorial and communal identities. Postmodernism is a challenging notion for state power to surrender to. Hence, states resort to constituents of modernity to defend their hegemony. 
Digital communication has rendered geopolitical boundaries porous and, to a large extent, redundant. Besides, digital capitalists have emerged as global superpowers - politically, socially and economically. States are dependent on the surveillance mechanism designed and offered by social media companies. Big data commodities allow states to maintain their so-called sovereignty. Even national leaders use social media profiles, where they have the same level of access like pedestrian citizens. The states are therefore in a crisis. Digital enterprises threaten to displace them and determine their political future. States battle this crisis by re-invoking their past affiliations, and archaic constituents of modernity that once framed the idea of nationhood.

Digital enterprises, while creating digital social equivalents on networking sites, intervene in the governance of states by making both citizens and states dependent on big data commodities. As a result, while the interventionist state that the Hindu right-wing tries to forge exists in a simulacral and performative form in digital dialogues, social media companies with their well-demarcated virtual territories and governance policies emerge as global superpowers. It is the continuity of the neoliberal decline of the state that began, according to Michel Foucault, with Nazism in Germany. ${ }^{16}$ The decline now culminates in the complete dissolution of the state at the hands of digital capitalists, where the state endeavours to retain its nonexistent sovereignty by invoking sectarian politics.

Chatterjee writes that secularism is not necessarily a neutral and rational enterprise but a flexible and strategic enterprise of governmentality. It involves coercion and struggle. In Foucauldian governmentality, discipline is latent in sovereignty, which governmentality absorbs in its folds. Chatterjee claims that there are occasions when governmentality is unable to appropriate sovereignty, 
and the ground of contestation between them emerges as the ground of discipline, the site where the cultural rights of the minority are asserted. ${ }^{17}$ Hence, in secularism, the rifts and the sites of contestation are bound to persist in a culturally and communally diverse country like India. This revival of religious or non-secular sentiments at best can be called a neo-modern phenomenon where postmodern nationstates revive past conventions to justify their contemporary existence.

\section{Notes}

\footnotetext{
1 "Several Countries for Muslims but not a Single One for Hindus: Gadkari on Citizenship Act Row," News18 (December 18, 2019), https://www.news18.com/news/politics/several-countries-for-muslims-butnot-a-single-one-for-hindus-gadkari-on-citizenship-act-row-2427997.html.

${ }^{2}$ Partha Chatterjee, "Secularism and Toleration,” Economic and Political Weekly vol. 29, no. 28 (July 9, 1994): 1768-77.

${ }^{3}$ Partha Chatterjee, "Populations in Political Society," in The Politics of the Governed: Reflection on Popular Politics in Most of the World (Delhi: Permanent Black, 2004), 27-52.

${ }^{4}$ Arundhati Roy, "The Doctor and the Saint," Introductory essay in Annihilation of Caste by B.R. Ambedkar [1936], ed. S. Anand (London: Verso, 2014).

${ }^{5}$ Chatterjee, "Secularism and Toleration," 1770.

${ }^{6}$ Krishnadas Rajagopal, "Sabarimala Issue Explosive Now: Supreme Court," The Hindu (December 13, 2019), https://www.thehindu.com/news/national/be-patient-supreme-court-tells-women-seekingprotection-to-enter-sabarimala-temple/article30295564.ece.

${ }^{7}$ Timothy Brennan, "The National Longing for Form," in Salman Rushdie and the Third World: Myths of the Nation (New York: Palgrave Macmillan, 1989), 79-117.

${ }^{8}$ Homi K. Bhabha, "Introduction: Narrating the Nation," in Nation and Narration, ed. Homi K. Bhabha (London: Routledge, 1990), 1-7, 1.

${ }^{9}$ Timothy Brennan, "The National Longing for Form," in Nation and Narration, ed. Homi K. Bhabha (London: Routledge, 1990), 44-70, 67.

${ }^{10}$ Chatterjee, "Secularism and Toleration," 1768.

${ }^{11}$ Ibid., 1769.

${ }^{12}$ Ashis Nandy, "The Politics of Secularism and the Recovery of Religious Tolerance," in Mirrors of Violence: Communities, Riots and Survivors in South Asia, ed. Veena Das (Delhi: Oxford University Press, 1990), 69-93.
} 
13 Rohit Chopra, "The Technocultural Hindu Nationalism of Globalized India," in Technology and Nationalism in India: Cultural Negotiations from Colonisation to Cyberspace (Amherst, MA: Cambria Press, 2008), 135-80, 161

${ }^{14}$ Chatterjee, "Secularism and Toleration," 1769.

15 Ibid., 1768

${ }^{16}$ Michel Foucault, "Five: 7 February 1979," in The Birth of Biopolitics: Lectures at the Collége de France 1978-1979, ed. Michel Senellart, trans. Graham Burchell (New York: Picador, 2004), 101-28, 111.

${ }^{17}$ Chatterjee, "Secularism and Toleration," 1774. 


\section{The Birth of Post-secularity from the Spirit of Religious Unmusicality}

Tomas Sodeika

Vilnius University, Lithuania

\section{Introduction}

This paper discusses Jürgen Habermas's attitude to the current state of religion and the origin and meaning of his proposed notion of postsecularity. Nicholas Adams noted that "Habermas is an unusual atheistic and secular philosopher: he makes positive claims about religion in modern society at the same time as insisting that moral theory must be post-religious or post-traditional."1 The adjective "postsecular" became popular after Habermas's speech "Faith and Knowledge" (Glauben und Wissen) on 14 October 2001 on receiving the Peace Prize of the German Publishers and Booksellers Association at St. Paul's Church in Frankfurt am Main. Since 1849, St. Paul's Church has been the symbol of German democracy: it became the seat of the Frankfurt National Assembly (Frankfurter Nationalversammlung), the first democratically elected German legislative body, which announced and published the first democratic constitution. In his speech, Habermas labeled the modern social order as "post-secular society." Let us look at this notion a bit closer. What did he mean by that?

\section{Secularization and Modernity}

At first glance, the very notion of a post-secular society may suggest the idea of a straight-line of historical development. According to this, the pre-secular world would first have followed secularization, which in turn would be replaced by a post-secular society. To some extent, this observation can be considered as correct. As is well known, the 
term "secularization" comes from the 17th century and primarily indicates the enforced transfer of church property to the state. Yet the process of secularization itself implies several further phenomena. Central to these is the emancipation of secular spheres from religious supremacy: politics, economics, law, science, education, and art are increasingly freed from the prescriptions and control of religion and evolve according to their own logic. Thus religion is gradually forced out of the public sphere into the private sphere with the result that religious beliefs begin to erode and their transmission increasingly diminishes. And the influence of institutions that are considered "religious" in society and in the life of individuals rapidly decreases. In his speech on "Faith and Knowledge," Habermas noted that the word secularization had at first a juridical meaning:

Das Wort Säkularisierung hatte zunächst die juristische Bedeutung der erzwungenen Übereignung von Kirchengütern an die säkulare Staatsgewalt. Diese Bedeutung ist auf die Entstehung der kulturellen und gesellschaftlichen Moderne insgesamt übertragen worden. Seitdem verbinden sich mit »Säkularisierung« entgegengesetzte Bewertungen - je nachdem ob wir die erfolgreiche Zähmung der kirchlichen Autorität durch die weltliche Gewalt oder den Akt der widerrechtlichen Aneignung in den Vordergrund rücken. Nach der einen Lesart werden religiöse Denkweisen und Lebensformen durch vernünftige, jedenfalls überlegene Äquivalente ersetzt; nach der anderen Lesart werden die modernen Denk- und Lebensformen als illegitim entwendete Güter diskreditiert. Das Verdrängungsmodell legt eine fortschrittsoptimistische Deutung der entzauberten, das Enteignungsmodell eine verfallstheoretische Deutung der obdachlosen Moderne nahe. 
Beide Lesarten machen denselben Fehler. Sie betrachten die Säkularisierung als eine Art Nullsummenspiel zwischen den kapitalistisch entfesselten Produktivkräften von Wissenschaft und Technik auf der einen, den haltenden Mächten von Religion und Kirche auf der anderen Seite. Einer kann nur auf Kosten des anderen gewinnen, und zwar nach liberalen Spielregeln, welche die Antriebskräfte der Moderne begünstigen. ${ }^{2}$

The second aspect of this process is related to what can be called rationalization. Since the Enlightenment, religion has become strongly associated with a certain irrational principle, following which the human being is deprived of sovereignty. So it is not surprising that rationalization has taken the form of destroying religious "prejudices." The third aspect, in addition to these two aspects, which carries an evaluative element, may be labeled modernization, and originated in the ideas of Max Weber regarding the role of rationality in the transition from a traditional to a modern society. According to Habermas, "[d]er Begriff Modernisierung bezieht sich auf ein Bündel kumulativer und sich wechselseitig verstarkender Prozesse: auf Kapitalbildung und Ressourcenmobilisierung; auf die Entwicklung der Produktivkräfte und die Steigerung der Arbeitsproduktivitat; auf die Durchsetzung politischer Zentralgewalten und die Ausbildung nationaler Identitaten; auf die Ausbreitungvon politischen Teilnahmerechten, urbanen Lebensformen, formaler Schulbildung; auf die Säkularisierung von Werten und Normen usw."3

\section{The Benefits of Secularization, Rationalization, and Modernization}

At first glance, this triple process of secularization-rationalizationmodernization brings considerable benefits. These include, for example, a significant increase in individual freedom as a result of the 
declining influence of religious institutions, as well as the increase in knowledge of science independent of world-view restrictions or the widespread containment of religiously motivated conflicts by the secular state and a corresponding legal system. Such indisputable advantages have powered the conviction that the process of secularization is a straightforward process of progress that will inevitably lead from the darkness of unexplained conditions to the bright light of a civilization determined by scientific thought, technical innovations and a liberal way of life.

One might suspect that religion has become increasingly marginalized on this path, if not disappeared completely. But that is precisely what did not happen; rather, religion persists even in secularized life contexts: not only in the private sphere of life but also in the social public sphere. So, when Habermas speaks of a post-secular society, first of all, he means that the relationship between secularized society and religion has changed and that the tension between the two has not disappeared, but merely adopted a new form.

Of course, the democratic principle of the equality of all members of society requires that the interests of religious communities and individuals will be considered. But according to Habermas, this does not mean that religious members of post-secular society should be merely tolerated as a kind of handicapped persons who cannot be "enlightened" and "cured" from "religious superstitions" due to their innate mental limitations or whatever.

According to Habermas, secularized society needs the help of its religious members, because it is becoming increasingly clear that the process of secularization involves not only profits but also losses and threats. Habermas admits that the Enlightenment's project of the total "rationalization" of human life in such a way that the exclusive motive of any activity would be human reason, has been in crisis 
because, in the process of developing the "rational" structures of society, "rationality" itself attained a distorted form - the form of instrumental rationality. In order not to become blind to these losses and dangers, secularized societies must take religions seriously and involve them in the process of social self-understanding. Insofar as they do so, they are post-secular societies.

\section{The Helplessness of Instrumental Reason}

An illustrative example of the helplessness of instrumental reason is its inability to resolve the question about the permissibility of interfering in the human genome by cloning or modifying its genetic code. The development of genetic technologies eliminates the distinction between the artificially produced and what arises naturally. Thus the difference between the technical processing of the material and the "cultivating" way of dealing with the living disappears too.

Habermas notes that artificially changing our genetic structure shifts the line between what we are by nature and what we freely decide and do ourselves. In this way, the very structure of our moral experience has changed. In the naturalistic treatment of human beings, Habermas sees the infringement of the dignity of human beings and the equality of all people.

In an article published 1998 in Süddeutsche Zeitung, he writes: "Die neuen Angebote stoßen offensichtlich auf das Interesse von Abnehmern. Und dieses Interesse ist oft so überzeugend, daß moralische Bedenken im Laufe der Zeit verblassen. (...) Aber mit dem Projekt, Menschen zu klonen, kommt ein, wie mir scheint, schwerwiegendes Argument ins Spiel. Der archaische Abscheu, den wir vor geklonten Ebenbildern empfinden, hat einen rationalen Kern." ${ }^{4}$ It is important to note that Habermas's argument against the 
cloning of human beings is "archaischeAbscheu" (archaic revulsion) in which, according to him, a "rationaler Kern" (rational core) is included.

Our inability to solve the moral problems arising in the life sciences by means of logical reasoning and of finding convincing arguments in defense of human dignity is onlyone particular case of the whole, which Habermas calls "entgleisende Modernisierung" (de-railing modernity). Habermas points out that practical reason cannot be sure of the insights of the theory of justice to counteract the failure of modernization: "Die reine praktische Vernunft kann sich nicht mehr sicher sein, allein mit Einsichten einer Theorie der Gerechtigkeit in ihren blossen Händen einer entgleisenden Modernisierung entgegenwirken zu können. Dieser fehlt die Kreativität der sprachlichen Welterschließung, um ein ringsum verkümmertes normatives Bewusstsein aus sich heraus zu regenerieren." ${ }^{5}$

According to Habermas the main problem of pure practical reason is the language because the: "Die Sprache des Marktes dringt heute in alle Poren ein und preßt alle zwischenmenschlichen Beziehungen in das Schema der selbstbezogenen Orientierung an je eigenen Präferenzen. Das soziale Band, das aus gegenseitiger Anerkennung geknüpft wird, geht aber in den Begriffen des Vertrages, der rationalen Wahl und der Nutzenmaximierung nicht auf." 6

The "language of the market" today penetrates all pores and forces all interpersonal relationships into the scheme of the self-centered orientation of one's preferences:

Die praktische Vernunft leistet Begründungen für die egalitäruniversalistischen Begriffe von Moral und Recht, die die Freiheit des Einzelnen und die individuellen Beziehungen des einen zum anderen auf eine normativ einsichtige Weise 
bestimmen. Aber der Entschluss zum solidarischen Handeln im Anblick von Gefahren, die nur durch kollektive Anstrengungen gebannt werden können, ist nicht nur eine Frage der Einsicht. Kant hat diese Schwäche der Vernunftmoral durch die Ermutigungen seiner Religionsphilosophie wettmachen wollen. Aber im Lichte derselben spröden Vernunftmoral begreift man, warum der aufgeklärten Vernunft die religiös konservierten Bilder vom sittlichen Ganzen - vom Reich Gottes auf Erden als kollektiv verbindliche Ideale entgleiten müssen. Gleichwohl verfehlt die praktische Vernunft ihre eigene Bestimmung, wenn sie nicht mehr die Kraft hat, in profanen Gemütern ein Bewusstsein für die weltweit verletzte Solidarität, ein Bewusstsein von dem, was fehlt, von dem, was zum Himmel schreit, zu wecken und wachzuhalten. ${ }^{7}$

\section{The 'Rescuing Translation' and its Limits}

And yet, unlike postmodernists, Habermas believes that the project of modernization can and must be continued and that communicative reason can solve the new problems that have arisen. That is why he requires expanding the circle of participants of communicative activities, namely, to include religious members of society as equal partners of communication. From his point of view, the acknowledgment of religious members of society as equal partners of communication expands the possibilities of communicative reason. We must recognize that religion as such does not except any reason but rather represents an alternative form of reason. And exactly this alternative form of reason becomes peculiarly relevant due to the changed reality.

Habermas regards religion not only as a collection of non-verified dogmas which reason must overcome and replace with rational 
statements but also as a depository of moral sensibility and deep intuitive insights, which may complement secular reason. Such complementation must be realized in a new form of communicating action which Habermas designates with the term "rescuing translation" (rettende Übersetzung), which is a paraphrase of Walter Benjamin's term "rescuing critics" (rettende Kritik) and means the retelling of religious content in a secular language. According to Habermas, thanks to such a translation, the content of biblical notions becomes accessible beyond the boundaries of the religious community, i.e., to people of different faith traditions or of no faith.

For Habermas, the main task of post-secular society is to give the feelings, preserved in religions, a general resonance. He is convinced that the potential of religious language (its "encrypted semantic potential") can be unfolded into "an inspiring power" if it is transformed into "reasonable speech" (begründende Rede) so that its "profane truth" can be heard. He sums up his position by using the notion of the regime of translation, which means, in this milieu, secularization: "Moralische Empfindungen, die bisher nur in religiöser Sprache einen hinreichend differenzierten Ausdruck besitzen, können allgemeine Resonanz finden, sobald sich für ein fast schon Vergessenes, aber implizit Vermisstes eine rettende Formulierung einstellt. Eine Säkularisierung, die nicht vernichtet, vollzieht sich im Modus der Übersetzung."8

At first sight, it seems that we are faced with a local problem: how to replace the religious message with the message related to the area of the secular. Of course, such a replacement must be as compatible as possible. But what does the compatibility of the messages mean? Let us take an example. In Genesis 1:26 we read: "Then God said, 'Let us make man in our image, in our likeness, and let them rule over the fish of the sea and the birds of the air, over the livestock, over all the 
earth, and over all the creatures that move along the ground'." For secularized people, who are educated in modern schools and are convinced that the human race arose not because of a divine decision, but because of a long and very complicated evolution of living beings, the biblical story of the creation of man seems to be a kind of fairy tale, a spawn of the imagination of ancient storytellers. Accordingly, the idea of man's godlikeness seems to be meaningless.

However, for Habermas, the post-secular reading of the biblical story and its "rescuing translation" should reveal that the idea of the human being as the image and likeness of God can be understood as the idea of the "equal dignity of all human beings" ("die gleiche und unbedingt zu achtende Würde aller Menschen") that has to be respected unconditionally. $\mathrm{He}$ is convinced that such a "rescuing translation" "erschließt über die Grenzen einer Religionsgemeinschaft hinaus den Gehalt biblischer Begriffe einem allgemeinen Publikum von Andersgläubigen und Ungläubigen." 9

But is it the case that in such a translation the content of the biblical image of God-likeness of the human being should be "rescued"? Is it true that the "God-likeness" of man and his "dignity" are the same? It is obvious that the answer can be positive only when we have to do with the translation of the cognitive aspect of the biblical message. However, in this case for Habermas what is more important is the idea of the unconditional respect of each human being.

Let us note that the unconditional respect is: (1) not a cognitive but rather an emotive category; (2) the subjective correlate of the holy (or holiness) which is the constitutive moment of the biblical concept of God. So it seems useful to recall here the phenomenological description of the Holy by Rudolf Otto. Complementing the insight of Nathan Söderblom, according to whom "Holines is (...) even more essential than the notion of God" and that the "[r]eal religion may 
exist without a definite concept of divinity, but there is no real religion without a distinction between the holy and profane."10 Otto has shown that the holy reveals itself exclusively by virtue of a specific sensitivity that he designates as sensus numinis. ${ }^{11}$

\section{Awareness of Our Religious Unmusicality as Docta Ignorantia}

But just here the problem arises. Let us remember that in the same speech in which the notion of post-secular society was introduced, Habermas characterizes the secularized members of modern society as "religiously unmusical" (religiös Unmusikalische). ${ }^{12}$ This characteristic, borrowed from Max Weber, means the absence of a specific sensitivity or ability to immediately experience religious content. It is not difficult to guess that "religious unmusicality" and the deficiency of sensus numinis are closely interconnected or even the same thing. But if so, we have to admit that we, "religiously unmusical" beings, are unable to perceive the moment of unconditional respect in such a way that it awakens in us a positive feeling that motivates our attitude towards other people.

Does it mean that Habermas's project is doomed to a fiasco because we cannot overcome our "religious unmusicality"? In my opinion quite the contrary. The point is that when we become aware of our religious unmusicality, then the process of dialectical negativity like Socratic "knowing of unknowing" or the docta ignorantia of Nicholas of Cusa, starts. The "rescuing translation," which, according to Habermas, is the framework of post-secular discourse, can therefore be considered not as the "rescue" of something "that is missing" in the process of secularization, i.e., not as the simple reclaiming or bringing back of the elements of religious content or their restitution in an altered secular form, but as the practice, the very performance of which helps us to become aware of our "religious unmusicality." This is no small 
task, as may seem at first glance, because a clear awareness of our limitations - ein Bewusstsein von dem, was fehlt - is the best safeguard against confidence in our pseudo-infallibility and our attempts to completely control the communicative situation. That is why it seems to be quite reasonable to say that post-secularity arises when we become aware of our religious unmusicality.

\section{Funding}

This project has received funding from the European Social Fund (project No 09.3.3-LMT-K-712-01-0085) under a grant agreement with the Research Council of Lithuania (LMTLT).

\section{Notes}

\footnotetext{
${ }^{1}$ Nicholas Adams, Habermas and Theology (Cambridge: Cambridge University Press, 1996),

2 Jürgen Habermas, “Glauben und Wissen,” in Zeitdiagnosen (Frankfurt am Main: Suhrkamp, 2003), 251.

${ }^{3}$ Jürgen Habermas, Der philosophische Diskurs der Moderne (Frankfurt am Main: Suhrkamp, 1985), 10.

${ }^{4}$ Jürgen Habermas, “Genetische Sklavenherrschaft?” in Postnationale Konstellation (Frankfurt am Main: Suhrkamp, 1998), 243.

5 Jürgen Habermas, "Die Grenze zwischen Glauben und Wissen. Zur Wirkungsgeschichte und aktuellen Bedeutung von Kants Religionsphilosophie," in Zwischen Naturalismus und Religion. Philosophische Aufsätze (Frankfurt am Main: Suhrkamp, 2005), 218.

${ }^{6}$ Habermas, Glauben und Wissen, 257.

${ }^{7}$ Habermas, "Ein Bewusstsein von dem, was fehlt," in Ein Bewußtsein von dem, was fehlt. Eine Diskussion mit Jürgen Habermas, Hg. v. Michael Reder und Josef Schmidt (Frankfurt am Main: Suhrkamp, 2008), 30-31.

${ }^{8}$ Jürgen Habermas, Glauben und Wissen, 29.

9 Jürgen Habermas, "Vorpolitische Grundlagen des demokratischen Rechtsstaates?” in Jürgen Habermas und Josef Ratzinger, Dialektik der Säkularisierung. Über Vernunft und Religion (Freiburg: Herder, 2005), 32.

${ }^{10}$ Nathan Söderblom, "Holiness," in the Encyclopaedia of Religion and Ethics, ed. James Hastings (Edinburgh: T. and T. Clark, 1913), vol. 6, 731.

${ }^{11}$ Rudolf Otto, Das Gefühl des Überweltlichen (München: C. H. Beck’sche Verlagsbuchhandlung, 1932), $53 f$.

${ }^{12}$ Habermas, Glauben und Wissen, 261.
} 
The Rehabilitation of Myth, Post-Ontology, and Rhetoric Lina Vidauskyte

\section{Vilnius University, Lithuania}

\section{Introduction}

In this essay, I focus on the question of how rhetoric works as a postontological principle and discuss the problem of the rehabilitation of myth in post-secular thinking. The question of post-secularity encompasses many aspects, including politics, religion, and philosophy. Besides, we can say that one of the main issues of the post-secular discourse is the so-called return or rehabilitation of myth. Since the early days of Romanticism, the followers of this movement declared that the Enlightenment and its apotheosis of rationality should be criticized. Much later Theodor Adorno wrote about dialectics and the myth of the Enlightenment. No wonder that after the two World Wars, and especially after the strange and suspicious phenomenon of the cult of personality, we can see very clearly that rationality, logos, can no longer be treated as the only source of truth. Since the thesis vom Mythos zum Logos, announced by Wilhelm Nestle in 1919, became an undisputed part of the Western philosophical tradition, one of Germany's most important post-war philosophers, Hans Blumenberg (1920-1996), has questioned this formula and offered his project of "metaphorology," viz., the research on boundaries and interplays between metaphors and concepts, and an intellectually intriguing "work on myth." According to Blumenberg, myth appears again and again after the Enlightenment and its critical attitude to mythical thinking and famous formula vom Mythos zum Logos is simply misleading. Following F. W. J. Schelling's idea about the inseparability of mythological and historical (and 
philosophical) myths, Blumenberg declares that myth is a legitimate part of logos.

\section{Myth and Rhetoric}

Myth plays a major role in rhetoric, and, for Blumenberg, rhetoric is not just an instrument of convincing but, also, a post-ontological principle. Blumenberg emphasizes that in "the currency of rhetoric, handbooks become ways of utilizing myth that converge in their tendencies. In the language of the process that is typified in the formula 'from mythos to logos,' it is, perhaps, the no longer surpassable subjugation by logos, when myth's principle of formation, 'conceptualized,' dominates the mode of work on myth. Logos exhibits myth not as its product, not as one of its authentic processes, but as something that it has understood and categorized as though the museum already existed, that late phase of the successful presentation of what the present preserves so as not to be it any longer, and in relation to which it always enjoys this distance at the same time. Mythology has become one of the provinces of logos, insofar as logos has domesticated archaic reality in the dimension of time, too, and administers it in the manner of an antiquarian." 1

The other significant term Blumberg uses, which coincides with rhetoric, is his concept of the absolutism of reality (Absolutismus der Wirklichkeit): in the same way that a person is defenseless in front of an absolutist governor, human beings cannot control the conditions of their existence. In Blumberg's words: "[w]hat it means is that man came close to not having control of the conditions of his existence and, what is more important, believed that he simply lacked control of them. It may have been earlier or later that he interpreted this circumstance of the superior power [Übermächtigkeit] of what is (in 
each case) other [i.e., not himself] by assuming the existence of superior powers [Übermächten]."2

Not being able to access the whole of reality is the essence of what Blumenberg calls historicity, finitude or contingency. Blumenberg postulates intentionality of consciousness without an object, i.e. anxiety (Angst) which precedes the fragile stability of symbolic practices distancing the object from consciousness to let it grasp its contingency. Concepts are unable to grasp the world, reality, and contingency, while art and myth are a much more suitable instrument for this operation. Blumenberg asserts that we deal with contingency by using rhetorical techniques.

Being has primacy over consciousness as was postulated by the early German Romantics such as Novalis, Hölderlin, and Friedrich Schlegel. Under such circumstances, for Blumenberg the only question, or in other words, the "fundamental question" (Grundfrage) that has meaning is: how do we deal with this contingency with our mortality, our vulnerability? Human beings can conceal contingence in various ways: through the invention of tools and artifacts that help them overcome their biological deficiency, and in general through the context of sense provided by culture. Culture, in general, means all symbolic practices, rituals, and, of course, rhetoric as such. Blumenberg writes, that "the animal symbolicum masters the reality that is originally lethal for him by letting it be represented; he looks away from what is uncanny or uncomfortable for him and toward what is familiar." 3

Blumenberg's philosophical project is often labeled "philosophical anthropology." As a research paradigm, philosophical anthropology is an attempt to provide a theory of "the human" that avoids speculative idealism and mere accumulative scientism. Blumenberg states that 
"[t]he varieties of what we now call philosophical anthropology can be reduced to one pair of alternatives: Man can be viewed either as a poor or as a rich creature. The fact that man is not fixed, biologically, to a specific environment can be understood either as a fundamental lack of proper equipment for self-preservation or openness to the fullness of a world that is no longer accentuated only in terms of vital necessities. Man is defined by what he lacks or by the creative symbolism with which he makes himself at home in worlds of his own." 4

For Blumenberg, "anthropology" means the attempt to understand human existence from itself, not having its reason in "Being", "God" or whatever, such as it had supposedly been the case throughout the history of thinking. Blumenberg's theory of myth has its source in early German Romanticism and in Schelling's late philosophy. The early German Romantics criticized Fichte's starting point in philosophy: selfconsciousness. For the Romantics such explanation meant a step back from Kant; according to them, there are no fundamental principles from which thinking starts, and if individual consciousness is considered as the first principle it becomes an absolute consciousness. In a similar spirit, Blumenberg criticizes Heidegger's Being and the Freudian libido; such final philosophical myths have one meaning everything arises from the One, viz., metaphysics. For Blumenberg "[r]hetoric's anthropological importance stands out best against the background of the metaphysics that has been dominant since antiquity." In that way, the Blumenbergian approach to philosophy and rhetoric has some similarity to French philosopher Barbara Cassin's position and her interest in Sophistic history, and here lies the direct connection with the critical attitude to ontology.

In her conversation with Penelope Deutcher, Cassin emphasizes that "[t]he sophistic history is a history of neglected traditions, a history of alternative paths and a history of repressed traditions. What is 
essential is to have a plurality, instead of a single path. That single path of ontology, and the dominant path of ontology, for me, goes from Parmenides to Plato, via a certain reading of Aristotle up to Heidegger. I'm interested in showing how it goes even up to Habermas, who might seem to be different, but for me is just the same. The history of philosophy, the royal road, as history of ontology and phenomenology, or a history of communication, takes a path that one can't manage to trace, that one can't identify as a path, unless one looks at what it was not, what was, even materially, left to one side."6

\section{Rhetoric and the Truth}

Rhetoric has to do with the consequences of possessing the truth or with the difficulties that result from the impossibility of obtaining the truth. Man exercises his disposition over the truth he possesses with the aid of rhetoric. But rhetoric is not manipulation as it was in the Platonic tradition. Rather, it is the activity of introducing order into reality at the anthropological level is at the same time an ontological process of the creation of reality, both external and internal. Using rhetorical tools man constructs his own reality. But even the word a 'tool' is not appropriate for this purpose, because, as Blumberg argues, "rhetoric does not 'lend' itself to the truth, it is not an instrument but pure expression; the brilliance of the diction is the brilliance of truth itself, the direct self-translation of the 'matter' into language and its persuasive force." " So rhetoric is diction, a kind of technique of speech that appears as a special case of rule-governed modes of behavior that produce something to be understood, set up signs, bring about an agreement or provoke contradictions. ${ }^{8}$ For instance, this interpretation of rhetoric is directly opposed to Foucault's ontology of truthful languages (parresia), which he developed in his lecture course at Collége de France in 1983-1984. ${ }^{9}$ 
The specificity of rhetoric can be outlined with Blumenberg's term Unbegreifflichkeit ("unconceptuability"), 10 owing to which "absolute metaphors" (absolute Metaphern) take a special place between metaphors, because they present both a global interpretation of the world and self and resistance to being reduced to concepts. ${ }^{11}$ But metaphors and myth as primarily rhetorical tools were banned from a philosophy. Blumenberg offers to imagine for a moment that modern philosophy has proceeded according to the methodological program set out for it by Descartes, and had arrived at that definitive conclusion. Traditionally, clarity and distinctness were the rules for philosophical language, so definition was an absolute requirement. ${ }^{12}$ All elements of figurative language and form or, in the broad sense, of the terms, were connected to logic and, finally, metaphors had to be carefully to be avoided. But as noted above, we still use metaphors and myths in our philosophical discourse. This means that rhetoric is indeed philosophy, and reason is therefore seen by Blumenberg as rhetorically shaped. The function of reason is to uncover or to cover the finitude of human existence.

German philosopher Odo Marquard writes that, because we do need the "discussed world," we live in the "narrated world." This is precisely why we cannot live without myths: narrare necesse est (to narrate is necessary). ${ }^{13}$ He insists that we cannot simply lay myths aside like clothes, although it is also true that laying clothes aside is sometimes not entirely simple: "[m]ythonudism strives for something impossible; because every demythologization is a well-compensated process: the more myths one takes off, the more myths stay on." ${ }^{14}$

That is why metaphorology, as a sub-branch of philosophy, is necessary: metaphorology explains and shows how mythos works as an integral part of logos, and when logos finishes its work, the myth continues its work. But it is precisely one myth, claiming that 
everything comes from the One, that is the riskiest, and the political history of the $20^{\text {th }}$ century is good evidence of it. That is why we need polymythical thinking.

Marquard explains the difference between monomythical and polymythical thinking, and insists that

[t]here are poisonous myths; what is always dangerous is, at least, the monomyth; polymyths, on the other hand, are harmless. The important thing is that one must be free to have many myths many stories. Someone who, together with all other human beings, has and can have only one myth - only one story - is in a bad way. So the rule is: polymythical thinking is wholesome, monomythical thinking is harmful. Persons who, in their living and storytelling, participate, polymythically, in many stories, are free, by virtue of one story, from the other, and vice versa (and multiply so, in a crisscross fashion, by further interferences). Persons, on the other hand, who, monomythically, can and must participate, in their living and their storytelling, in only one myth, do not have this freedom: they are entirely possessed by it - as though by a nonmythical synchronization of mythical entanglements - body and soul. On account of their compulsion to identify completely with this single story, they fall prey to narrative atrophy and end up in what one can call the unfreedom of identity that results from a lack of nonidentity. On the other hand, the latitude of freedom that goes with nonidentities, which is lacking in the case of the monomyth, is granted by the polymythical plurality of myths. ${ }^{15}$

For Marquard, polymythical thinking is similar to an old principle of the Skeptics; the great purpose of that principle is a separation of powers. The great Roman orator Cicero insisted that skeptical epoché 
is the best philosophical position. According to him, some statements can be similar to the truth, even if they are not correct. Each statement cannot be the undeniable truth, they only can be probable.

The greatest skeptic of modernity, Michel de Montaigne, formulated and substantiated the method of philosophical skepticism. A critical assessment of Christian dogmatism and religious morality allowed the thinker to pave the way for new ideas. Montaigne was concerned not only about the truth of science and the opinions of the authorities but also emphasized the dialectic of opinions, multiplicity. By stressing the diversity of views on nature and people, Montaigne sought to free man from the bending of dogmatic thinking, the yoke of medieval prejudices and customs. He understood philosophy as it was in ancient Greece, as the "most valuable of all arts, the art of living well."16 Montaigne, once his public career ended, returned to his solitude in his castle's tower and devoted his time to reading and writing: he wrote about his own experiences without giving any final verdict - which suffocates personal freedom - the major achievement of skeptical doubt, as Marquard writes:

[F]reedoms are the result of the separation of powers. An appreciation of these freedoms is found not in the philosophy of principles but in skepticism. This appreciation affects, at the same time, the role played by skeptical doubt; as the separation even of those powers that we call our convictions, skeptical doubt is an appreciation of the separation of powers. Skepticism's doubt is not absolute perplexity but is rather a manifold sense of the isosthenes diaphonia (evenly balanced disagreement), the balance not only of conflicting dogmas but also of conflicting realities - which by that very fact (divide et liberaliter vive!) allows individuals freedoms and vouchsafes 
them the relief from the absolute that is also and above all provided, as Hans Blumenberg has shown, by the separation of powers in myth. ${ }^{17}$

\section{Conclusion: We Cannot Live Without Myths}

Nevertheless, even if we take into account the benefits of polymythical thinking, Blumenberg affirms the impossibility of finding answers to the fundamental questions, and that actually means "anthropology": reality does not take care of human beings. Moreover, according to Blumenberg, reality has no meaning because we die: it is what he terms the "absolutism of reality." But rhetoric plays its role in the face of political authorities, because "[r]hetoric teaches us to recognize rhetoric, but it does not teach us to legitimate it." 18

The theoretical foundation of rhetoric contains an authentic connection between a stylistic principle and a view of the world. Human beings need the art of persuasion only to the extent that they lack access to a reality that can convey truth. As the art of persuasion, rhetoric is also distinguished by the fact that it distances itself from the mere power of command. ${ }^{19}$ On the ontological level, as noted before, against the pressures of reality human beings place a symbolic world so as to be able to live on in that reality. As Blumenberg states, "the human relation to reality is indirect, circumstantial, delayed, selective, and above all metaphorical." 20 Rhetoric is the art of delaying. The Greek myths are examples of this art of delaying. What the myths are intended to do is to place divine, arbitrary power (i.e. absolute power) within certain boundaries. Marquard similarly insists that "the mythical technique - the telling of stories - is ... the art of bringing available truth within the reach of what we are equipped to handle in life. For the truth is, as a rule, not yet there when it is either (like the results of the exact sciences, as, for example, formulas) too abstract to 
connect with or (for example, the truth about life, which is death) unbelievably awful. In such cases, stories - myths - not only can but must come forward in order to tell these truths into our life-world, or to tell them, in our life-world, at the kind of distance at which we can bear them."21 Humankind simply cannot live without myths.

\section{Funding}

This project received funding from the European Social Fund (project No 09.3.3-LMT-K-712-01-0085) under a grant agreement with the Research Council of Lithuania (LMTLT).

\section{Notes}

\footnotetext{
${ }^{1}$ Hans Blumenberg, Work on Myth (Cambridge, MA: The MIT Press, 1985), 350.

2 Ibid., 3-4.

${ }^{3}$ Hans Blumenberg, "An Anthropological Approach to the Contemporary Significance of Rhetoric," in After Philosophy? End or Transformation, ed. Kenneth Baynes, James Bohman, and Thomas McCarthy, trans. Robert M. Wallace. (Cambridge, MA: The MIT Press, 1987), 440.

${ }^{4}$ Ibid.,429.

${ }^{5}$ Ibid.,432.

6 "Interview Two with Barbara Cassin. Philosophical Displacements," Women's Philosophy Review 24 (2000): 34 .

${ }^{7}$ Hans Blumenberg, Paradigms for Metaphorology (Ithaca, NY: Cornell University Press, 2010), 38.

${ }^{8}$ Blumenberg, "An Anthropological Approach,” 431.

${ }^{9}$ Michel Foucault, Le Courage de la vérité. Le Gouvernement de soi et des autres II (Paris: GallimardSeuil, 2008).

${ }^{10}$ See also Hans Blumenberg, "Prospect for a Theory of Nonconceptuality," in Shipwreck with Spectator: Paradigm of a Metaphor of Existenze (Cambridg, MA: The MIT Press, 1997), 81-102.

${ }^{11}$ César González Cantón, “Absolutism: Blumeneberg’s Rhetoric as Ontological Concept,” in Hans Blumenberg. Nuovi paradigm d'analisi (Roma: Arcane, 2010), 126.

${ }^{12}$ Blumenberg, Paradigms for a Metaphorology, 1.

${ }^{13}$ Odo Marquard, Farewell to Matters of Principle. Philosophical Studies (New York: Oxford University Press, 1989), 91.

${ }^{14}$ Ibid., 91.

15 Ibid., 93.
} 
${ }^{16}$ Michel de Montaigne, The Complete Essays of Montaigne (Stanford, CA: Stanford University Press, 1992), 124

${ }^{17}$ Marquard, Farewell to Matters of Principle, 17.

${ }^{18}$ Blumenberg, "An Anthropological Approach," 448.

${ }^{19}$ Hans Blumenberg, The Genesis of Copernican World (Cambridge, MA: The MIT Press, 1987), 204.

${ }^{20}$ Blumenberg, “An Anthropological Approach,” 439.

${ }^{21}$ Marquard, Farewell to Matters of Principle, 90. 


\section{Homage to Professor Ezra Talmor, Founder of ISSEI}

Edna Rosenthal

University of Zaragoza, 3 July 2019

That we are gathered here today is the result of my biography. For the journal I edit with Wayne Cristaudo, and the concept of this conference - were the brainchild of my father, Ezra Talmor, who died last May, and my late mother, Sascha Talmor. They founded the journal and Society in the early 1980s almost 40 years ago.

Ezra died at his home in Kibbutz Nachshonim. He would have been 102 years old this very day. Many people attended his funeral - many more than we expected. Members of the kibbutz, older and younger, former colleagues from Haifa University, where he taught philosophy for more than 40 years, and a group of devoted students who continued to meet with him years after he retired. He had lived a long, good, happy and productive life.

His life was shaped by the major political and ideological currents that defined the 20th century. He was born in 1917 when the First World War was coming to an end, The Big War that was supposed to End all Wars; 1917 was also of course the year of the Russian Revolution. What world-defining events! What historic convulsions these were! Not to speak of what followed in the next decades of the century. But we all know the historical sequence leading to the present.

With these events in the background, Ezra's own life followed a dual track: his love of philosophy and realizing the socialist ideal of the kibbutz, which he and his friends founded 70 years ago. Theory and Praxis went hand in hand. Growing up in Cairo, he first discovered Marxism in his late teens, shortly afterwards, Zionism, and then, after emigrating to Palestine in 1945 and meeting Sascha, he discovered 
philosophy. The improbable combination of the pursuit of philosophy on the one hand, and the idealistic project of creating a new way of life in the fledgling kibbutz, led to some bitter crises between my parents and the political leaders of the kibbutz movement and political party. Yet despite these tensions and against all the odds, Ezra and Sascha somehow managed to continue their studies, and to remain kibbutz members till the end of their life.

In the late 1960s they started teaching at the newly founded university of Haifa in the Philosophy and English departments respectively. But Sascha died 15 years ago, when Ezra was still teaching and supervising $\mathrm{PhD}$ students at the University, and continued working on the journal and conferences... so that was when I joined him and Rachel Ben David his long-time editorial assistant.

By 2014 when he was already 97 years old and intending to come to our conference at the Catholic University of Portugal in Porto (whose co-chair, Professor Yolanda Espina, by the way, is with us here today), his doctor told him he was too old to travel. Instead, he welcomed the conference participants in a short video from which we've shown you two short passages. By then he could hardly read...

In this video, and in his written closing address on the last day of the conference, he summed up his life's work as an attempt to reconcile his philosophy and political outlook. He tried to explain why he had slowly lost faith in Marxism, though not, as he said, "in its moral message," on which I want to quote two short passages:

The first relates to the dream of the perfect society:

"Society is not a scientific experiment. You cannot invent a new society, and perhaps that is why the kibbutz failed: it was too artificial; it discounted the hidden forces that drive our life." 
The second passage touches on these "hidden forces that drive our life":

"My life's motto has always been: Hate Evil. I didn't learn this from books on philosophy. It was my mother who taught me to distinguish between good and evil: her absolute, unconditional love implanted in me the imperative to fight against any form of injustice. Because the first language we learn is our mother's love, I see evil as the denial of this love. Language and life are one: language is the expression of our love of life, of our creativity and productive capacities - our turning towards or away from life. .. Thus for me Ethics is not a metalanguage of philosophers but is continuous with all our thoughts and actions. It is embedded in the minutiae of daily life."

This then is Ezra and Sacha's legacy; this is what ISSEI stands for, and what The European Legacy stands for: we cannot cease from the struggle for the common good, we cannot cease from developing our thought... the two go hand in hand.... and it is this struggle that forges our identities.

I want, in conclusion, to read a few sentences from Professor HeinzUwe Haus's tribute to Ezra and Sascha as the founders of ISSEI:

"I remember our first meeting in Aalborg in 1992. I just came out of the Peaceful Revolution which brought two working groups to one of the new political parties: one for culture and the other for European affairs. "Return to Europe" was the motto of our civic movement months earlier in its fight against the totalitarian regime (in the GDR). Now, after our self-liberation, we were looking for allies in the West to implement our goals. Sascha and Ezra were listeners and advisers from the first moment on. And they asked me to join ISSEI's Executive Committee! That was the kind of practical understanding and leadership both exhibited all their life. It was this dialectical 
mindset which nurtured their vision of a permanent platform for an international study of European ideas.

The essence of all this is that Sascha and Ezra created an academic family, not just friends. I trust that we will carry on their spirit."

I end this homage by addressing the following quotation in gratitude to all of you, long-standing and new members, friends, and contributors to our journal.

In his condolence note following Ezra's death in May 2019, British historian Theodore Zeldin, founding member of ISSEI, wrote:

"[Ezra's] brilliant initiative in establishing a journal which encourages thinking on such a wide range of important subjects is now more relevant than ever. I congratulate and thank you for developing his vision and adding to his achievements." 
Name Index

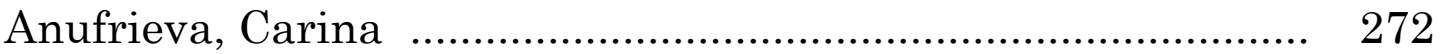

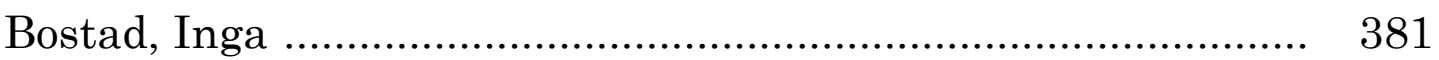

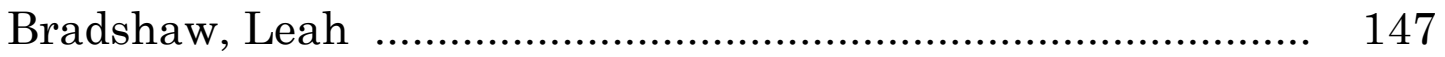

Carbonero, Domingo …………............................................. 475

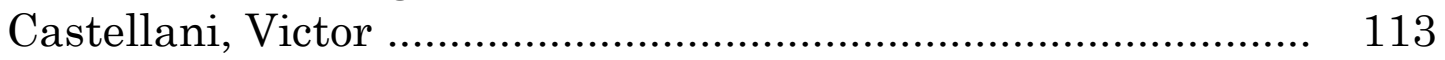

Cristaudo, Wayne ................................................................... 324

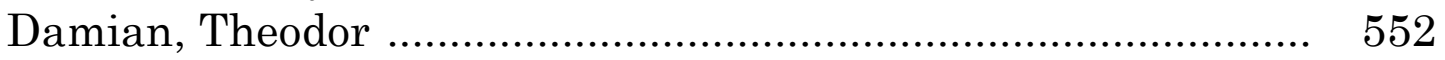

Debono, Mark ...................................................................... 391

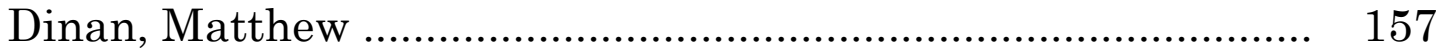

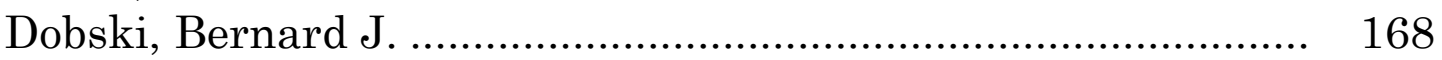

Drousioti, Kalli ................................................................... 400

Elnécavé, Claudine ……...................................................... 359

García Grados, Carlos ............................................................. 583

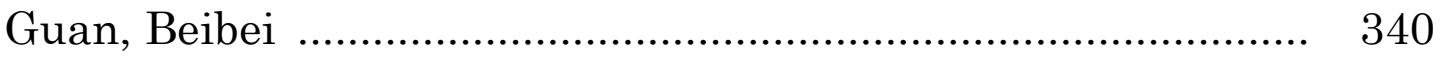

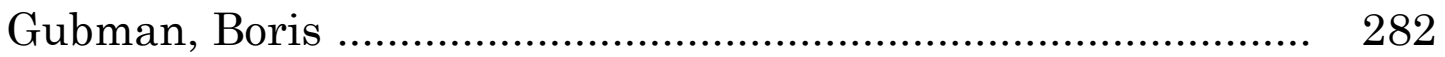

Hahn, Frank .................................................................... 488

Haus, Heinz-Uwe ................................................................. 363

Hildebrandt, Reinhard ...................................................... 504

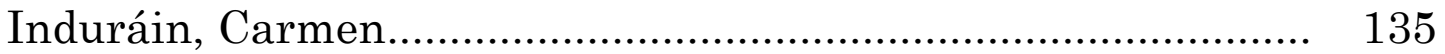

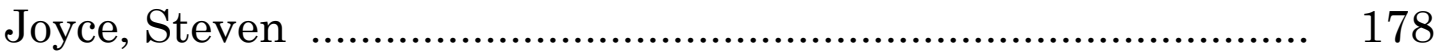

Kataliakos, Giorgos .............................................................. 410

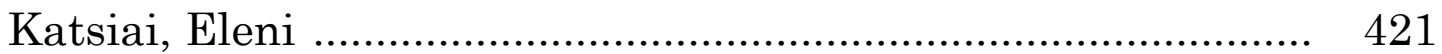

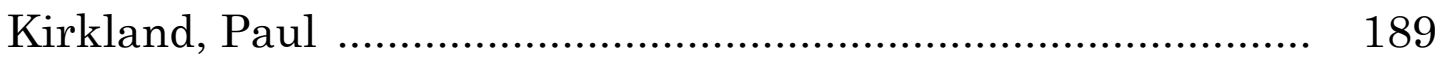

Kondrič Horvat, Vesna .......................................................... 52

Koutselini-Ioannides, Mary ……............................................ 421

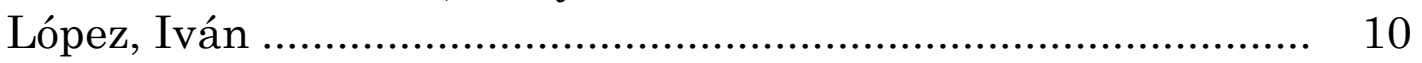

Lück-Hildebrandt, Simone ..................................................... 528

MacEwen, Philip ……........................................................ 30

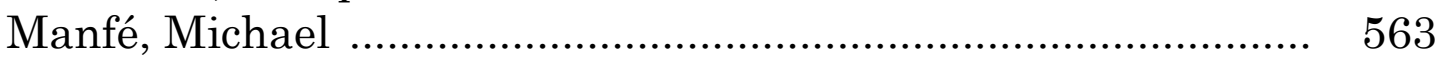

Negy, Kenneth Alarcón .......................................................... 314

Nikitina, Erbina …............................................................. 293

Palmer, Gesine ................................................................. 538

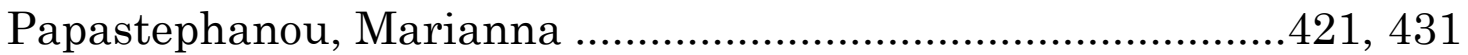

Parra, José Daniel ................................................................ 200

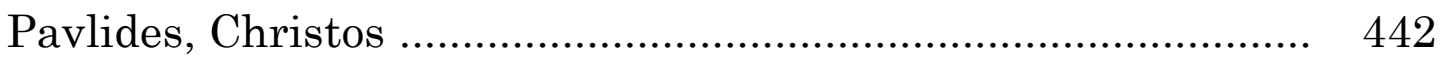

Planinc, Emma ................................................................. 208

Potamskaya, Vera ….......................................................... 304

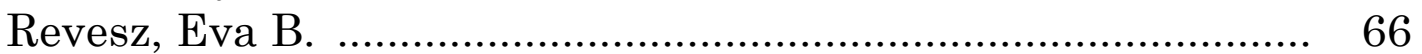

Rindisbacher, Hans J. ......................................................... 76

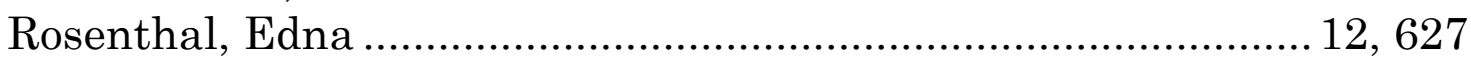

Rosenthal, Ruvik ............................................................. 350

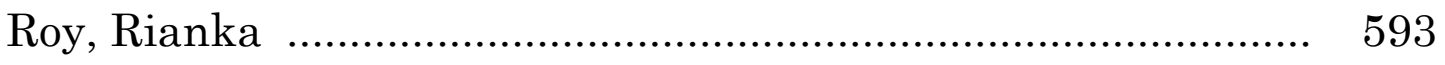




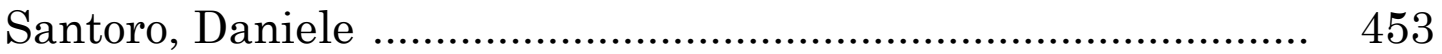

Schulz Meinen, Haimo ……………........................................ 217

Schwerin-High, Friederike von …........................................ 89

Senigaglia, Cristiana …........................................................ 102

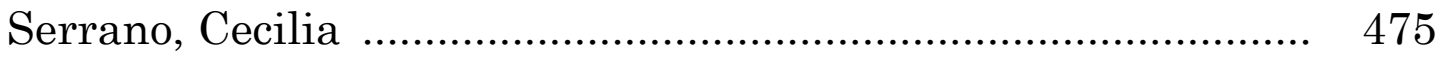

Simms, Luma …............................................................. 227

Sîrghie, Anca ……................................................................ 573

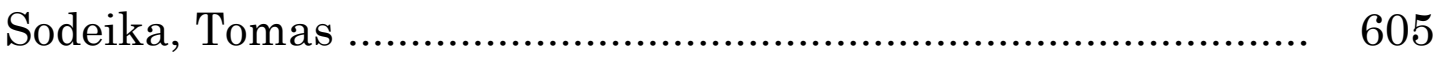

Sokolon, Marlene K. ............................................................ 239

Strand, Torill ....................................................................... 463

Trifonov, Gennadiy .............................................................. 293

Tweyman, Stanley …............................................................ 42

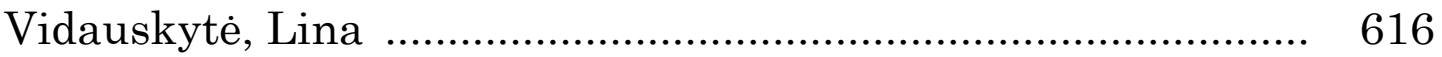

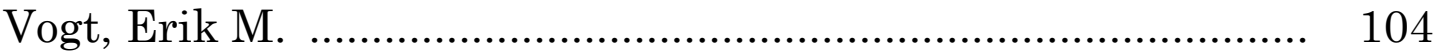

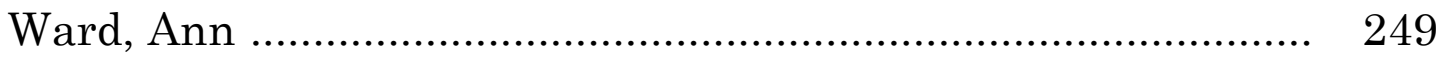

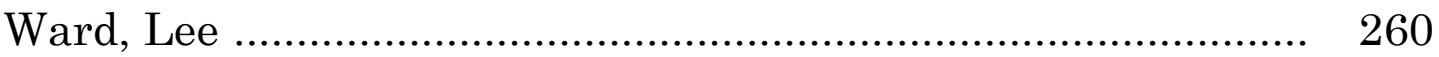

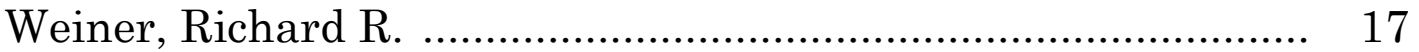




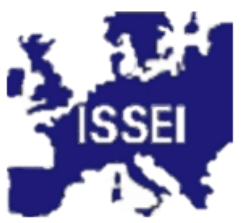

\section{in: Universidad \\ îi}

